ESCOLA POLITÉCNICA DA UNIVERSIDADE DE SÃO PAULO

JOÃO PAULO MACEDO GUERRA

\title{
AVALIAÇÃO DE DESEMPENHO TERMODINÂMICO E AMBIENTAL DE CENÁRIOS DE COGERAÇÃO ELÉTRICA EM USINAS AUTÔNOMAS
}

SÃo PAULO 
JOÃO PAULO MACEDO GUERRA

AVALIAÇÃO DE DESEMPENHO TERMODINÂMICO E AMBIENTAL DE CENÁRIOS DE COGERAÇÃO ELÉTRICA EM USINAS AUTÔNOMAS

Dissertação apresentada à Escola Politécnica da Universidade de São Paulo como requisito necessário para a obtenção do título de Mestre em Engenharia.

SÃO PAULO 
JOÃO PAULO MACEDO GUERRA

\title{
AVALIAÇÃO DE DESEMPENHO TERMODINÂMICO E AMBIENTAL DE CENÁRIOS DE COGERAÇÃO ELÉTRICA EM USINAS AUTÔNOMAS
}

\author{
Dissertação apresentada à Escola Politécnica \\ da Universidade de São Paulo como requisito \\ necessário para a obtenção do título de \\ Mestre em Engenharia \\ Área de Concentração: Engenharia Química \\ Orientador: Prof. Dr. Luiz Alexandre Kulay
}

SÃO PAULO 
FICHA CATALOGRÁFICA

Guerra, João Paulo Macedo

Avaliação de desempenho termodinâmico e ambiental de cenários de cogeração elétrica em usinas autônomas / J.P.M. Guerra. -- São Paulo, 2014.

$345 \mathrm{p}$.

Dissertação (Mestrado) - Escola Politécnica da Universidade de São Paulo. Departamento de Engenharia Química.

1.Cogeração de energia elétrica 2.Análise energética 3.Ciclo de vida (Avaliação) I.Universidade de São Paulo. Escola Politécnica. Departamento de Engenharia Química II.t. 
Dedico este trabalho à minha mãe, pela sua vida de dedicação aos filhos e ao meu irmão Walysson, pela sua humildade inspiradora e pelo seu exemplo de perseverança. 


\section{AGRADECIMENTOS}

Em primeiro lugar, agradeço ao egrégio professor Dr. Luiz Alexandre Kulay pelo seu comprometimento no desenvolvimento desse trabalho, pela orientação consistente e, sobretudo, pela amizade cultivada e pelo exemplo de lealdade, principalmente nos momentos mais difíceis.

Aos nobres colegas e amigos do GP2 que de certa forma contribuíram para a elaboração desse trabalho, pelas experiências trocadas e pelo companheirismo ao longo desta caminhada: Alex, Letícia, Henrique e Victor.

Ao amigo Lauro pelo incentivo à elaboração desse esforço de pesquisa, e seu irmão Álvaro Meneguetti, que gentilmente disponibilizou a usina Santa Terezinha, Unidade Paranacity para coleta de dados e acompanhamento do processo produtivo.

Aos amigos Marcelo, Ricardo, Diogo e Isabela, que acompanharam e incentivaram minha dedicação nesse trabalho e foram excelentes companhias durante minha estadia em São Paulo. 
"O cientista é um apaixonado da verdade pelo próprio amor à verdade, aonde quer que ela leve"

Luther Burbank

"Procure ser um homem de valor, em vez de ser um homem de sucesso"

Albert Einstein 


\section{RESUMO}

A descentralização do setor de eletricidade brasileiro associado à premente necessidade de aumento da oferta de energia elétrica tem fomentado a busca por fontes alternativas para produção de energia elétrica. Este fato motiva empresas do setor sucroalcooleiro a produzir eletricidade a partir da queima do bagaço de canade-açúcar em sistemas de cogeração, elevando dessa forma a capacidade de geração de energia elétrica exatamente no período de menor oferta hídrica. A geração de eletricidade a partir da biomassa canavieira revela-se uma opção interessante, pois além de ser produzida de forma distribuída e próxima aos centros consumidores, tem criado oportunidades a destilarias e usinas de açúcar para aumentarem seus portfólios de produtos.

Nesse aspecto, o presente estudo se propõe a apresentar e discutir possibilidades de cogeração de energia elétrica em usinas autônomas (destilarias) em diferentes condições de processo e operação. Para atender a estes propósitos, foram definidos cenários de cogeração e desenvolvidos modelos para simulação e análise da produção de energia térmica e elétrica bem como estimar os impactos ambientais associados, considerando um sistema de cogeração que opera através do ciclo Rankine, que é o sistema mais utilizado pelas usinas brasileiras. Os cenários foram analisados a partir das técnicas de Análise Exergética (Análise Termodinâmica de Primeira e Segunda Lei) e Avaliação de Ciclo de Vida (ACV). Adotou-se para o caso da avaliação ambiental um enfoque do "berço ao portão da fábrica", conforme diretrizes metodológicas descritas nas normas ISO 14040 e 14044. A unidade funcional adotada foi "gerar 1,0 MWh de eletricidade excedente em sistema de cogeração energética". O sistema de produto compreende as cargas ambientais da etapa industrial e da produção agrícola da cana-de-açúcar.

Especialistas no setor e pesquisadores da área sugerem concentrar esforços de melhoria de desempenho termodinâmico na elevação das propriedades de estado do vapor na saída da caldeira de 20 bar até 100 bar, e simulação de sistemas de cogeração com reaquecimento e regeneração, que são melhorias técnicas próprias de centrais termelétricas, mas com potencial de aproveitamento pelo setor sucroalcooleiro. Os cenários foram projetados com base em diferentes combinações dessas condições considerando duas possibilidades de utilização da biomassa como 
fonte de energia térmica: exclusivamente bagaço de cana-de-açúcar; e uma composição de bagaço e palha. A comparação dos desempenhos termodinâmicos e ambientais dos cenários ocorreu principalmente em termos da geração específica de eletricidade, da eficiência exergética, do perfil destruição de exergia ao longo do ciclo e dos perfis de impactos ambientais potenciais.

Os resultados obtidos indicam que a eficiência exergética é aumenta com a elevação das funções de estado do vapor superaquecido na alimentação da turbina, e ao aumento do grau de complexidade do ciclo Rankine, conseguido à medida que arranjos com reaquecimento e regeneração são integrados ao ciclo. Esses arranjos mostraram-se efetivos na melhoria dos desempenhos exergético e ambiental dos sistemas de cogeração a partir da queima do bagaço e da palha da cana-de-açúcar.

Em termos de desempenho ambiental, observou-se a redução sistêmica de efeitos negativos associada ao aumento da eficiência do ciclo termodinâmico. Os resultados da ACV ratificaram também, que a melhoria da eficiência exergética do sistema é seguida de redução de impactos ambientais. Os melhores resultados ambientais, tanto em termos relativos, como absolutos, foram obtidos aproveitando a palha como fonte de energia térmica na caldeira, na condição de geração de vapor a 100 bar e $511{ }^{\circ} \mathrm{C}$, com ciclo Rankine que utiliza reaquecimento e regeneração simultaneamente, numa proposta chamada de ciclo Resultante, cuja redução de impactos ambientais ocorreu entre 5,3\% e 15,6\% nas categorias analisadas.

Palavras-chave: cogeração via cana-de-açúcar; ciclo Rankine; análise energética, análise exergética; Avaliação do Ciclo de Vida (ACV). 


\begin{abstract}
The decentralization of the Brazilian electricity sector in association with the internal electricity supply crisis has encouraged companies in the sugarcane industry to produce electricity by burning sugarcane bagasse in cogeneration plants. This approach reduces the environmental impact of the sugarcane production and has opened up opportunities for distilleries and annex plants to increase their product portfolios. Potential scenarios for technically and environmentally improving the cogeneration performance were analyzed by using Thermodynamic analysis and Life Cycle Assessment (LCA). The method used in this study aimed to provide an understanding and a model of the electrical and thermal energy production and the environmental impacts of conventional vapor power systems which operate with Rankine cycle that are commonly used by Brazilian distilleries. Vapor power system experts have suggested focusing on the following technical improvement areas: increasing the properties of the steam from 20 to 100 bar, regeneration and reheating. The case scenarios were projected based on different Rankine cycle configurations and two possibilities of biomass utilization: only sugarcane bagasse or sugarcane bagasse with straw.
\end{abstract}

The LCA was carried out according to ISO 14040 and 14044 regulations, with focus "from cradle to gate". A Functional unit of: "To delivery 1.0 MWh of electricity to the power grid using cogeneration system" was defined. The product system covers the environmental burdens of the industrial stage and the agricultural production of sugarcane.

Thermodynamic evaluation indicated that the energy efficiency and the potential net power exported to the grid increase as the pressure at which the vapor leaves the boiler increases.

From the LCA, it was noted that the improved energy performance of the system is accompanied by reduced environmental impacts for all evaluated categories. In addition, vapor production at 100 bar and $511{ }^{\circ} \mathrm{C}$ resulted in greater environmental gains, both in absolute and relative terms. Reheating and regeneration concepts were found to be considerably effective in improving the energy and environmental 
performance of cogeneration systems by burning sugarcane bagasse and straw. For the evaluated categories, the results indicated that the proposed modifications are favorable for increasing the efficiency of the thermodynamic cycle and for decreasing the environmental impacts of the product system. The best results were obtained using bagasse and straw in the boiler furnace and using reheat-regenerative Rankine cycle. In this case it was noted a reduction between $5.3 \%$ and $15.6 \%$ over all impact categories analysed.

Keywords: cogeneration, sugarcane industry, Rankine cycle, energetic analysis, exergetic analysis, Life Cycle Assessment (LCA). 


\section{LISTA DE ILUSTRAÇÕES}

FIGURA 1 - SÉRIE HISTÓRICA DA PRODUÇÃO DOS PRINCIPAIS PAÍSES PRODUTORES DA CANA-DE-AÇÚCAR, EM MILHÕES DE TONELADAS

(MAPA, 2013)

FIGURA 2 - MAPA DE PRODUÇÃO DE CANA-DE-AÇÚCAR NO BRASIL (ÚNICA, 2013) ....................................................23

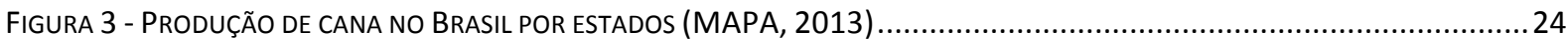

FIGURA 4 - DIAGRAMA DE BLOCOS SIMPLIFICADO PARA PRODUÇÃO DE ETANOL ANIDRO A PARTIR DA CANA-DE-AÇÚCAR NUMA USINA

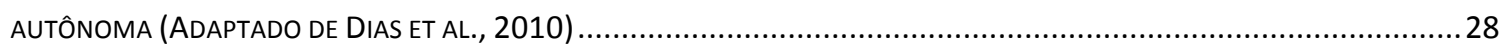

FIGURA 5 - EVOLUÇÃO DA PRODUÇÃO DE ETANOL ANIDRO, SEGUNDO GRANDES REGIÕES - 2002 A 2013 (ANP,2013) ...............29

FIGURA 6 - EVOLUÇÃO DA PRODUÇÃO DE ETANOL HIDRATADO, POR GRANDES REGIÕES - 2003 A 2012 (ANP, 2013) .................30

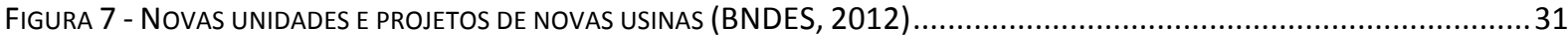

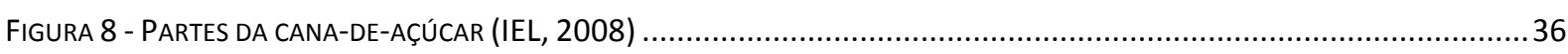

FIGURA 9 - DIAGRAMA DE BLOCOS E DIAGRAMA T-S DO CICLO DE CARNOT (VAN NESS, 2007) ...........................................40

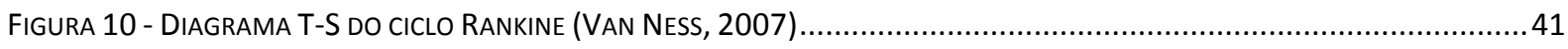

FIGURA 11 - REPRESENTAÇÃO DE UM CICLO RANKINE CONVENCIONAL DE UM SISTEMA DE COGERAÇÃO...................................43

FIGURA 12 - DiAgRAMA T-S DO CICLO RANKINE COM SUPERAQUECIMENTO (VAN NESS, 2007) ........................................45

FIGURA 13 - INFLUÊNCIA DA PRESSÃO DO VAPOR NA SAÍDA DA CALDEIRA (VAN NESS, 2007) .............................................45

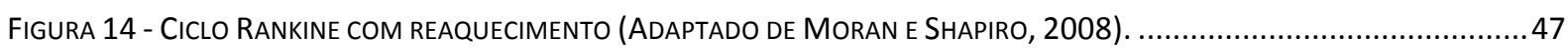

FIGURA 15 - REAQUECIMENTO COM INFINITOS TROCADORES DE CALOR (BRÄSCHER, 1991). ..............................................48

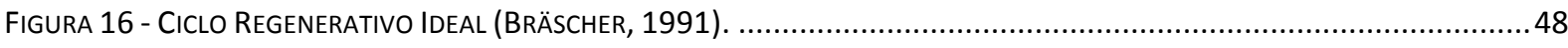

FIGURA 17 - VolUME DE CONTROLE PARA UMA MASSA LEVADA ATÉ AS CONDIÇÕES DO AMBIENTE. .........................................53

FIGURA 18 - ESQUEMA DA ANÁLISE DE CICLO DE VIDA DE UM PRODUTO (GRIPP, 2013) . ...............................................60

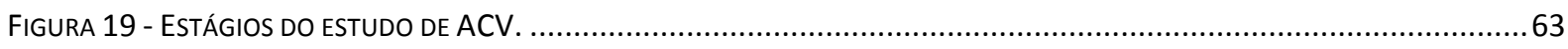

FIGURA 20 - REPRESENTAÇÃO DA PROPOSTA DE UM CICLO RANKINE COM REAQUECIMENTO PARA UM SISTEMA DE COGERAÇÃO. ......81

FiguRA 21 - REPRESENTAÇÃo dA PROPOSTA DE UM CICLO RANKINE REGENERATIVO PARA UM SISTEMA DE COGERAÇÃO. ................82

FIGURA 22 - REPRESENTAÇÃO DA PROPOSTA DE UM CICLO RANKINE RESULTANTE PARA UM SISTEMA DE COGERAÇÃO....................83

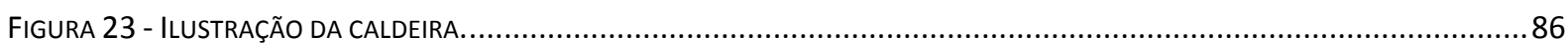

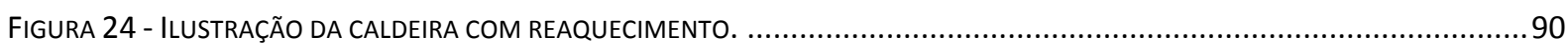

FIGURA 25 - DIAGRAMA H-S PARA ILUSTRAÇÃO DA EFICIÊNCIA DA TURBINA (ADAPTADO DE LI ET AL, 1985).............................93

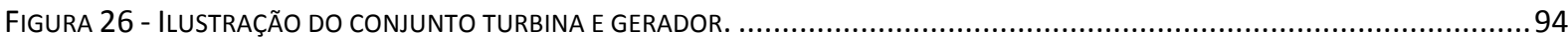

FIGURA 27 - ILUSTRAÇÃO DO CONJUNTO CONDENSADOR E TORRE DE RESFRIAMENTO. ....................................................97

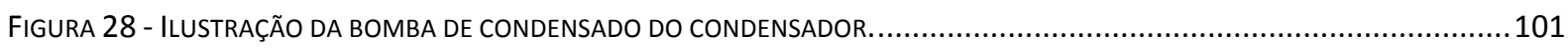

FIGURA 29 - DIAGRAMA H-S PARA ILUSTRAR EFICIÊNCIA DA BOMBA (ADAPTADO DE LI ET AL, 1985). ....................................102

FIGURA 30 - REPRESENTAÇÃO DO DESAERADOR DO SISTEMA DE COGERAÇÃO.......................................................... 104 
FiguRA 31 - ILUSTRAÇÃO DE UM TROCADOR DE CALOR DO CICLO REGENERATIVO. 109

FIGURA 32 - ESQUEMA SIMPLIFICADO DO SISTEMA TURBOGERADOR N ${ }^{\circ} 1$ DA UTE-STP.

FIGURA 33 - ESQUEMA SIMPLIFICADO DO SISTEMA TURBOGERADOR N ${ }^{\circ} 2$ DA UTE-STP.

FiguRA 34 - REPRESENTAÇÃO DO SISTEMA DE PRODUTO ANALISADO.

Figura 35 - CicLo de VAPOR CONVENCIONAL PARA UMA PLANTA DE COGERAÇÃo (INTERFACE DO SIMULADOR).

Figura 36 - Ciclo de VAPOR COM REAQUECIMENTO PARA UMA PLANTA dE COGERAÇÃo (INTERFACE do SiMULAdor). 137

Figura 37 - CiClo de VAPOR Regenerativo PARA uma PLANTA de COGERAÇão (INTERFACE do SimULAdOR). 148

FIGURA 38 - CICLO DE VAPOR RESULTANTE PARA UMA PLANTA DE COGERAÇÃo (INTERFACE DO SIMULADOR). 161

FiguRA 39 - MOINHO HAYBUSTER SENDO ALIMENTADO COM FARDO DE PALHA. 188

FIgURA 40 - COMPARAÇÃO dOS RESULTAdOS DA AVALIAÇÃO DE IMPACTOS AMBIENTAIS ASSOCIADOS À GERAÇÃO DE 1,0 MWH DE ELETRICIDADE EXCEDENTE EM SISTEMA COM CICLO CONVENCIONAL, COM E SEM UTILIZAÇÃO DE PALHA. 196

FIgURA 41 - COMPARAÇÃO dOS RESULTAdOS DA AVALIAÇÃO DE IMPACTOS AMBIENTAIS ASSOCIADOS À GERAÇÃO DE 1,0 MWH DE ELETRICIDADE EXCEDENTE EM SISTEMA COM REAQUECIMENTO, COM E SEM UTILIZAÇÃO DE PALHA. 197

FIgURA 42 - COMPARAÇÃO dOS RESULTADOS DA AVALIAÇÃO DE IMPACTOS AMBIENTAIS ASSOCIADOS À GERAÇÃO DE 1,0 MWH DE ELETRICIDADE EXCEDENTE EM SISTEMA COM CICLO REGENERATIVO, COM E SEM UTILIZAÇÃO DE PALHA........ 198

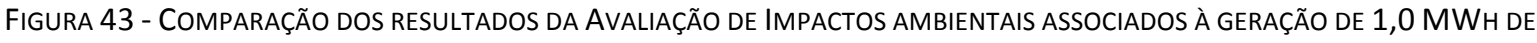
ELETRICIDADE EXCEDENTE EM SISTEMA COM CICLO RESULTANTE, COM E SEM UTILIZAÇÃO DE PALHA. 199

Figura 44 - COMPARAÇÃo dOS RESULTAdOS DA AVALIAÇÃo DE IMPACTOS AMBIENTAIS ASSOCIAdOS À GERAÇÃO DE 1,0 MWH DE ELETRICIDADE EXCEDENTE EM SISTEMA COM CICLO CONVENCIONAL, COM E SEM UTILIZAÇÃO DE PALHA, ADOTANDO CRITÉRIO ENERGÉTICO DE ALOCAÇÃO NO SISTEMA DE COGERAÇÃO.

GRÁFICO 1 - RESULTADOS DA EFICIÊNCIA ENERGÉTICA E EXERGÉTICA PRA OS CENÁRIOS I A V.

GRÁFICO 2 - RESULTADO dOS INDICADORES DE PERFORMANCE ESPECÍFICOS, PARA OS CENÁRIOS I A V.

GRÁFICO 3 - RESULTADOS DA ANÁLISE ENERGÉTICA PARA OS CENÁRIOS I A V

GRÁFICO 4 - RESULTADOS DA ANÁLISE EXERGÉTICA PARA OS CENÁRIOS I A V.

GRÁFICO 5 - RESULTADOS DA EFICIÊNCIA ENERGÉTICA E EXERGÉTICA PRA OS CENÁRIOS VI A X.

GRÁFICO 6 - RESULTADO DOS INDICADORES DE PERFORMANCE ESPECíFICOS, PARA OS CENÁRIOS VI A X.

GRÁFICO 7 - RESULTADOS DA ANÁLISE ENERGÉTICA PARA OS CENÁRIOS VI A X. 135

GRÁFICO 8 - RESULtAdOS DA ANÁLISE EXERGÉtICA PARA OS CENÁRIOS VI A X. 136

GRÁFICO 9 - RESULTADOS DA EFICIÊNCIA ENERGÉTICA E EXERGÉTICA PRA OS CENÁRIOS XI A XV.

GRÁFICO 10 - RESULTADO DOS INDICADORES DE PERFORMANCE ESPECÍ́FICOS, PARA OS CENÁRIOS XI A XV.

GRÁFICO 11 - RESULTADOS DA ANÁLISE ENERGÉTICA PARA OS CENÁRIOS XI A XV.

GRÁFICO 12 - RESULTADOS DA ANÁLISE EXERGÉTICA PARA OS CENÁRIOS XI A XV.

GRÁFICO 13 - RESULTADOS DA EFICIÊNCIA ENERGÉTICA E EXERGÉTICA PRA OS CENÁRIOS XVI A XX.

GRÁFICO 14 - RESULTADO dOS INDICADORES DE PERFORMANCE ESPECÍFICOS, PARA OS CENÁRIOS XVI A XX. 
GRÁFICO 15 - RESULTADOS DA ANÁLISE ENERGÉTICA PARA OS CENÁRIOS XVI A XX. 146

GRÁFICO 16 - RESULTADOS DA ANÁliSE EXERGÉTICA PARA OS CENÁRIOS XVI A XX.

GRÁFICO 17 - RESULTADOS DA EFICIÊNCIA ENERGÉTICA E EXERGÉTICA PRA OS CENÁRIOS XXI A XXV.

GRÁFICO 18 - RESULTADO DOS INDICADORES DE PERFORMANCE ESPECÍFICOS, PARA OS CENÁRIOS XXI A XXV. 150

GRÁFICO 19 - RESULTADOS DA ANÁLISE ENERGÉTICA PARA OS CENÁRIOS XXI A XXV. 152

GRÁFICO 20 - RESULTADOS DA ANÁLISE EXERGÉTICA PARA OS CENÁRIOS XXI A XXV 153

GRÁFICO 21 - RESULTADOS DA EFICIÊNCIA ENERGÉTICA E EXERGÉTICA PRA OS CENÁRIOS XXVI A XXX. 154

GRÁFICO 22 - RESULTADO DOS INDICADORES DE PERFORMANCE ESPECÍ́FICOS, PARA OS CENÁRIOS XXVI A XXX. .156

GRÁFICO 23 - RESULTADOS DA ANÁLISE ENERGÉTICA PARA OS CENÁRIOS XXVI A XXX. 158

GRÁFICO 24 - RESULTADOS DA ANÁLISE EXERGÉTICA PARA OS CENÁRIOS XXVI A XXX. 159

GRÁFICO 25 - RESULTADOS DA EFICIÊNCIA ENERGÉTICA E EXERGÉTICA PRA OS CENÁRIOS XXXI A XXXV. 162

GRÁFICO 26 - RESULTADO DOS INDICADORES DE PERFORMANCE ESPECÍFICOS, PARA OS CENÁRIOS XXXI A XXXV. 163

GRÁFICO 27 - RESULTADOS DA ANÁLISE ENERGÉTICA PARA OS CENÁRIOS XXXI A XXXV. 164

GRÁFICO 28 - RESULTADOS DA ANÁLISE EXERGÉTICA PARA OS CENÁRIOS XXXI A XXXV. 165

GRÁFICO 29 - RESULTADOS DA EFICIÊNCIA ENERGÉTICA E EXERGÉTICA PRA OS CENÁRIOS XXXVI A XL. 167

GRÁFICO 30 - RESULTADO DOS INDICADORES DE PERFORMANCE ESPECÍFICOS, PARA OS CENÁRIOS XXXVI A XL. 168

GRÁFICO 31 - RESULTADOS DA ANÁLISE ENERGÉTICA PARA OS CENÁRIOS XXXVI A XL.... 169

GRÁFICO 32 - RESULTADOS DA ANÁLISE EXERGÉTICA PARA OS CENÁRIOS XXXVI A XL. 170

GRÁFICO 33 - INFLUÊNCIA DA ADIÇÃO DE TROCADORES DE CALOR SOBRE A EFICIÊNCIA EXERGÉTICA DO CICLO RANKINE, NA CONDIÇÃO DE PRESSÃO DE OPERAÇÃO DE 20 BAR. .343

GRÁFICO 34 - INFLUÊNCIA DA ADIÇÃO DE TROCADORES DE CALOR SOBRE A EFICIÊNCIA EXERGÉTICA DO CICLO RANKINE, NA CONDIÇÃO DE PRESSÃO DE OPERAÇÃO DE 45 BAR. 344

GRÁFICO 35 - INFLUÊNCIA DA ADIÇÃO DE TROCADORES DE CALOR SOBRE A EFICIÊNCIA EXERGÉTICA DO CICLO RANKINE, NA CONDIÇÃO DE PRESSÃO DE OPERAÇÃO DE 67 BAR. 344

GRÁFICO 36 - INFLUÊNCIA DA ADIÇÃO DE TROCADORES DE CALOR SOBRE A EFICIÊNCIA EXERGÉTICA DO CICLO RANKINE, NA CONDIÇÃO DE PRESSÃO DE OPERAÇÃO DE 80 BAR. 345

GRÁFICO 37 - INFLUÊNCIA DA ADIÇÃO DE TROCADORES DE CALOR SOBRE A EFICIÊNCIA EXERGÉTICA DO CICLO RANKINE, NA CONDIÇÃO DE PRESSÃO DE OPERAÇÃO DE 100 BAR. 


\section{LISTA DE TABELAS}

TABELA 1 - SUCESSÃO DE TRANSFORMAÇÕES TERMODINÂMICAS OCORRIDAS NO CICLO CARNOT (VAN NESS, 2007) . .40

TABELA 2 - SUCESSÃO DE TRANSFORMAÇÕES TERMODINÂMICAS OCORRIDAS NO CICLO RANKINE (VAN NESS, 2007) .41

TABELA 3 - DISTRIBUIÇÃO DAS PRESSÕES DE OPERAÇÃO DAS CALDEIRAS NAS USINAS BRASILEIRAS (IDEA, 2012) ........................42

TABELA 4 - CARACTERÍSTICAS dOS CENÁRIOS AVALIAdOS PARA O SISTEMA DE COGERAÇÃO. ................................................77

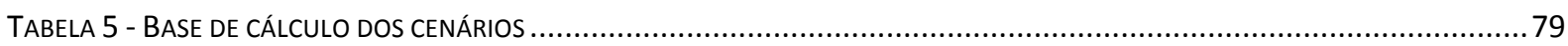

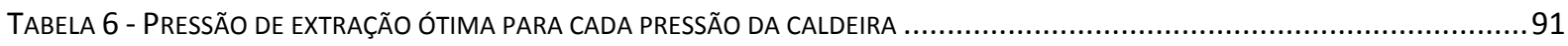

TABELA 7 - RESUMO DAS CARACTERÍSTICAS TÉCNICAS DOS EQUIPAMENTOS INSTALADOS NA UTE-STP................................116

TABELA 8 - DESVIOS NA FORMA DE ERROS PERCENTUAIS DO MODELO EM RELAÇÃO OS SISTEMAS DA UTE-STP..........................118

TABELA 9 - CARACTERÍSTICAS DOS CENÁRIOS DE COGERAÇÃO COM CICLO RANKINE CONVENCIONAL. ......................................125

TABELA 10 - CARACTERÍSTICAS dOS CENÁRIOS DE COGERAÇÃo COM CICLO RANKINE COM REAQUECIMENTO.............................138

TABELA 11 - CARACTERÍSTICAS doS CENÁRIOS DE COGERAÇÃo COM CICLO RANKINE REGENERATIVO. .....................................148

TABELA 12 - CARACTERÍSTICAS dos CENÁRIOS DE COGERAÇÃo COM CICLO RANKINE RESULTANTE........................................161

TABELA 13 - INVENTÁRIO CONSOLIDADO DA PRODUÇÃO DE 1 KG DE CANA - COM QUEIMADA PRÉVIA PERCENTUAL DEFINIDA, SEM APROVEITAMENTO DA PALHA.

TABELA 14 - INVENTÁRIO CONSOLIDAdO DA PRODUÇÃo dE 1 KG DE CANA - CENÁRIO FUTURO, SEM QUEIMADA PRÉVIA E COM

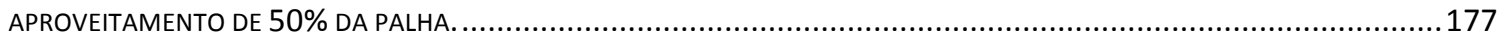

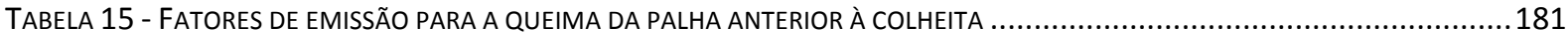

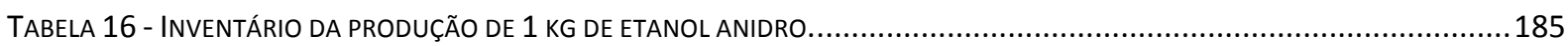

TABELA 17 - FATORES DE EMISSÃO PARA A QUEIMA DE ÓLEO DIESEL EM MAQUINÁRIOS AGRÍCOLAS. ......................................186

TABELA 18 - PeRCENTUAIS DE ALOCAÇÃo PARA CENÁRIOS SEM APROVEITAMENTO DA PALHA. ...........................................190

TABELA 19 - PeRCENTUAIS DE ALOCAÇÃo PARA CENÁRIOS COM APROVEITAMENTO DA PALHA. ..........................................190

TABELA 20 - Resultados da AVALIAÇÃO de IMPACtOS AMBIENTAIS PARA OS CENÁRIOS I A V ASSOCIAdOS À GERAÇÃO DE 1,0 MWH DE ELETRICIDADE EXCEDENTE, NA UNIDADE DE COGERAÇÃO.

TABELA 21 - Resultados da AVALIAÇÃo de IMPACtOS AMBIENTAIS PARA OS CENÁRIOS VI A X ASSOCIAdos À GERAÇÃo de 1,0 MWH DE ELETRICIDADE EXCEDENTE, NA UNIDADE DE COGERAÇÃO. ...........................................................194

TABELA 22 - PERCENTUAIS DE ALOCAÇÃO POR CRITÉRIO ENERGÉTICO PARA CENÁRIOS SEM APROVEITAMENTO DA PALHA..............206

TABELA 23 - PeRCENTUAIS de ALOCAÇÃo POR CRITÉRIO ENERgÉTICO PARA CENÁRIOS COM APROVEITAMENTO dA PALHA. .............206

TABELA 24 - INFLUÊNCIA DA ADIÇÃO DE TROCADORES DE CALOR SOBRE A EFICIÊNCIA EXERGÉTICA DO CICLO RANKINE, NA CONDIÇÃO DE PRESSÃO DE OPERAÇÃO DE 20 BAR.

TABELA 25 - INFLUÊNCIA DA ADIÇÃO DE TROCADORES DE CALOR SOBRE A EFICIÊNCIA EXERGÉTICA DO CICLO RANKINE, NA CONDIÇÃO DE PRESSÃO DE OPERAÇÃO DE 45 BAR.

TABELA 26 - INFLUÊNCIA DA ADIÇÃO DE TROCADORES DE CALOR SOBRE A EFICIÊNCIA EXERGÉTICA DO CICLO RANKINE, NA CONDIÇÃO DE PRESSÃO DE OPERAÇÃO DE 67 BAR.

TABELA 27 - INFLUÊNCIA DA ADIÇÃO DE TROCADORES DE CALOR SOBRE A EFICIÊNCIA EXERGÉTICA DO CICLO RANKINE, NA CONDIÇÃO DE PRESSÃO DE OPERAÇÃO DE 80 BAR. 
TABELA 28 - INFLUÊNCIA DA ADIÇÃO DE TROCADORES DE CALOR SOBRE A EFICIÊNCIA EXERGÉTICA DO CICLO RANKINE, NA CONDIÇÃO DE PRESSÃO DE OPERAÇÃO DE 100 BAR. 


\section{SUMÁRIO}

1. INTRODUÇÃO

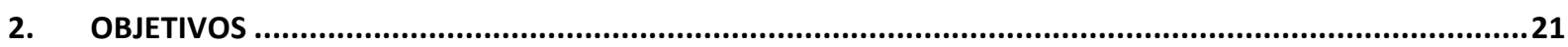

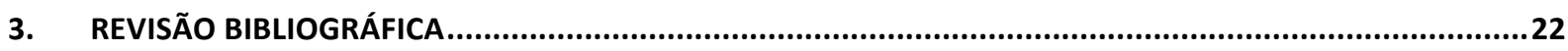

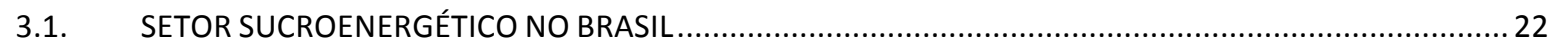

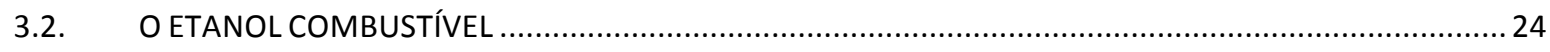

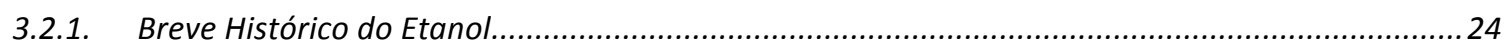

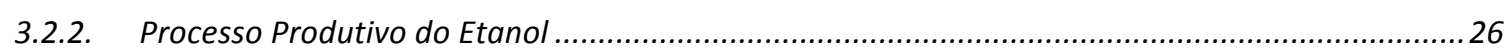

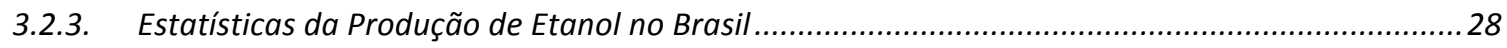

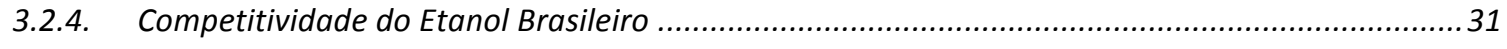

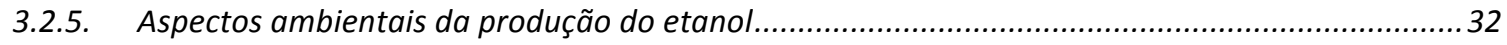

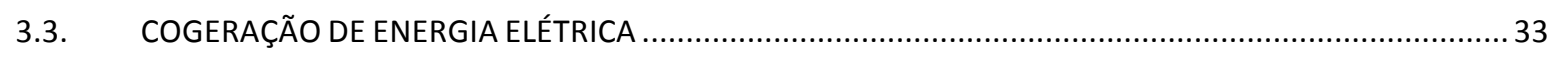

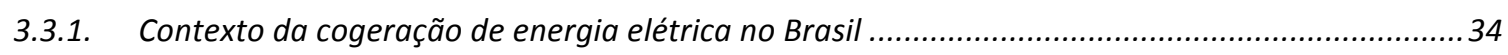

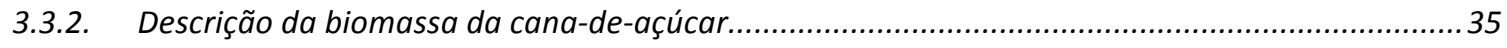

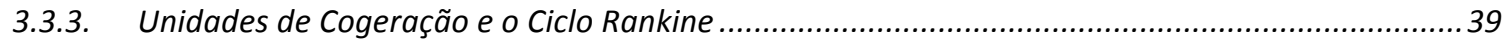

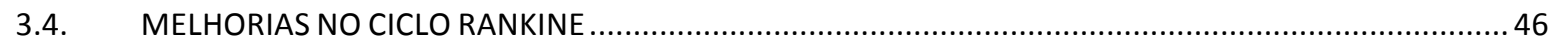

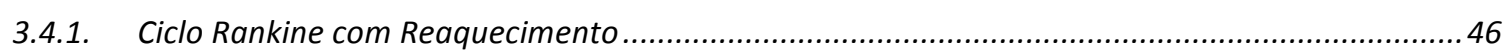

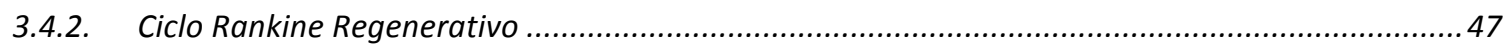

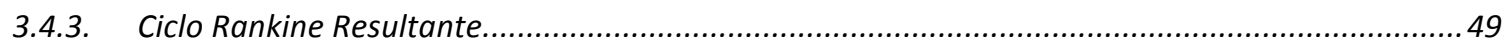

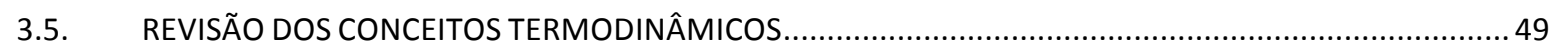

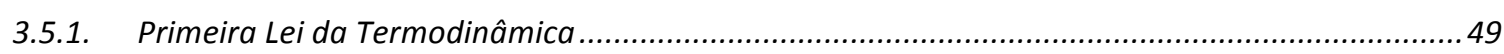

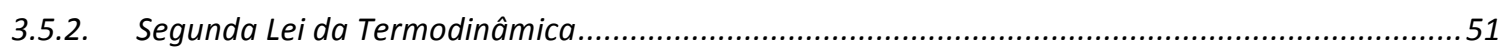

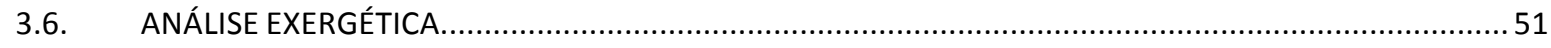

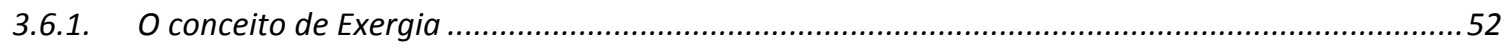

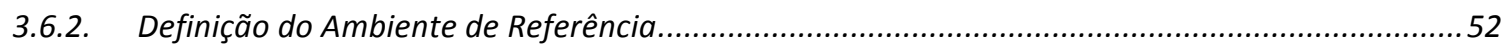

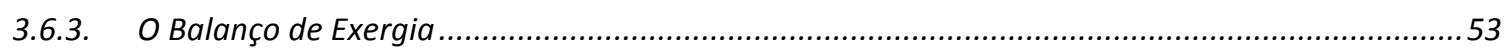

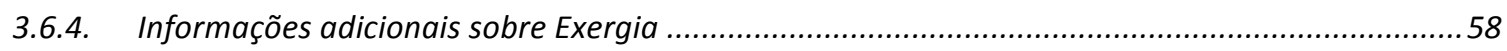

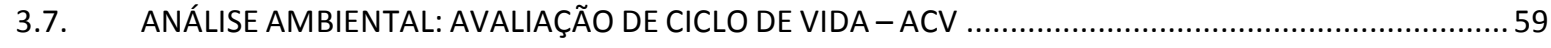

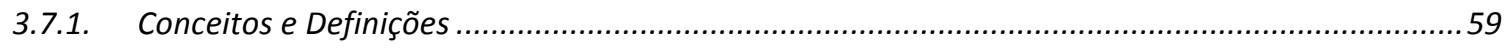

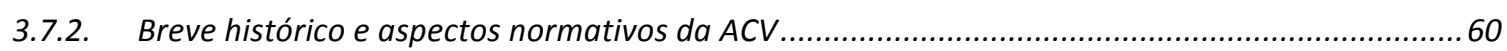

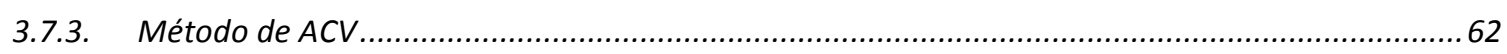

3.8. ESTUDOS CIENTÍFICOS ENVOLVENDO ACV E ANÁLISE EXERGÉTICA................................................. 69

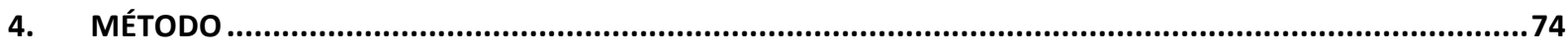

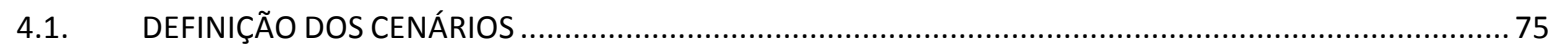

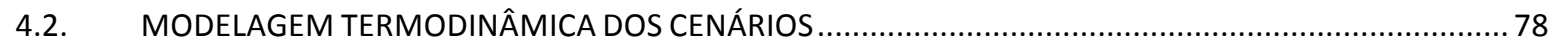


4.2.1. Premissas e Definição dos parâmetros operacionais dos cenários.........................................78

4.2.2. A ferramenta usada para construção dos modelos matemáticos .............................................80

4.2.3. Características específicas dos arranjos com reaquecimento e regenerativo ..............................80

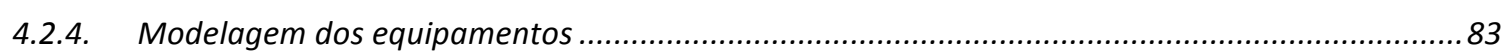

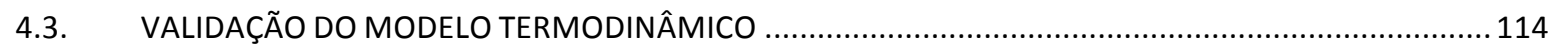

ASPECTOS ESPECÍFICOS PARA AVALIAÇÃO AMBIENTAL ......................................................... 119

4.4. 119

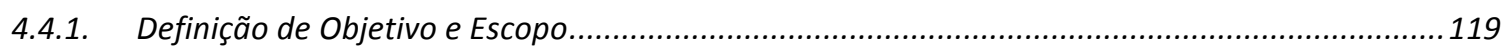

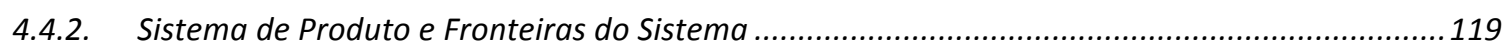

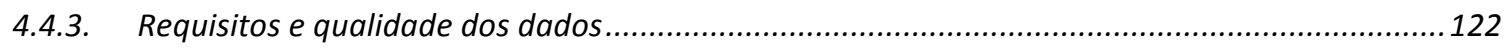

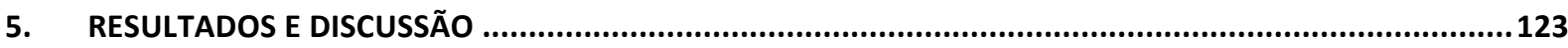

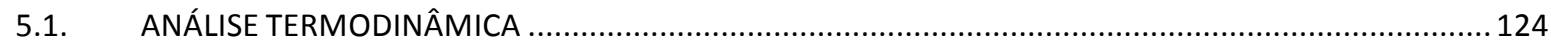

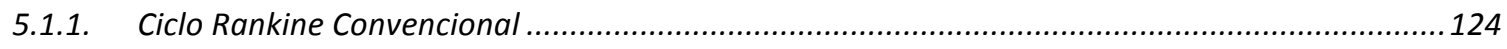

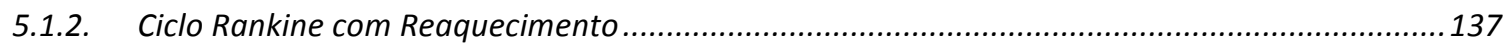

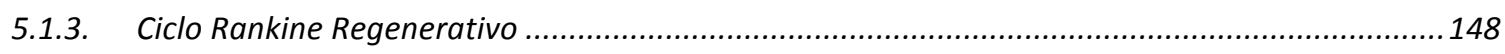

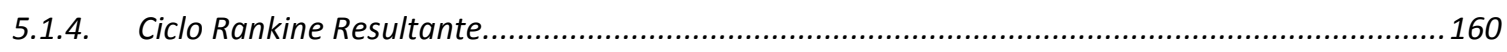

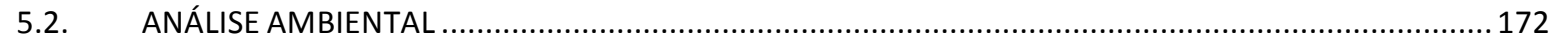

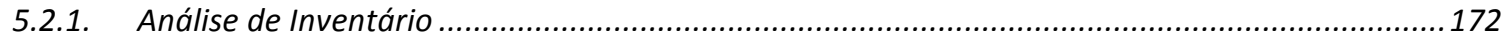

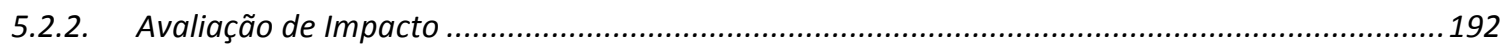

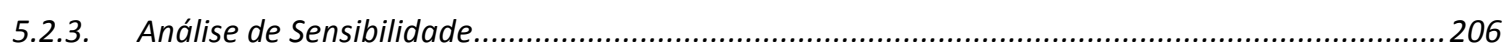

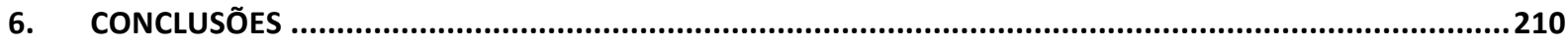

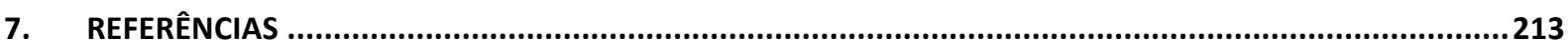

APÊNDICE A - MODELAGEM DO SISTEMA DE COGERAÇÃO COM CICLO RANKINE CONVENCIONAL..............226 APÊNDICE B- MODELAGEM DO SISTEMA DE COGERAÇÃO COM CICLO RANKINE COM REAQUECIMENTO ...245 APÊNDICE C- MODELAGEM DO SISTEMA DE COGERAÇÃO COM CICLO RANKINE REGENERATIVO ................264 APÊNDICE D- MODELAGEM DO SISTEMA DE COGERAÇÃO COM CICLO RANKINE RESULTANTE...................265 APÊNDICE E- MODELAGEM DO SISTEMA DE COGERAÇÃO COM CICLO RANKINE REGENERATIVO PARA AVALIAÇÃO DA INFLUÊNCIA DO NÚMERO DE TROCADORES DE CALOR NA EFICIÊNCIA EXERGÉTICA. 312 APÊNDICE F - RESULTADOS DA ANÁLISE PARAMÉTRICA PARA DETERMINAR A INFLUÊNCIA DA ADIÇÃO DE TROCADORES DE CALOR NO CICLO CONVENCIONAL, OBTENDO ASSIM O CICLO REGENERATIVO. 


\section{INTRODUÇÃO}

Há aproximadamente quatro décadas, vem se discutindo em todo o mundo a incorporação de fontes renováveis à matriz energética das diversas nações. Seja por causa da instabilidade econômica do preço do petróleo bruto, ou mesmo, devido aos impactos ambientais associados a diversos estágios da cadeia de suprimentos dos recursos fósseis. Esse enfoque deriva de uma cultura ambiental recente, que revisou paradigmas do modelo Desenvolvimentista em que os processos industriais eram realizados apenas com a preocupação de gerar bens de produção e consumo, a despeito dos efeitos que proporcionassem sobre o entorno (Gil et al., 2013).

O uso de fontes de energia mais limpas tem se tornado um assunto de interesse para a sociedade (Gonzáles-García et al., 2012; Luo et al., 2008). Nesse contexto, o Brasil merece especial destaque, em virtude de sua matriz energética apresentar elevada taxa de modais de origem renovável. Registros oficiais do Ministério de Minas e Energia revelam que 45,4\% de toda a energia produzida no país em 2010 têm origem em recursos naturais que não são finitos (MME, 2011). Registros oficiais da mesma instituição governamental datados de 2013, reportam que $85 \%$ da energia elétrica nacional é originada por fontes renováveis, sendo a oferta hidráulica responsável por 70,1\%. A mesma fonte dá conta de que a oferta de energia elétrica cresceu 3,9\% naquele período, sendo o modal eólico foi aquele a aportar maior incremento, com $86,7 \%$, muito embora sua participação compreenda apenas 0,9\% da oferta interna de eletricidade do país (BEN, 2013). A título situacional, observa-se que em 2013, a bioeletricidade sucroenergética representou 3,0\% do consumo nacional de energia elétrica (ÚNICA, 2014).

O crescimento da frota de veículos bicombustíveis no Brasil tem justificado a forte expansão da demanda por etanol no mercado interno. O Ministério de Minas e Energia, por meio da Empresa de Pesquisa Energética (EPE), estima que a demanda por etanol deverá triplicar no curso desta década, passando de 27 bilhões de litros em 2010, para 73 bilhões em 2020 já incluidos 6,8 bilhões de litros para exportação (MME, 2011). Como desdobramentos imediatos desse desempenho, decorrem um aumento proporcional da geração da biomassa canavieira e, consequente, no potencial de geração de energia elétrica a partir da cogeração. Somem-se a este fato, outros dois elementos não menos essenciais: $O$ alto grau de 
vulnerabilidade a que se expõea geração de energia elétricano país em virtude de oscilações recorrentes nos níveis das barragens; e a manifesta preocupação da sociedade moderna com as mudanças climáticas (Sousa e Macedo, 2010).

Segundo dados do Ministério da Agricultura, Pecuária e Abastecimento, o Brasil tem se destacado como líder mundial na produção de cana-de-açúcar. O caldo da canade-açúcar é consumido na produção de etanol e açúcar. No entanto, até recentemente o tecido vegetal remanescente da cana, o bagaço, não tinha qualquer aplicação, sendo subutilizado ou descartado na natureza e portanto, gerando inexoravelmente impactos ambientais. Tecnologias têm sido desenvolvidas ao longo dos últimos anos a fim de mudar essa situação. A mais consolidada dessas abordgens é a utilização do bagaço para produção de vapor e eletricidade, (MAPA, 2012). Por conta disso, as usinas tornaram-se potencialmente auto-suficientes em termos energéticos e até, em muitos casos, se credenciaram a exportar o excedente de eletricidade gerada para a rede concessionária. Com isso, a cogeração energética passou a ser uma alternativade alta eficiência de uso racional de combustível primário com vistas às produções de eletricidade e calor (Bocci et al., 2009; Tina e Passarello, 2011).

A perspectiva de exportar eletricidade para a rede nacional, inclusive durante os períodos de entressafra, motivou as usinas brasileiras de etanol e açúcar a investirem em sistemas de cogeração nos últimos anos. No entanto a componente ambiental associada à cogeração de eletricidade deve ser aspecto mandatório em avaliações que pretendam viabilizar a integração ao grid nacional como alternativa de suprimento.

Por outro lado, teem crescido os questionamentos quanto a relação de dependência entre a produção de etanol e o processamento agrícola, a necessidade de aumento das áreas agricultáveis, e a possível competição com a produção de alimentos. Tais discussões fomentaram a corrida tecnológica em busca de processos mais eficientes e com custos de produção atrativos para produção do etanol a partir de resíduos de biomassa, chamado de etanol celulósico, ou de segunda geração (Petrobras, 2012; CTC, 2014).

Nesse cenário, a biomassa da cana, composta por bagaço e palha, tornou-se também uma opção de matéria-prima para produção do etanol. Segundo dados da 
Embrapa, a utilização do bagaço e da palha teria potencial para elevar a produção de etanol em até $40 \%$, para uma mesma área plantada. A combinação das rotas de primeira e segunda geração na produção de etanol de cana-de-açúcar permitirá obter maior quantidade de combustível sem aumentar o volume de matéria-prima plantada, porém, em detrimento da disponibilidade de bagaço para a cogeração elétrica (Embrapa, 2014).

De forma geral, há um ritmo cada vez mais intenso da exploração dos recursos naturais para que possam ser atendidas as demandas de uma população mundial que não apenas continua a crescer, mas também, e principalmente, que exercita padrões de consumo cada vez mais elevados. A longo prazo, tal ritmo evidentemente não pode ser sustentado por um motivo bastante simples: os recursos naturais que o planeta pode fornecer para o atendimento das necessidades e desejos humanos são finitos. Essa limitação precisa ser levada em conta para que a melhoria do padrão de vida experimentada pelas sociedades humanas, sobretudo nos últimos séculos, possa ser mantida também no longo prazo (Gripp, 2013).

O desenvolvimento tecnológico tem papel fundamental no equacionamento de uma solução robusta para esse quadro desfavorável. Para que o ritmo de exploração dos recursos naturais e de geração de rejeitos pelas atividades humanas seja compatível com os ciclos naturais de renovação desses próprios recursos, torna-se cada vez mais urgente desenvolver tecnologias menos recurso-intensivas e/ou que permitam reduzir, reaproveitar e reciclar resíduos gerados, os quais, muitas vezes, possuem grande potencial para tornarem-se novamente recursos (Gripp, 2013).

No campo energético, esse estado de coisas insita o meio acadêmico a buscar combustíveis alternativos aos de origem fóssil, derivados de fontes renováveis e com bom desempenho ambiental associado. No caso específico da biomassa, este esforço se concentra em duas vertentes: a viabilização de fontes de provimento de energia antes não aproveitadas, ou mesmo, que ainda não foram testadas; e o aumento da eficiência energética dos processos de cogeração. Em qualquer dos dois enfoques, o estudo detalhado dos impactos ambientais associados aos produtos, aparece como balizador visando agregar mais valor ao produto.

Para que as avaliações ambientais sejam efetivas não há outra possibilidade que realizá-las segundo uma abordagem sistêmica - que compreenda o ciclo de vida -, 
a fim de detectar, de maneira precisa, pontos positivos e deficiências associadas a substituição de recursos energéticos. Ao medir os efeitos causados por produtos de origem renovável sobre o ambiente no exercício do atendimento de necessidades energéticas, esta leitura possibilita implantar ações e estratégias além da fronteira do processo de transformação, evitando soluções unilaterais, devido transferência de cargas ambientais entre diferentes impactos, regiões ou receptores, ou seja, na relação ambiente e qualidade de vida humana. Nesse cenário, a inclusão de etapas como preparo do solo, extração de recursos, transporte, produção, uso, manutenção e descarte final do produto é intrínseca à análise. Tais características metodológicas adicionadas ao levantamento quantitativo dos impactos ambientais relacionados ao exercício da função de um produto caracterizam a base do método de Avaliação do Ciclo de Vida (ACV) (Kulay, 2000).

Por outro lado, tratando-se especificamente do uso de biomassa da cana-de-açúcar como fonte energética, um diagnóstico termodinâmico efetivo sobre qualquer dos padrões de sistemas de cogeração mais utilizados no Brasil, que sirva para formar uma base sólida para tomada de decisões e aplicação de ações de engenharia, passa, necessariamente, por uma análise exergética. Segundo Oliveira Jr. (2012), exergia é a parte da energia que pode ser completamente convertida em outras formas de energia, ou seja, trabalho. Normalmente, o que se observa nas análises de sistemas térmicos é a tentativa de diagnosticar o desempenho de unidades geradoras por meio de análise energética, restrita a Primeira Lei da Termodinâmica. No entanto, a despeito dos resultados que oferece, Oliveira Jr. (2012) argumenta que essa análise considera todas as formas de energia como equivalentes, não sendo possível contabilizar a capacidade de realizar trabalho que está sendo perdida ao longo de um processo, nem onde ocorrem suas irreversibilidades.

Como solução a essa limitação, Torres (1999) sugere aferir o desempenho do sistema considerando também a Segunda Lei da Termodinâmica; ou seja, realizando uma Análise Exergética. Segundo Tsatsaronis e Park (2002) a Análise Exergética complementa a análise energética ao oferecer uma melhor medida da magnitude da energia perdida em relação à energia total fornecida sob a forma de insumo energético; uma medida da "qualidade" da energia do ponto de vista termodinâmico; uma variável para definir a eficiência racional que é a relação entre a 
exergia do efeito desejado e a exergia necessária ao processo, para o sistema energético.

Diante dessas constatações, elevam-se à categoria de requisitos essenciais a qualquer análise de cenário de cogeração que simule a aplicação de técnicas factíveis de melhoria de desempenho energético e a utilização de biomassa, o conhecimento e a quantificação dos desdobramentos ambientais e energéticos a eles associados, com o intuito não apenas de identificar aspectos chave destas ações, como também, de dar fundamentação consistente a processos de tomada de decisão, incorporando, sobretudo a variável ambiental. 


\section{OBJETIVOS}

Tendo em vista o contexto apresentado por ocasião do capítulo de Introdução deste documento, o presente estudo se propõe, no nível de objetivo geral, a produzir um diagnóstico termodinâmico e ambiental da cogeração de energia elétrica em usinas autônomas para diferentes condições de processo e operação dessa tecnologia.

Desta forma, para atendimento ao propósito antes enunciado, esta iniciativa foi estruturada na forma dos marcos intermediários, ou objetivos específicos, que estão descritos a seguir:

- Construção de modelo conceitual e representativo de um sistema de cogeração real, que permita comparar condições operacionais e de projeto para diferentes status de implementação de alternativas tecnológicas voltadas ao aumento da eficiência termodinâmica;

- Avaliação de desempenhos termodinâmico e ambiental do sistema em questão para distintas condições de projeto e composições de combustíveis derivados de biomassa (bagaço e palha) como fonte de energia térmica.

Além disso, como intentos complementares, porém não menos importante e que são imediatamente decorrentes desta iniciativa, podem-se ainda citar:

- Apresentar uma contribuição à indústria sucroalcooleira plasmada na forma de aferição técnica de potenciais ações de melhoriade eficiência energética sobre o ciclo termodinâmico Rankine;

- Avaliar a importância de se incorporar a variável ambiental de âmbito sistêmico a projetos de engenharia voltados ao setor sucroalcooleiro com vistas a dar suporte a processos gerenciais de tomada de decisão. 


\section{REVISÃO BIBLIOGRÁFICA}

Este capítulo discorre sobre o setor sucroalcooleironos âmbitos de suastendências de produção e consumo do etanol combustível e dacogeração energética no Brasil. Além disso, apresenta uma breve revisão bibliográfica sobre as técnicas de Análise Exergética e de Avaliação do Ciclo de Vida (ACV).

O mesmo arrazoado se encerra com uma descrição sucinta de estudos publicadosrecentemente na literatura acadêmico-científico que associaram de alguma forma análises de desempenho ambiental e exergética, com os interesses de verificação e de aprimoramento de sistemas de produção de energia elétrica.

\subsection{SETOR SUCROENERGÉTICO NO BRASIL}

O setor sucroalcooleiro brasileiro congrega empresas que produzem açúcar e/ou etanol, ou que atuam em algum elo da cadeia produtiva desses elementos. No Brasil, este setor está diretamente relacionado às culturas de cana-de-açúcar, por se tratardo principal insumo dos processos produtivos em questão (Lins e Saavedra, 2007).

Destacam-se os seguintes produtos do processo industrial sucroalcooleiro: açúcar; etanol combustível e de uso comum, empregadona confeccção de bebidas alcoólicas e para limpezas domésticas; vinhoto; levedura de cana e a eletricidade. $\mathrm{O}$ bagaço tem sido utilizado como fonte de energia térmica em sistemas de cogeração instalados na maioria das usinas sucroalcooleiras do Brasil. Com incorporação da eletricidade atualmente gerada a partir da cogeração, o setor também passou a ser chamado de setor sucroenergético (ÚNICA, 2013).

A cana-de-açúcar é uma das mais importantes culturas brasileira. Apresenta um ciclo produtivo de cinco anos e com produtividade média variável entre 65 e 120 t/hasempre dependendo da região em que o cultivo ocorre, e da tecnologia agrícola ali aplicada (MAPA, 2013). Na safra 2011/2012 a cana ocupou 8,5 milhões de hectares - cerca de $2 \%$ de toda a terra arável do país (CONAB, 2012). Com esse desempenho, o Brasil se consolida como maior produtor mundial do ativo agrícola, seguido por Índia, China, Tailândia, México e Paquistão, como mostra a Figura 1. 


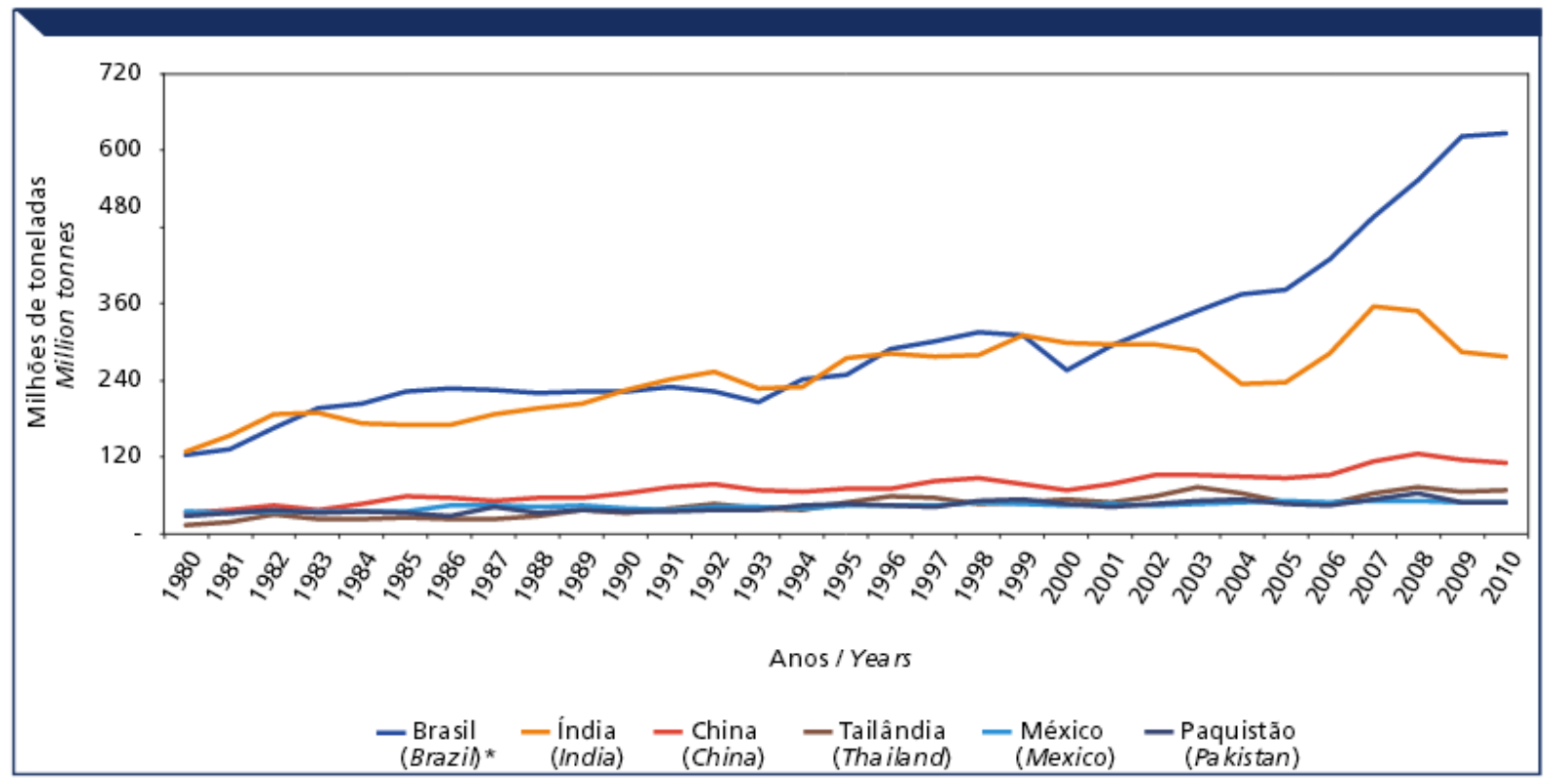

Figura 1 - Série histórica da produção dos principais países produtores da cana-de-açúcar, em milhões de toneladas (MAPA, 2013)

Segundo dados da ÚNICA (2013), em 2012 haviam 437 usinas sucroalcooleiras ativas no território nacional. O cultivo de cana-de-açúcar se difunde pelas cinco regiões do país; no entanto, aparece mais concentrado nas regiões sul, centrooeste, sudeste e nordeste, assim como aparece destacado no mapa constante da Figura 2.

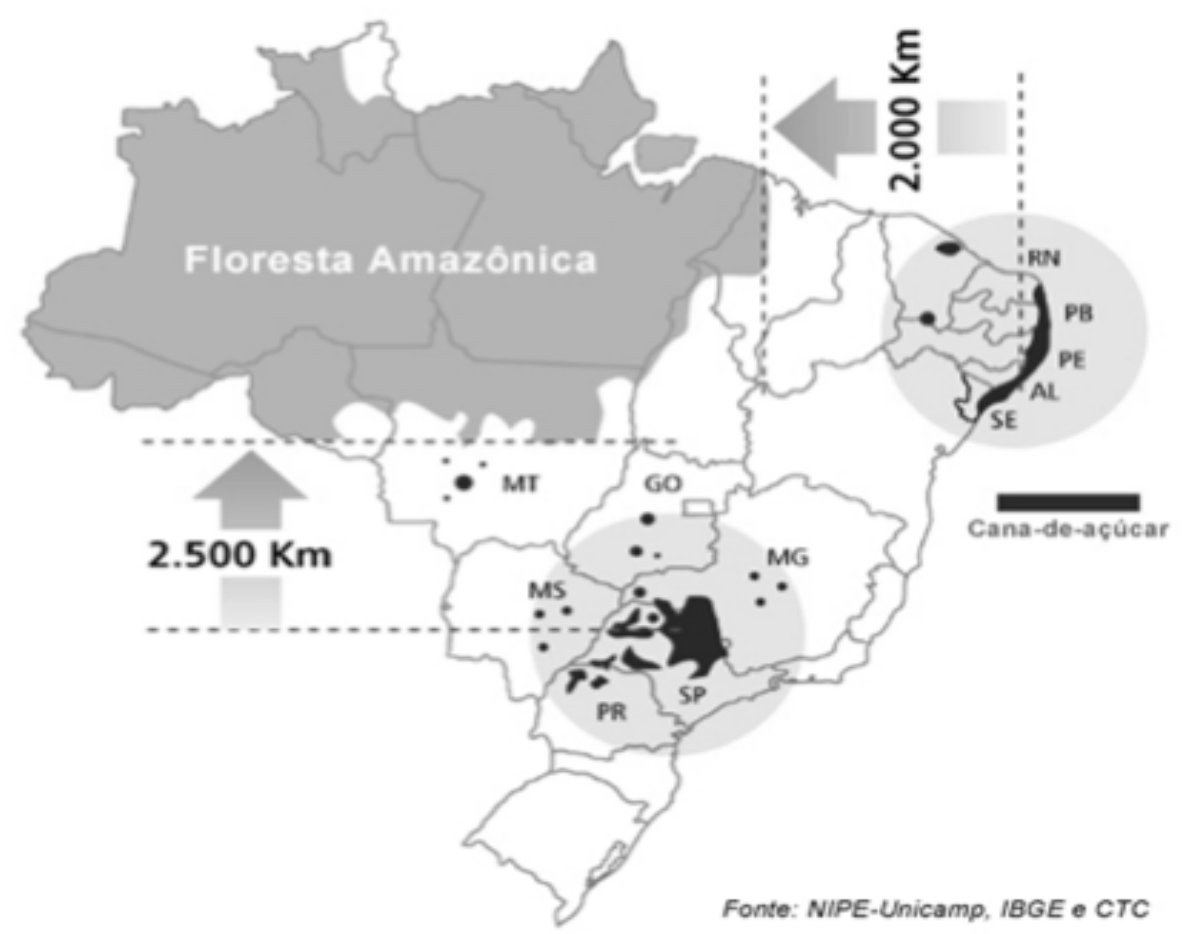

Figura 2 - Mapa de produção de cana-de-açúcar no Brasil (ÚNICA, 2013). 
O estado de São Paulo aparece como o maior produtor nacional de cana-de-açúcar, respondendo por $61,8 \%$ de sua produção (MAPA, 2013). Nesta região ocorrem também a maior produtividade agrícola do país, entre 80 e 98 t/ha ao longo de cinco colheitas sucessivas entre reformas de terreno. Registram-se em São Paulo picos de produçãoda ordem de 140 t/ha, atingidos em geral no primeiro ano de cultivo (MAPA, 2013). A Figura 3 apresenta a distribuição da produção de cana-de-açúcar porestados brasileiros.

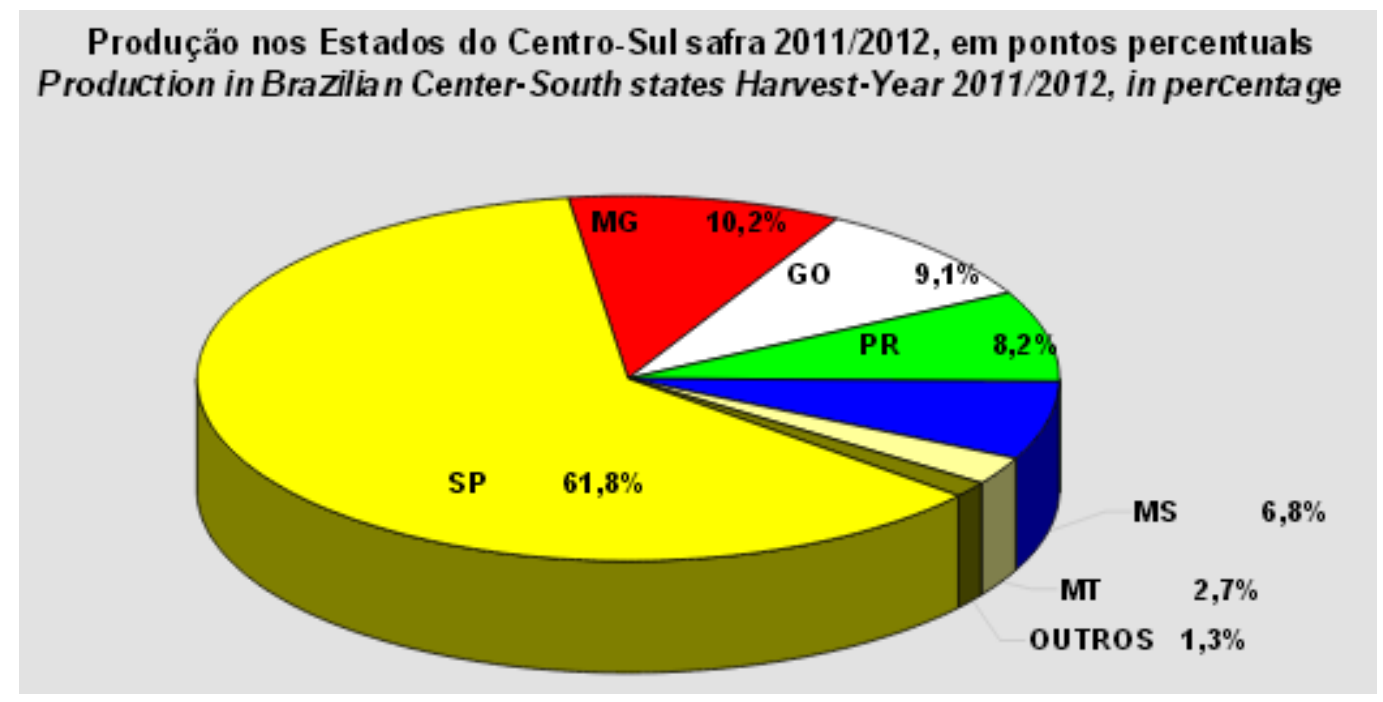

Figura 3 - Produção de cana no Brasil por estados (MAPA, 2013)

\subsection{O ETANOL COMBUSTÍVEL}

\subsubsection{BREVE HISTÓRICO dO ETANOL}

Ao longo dos tempos, a sociedade adotou os derivados de petróleo como fonte de fornecimento de energia em detrimento de fontes renováveis, devido a seu custo mais acessível, e ao fato dos ativos energéticos de origem agrícola serem destinados ao mercado alimentício. Entretanto, o aumento dos preços do petróleo cru - em virtude de impostos, tensões políticas e conflitos armados, descobertas de novas reservas menos acessíveis, e mesmo, de inovações tecnológicas - estimulou a busca por fontes alternativas a ele e a seus derivados. Dentre essas, ganhou especial projeção o etanol. 
Desde o início do século $X X$, Henry Ford já utilizava etanol como combustível em motores de combustão interna; porém, devido ao baixo custo da gasolina praticado à época este visionário viu-se obrigado a adaptar seus motores a fontes não renováveis (Marcoccia, 2007). Nessa mesma toada, data de 1925 o primeiro teste realizado no Brasil com um veículo movido a etanol, segundo informativo do Instituto Nacional de Tecnologia (INT, 1979).

Apesar dos esforços, os preços acessíveis do petróleo impediram que o etanol se popularizasse como combustível. Ao longo do período que compreendeu a Primeira Guerra Mundial, o uso do etanol industrial apresentou significativo crescimento, alcançado a produções entre 50 e 60 milhões de galões por ano. Essa produção marca o primeiro pico do uso de etanol nos Estados Unidos, que foi desacelerado nos anos seguintes devido a uma série de restrições impostas pelo governo. A Segunda Guerra Mundial revitalizou novamente a produção do etanol, muito utilizado na produção de borracha sintética e também misturado à gasolina. Devido a problemas de abastecimento de petróleo, mistura combustível chegou a conter $42 \%$ de etanol. No entanto, já no pós-guerra constata-se mais uma vez a deterioração da produção de etanol, que fica restrito ao uso industrial e farmacêutico (Menezes, 1980).

A terceira onda do etanol veio em 1973, com a crise mundial do petróleo, quando os preços da gasolina apresentaram uma alta expressiva. Nas décadas de 1970 e 1980, o etanol era utilizado como $10 \%$ da mistura com gasolina para uso combustível. No início da década de 1990, o preço do petróleo já apresentava significativa redução, levando mais uma vez à contração de mercado do etanol combustível nos EUA. Após a descoberta de que o MTBE (éter metil terci-butílico), um dos aditivos usados na gasolina, era contaminante persistente de corpos d'água, o etanol começou a ser usado como alternativa. A crise energética que marcou o início do século XXI também contribuiu para retomada do crescimento dos combustíveis e fontes energéticas sustentáveis (Pellegrini et al. 2009; Marcoccia, 2007).

Já no Brasil, a produção de cana-de-açúcar foi sempre beneficiada devido aos fatores climáticos e de colonização. Também afetado pela crise de 1973, o governo brasileiro lançou o "Programa Nacional do álcool", também conhecido como "Pró- 
alcool", visando substituir uma parcela significativa do consumo de combustíveis de origem fóssil por etanol de cana-de-açúcar produzido no país. Uma medida inicial foi expandir a mistura de etanol anidro na gasolina para 20\%. Em 1976, logo após outra crise econômica o governo passou a incentivar também o desenvolvimento de carros que usassem o etanol puro como combustível, ao invés de gasolina. Nessa época a tecnologia de carros Flex ainda não estava disponível e os consumidores tinham que escolher entre carros que rodassem com a mistura de gasolina com $20 \%$ de etanol ou com etanol puro. O sucesso do programa deve-se em parte às medidas regulatórias tomadas pelo governo, que visavam amortecer oscilação dos preços de gasolina e etanol por meio da ação da Petrobrás como agente interventor (Bertelli, 2005; BNDES, 2008).

A partir de 2003, os carros com tecnologia Flex passaram a ser comercializados em larga escala, permitindo que o consumidor escolhesse com maior liberdade 0 combustível que pretende utilizar. Com isso, já em 2008, exatos $87 \%$ das vendas de automóveis novos já eram de carros com a tecnologia flex (ÚNICA, 2013).

Verifica-se atualmente, não apenas no Brasil, mas também em outras partes do planeta o crescimento de investimentos em tecnologias de produção sustentável de combustíveis - casos do biodiesel e etanol de primeira e segunda geração -, e de energia - como cogeração, hidrelétricas, fontes eólicas, energia de marés e ondas, entre outras (Freudenberger, 2009; ÚNICA, 2013).

\subsubsection{Processo Produtivo do Etanol}

No Brasil, a produção de cana compreende os estágios de preparação do solo, plantio, tratos culturais e colheita. Os processos de preparo do solo e tratos culturais consomem macronutrientes primários - na forma de amônia, uréia, superfosfatos, ou mesmo fosfatos de mono e diamônio, além de cloreto de potássio -, corretivos de acidez e defensivos agrícolas - triazina, diuron, ametrina, diquat e 2,4-D essenciais para propiciar o crescimento adequado do cultivo (CTC, 2012). Máquinas agrícolas e, por consequência, óleo diesel, são parte integrante desta rota tecnológica, dado que 63,65\% da cana-de-açúcar colhida em São Paulo advêm de mecanização (Sugawara, 2012). 
A cana colhida é então encaminhada às usinas sucroalcooleiras por meio de modal rodoviário. Nestas, a produção de etanol se dá via fermentação alcoólica por leveduras do gênero Saccharomyces cerevisiae em condições controladas de temperatura $\left(20-30^{\circ} \mathrm{C}\right)$ e $\mathrm{pH}(4,5-5,5)$.

O sistema de preparo e extração é baseado em moendas ou difusores, em que a obtenção do caldo ocorre sobpressão regulada, a qual será proporcionada por rolos montados em conjuntos com quatro a sete ternos de moenda sucessivos. O número de conjuntos faz variar a eficiência de moagem desde $94 \%$ até $97 \%$ em termos de volume de caldo extraído (Braunbeck e Cortez, 2005).

No conjunto de rolos da moenda, o caldo que contém a sacarose é separado da fibra (bagaço), e segue para a produção de etanol ou açúcar. O tratamento químico do caldo ocorre por meio de calagem, aquecimento e decantação. Uma vez tratado, o caldo é evaporado para ajustar sua concentração de açúcares e, eventualmente, misturado com melaço residual da linha de produção de açúcar. O produto desta etapa, denominado mosto, prossegue para a fermentação. A adição de leveduras ao mosto permite que o mesmo seja fermentado dando origem ao vinho com concentração de $7 \%$ a $10 \%$ de etanol, após um período de 8 a 12 horas. $\mathrm{Na}$ destilação, o etanol é recuperado inicialmente na forma hidratada, com aproximadamente $96^{\circ} \mathrm{GL}$ seguindo nesse forma para produção de etanol anidro quando couber (CGEE e BNDES, 2008). 


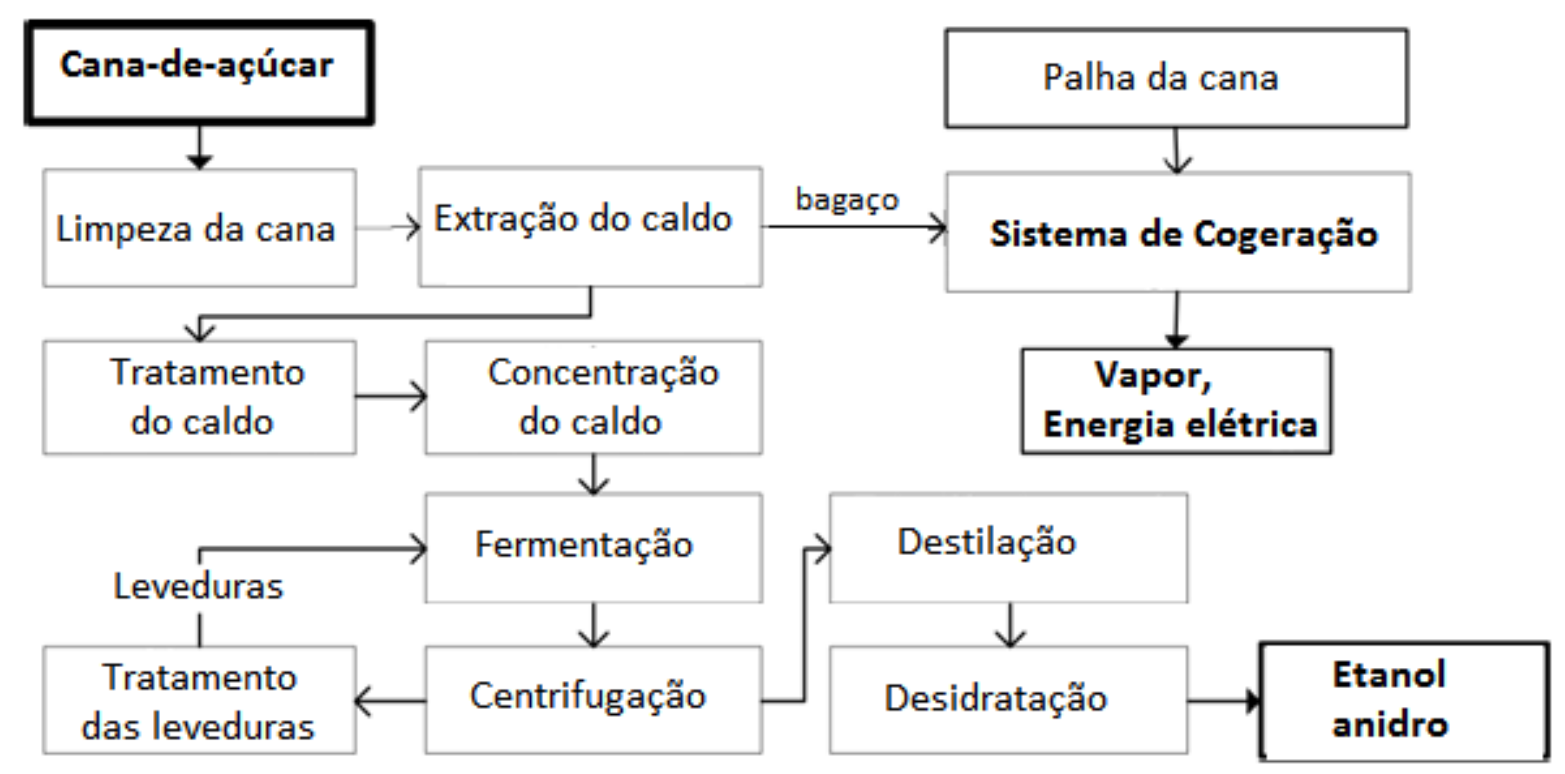

Figura 4 - Diagrama de blocos simplificado para produção de etanol anidro a partir da cana-de-açúcar numa usina autônoma (Adaptado de Dias et al., 2010)

Numa destilaria ou usina autônoma, toda cana processada serve à produção de açúcares destinados à fermentação, com vistas a obtenção de etanol. As etapas principais do processo de produção de etanol a partir de cana-de-açúcar em uma usina autônoma são ilustradas na Figura 4.

Observe-se por fim que o etanol pode ser produzido a partir de praticamente todos os açúcares fermentescíveis, como por exemplo, oriundos da cana-de-açúcar, do milho, da beterraba, entre outros.

\subsubsection{Estatísticas da Produção de Etanol no Brasil}

Segundo o Anuário Estatístico Brasileiro do Petróleo, Gás Natural e Biocombustível de 2013, a produção total de etanol (anidro e hidratado) no Brasil atingiu em 2012 o patamar de 23,8 bilhões de litros, impulsionada pelo crescimento $11,4 \%$ da produção de etanol anidro em relação a 2011 (ANP, 2011). O Sudeste foi a região do país que mais produziu, 6,3 bilhões de litros, com destaque para São Paulo, cujo desempenhorespondeu por $55,7 \%$ da produção nacional. A Figura 5 apresenta o histórico da produção de etanol anidro de 2003-2012. 


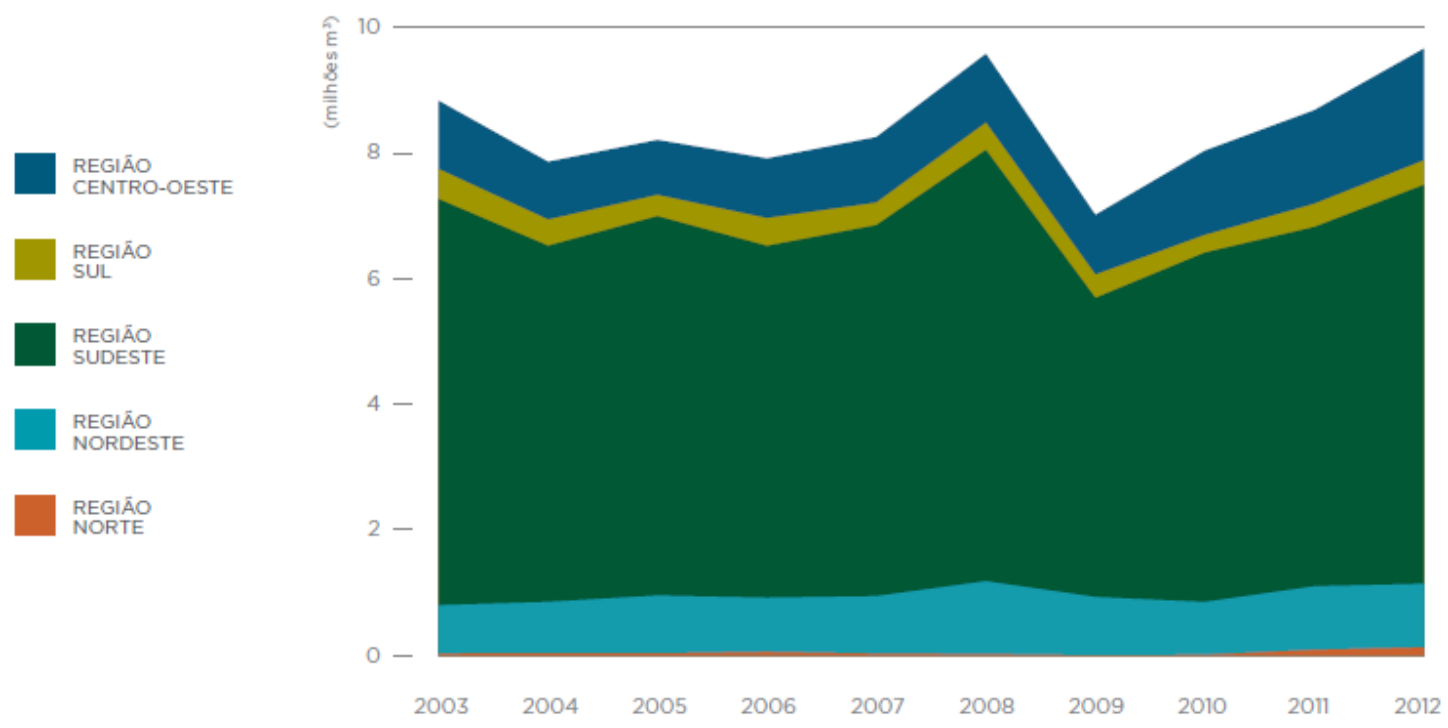

Figura 5 - Evolução da produção de etanol anidro, segundo grandes regiões - 2002 a 2013 (ANP,2013)

A partir de 2010 observa-se uma tendência de aumento na produção de etanol anidro; tendo em vista que a ampliação de terras agricultáveis para a cultura de cana não acompanhou tal expansão nota-se, por conseguinte, a redução deprodução de etanol hidratado, no mesmo período, assim como aparece indicado Figura 6. 


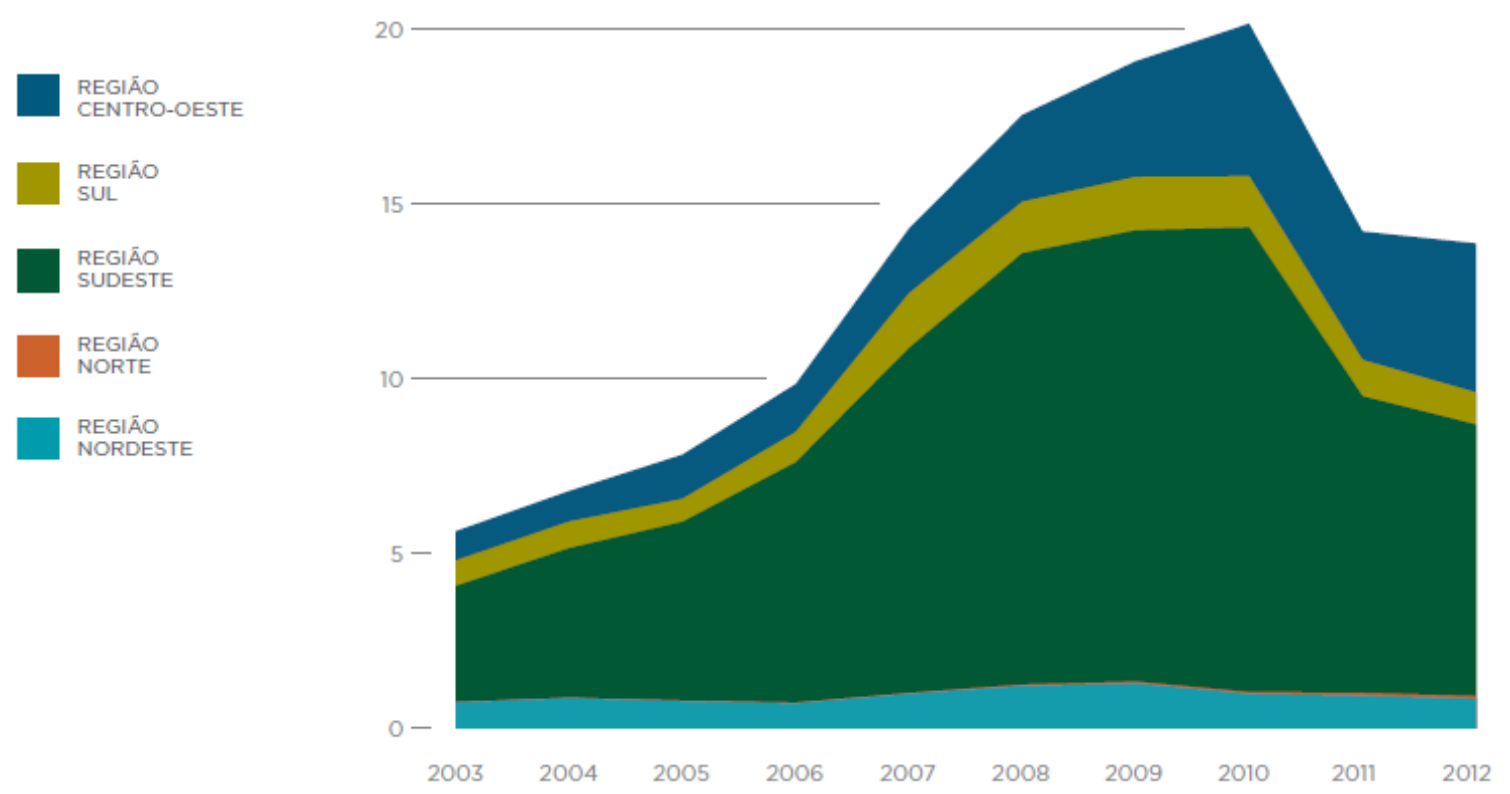

Figura 6 - Evolução da produção de etanol hidratado, por grandes regiões - 2003 a 2012 (ANP, 2013)

Em 2012, a produção de etanol hidratado caiu 2,4\% em relação à safra de 2011 . O Sudeste manteve-se como maior produtor do país, com $56 \%$ do total nacional, e São Paulo representou $46,4 \%$ da produção nacional (ANP, 2013).

Em 2012, o Brasil exportou 3,1 bilhões de litros de etanol, principalmente para os Estados Unidos; por outro lado, com a queda de produção ocorrida em anos anteriores foi necessário importar 554 milhões de litros de etanol, sendo a quase a totalidade desse volume advinda, curiosamente, também dos Estados Unidos (ANP, 2013).

Desde a introdução dos veículos flex em 2003, o setor sucroenergético cresceu de maneira vertiginosa até a crise financeira mundial, em 2008. Desde então, o mercado brasileiro vem apresentado descompasso entre a oferta efetiva e a demanda potencial por etanol. O aumento da demanda tem ocorrido principalmente devido à expansão dos veículos flex, enquanto a oferta de etanol não apresentou grandes avanços em razão da ausência de investimentos no setor sucroenergético em capacidade produtiva nova (expansões e greenfields) nos últimos anos. 
A partir de 2008, houve um estreitamento da rentabilidade do combustível no mercado doméstico que contribuiu para a redução de investimentos nos chamados Projetos Greenfields, que consistem em projetos incipientes de novas e modernas unidades de produção, como mostra a Figura 7. Estima-se um déficit na produção de etanol no Brasil até 2015 (BNDES, 2012).

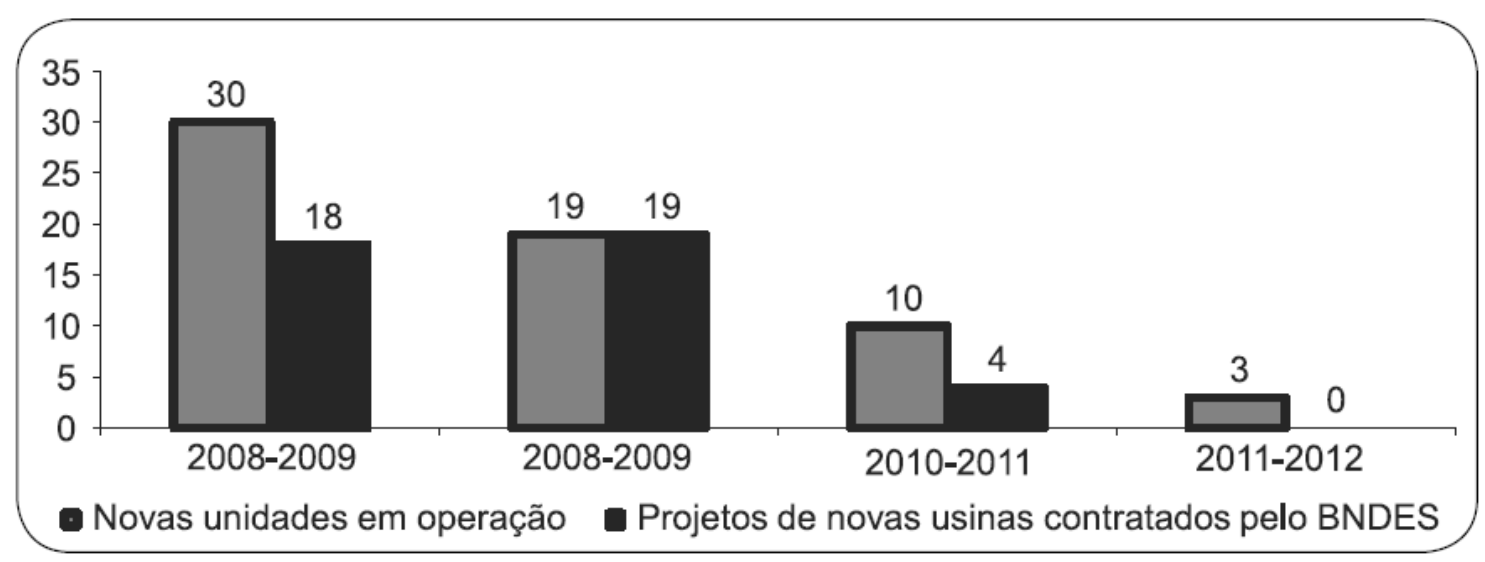

Figura 7 - Novas unidades e projetos de novas usinas (BNDES, 2012)

Frente a esse cenário, torna-se clara a necessidade de buscar novas tecnologias para aumentar a eficiência dos processos produtivos no país, a fim de reduzir custos e a gerar mais produtos a partir da mesma quantidade de recursos primários.

\subsubsection{COMPETITIVIDAdE do ETANOL BRAsileiRo}

A busca por alternativas de matérias-primas de fontes renováveis tem sido uma preocupação mundial. Nesse segmento, o etanol brasileiro proveniente de cana-deaçúcar figura como dos mais competitivos. $O$ aumento do consumo de etanol no mercado interno provocado pela crescente venda de veículos "flex-fuel" e o potencial aumento do mercado externo devido às preocupações com o Aquecimento Global se desdobrou em aumento da demanda e do consumo de etanol (Braunbeck e Cortez, 2005).

Segundo Goldemberg et al., (2008), o etanol brasileiro é competitivo quando comparado à gasolina devido ao custo relativamente baixo de produção que o país pratica. Essa competitividade deve-se a avanços e inovações tecnológicas ocorridos 
na etapa agrícola e industrial, desde o início do Programa Proalcool até os dias de hoje. A melhoria dos processos de produção e a integração energética com a cogeração de vapor e eletricidade produzidos pelo bagaço de cana-de-açúcar para suporte a esse mesmo processamento são exemplos dos avanços tecnológicos ocorridos na etapa industrial. Contudo, existem oportunidades a serem exploradas para tornar o produto mais competitivo, como por exemplo, o desenvolvimento da tecnologia para o processo produtivo industrial do etanol de segunda geração a partir da biomassa da cana-de-açúcar, que apresenta grande potencial para o aumento da produtividade do etanol brasileiro (ÚNICA, 2013; CTC, 2014).

\subsubsection{ASPECTOS AMBIENTAIS DA PRODUÇÃO DO ETANOL}

Apesar das características de sazonalidade, a situação econômica para a atividade canavieiratem se demonstrado favorável nos últimos anos; no entanto, movimentos em torno da implantação de ações de desenvolvimento sustentável, sobretudo no Estado de São Paulo, criam contrates importantes quanto a produzir biocombustíveis em detrimento de alimentos.

Medidas como a certificação de usinas e plantações visam a ampliação de mercados, ao sugerir uma imagem de produção mais limpa e sustentável. No entanto, segue ativa uma ampla discussão entre produtores, comunidades locais e organismos de regulamentação ambiental quanto aos problemas socioambientais relacionados à indústria sucroalcooleira e a produção canavieira.

Aspectos ligados à monocultura da cana-de-açúcar, com o uso intensivo de produtos químicos - fertilizantes e agrotóxicos; a queimada das lavouras, que afeta a qualidade do ar, destroi micro-organismos do solo, e inside sobre a fauna local; e também do derrame de vinhaça e da água de lavagem da cana nos rios, gerando assoreamento e contaminação dos corpos hídricos são também objetos de critica. (Goldemberg et al., 2008).

A realidade do setor é heterogênea; estudos mostram que já existem tecnologias capazes de reduzir os impactos ambientais associados às atividades da indústria sucroalcooleira e produção canavieira. Nesse contexto destaca-se, portanto, a importância de se realizar uma varredura adequada do desempenho ambiental da 
produção do etanol. A fim de proporcionar um diagnóstico consistente, esta deveria ocorrer de maneira sistêmica em termos de abrangência, segundo o conceito de ciclo de vida. Estudos acadêmicos efetuados dentro desse recorte serão apresentados mais a frente, no capítulo específico sobre Avaliação de Ciclo de Vida.

\subsection{COGERAÇÃO DE ENERGIA ELÉTRICA}

O sistema de cogeração é responsável pelo suprimento de energia térmica e elétrica nas usinas de cana-de-açúcar. A cogeração é um processo no qual uma fonte de energia primária alimenta uma máquina ou aparelho térmico que, de sua parte e pela reação de combustão, transforma a energia química do combustível em mecânica de eixo, a qual é convertida em energia elétrica por meio de geradores (Balestieri, 2002).

Os primeiros sistemas de cogeração passaram a ser instalados no mundo a partir da primeira década do século $X X$, motivados pela necessidade de independência energética, em vista das crises sistêmicas no setor elétrico. A cogeração de energia elétrica passou a ser uma prática adotada pela agroindústria sucroalcooleira, em virtude da disponibilidade de bagaço (Gomazako e Oliveira, 2007).

O Instituto Nacional de Eficiência Energética (INEE) aponta que a importância da cogeração enquanto medida de eficiência energética levou a União Européia a estabelecer, como meta para 2010 , o patamar de $18 \%$ da energia por ela consumida ser cogerada a partir de biomassa. Em países como Holanda e Finlândia, esta forma de produção já representa mais de $40 \%$ da potência instalada, o que denota uma tendência global.

Nos últimos anos, o excedente de eletricidade produzida nas unidades de cogeração tem sido exportado para a rede concessionária e vendido via leilões promovidos pela Agencia Nacional de Energia Elétrica (ANEEL), sob as diretrizes do Ministério de Minas e Energia (MME, 2011). Na safra de 2009/2010, menos de 30\% das usinas de cana-de-açúcar com capacidade de moagem inferior a 2,0 Mt exportaram eletricidade para a rede (Nyko et al., 2011). 
O cenário nacional apresenta uma fundamentada oportunidade de aumentar a geração e exportação de eletricidade para a rede, a partir da modernização dos sistemas de cogeração, com projetos orientados para melhorar tanto a eficiência energética quanto reduzir os impactos ambientais.

\subsubsection{CONTEXTO DA COGERAÇÃo DE ENERGIA ELÉtRICA NO BRASIL}

As crises do petróleo ocorridas no curso dos anos 1970 provocaram sérias consequências à economia mundial. Para efeito de mitigação deste quadro, dois grupos de ação foram implementados: a redução do consumo de energia; e a busca por combustíveis alternativos. Nesse contexto, a utilização de bagaço de cana-deaçúcar e de outros tipos de biomassa como insumo energético passaram a ser alternativas para diversificação da matriz energética brasileira (Camargo al., 1990; Dantas, 2010).

O bagaço de cana gerado na produção de açúcar e etanol já foi tratado como resíduo industrial nas décadas de 1970 e 1980 (Camargo al., 1990). No entanto, atualmente, o bagaço é considerado como subproduto de processo que apresenta várias aplicações industriais; além do uso como insumo energético, destaca-se também seu uso potencial como insumo para produção de etanol de segunda geração (Dantas, 2010). A perspectiva de aproveitamento energético do bagaço de cana abriu novas possibilidades de mercado. No entanto, e para tornar viável esta alternativa, a melhoria de desempenho - também em termos energéticos - dos processamentos de açúcar e etanol, bem como, das unidades de cogeração, assumiu status de componente estratégica em termos de rentabilidade para o setor sucroalcooleiro.

Por outro lado, a descentralização do setor elétrico brasileiro, iniciada no final da década de 1990, e a crise no abastecimento de eletricidade no início dos anos 2000 incentivaram as usinas sucroalcooleiras a produzirem excedentes de energia elétrica para comercialização (Neoenergia, 2011). Segundo o Ministério de Minas e Energia (MME), em 2010, o bagaço de cana-de-açúcar foi responsável por 3,4\% de toda energia gerada no país, correspondente a 18,5 TWh - dos quais 9,7 TWh foram consumidos pelo próprio setor, enquanto que os demais $8,8 \mathrm{TWh}$ destinaram-se a 
abastecer a matriz energética nacional. No mesmo período, dentro do subgrupo de biomassa, essa fonte correspondeu a $66 \%$ de toda energia gerada (MME, 2011).

No setor sucroalcooleiro há ainda um potencial adicional a ser explorado para a cogeração, que compreende o aproveitamento da palha de cana-de-açúcar, insumo que tradicionalmente é queimada durante a colheita ou deixada no campo. Um grande trabalho tem sido realizado no Brasil na busca de melhores técnicas para a colheita/transporte dessa biomassa, assim como para aferição de sua disponibilidade energética real (Nyko et al., 2011).

O aproveitamento da palha na cogeração será incentivado pelo fato de que, no estado de São Paulo, a lei $n^{\circ} 11.241$ de 2001 proibirá a queima da palha em área mecanizável (inclinação do solo menor que 12\%) e não-mecanizável, respectivamente nos anos 2021 e 2031. Apesar disso, o governo paulista assinou um Protocolo Agroambiental em que se compromete a cessar a queima até 2014 em área mecanizável e até 2017 em área não-mecanizável. Sendo assim, a introdução gradual da palha gera novos desafios que exigem constante evolução tecnológica para melhor aproveitamento do seu potencial energético, com possibilidade de estender a operação das caldeiras para além do período de processamento da cana (CTC, 2012). Um estudo realizado pelo Instituto Euvaldo Lodi (IEL) em 2008, em parceria com a Confederação Nacional da Indústria (CNI) e a usina Itaipu Binacional, apontou que a biomassa da cana tem condições de adicionar ao sistema elétrico brasileiro aproximadamente $15 \mathrm{GW}$ até 2020, o que equivaleria a incorporar uma nova Itaipu no parque gerador nacional. Esta constatação consolida a opinião de que o setor pode ainda contribuir, em muito, para o suprimentoda crescente demanda por energia no país (IEL, 2008).

\subsubsection{DESCRIÇÃO DA BIOMASSA DA CANA-DE-AÇÚCAR}

Segundo as estatísticas da União da Indústria de Cana-de-Açúcar (UNICA), na safra 2008/2009 o Brasil processou cerca de 570 milhões de toneladas de cana, produzindo ao redor de 160 milhões de toneladas de bagaço. Toda cana-de-açúcar produzida no Brasil ainda apresenta potencial de aproximadamente 140 milhões de toneladas de palha - folhas e ponteiros -, sendo que uma pequena fração desse 
total acompanhou os colmos de cana até a indústria e o restante foi queimado ou permaneceu no campo.

A palha é a denominação popular para as partes "não colmos" da cana-de-açúcar, ou seja, toda parte aérea da planta menos os colmos industrializáveis, conforme apresentado na Figura 8. Assim, a palha é composta pelas folhas verdes e secas e pelos ponteiros de cana, formados pelos entrenós imaturos do topo ("palmito") e folhas novas enroladas ao redor. O bagaço, por sua vez, é um subproduto do processo de moagem dos colmos na produção de açúcar e do etanol (IEL, 2008).

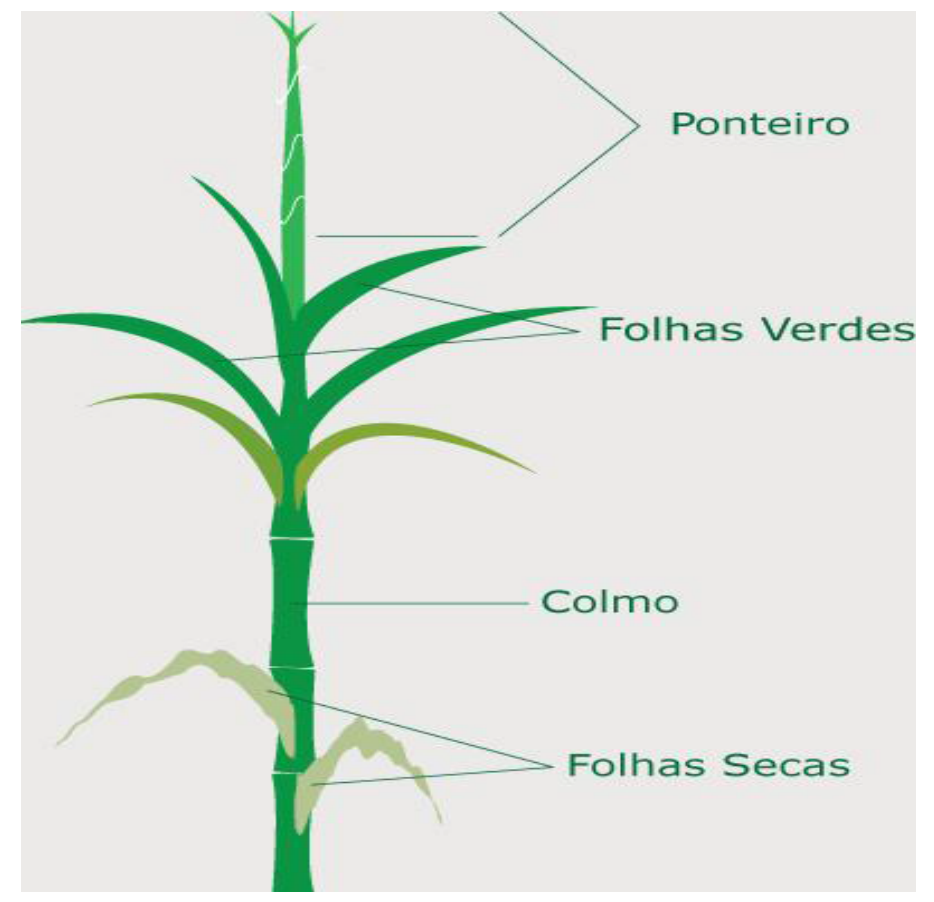

Figura 8 - Partes da cana-de-açúcar (IEL, 2008)

As características tanto da palha como do bagaço apresentam variações em função do local de coleta do material, sistema de despalha e colheita, condições climáticas no local, estágio de desenvolvimento vegetativo da cultura, entre outras (CTC, 2012). Sendo assim, para modelagem, torna-se necessário a obtenção e utilização de dados médios.

A qualidade da biomassa para fins energéticos pode ser medida por meio de seu Poder Calorífico; ou seja, a quantidade de energia liberada na combustão completa de um combustível. Ele pode ser dividido em: superior (PCS), em que a água encontra-se no estado líquido nos produtos de combustão, o que quer dizer que foi 
recuperada a parcela correspondente à entalpia de condensação da água; e inferior $(\mathrm{PCl})$, no qual a água encontra-se na forma de vapor nos produtos de combustão (Cortez, 2010).

Em base úmida, o bagaço amostrado em diversas usinas e situações no Brasil mostrou grande amplitude dos resultados quanto ao Poder Calorífico (CTC, 2012). Dias et al. (2010), em estudo que tratou de simular a produção de etanol a partir da cana em uma destilaria autônoma, adotaram os seguintes valores médios para o bagaço com $50 \%$ de umidade (base úmida): $\mathrm{PCl}_{\text {bagaço }}=7.565 \mathrm{~kJ} / \mathrm{kg}$, e para palha com $15 \%$ de umidade (base umida): $\mathrm{PCl}_{\text {palha }}=12.960 \mathrm{~kJ} / \mathrm{kg}$. As simulações efetuadas neste estudo acompanharam os mesmos valores.

Os valores percentuais de bagaço gerado na usina e palha gerada no campo associados a $1,0 \mathrm{t}$ cana processada variam com as práticas culturais $\mathrm{e}$ as peculiaridades regionais. Lora et at. (1997), estabeleceu um modelo para quantificar a quantidade de biomassa residual da cultura da cana-de-açúcar, a partir dos seguintes parâmetros:

- Coeficiente de Resíduos (CR): relação entre a quantidade de resíduo total (em base seca) e a massa da colheita com umidade do campo (MC);

- Coeficiente de Disponibilidade (CD): relação entre a quantidade de resíduo disponível (em base seca) e a massa total de resíduos, em \%;

- Quantidade Total de Resíduos (CRE): CRE = MC $\times$ CR

A partir do modelo, quando se analisa o bagaço como resíduo, os pesquisadores apresentam um coeficiente de resíduo variável entre 0,125 e 0,15 e um coeficiente de disponibilidade de $100 \%$, ou seja, quando toda a biomassa encontra-se em condições técnico-econômicas de aproveitamento.

O parâmetro fundamental para análise do bagaço de cana é o coeficiente de resíduo, determinado pela variedade da cana-de-açúcar e seu teor de fibras. O coeficiente de disponibilidade é tende na verdade a ser sempre $100 \%$ pelo fato de o material já se encontra no pátio da usina. Portanto, a quantidade total de bagaço disponível varia entre 125 e $150 \mathrm{~kg} / \mathrm{t}$ cana, em base seca, ou 250 a 300 kg/tcana, com $50 \%$ de umidade (Corrêa Neto, 2001). 
No caso da palha, Corrêa Neto (2001) a partir do trabalho de Lora et al. (1997), sugere um coeficiente de resíduo entre 0,20 e 0,30, e um coeficiente de disponibilidade a ser definido. A situação hipotética de coeficiente de disponibilidade de $100 \%$ consideraria a hipótese de que a palha possa ser integralmente aproveitada (Corrêa Neto, 2001).

O aproveitamento da palha é determinado principalmente pelo coeficiente de disponibilidade, que varia em função: da condição de topologia da área plantada; do tipo de colheita (mecanizada ou manual); do impacto da queima; e da disponibilidade de tecnologias e infra-estrutura de processamento e de transporte. A respeito destas condições deve-se acrescentar a variabilidade da quantidade de biomassa que deve ser deixada no campo para cumprir o papel de adubo ou para preservação das características do solo, dada a multiplicidade de tipos de lato-solo em que a cana-de-açúcar é plantada (Corrêa Neto, 2001; Seabra et al., 2012).

Pesquisadores, como Cardoso et al. (2013), consideraram cenários de recuperação de palha para cogeração elétrica com percentuais de recuperação de $30 \%, 50 \%$ e, no máximo, $70 \%$. O interesse pelo aproveitamento da palha tem crescido recentemente, principalmente devido à possibilidade de utiliza-la como fonte de energia térmica e para produção de etanol de segunda geração (Leite et al., 2009; Seabra et al., 2010; Dias et al., 2012).

O desafio está na recuperação da palha depositada no campo após a colheita mecanizada. Segundo Cardoso et al. (2013), a questão compreende saber quanto de palha poderia ser removida do campo de forma a melhorar a tornar a cadeira produtiva da cana-de-açúcar ainda mais sustentável. Não há, por exemplo, consenso quanto à quantidade de material a ser deixado no campo (Torquato, 2012).

Vários pesquisadores estão buscando uma solução para elucidar esse problema. Uma Biorrefinaria Virtual de cana (BVC) está sendo construída para avaliar questões técnicas, econômicas e ambientais associadas ao tema considerando a cadeia completa da produção de cana (Cavalett et al., 2012; Dias et al., 2012).

Neste estudo adotou-se a partir de informações disponíveis em literatura abalizada a referência de produção de $280 \mathrm{~kg}_{\text {bagaço }}\left(50 \%\right.$ umidade) $/ \mathrm{t}_{\text {cana }}$, e $140 \mathrm{~kg}$ palha (base seca) $/ \mathrm{t}_{\text {cana }}$ 
equivalentes a 164,7 kg palha(15\% umidade) $/ \mathrm{t}$ cana (Ensinas, 2008); Seabra, 2008;Dias et al., 2010; Cardoso et al. ,2013),

Assim como será discutido mais adiante, as simulações efetuadas para a unidade de cogeração foram realizadas com duas possibilidades de utilização de biomassa na caldeira: a primeira contempla queima de bagaço na caldeira com coeficiente de aproveitamento de 100\%; a segunda contempla além da queima plena do bagaço, também a queima da palha com $50 \%$ de aproveitamento. O excedente de palha para este segundo caso foi tratado como resíduo deixado no campo É importante comentar que o setor sucroalcooleiro, em seus primórdios, ignorava a possibilidade de aproveitamento do bagaço e muito menos da palha. As usinas compravam energia elétrica das concessionárias locais e queimava óleo combustível. Com o passar do tempo, o uso do bagaço foi se tornando rotina no processo de cogeração, pois permitia produzir energias: térmica, para o processo industrial; e elétrica, para a movimentação mecânica da indústria, iluminação e outros fins (Romão Junior, 2009).

\subsubsection{UnidAdes de CogeraçÃo E o CiClo RANKINE}

A possibilidade da venda do excedente energético impulsionou a busca por melhores eficiências das unidades de cogeração, que geralmente são plantas de potência com ciclo a vapor, cujo fluido de trabalho - água $\left(\mathrm{H}_{2} \mathrm{O}\right)$ - escoa em estado estacionário, com auxílio de bombas, através da caldeira, turbina e condensador. Nesse arranjo, não há contato entre o fluido de trabalho e a fonte de calor (Pellegrini et al. 2009).

Historicamente, os conceitos de ciclo, reversibilidade, e máximo rendimento para uma máquina térmica, foram introduzidos em 1824 pelo engenheiro francês Sadi Carnot, na publicação "Reflections on the Motive Power of fire" (Bräscher, 1991). O ciclo a vapor ideal é chamado de Ciclo de Carnot, que opera de maneira reversível. Este é constituído por duas etapas isotérmicas conectados por outras duas adiabáticas, tal como apresentado a seguir no esquema da Figura 9 (Van Ness, 2007). 


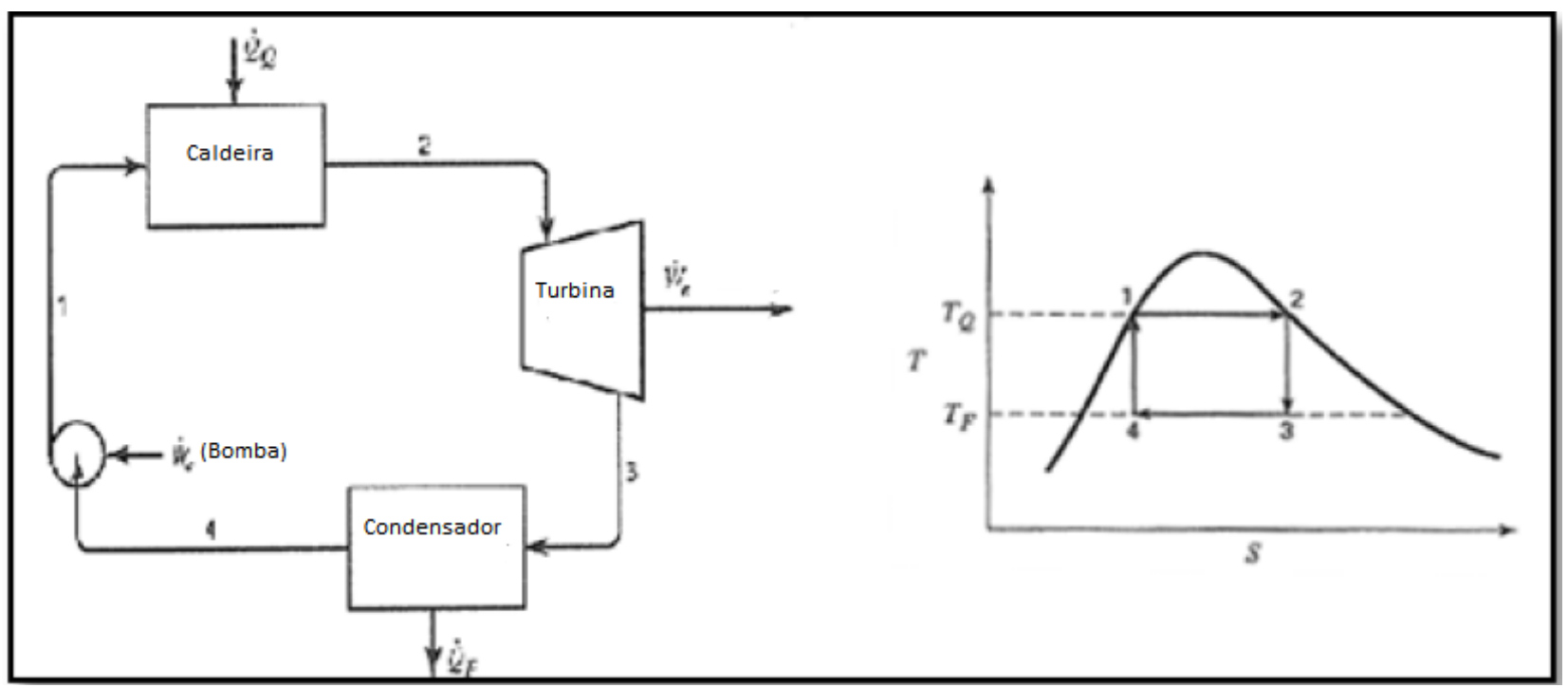

Figura 9 - Diagrama de blocos e diagrama T-S do ciclo de Carnot (Van Ness, 2007)

As transformações termodinâmicas ocorridas no Ciclo de Carnot compreendem as etapas de: vaporização; expansão adiabática reversível; condensação parcial do vapor saturado; e compressão isentrópica, descritas na Tabela 1.

Tabela 1 - Sucessão de transformações termodinâmicas ocorridas no ciclo Carnot (Van Ness, 2007)

\begin{tabular}{ll}
\hline \multicolumn{1}{c}{ Transformações termodinâmicas do Ciclo de Carnot } \\
\hline $1 \rightarrow 2$ & $\begin{array}{l}\text { Vaporização na caldeira: água líquida saturada absorve calor a uma } \\
\text { temperatura constante } T_{Q} \text {, e produz vapor saturado }\end{array}$ \\
\hline $2 \rightarrow 3$ & $\begin{array}{l}\text { Expansão adiabática e reversível do vapor saturado na região bifásica } \\
\text { para produzir uma mistura de líquido e vapor saturados a } T_{F}\end{array}$ \\
\hline $3 \rightarrow 4$ & Condensação na qual o calor é rejeitado a $T_{F}$ \\
\hline $4 \rightarrow 1$ & Compressão isoentrópica na bomba \\
\hline
\end{tabular}

Dadas as dificuldades de operacionalização das etapas de expansão e compressão bifásicas, o Ciclo de Carnot costuma, no entanto e em geral, ser substituído pelo ciclo Rankine em unidades geradoras de potência de usinas de cana-de-açúcar (Sosa-Arnao, 2008). A produção de energia no ciclo Rankine considera por transformações termodinâmicas os estágios de: aquecimento isobárico; expansão; condensação; e produção de líquido sub-resfriado. A Figura 10 e a Tabela 2 descrevem na forma do Diagrama T-S (Temperatura e Entropia) e as transformações termodinâmicas do Ciclo Rankine. 


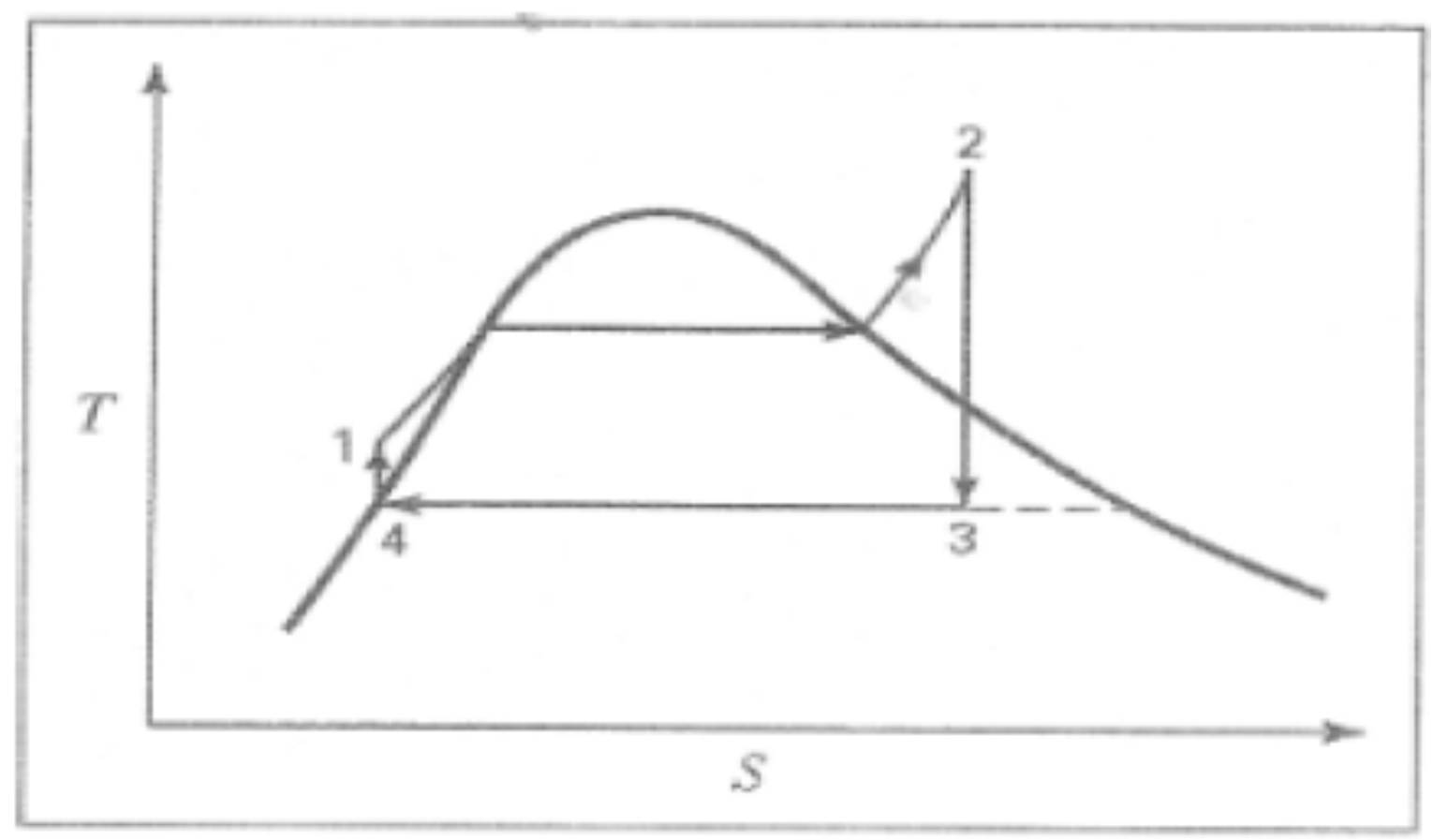

Figura 10 - Diagrama T-S do ciclo Rankine (Van Ness, 2007)

Tabela 2 - Sucessão de transformações termodinâmicas ocorridas no ciclo Rankine (Van Ness, 2007)

\begin{tabular}{ll}
\hline \multicolumn{1}{c}{ Transformações termodinâmicas do Ciclo de Rankine } \\
\hline $1 \rightarrow 2$ & Aquecimento a pressão constante em uma caldeira. \\
\hline $2 \rightarrow 3$ & $\begin{array}{l}\text { Expansão do vapor na região bifásica para produzir uma mistura de líquido e } \\
\text { vapor saturados. }\end{array}$ \\
\hline $3 \rightarrow 4$ & Condensação total no qual o calor é rejeitado a $\mathrm{T}_{\mathrm{F}}$ \\
\hline $4 \rightarrow 1$ & $\begin{array}{l}\text { Bombeamento do líquido saturado até a pressão da caldeira, produzindo } \\
\text { líquido comprimido (sub-resfriado). }\end{array}$ \\
\hline
\end{tabular}

Nas décadas de 1970 e 1980 as unidades de cogeração operavam com caldeiras capazes de produzir vapor em torno de 20 bar e $300^{\circ} \mathrm{C}$, e se valiam de turbinas de contrapressão. Esse quadro sofreu significativa remodelação no sentido de aumentar a eficiência da cogeração. Os projetos mais modernos utilizam sistemas que geram vapor com pressões entre $44-100$ bar e temperaturas acima de $480^{\circ} \mathrm{C}$, e turbinas de extração-condensação (Sosa-Arnao, 2008). Porém a grande maioria das usinas ainda operam em baixas condições de pressão e temperatura (Tabela 3). 
Tabela 3 - Distribuição das pressões de operação das caldeiras nas usinas brasileiras (IDEA, 2012)

\begin{tabular}{cc}
\hline Pressão de operação (bar.a) & Número de usinas no Brasil \\
\hline 21 & 243 \\
\hline 42 & 40 \\
\hline 67 & 124 \\
\hline 100 & 11 \\
\hline
\end{tabular}

A tendência natural é de que cada vez mais usinas alcancem pressões de operação de 67 a 100 bar e temperaturas acima de $500^{\circ} \mathrm{C}$; desta forma, além de atender às demandas internas, gerar-se-á um excedente expressivo de eletricidade destinado ao suprimento de outros mercados (IDEA, 2012).

Melhorias no arranjo dos equipamentos e aproveitamento da energia no ciclo a vapor são aspectos ainda pouco explorados no setor sucroalcooleiro que também podem aumentar a eficiência global da cogeração. Sistemas de reaquecimento e regeneração são exemplos de melhorias do ciclo Rankine. Estesreaquecem o vapor parcialmente expandido pela passagem deste pelo banco de tubos da caldeira, e aumentam a temperatura da água de alimentação da caldeira por meio de trocas térmicas com vapor extraído da turbina (Moran e Shapiro, 2008).

\subsubsection{Conceitos para modelagem do Ciclo Rakine na cogeração}

O ciclo termodinâmico Rankine é o modelo conceitual mais utilizado pelas unidades de cogeração que operam a partir da queima de bagaço de cana para modelar o comportamento termodinâmico do processo de conversão de calor em trabalho mecânico (Sosa-Arnao, 2008; Dias et al., 2011). A Figura 11 mostra um ciclo Rankine Convencional, usado tradicionalmente nas usinas brasileiras. 


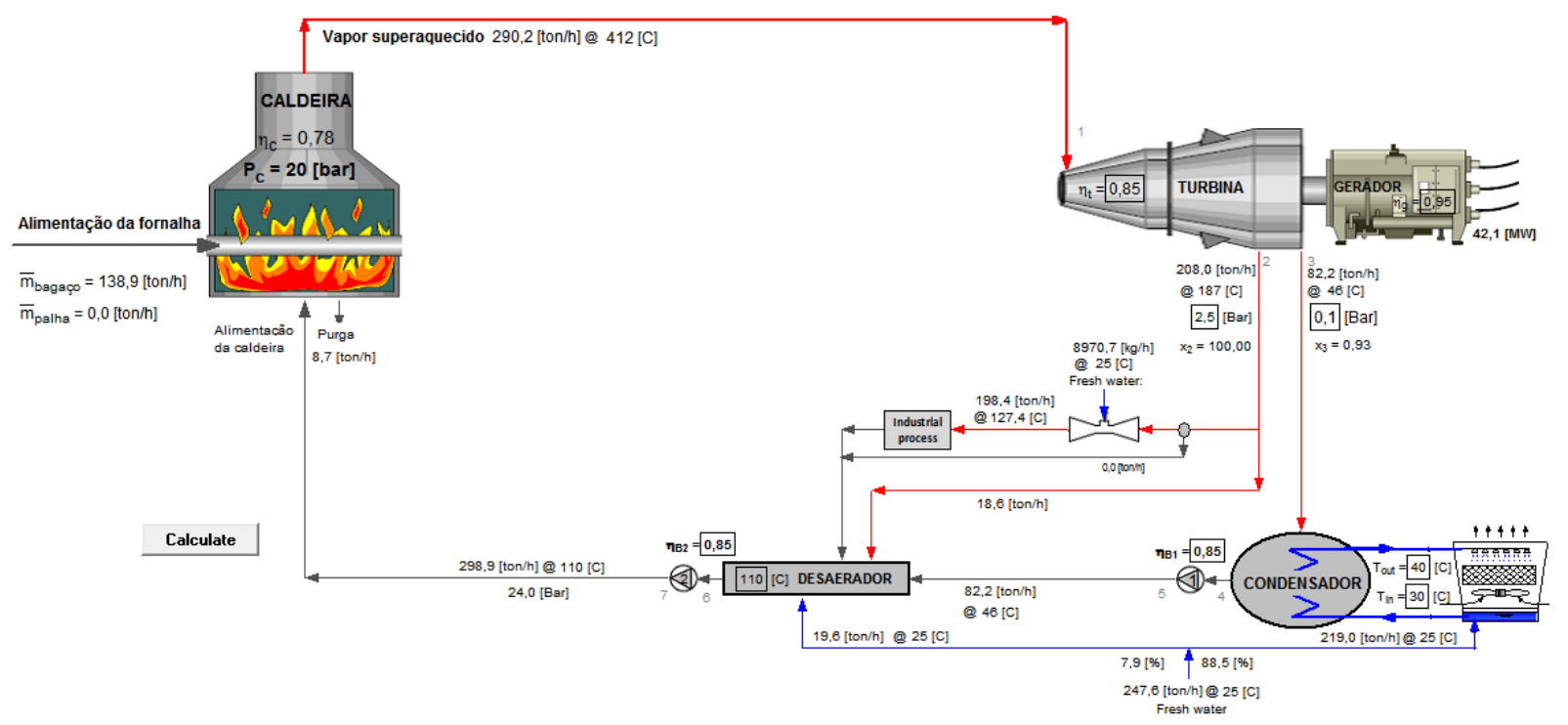

Figura 11 - Representação de um ciclo Rankine convencional de um sistema de cogeração.

O fluido de trabalho é bombeado para a caldeira sob alta pressão para se tornar vapor saturado seco, através do contato indireto com a fonte térmica de energia gerada a partir da queima do bagaço e da palha. O vapor passa através da turbina e ao expandir produz trabalho de eixo. Evita-se usar vapor saturado na entrada da turbina afim de não comprometer a vida útil do equipamento, por conta da erosão das pás. Justifica-se então a recomendação de utilizar superaquecedores nas caldeiras a fim de obter vapor superaquecido. A associação de caldeiras com superaquecedores é chamada de gerador de vapor (Moran e Shapiro, 2008).

No ciclo termodinâmico, o vapor superaquecido se expande através da turbina, que está conectada a um gerador de eletricidade, convertendo trabalho de eixo em energia elétrica. Em turbinas de extração-condensação, uma fração de vapor é extraída a um ponto intermediário da turbina e desviada para a produção de etanol, ilustrada na Figura 11 pela caixa descrita como "processo industrial".

A fração remanescente de vapor expande até o ponto de saída da turbina a uma pressão inferior à pressão atmosférica e passa através de um condensador a fim de condensar o fluido de trabalho à pressão constante. A água de refrigeração torna-se líquido saturado após a troca de calor, sendorecirculado até a torre de resfriamento evaporativa, onde a energia da condensação do fluido de trabalho é rejeitada para a atmosfera. 
Após a condensação o fluido de trabalho passa por um desaerador, entrando em contato com o condensado que retorna da unidade de produção de etanol, onde nova troca térmica acontece. A desaeração é necessária para manter a pureza do fluido de trabalho e para minimizar a corrosão (Moran e Shapiro, 2008). Finalmente o fluido de trabalho é bombeado de volta para o gerador de vapor e o ciclo se completa.

\subsubsection{Efeito do superaquecimento do vapor na caldeira}

Conforme apresentado a seguir na Figura 12, o superaquecimento do vapor na saída da caldeira do ponto 3 para o ponto 3', proporciona duas vantagens importantes para o ciclo Rankine:

I. Aumento do título (ou qualidade) do vapor na cauda da turbina (ponto 4'). Caso a umidade nos estágios de baixa pressão da turbina exceda cerca de $10 \%$, não há somente uma diminuição na eficiência da turbina, mas também a erosão das paletas da mesma pode ocasionar um problema grave.

II. Aumento do rendimento térmico do ciclo, representado pelo aumento da área 3 - 3' - 4' - 4, do diagrama T-S indicado na Figura 10. 


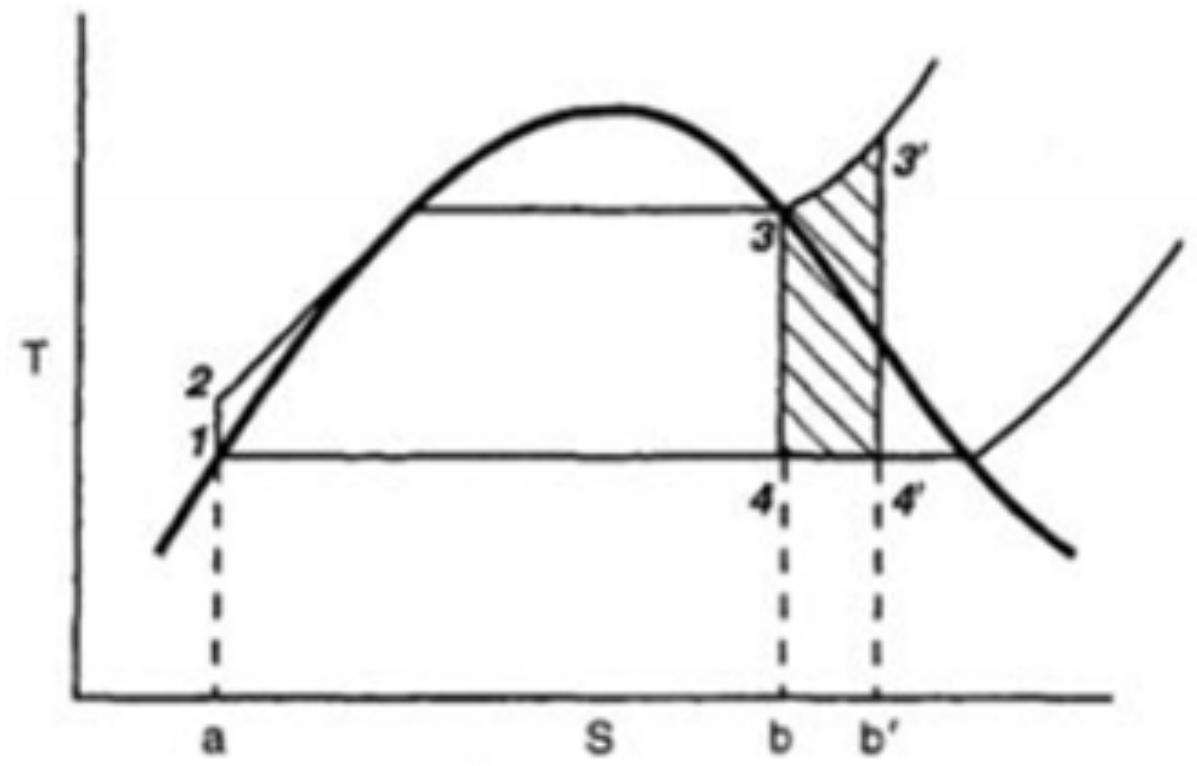

Figura 12 - Diagrama T-S do ciclo Rankine com superaquecimento (Van Ness, 2007)

\subsubsection{Efeito da pressão do vapor na saída da caldeira}

A Figura 13 mostra na forma do diagrama T-S a influência do aumento da pressão de vapor na saída da caldeira para um ciclo Rankine.

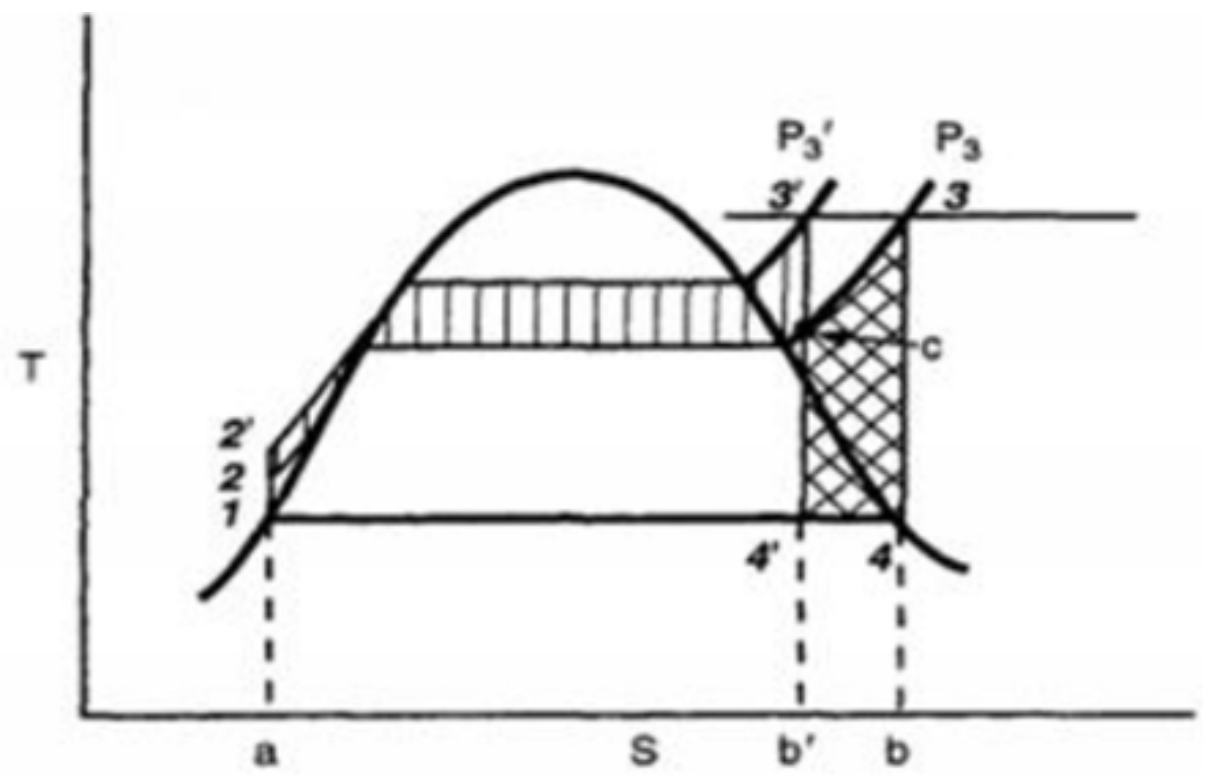

Figura 13 - Influência da pressão do vapor na saída da caldeira (Van Ness, 2007). 
Note-se quea elevaçãoda pressão do vapor (ponto 3') provoca aumento do trabalho na área hachurada simples e diminuição na área hachurada dupla. Dessa forma o trabalho líquido tende a permanecer o mesmo, mas o trabalho rejeitado (área a - 1 4' - b') diminui; portanto o rendimento do ciclo Rankine aumenta com o aumento da pressão máxima do vapor. Nota-se, no entanto, que o título no ponto 4' é menor que no ponto 4. Assim, muito embora seja desejável extrair ao máximo a energia do fluido de trabalho por expansão, deve-se manter o titulo do vapor de cauda da turbina em torno de $90 \%$, sempre no sentido de, como já discutido, preservar a integridade física do equipamento.

\subsection{MELHORIAS NO CICLO RANKINE}

Em grandes centrais termelétricas tradicionalmente são realizadas modificações no ciclo Rankine com o objetivo de aumentar sua eficiência térmica. Uma modificação comum é a interrupção da expansão do vapor na turbina para adicão de mais calor processo conhecido como Reaquecimento (Bräscher, 1991; Moran e Shapiro, 2008).

Outra forma de promovermelhorias de eficiência térmica na planta compreende o aumento da temperatura média do fluído introduzido no ciclo e, a redução da diferença de temperatura entre a fonte quente e o líquido comprimido que é alimentado na caldeira. Esse processo de aquecimento gradual do líquido comprimido é conhecido como Regeneração (Moran e Shapiro, 2008; Bräscher, 1991).

\subsubsection{Ciclo Rankine com Reaquecimento}

No ciclo com reaquecimento, o vapor da caldeira é submtido a uma expansão nos estágios de alta pressão da turbina e, em seguida, é desviado de seu fluxo normal, retornando para o reaquecedor. A temperatura do vapor é novamente elevada para sua condição original, sendo então redirecionado para os demais estágios da turbina, dando sequência à produção de trabalho. O diagrama desse ciclo é apresentado na Figura 14. 


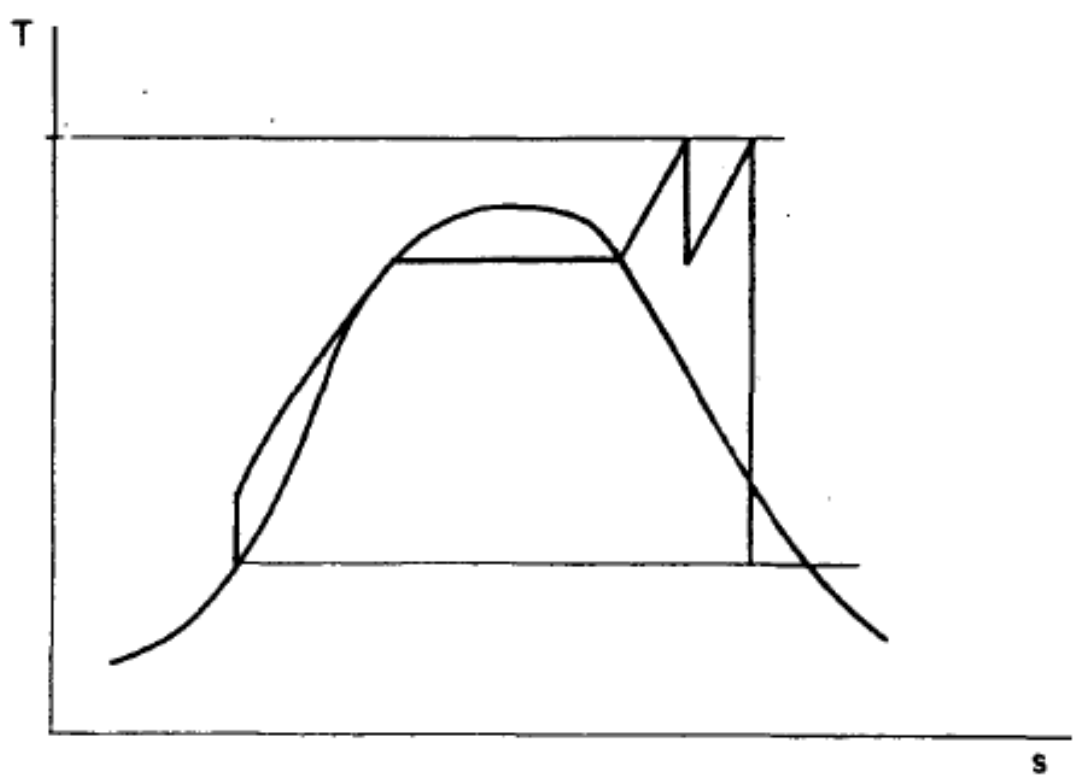

Figura 14 - Ciclo Rankine com reaquecimento (Adaptado de Moran e Shapiro, 2008).

Uma vantagem adicional do ciclo Rankine com reaquecimento consisteda redução da umidade do vapor na exaustão da turbina, elevando o rendimento dos últimos estágios e diminuindo a incidência deproblemas de cavitação das pás. Espera-se um aumento de 4-6\% na eficiência do ciclo, contudo vale salientar que o reaquecimento implica em detalhamentos técnicos adicionais e aumento nos custos por parte de novas tubulações e acessórios (Salisbury, 1974; Shlyakhin, 2005).

\subsubsection{Ciclo Rankine Regenerativo}

Esse ciclo consiste no aquecimento do líquido comprimido, através do vapor em expansão na turbina, com temperaturas levemente superiores àquelas do líquido a ser aquecido, resultando em trocas térmicas com menor grau de irreversibilidade. $O$ ciclo regenerativo ideal seria aquele onde o aquecimento do líquido comprimido ocorreria com diferenças infinitesimais de temperatura, como apresentado na Figura 15. Isso resultaria em infinitas extrações de vapor a serem efetuadas na turbina, para o aquecimento da água de alimentação em trocadores de calor (Bräscher, 1991; Van Wylen, 1984; Moran e Shapiro, 2008). 


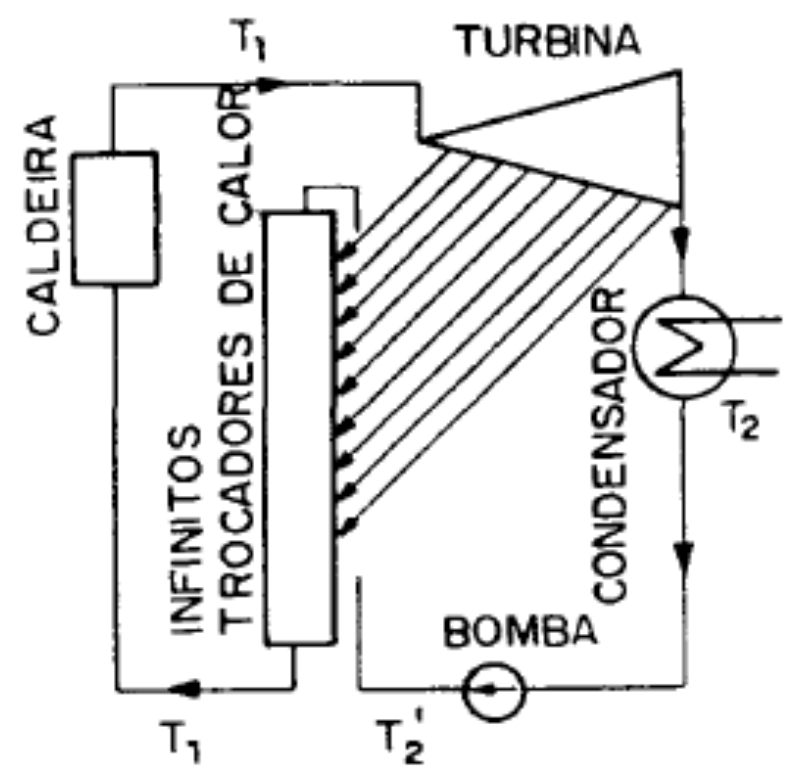

Figura 15 - Reaquecimento com infinitos trocadores de calor (Bräscher, 1991).

Tecnicamente, mesmo que possibilite maiores ganhos de eficiência, a construção de uma turbina com infinitas extrações de vapor não é possível na prática;além disso, não seria economicamente viável utilizar um número de trocadores de calor muito elevado no ciclo. A Figura 16 apresenta o diagrama T-s para o ciclo regenerativo ideal.

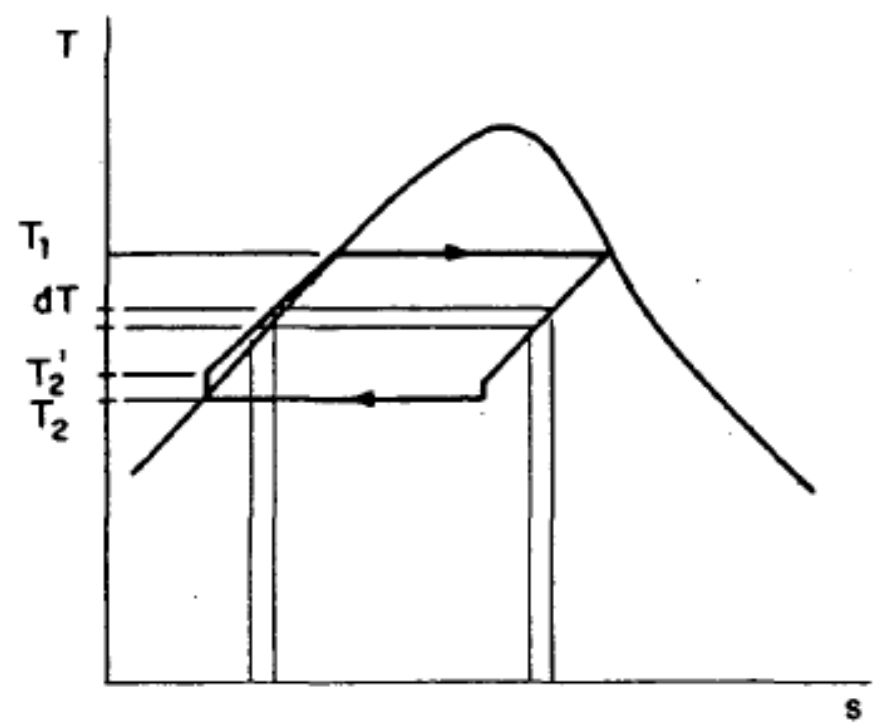

Figura 16 - Ciclo Regenerativo Ideal (Bräscher, 1991). 
No processo ideal descrito na Figura 16, as trocas de calor ocorrem infinitesimalmente, o que tende a eliminar as irreversibilidades do processo de aquecimento do líquido comprimido. Em um ciclo real, o processo de aquecimento do líquido comprimido ocorre em um número finito de trocadores de calor. Essa limitação se dá devido a aspectos operacionais e econômicos, onde o objetivo corresponde à máxima taxa de atratividade do capital investido (Bräscher, 1991).

\subsubsection{Ciclo Rankine Resultante}

O ciclo Resultante consiste na união das duas variações apresentadas anteriormente para ociclo Rankine, resultando no ciclo regenerativo com reaquecimento. Nesse caso, vapor a alta pressão desaída da caldeira expande na turbina sendoa seguir desviado para o reaquecedor. Neste equipamento, sua temperatura será ajustada à condição original de saída da caldeira. Após esse processo, o vapor torna a produzir trabalho nos demais estágios da turbina.

Ao deixar a secção de baixa pressão da turbina, o vapor é encaminhado à unidade de condensação, na qualatinge a condição de líquido saturada. Esta então é direcionada para o trem de trocadores de calor por intermédio das bombas de condensado e de alimentação. No trem de trocadores a água é aquecida pelo vapor proveniente das extrações ao longo da turbina, fechando o ciclo e retornando para caldeira, para que sua temperatura seja novamente elevada até a condição o patamar de partida dentro do espectro de vapor superaquecido (Bräscher, 1991; Moran e Shapiro, 2008).

\subsection{REVISÃO DOS CONCEITOS TERMODINÂMICOS}

\subsubsection{PRIMEIRA LEI DA TERMODINÂMICA}

A maneira clássica de determinar o desempenho térmico de sistemas ocorre a partir da Primeira Lei da Termodinâmica. Esta análise permite, sob o ponto de vista da 
energia, definir o desempenho de cada equipamento e também o desempenho global do sistema (Horlock, 1997).

Apesar de muito difundida, esta metodologia tem suas limitações, pois não contabiliza a qualidade da energia, ou seja, não se preocupa com as irreversibilidades inerentes de todos os processos. Para que se possa considerar este aspecto é necessário fazer uso conjunto da Segunda Lei da Termodinâmica, por meio de uma análise exergética (Kotas, 1995).

Fiomari (2004) destaca que uma análise baseada na Segunda Lei não substitui as avaliações feitas com base na eficiência energética, mas sim as complementa, permitindo cálcular tanto do valor termodinâmico de um fluxo, em termos do trabalho mecânico que poderia ser extraído dele, como também determinar as ineficiências e perdas termodinâmicas reais dos processos associados ao sistema em análise.

A eq. (3.1) mostra que em regime permanente, a taxa total do fluxo de massa entrando no volume do controle é igual à taxa total do fluxo de massa que sai do volume do controle. A eq. (3.2) estabelece que, para a mesma condição, a taxa total da energia entrando no volume de controle é igual à taxa total de energia deixando o volume de controle, já desconsiderando as variações de energia cinética e potencial (Van Wylen, 1984; Van Ness, 2007).

$$
\begin{gathered}
\sum \dot{m}_{e}-\sum \dot{m}_{s}=0 \\
\sum \dot{Q}_{v c}-\dot{W}_{v c}+\sum \dot{m}_{e} h_{e}-\sum \dot{m}_{s} h_{s}=0
\end{gathered}
$$

Onde:

e = fluxo de massa que entra no volume de controle $(\mathrm{kg} / \mathrm{h}) ;$

$\mathrm{s}=$ Fluxo de massa que sai do volume de controle $(\mathrm{kg} / \mathrm{h})$;

$h_{e}=$ entalpia específica na entrada do volume de controle $(\mathrm{kJ} / \mathrm{kg})$;

$h_{s}=$ entalpia específica na saída do volume de controle $(\mathrm{kJ} / \mathrm{kg})$;

$v c=$ taxa de transferência de calor para o volume de controle $(\mathrm{kJ} / \mathrm{h})$; 
$v c=$ Potência referente ao volume de controle $(\mathrm{kJ} / \mathrm{h})$.

\subsubsection{SEgunda LEI DA TERMODINÂMICA}

As irreversibilidades de determiandoprocesso são quantificadas pela Segunda Lei da Termodinâmica, por meio da variação de entropia. Para processos que ocorrem em regime permanente dentro deum volume de controleo balanço de entropia é definido pela eq. (3.3):

$$
\dot{S}_{g e r}+\sum\left(\frac{\dot{Q}_{v c, i}}{T_{i}}\right)+\sum \dot{m}_{e} s_{e}-\sum \dot{m}_{s} s_{s}=0
$$

Onde as novas variáveis são:

$\mathrm{S}_{\mathrm{e}}=$ entropia específica na entrada do volume de controle $(\mathrm{kJ} / \mathrm{kg} . \mathrm{K})$;

$\mathrm{s}_{\mathrm{s}}=$ entropia específica na saída do volume de controle $(\mathrm{kJ} / \mathrm{kg} \cdot \mathrm{K})$;

$\mathrm{Tj}$ - temperatura superficial do volume de controle $(\mathrm{K})$;

$=$ geração de entropia no volume de controle $(\mathrm{kJ} / \mathrm{kgK}) ; \geq 0$.

Para prever se um processo qualquer que envolve interações de energia pode de fato ocorrer, ou se os sentidos das transferências do calor são possíveis, pode-se utilizar a equação de balanço de entropia. A partir dessa decisão, admiti-se compulsoriamente que a Segunda Lei governa o limite de conversão entre diferentes formas de energia. Para um processo ser possível do ponto de vista termodinâmico é necessário que ger $\geq 0$ (Van Wylen, 1984; Van Ness, 2007;Moran e Shapiro, 2008).

\subsection{ANÁLISE EXERGÉTICA}

Um dos objetivos da Termodinâmica é estabelecer critérios gerais capazes de avaliar o funcionamento de sistemas industriais nos quais a energia tem um papel importante. Os métodos clássicos de Primeira Lei da Termodinâmica tratam todas as formas de energia como equivalentes, sem diferenciar os graus de qualidade 
daquelas que cruzam as fronteiras do sistema. O método exergético é um método mais abrangente de análise que, como apresentado anets, combina a Primeira e a Segunda Lei da Termodinâmica. A partir dessa abordagempode-se estimar o trabalho útil potencial - ou exergia - que foi fornecida para o sistema e consumida ou destruída ao longo dos processos devidos às irreversibilidades (Kotas, 1995).

A análise exergética é capaz de apresentar uma distribuição de irreversibilidades ao longo de todo o processo de uma planta, sendo capaz de identificar as etapas que mais contribuem para a sua ineficiência energética em geral. Isso ocorre por meio da formulação de um diagnóstico termodinâmico a partir do qual se destacam pontos para aplicação de ações de engenharia de forma a contribuir para a elevação da eficiência global do processo (Torres, 1999; Oliveira Jr., 2012).

\subsubsection{O CONCEITO DE EXERGIA}

Exergia pode ser definida como a máxima quantidade de trabalho obtida quando uma massa é trazida até um estado de equilíbrio termodinâmico com os componentes comuns do meio ambiente, através de processos reversíveis, envolvendo interações apenas com os componentes deste mesmo meio. Exergia também pode ser definida como a mínima quantidade de trabalho útil requerido se uma quantidade de matéria às condições ambiente é levada até outro estado termodinâmico (Szargut; Morris; Steward; 1988).

\subsubsection{DEFINIÇÃo do AmbIENTE de REFERÊNCIA}

A definição do ambiente de referência é de fundamental importância na análise exergética. Isso porque a exergia consiste de atributo tanto das propriedades termodinâmicas do sistema (pressão, temperatura e composição), quanto do sistema definido como ambiente de referência (Bejan; Tsatsaronis; Moran, 1996). De maneira ampla, o ambiente de referência é considerado como sendo composto pelas substâncias que existem em abundancia em estado estável e em forma natural na atmosfera, nos oceanos e na camada terrestre, a uma pressão de 1 atm e 
temperatura de 298,15 K. (Szargut; Morris; Steward; 1988). Essa premissa será adotada também neste trabalho.

Outras definições importantes são: a caracterização dos estados de referência restrito e estado morto. O primeiro define-se como sendo o estado no qual o sistema alcança o equilíbrio mecânico e térmico com o ambiente.

O estado morto ocorre quando o sistema chega também até o equilíbrio químico como ambiente. Dessa forma, além das condições de pressão e temperatura, a composição química das espécies que integram o sistema também se torna igual às das condições ambiente (Szargut; Morris; Steward; 1988).

\subsubsection{O BALANÇO DE EXERGIA}

Os sistemas estudados neste trabalho serão, por premissa, modelados como volumes de controle (VC) em regime permanente. Os modelos para análise exergética são deduzidos a partir da equação fundamental do balanço exergético. A Figura 17 representa um sistema aberto que passa de um estado termodinâmico qualquer para o estado definido como ambiente.

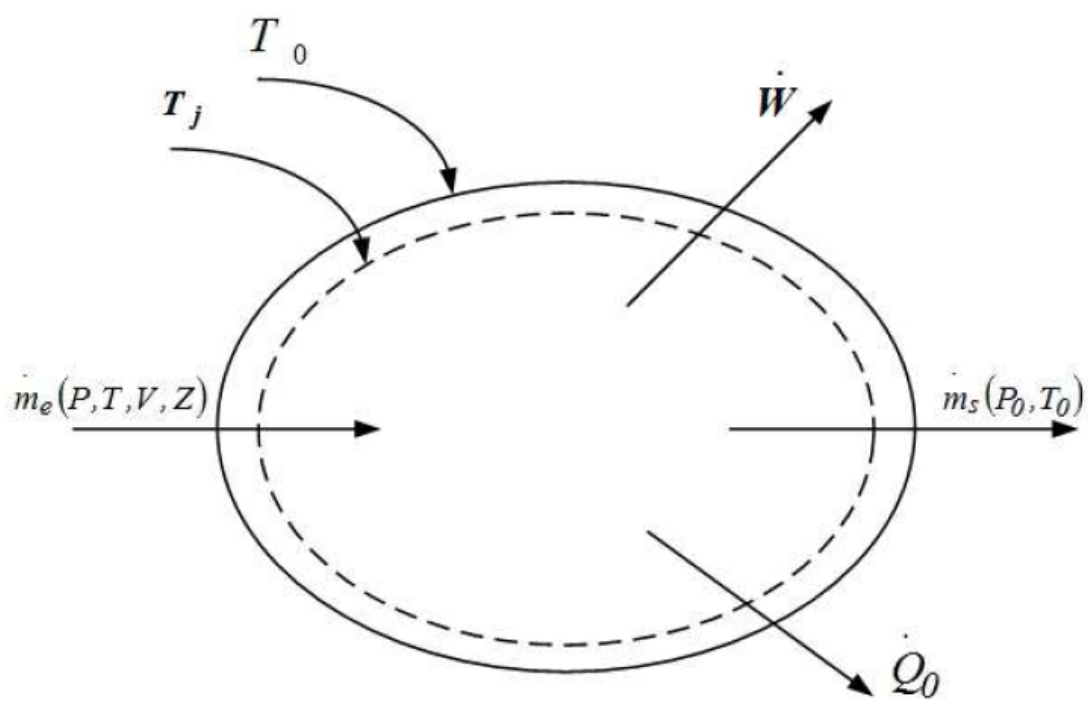

Figura 17 - Volume de controle para uma massa levada até as condições do ambiente. 
Adedução das equações para volumes de controle, não considera efeitos magnéticos, nucleares, elétricos e de tensão superficial. A equação 3.4 representa a aplicação da Primeira Lei da termodinâmica para o volume de controle levando o fluxo de massa até as condições de equilíbrio com o ambiente (Moran; Shapiro, 2008):

$$
\frac{d(U+K E+P E)_{v c}}{d t}=\dot{Q}-\left(\dot{W}-p_{0} \frac{d V_{v c}}{d t}\right)+\sum_{e} \dot{m}\left(h+1 / 2 V^{2}+g z\right)-\sum_{s} \dot{m}\left(h_{0}\right)
$$

Onde:

$\mathrm{U}=$ energia Interna $(\mathrm{kJ})$;

$\mathrm{KE}=$ energia Cinética $(\mathrm{kJ})$;

$\mathrm{PE}=$ energia Potencial $(\mathrm{kJ})$;

$\mathrm{Q}=\operatorname{calor}(\mathrm{kJ})$;

$\mathrm{W}=$ trabalho $(\mathrm{kJ})$;

$p=$ pressão (bar);

$\mathrm{V}=$ volume $(\mathrm{m} 3)$, velocidade $(\mathrm{m} / \mathrm{s})$;

$\mathrm{m}=$ massa $(\mathrm{kg})$;

$\mathrm{h}=$ entalpia específica $(\mathrm{kJ} / \mathrm{kg})$;

$\mathrm{g}$ = aceleração da gravidade (m/s2), Energia livre de Gibbs molar (kJ/kmol);

$z=$ elevação $(m)$

Em que os subscritos introduzidos representam respectivamente: $\mathrm{e}=$ Entrada; $\mathrm{s}=$ Saída; "0" = condições no ambiente de referência e "j" condições na fronteira do volume de controle. Já o sobrescrito "." representa fluxo ou taxa de transferência. 
Para o mesmo volume de controle, a aplicação do balanço de entropia resulta na equação 3.5 .

$$
\frac{d(S)_{v c}}{d t}=\sum_{j} \frac{\dot{Q}}{T_{j}}+\sum_{e} m_{e} s_{e}-\sum_{s} \dot{m}_{s} s_{O}+\dot{S}_{g e n}
$$

Onde as novas variáveis introduzidas são:

$\mathrm{S}=$ entropia $(\mathrm{kJ} / \mathrm{K})$;

$\mathrm{S}_{\mathrm{gen}}=$ entropia gerada $(\mathrm{kJ} / \mathrm{K})$;

$\mathrm{s}=$ entropia específica $(\mathrm{kJ} / \mathrm{kg} \mathrm{K})$;

$\mathrm{T}=$ temperatura $(\mathrm{K})$.

Separando a troca de calor com o ambiente $\left(Q_{0}\right)$ das equações apresentadas e multiplicando a equação do balanço de entropia por $\mathrm{T}_{0}$, obtêm-se a expressão geral para o balanço de exergia em estado estacionário, (eq. 3.6), resultado da combinação linear as equações da Primeira e Segunda Lei da Termodinâmica.

$$
\left.\frac{d\left(U+K E+P E-T_{0} S\right)_{v c}}{d t}=\sum_{j}\left(1-\frac{T_{0}}{T_{j}}\right) \dot{Q_{j}}-\left(\dot{W}-p_{0} \frac{d V_{v c}}{d t}\right)+\sum \dot{m}\left(h-h_{0}\right)-T_{0}\left(s-s_{0}\right)+1 / 2 V^{2}+g Z\right)-T_{0} S_{g e n}
$$

Quando simplificados em termos da exergia, os termos da equação 3.6, assumem a apresentação indicada na equação 3.7 , respectivamente.

$$
\frac{d B_{v c}}{d t}=\dot{B}-\dot{B}+\sum \dot{m} b-\dot{B}
$$

Onde:

= a taxa de variação da exergia em relação ao tempo no volume de controle VC;

$\mathrm{B}^{\mathrm{Q}}=$ fluxo de exergia associado ao fluxo de calor devido à diferença de temperatura entre a fronteira $T_{j}$ e o ambiente $T_{0}$; 
$\mathrm{B}^{\mathrm{W}}=$ trabalho útil obtido no processo;

$b$ = exergia específica associada aos fluxos de massa;

$\mathrm{B}_{\mathrm{D}}=$ exergia destruída no processo.

Na hipótese do sistema atingir o equilíbrio termodinâmico com o ambiente, a exergia associada aos fluxos de massa (b), passa a ser representada pela equação 3.8.

$$
b=b^{F}+b^{K}+b^{P}+b^{C H}
$$

Em que os termos: $b^{F}, b^{K}, b^{P}$ e $b^{C H}$; representam respectivamente às parcelas de exergia física, cinética, potencial e química.

Exergia física $\left(b^{F}\right)$ é a exergia obtida quando o sistema atinge as condições de equilíbrio térmico e mecânico com o ambiente, ou seja, atinge o estado restrito. $A$ Exergia cinética $\left(b^{\mathrm{K}}\right)$ representa o trabalho que pode ser produzido quando a massa é levada até o estado de repouso. Já a Exergia potencial $\left(b^{P}\right)$ compreende o trabalho que pode ser produzido quando a massa é levada até o estadode referência. Por fim, a Exergia química $\left(b^{\mathrm{CH}}\right)$ consiste do máximo trabalho que pode ser produzido quando o sistema passa do estado restrito para o estado morto, o que compreendeatingir simultaneamenteo equilíbrio mecânico, térmico e químico com o ambiente. Segundo Kotas (1995), as equações para cada termo da exergia supramencionado são definidas a seguir:

$$
\begin{gathered}
b^{F}=\left(h-h_{0}\right)-T_{0}\left(s-s_{0}\right) \\
b^{K}=\frac{1}{2} V^{2} \\
b^{P}=g Z
\end{gathered}
$$




$$
b^{C H}=-\Delta G+\left\{\sum_{p} n b^{C H}-\sum_{R} n b^{C H}\right\}
$$

Para obtenção da exergia química $\left(b^{\text {ch }}\right)$ a partir da equação 3.12 , considere-se a variável " $n$ " como o número de mols, e que os índices"P" e "R" se refiram aos produtos e aos reagentes de uma reação, respectivamente.

Para misturas de substâncias, a exergia química pode a ser calculada a partir da equação 3.13 (Oliveira Jr., 2012).

$$
b^{C H}=\sum_{i} x_{i} b_{i}^{C H}+R T_{0} \sum_{i} x_{i} \ln \left(\gamma_{i} x_{i}\right)
$$

Onde as novas variáveis introduzidas são:

$\mathrm{R}=$ constante universal dos gases $(\mathrm{kJ} / \mathrm{kmol} . \mathrm{K})$;

$\gamma=$ coeficiente de atividade;

x = fração mássica.

O subscrito "i" refere-se a cada componente de uma mistura

Segundo o teorema de Gouy-Stodola, a exergia destruída no processo, representada pelo termo índice ' $\mathrm{B}_{\mathrm{D}}$ ', está relacionada à geração de entropia no processo, conforme apresentado pela equação 3.14 (Kotas, 1995; Oliveira Jr., 2012).

$$
\dot{B}_{D}=T_{0} \dot{S}_{g e n}
$$


Onde a taxa de destruição de exergia (D) é dada pelo produto entre a temperatura do ambiente de referência $\left(T_{0}\right)$ e taxa de geração de entropia $\left(\dot{S}_{\text {gen }}\right)$ do processo.

A partir da definição de exergia, da associação das equações do balanço de exergia, e das equações que expressam seus componentes individuais com os princípios de conservação de massa, é possível modelar os processos que compõem os sistemas de cogeração utilizados nas indústrias sucroalcooleiras, alémdos cenários a serem propostos neste estudo.

\subsubsection{INFORMAÇÕES ADICIONAIS SOBRE EXERGIA}

Complementarmente ao exposto anteriormente faz-se ainda necessário apresentar informações adicionais com relação à exergia. Preliminarmente, explique-se que esta não é uma variável conservativa. Pode aumentar ou diminuir nos processos de transformação de matéria e energia, ser armazenada nas substâncias da natureza como acontece nos minerais e nos combustíveis, pode ser destruída, ou não ser utilizada, terminando nos rejeitos e ocasionando problemas ambientais (Arredondo, 2009).

A disponibilidade de recursos deve ser medida não apenas em função de suas quantidades, mas também, pela qualidade que dispõem. Como exergia é a parte da energia que pode ser convertida em trabalho, a mesma permite relacionar a energia com a qualidade. Por exemplo, as energias cinética, elétrica e potencial, podem ser transformadas totalmente em trabalho mecânico, portanto, seu conteúdo exergético é exergia pura. Já o calor não pode ser convertido completamente em trabalho, porque sempre haverá calor rejeitado para o ambiente, conseqüentemente, seu valor exergético será sempre menor (Arredondo, 2009). 


\subsection{ANÁLISE AMBIENTAL: AVALIAÇÃO DE CICLO DE VIDA - ACV}

\subsubsection{CONCEITOS E DEFINIÇÕES}

Silva (2010), apresenta o conceito de Ciclo de Vida como o conjunto de todas as interações antrópicas realizadas com o meio ambiente, que são necessárias para que um produto cumpra a contento as funções para as quais foi concebido. O ciclo de vida se estende desde a extração dos recursos naturais, percorrendo todos os elos de sua cadeia produtiva, por seu uso e chegando até o descarte, ou disposição final.

Por analogia e extensão, a Avaliação do Ciclo de Vida (ACV) pode então ser entendida comouma técnica de gestão desenvolvida com o intuito de fornecer um diagnóstico quantitativo do desempenho ambiental do conjunto de etapas antrópicas que devem ser cumpridas para que um produto - mas também, um processo, ou serviço - cumpra com os propósitos para os quais este foi produzido ou exercitado (Silva, 2012).

Em suma, a ACV faz uso da abordagem sistêmica para avaliar o desempenho ambiental de um produto, processo, ou serviço no exercício de umafunção. Esta avaliação magnifica, em termos de impactos sobre o entorno, o uso de recursos e a geração de rejeitos na forma de matéria e energia que circulam através de fronteiras reais, ou hipotéticas, que separam certo ciclo de vida do ambiente em que o mesmo se inscreve. A Figura 18 descreve etapas genéricas de um ciclo de vida, destacando fluxos de matéria-prima, correntes de reciclo, e cenários de destinação final de resíduos. 


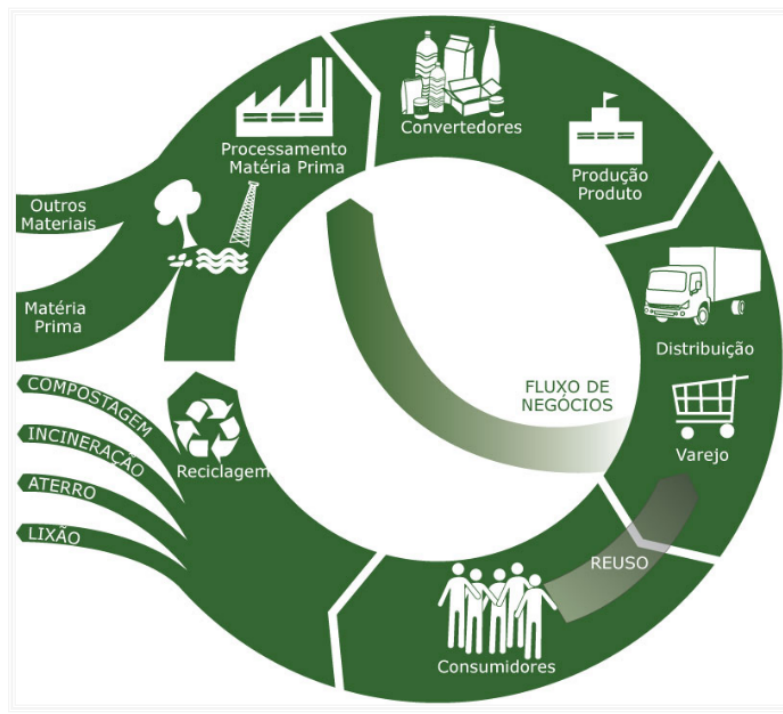

Figura 18 - Esquema da Análise de Ciclo de vida de um produto (Gripp, 2013).

As correntes de matéria e energia que definem as interações do ciclo de vida de um produto - processo ou serviço - com o entorno são denominados aspectos ambientais. Por outro lado, conceitua-se o termo impacto ambiental no âmbito de atuação da ACV como modificações efetuadas sobre o meio ambiente em decorrência da ação de aspectos ambientais (Baumann e Tillman, 2004; ABNT, 2009a).

\subsubsection{BREVE HISTÓRICO E ASPECTOS NORMATIVOS DA ACV}

Relatos de Chehebe (2002) dão conta que o primeiro estudo na busca de se inventariar o desempenho ambiental de um produto, com enfoque no consumo de energia, matérias-primas, água, e em partes nas emissões geradas no processo de fabricação, ocorreu entre final da década de 1960 e início da década de 1970. Esta análise, desenvolvida para a Coca-Cola Co., foi motivada pela mudança de atitude da organização na busca de medidas preventivas quanto à ocorrência de impactos ambientais. Inicialmente denominado de Resource Enviromental Profile Analysis (REPA), o estudo buscava a resposta para a pergunta "Qual recipiente tem o menor lançamento de rejeitos no ambiente e menos afeta as reservas de recursos naturais?". Diferenciando-se de outros estudos realizados à época, focados essencialmente em inventariar consumos energéticos, este trabalho quantificava 
também matérias-primas e perdas ocorridas ao longo do processo de fabricação de cada recipiente.

Aproximadamente um ano após a elaboração do REPA, foram conduzidos outros dois inventários de consumo de energia no ciclo de vida de embalagens. SegundoBaumann e Tillman (2004), esses esforços ocorreram dentro do meio acadêmico, por universidades nos Estados Unidos.

Entre as décadas de 1970 e 1980, a realização de trabalhos para a quantificação dos consumos e impactos associados ao exercício da função de um produto disseminou-se por diversos países na Europa, viabilizando a fundamentação teórica necessária para a concepção do conceito de Avaliação do Ciclo de Vida (ACV). Entretanto, a ausência de padronização metodológica nos estudos até então publicados alimentava certo ceticismo por parte da comunidade científica, sobretudo a respeito da credibilidade dos resultados obtidos. A partir desta constatação, surgem grupos de pesquisa que se dedicam a desenvolver mecanismos eprocedimentos confiáveis e exequíveis para a avaliação das interações entre um produto e o meio ambiente sob o enfoque sistêmico de ciclo de vida.

É neste contexto que na década de 1980 a Europa retoma e incrementa a técnica de ACV para produtos e serviços. Desta feita, porém, conceitos então disponíveis de desenvolvimento ambiental foram aplicados no sentido de magnificar os impactos das interações entre produtos e o meio ambiente. No mesmo período, a ACV é indicada pela Comunidade Europeia para o monitoramento do consumo de recursos naturais e geração de resíduos no processamento de polimeros (Chehebe, 2002).

Ao perceber a importância que o tema adquiria, a SETAC - Society of Environmental Toxicology and Chemistry - organiza entre 1990 a 1993 nove conferências de âmbito internacional com o intuito de reforçar a base conceitual da ACV, e de difundi-la pelo planeta. Essas iniciativas resultaram na elaboração do SETAC Guidelines for Life Cycle Assessment: a Code of Practice, primeiro documento voltado à padronização da técnica (Mourad, Garcia e Vilhena, 2002).

Subsidiado pelo trabalho da SETAC, a International Organization for Standardization (ISO) decidiu, em 1996, pela normatização e a padronização das práticas e condutas de realização de estudos de ACV. Um longo caminho foi percorrido até 
que as normas ISO 14040, ISO 14041, ISO 14042 e ISO 14043 fossem compiladas. Em 2006, este conjunto passou por uma releitura do que decorreram a forma revisada da ISO 14040 e a ISO 14044, em torno da qual se fundiram as outras normas de fundo metodológico (Silva, 2010). Estes arrazoados normativos tratam respectivamente de Princípios e Estrutura, e Requisitos e Diretrizes da Avaliação do Ciclo de Vida. A elas se somaram outras normas, de aplicação em situações específicas associadas a prática da ACV. Tratam-se das normas ISO 14047, de exemplos ilustrativos de aplicação da ISO 14044 em situações de impacto ambiental; e ISO 14048, que trata do formato de documentação de dados (Monteiro, 2008).

No Brasil a difusão das normas ficou a cargo da Associação Brasileira de Normas Técnicas (ABNT). Convocando voluntariamente especialistas brasileiros no tema, a instituição vem organizando a tradução dos conjuntos gerados pela série 14040 da ISO. Estão disponíveis para consulta nesse segmento as normas ABNT NBR ISO 14040 e 14044, editadas em 2009 (Silva, 2012).

\subsubsection{MÉtodo de ACV}

Um estudo de ACV consiste, em termos de método, do cumprimento de quatro etapas, sendo uma delas, de planejamento, duas outras, etapas executivas e, por fim, aquela que irá aferir aspectos de consistências e representatividade do estudo (Ribeiro, 2009). Na forma como estão organizadas na norma ABNT NBR ISO 14040, estas se intitulam, respectivamente: Definição de Objetivo e Escopo; Análise de Inventário; Avaliação de Impactos Ambientais; e, Interpretação.

Tais ações são representadas na Figura 19 seguindo o encadeamento em que devem ser exercitadas. Destaque-se nesta disposição a iteração entre as etapas, motivada por readequações sucessivas de premissas em decorrência de dificuldades surgidas por conta do avanço do estudo.

Passam agora a serem descritos de maneira sintética, porém consubstanciada, elementos constituintes e características de cada etapa de um estudo de ACV. 


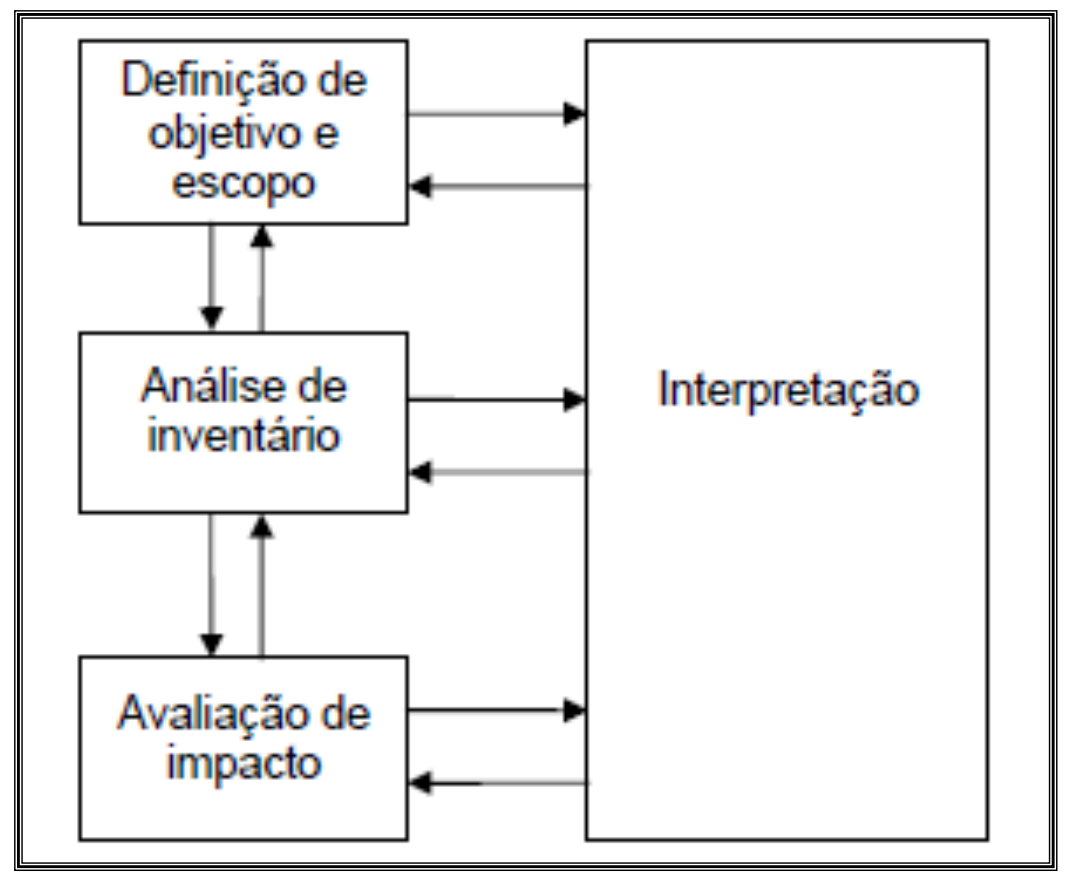

Figura 19 - Estágios do estudo de ACV.

(Fonte: Adaptado da norma ABNT NBR ISO 14040:2009)

\subsubsection{Definição de objetivo e escopo}

A Definição de Objetivos se ocupa em descrever de maneira clara e inequívoca os propósitos do estudo; os motivos e utilizações para asquais este será desenvolvido; e o público-alvo a que seus resultados se destinam.

Na Definição de Escopo são estabelecidas premissas, condicionantes e orientações de caráter geral para o estudo. Estes requisitos são fundamentais no sentido de: estabelecer a função a ser exercitada pelo produto, processo, ou serviço em análise; estabelecer as fronteiras que separam o espectro de aplicação da ACV de suas vizinhanças; regrar o processo de coleta de dados; e definir os impactos ambientais para os quais o desempenho ambiental será mensurado. Segundo as normas ABNT NBR ISO 14040 e 14044 (2009a, 2009b), serão definidos principalmente nesta etapa os seguintes elementos:

Função do sistema de produto: estabelece o propósito para o qual o produto, processo ou serviço em análise terá seu desempenho ambiental diagnosticado pela ACV. 
Unidade funcional: quantifica o exercício da função a ser desempenhada pelo produto de acordo com o escopo da ACV. A Unidade Funcional pode ser entendidacomo a base de cálculo para a quantificação das entradas e saídas do sistema. Trata-se de um valor arbitrário.

Fluxo de referência: quantidade de produto necessário para atender a unidade funcional estabelecida para o estudo. Para efeito de seu estabelecimento, deve-se levar em conta o desempenho técnico do produto no exercício da função.

Fronteiras do Sistema de Produto: delimita a abrangência do estudo, em relação ao sistema natural - ou Biosfera -, e a outros sistemas antrópicos - Tecnosfera. Nesse sentindo, a fronteira delimita o conjunto de processos elementares que proporcionam o atendimento da função previamente definida e que modela o ciclo de vida de um produto.

Sistema de produto: conjunto de processos elementares conectados entre si por meio de fluxos materiais ou energéticos, a partir do qual se viabiliza o atendimentoda função previamente definida.

Procedimentos de alocação: válido apenas para estudo de ACV com enfoque dito atribucional, estes procedimentos buscam distribuir com o menor grau de imprecisão póssivelconsumos e gerações de matéria e de energia ocorridos à montante de uma ação atrópica da qual se originem diferentes produtos. Para tanto, são empregados critérios diversos baseados em componentes físicas - como massa -; ou econômicas. Os procedimentos de alocação podem ser objeto de avaliação baseadas em juízo de valor, que poderiam se reverter em implicações negativas em termos de veracidade dos resultados finais gerados pelo estudo.

Critérios de exclusão de dados: rotinas quantitativas - na forma de contribuições cumulativas de massa e de energia para certo processo elementar - ou qualitativas, baseadas em grau de relevância ambiental, utilizadas para selecionar aspectos ambientais a serem considerados em cada processo elementar que compõe o sistema de produto.

Requisitos de qualidade: especificam as características dos dados a serem usados na modelagem do sistema de produto com vistas a atender de maneira stisfatória os objetivos pré-estabelecidos para o estudo de ACV. Nestes se incluem os seguintes 
parâmetros: grau de antiguidade dos dados a serem coletados; área geográfica em que ocorre cada processo integrantedo sistema de produto; tecnologias envolvidas; precisão, completeza e representatividade dos dados; reprodutibilidade dos métodos usados ao longo da ACV; fonte dos dados e incertezas da informação.

Categorias de impacto e Metodologia para a avaliação de impacto: define o método mais adequado para magnificação da influência dos aspectos ambientais, bem como, identifica dentro deste, categorias de impacto a serem utilizadas no estudo de ACV. Os objetivos definidos para o estudo serão elementos essenciais neste processo de seleção.

Análise crítica: verifica se o estudo atende aos ditames metodológicos que pautam a aplicação da técnica de ACV, bem como, aos requisitos estabelecidos na fase de planejamento da própria iniciativaquanto à metodologia, aos dados e ao relatório.

Além da fixaçãodessas bases a etapa de Definição de Objetivo e Escopo contempla eventuais limitações e suposições incorporadas para efeito e ao longo do andamento da ACV, a fim de relatar de forma fiel, completa e consistente os resultados do trabalho (ABNT, 2009a).

\subsubsection{Análise de Inventário}

Segundo Santos (2005), a análise do Inventário de Ciclo de Vida (ICV) consiste de um procedimento sistemático, gradual e objetivo para quantificar os fluxos de matériae energia que permeiam as fronteiras do sistema de produto ao longo de todo ociclo de vida. O primeiro passo a ser realizado nesse âmbito, consiste na coleta de dados. Esta ação deverá ser conduzida de forma que ao final do processo, os dados que a partir dela forem gerados reflitam com elevado grau de representatividade os fluxos de entrada e saída de matéria e energia que descrevem a relação entre o sistema de produto em análise e o meio ambiente ou outro sistema.

Para que a coleta de dados seja efetiva em seus propósitos, algumas ações prévias a esta incursão - que corresponde à etapa mais exaustiva da $A C V$, como a 
construção de um fluxograma de processo, a elaboração de dispositivos para coleta e registro de dados, e a descrição do objeto em estudo - devem ser providenciadas.

Os dados utilizados para o estudo podem ser obtidos em campo (dados primários) ou em literatura (dados secundários). Dados quantitativos utilizados na comparação de materiais ou processos e dados qualitativos empregados para a descrição de aspectos ambientais ou etapas não quantificáveis, podem ser selecionados a partir da aplicação dos critérios de exclusão (ABNT, 2009b).

Após a coleta, os dados são tratados, a fim de se adequarem ao fluxo de referência constituído para o estudo. Nesse instante, devem também ser incorporados os critérios de alocação a fim de proceder uma ponderação minimamente coerente de aspectos ambientais entre os distintos produtos gerados em determinado processo inscrito no sistema de produto.

Dada a característica iterativa da ACV, Ribeiro (2009) destaca que na elaboração do inventário será necessário fazer uso de procedimentos de análises de sensibilidade para eventuais redefinições da fronteira do sistema, exclusão de aspectos ambientais, ou de processos elementares identificados como não significativos para o estudo. As normas que dispõe sobre o método recomendam ainda que essa mesma abordagem seja utilizada em caso de alocação (ABNT, 2009b).

O produto final da etapa de ICV compreende uma planilha constituída por aspectos ambientais, ajustados ao fluxo de referência do estudo e, quando for necessário, tratados por meio da aplicação de critérios de alocação.

\subsubsection{Avaliação de Impactos Ambientais}

A Avaliação de Impactos Ambientais do Ciclo de Vida (AICV) analisa as magnitudes e significâncias dos impactos ambientais potenciais causados sobre o ambiente e sobre o ser humano, relacionados ao atendimento da função exercitada pelo produto, processo, ou serviço objeto do estudo.

De acordo com as normas da série ISO 14040 a AICV é composta por elementos obrigatórios e opcionais. Como elementos obrigatórios têm-se: Seleção de 
categorias de impactos e de seus respectivos indicadores; Classificação; Caracterização; e, Definição do Perfil de Impacto Ambiental (ABNT, 2009a).

De acordo com Pereira (2004), a Seleção das Categorias de Impacto Ambiental baseia-se nos resultados do ICV, particularmente emaspectos ambientais de maior relevância parao estudo. Feito isso, as categorias de impacto são relacionadas com os resultados gerados pelo ICV, segundo procedimento que ocorre em duas etapas: primeiramente em termos qualitativos - via Classificação -; para a seguir, efetuar-se uma interação quantitativa - por Caracterização.

A quantificação dos resultados para cada categoria de impacto é realizada com base no estabelecimento de fatores de equivalência, os quais são representados algebricamente por um composto capaz de expressar a magnitude de contribuição das demais substâncias para certa categoria de impacto. A partir da expressão em termos dessa referência, são definidos fatores de equivalência para cada substância dentro da respectiva categoria de impacto. Assim sendo, as contribuições de todos os fluxos de matéria e energia dentro do referido efeito, passarão a serem expressas a partir dessas mesmas substâncias de referência.

A composição dos desempenhos ambientais do atendimento da função expressa em todas as categorias gera o chamado Perfil de Impacto Ambiental.

A ACV considera categorias de impacto tais como: Mudança climática; Redução (ou Depleção) da camada de ozônio; Acidificação; Depleção de recursos abióticos; Eutrofização, Formação de foto-oxidantes, Depleção de Recursos hídricos e Fósseis, Transformação e Ocupação do solo, Toxicidade humana e Ecotoxicidade, entre outros.

\subsubsection{Interpretação}

A etapa de Interpretação compreende a identificação dos temas de maior relevância ambiental, a partir do que serão avaliados os resultados do estudo com o intuito de propor recomendações e estabelecerde eventuais ajustes em sua estruturação.

O desenvolvimento minucioso de todas as etapas relatadas, que por essência da metodologia estão inter-relacionadas, é fundamental para o êxito da $A C V$, na tarefa 
de evidenciar os impactos ambientais associados ao objeto de estudo, segundo um enfoque holistico.

Desta forma, a ACV se apresenta como ferramenta importante dentro dos sistemas de gestão, discutindo com clareza e objetividade as questões ambientais relacionadas ao gerenciamento de recursos ambientais e à identificação de pontos críticos de processos e produtos, possibilitando aperfeiçoar sistemas, insumos e matérias-primas, e desenvolver novas tecnologias.

O conjunto dos indicadores de categoria de impacto (perfil ambiental) do produto é analisado na última fase da ACV, a fase de interpretação dos resultados. Esta etapa de análise crítica, objetiva combinar, resumir e discutir as constatações da análise de inventário e da avaliação de impacto, de maneira iterativa aos objetivos e escopo da $\mathrm{ACV}$, bem como da natureza e da qualidade dos dados coletados.

\subsubsection{Usos e aplicações}

Atualmente, a expansão do interesse pela técnica de ACV coincide com uma diversidade de aplicações e usos a que a mesma se destina em diferentes frentes, tais como Setores Industrial e Agrícola, Agências Governamentais e Organizações não Governamentais (ONG), Organismos reguladores, e mesmo, o mercado consumidor. Neste contexto, destacam-se como aplicações da ACV: identificação de oportunidades de melhoria de desempenho ambiental; comparação de desempenho ambiental de produtos com mesma função; concessão de rótulos ou selos; projeto de novos produtos e processos, ou remodelação dos já existentes, a partir da variável ambiental; comunicação ambiental; entre outras (Silva e Kulay, 2006).

Na primeira das vertentes - de identificação de oportunidades de melhoria - a ACV é conduzida com o intuito de aprimorar processos e produtos, por meio de busca de novos insumos, fontes alternativas de energia ou tecnologias capazes de atender às funções originalmente previstas para o produto, mas com menores impactos ambientais. Isso é possível pelo fato de a técnica explorar o desempenho ambiental do objeto em estudo em cada etapa de seu ciclo de vida, possibilitando identificar a origem dos impactos ambientais mais significativos. 
De forma similar, a ACV pode ser adotada como meio de verificação de desempenho no processo de concepção de novos produtos, de forma que este seja concebido com um melhor desempenho ambiental que seu predecessor para o exercício de uma mesma função.

A ACV se propõe também a fornecer dados quantitativos de desempenho ambiental para a verificação de atendimento de critérios estabelecidos por selos ou rótulos desenvolvidos por governos, ONGs ou até mesmo pela indústria. Esta aplicação é amplamente utilizada para difusão de informações aos consumidores e usuários dos produtos, de forma que estes possam atribuir ao seu critério de escolha a matéria ambiental (Baumann e Tillman, 2004).

Por fim, a ACV propicia também a identificação de estratégias capazes de alterar o desempenho ambiental de produto, processos e serviços que cumpram a mesma função por meio de vias distintas. Neste cenário, as análises têm como objetivo verificar que estratégias diferenciam um produto do outro em termos ambientais. A minimização de rejeitos no processo, ações de prevenção à poluição, capacidade de reúso e reciclagem e substituição de insumos são algumas das causas potenciais de mudança de desempenho ambiental que podem ser identificadas a partir do uso da ACV (Silva e Kulay, 2006).

\subsection{ESTUDOS CIENTÍFICOS ENVOLVENDO ACV E ANÁLISE EXERGÉTICA}

O método da Avaliação de Ciclo de Vida (ACV) tem sido usado amplamente para avaliar os impactos ambientais dos processos industriais (Gaudreault et al. 2010). Nos últimos anos, vários pesquisadores se dedicaram ao estudo da análise termodinâmica de combustíveis renováveis, enquanto outros estudaram o desempenho ambiental através da ACV para esses mesmos bens de consumo.

No cenário global, Nguyen et al. (2008) realizaram uma ACV para etanol de canade-açúcar produzido segundo condições de processamento da Tailândia. Neste caso a ACV ajudou a identificar áreas em que a produção do etanol deveria ocorrer de forma a melhorar seu desempenho ambiental. 
Renouf et al. (2011) realizaram uma ACV para produtos produzidos a partir da canade-açúcar da Austrália, concluindo que os impactos ambientais dos produtos estavam principalmente associados a fatores tais como características dos sistemas de processamento da cana, e a variabilidade dos cultivos.

No Brasil, Cavalett et al. (2013), discutiram o assunto realizando ACV comparativa entre o etanol e a gasolina para diferentes métodos de Avaliação de Impacto de Ciclo de Vida (AICV). Como das principais conclusões do estudo consta a significante influência dos métodos de AICV nos resultados da pesquisa. O trabalho conclui que apesar de haver certa concordância em termos de resultados equivalentes quando se utiliza diferentes métodos de AICV no nível Midpoint, a utilização de métodos de indicadores únicos a partir de diferentes métodos de AICV conduzem a diferentes conclusões. De forma geral os resultados comparativos mostraram que o etanol apresentou melhor desempenho ambiental que a gasolina nas principais categorias de impacto, utilizando cinco diferentes médotos de AICV no nível Midpoint. $O$ trabalho concluiu também que a decisão sobre o melhor combustível depende de quais impactos ambientais são priorizados. Por outro lado, não foi possível estabelecar uma análise a partir de indicadores únicos mais apropriada para realizar esse estudo comparativo.

No caso específico de etanol e plantas de cogeração, Ometto et al. (2009) realizaram uma ACV do combustível etanol da cana-de-açúcar no Brasil, concluindo que o ciclo de vida deste combustível traz aportes negativos em diversas categorias de impacto ambiental: aquecimento global, formação de ozônio, acidificação, enriquecimento de nutrientes, ecotoxicidade e toxicidade humana. Entretanto, em termos de consumo de energia o balanço é positivo. Os autores apontam ainda que o etanol consome menos energia do que sua própria produção, principalmente devido aos sistemas de cogeração de eletricidade, mas classificam o processo como altamente dependente de água.

Guerra et al. (2014), realizaram uma análise comparativa entre cenários de cogeração elétrica a partir da queima do bagaço da cana em usina autônoma utilizando ACV e análise Termodinâmica de Primeira Lei. Os cenários abordaram principalmente alterações nos arranjos do ciclo Rankine, tomando porbase o ciclo Convencional, tradicionalmente usado nos sistemas de cogeração, e simulando a 
adoção de técnicas de melhoria de eficiência do ciclo, como Regeneração e Reaquecimento, considerando duas condições de pressão e temperaturaem que o vapor é gerado na caldeira: 67 bar e $480{ }^{\circ} \mathrm{C}$ ou 100 bar e $520^{\circ} \mathrm{C}$. Foram analisados oito estudos de caso a partir da combinação desses arranjos e condições operacionais, utilizando a mesma base de cálculo de produção agrícola e consumos de energia para produção de etanol. Concluiu-se que com utilização de tecnologias de melhoria na eficiência energética do ciclo Rankine aplicado à unidade de cogeração, houve uma redução sistêmica dos impactos ambientais associados à eletricidade gerada, mesmo tratando de uma ação restrita a somente um estágio do ciclo de vida.

Sobre a utilização da palha na cogeração, há vários pontos em discussão sobre o tema conforme apresentado. Vários pesquisadores têm se dedicado em realizar pesquisas sobre o assunto. Cardoso et al. (2013), realizaram uma avaliação técnica e econômica sobre a recuperação da palha da cana para produção de bioenergia, concluíndo que a recuperação da biomassa via enfardamento apresenta maior custo por unidade de massa em comparação ao sistema em que a palha seja colhida e transportada junto com os colmos da cana.

No caso da utilização da análise exergética em sistemas térmicos, Moran (1989) estudou sistemas térmicos desde os conceitos iniciais, que servem de base para se estabelecer e definir a exergia, até a aplicação a ciclos de potência. O autor debruçou-se também a aplicação da análise exergética aos componentes principais de uma usina de potência ciclo térmico de Rankine a vapor d'água.

Moran e Shapiro (2008), apresentam uma grande variedade de arranjos construtivos para usinas térmicas a vapor de geração de eletricidade, nas quais a água é o fluido de trabalho. A produção aborda a modelagem ciclos Rankine com reaquecimento e regeneração para centrais termelétricas. Os componentes principais de uma usina de potência são desdobrados em vários subsistemas principais, facilitando a análise termodinâmica, a qual envolve a aplicação dos princípios de conservação da massa e da Primeira e Segunda Lei da Termodinâmica.

Em termos de aplicação da análise exergética na produção de etanol e sistemas de cogeração, pesquisadores como Ensinas et al. (2008), estudaram a redução da geração de irreversibilidades no processo produtivo de açúcar e etanol, utilizando 
análise exergética. Os autores concluíram que as principais contribuições para geração de irreversibilidades estão no sistema de cogeração, extração do caldo e fermentação.

Ensinas et al. (2007), estudaram a redução da demanda de vapor no processo de produção de açúcar e etanol, e alternativas de sistemas de cogeração em usinas de cana, com objetivo de aumentar a capacidade de geração de eletricidade. Quatro configurações para o sistema de cogeração foram estudados: ciclo Rankine convencional com turbina de contra-pressão; ciclo convencional acoplado a turbina de extração-condensação;gaseificação da biomassa da cana; e ciclo combinado com gaseificação de biomassa (BIG-CC) que produz combustível para turbina a gás.Arranjos considerando ciclos com reaquecimento e regeneração que serão analisados nessa dissertação não foram estudados nesse artigo. Os autores concluíram que a demanda de vapor nos processos de produção de açúcar e etanol pode ser reduzida via integração térmica. $\mathrm{Na}$ análise comparativa entre alternativas de cogeração, a configuração BIG-CC apresentou o maior potencial de geração de eletricidade. Desde que barreiras técnicas e econômicas sejam superadas e o processo se torne viável, estepoderia proporcionar um aumento de $70 \%$ na geração de eletricidade.

Kamate et al. 2009, realizaram análise exergética em sistemas de cogeração de usinas de açúcar com ciclo Rankine convencional. Os autores concluíram que dentre os equipamentos que compõem o sistema de cogeração a caldeira apresenta menor eficiência exergética, e a turbina, o mais elevado desempenho.

Arredondo (2009), realizou uma avaliação exergética e exergo-ambiental para diferentes rotas de produção de biocombustíveis, concluindo que a produção de biodiesel apresentou maior eficiência exergética $(74,7 \%)$, seguido da produção de açúcar e etanol (45,5\%), produção de etanol usando a polpa da banana $(35,1 \%)$, usando a banana $(24,5 \%)$ e usando o pedúnculo da banana $(12,2 \%)$. O autor propôs ainda um indicador exergético de renovabilidade visando a caracterização ambiental dos processos.

Pellegrini et al., (2009) realizaram estudo termoeconômico baseado em análise exergética para sistemas de cogeração com ciclos de vapor supercrítico e com ciclo combinado com gaseificação de biomassa. Concluiu-se que a utilização desses 
ciclos podem gerar três vezes mais eletricidade excedente quando comparado com os sistemas atuais de turbinas de extração-condensação.

Dantas (2010) faz uso da Termodinâmica para avaliar o sistema de cogeração de usinas sucroalcooleiras do estado de São Paulo em duas condições de pressão na caldeira, em termos energético, exergético e ambiental, utilizando o indicador de eficiência exergética como referência para desempenho ambiental. $O$ autor conclui que as unidades que operavam com sistemas de alta pressão (63 bar) apresentaram melhor desempenho exergético e ambiental em relação aos sistemas de baixa pressão (20 bar), com respectivamente $31 \%$ contra $26 \%$ de performance exergética. No mesmo trabalho, Dantas também sugere que seja feito uma ACV do processo para obter uma abordagem ambiental sistêmica, desde a preparação dos recursos naturais até a obtenção dos produtos finais. 


\section{MÉTODO}

A fim de atender de maneira satisfatória aos objetivos a que se propõe, a presente iniciativa de pesquisa foi organizada, em termos de Método de Trabalho na forma de cinco etapas descritas a seguir:

I. Revisão Bibliográfica: procedeu-se levantamento junto a fontes consistentes e referenciáveis, de dados e informações capazes de fornecer a base conceitual necessária à realização das análises exergéticas e de desempenho ambiental, tanto no que diz respeito à técnica de ACV quanto ao processo de manufatura;

II. Definição de cenários: com base nos levantamentos efetuados na etapa de Revisão Bibliográfica, visitas de campo a unidades do setor sucroalcooleiro, e sugestões de especialistas, foram definidos cenários de cogeração elétrica em usinas autônomas para análise de desempenho ambiental e exergético;

III. Análise Exergética: construiram-se modelos matemáticos capazes de aplicar o método de análise exergética e simular os cenários de cogeração previamente definidos. A partir desta abordagem pretendeu-se determinar as ineficiências termodinâmicas do objeto estudo, bem como identificar as causas potenciais deste fenômeno e consolidar oportunidades de melhoria através dos cenários propostos.

IV. Avaliação de desempenho ambiental: esta análise foi conduzida por meio da aplicação da técnica de Avaliação de Ciclo de Vida (ACV). Tal opção se deve, em síntese, aos caracteres sistêmico, analítico e quantitativo que a abordagem em questão proporciona. A partir desta abordagemfoi possível identificarfocos potenciais de implementação de ações de melhoria de desempenho ambientaldentro das condições de contorno especificadas previamente por ocasião da modelagem do comportamento do objeto de estudo; 
V. Análise crítica dos resultados: procedimento que ocorreuem dois níveis: o primeiro tratou da abordagem conceitual empregada na identificação dos focos de melhoria de desempenho termodinâmico e ambiental; e o segundo nível abordou de forma diretaa discussão dos resultados efetivamente obtidos por conta do processo em si.

\subsection{DEFINIÇÃO DOS CENÁRIOS}

Partindo de informações obtidas ao longo do processo de Revisão Bibliográfica, de visitas a unidades industrias de processamento e, de orientações de especialistas na matéria foram definidos 40 (quarenta) cenários possíveis de cogeração elétrica para modelagem da análise exergética e posterior análise ambiental. As principais características que distinguem cada qual dessas possibilidades são: $O$ arranjo do ciclo Rankine; potencial de aproveitamento da palha como combustível; e funções de estadopossíveis para o vapor emanado da caldeira, a serem usadas depois no projeto do gerador de vapor.

A Tabela 4 sumariza e enuncia os arranjos do ciclo Rankine, bem como os parâmetros que distinguem e caracterizam cada cenário. Este conjunto tem $\mathrm{O}$ objetivo estabelecer condições de projeto bem definidas para analisar o desempenho termodinâmico e ambiental de usinas de cogeração elétrica que operam através do ciclo Rankine convencional, e simular quais seriam os resultados caso as técnicas de aumento de eficiência utilizadas por termelétricas - casos de reaquecimento e/ou regeneração - fossem aplicadas também em usinas de cogeração.

As bases teóricas para proposição de tais arranjos provem principalmente da descrição detalhada de ganhos de eficiência em usinas termelétricascuja cogeração se dá com turbinas de extração-condensaçãoobtidas em Moran e Shapiro (2008).

A possibilidade de utilizar a palha como combustível na caldeira também foi abordada nos cenários, por representar uma potencial fonte de energia, apesar das dificuldades operacionais de manuseio e transporte. 
O trabalho de Dantas (2010), ao estudar o desempenho termodinâmico dos sistemas de cogeração de duas usinas sucroalcooleiras contribuiu também significativamente para inclusão de cenários que contemplem o aumento da pressão do fluido de trabalho na saída da caldeira. 
Tabela 4 - Características dos cenários avaliados para o sistema de cogeração.

\begin{tabular}{|c|c|c|c|}
\hline$\frac{\text { Contryon }}{\text { ations }}$ & 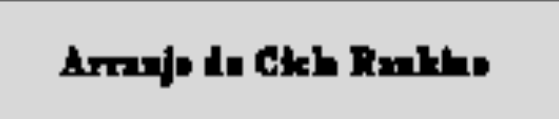 & $\begin{array}{l}\text { Tewde } \\
\text { polln }\end{array}$ & 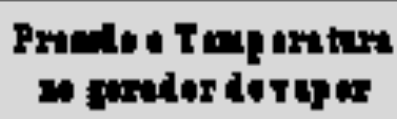 \\
\hline $\begin{array}{l}\text { I } \\
\text { II } \\
\text { III } \\
\text { IV } \\
\text { V }\end{array}$ & \multirow{2}{*}{ 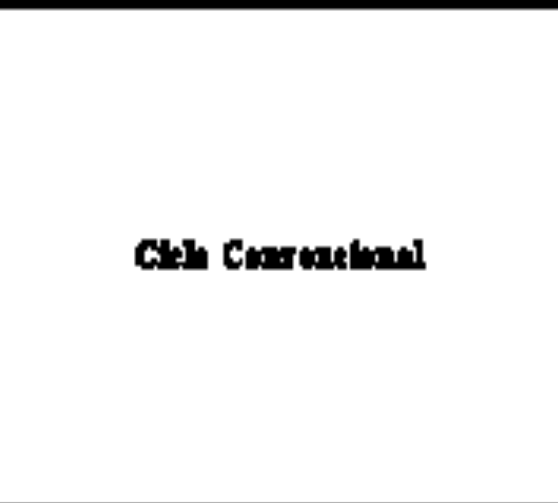 } & Mll. & 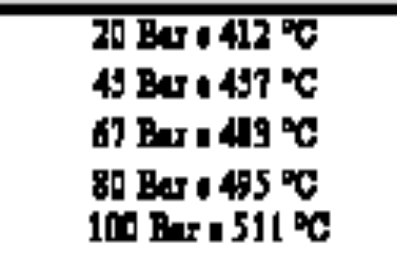 \\
\hline $\begin{array}{l}\text { VI } \\
\text { VII } \\
\text { YIII } \\
\mathbf{x} \\
\mathbf{X}\end{array}$ & & Sin & 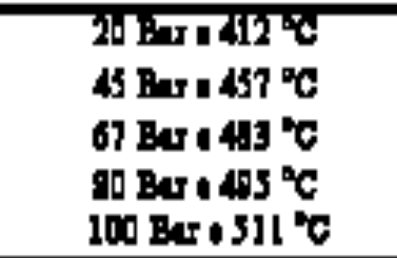 \\
\hline $\begin{array}{l}\mathrm{XI} \\
\mathrm{XII} \\
\mathbf{x I I I} \\
\mathbf{X I V} \\
\mathrm{XT}\end{array}$ & \multirow{2}{*}{ 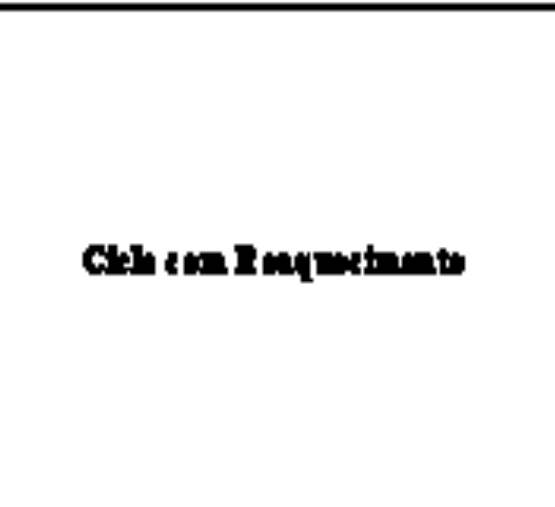 } & Ma & 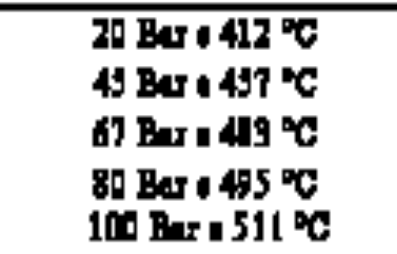 \\
\hline $\begin{array}{l}\mathrm{XFI} \\
\mathrm{XFII} \\
\mathrm{XVIII} \\
\mathbf{X I} \\
\mathbf{X X}\end{array}$ & & Sln & 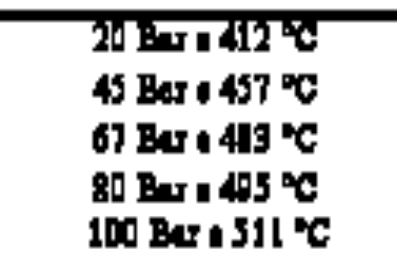 \\
\hline 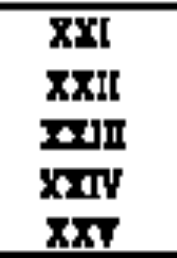 & \multirow{2}{*}{ Chel Rej netro } & M. & 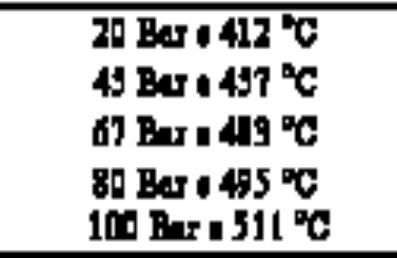 \\
\hline $\begin{array}{l}\mathrm{XXFI} \\
\mathbf{X X F I I} \\
\mathbf{x V I I} \\
\mathrm{XEI} \\
\mathbf{X X X}\end{array}$ & & Sln & 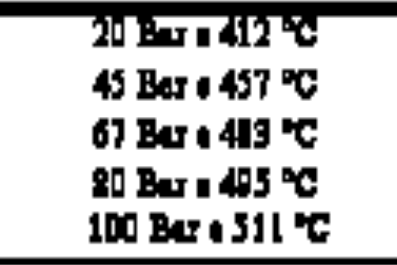 \\
\hline 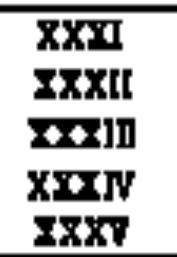 & \multirow{2}{*}{ 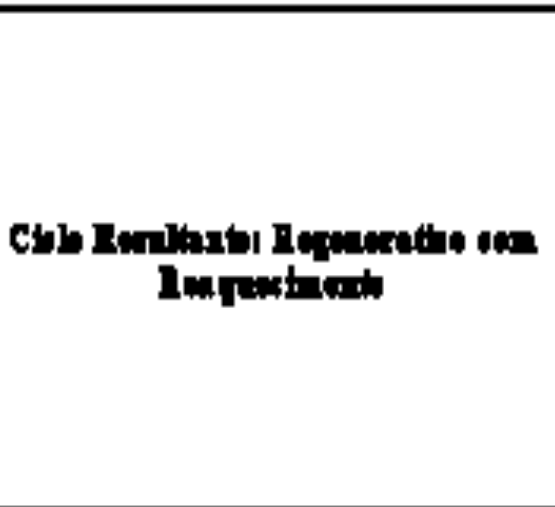 } & Sho & 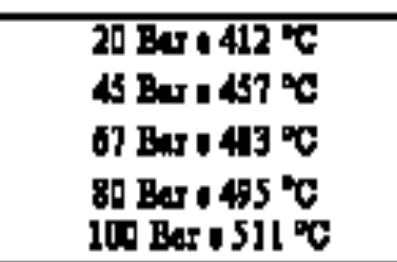 \\
\hline 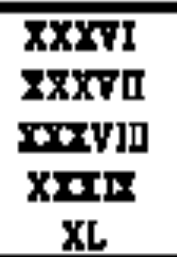 & & Sln & 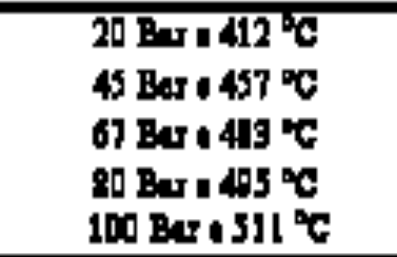 \\
\hline
\end{tabular}


Nesse aspecto, foram definidascinco condições operacionais de produção de vapor superaquecido à saída gerador de vapor, variando entre 20 e $100 \mathrm{bar}$, e mantendo o mesmo grau de superaquecimento em todos os casos. Essa medida visou reduzir o número de graus de liberdade e enfatizar o foco na variação de pressão da caldeira e alimentação da turbina.

Esse conjunto de cenários possibilitou a análise de desempenho exergético à medida que se efetuam melhorias no ciclo Rankine, bem como, proporcionou uma avaliação semelhante para a condição de aumento da pressão do fluido de trabalho de cada arranjo, além de avaliar os efeitos da utilização da palha como fonte de energia térmica na caldeira.

\subsection{MODELAGEM TERMODINÂMICA DOS CENÁRIOS}

\subsubsection{Premissas E DeFINIÇÃo dos ParÂMETROS OPERACIONAIS dOS CENÁRIOS}

Os ciclos termodinâmicos dos cenários propostos são compostos pelos seguintes equipamentos: Caldeira, turbina, condensador, bombas, desaerador, trocadores de calor (para o ciclo regenerativo), dessuperaquecedor e purgador. As modelagens foram realizadas considerando o ciclo termodinâmico em regime permanente. Além disso, admitiu-se que todo bagaço gerado é consumido na caldeira.

Em todos os cenários, uma fração de vapor saturado seco a 2,5 bar é extraída da turbina para ser usado no processo de produção do etanol e também para controlar a temperatura no desaerador. Esta é alimentada de forma a atingir o "set point" de desaeração de $110{ }^{\circ} \mathrm{C}$, um valorregularmente utilizado em sistemas de cogeração (Sosa-Arnao, 2008).

A extração de vapor da turbina a 2,5 bar é convencionalmente chamada de vapor de escape. O vapor de saída da turbina, chamado de vapor de cauda, atinge 0,1 bar de pressão e é condensado ao passar pelo condensador.Foram desprezadas perdas de carga das tubulações responsáveis pelo transporte do fluido de trabalho ao longo do ciclo termodinâmico. 
Nos balanços de energia, realizados individualmente nos equipamentos auxiliares como bombas, desaerador, dessuperaquecedor, purgadores e tubulações, foram desprezadas perdas energéticas.

Os cálculos adotados nas simulações de todos os cenários tomarampor premissa a produção de etanol anidro em destilaria autônoma de cana-de-açúcar com capacidade de moagem de 2,5 Mt por safra (210 dias).

Os consumos específicos de energia térmica e eletricidade adotados para produção de etanol em todos os cenários foram: $400 \mathrm{~kg}$ vapor saturado a 2,5 bar e $30 \mathrm{kWh}$ para cada tonelada de cana processada (tc). O resumo das premissas comuns a todos os cenários encontra-se indicado a seguir na Tabela 5.

Tabela 5 - Base de cálculo dos cenários

\begin{tabular}{lcc}
\hline Parâmetros & Valores & Unidades \\
\hline Cana moída total & 2.500 .000 & tc \\
Dias de safra (destilaria em operação) & 210 & Dias \\
Eficiência térmica da caldeira - 20 bar & 78 & $\%$ \\
Eficiência térmica da caldeira - 45 bar & 82 & $\%$ \\
Eficiência térmica da caldeira - 67 bar & 86 & $\%$ \\
Eficiência térmica da caldeira - 80 bar & 88 & $\%$ \\
Eficiência térmica da caldeira - 100 bar & 88 & $\%$ \\
Eficiência isentrópica da turbine & 85 & $\%$ \\
Eficiência do gerador & 95 & $\%$ \\
Eficiência isentrópica das bombas & 85 & $\%$ \\
Temperatura no desaerador & 110 & ${ }^{\circ} \mathrm{C}$ \\
PCl do bagaço (50\% umidade) & 7565 & $\mathrm{~kJ} / \mathrm{kg}$ \\
PCl da palha (15\% umidade) & 12960 & $\mathrm{~kJ} / \mathrm{kg}$ \\
Total de bagaço produzido na destilaria (50\% de umidade) & 280 & $\mathrm{~kg} / \mathrm{tc}$ \\
Total de palha produzida no campo (base seca) & 140 & $\mathrm{~kg} / \mathrm{tc}$ \\
Consumo de vapor no processo & 400 & $\mathrm{~kg} / \mathrm{tc}$ \\
Consumo de eletricidade no processo & 30 & $\mathrm{kWh} / \mathrm{tc}$ \\
Pressão de extração na turbina para uso no processo (vapor de & & \\
escape) & 2,5 & $\mathrm{Bar}$ \\
Pressão de extração na turbina para condensação (vapor de & & \\
cauda) & 0,1 & $\mathrm{Bar}$ \\
\hline
\end{tabular}

As informações acima enunciadas foram obtidos de trabalhos científicos publicados junto à literatura por Ensinas (2008); Seabra (2008);Dias et al. (2009); Dias et al. (2010); Oliveira Jr. (2012); Cardoso et al. (2013); e Cavalett et al. (2012). 


\subsubsection{A FERRAMENTA USADA PARA CONSTRUÇÃo DOS MODELOS MATEMÁTICOS}

Os modelos termodinâmicos e a interface do simulador foram construídos utilizando como ferramenta o software Engineering Equation Solver (EES). A função básica do EES é resolver um conjunto de equações algébricas, muito embora o programa disponha de ferramentas de otimização. As equações são inseridas pelo operador para efeito de composição do modelo em estudo. A interface de simulação também deve ser construída, permitindoque a apresentação seja customizada no sentido de facilitar sua compreensão. Com as propriedades de estado bem definidas, respeitando os graus de liberdade, pode-se usar o EES para estimar as propriedades físico-químicas e termodinâmicas do fluido de trabalho, possibilitando realizar simulações em diversas condições operacionais (EES, 2013).

\subsubsection{Características específicas dos arRanjos com REAQUECIMENTO E REGENERATIVO}

A única diferença entre a proposta que considera a utilização de reaquecimento no ciclo Rankinepara um modelo Convencional de cogeração consiste da extração integral de vapor superaquecido da turbina para ser reaquecido na caldeira e depois retornar aos demais estágios da turbina.

A Figura 20 apresenta uma ilustração para ciclo Rankine com Reaquecimento num sistema de cogeração, construído no software EES. 


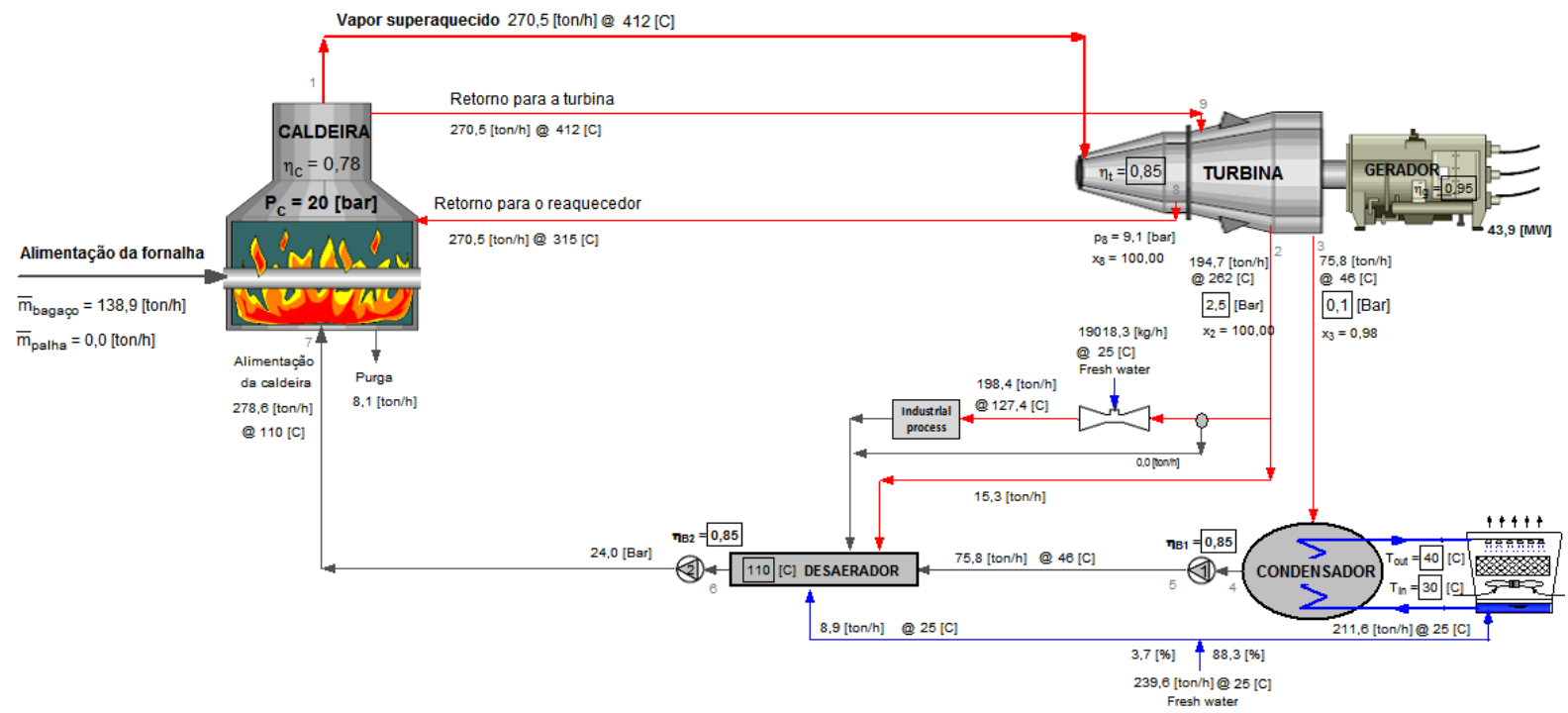

Figura 20 - Representação da proposta de um ciclo Rankine com Reaquecimento para um sistema de cogeração.

Conforme ilustrado na Figura 20, o ponto de pressão de extração na turbina para reaquecimento no superaquecedor da caldeirafoi determinado via otimização das condições de processo, para diferentes pressoes de operação da caldeira $(20,45$, 67, 80 e 100 bar). Para tanto, fez-se uso do Método de Aproximações Quadráticas um recurso comumente utilizado para otimizar uma função objetivo quando com apenas um grau de liberdade (Byrd, 2013;EES, 2013).

Liu et al. (2012), utilizaram o Método de Aproximações Quadráticas, por exemplo, para otimizar a temperatura de evaporação de um Ciclo Rankine Orgânico (ORC), adotando como função objetivo a eficiência de Segunda Lei da Termodinâmica e como variável independente a temperatura de evaporação. Na presente iniciativa, o método prestou-se à otimização para os cenários com Reaquecimento e Regeneração. Em ambos os casos, a função objetivo definida foi também a eficiência de Segunda Lei, aqui chamada de eficiência exergética do ciclo Rankine. Durante o processo de otimização do ciclo com reaquecimento, a eficiência exergética é maximizada via ajuste da pressão de extração da turbina para reaquecimento.

Conforme já discutido no Capítulo 3 , em centrais termelétricas é vantajoso pelo ponto de vista termodinâmico para o ciclo de Rankine, pré-aquecer a água de alimentação, num ciclo chamado de Regenerativo. As formas usuais de realizar o 
preaquecimento compreendem o uso de trocadores de calor externos à caldeira, onde o fluido quente é vapor extraído da turbina e o fluido frio, a água de alimentação. Os fluidos quente e frio não se misturam já que a troca térmica ocorre por contato indireto (El-Wakil, 2002; Graciano, 2007). A Figura 21 apresenta uma ilustração da proposta para ciclo Rankine Regenerativo num sistema de cogeração, construída no EES.

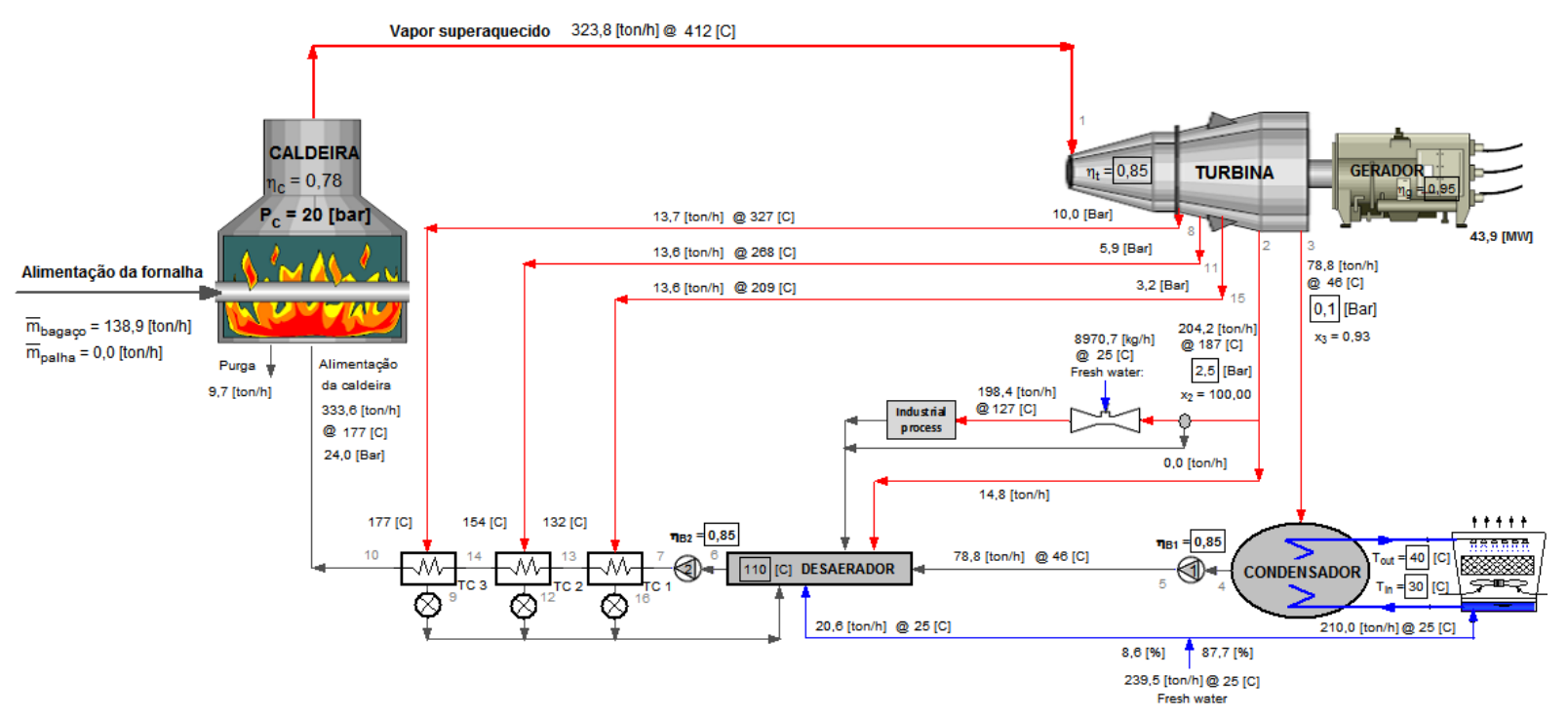

Figura 21 - Representação da proposta de um ciclo Rankine Regenerativo para um sistema de cogeração.

No ciclo Regenerativo, a eficiência exergética é maximizada a partir da otimização da pressão ótima de extração do vapor para alimentar cada trocador de calor do ciclo. Mais detalhes sobre a metodologia utilizada nesse procedimento serão tratados mais adiante em tópico específico desta produção.

O número de trocadores de calor adotado nos cenários com regeneração foi estimado por análise paramétrica por meio de simulações com até dez trocadores de calor, e será discutido apresentado também em uma etapa subsequente. De qualquer forma, verificou-se que o uso de mais de três trocadores de calor em série para aquecer a água de alimentação da caldeira contribui de forma discreta para o aumento da eficiência do ciclo regenerativo. Da conjuminação de conceitos de Reaquecimento e Regeneração em um único ciclo, concebe-se o ciclo Resultante. A 
Figura 22 traz uma ilustração da proposta para o ciclo Rankine Resultante num sistema de cogeração, construída no EES.

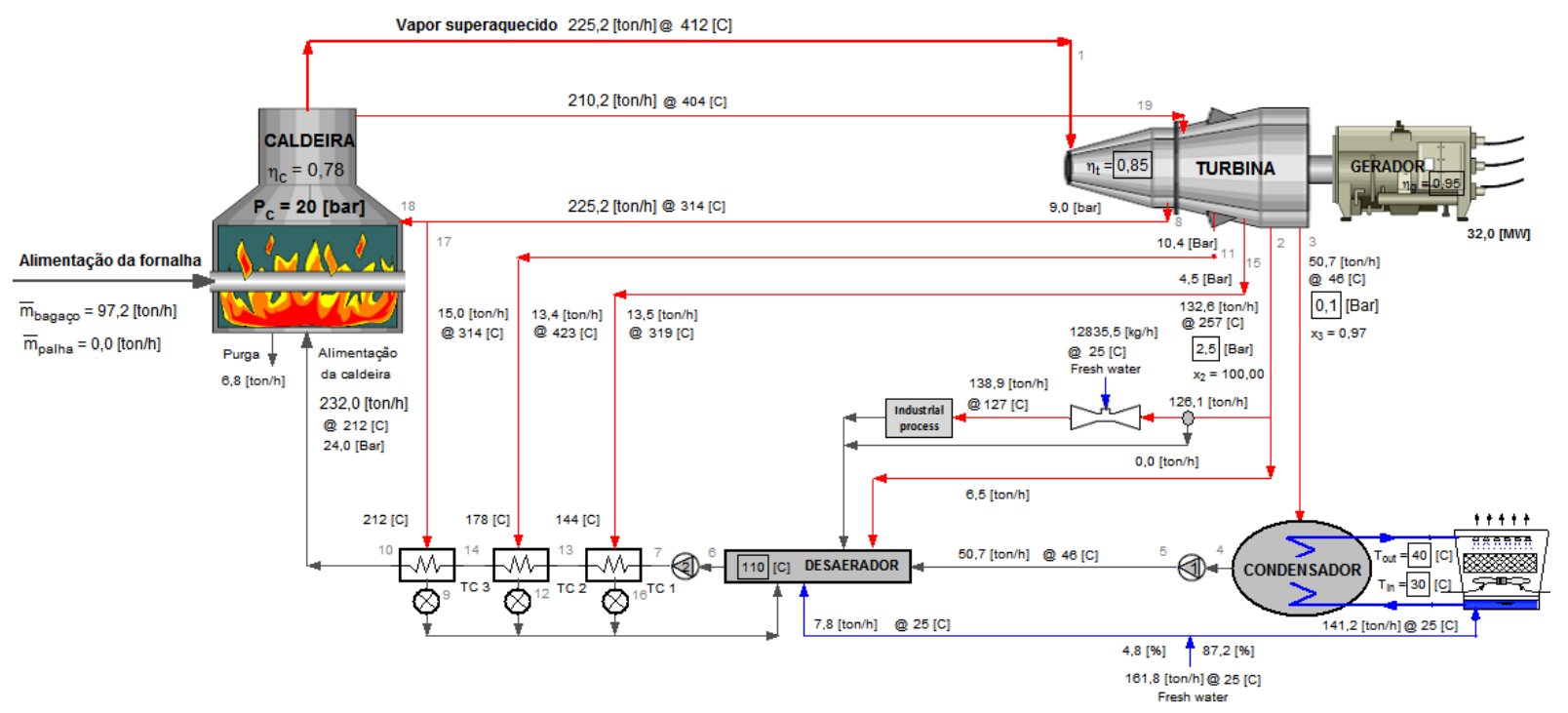

Figura 22 - Representação da proposta de um ciclo Rankine Resultante para um sistema de cogeração.

\subsubsection{MOdELAgEm dOS EQUiPAMENTOS}

Foram construídos cinco simuladores capazes de realizar análises Termodinâmicas de Primeira Lei e Segunda Lei - análise exergética, sendo: um simulador para cada arranjo do ciclo Rankine (Convencional, Reaquecimento, Regenerativo e Resultante) e um simulador específico para avaliaçãoda influência do número de trocadores de calor no ciclo regenerativo.

Os simuladores foram construídos no EES a partir da modelagem matemática dos processos, a partir da aplicação dos princípios de conservação de massa e energia, de balanços de exergia, entropia, e de funções de estado para determinação das propriedades termodinâmicas em cada equipamento do ciclo. Foram utilizados dados reais para os parâmetros de desempenho dos equipamentos da planta de cogeração, como bombas, turbina, caldeira e gerador, obtidos de dados de processo das usinas de cogeração Costa Pinto, do grupo Raízen no estado de São Paulo e Usaçúcar, do Grupo Santa Terezinha, no estado do Paraná. Valores de entalpias e 
entropias foram calculadas a partir da biblioteca de propriedades termodinâmicas do EES.

Os principais indicadores de desempenho calculados pelos simuladores para cada cenário foram: eficiência energética (\%), eficiência exergética (\%), Geração específica de eletricidade (kWh/tc), Eletricidade exportada (kWh/tc), consumo de água na torre de resfriamento ( $\mathrm{kg} / \mathrm{tc})$, consumo de água deionizada $(\mathrm{kg} / \mathrm{tc})$. Some-se a esse conjunto perdas energéticas, e taxas de destruição de exergia nos principais equipamentos do ciclo, os quais que permitiram então obter diagnósticos de Primeira Lei e Segunda Lei da Termodinâmica:

I. Diagnóstico de Primeira Lei: Perdas energéticas na caldeira (\%), perdas energéticas na turbina (\%), perdas energéticas no condensador (\%) e perdas energéticas nos equipamentos auxiliares (\%).

II. Diagnóstico de Segunda Lei compreende a análise exergética: Destruição exergética na caldeira (\%), destruição exergética na turbina (\%), destruição exergética no condensador (\%) e destruição exergética nos equipamentos auxiliares (\%).

Nos tópicos descritos a seguir, serão apresentadas de forma resumidaas modelagens dos principais equipamentos do ciclo termodinâmico em estudo. Versões detalhadas dos mesmos modelos constam dos Apêndices A até D.

\subsubsection{Caldeira}

A caldeira é o elemento responsável pela transferência de calor dos produtos da combustão para o fluido de trabalho. Trata-se de um dos elementos mais importantes do ciclo quando analisado sob o ponto de vista da Segunda Lei da Termodinâmica, pois é será ali a residirem as maiores irreversibilidades do sistema, originadas dos processos de combustão e transferência de calor (Bräscher, 1991; Tsatsaronis, 2002). 
O vapor produzido na caldeira é gerado pela transformação da energia química do combustível em calor. A biomassa proveniente da cana-de-açúcar é queimada na fornalha da caldeira, onde o calor é transferido principalmente por radiação para os feixes de tubos que transportam a água de alimentação. Após a fornalha, os gases de combustão passam através do superaquecedor, onde o vapor tem sua temperatura elevada acima da saturação.

Ao deixar o superaquecedor, os gases de combustão ainda possuem alta temperatura e normalmente os geradores de vapor empregam equipamentos adicionais de superfície de transferência de calor para melhor aproveitar a energia dos gases de combustão. Estas superfícies incluem reaquecedores, economizadores e pré-aquecedores de ar (Bräscher, 1991; Anon, 2005).

No presente trabalho, a modelagem desenvolvida para a caldeira teve enfoque apenas na transferência de energia térmica para o vapor de água. Isto foi possível, uma vez que, para cada condição de pressão da caldeira em cada cenário, de 20 a 100bar, adotou-se uma eficiência térmica globalestabelecida a partir de dados de literatura, depoimento de especialistas do setor, e visitas técnicas Tais valores constam da Tabela 5. Não se preparou qualquer modelo para analise dos processos específicos de transferência de calor e combustão, pelo fato destes não estarem enquadrados nos objetivos do trabalho.

Sob o ponto de vista do modelo, a quantidade de calor introduzida na caldeira é conhecida através da vazão mássica dos combustíveis e dos respectivos valores de poder calorífico inferior; além disso, devem-se conhecer as propriedades da água de alimentação e saída de vapor da caldeira para se determinar a vazão do fluido de trabalho que irá alimentar a turbina. Na alimentação da caldeira, as propriedades da água serão determinadas pela condição de saída do desaerador - para os ciclos Convencional e com Reaquecimento - ou pela condição de saída do trem de trocadores de calor, que promovem seu pré-aquecimento - para os ciclos regenerativo e resultante. Quanto às condições de saída, estas são especificadas pelo projeto da própria caldeira, admitiu-segrau de superaquecimento de $200{ }^{\circ} \mathrm{C}$, determinando assim a temperatura do vapor superaquecido com base na pressão da caldeira, e por meio da aplicação da equação 4.1 (Moran \& Shapiro, 2008) : 
Temperatura de saída do superaquecedor:

$T_{1}=T_{\text {sat }}\left(\right.$ water $\left.; P=P_{c}\right)+G_{\text {super }}$

Onde:

$\mathrm{T}_{1}=$ temperatura do vapor superaquecido $\left({ }^{\circ} \mathrm{C}\right)$;

$\mathrm{T}_{\text {sat }}\left(\right.$ water; $\left.\mathrm{P}=\mathrm{P}_{\mathrm{c}}\right)$ = temperatura de saturação d água na pressão da caldeira $\left({ }^{\circ} \mathrm{C}\right)$;

$\mathrm{G}_{\text {super }}=$ grau de superaquecimento $\left({ }^{\circ} \mathrm{C}\right)$

A quantidade de calor introduzida na caldeira é dada pela vazão mássica do bagaço e/ou palha. Essa quantidade de calor é chamada de energia disponível, enquanto a quantidade de energia efetivamente absorvida pelo fluido de trabalho denomina-se energia útil. A diferença entre energia disponível e energia útil ocorre devido a perdas de energia, nos vários equipamentos da instalação (Singer, 1981). A Figura 23 representa a caldeira do modelo construído.

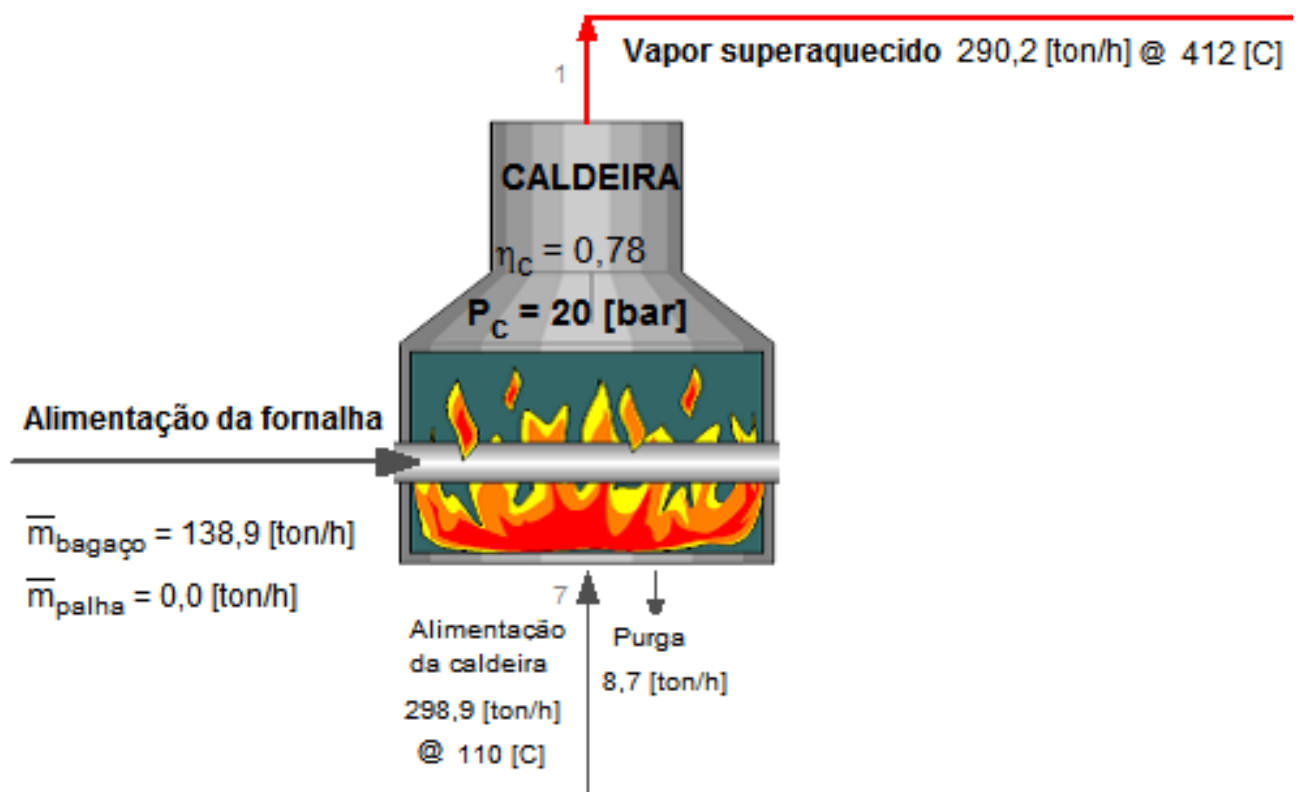

Figura 23 - Ilustração da caldeira. 
Tomando como referência a Figura 23, o balanço de massa na caldeira é dado por:

$$
\begin{aligned}
& \dot{\mathrm{m}}_{\text {agua }}=\dot{\mathrm{m}}_{\text {vapor }}+\dot{\mathrm{m}}_{\text {purga }} \\
& \dot{\mathrm{m}}_{\text {purga }}=\mathrm{Y}_{\text {purga }} \cdot \dot{\mathrm{m}}_{\text {vapor }}
\end{aligned}
$$

Onde:

água = vazão mássica da água de alimentação da caldeira (ton/h);

vapor = vazão mássica de geração de vapor superaquecido (ton/h);

purga = vazão mássica de purga da caldeira (ton/h);

$\mathrm{Y}_{\text {purga }}=$ taxa de purga (\%);

$P_{c}=$ pressão de operação da caldeira (bar).

Balanço de energia na caldeira:

$$
\begin{aligned}
& \dot{\mathrm{m}}_{\text {agua }} \cdot \mathrm{h}_{7}+\dot{\mathrm{Q}}_{\mathrm{c}}=\dot{\mathrm{m}}_{\text {rapor }} \cdot \mathrm{h}_{1}+\dot{\mathrm{m}}_{\text {purga }} \cdot \mathrm{h}_{\text {purga }} \\
& \dot{\mathrm{Q}}_{\mathrm{c}}=\left(\dot{\mathrm{m}}_{\text {bagaço }} \cdot \mathrm{PCl}_{\text {bagaço }}+\dot{\mathrm{m}}_{\text {palha }} \cdot \mathrm{PCl}_{\text {palha }}\right) \cdot \eta_{\mathrm{c}} \\
& \mathrm{POT}_{\text {entrada }}=\dot{\mathrm{m}}_{\text {bagaço }} \cdot \mathrm{PCl}_{\text {bagaço }}+\dot{\mathrm{m}}_{\text {palha }} \cdot \mathrm{PCl}_{\text {palha }}
\end{aligned}
$$

Onde:

$\mathrm{h}_{7}=$ entalpia específica da água de alimentação da caldeira $(\mathrm{kJ} / \mathrm{kg})$;

$\mathrm{h}_{1}=$ entalpia específica do vapor superaquecido $(\mathrm{kJ} / \mathrm{kg})$;

$\mathrm{h}_{\text {purga }}=$ entalpia específica da purga da caldeira $(\mathrm{kJ} / \mathrm{kg})$; 
$Q_{c}=$ energia útil $(\mathrm{kJ} / \mathrm{kg})$;

$\mathrm{POT}_{\text {entrada }}=$ potência de entrada ou energia disponível $(\mathrm{kJ} / \mathrm{kg})$;

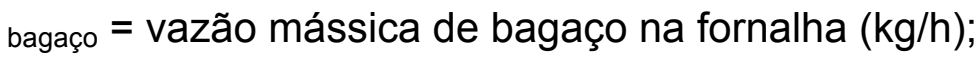

palha = vazão mássica de palha na fornalha $(\mathrm{kg} / \mathrm{h})$;

$\eta_{c}=$ eficiência térmica da caldeira (\%);

$\mathrm{PCl}_{\text {bagaço }}=$ poder calorífico inferior do bagaço $(\mathrm{kJ} / \mathrm{kg})$;

$\mathrm{PCl}_{\text {palha }}=$ poder calorífico inferior da palha $(\mathrm{kJ} / \mathrm{kg})$.

Conhecendo a eficiência da caldeira e a energia disponível da biomassa, pode-se então obter a energia útil.Sabendo-se a taxa de purga (estimada nesse caso em 3\% da vazão de vapor), estimam-se as vazões mássicas de vapor superaquecido e purga.

Cálculo das perdas energéticas na caldeira:

Boiler $_{\text {losses }}=\mathrm{POT}_{\text {entrada }} \cdot(1-n \mathrm{c})$

Boiler $_{\text {losses. perc }}=\frac{\text { Boiler }_{\text {losses }}}{\mathrm{POT}_{\text {entrada }}} \cdot 100$

Onde:

Boiler $_{\text {losses }}=$ perdas energéticas na caldeira $(\mathrm{kJ} / \mathrm{h})$;

Boiler $_{\text {losses.perc }}=$ perda energética percentual na caldeira $(\%)$. 
Balanço de exergia:

$$
\begin{aligned}
& \mathrm{B}_{7}+\mathrm{B}_{\text {fuel }}=\mathrm{B}_{1}+\mathrm{B}_{\text {purga }}+\text { Bdest }_{\text {boiler }} \\
& \mathrm{B}_{1}=\dot{\mathrm{m}}_{\text {vapor }} \cdot\left(\mathrm{h}_{1}-\mathrm{h}_{0}-\left((\mathrm{TO}+273,15) \cdot\left(\mathrm{s}_{1}-\mathrm{s}_{0}\right)\right)\right) \\
& \mathrm{B}_{\text {purga }}=\dot{\mathrm{m}}_{\text {purga }} \cdot\left(\mathrm{h}_{\text {purga }}-\mathrm{h}_{0}-\left((\mathrm{TO}+273,15) \cdot\left(\mathrm{s}_{\text {purga }}-\mathrm{s}_{0}\right)\right)\right) \\
& \text { Bdest }_{\text {boiler.perc }}=\frac{\text { Bdest }_{\text {boiler }}}{\mathrm{B}_{\text {fuel }}} \cdot 100
\end{aligned}
$$

Onde:

$\mathrm{B}_{7}=$ exergia da corrente de água de alimentação $(\mathrm{kJ} / \mathrm{h})$;

$\mathrm{B}_{\text {fuel }}=$ exergia do combustível de alimentação $(\mathrm{kJ} / \mathrm{h})$;

$\mathrm{B}_{1}=$ exergia da corrente de vapor superaquecido $(\mathrm{kJ} / \mathrm{h})$;

$\mathrm{B}_{\text {purga }}=$ exergia da corrente de purga $(\mathrm{kJ} / \mathrm{h})$;

$S_{\text {purga }}=$ entropia específica da corrente de purga (kJ/kg.K);

$\mathrm{s}_{0}=$ entropia específica da água no estado de referência $(\mathrm{kJ} / \mathrm{kg} . \mathrm{K})$;

$\mathrm{h}_{0}=$ entalpia específica da água no estado de referência $(\mathrm{kJ} / \mathrm{kg})$;

T0= temperatura no estado de referência $(K)$;

Bdest $_{\text {boiler }}=$ taxa de destruição de exergia na caldeira $(\mathrm{kJ} / \mathrm{h})$;

Bdest $_{\text {boiler.perc }}=$ percentual de destruição de exergia na caldeira $(\mathrm{kJ} / \mathrm{h})$.

Desde o balanço exergético pode-se determinar a taxa de destruição de exergia em qualquer equipamento. No exemplo da caldeira, pode-se calcular a participação desse equipamento na destruição da capacidade de realizar trabalho do ciclo Rankine. 
Caso o ciclo Rankine comporte reaquecimento, após o vapor superaquecido passar pelo estágio de alta pressão da turbina, este retorna para o reaquecedor como forma de recompor a temperatura inicial para depois, e mais uma vez, tornar para os demais estágios da turbina. A Figura 24 apresenta uma ilustração da caldeira com corrente de reaquecimento utilizada na modelagem, construída no EES.

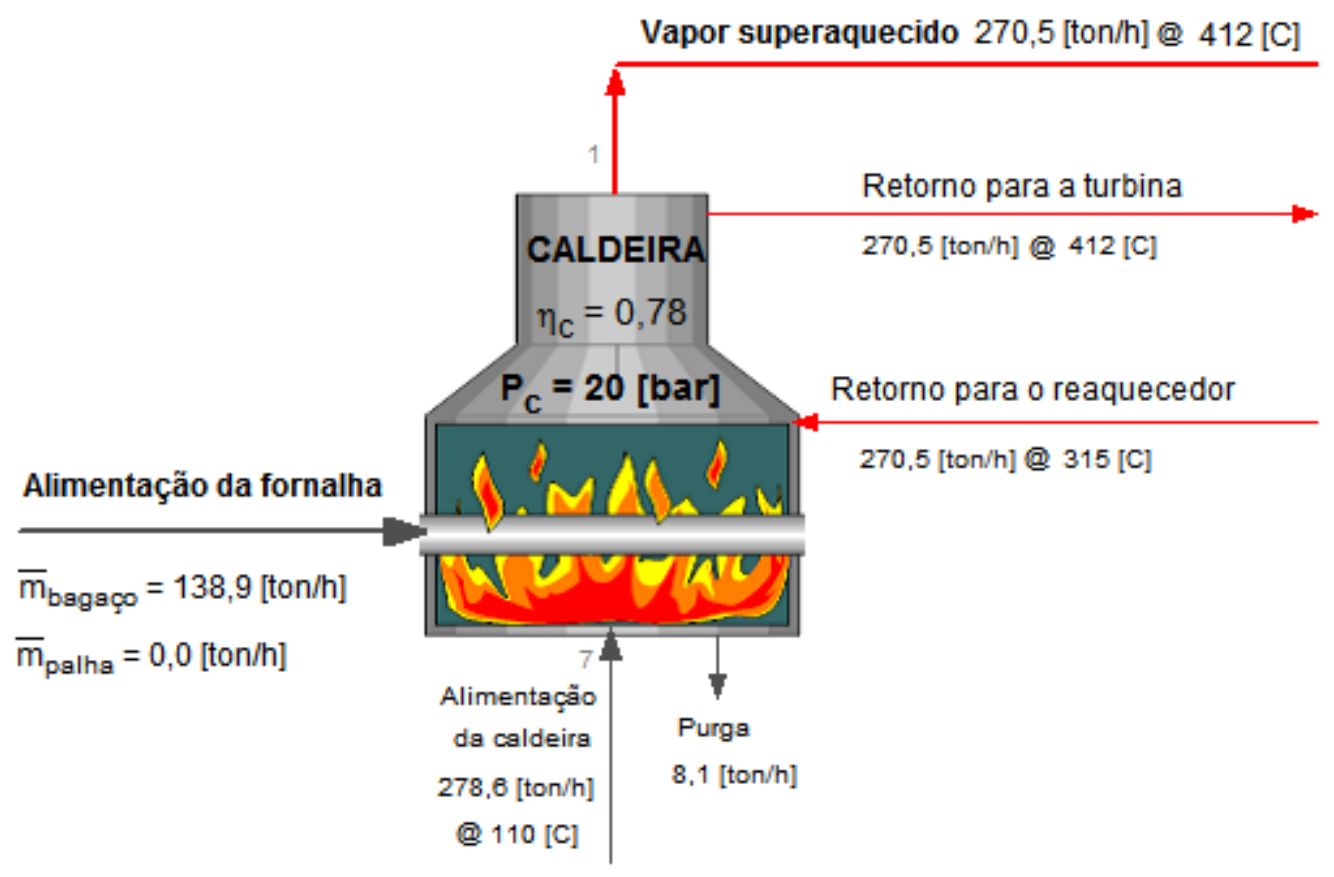

Figura 24 - llustração da caldeira com reaquecimento.

O balanço de massa na caldeira é semelhante àquele já apresentado; contudo uma parcela da energia útil da caldeira passa a ser fornecida para a corrente de vapor que retorna. Por conta disso, o balanço de energia se altera.

Balanço de energia:

$$
\begin{aligned}
& \dot{\mathrm{m}}_{\text {agua }} \cdot \mathrm{h}_{7}+\dot{\mathrm{Q}}_{\mathrm{c}}=\dot{\mathrm{m}}_{\text {vapor }} \cdot \mathrm{h}_{1}+\dot{\mathrm{m}}_{\text {purga }} \cdot \mathrm{h}_{\text {purga }}+\dot{\mathrm{Q}}_{\text {reaa }} \\
& \dot{\mathrm{Q}}_{c}=\left(\dot{\mathrm{m}}_{\text {bagaço }} \cdot \mathrm{PCl}_{\text {bagaço }}+\dot{\mathrm{m}}_{\text {palha }} \cdot P \mathrm{PCl}_{\text {palha }}\right) \cdot \eta_{c}
\end{aligned}
$$


$\dot{\mathrm{Q}}_{\text {reaq }}=\dot{\mathrm{m}}_{\text {vap.reaq }} \cdot\left(\mathrm{h}_{9}-\mathrm{h}_{8}\right)$

Onde as novas variáveis apresentadas são:

reaq $=$ energia utilizada para reaquecer a corrente de vapor que retorna para 0 reaquecedor $(\mathrm{kJ} / \mathrm{h})$;

$\mathrm{h}_{8}=$ entalpia específica da corrente de vapor que retorna para o reaquecedor $(\mathrm{kJ} / \mathrm{kg})$;

$h_{9}=$ entalpia específica da corrente de vapor que retorna para a turbina após ser reaquecida $(\mathrm{kJ} / \mathrm{kg})$;

O balanço exergético é aplicado confome metodojá descrito para a proposta com reaquecimento, cujas equações e códigos estão contidos nos Apêndices A até D.

A determinação da pressão ótima de extração para o reaquecimento foi obtida com Método de Aproximações Quadráticas, para caso que considerou por função objetivo a eficiência exergética do ciclo Rankine. A eficiência exergética é maximizada por ajuste da pressão de extração da turbina para reaquecimento, determinando assim a pressão ótima para reaquecimento.

A otimização dos cenários com reaquecimento mostrou que cada condição de pressão da caldeira (20 - 100 bar), possui um ponto de extração. Estes valores estão indicados a seguir na Tabela 6. Por meio dessa abordagem ocorreu o estabelecimento das pressões de extração para reaquecimento de cada cenário de cogeração proposto.

Tabela 6 - Pressão de extração ótima para cada pressão da caldeira

\begin{tabular}{cc}
\hline $\begin{array}{c}\text { Pressão da caldeira } \\
\text { ( bar })\end{array}$ & $\begin{array}{c}\text { Pressão de extração ótima para } \\
\text { reaquecimento } \\
\text { ( bar })\end{array}$ \\
\hline 20 & 9,1 \\
45 & 15,8 \\
67 & 21,1
\end{tabular}


Em grandes centrais termelétricas, a pressão ótima de extração está normalmente em torno de $20 \%$ da pressão de operação da caldeira (Bräscher, 1991). A partir da análise da Tabela 6 , observa-se que para unidades de cogeração do setor sucroalcooleiro, a pressão ótima de extração ficou acima de $27,4 \%$ em todos os cenários, diferentemente das centrais termelétricas mencionadas, como era esperado, uma vez que na cogeração há extração intermediária de vapor para ser usado no processo de produção de etanol.

\subsubsection{Turbina}

A turbina é o equipamento responsável pela conversão de energia térmica em energia cinética resultando em energia mecânica de eixo, que irá acionar o gerador. Cada estágio da turbina é projetado para produzir uma quantidade de trabalho a partir de um montante de energia térmica (Shlyakhin, 2005).

A eficiência para uma turbina real, conhecida como eficiência isentrópica, é definida pela razão entre o trabalho de eixo real e o trabalho de eixo na expansão isentrópica (ideal), para as mesmas condições de estado de entrada na turbina e mesma pressão de saída. Essa relação de trabalho produzido e energia térmica disponível resulta na eficiência interna do estágio (Salisbury, 1974; Moran \& Shapiro, 2008).

A definição matemática da eficiência isentrópica da turbina está indicada na eq. 4.2:

$\eta_{t}=\frac{h_{1}-h_{2}}{h_{1}-h 2 \text { iso }}$

Onde: 
$\mathrm{h}_{1}=$ entalpia específica do vapor na entrada de um determinado estágio da turbina $(\mathrm{kJ} / \mathrm{kg})$;

$\mathrm{h}_{2}=$ entalpia específica do vapor na saída de um determinado estágio da turbina $(\mathrm{kJ} / \mathrm{kg})$

$\mathrm{h}_{\text {2iso }}=$ entalpia na condição ideal de expansão isentrópica na saída de um determinado estágio da turbina $(\mathrm{kJ} / \mathrm{kg})$

$\eta_{t}=$ eficiência isentrópica da turbina (\%)

As entalpias envolvidas em eq. 4.2 se referem aos pontos indicados no diagrama Entalpia vs. Entropia específicas (h-s) da Figura 25. O diagrama ressalta o trabalho perdido devido irreversibilidades, ou seja, a diferença entre o trabalho isentrópico e o trabalho real, $\mathrm{h}_{2}-\mathrm{h}_{2 \text { iso }}$.

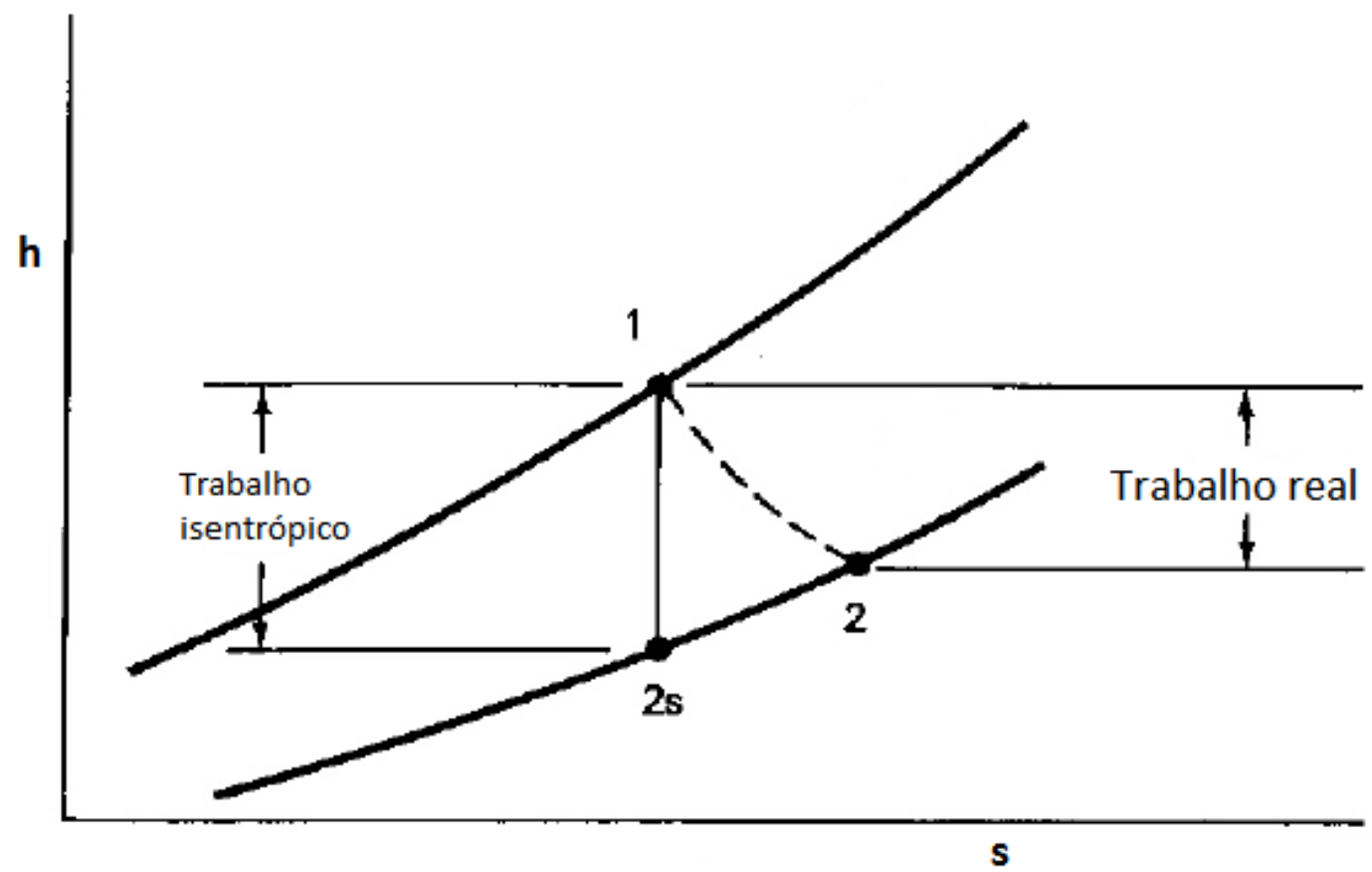

Figura 25 - Diagrama h-s para ilustração da eficiência da turbina (adaptado de Li et al, 1985).

A Figura 26 representa o conjunto turbina e gerador do modelo construído com auxílio de EES. A turbina é alimentada pela corrente de vapor superaquecido proveniente da caldeira. No caso do ciclo Rankine convencional, há somente duas 
correntes de vapor de saída: a corrente do vapor de escape a 2,5 bar (corrente 2 da Figura 21) que será utilizado como fonte de energia térmica no processo e, a corrente de vapor de cauda (corrente 3 da Figura 26), extraída a 0,1 bar, a ser direcionada para o condensador.

Empregando-se a equação 4.2 determina-se a entalpia real do vapor extraído para o processo por intermédio da eficiência isentrópica (Li et al.,1985; Moran \& Shapiro, 2008). A aplicação da equação 4.2 para a turbina ilustrada na Figura 26 segue abaixo:

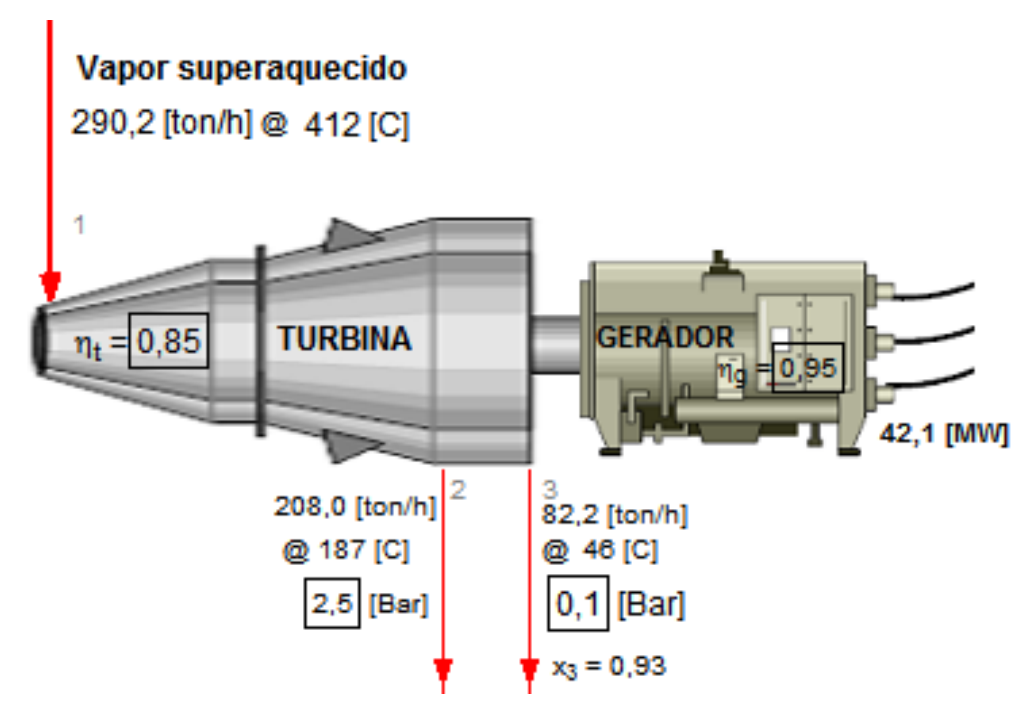

Figura 26 - llustração do conjunto turbina e gerador.

$$
\begin{aligned}
\eta_{t} & =\frac{h_{1}-h_{2}}{h_{1}-h 2_{\text {iso }}} \\
\eta_{t} & =\frac{h_{1}-h_{3}}{h_{1}-h 3_{\text {iso }}}
\end{aligned}
$$

Onde:

$h_{1}=$ entalpia específica do vapor na entrada na turbina $(\mathrm{kJ} / \mathrm{kg})$;

$\mathrm{h}_{2}=$ entalpia específica do vapor de escape da turbina $(\mathrm{kJ} / \mathrm{kg})$; 
$\mathrm{h}_{\text {2iso }}=$ entalpia específica do vapor de escape na condição ideal de expansão isentrópica $(\mathrm{kJ} / \mathrm{kg})$;

$\mathrm{h}_{3}=$ entalpia específica do vapor de cauda da turbina $(\mathrm{kJ} / \mathrm{kg})$;

$\mathrm{h}_{\text {3iso }}=$ entalpia específica do vapor de cauda na condição ideal de expansão isentrópica $(\mathrm{kJ} / \mathrm{kg})$;

$\eta_{t}=$ eficiência real da turbina.

Balanço de massa na turbina:

$$
\dot{\mathrm{m}}_{\mathrm{vapor}}=\dot{\mathrm{m}}_{\mathrm{vap} \text { escape }}+\dot{\mathrm{m}}_{\mathrm{vap} \text {.cauda }}
$$

Onde:

vapor = vazão mássica do vapor superaquecido de alimentação da turbina (ton/h);

vap.escape = vazão mássica do vapor de escape (ton/h);

vap.cauda = vazão mássica do vapor de cauda (ton/h).

Cálculo das potências elétricas:

$$
\begin{aligned}
& \mathrm{POT}_{\text {elétr.gerada }}=\left(\mathrm{POT}_{1}+\mathrm{POT}_{2}\right) \cdot \eta_{\mathrm{g}} \\
& \text { POT }_{1}=\dot{\mathrm{m}}_{\text {vap.escape }} \cdot\left(\mathrm{h}_{1}-\mathrm{h}_{2}\right) \\
& \mathrm{POT}_{2}=\dot{\mathrm{m}}_{\text {vap.cauda }} \cdot\left(\mathrm{h}_{1}-\mathrm{h}_{3}\right)
\end{aligned}
$$

Onde:

$\mathrm{POT}_{\text {elétr.gerada }}=$ potência elétrica gerada no turbogerador $(\mathrm{kJ} / \mathrm{h})$;

$\mathrm{POT}_{1}=$ potência elétrica gerada associada ao vapor de escape $\mathrm{kJ} / \mathrm{h}$ );

$\mathrm{POT}_{2}=$ Potência elétrica gerada associada ao vapor de cauda $(\mathrm{kJ} / \mathrm{h})$; 
$\eta_{\mathrm{g}}=$ eficiência do gerador (\%).

A partir dessas equações determina-se então a potência elétrica total gerada no turbogerador.

Balanço de exergia na turbina:

$$
\begin{aligned}
& \text { Bdest }_{\text {turbine }}=\mathrm{B}_{1}-\left[\mathrm{B}_{2}+\mathrm{B}_{3}+\frac{\mathrm{POT}_{\text {elétr.gerada }}}{\eta g}\right] \\
& \mathrm{B}_{1}=\dot{\mathrm{m}}_{\text {vapor }} \cdot\left(\mathrm{h}_{1}-\mathrm{h}_{0}-\left((\mathrm{TO}+273,15) \cdot\left(\mathrm{s}_{1}-\mathrm{s}_{0}\right)\right)\right) \\
& \mathrm{B}_{3}=\dot{\mathrm{m}}_{\text {vap.cauda }} \cdot\left(\mathrm{h}_{3}-\mathrm{h}_{0}-\left((\mathrm{TO}+273,15) \cdot\left(\mathrm{s}_{3}-\mathrm{s}_{0}\right)\right)\right) \\
& \text { Bdest }_{\text {turbine. perc }}=\frac{\text { Bdest }_{\text {turbine }}}{\mathrm{B}_{\text {fuel }}} \cdot 100
\end{aligned}
$$

Onde as novas variáveis introduzidas são:

$B_{2}=$ exergia da corrente de vapor de escape $(k J / h)$;

$B_{3}=$ exergia da corrente de vapor de cauda $(k J / h)$;

$\mathrm{s}_{2}=$ entropia específica da corrente de vapor de escape $(\mathrm{kJ} / \mathrm{kg} . \mathrm{K})$;

$\mathrm{s}_{3}=$ entropia específica da corrente de vapor de cauda $(\mathrm{kJ} / \mathrm{kg} . \mathrm{K})$;

$\mathrm{h}_{2}=$ entalpia específica da corrente de vapor de escape $(\mathrm{kJ} / \mathrm{kg})$;

$\mathrm{h}_{3}=$ entalpia específica da corrente de vapor de cauda $(\mathrm{kJ} / \mathrm{kg})$;

Bdest $_{\text {turbine }}=$ taxa de destruição de exergia na turbina $(\mathrm{kJ} / \mathrm{h})$;

Bdest $_{\text {turbine.perc }}=$ percentual de destruição de exergia na turbina $(\mathrm{kJ} / \mathrm{h})$. 
Através do balanço exergético pode-se determinar a taxa de destruição de exergia na turbina; ou seja, qual a participação da turbina na destruição da capacidade de realizar trabalho no ciclo Rankine.

Este método foi replicado de maneira idêntica em termos de passos operacionais na modelagem das turbinas com extrações intermediárias adicionais, para os casos dos cenários com reaquecimento e regeneração.

\subsubsection{Condensador}

A unidade de condensação é responsável por rejeitar calor do sistema para o meio ambiente, condensando o vapor de cauda da turbina em líquido saturado. A unidade condensadora é projetada com o intuito de proporcionara pressão de condensação desejada (Stoecker, 1989; Staff, 2006). No presente trabalho, adotou-se pressão de condensação de 0,1 bar um parâmtroconsagrado para dimensionamentos dessa naturea em unidades de cogeração usadas pelo setor sucroalcooleiro que operam com extração-condensação, e também adotado nos sistemas de cogeração elétrica das usinas que foram visitadas. A Figura 27 representa o conjunto condensador e torre de resfriamento para o ciclo Rankine convencional, construído no EES.

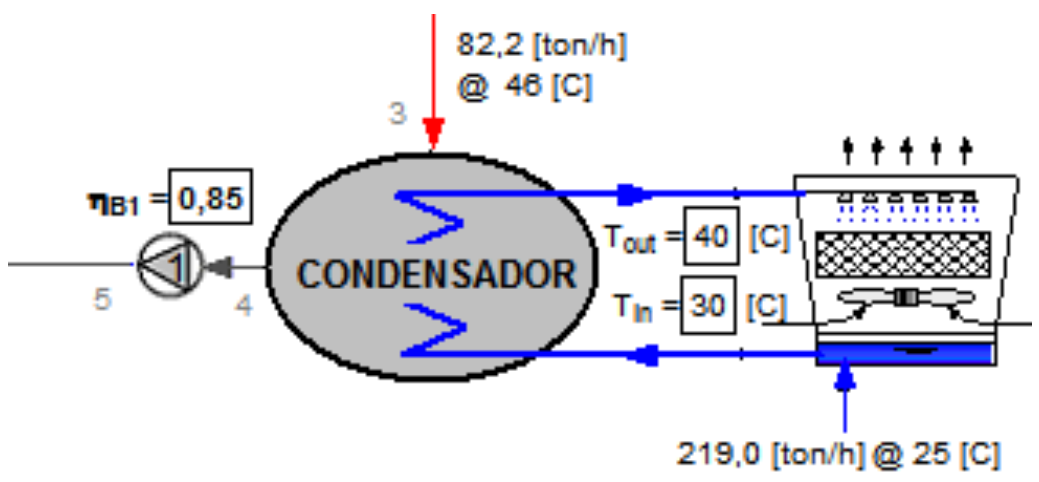

Figura 27 - llustração do conjunto condensador e torre de resfriamento.

O vapor de cauda (corrente 3 da Figura 27), circula pelo condensador via corrente 3 e 4. As condições de temperatura de entrada e saída da água de recirculação da 
torre são parâmetros de projeto de torres de resfriamento. Pode-se investir em equipamentos maiores para se trabalhar com temperaturas mais baixas ou dimensionar de forma a obter o melhor retorno sobre investimento (Skrotzi, 1960; Oliveira, 2010). As torres de resfriamento são especificadas com baseem considerações econômicas e restrições impostas pelo sistema. No projeto, deve-se garantir a remoção dedemanda térmica do processo e assegurar uma temperatura mínima para a água resfriada. O valor dessa temperatura constitui uma das considerações essencias de projeto de uma torre de resfriamento, tendo grande impacto no seu custo (Cortinovis, 2004).

Em todos os cenários estudados, adotou-se a temperatura da água de saída da torre (entrada no condensador) como sendo de $30{ }^{\circ} \mathrm{C}$, e de retorno para torre (saída do condensador) de $40{ }^{\circ} \mathrm{C}$. Essa consideração determinou a vazão de recirculação da bomba, uma vez conhecido a taxa de transferência de energia térmica da corrente quente (vapor de cauda) para a corrente fria (água de recirculação). Vale ressaltar, que em todos os cenários, foi adotado que o vapor de calda é extraído a 0,1 bar

O Balanço de massa e energia no condensador (referente à Figura 27):

$$
\begin{aligned}
& \dot{\mathrm{m}}_{\text {vap.cauda }}=\dot{\mathrm{m}}_{4} \\
& \dot{\mathrm{Q}}_{\text {out }}=\dot{\mathrm{m}}_{\text {vap.cauda }} \cdot\left(\mathrm{h}_{3}-\mathrm{h}_{4}\right)
\end{aligned}
$$

Onde:

out $=$ calor transferido do vapor de cauda para água de recirculação da torre $(\mathrm{kJ} / \mathrm{h})$;

$\mathrm{h}_{3}=$ entalpia específica da corrente de vapor de cauda na entrada do condensador $(\mathrm{kJ} / \mathrm{kg})$;

$\mathrm{h}_{4}=$ entalpia específica da corrente de líquido saturado na saída do condensador $(\mathrm{kJ} / \mathrm{kg})$;

${ }_{4}$ = vazão mássica de líquido saturado na saída do condensador (kg/h).

Balanço de massa e energia na torre de resfriamento (referente à Figura 27): 


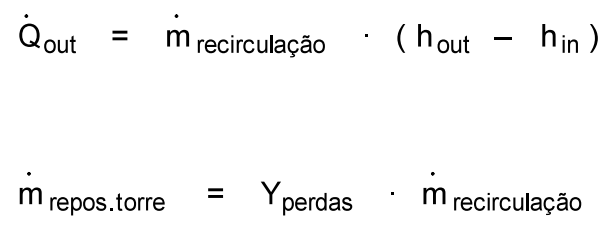

Onde:

$\mathrm{h}_{\text {in }}=$ entalpia específica da corrente de água de resfriamento na entrada do condensador $(\mathrm{kJ} / \mathrm{kg})$;

$\mathrm{h}_{\text {out }}=$ entalpia específica da corrente de água de resfriamento na saída do condensador $(\mathrm{kJ} / \mathrm{kg})$;

recirculação = vazão mássica da água de recirculação da torre $(\mathrm{kg} / \mathrm{h})$;

repos.torre = vazão mássica da água de reposição da torre $(\mathrm{kg} / \mathrm{h})$;

$\mathrm{Y}_{\text {perdas }}=$ percentual de perda de água na torre de resfriamento em relação à vazão de recirculação (\%).

A reposição de água na torre de resfriamento é necessária para suprir as perdas de processo por evaporação, arraste e purga (Al-Waked, 2006; Oliveira, 2010). Cortinovis (2004) descreve os balanços de massa e de energia em uma instalação típica que dispõe de torre de resfriamento em operação com fonte de calor em circuito fechado, um arranjo semelhante ao da proposta da modelagem desse trabalho.

Nos balanços de massa e energia da torre de resfriamento, considera-se condição de regime permanente. Assim, a vazão de água reposição é igual ao somatório de todas as perdas da torre, no que se referem à vazão da água evaporada, arraste e purgas. Cheremisinoff (1986), e El-dessouky et al. (1997) relatam que em condições normais de operação, as perdas por evaporação e arraste serão inferiores a 2 \%. Existem, no entanto, outras referênciasque consideram que as perdas de água podem atingir até $10 \%$ da vazão de água que circula no sistema (Ogboja, 1987; e Oliveira, 2010). Neste caso, adotou-se para todos os cenários uma perda total de 
$5,0 \%$ da vazão de água que recircula no sistema, entre o condensador e a torre de resfriamento.

Perdas de energia no condensador:

$$
\begin{aligned}
& \mathrm{POT}_{\text {condensador }}=\dot{\mathrm{Q}}_{\text {out }} \\
& \mathrm{POT}_{\text {condensador.perc }}=\frac{\mathrm{POT}_{\text {condensador }}}{\mathrm{POT}_{\text {entrada }}} \cdot 100
\end{aligned}
$$

Onde:

$\mathrm{POT}_{\text {condensador }}=$ potência perdida no condensador $(\mathrm{kJ} / \mathrm{h})$;

$\mathrm{POT}_{\text {condensador.perc }}=$ potência percentual perdida no condensador $(\%)$.

Balanço de exergia no condensador:

$$
\begin{aligned}
& \text { Bdest }_{\text {condenser }}=\mathrm{B}_{3}-\mathrm{B}_{4} \\
& \mathrm{~B}_{4}=\dot{\mathrm{m}}_{\text {vap.cauda }} \cdot\left(\mathrm{h}_{4}-\mathrm{h}_{0}-\left((\mathrm{TO}+273,15) \cdot\left(\mathrm{s}_{4}-\mathrm{s}_{0}\right)\right)\right) \\
& \text { Bdest }_{\text {condenser.perc }}=\frac{\text { Bdest }_{\text {condenser }}}{\mathrm{B}_{\text {fuel }}} \cdot 100
\end{aligned}
$$

Sendo:

$\mathrm{B}_{4}=$ exergia da corrente do líquido saturado na saída do condensador $(\mathrm{kJ} / \mathrm{h})$;

$\mathrm{s}_{4}=$ entropia específica da corrente do líquido saturado na saída do condensador $(\mathrm{kJ} / \mathrm{K})$;

Bdest. $_{\text {. condenser }}=$ exergia destruída no condensador $(\mathrm{kJ} / \mathrm{h})$;

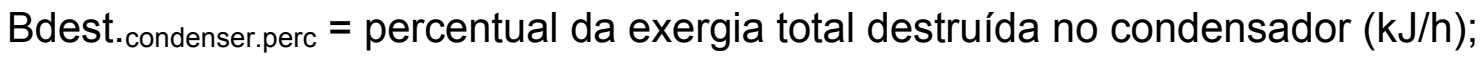




\subsubsection{Bombas}

A fim de que a água de alimentação extraída da unidade de condensação, retorne à caldeira, faz-se necessário bombeamento, do que decorre imediatamente elevação naturalde pressão. $\mathrm{Na}$ cogeração o bombeamento é realizado em dois estágios: no primeiro estágio, encontra-se o grupo de bombas responsável pela extração da água saturada da unidade condensadora, denominado bomba de condensado. No segundo estágio, está o grupo de bombas que elevará a pressão da água de alimentação até a pressão final. Normalmente essa condição de bombeamento estará submetida a grandes diferenciais de pressão (Oliveira, 2010). Adotou-se para todos os cenários em análise que a pressão de alimentação é $20 \%$ superior à pressão de operação da caldeira.

Trabalho deve ser fornecido para que as bombas movam líquido de baixa até alta pressão. Parte desse trabalho é perdido dadas as irreversibilidades do processo. A eficiência de uma bomba pode ser definida como sendo o inverso da eficiência de uma turbina; ou seja, é a razão entre o trabalho isentrópico e o trabalho real fornecido quando se opera entre duas pressões (Moran e Shapiro, 2008). A Figura 28 mostra a bomba 1 que desloca líquido saturado do condensador para o desaerador.

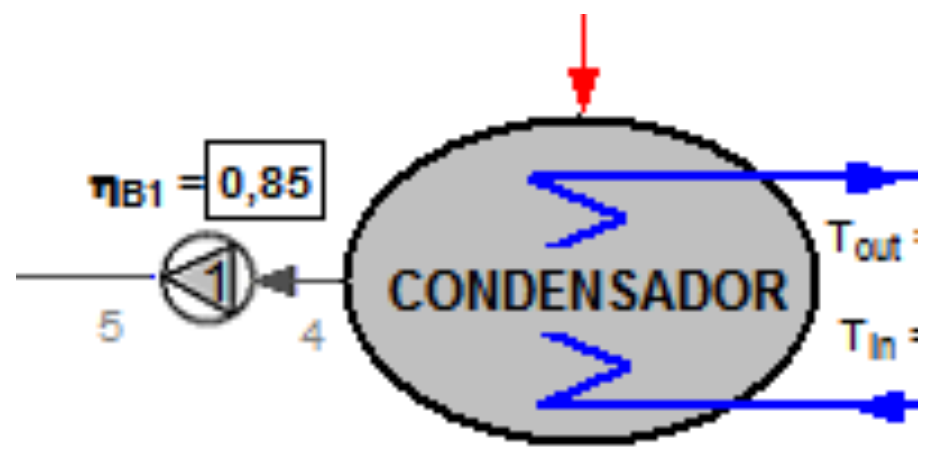

Figura 28 - llustração da bomba de condensado do condensador.

A eficiência isentrópica da bomba será calculada por: 
$\eta_{\mathrm{B} 1}=\frac{\mathrm{h}_{4}-\mathrm{h} 5_{\text {iso }}}{\mathrm{h}_{4}-\mathrm{h}_{5}}$

Onde:

$\mathrm{h}_{4}=$ entalpia específica do líquido saturado na saída do condensador $(\mathrm{kJ} / \mathrm{kg})$;

$\mathrm{h}_{5}=$ entalpia específica do líquido na saída da bomba $(\mathrm{kJ} / \mathrm{kg})$;

$\mathrm{h}_{\text {5iso }}=$ entalpia específica do líquido na saída da bomba na condição ideal de compressão isentrópica $(\mathrm{kJ} / \mathrm{kg})$;

$\eta_{\mathrm{B} 1}=$ eficiência isentrópica da bomba.

Para este estudo adotou-se uma eficiência isentrópica da bomba de $85 \%$, com base em dados de catálogo obtidos nas usinas visitadas. No intuito de ilustrar a estimativa da eficiência isentrópica a Figura 29 mostra diagrama Entalpia vs Entropia específicas (h-s) para a bomba em questão .

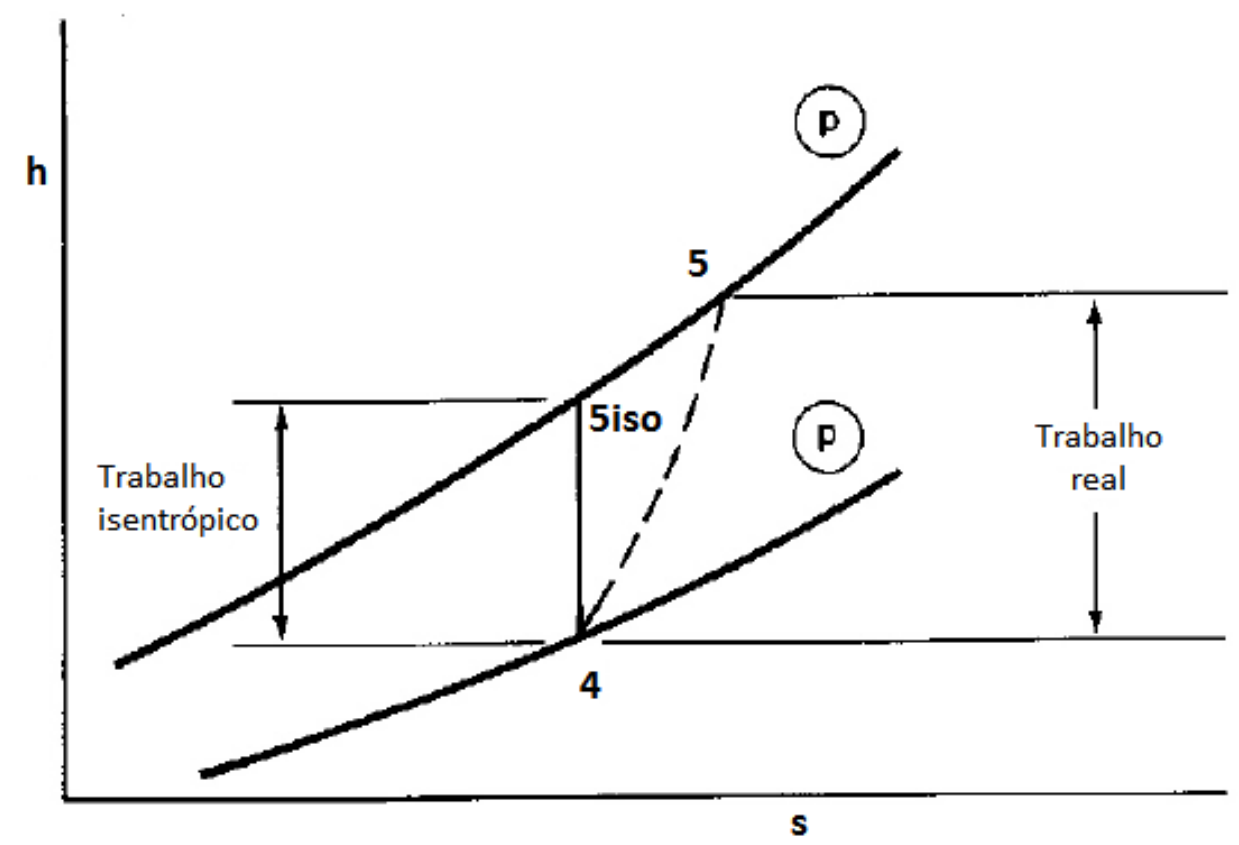

Figura 29 - Diagrama h-s para ilustrar eficiência da bomba (Adaptado de Li et al, 1985). 
Como indicado na Figura 29, o trabalho perdido pela bomba, dado por $h_{5}-h 5_{\text {iso }}$ é reduzido à medida que a pressão de descarga se aproxima da pressão isentrópica de descarga.

Cálculo da potência consumida e balanço de exergia na bomba B1:

$$
\begin{aligned}
& \text { POT }_{B 1}=\dot{m}_{\text {vap.cauda }} \cdot\left(h_{5}-h_{4}\right) \\
& \text { Bdest }_{B 1}=B_{4}-B_{5}+\text { POT }_{B 1} \\
& \mathrm{~B}_{5}=\dot{\mathrm{m}}_{\text {vap.cauda }} \cdot\left(h_{5}-h_{0}-\left((T 0+273,15) \cdot\left(s_{5}-s_{0}\right)\right)\right) \\
& \text { Bdest }_{\text {B1. perc }}=\frac{\text { Bdest }_{B 1}}{B_{\text {fuel }}} \cdot 100
\end{aligned}
$$

Onde as novas variáveis incluídas são:

$\mathrm{POT}_{\mathrm{B} 1}=$ potência consumida pela bomba B1 $(\mathrm{kJ} / \mathrm{h})$;

$B_{5}=$ exergia da corrente do líquido no recalque da bomba $(k J / h) ;$

Bdest $_{\mathrm{B} 1}=$ exergia destruída pela bomba B1 $(\mathrm{kJ} / \mathrm{h})$;

Bdest $_{\mathrm{B} 1 \text {.perc }}=$ percentual de exergia destruída pela bomba $\mathrm{B} 1(\mathrm{~kJ} / \mathrm{h})$;

$\mathrm{s}_{5}=$ entropia da corrente do líquido no recalque da bomba $(\mathrm{kJ} / \mathrm{K})$.

A bomba de alimentação da caldeira foi modelada utilizando os mesmo conceitos apresentados para a modelagem da bomba do condensador.

\subsubsection{Desaerador}

O desaerador é um equipamento projetado para remover gases não condensáveis do sistema, e para realizar o pré-aquecimento da água de alimentação da caldeira. A Figura 30 apresenta um esquema do desaerador construído no EES. 


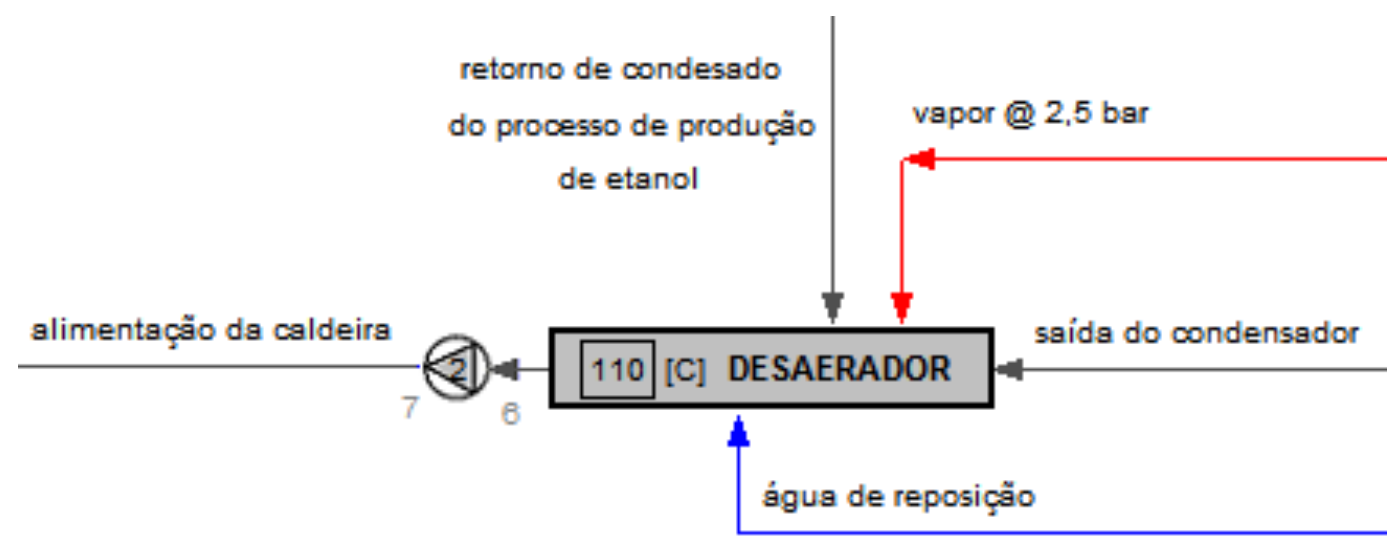

Figura 30 - Representação do desaerador do sistema de cogeração.

Balanço de massa no desaerador:

$\dot{\mathrm{m}}_{\text {retomo }}+\dot{\mathrm{m}}_{\text {vap.desaerador }}+\dot{\mathrm{m}}_{\text {vap.cauda }}+\dot{\mathrm{m}}_{\text {rep.desaerador }}=\dot{\mathrm{m}}_{\text {aqua }}$

Balanço de energia (eq. hh):

$\dot{\mathrm{m}}_{\text {retomo }} \cdot \mathrm{h}_{\text {cond }}+\dot{\mathrm{m}}_{\text {vap.desarardor }} \cdot \mathrm{h}_{2}+\dot{\mathrm{m}}_{\text {vap.cauda }} \cdot \mathrm{h}_{5}+\dot{\mathrm{m}}_{\text {rep.desaerador }} \cdot \mathrm{h}_{\text {rep. .es }}=\dot{\mathrm{m}}_{\text {aqua }} \cdot \mathrm{h}_{6}$

Onde:

retorno = vazão mássica do retorno de condensado do processo de produção do etanol $(\mathrm{kg} / \mathrm{h})$;

vap.desaerador $=$ vazão mássica do vapor utilizado no desaerador para atingir set point de desaeração $(\mathrm{kg} / \mathrm{h})$;

vap.cauda = vazão mássica do vapor de cauda da turbina, que após passar pelo condensador, é bombeado para o desaerador $(\mathrm{kg} / \mathrm{h})$;

rep.desaerador = vazão mássica de reposição de água no desaerador $(\mathrm{kg} / \mathrm{h})$;

agua = vazão mássica da água de alimentação da caldeira $(\mathrm{kg} / \mathrm{h})$;

$\mathrm{h}_{\text {cond }}=$ entalpia específica da corrente de condensado que retorna do processo de produção de etanol $(\mathrm{kJ} / \mathrm{kg})$; 
$\mathrm{h}_{2}=$ entalpia específica da corrente de vapor @ 2,5 bar que alimenta o desaerador $(\mathrm{kJ} / \mathrm{kg})$;

$h_{5}=$ entalpia específica da corrente de condensado vindo do condensador $(\mathrm{kJ} / \mathrm{kg})$;

$\mathrm{h}_{\text {rep.des }}=$ entalpia específica da corrente de água de reposição do desaerador $(\mathrm{kJ} / \mathrm{kg})$;

$h_{6}=$ entalpia específica da corrente de água na saída do desaerador $(\mathrm{kJ} / \mathrm{kg})$;

Do ponto de vista de modelagem, a vazão de água de alimentação da caldeira é um parâmetro conhecidovia balanços de massa e energia. Conforme foi apresentado no tópico que trata das premissas e definição dos parâmetros operacionais dos cenários, o retorno de condensado do processo de produção de etanol também é conhecido, já que o consumo de vapor saturado para produção de etanol foi fixado em $400 \mathrm{Kg} / \mathrm{t}_{\text {cana. }}$.

Admitiu-se que $90 \%$ do vapor saturado utilizado retorna na forma de condensado para o desaerador; o restante se perde ao longo do processo.

Como as propriedades de estado das correntes são conhecidas, determinou-se então a vazão da água de reposição do desaerador e o consumo de vapor utilizado para atingir o set point de $110^{\circ} \mathrm{C}$ do desaerador, fechando os balanços.

No balanço de energia do desaerador foram desprezadas perdas de calor para o ambiente (processo adiabático). Portanto, pela análise de Primeira Lei não há perdas energéticas no desaerador.

Conforme apresentado anteriormente no capítulo que trata do balanço de exergia, a taxa de destruição de exergia pode ser determinada via balanço exergético ou balanço de entropia, para que depoisseja aplicado teorema de Gouy-Stodola.

Balanço de energia no desaerador:

$\mathrm{s}_{\text {ger.desaerador }}=\dot{\mathrm{m}}_{\text {agua }} \cdot \mathrm{s}_{6}-\left(\dot{\mathrm{m}}_{\text {retorno }} \cdot \mathrm{s}_{\text {cond }}+\dot{\mathrm{m}}_{\text {vap.desaerador }} \cdot \mathrm{s}_{2}+\dot{\mathrm{m}}_{\text {vap.cauda }} \cdot \mathrm{s}_{5}+\dot{\mathrm{m}}_{\text {rep.desaerador }} \cdot \mathrm{s}_{\text {agua }}\right)$

Onde: 
$\mathrm{S}_{\text {ger.desaerador }}=$ taxa de geração de entropia no desaerador (kJ/ h.K);

$\mathrm{S}_{6}=$ entalpia específica da corrente de água na saída do desaerador (kJ/kg.K);

$\mathrm{S}_{\mathrm{cond}}=$ entalpia específica da corrente de retorno de condensado do processo de produção de etanol (kJ/kg.K);

$\mathrm{s}_{2}=$ entalpia específica da corrente de vapor a 2,5 bar que alimenta o desaerador (kJ/kg.K);

$\mathrm{S}_{5}=$ entalpia específica da corrente de condensado do vapor de cauda bombeada para o desaerador (kJ/kg.K);

$S_{\text {agua }}=$ entalpia específica da corrente de água de reposição desaerador (kJ/kg.K).

A partir do teorema de Gouy-Stodola, determina-se a taxa de destruição de exergia:

$$
\text { Bdest }_{\text {desaerador }}=(\mathrm{TO}+273,15) \cdot \mathrm{S}_{\text {ger.desaerador }}
$$

Bdest $_{\text {desaerador.perc }}=\frac{\text { Bdest }_{\text {desaerador }}}{\mathrm{B}_{\text {fuel }}} \cdot 100$

Onde:

$\mathrm{B}_{\text {dest.desaerador }}=$ taxa de destruição de exergia no desaerador $(\mathrm{kJ} / \mathrm{h})$;

Bdest.desaerador.perc $=$ percentual de exergia destruída no desaerador (\%).

\subsubsection{Trocadores de Calor do Ciclo Regenerativo}

$\mathrm{Na}$ modelagem do ciclo Rankine Regenerativo são utilizados trocadores de calor para elevar gradualmente a temperatura do líquido comprimido a ser alimentado na caldeira. Bräscher (1991) modelou uma central termelétrica considerando três tipos de trocadores de calor: de contato; de superfície; e de superfície com resfriador de dreno. No presente trabalho considerou-se a utilização de trocadores de calor de superfície, do tipo multitubulares, também chamados de trocadores tipo 'casco e 
tubo'. Estes equipamentos são muito utilizados para realizar troca térmica entre dois fluidos nos processos industriais. São compostos de um feixe de tubos envolto numa carcaça. Um dos fluidos escoa no interior dos tubos, enquanto o outro fluido escoa no lado de fora dos tubos e no interior da carcaça. A grande utilização deste tipo de equipamento está ligada à sua construção resistente, flexibilidade de projeto, e à fácil adaptação às condições de operação do processo (Ravagnani, 2012).

Como os trocadores de calor reais possuem área finita, a temperatura da corrente fria à saída do trocador sempre difere da temperatura de condensação do vapor de extração da turbina. Se a área de troca térmica for pequena, a temperatura da corrente fria na saída será bem menor do que a temperatura de condensação do vapor extraído da turbina. Se superfície de troca térmica aumenta, a temperatura de saída da corrente fria se aproxima da temperatura de condensação. Este aspecto construtivo se reflete em um parâmetro chamado de diferença de temperatura terminal (TTD). Portanto, se a pressão de extração da turbina é conhecida, a temperatura corrente fria na saída do trocador de calor pode ser determinada, uma vez estabelecido a TTD como parâmetro de projeto (Singer, 1981; Bräscher, 1991).

Definição da diferença de temperatura terminal:

$T T D=T_{\text {sat }}-T_{\text {saida }}$

Onde:

$\mathrm{T}_{\text {sat }}=$ temperatura de condensação do vapor de extração no trocador de calor $\left({ }^{\circ} \mathrm{C}\right)$;

$\mathrm{T}_{\text {saida }}=$ temperatura da corrente fria na saída dos tubos do trocador de calor $\left({ }^{\circ} \mathrm{C}\right)$.

Ao modelar uma central termelétrica com ciclo regenerativo com sete trocadores de calor Brascher (1991) utilizou o mesmo valor de TTD - de 3,5 ${ }^{\circ} \mathrm{C}$ - para todos os trocadores. Este mesmo valor será utilizado para a modelagem dos cenários em que há regeneração no ciclo Rankine. A TTD pode portanto ser consideradapropriedade de um trocador, já que especifica o desempenho do equipamento. Trocadores com TTD muito pequena, implicam em grandes áreas de troca térmica, e conseqüente 
aumento do capital investido. Vale ressaltar, que a TTD é utilizada frequentemente na bibliográfica específica de usinas termelétricas a vapor (Salisbury,1974;Li et al., 1985; e Bräscher, 1991).

O aumento da eficiência do ciclo Rankine em centrais termelétricas ocorre através da utilização de ciclos regenerativos com trocadores de calor. Grandes centrais utilizam um número elevado de trocadores de calor para esse fim. Para isso é necessário realizar extrações em múltiplos estágios nas turbinas, de maneira a fornecer vapor a esses equipamentos. Normalmente grandes turbinas já são projetadas com vários pontos de extração que podem ser utilizados para aquecimento das correntes de alimentação das caldeiras (El-Wakil, 2002).

Dado um número $n$ de trocadores de calor (TC), será necessário determinar quais pressões de extração estarão associadas a cada unidade. As pressões de extração irão possibilitar o mesmo incremento de temperatura em cada TC até o ponto de alimentação da caldeira. $O$ incremento de temperatura ótimo do ciclo, $\Delta T_{\mathrm{opt}}$, depende do número de trocadores de calor utilizado (El-Wakil, 2002). Portanto pode-se admitir que:

$\mathrm{T}_{\text {saida }}=\mathrm{T}_{\text {entrada }}+\Delta \mathrm{T}_{\mathrm{opt}}$

Onde:

$\mathrm{T}_{\text {saida }}=$ temperatura da corrente fria na saída dos tubos do trocador de calor $\left({ }^{\circ} \mathrm{C}\right)$;

$\mathrm{T}_{\text {entrada }}=$ temperatura da corrente fria na entrada do trocador de calor $\left({ }^{\circ} \mathrm{C}\right)$;

$\Delta \mathrm{T}_{\mathrm{opt}}=$ incremento de temperatura ótimo para determinado número de trocadores de calor $\left({ }^{\circ} \mathrm{C}\right)$.

Uma vez estimado $\Delta T_{\text {opt }}$ calcula-se a temperatura da corrente fria na saída dos tubos do trocador de calor ( $T_{\text {saida }}$ ) e a partir de TTD, obtém-se a temperatura de condensação do vapor $\left(T_{\text {sat }}\right)$. Com esse dado é possível então determina-se a pressão de saturação do mesmo fluído, que será a pressão ótima $\left(P_{\mathrm{opt}}\right)$ de extração na turbina. 
O método utilizado para determinar o número de trocadores de calor baseou-se nos conceitos supracitados. Inicialmente incluiu-se no ciclo Rankine convencional um trocador de calor para regeneração. A seguir, procedeu-se a otimização da eficiência exergética do ciclo a partir do método de aproximações quadráticas, tendo como única variável independente $\mathrm{o}$ incremento de temperatura no trocador de calor. $\mathrm{A}$ condutapermitiu obter $\Delta T_{\text {opt }}$ de forma a maximizar a eficiência do ciclo.Assim determina-se o ponto ótimo de extração da turbina para, o trocador de calor em questão.

O mesmo método foi repetido, após adições sucessivas de trocadores de calor ao ciclo, até que o limite de dez unidades fosse atingido. Procedeu-se então uma análise paramétrica, na qual foi inserido um trocador de calor de cada vez e analisado o desempenho exergético, para determinar o número adequado de trocadores que seria utilizado no ciclo regenerativo. A Figura 31 ilustra um dos trocadores de calor instalado logo após a bomba do desaerador.

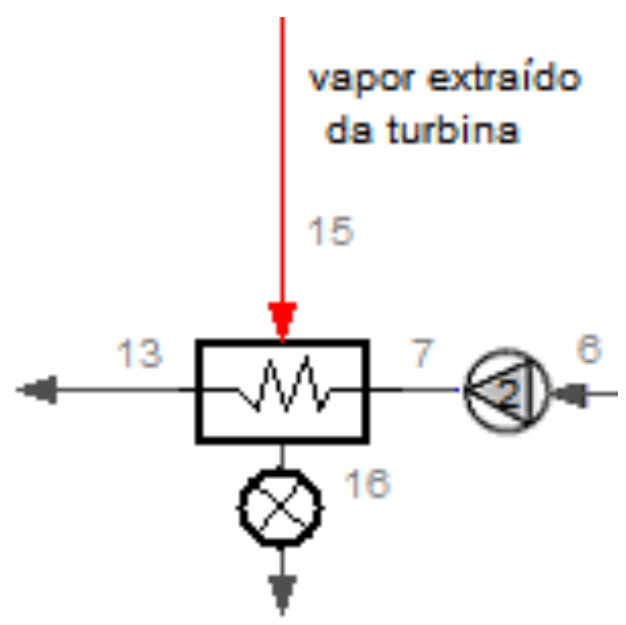

Figura 31 - Ilustração de um trocador de calor do ciclo regenerativo.

A aplicação do método em conjunto com os balanços de massa e exergia para o trocador de calor ilustrado na Figura 26 está exposto a seguir:

Balanço de energia: 
$\dot{m}_{7} \cdot\left(h_{7}-h_{13}\right)+\dot{m}_{15} \cdot\left(h_{15}-h_{16}\right)=0$

Aplicação do método TTD:

$T T D=T_{\text {sat } ; \mathrm{TC}}-\mathrm{T}_{13}$

$T_{13}=T_{7}+\Delta T_{\text {opt }}$

$P_{15}=P_{\text {sat }}\left(\right.$ water $\left.; T=T_{\text {sat } ;} \mathrm{TC}\right)$

Onde:

$h_{7}=$ entalpia específica da corrente fria na entrada do trocador de calor $(\mathrm{kJ} / \mathrm{kg})$;

$h_{13}=$ entalpia específica da corrente fria na saída do trocador de calor $(\mathrm{kJ} / \mathrm{kg})$;

$\mathrm{h}_{15}=$ entalpia específica da corrente de vapor na entrada do trocador de calor $(\mathrm{kJ} / \mathrm{kg})$;

$\mathrm{h}_{16}=$ entalpia específica da corrente de condensado na saída do trocador de calor $(\mathrm{kJ} / \mathrm{kg})$;

7 = vazão mássica da corrente fria $(\mathrm{kg} / \mathrm{h})$;

15 = vazão mássica da corrente quente (vapor) $(\mathrm{kg} / \mathrm{h})$;

$\mathrm{T}_{\text {sat.TC }}=$ temperatura de condensação do vapor de extração no trocador de calor $\left({ }^{\circ} \mathrm{C}\right)$;

$\mathrm{T}_{7}=$ temperatura da corrente fria na entrada do trocador de calor $\left({ }^{\circ} \mathrm{C}\right)$;

$\mathrm{T}_{13}=$ temperatura da corrente fria na saída do trocador de calor $\left({ }^{\circ} \mathrm{C}\right) ;$

$P_{15}=$ pressão de saturação do vapor de extração da turbina (bar).

A aplicação do balanço de exergia: 
- Bdest $t_{T C}=\dot{m}_{15} \cdot\left(h_{16}-h_{15}\right)+\dot{m}_{7} \cdot\left(h_{13}-h_{7}\right)-T 0 \cdot\left(\dot{m}_{15} \cdot\left(s_{16}-s_{15}\right)+\dot{m}_{7} \cdot\left(s_{13}-s_{7}\right)\right)$

Bdest $_{\mathrm{TC} \text { perc }}=\frac{\text { Bdest }_{\mathrm{TC1}}}{\mathrm{B}_{\mathrm{fuel}}} \cdot 100$

Onde:

Bdest $_{\mathrm{TC}}=$ taxa de destruição de exergia no trocador de calor $(\mathrm{kJ} / \mathrm{h})$;

Bdest $_{\mathrm{TC}}$.perc $=$ percentual de exergia destruída no trocador de calor $(\%)$.

Para se determinar o número efetivo de trocadores de calor a serem utilizados nos ciclos regenerativos dos cenários propostos, avaliou-se a influência da adição de cada trocador de calor em termos da eficiência exergética em cada condição de pressão pré-estabelecida nos cenários. A modelagem construída no EES para essa avaliação está descrita em detalhes no Apência $E$.

O critério de escolhado arranjo mais adequado consistiu em determinar o ganho de eficiência exergética associada a adição de outro trocador ao conjunto. Quando esse benefício mostrou-se inferior a $0,5 \%$ para todas as condições de pressão em análise, o processo foi estancado. Isso ocorreu quando o quarto trocador foi adicionado à série. Portanto, foram adotados três trocadores de calor para todos os cenários propostos em que há regeneração. Os resultados da avaliação estão contidos no Apêndice F.

A modelagem do dessuperaquecedor e do purgador de condensado do vapor de escape destinado ao processo de produção de etanol foi realizada seguindo a mesma metodologia. Os códigos computacionais criados para esse fim, bem como o conjunto de equações resultantes estão contidos nos Apêndices $A$ até $D$.

Desta forma, foram então construídos os simuladores do sistema de cogeração que operam segundo os ciclos Rankine Convencional, com Reaquecimento, Regenerativo e Resultante.

Foram também incluídos nos simuladores, modelos para determinação de parâmetros indicadores de desempenho dos cenários propostos - apresentados no 
início desse capítulo -, bem como as eficiências de Primeira e Segunda Lei da Termodinâmica do sistema de cogeração; ou seja, eficiências energética e exergética, respectivamente.

A estimativa dessas eficiências é feita a partir da razão entre o efeito útil esperado e o insumo total requerido. Na análise de Primeira Lei, o efeito útil consiste da geração de energia térmica na forma de vapor, usado para produção de etanol, e da energia elétrica gerada. $O$ insumo requerido é energia térmica alimentada na caldeira.

$\mathrm{Na}$ análise de Segunda Lei, o efeito útil reside na geração exergética sob a forma de vapor usado para produção de etanol e, também, da eletricidade gerada, que é exergia pura. $O$ insumo requerido consiste de sua parte da exergia intrínseca ao combustível que alimenta a caldeira.

Cálculo da eficiência energética global aparece retratado em termos matemáticos pelas equações indicadas a seguir:

$$
\begin{aligned}
& \eta E_{\text {Energética. Global }}=\left[\frac{\mathrm{POT}_{\text {elétr.líquida }}+\mathrm{POT}_{\text {processo }}}{\mathrm{POT}_{\text {entrada }}}\right] \cdot 100 \\
& \mathrm{POT}_{\text {elétr.liquida }}=\mathrm{POT}_{\text {elétr.gerada }}-\mathrm{POT}_{\text {elétr.consumida }} \\
& \mathrm{POT}_{\text {processo }}=\dot{\mathrm{m}}_{\text {vap. processo }} \cdot\left(\mathrm{h}_{\text {pro }}-\mathrm{h}_{\text {sat }}\right) \\
& \mathrm{POT}_{\text {elétr.consurida }}=\mathrm{POT}_{\mathrm{B} 1}+\mathrm{POT}_{\mathrm{B} 2} \\
& \mathrm{POT}_{\mathrm{B} 1}=\dot{\mathrm{m}}_{\mathrm{vap.cauda}} \cdot\left(\mathrm{h}_{5}-\mathrm{h}_{4}\right) \\
& \mathrm{POT}_{\mathrm{B} 2}=\dot{\mathrm{m}}_{\text {agua }} \cdot\left(\mathrm{h}_{7}-\mathrm{h}_{6}\right)
\end{aligned}
$$

Onde, as novas variáveis são:

$\eta_{\text {Energética.Global }}=$ Eficiência energética global da unidade de cogeração (\%);

$\mathrm{POT}_{\text {elétr.gerada }}=$ potência elétrica gerada no turbogerador $(\mathrm{kJ} / \mathrm{h})$;

$\mathrm{POT}_{\text {elétr.consumida }}=$ potência elétrica consumida pelas bombas no ciclo $(\mathrm{kJ} / \mathrm{h})$; 
$\mathrm{POT}_{\mathrm{B} 1}=$ potência elétrica consumida pelas bomba de condensado na saída do condensador $(\mathrm{kJ} / \mathrm{h})$;

$\mathrm{POT}_{\mathrm{B} 2}=$ potência elétrica consumida pelas bomba de alimentação da caldeira $(\mathrm{kJ} / \mathrm{h})$; $\mathrm{POT}_{\text {processo }}=$ potência utilizada no processo de produção de etanol associado ao consumo de vapor saturado a $2,5 \mathrm{bar}(\mathrm{kJ} / \mathrm{h})$;

$\mathrm{h}_{\text {pro }}=$ entalpia específica do vapor saturadoconsumido no processo de produção de etanol $(\mathrm{kJ} / \mathrm{kg})$;

$\mathrm{h}_{\text {sat }}=$ entalpia específica do condensado na pressão de saturação de $2,5 \mathrm{bar}(\mathrm{kJ} / \mathrm{kg})$.

À luz da Segunda Lei da Termodinâmica, calcula-se a eficiência exergética a partir das seguintes equações:

$$
\begin{aligned}
& \eta_{\text {Exergética. Global }}=\left[\frac{P O T_{\text {elétr.liquida }}+\text { Exergia }_{\text {cons. processo }}}{B_{\text {fuel }}}\right] \cdot 100 \\
& B_{3}=\dot{m}_{\text {vap.cauda }} \cdot\left(h_{3}-h_{0}-\left((T 0+273,15) \cdot\left(s_{3}-s_{0}\right)\right)\right)
\end{aligned}
$$

Sendo:

Exergia $_{\text {cons.processo }}=$ exergia consumida no processo de produção de etanol associada ao consumo de vapor saturado $(\mathrm{kJ} / \mathrm{h})$;

$\mathrm{S}_{\text {pro }}=$ entropia específica do vapor saturado que é consumido no processo de produção de etanol (kJ/kg.K).

$\mathrm{Na}$ abordagem de Segunda Lei para a cogeração, as formas de energia cogeradas (térmica, na forma de vapor, e elétrica) são convertidas em exergia. Nessa nova formasão trazidas para uma mesma base de cálculo a fim de que eficiência exergética do sistema seja então determinada. 


\subsection{VALIDAÇÃO DO MODELO TERMODINÂMICO}

Após terem sido construídos modelos termodinâmicos para simular 0 comportamento dos cenários de cogerção estabelecidos neste estudo, o passo seguinte consistiu em validar esses conjuntos. Para tanto, optou-se por uma abordagem fenomenológica, levada adiante na forma das ações executivas indicadas a seguir:

I. Identificação sistemas reais de cogeração que operassem com, ao menos, duas das condições de pressão e temperatura adotadas para composição dos cenários sob análise (20, 45, 67, 80 e 100bar).

II. Coleta de dados no campo e caracterização dos sistemas reais de cogeração escolhidos;

III. Ajuste dos parâmetros médios de processo do sistema de cogeração real ao modelo termodinâmico;

IV. Comparação dos resultados de parâmetros de produção de eletricidade reais do conjunto turbogerador com aqueles estimados pelo modelo computacional, por meio de análise de diferenças.

Contatos estabelecidos junto às usinas do Grupo Santa Terezinha Ltda - subsidiária da holding do Grupo Santa Terezinha Ltda. - USAÇÚCAR, abriram a oportunidade para coleta de dadosjunto aoo sistema de cogeração daplanta de Paranacity/PR. A unidade possui dois sistemas de cogeração que operam em condições diferentes de pressão e temperatura. Portanto, atende aos requisitos estabelecidos para seleção do sistema que serviria de referência ao processo de validação.

A unidade de cogeração encontra-se cadastrada na ANEEL com a denominação de UTE Central Geradora Termoelétrica Santa Terezinha Paranacity (UTE-STP), ou seja, como uma produtora de energia elétrica autônoma e independente. A empresa está conectada ao Sistema Interligado Nacional - SIN, por intermédio da subestação da Companhia Paranaense de Energia - Copel (Usina Santa Terezinha Ltda, 2008) 
A Unidade Paranacity possui capacidade instalada de moagem de 3,1 milhões de toneladas de cana e o período de safra é entre 210 e 220 dias. Contudo, com o volume de matéria-prima disponível nos últimos anos, a média de moagem por safra tem sido 2,8 milhões de toneladas de cana. A unidadepossui área de plantio de 35.000 ha, na qual 30.000 ha são destinados à colheita, 1.500 ha para formação de mudas e os demais 3.500 ha para realizar novos plantios.

Em termos de controle de processo, coleta e análise de dados, a planta possui alto nível de automação, exercitado por meio de sistemas supervisórios que se utilizam de tecnologias de computação e comunicação para tornar automáticas ações sobre os processos industriais.

A UTE-STP possui instalados dois conjuntos de turbogeradores para geração de energia elétrica em sistemas totalmente independentes, ambos da marca TGM/WEG, com a configuração tecnológica para o ciclo de vapor do tipo Rankine, o mesmo que está indicado nesse estudo como ciclo Rankine Convencional (Usina Santa Terezinha Ltda, 2008).

O primeiro sistema é constituído por turbina da marca TGM, modelo TM $25000 \mathrm{~A}$, e gerador da marca WEG, modelo SPW 1250, de capacidade nominal de 37,5 MVA, ou $30 \mathrm{MW}$ de potência. A alimentação do sistema ocorre via caldeira do tipo aquatubular, marca Caldema, modelo SupGB - AUP-50-6GB-PSE.A operação em regime nominal do sistema compreende produção horária de $160 \mathrm{t}$ de vapor superaquecido a 65 bar e $480{ }^{\circ} \mathrm{C}$.

A unidade foi projetada como sendo de contrapressão; ou seja, após receber vapor superaquecido da caldeira Caldema, o turbogerador transmite a maior parte (140 t/h) a uma pressão de 2,5 bar para o processo industrial de produção de açúcar e etanol. Uma parcela do vapor alimentado na turbina é extraído na pressão de 22 bar, que é chamado na usina de "vapor de tomada", e utilizado para complementar a produção de vapor das caldeiras que alimentam o segundo sistema turbogerador e as moendas. No sistema de contrapressão só é possível operar no período de safra.

O segundo sistema de turbogerador é constituído também por uma turbina da marca TGM, modelo TMC 25000 A, e por um gerador da marca WEG, modelo SPW 800. Esse conjunto possui capacidade nominal de 20,0 MVA (até 16 MW de potência). 
Alimentação do segundo conjunto turbogerador ocorre por meio de duas caldeiras da marca Dedini, instaladas em paralelo, e denominadas C-1 e C-2. As caldeiras também são do tipo aquatubular, de capacidade de geração de vapor superaquecido de $90 \mathrm{t} / \mathrm{h}$ e $70 \mathrm{t} / \mathrm{h}$, respectivamente, a pressão de 22 bar e temperatura $320^{\circ} \mathrm{C}$. Do total de vapor gerado, apenas $39 \mathrm{t} / \mathrm{h}$ alimentam o segundo turbogerador; o restante é utilizado para acionar as moendas.

Esta unidade foi projetada como sendo de extração-condensação, que é um sistema mais versátil e que possibilita a geração de energia elétrica inclusive no período de entressafra (Sosa-Arnao, 2008). Nesse sistema o vapor é extraído da turbina a uma pressão de 0,1 bar e condensado em torre de resfriamento evaporativa. O condensado é então bombeado para um desaerador que opera a $110^{\circ} \mathrm{C}$ e retorna para caldeira para completar o ciclo. Observe-se que o sistema é semelhante ao que foi modelado nos cenários desse trabalho. As principais características técnicas dos equipamentos instalados na UTE Santa Terezinha Paranacity são apresentadas na Tabela 7.

Tabela 7 - Resumo das características técnicas dos equipamentos instalados na UTE-STP.

\begin{tabular}{|c|c|c|c|c|}
\hline Sistemas de turbogeradores & \multicolumn{2}{|c|}{ Contrapressão } & \multicolumn{2}{|c|}{ Extração/condensação } \\
\hline Características e capacidade dos equipamentos & Caldeira & Turbogerador & Caldeiras & Turbogerador \\
\hline Modelo: & $\begin{array}{l}\text { Caldema } \\
\text { SupGB }\end{array}$ & SPW-1250 & $\begin{array}{c}\text { Dedidi } \\
\text { C-1 e C-2 }\end{array}$ & SPW-800 \\
\hline Ano de fabricação & 2003 & 2009 & 1982 / 1992 & 2009 \\
\hline Pressão de entrada de vapor (bar) & - & 65 & - & 22 \\
\hline Pressão de saída de vapor (bar) & 65 & 2,5 & 22 & 0,1 \\
\hline Temperatura do vapor superaquecido gerado ( C) & 480 & - & 320 & - \\
\hline Produção de vapor (t/h) & 160 & - & 70 e 90 & - \\
\hline Vazão de vapor na entrada da turbina $(\mathrm{t} / \mathrm{h})$ & - & 160 & - & 39 \\
\hline Potência nominal do gerador (KVA) & - & 37,5 & - & 20,0 \\
\hline Capacidade de produção de energia elétrica (MW) & - & 30,0 & - & 16,0 \\
\hline Produção atual de energia elétrica média (MW) & - & 26,0 & - & 8,1 \\
\hline
\end{tabular}

Os dois sistemasda UTE-STP estão ilustrados de forma simplificada nas Figuras 32 e 33, respectivamente. 


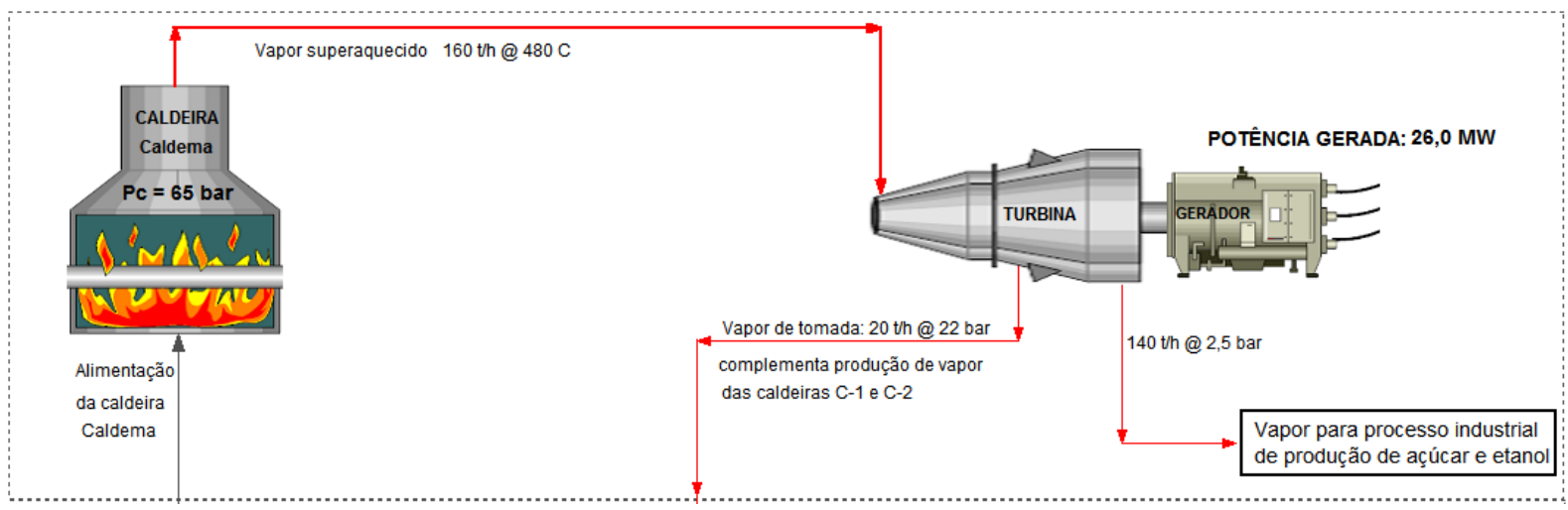

Figura 32 - Esquema simplificado do Sistema Turbogerador $\mathrm{N}^{\circ} 1$ da UTE-STP.

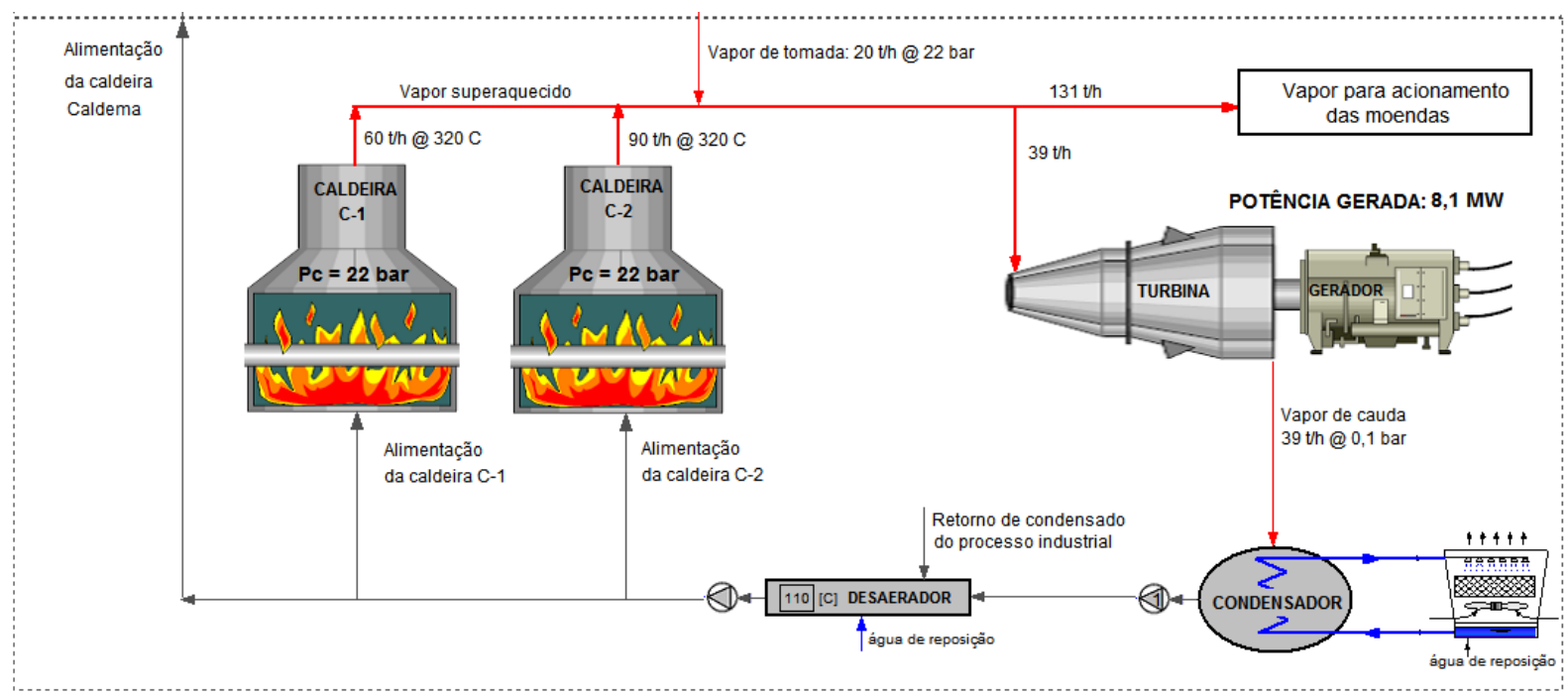

Figura 33 - Esquema simplificado do Sistema Turbogerador $\mathrm{N}^{\circ} 2$ da UTE-STP.

Pode-se verificar que no primeiro sistema, a potência média gerada está $13,3 \%$ abaixo da nominal (26,0 MW real contra 30,0 MW nominal) e no segundo conjunto, esta é 49,4\% inferior à nominal (8,1 MW real contra 16,0 MW nominal). Isso mostra que o turbogerador está superdimensionado para a capacidade de geração de vapor das caldeiras atuais.

De fato, o turbogerador foi projetado já prevendo um aumento na geração de vapor que ocorrerá no futuro, já que há previsão de substituição das caldeiras C-1 e C-2 por uma caldeira moderna de alta pressão. Atualmente, da potência total gerada na usina de 34,1 MW de eletricidade, sendo 10,5 MW são para o autoconsumo. O excedente é exportado para rede da Copel. 
Com a caracterização do sistema de cogeração real para validação do modelo termodinâmico, os dados das vazões foram ajustados no modelo construído para representar um ciclo Rankine Convencional, que mais se assemelha às condições operacionais da UTE-STP. A Tabela 8 traz os resultados comparativos de geração de energia elétrica entre o sistema real da UTE-STP e os valores estimados pelo modelo, bem como as diferentes percentuais entre ambos. Essas diferenças foram determinadas em termos de erro percentual cuja expressão matemática, aparece a seguir:

Onde:

$X=$ variável de interesse.

Tabela 8 - Desvios na forma de erros percentuais do modelo em relação os sistemas da UTE-STP.

\begin{tabular}{ccccccc}
\hline $\begin{array}{c}\text { Sistema } \\
\text { de cogeração }\end{array}$ & $\begin{array}{c}\text { Alimentação } \\
\text { de vapor na } \\
\text { turbina (t/h) }\end{array}$ & $\begin{array}{c}\text { Pressão } \\
\text { (bar) }\end{array}$ & $\begin{array}{c}\text { Temperatura } \\
\text { ( C) }\end{array}$ & $\begin{array}{c}\text { Potência gerada } \\
\text { real } \\
\text { (MW) }\end{array}$ & $\begin{array}{c}\text { Potência gerada } \\
\text { pelo modelo } \\
\text { (MW) }\end{array}$ & $\begin{array}{c}\text { Erro } \\
\text { percentual } \\
(\%)\end{array}$ \\
\hline 1 & 39 & 22 & 320 & 8,1 & 7,9 & $-2,5 \%$ \\
2 & 160 & 65 & 480 & 26,0 & 25,0 & $-3,8 \%$ \\
\hline
\end{tabular}

A partir das indicações da Tabela 8, observa-se que o maior erro percentual ocorreu no sistema com maior pressão (65 bar), em que a estimativa para geração da potência elétrica ficou 3,8\% abaixo do resultado real do sistema de cogeração. $\mathrm{Na}$ condição de operação do sistema a22baro resultado foi inferior ao da condição real em 2,5\%.Bräscher (1991), em seu trabalho de modelagem de uma central termelétrica, utilizou o mesmo parâmetro de erro percentual para validar sua modelagem, e obteve um erro percentual máximo de 4,0\% nos resultados de potência gerada, o que foi considerado pelo autor como um nível satisfatório. Dessa forma, os modelos foram considerados válidos. 


\subsection{ASPECTOS ESPECÍFICOS PARA AVALIAÇÃO AMBIENTAL}

\subsubsection{DefiniçÃo de Objetivo e Escopo}

$\mathrm{O}$ estudo de ACV foi realizado ao partir do empadronamento normativo descrito pelas normas ISO 14040 (2009a) e 14044 (2009b). Assim, no que se refere à Definição de Objetivos a iniciativa se propôs a efetuar uma análise ambiental de ações para melhoria de desempenho de unidades de cogeração de energia elétrica a partir de queima de bagaço e de palha da cana-de-açúcar. Quanto ao enfoque metodológico decidiu-se por uma abordagem do tipo "berço ao portão". Assim, processamentos que ocorrem nas etapas de pós-produção do ciclo de vida foram desconsiderados pela análise.

Em termos de Definição de Escopo foram estabelecidos os requisitos que se seguem:

Função: produzir energia elétrica excedente em sistema de cogeração movido por bagaço e palha de cana-de-açúcar em condições desta ser absorvida pela rede concessionária;

Unidade Funcional (UF): por se tratrar de um estudo desenvolvido sob um enfoque metodológico do tipo 'berço-ao-portão', não há sentido em arbitrar-se um valor de UF, mas sim, e antes, de estabelecer-se o Fluxo de Referência (FR). Por outro lado, dado o caráter de verificação desta análise, decidiu-se que os valores de FR seriam estabelecidos em termos do consumo de bagaço de cana. Para isso, admitiu-se por premissa que o sistema de cogeração movido por bagaço e palha de cana-deaçúcar deveria se capaz de disponibilizar 1,0 MWh de eletricidade para rede concessionária.

\subsubsection{Sistema de Produto e Fronteiras do Sistema}

Para análise do desempenho ambiental, manteve-se o foco da ACV na geração de eletricidade a partir da queima de bagaço e da palha da cana-de-açúcar no sistema de cogeração. 
O sistema de produto compreendeu as etapas de cultivo da cana, transporte dessa matéria-prima até a destilaria, a produção de etanol, e cogeração de eletricidade, esta última, descrita na forma dos cenários apresentados na Tabela 4. Nos cenários estudados em que há utilização da palha, subsistemas adicionais de enfardamento, transporte e moagem da palha são adicionados ao sistema de produto. O diagrama completo do sistema de produto é apresentado na Figura 34. Para ilustração, a taxa de exportação de eletricidade apresentada no sistema de produto se refere a do ciclo Convencional a 100 bar com utilização de palha. 


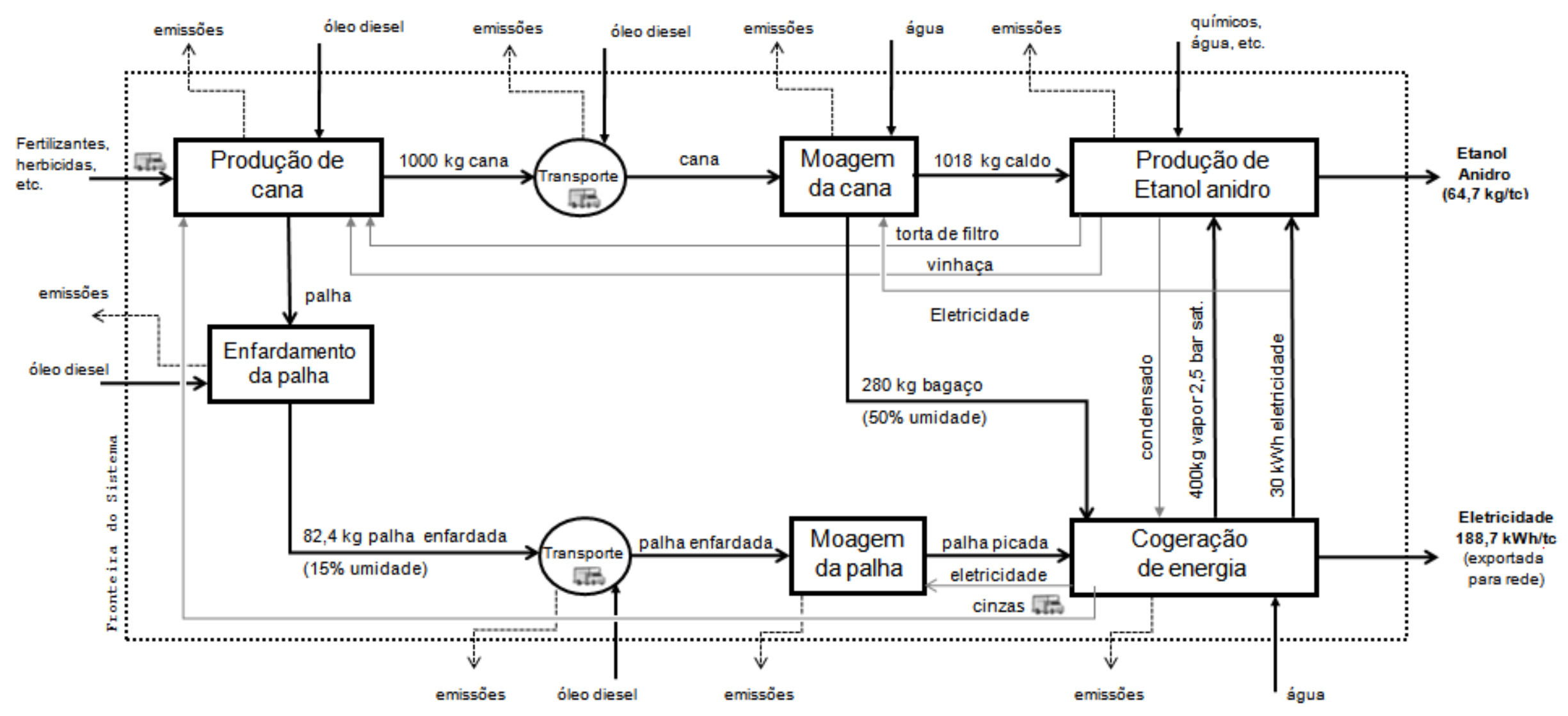

Figura 34 - Representação do sistema de produto analisado. 
A produção de etanol foi mantida constante em todos os cenários estudados, uma vez que as variações propostas nos cenários ocorrem somente no sistema de cogeração, para a mesma taxa de moagem de cana.

O modelo agrícola adotado nesse estudo seguiu os procedimentos e práticas convencionais adotadas no estado de São Paulo. A partir de indicações contidas em Sugawara (2012), definiu-se $86,5 t_{\text {cana }} /$ ha como produtividade agrícola média de cana-de-açúcar de ao longo de cinco safras. O preparo do solo ocorre, em $85 \%$ da área de forma mecânica e a colheita ocorre em $63 \%$ da área de forma mecanizada (Sugawara, 2012). Além disso, resíduos industriais tais como torta de filtro, vinhaça e cinzas da caldeira, são reutilizados como fonte de fornecimento de insumos ao cultivo agrícola. No que se refere aos cenários com utilização da palha, considerou a hipótese de um cenário futuro onde não há queima do canavial, no qual $50 \%$ da palha produzida é utilizada na caldeira e o restando deixado no campo.

\subsubsection{REQUISITOS E QUALIDADE DOS DADOS}

Fonte dos dados: a modelagem dos sistemas de produto foi realizada essencialmente a partir de dados secundários. Somente os dados de rendimento dos equipamentos (caldeira, turbina, gerador e bombas) na condição de operação a 67 bar são dados primários, obtidos na Usina Costa Pinto.

Qualidade dos dados: a Cobertura Temporal compreendeu o período de 2008 2011 para os dados da etapa agrícola, quando foi possível obter uma série histórica de dados consistente e representativa da realidade a que o estudo se propõe a examinar. Quanto à Cobertura Geográfica optou-se pelo estado de São Paulo em função de sua prevalência em termos de produção nacional de cana-de-açúcar e de etanol. Finalmente, no tocante à Cobertura Tecnológica admitiram-se as características, condicionantes, os aspectos construtivos e de processo anteriormente descritos.

Foi adotado um critério de alocação para cada etapa do sistema de produto inicialmente com base nos critérios mássico e exergético. Para fim de análise de sensibilidade, adotou-se o critério energético. Os critérios específicos para cada etapa serão discutidos no capítulo de Resultados e Discussão. 
Categorias de Impacto e Método para Avaliação de Impacto do Ciclo de Vida: No intuito de obter um perfil de impacto ambiental de amplo espectro, gerado por conjunto de indicadores analíticos selecionou-se o método ReCiPe Midpoint $(\mathrm{H})$ versão 1.08 (Goedkoop et al., 2012).

Dentro desse enfoque foram selecionadas para efeito de elaboração do estudo quatro categorias de impacto: Mudança Climática (CC); Formação de Materiais Particulados (PMF); Depleção de Água (WD); e Depleção de Fósseis (FD).

A seleção das categorias de impacto ocorreu em função das características do objeto de estudo, e do caráter na análise. Contribuições em termos de Radiação lonizante não foram levadas em conta devido a não aplicabilidade no escopo do estudo e também devido à baixa expressividade do modal nuclear na matriz energética nacional. Desenvolvimento na forma de Ecotoxicidade Marinha está fora do escopo de aplicação do estudo, bem como Uso e Ocupação do Solo Urbano. As depleções de Ozônio e Metais foram excluídas após análise de significância realizada no modelo de sistema de produto em termos dos potenciais contribuintes para os impactos ambientais. Impactos em termos de Toxicidade Humana, Acidificação Terrestre, Uso de Solo Agrícola e Transformação de Solo Natural foram avaliados previamente e a variação dos cenários em estudo proporcionou oscilações discretas sobre esses impactos. Assim, os mesmos foram desconsiderados pela análise.

Finalmente, aspectos ambientais da produção de bens de capital e infraestrutura, foram desprezados, após as simulações mostrarem influência discreta nos impactos ambientais.

\section{RESULTADOS E DISCUSSÃO}

O Capítulo de Resultados e Discussão está divido em duas etapas: Resultados da Análise Termodinâmica e Resultados da Análise Ambiental. 


\subsection{ANÁLISE TERMODINÂMICA}

Como já foi comentado antes, foram construídos quatro modelos computacionais para análise simultâneas de Primeira e Segunda Lei da Termodinâmica, para os diferentes arranjos do ciclo Rankine indicados na Tabela. São eles: Ciclo Convencional, com Reaquecimento, Regenerativo e Resultante (Regenerativo e Reaquecimento).

A análise do desempenho termodinâmico dos cenários foi conduzida por meio da comparação dos principais parâmetros indicadores de desempenho de cada cenário. As comparações foram tomadas com relação aos resultados dos cenários de referência, correspondentes ao ciclo Rankine Convencional. Inicialmente, avaliou-se a influência das condições de estado do vapor, nas hipóteses de se utilizar, ou não, a palha na caldeira, tal como descritoa seguir na Tabela .Posteriormente, os cenários foram utilizados como referência para avaliar a influência de alternativas de arranjos do ciclo Rankine (Tabela ).

\subsubsection{Ciclo Rankine Convencional}

Em todos os arranjos do ciclo Rankine estudados nesse trabalhoforam analisadosos efeitos das variações das condições de temperatura e pressão sobre os desempenhos termodinâmicos e ambientais, bem como efeitos do aproveitamento de $50 \%$ da palha gerada no campo como fonte de energia térmica.A interface produzida no simulador de processos para representar o ciclo Rankine convencional está apresentadaa seguir na Figura 35. A ampliação da Figura $35 \mathrm{com}$ maior resolução está no anexo $A$. 


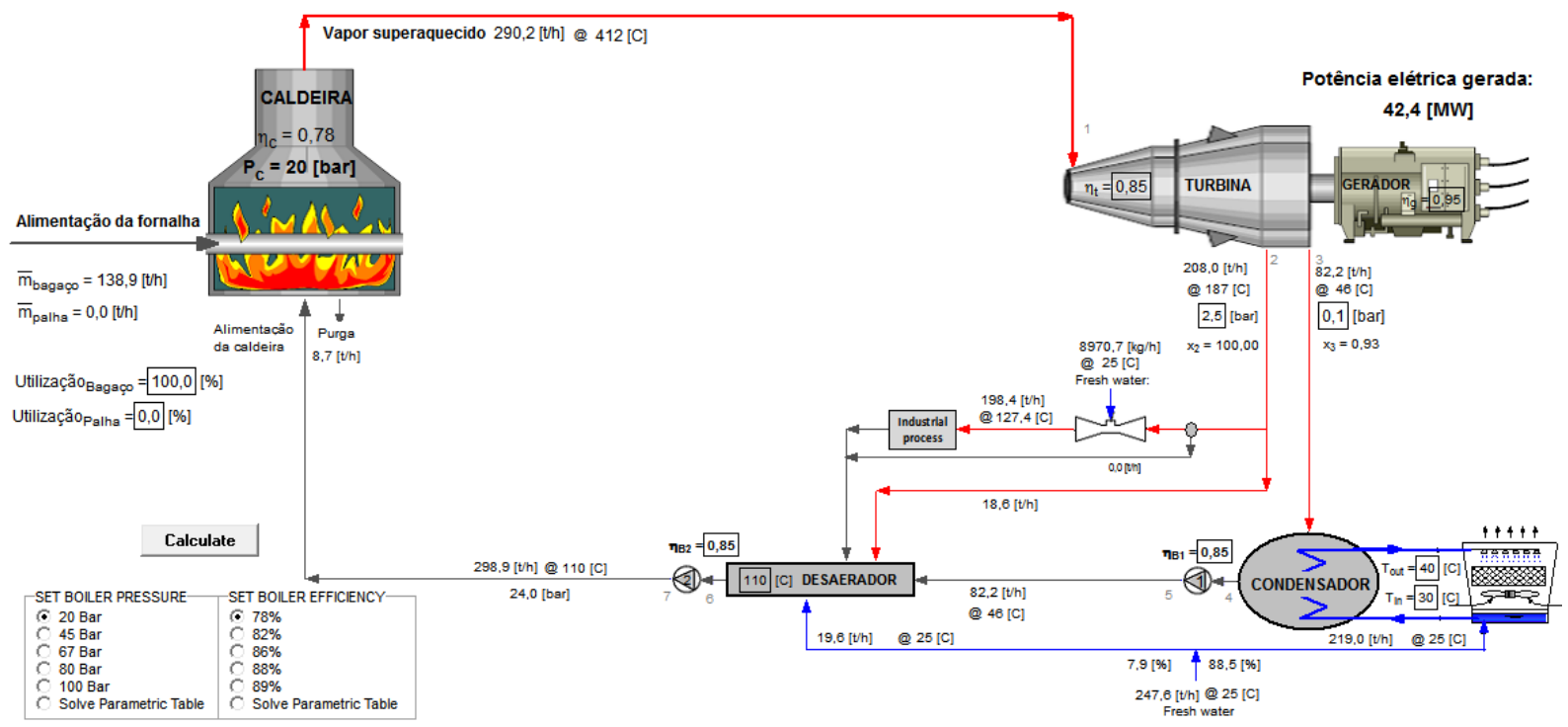

Figura 35 - Ciclo de vapor Convencional para uma planta de cogeração (Interface do simulador).

Esse simulador possibilita realizar a predição do comportamento dos cenários de I a X constantes na Tabela , que por sua vez, e como o leitor irá perceber, compreende um desdobramento da Tabela .

Tabela 9 - Características dos cenários de cogeração com ciclo Rankine Convencional.

\begin{tabular}{|c|c|c|c|}
\hline Cenários & A nromindo Cislo Donlin & Uso da & Pressão e Temperatura \\
\hline Número & 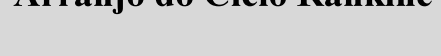 & palha & no gerador de vapor \\
\hline $\begin{array}{l}\text { I } \\
\text { II } \\
\text { III } \\
\text { IV } \\
\text { V }\end{array}$ & \multirow{2}{*}{ Ciclo Convencional } & Não & $\begin{array}{l}20 \text { Bar e } 412{ }^{\circ} \mathrm{C} \\
45 \text { Bar e } 457^{\circ} \mathrm{C} \\
67 \text { Bar e } 483{ }^{\circ} \mathrm{C} \\
80 \text { Bar e } 495{ }^{\circ} \mathrm{C} \\
100 \text { Bar e } 511^{\circ} \mathrm{C}\end{array}$ \\
\hline $\begin{array}{l}\text { VI } \\
\text { VII } \\
\text { VIII } \\
\text { IX } \\
\text { X }\end{array}$ & & Sim & $\begin{array}{l}20 \text { Bar e } 412^{\circ} \mathrm{C} \\
45 \text { Bar e } 457^{\circ} \mathrm{C} \\
67 \text { Bar e } 4833^{\circ} \mathrm{C} \\
80 \text { Bar e } 495^{\circ} \mathrm{C} \\
100 \text { Bar e } 511^{\circ} \mathrm{C}\end{array}$ \\
\hline
\end{tabular}

Os resultados serão analisados em duas etapas: sem aproveitamento da palha; e com aproveitamento da palha (contribuição de $50 \%$ do volume total gerado pelo processo agrícola). 


\subsubsection{Cenários I a V: Ciclo Convencional sem aproveitamento da palha}

Nessa etapa é considerada a premissa que toda palha gerada é deixada no campo. Os resultados das simulações que consolidam os principais indicadores de eficiência de processo em termos de Primeira e Segunda Lei da Termodinâmica, descritos pela eficiência energética e exergética respectivamente, são apresentados no Gráfico 1.

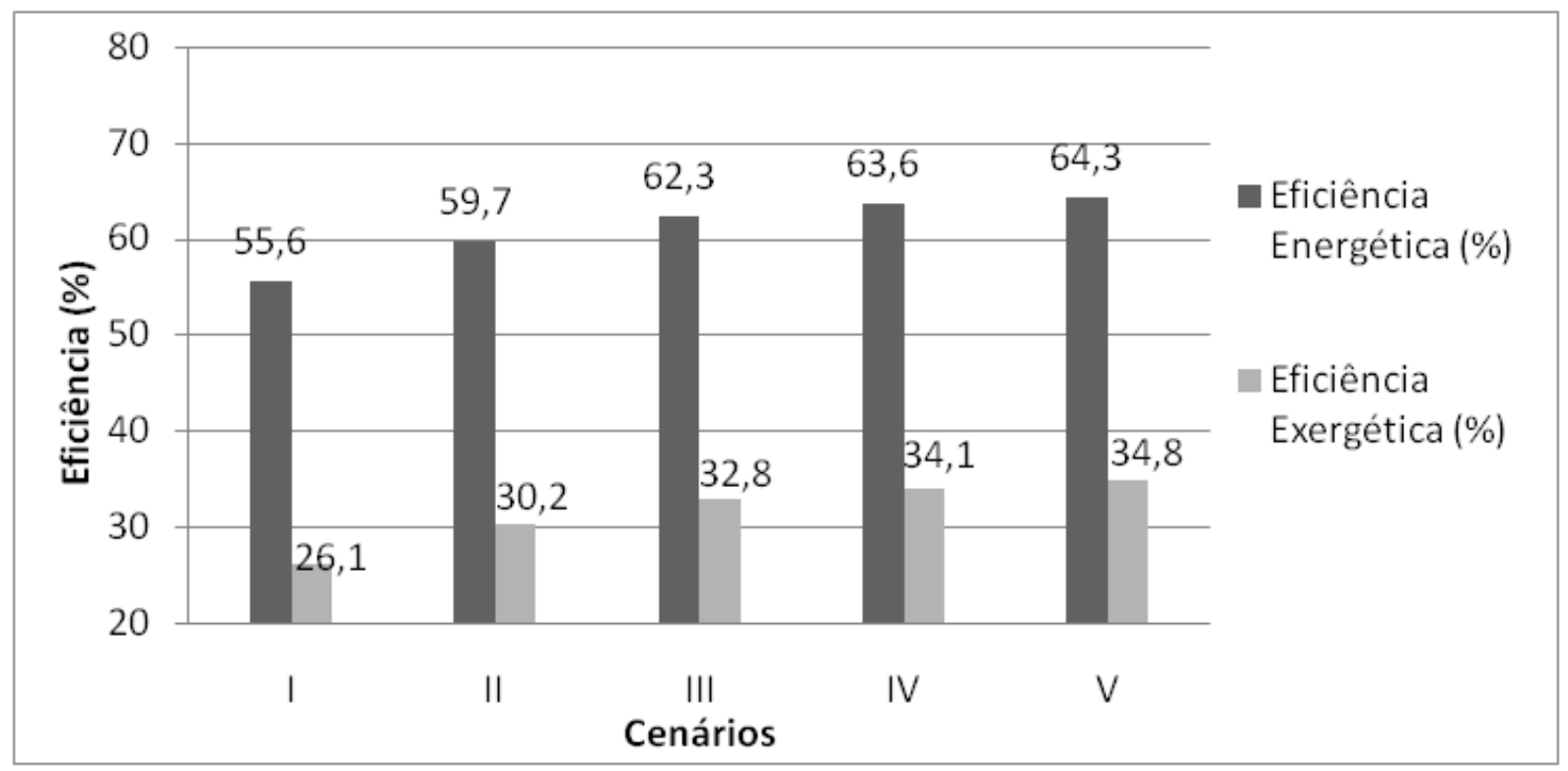

Gráfico 1 - Resultados da eficiência energética e exergética pra os cenários I a V.

Os resultados de produção total de eletricidade específica por tonelada de cana moída (tc), da projeção da capacidade de exportação de eletricidade específica para a rede, os consumos de água na torre de resfriamento e água deionizada para reposição na caldeira para cada cenário em estudo, são apresentados no Gráfico 2.

Os resultados consolidados nos Gráficos 1 e 2 indicam que o potencial de geração de eletricidade excedente, determinado pela taxa de eletricidade exportada aumenta à medida que a pressão de vapor na saída da caldeira se eleva. Crescem também as dificuldades para a construção de equipamentos dimensionados para condições de operação mais extremas, bem como aumenta a necessidade de utilizar tecnologias de segurança mais sofisticadas, conforme discutido antes.

Apesar dessas dificuldades em 2012 havia 124 usinas operando com geradores de vapor a 67 bar e 11 usinas operando a 100 bar (IDEA, 2012). Esse quadro demonstra a tendência do setor sucroalcooleiro nacional de investir em tecnologias 
cada vez mais avançadas para atingir resultados que lhe sejam atraentes em termos econômicos, eliminando preferencialmente, perdas e períodos de ociosidade das instalações.

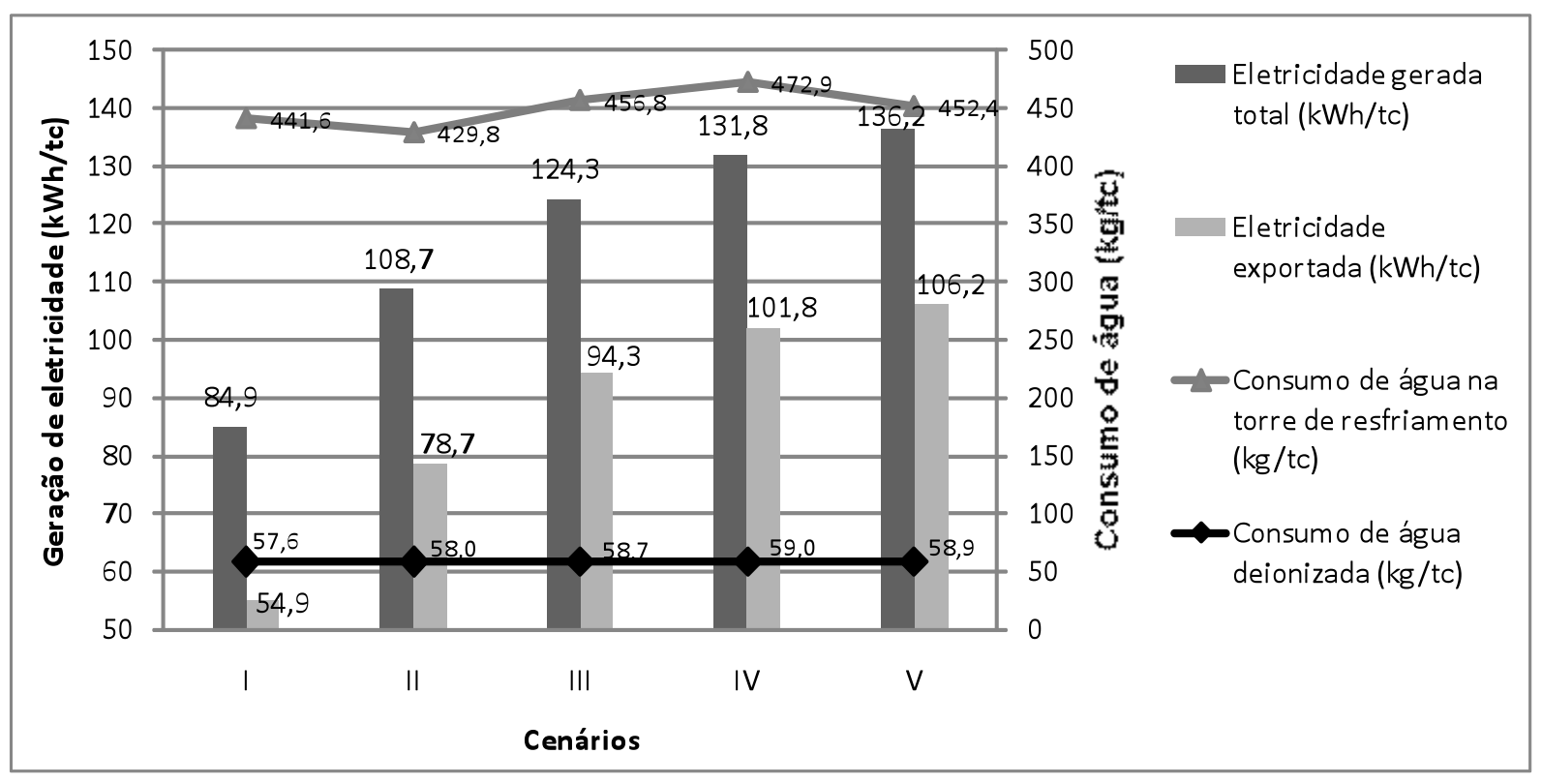

Gráfico 2 - Resultado dos indicadores de performance específicos, para os cenários I a V.

Verifica-se pelo conteúdo dos Gráficos 1 e 2, que para a condição de pressão de vapor mais elevada, obteve-se melhor eficiência exergética - de 34,8\% - e que a geração de eletricidade total atingiu 136,2 kWh/tc, o que corresponde a um aumento de $60,4 \%$ em relação ao cenário em que vapor de alta deixa a caldeira a 20 bar - a menor das pressões de operação avaliadas. Considerando o autoconsumo específico da usina autônoma de $30 \mathrm{kWh} / \mathrm{tc}, 0$ modelo estimou uma taxa de exportação de eletricidade de 106,2 kWh/tc para pessões de vapor de saída da caldeira de 100bar.

Em termos de consumos de água para arrefecimento e água para caldeira, não se percebeu variações significativas ou foi evidenciada alguma tendência de aumento, ou redução,de consumo com a elavação da pressão de vapor na caldeira para o sistema de cogeração operando com ciclo Rankine Convencional. Tal constatação é feita, mesmo sabendo-se da elevação da taxa de geração de eletricidade total,

Isso pode ser explicado considerando-se que uma redução do consumo de água na torre que seria alcançada em virtude do aumento da eficiência exergética do ciclo 
por conta da redução do rejeito de calor no conjunto condensador e torre. Isso ocorre dado o aumento da transferência de energia térmica para o fluido de trabalho do ciclo à medida que se aumenta a pressão da caldeira e se aumenta a eficiência térmica.

Observe-se que os aumentos na transferência de energia térmica da biomassa para o fluido de trabalho, e de eficiência térmica da caldeira elevam a geração de eletricidade. No entanto, proporcionam também mais calor rejeitado, e maior consumo de água para repor a evaporação, arraste e purga da torre.

Guerra et al. (2014), avaliaram o comportamento do consumo de água na torre de resfriamento em função do aumento de pressão na caldeira. Nesse caso, adotousea mesma eficiência térmica para caldeira em todos os cenários daquela análise $(20,45,67,80$ e 100 bar - que inclusive coincidem com os definidos para este estudo. Como resultado, os pesquisadores constataram uma tendência de queda no consumo de água não apenas na torre, mas também de água deionizada. Guerra et al (2014) explicar esses resultados pelo aumentode eficiência exergética do sistema de cogeração e, consequentemente, pela redução decalor foi rejeitado para o ambiente.

Uma análise energética para cada cenário em estudo foi realizada sob o enfoque da Primeira Lei da Termodinâmicacom objetivo de identificar as etapas do ciclo Rankine responsáveis pelas maiores perdas energéticas. Os resultados dessa investigação estão apresentados no Gráfico 3. 


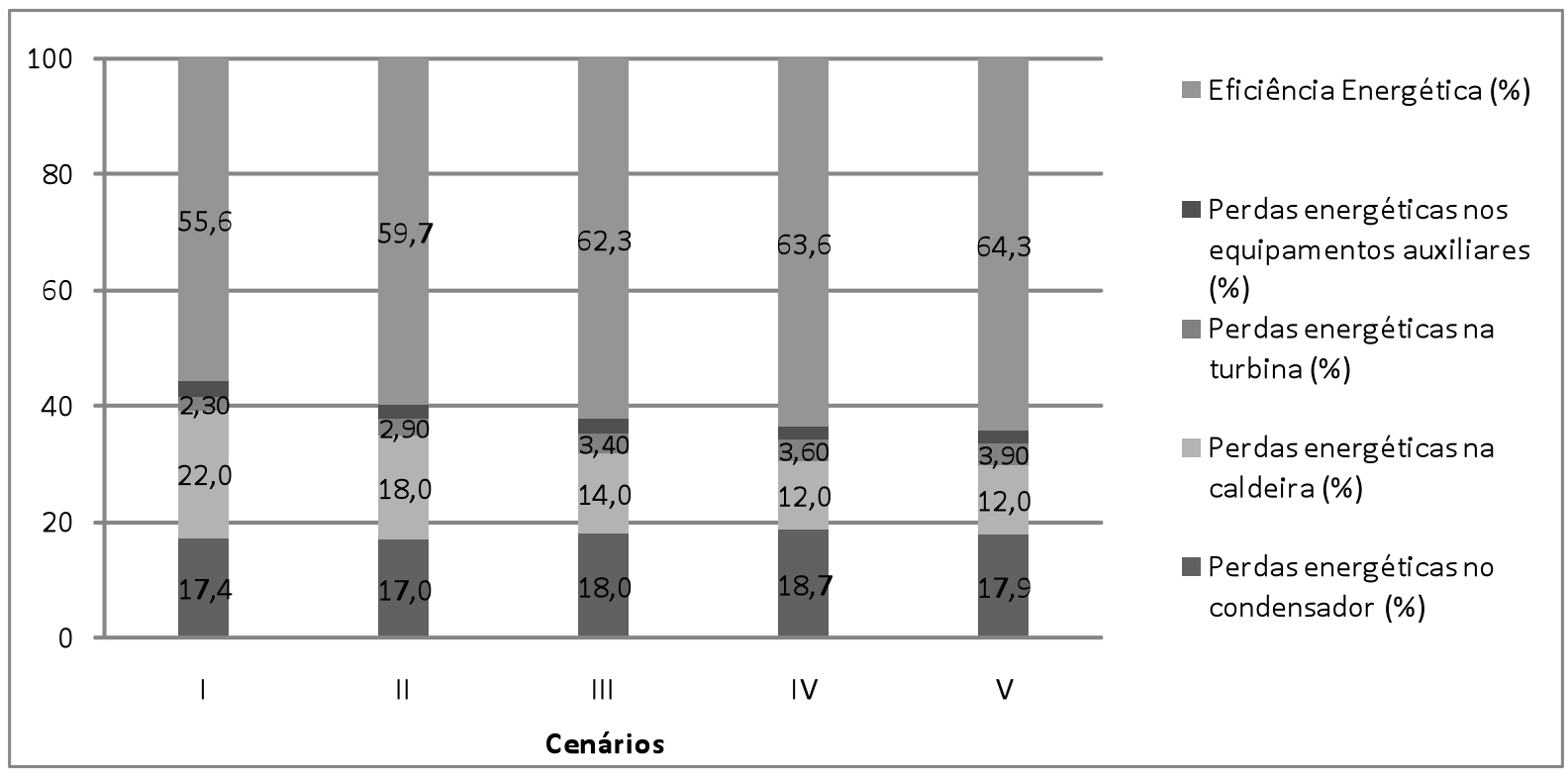

Gráfico 3 - Resultados da análise energética para os cenários I a V.

A avaliação revelou que para os cenários de 20 e 45 bar o elemento responsável pelas perdas energéticas é a caldeira, com contribuições de $22 \%$ e $18 \%$, respectivamente sobre a energia total alimentada. Esses dados refletem a ineficiênciado equipamento em transferir toda energia química dos combustíveis para o fluido de trabalho. Tais ineficiências são reduzidas com o aumento da pressão de operação na caldeira e com a implantaçãode tecnologias mais avançadas de materiais de construção e de isolamento, conforme discutido anteriormente.

Segue-se a essa na relação de precursores de perdas energéticas a operação unitária de condensação. De fato, verificam-se variações discretas de perdas energéticas no condensador entre as pressões analisadas. Contudo, a partir do cenário III, percebe-se uma inversão de papéis. Para pressões a partir de 67 bar, a análise clássica mostra que o condensador se converteno principal responsável pelas perdas, pois o efeito, já mencionado, de elevação de pressão de operação da caldeira melhora sua eficiência térmica global.

Para o cenário I, a análise mostra que $22 \%$ da energia total fornecida pela queima do bagaço de cana é perdida na caldeira e 17,4\%,na unidade de condensação. Já para o cenário Vpercebem-se os melhores resultados de geração elétrica, quando vapor a 100 bar será produzido. Os percentuais de descarte de energia na caldeira e 
na condensação nesse caso, correspondem a $12 \%$ e $17,9 \%$ da energia total alimentada.

Por outro lado, as perdas energéticas na turbina se elevam de 2,3\% para 3,9\% quando a pressão de alimentação teórica da turbina aumenta caminha em direção a 100 bar. Tal acréscimo é de certa forma esperado, dado que maiores quantidades de energias térmica e cinética passam a ser convertida em trabalho útil pela turbina (note-se que a eficiência energética global do sistema aumenta de 55,6\% para $64,3 \%)$.

A análise de Primeira Lei mostrouainda que as perdas energéticas nos equipamentos auxiliares permaneceram abaixo de $2,7 \%$ em todos os cenários e que o aumento da pressão não proporcionou variações significativas.

Apesar de fornecer informações indispensáveis, esta avaliação não gera dados sobre a qualidade das formas de energia que são perdidas ao longo do ciclo termodinâmico em estudo. Partindo do princípio de que o propósito do ciclo Rankine é converter energia térmica em trabalho útil, tais indicativosse tornam essenciais para a melhor compreensão do desempenho do ciclo. Conseqüentemente, a análise de Primeira Lei não é suficiente para proporcionar um diagnóstico de desempenho completo para a planta de cogeração. Para avaliar o comportamento do ciclo termodinâmico de forma mais efetiva, uma análise exergética foi realizada para a planta de cogeração em estudo. Os resultados das simulações são apresentados no Gráfico 4. 


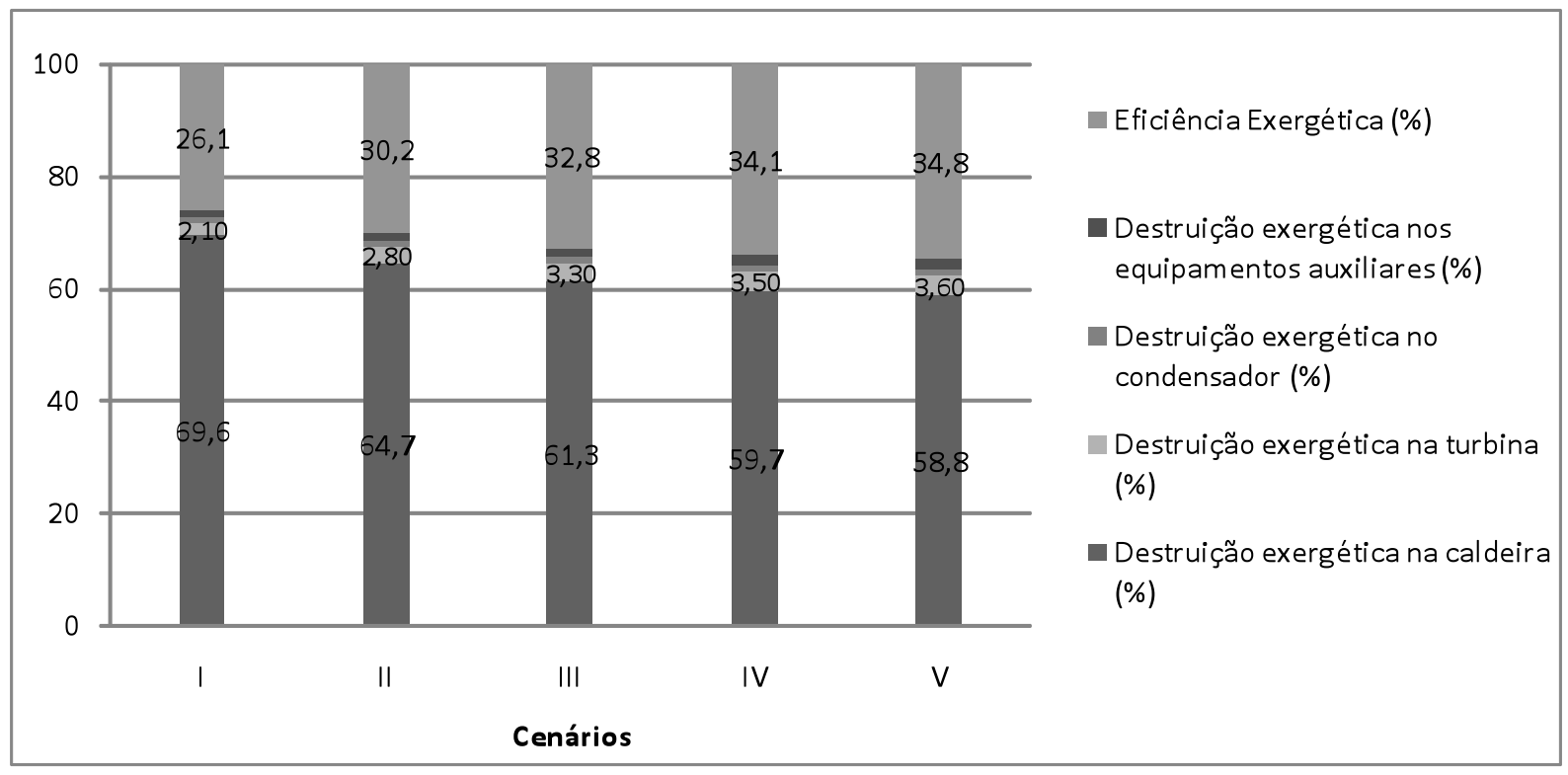

Gráfico 4 - Resultados da análise exergética para os cenários I a V.

Pode-se observar a partir do diagnóstico apresentado no Gráfico 4, que o elemento do ciclo responsável pela maior destruição exergética é a caldeira, devido em sua maior parteàs irreversibilidades geradas nas transferências térmicas, e à natureza intrínseca do processo de combustão que ocorre na fornalha. Nunca será possível eliminar completamente tais irreversibilidades, pois o processo de combustão está associado ao aumento da entropia. No entanto, é sempre possível reduzi-laspor meio da implementação deações de melhoriade controle operacional, em termos de adequação de taxa de purga, ajuste da relação ar-combustível, revisão do conceito tecnológico utilizado em termos de configuração, pressão de trabalho e isolamento, para evitar as perdas por convecção e radiação no vaso de pressão e nas linhas, entre outras medidas.

A partir da análise exergética, verificou-seque a mudança na concepção de um projeto que trabalha a 20 bar e para a aplicação de tecnologia que opera a 100 bar, pode provocar uma redução na destruição de exergia na caldeira de $69,6 \%$ para $58,8 \%$.

A destruição exergética na turbina aumentou de 2,1\% para 3,6\% com a elevação da pressão. Esseresultadoestá associado à maior conversão de energia ao longo dos estágios da turbina, dado que a eficiência exergética global do sistema cresce de $26,1 \%$ para $34,8 \%$. 
Verificou-se que a destruição de exergia no condensador escilou de 1,1\% (a 20 bar) para $1,2 \%$ (a 100 bar). Isso significa que a energia perdida no condensador é de "baixa qualidade" e apresenta pouco potencial de realizar trabalho; ou seja, encontra-se em condições de estado termodinâmico e químico bastante próximas às do equilíbrio com o ambiente de referência, ou de se atingir o estado morto. Como conseqüência desse diagnóstico, não seria recomendável dedicar esforços à recuperaçãoda energia perdida na unidade de condensação.

Já a exergia destruída em equipamentos auxiliares aumenta com a elevação de pressão. Na menor pressão de trabalho de 20 bar, esta representouuma perda 1,1\% em relação à energia total introduzida pelo combustível. No outro extremo, de 100 bar, correspondeu a 1,6\%. Isso ocorreu principalmente devido ao aumento da destruição de exergia associada ao bombeamento do fluido de trabalho a maiores pressões.

\subsubsection{Resultados dos cenários $\mathrm{VI}$ a X: Ciclo Convencional com aproveitamento da palha}

Nessa etapa considera-se a hipótesede que $50 \%$ da palha gerada pela atividade agrícola será aproveitada na caldeira como combustível, queimado conjuntamente ao bagaço. Os resultados das simulações para os cenários VI a X são apresentados nos Gráfico 5 e 6. 


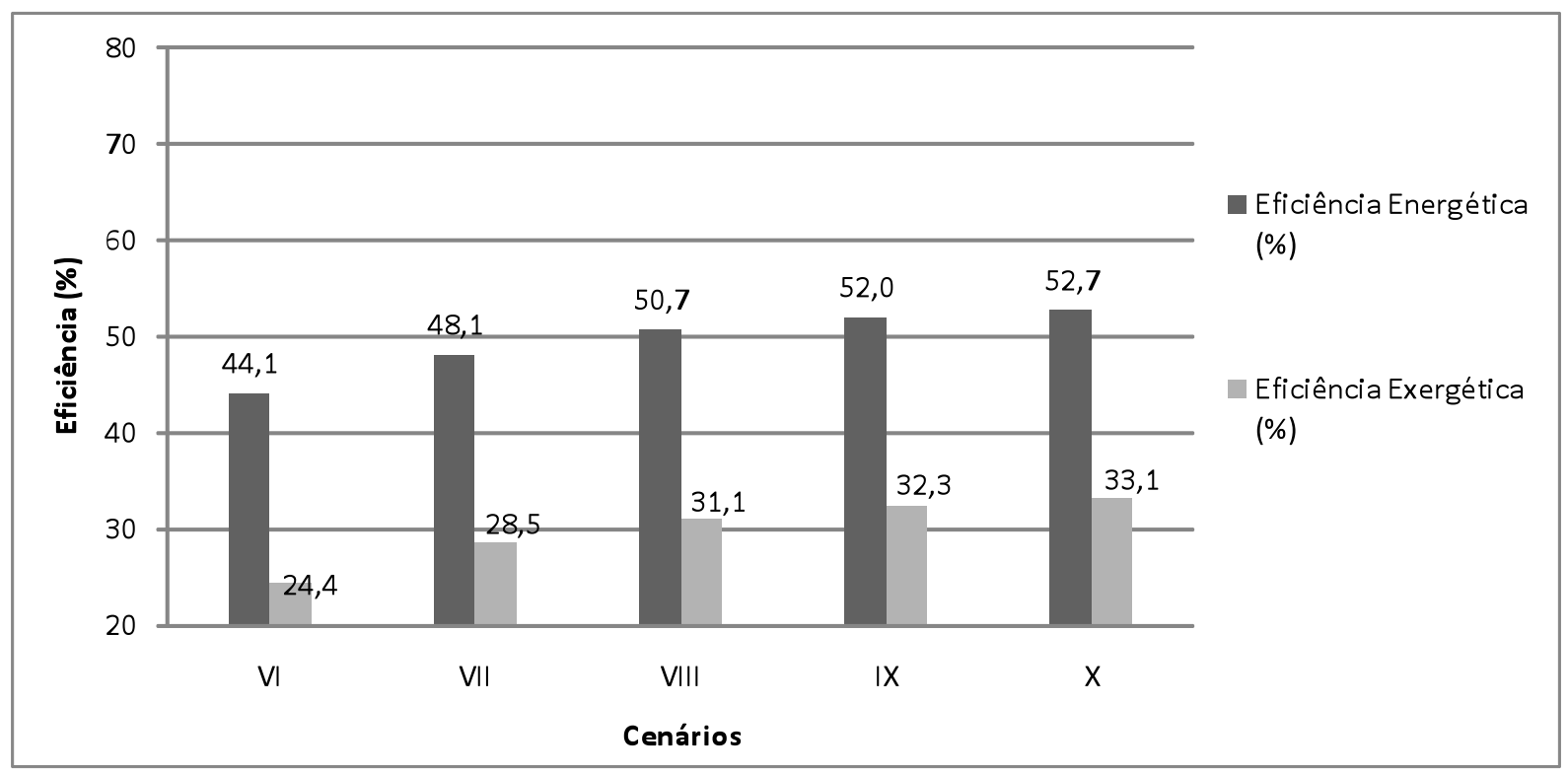

Gráfico 5 - Resultados da eficiência energética e exergética pra os cenários VI a X.

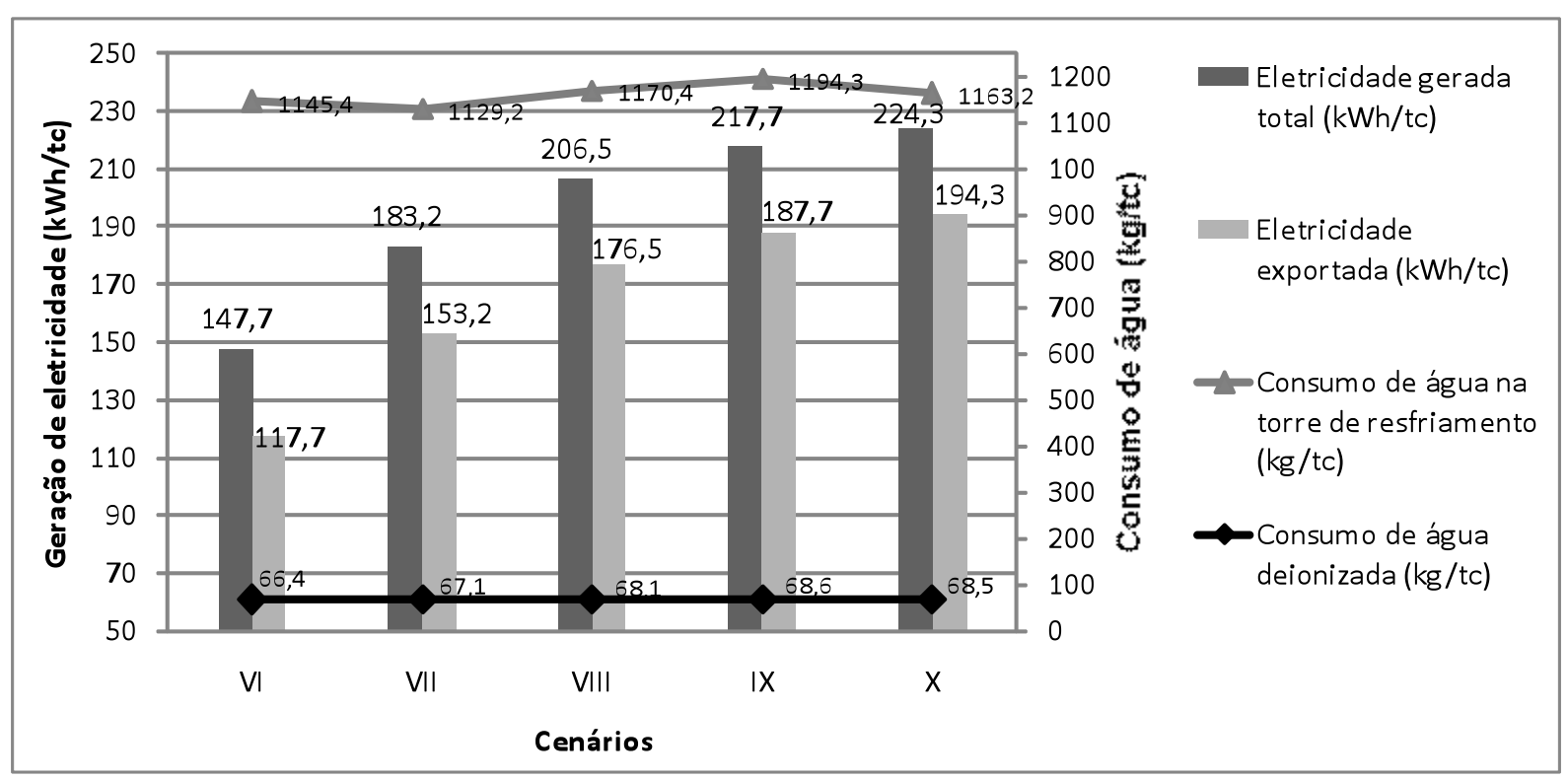

Gráfico 6 - Resultado dos indicadores de performance específicos, para os cenários VI a X.

Os resultados apresentados nos Gráficos 5 e 6 indicam quea taxa de eletricidade exportada aumenta à medida que a pressão do vapor na saída da caldeira se eleva. Como esperado, na condição de pressão de vapor mais elevada (cenário $\mathrm{X}$ ), obtevese a melhor eficiência exergética - de $33,1 \%$ - e maior geração de eletricidade $224,3 \mathrm{kWh} / \mathrm{tc}$, que corresponde a um aumento de 51,9\% em relação ao cenário de pressão mais baixa (cenário $\mathrm{VI}$ ). Já em relação a cenários I e $\mathrm{V}$, sempre para as 
mesmas condições de pressão e temperatura, a utilização da palha projetou ganhos da ordem de $65 \%$ em geração de eletricidade em todas as situações sob análise.

Por outro lado, nota-se que as eficiências globais do ciclo - energética e exergética foram menores em relação aos cenários em que não há utilização da palha. Isso ocorre pois os valores dessas eficiências dependem do percentual de distribuição da energia gerada entre energia térmica (vapor para processo) e energia elétrica no gerador. Assim, se forem mantidas as mesmas condições operacionais, quanto maior a fração da energia utilizada na forma de vapor, maior será também a eficiência do ciclo Rankine da cogeração. No caso da cogeração o vapor é produto final;ao ser extraído da turbina para ser utilizado como produto, este deixa de ser utilizado pelos processos de conversão na turbina e no gerador, nos quais há significantes perdas energéticas e exergéticas.

Um exemplo quantitativo disso ocorre na comparação de desempenhos entre os cenários $\mathrm{V}$ e $\mathrm{X}$. No cenário $\mathrm{V}, 64 \%$ da energia é gerada na forma de vapor e o restante como eletricidade. Já no cenário $X$, exatos $51,9 \%$ da energia é gerada como vapor. Em termos exergéticos, a situação em que não há reaproveitamento da palha (cenário $\mathrm{V}$ ), $33,5 \%$ da exergia é gerada como vapor enquanto $66,5 \%$ na forma de eletricidade. Quando essa biomassa se inclui (Cenário X) apenas $23,5 \%$ da exergia passa a ser produzida como vapor.

Por conta das premissas adotadas para o estudo, o consumo de vapor é constante em todos os cenários $(400 \mathrm{~kg} / \mathrm{tc})$. Logo, o aumento da energia térmica na caldeira por conta da recuperação da palha, após ser transferido para o fluido de trabalho é convertido em energia mecânica na turbina e posteriormente em energia elétricano gerador, sofrendo processos irreversíveis adicionais. Olhando segundo tal enfoque, comparações entre eficiências energéticas e exergéticas para sistemas de cogeração tornam-se coerentes quando se analisam cenários de mesma alimentação de energia térmica na caldeira e o mesmo consumo de vapor no processo.

Para sistema de cogeração operando com ciclo Rankine Convencional considerando queima da palha, a análise mostra não haver oscilações expressivas de consumo em termos dosconsumos de água de resfriamento e deionizada, com a elevação da pressão de vapor na caldeira. Por outro lado, em relação aos cenários onde não há 
queima da palha, houve um incremento de $15,9 \%$ no consumo de água deionizada e o consumo de água na torre multiplicou-se de 2,6 vezes.

Tais variações eram esperadas uma vez que a energia adicional fornecida pela palha foi utilizada para produção de energia elétrica, com o vapor percorrendo todos os estágios da turbina e rejeitando calor para o ambiente via o conjunto condensador e torre evaporativa, o que provoca necessariamente a reposição de água na torre. Os resultados da análise energética são apresentados no Gráfico 7 .

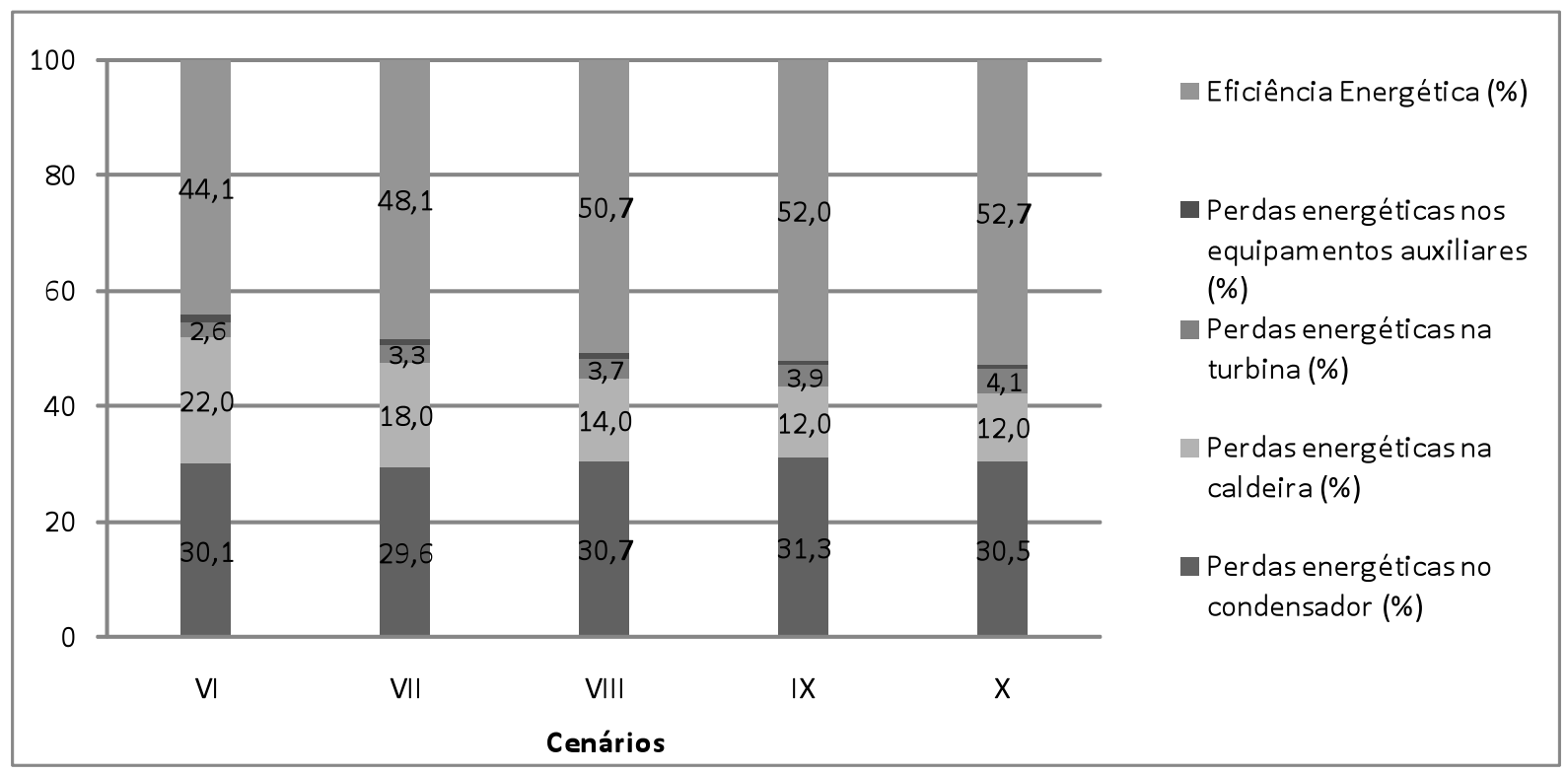

Gráfico 7 - Resultados da análise energética para os cenários VI a X.

Pode-se observar a partir da análise clássica, que o aumento da energia térmica associada ao uso da palha na caldeira, mudou o perfil de distribuição das perdas energéticas ao longo do ciclo em relação aos cenários onde o aproveitamento não ocorre.

Note-se ainda ser no condensadorem que se dão as maiores perdas energéticasem todas as condições de pressão na caldeira. $\mathrm{O}$ Gráfico 7 mostra que aproximadamente $30 \%$ da energia total fornecida pela queima do bagaço e da palha é desprezada no condensador e, que não há variações significativas desse total em função do aumento da pressão da caldeira nas condições de processo adotadas.

As perdas energéticas na turbina passamde $2,6 \%$ para $4,1 \%$ quando a pressão de alimentação teórica da turbina vaide 20 bar para 100 bar. Novamente, o acréscimo é 
de certa forma esperado uma vez que maiores quantidades de energias térmica e cinética são convertidas em trabalho útil pela turbina com o aumento da pressão.

A análise do Gráfico 7 também indicaque em todos os cenários a perda percentual de energia térmica para atmosfera na caldeira será constante para a respectiva condição de pressão, em relação aos cenários I a V. Isso ocorrepelo fato de que para cada condição de pressão de operação ter sido definido uma eficiência térmica global para caldeira.Verificou-se também que as perdas energéticas nos equipamentos auxiliares permanecem abaixo de $1,2 \%$ em todos os cenários. Isso indica que a utilização da palha na caldeirareduz a participação relativa desseselementos em termos de contribuição para o ciclo em relação aos cenários onde não há aproveitamento de biomassa.

O Gráfico 8 apresenta os resultados da análise exergética para os cenários $\mathrm{VI}$ a X.

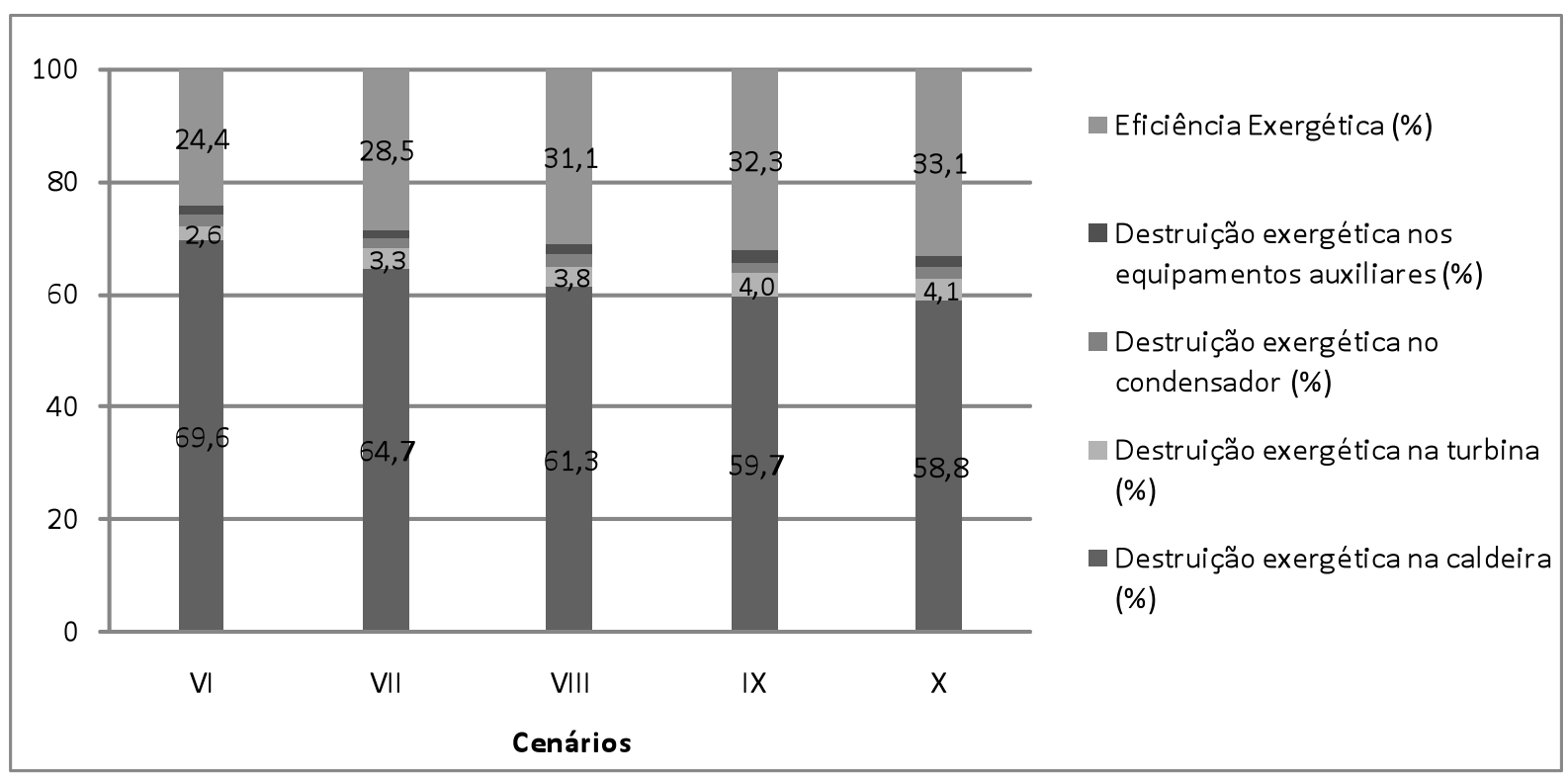

Gráfico 8 - Resultados da análise exergética para os cenários VI a X.

Pode-se observar a partir do diagnóstico exergético dos cenários VI a Xquetambém em mais essas situações o elemento responsável pela maior destruição exergética é a caldeira, com um perfil que coaduna os resultados para os cenários I a V.

O aumento da pressão de trabalho de 20 para 100 bar, associado ao nível tecnológico superior de construção das caldeiras de alta pressão, reduzem perdas energéticas e irreversibilidades. Assim, a destruição de exergia no equipamento 
diminui de $69,6 \%$ para 58,8\%, compensando o aumento na destruição de exergia na turbina e, por isso,resultando em aumento da eficiência exergética do ciclo, de $24,4 \%$ para $33,1 \%$.

A exergia destruída no condensador permaneceu em torno de $2,0 \%$ em todos os cenários; não se perceberam variações significantes destas perdascom a elevação da pressão. Já nos equipamentos auxiliares, a destruição exergéticacresceu de forma gradativa com o aumento da pressão, começando em 1,4\% no cenário VI e chegando a 2,0\% no cenário $X$. $O$ aumento da pressão de trabalho e a melhoria do conceito tecnológico da caldeiraproporcionam maior transferência de calor para o fluido de trabalho. Dessa forma, há maior a capacidade de recirculação de água no ciclo e, consequentemente mais trabalho é consumido pelas bombas de condensado e alimentação resultando em elevação da taxa de destruição de exergia.

\subsubsection{Ciclo Rankine com Reaquecimento}

O ciclo Rankine com Reaquecimentoestárepresentado na Figura 36. A ampliação da Figura 36 com maior resolução está no Apêndice B.

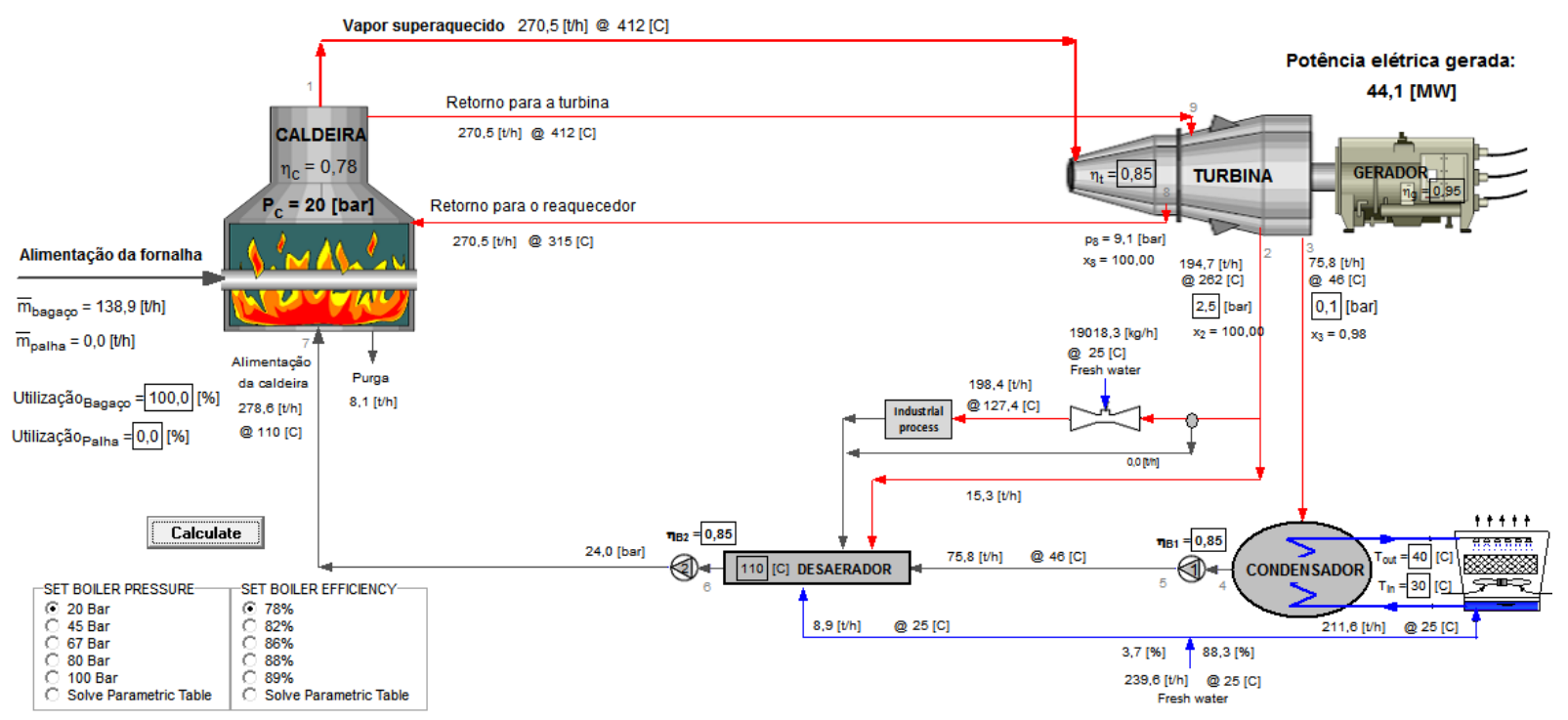

Figura 36 - Ciclo de vapor com Reaquecimento para uma planta de cogeração (Interface do simulador).

Esse modelo viabilizou a predição do comportamento termodinâmico para os cenários de $\mathrm{XI}$ a XX, os quais aparecem indicados a seguir na Tabela 2. 
Tabela 2 - Características dos cenários de cogeração com ciclo Rankine com Reaquecimento.

\begin{tabular}{c|c|c|c}
\hline Cenários & Arranjo do Ciclo Rankine & $\begin{array}{c}\text { Uso da } \\
\text { palha }\end{array}$ & $\begin{array}{c}\text { Pressão e Temperatura } \\
\text { no gerador de vapor }\end{array}$ \\
\cline { 1 - 2 } Número & & & 20 Bar e $412^{\circ} \mathrm{C}$ \\
XI & & Não & 45 Bar e $457^{\circ} \mathrm{C}$ \\
XII & & & 67 Bar e $483^{\circ} \mathrm{C}$ \\
XIII & \multirow{2}{*}{ Ciclo com Reaquecimento } & 80 Bar e $495^{\circ} \mathrm{C}$ \\
XIV & & & 100 Bar e $511^{\circ} \mathrm{C}$ \\
XV & & & 20 Bar e $412^{\circ} \mathrm{C}$ \\
\cline { 3 - 4 } XVI & & Sim & 65 Bar e $457^{\circ} \mathrm{C}$ \\
XVII & & & 67 Bar e $483^{\circ} \mathrm{C}$ \\
XVIII & & & 80 Bar e $495^{\circ} \mathrm{C}$ \\
XIX & & & 100 Bar e $511^{\circ} \mathrm{C}$ \\
XX & &
\end{tabular}

\subsubsection{Cenários XI a XV: Ciclo com Reaquecimento sem aproveitamento da palha}

Para efeito de realização desta verificação, admitiu-se que toda palha gerada por conta do processamento agrícola é deixada no campo. Além disso, tomaram-se por referências para esta avaliação os cenários I a V, correspondentes ao ciclo Rankine Convencional em situação semelhante quanto à biomassa. $O$ produto das simulações dos cenários $\mathrm{XI}$ a XVem termos das eficiências energéticas e exergéticas aparecem no Gráfico 9 .

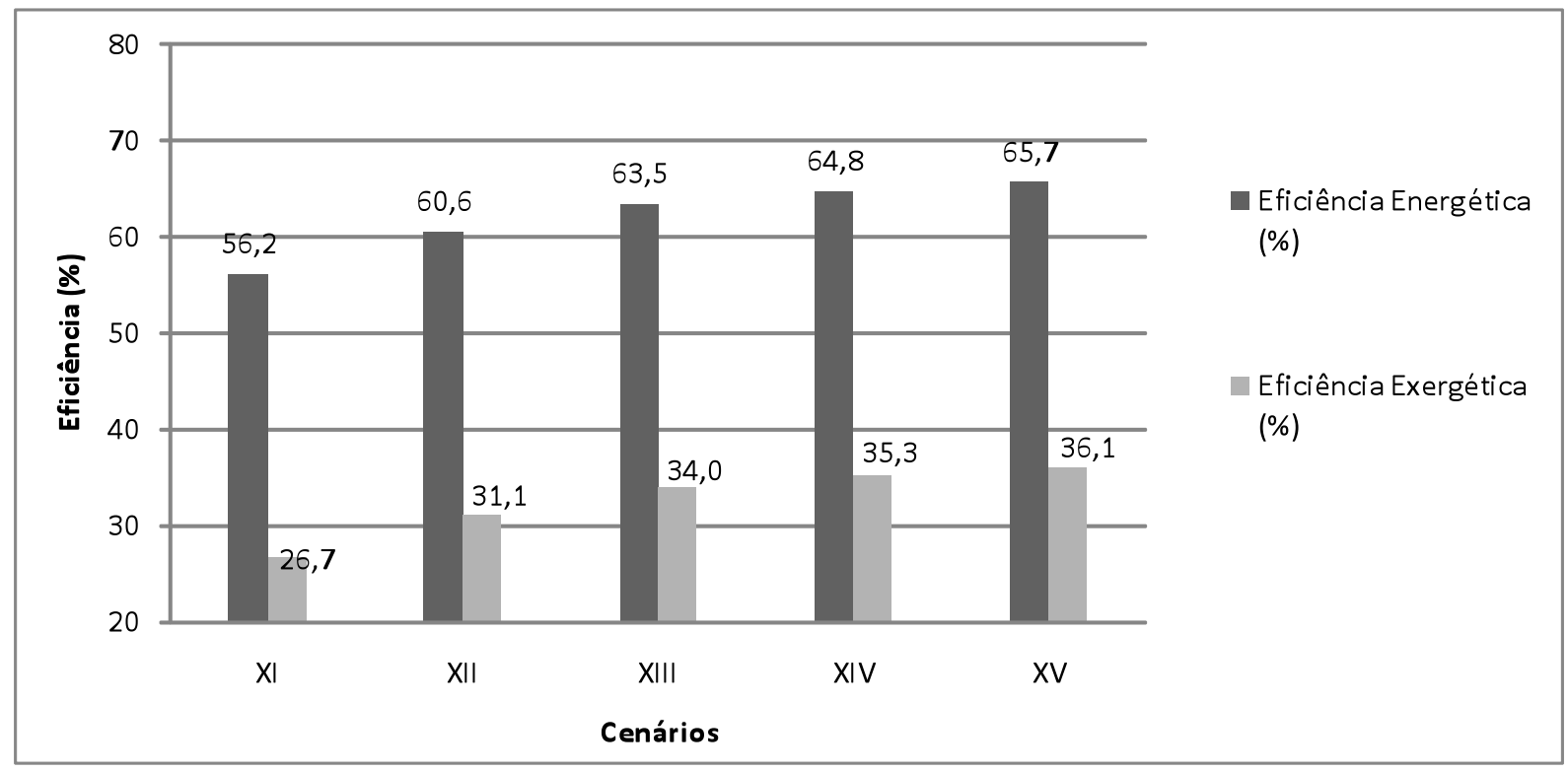

Gráfico 9 - Resultados da eficiência energética e exergética pra os cenários XI a XV. 
O Gráfico 9 mostra que as eficiências de Primeira e Segunda Lei do ciclo Rankine com Reaquecimento são amplificadas a medida que aumenta a pressão do vapor de saída da caldeira, uma tendência consonante com a do ciclo Rankine Convencional. Em comparação com os resultados dos cenários de referência (Gráfico 1) e avaliando-se apenas o efeito do Reaquecimento, nota-se melhoria das eficiências energéticas e exergéticas para quaisquer das condições de pressão de caldeira em análise.

A 20 bar a eficiência energética do ciclo Convencional foi de 55,6\% enquanto para o ciclo com Reaquecimento foi de $56,2 \%$, ou seja, um aumento de $1,1 \%$. Ao se realizar a mesma comparação para 100 bar percebe-se crescimento de $2,2 \%$.

Em termos exergéticos, o ganho associado ao efeito do Reaquecimento do ciclo foi da mesma foram expressivo - 2,3\% para 20 bar e 3,7\% para 100 bar - em comparação aos mesmos cenários de referência.

Os resultados das simulações dos cenários $\mathrm{XI}$ a XV em termos dos indicadores de performance específicos, por tonelada de cana moída, constam do Gráfico 10.

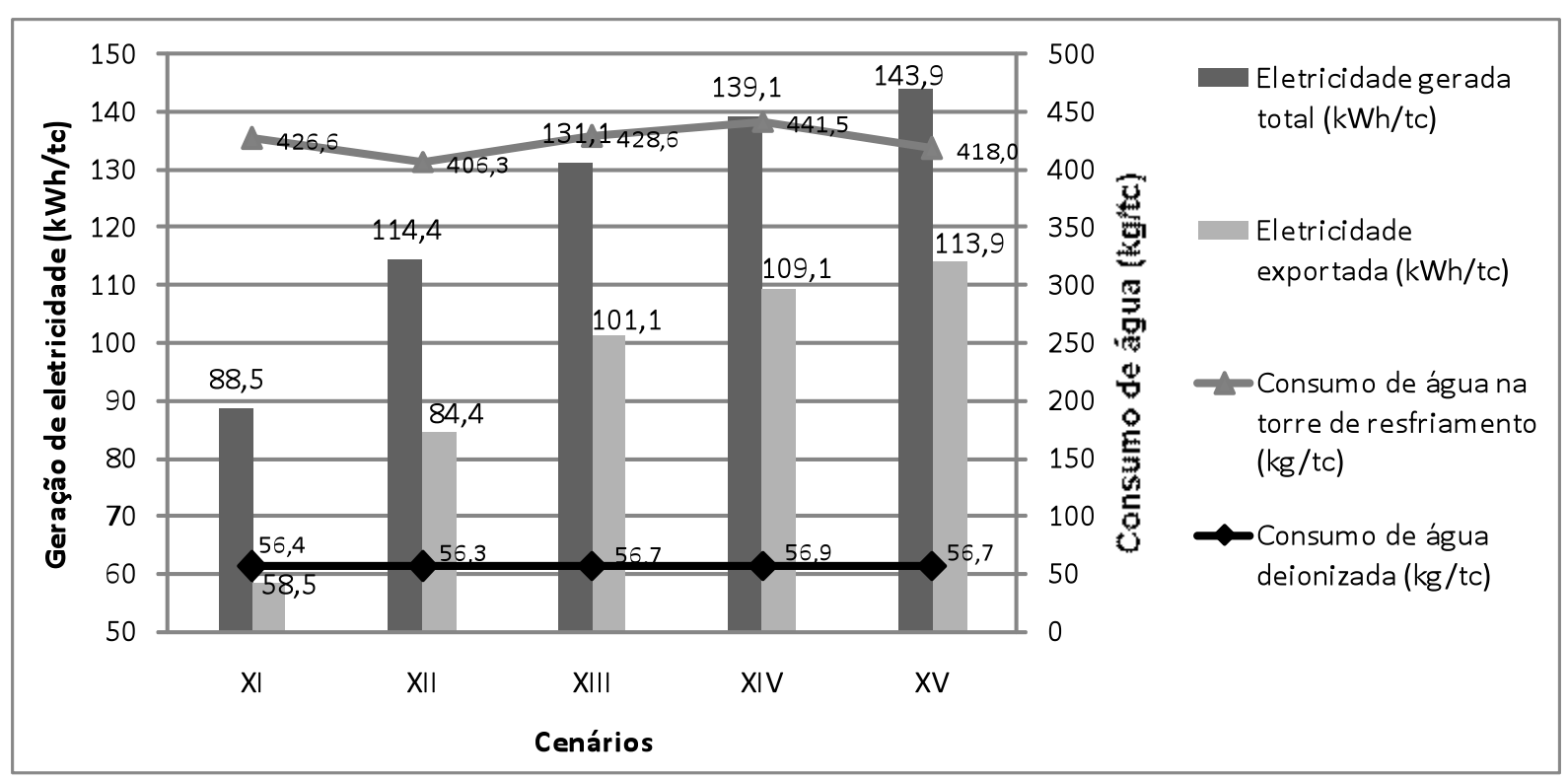

Gráfico 10 - Resultado dos indicadores de performance específicos, para os cenários XI a XV.

Desta análise verifica-se que a taxa de eletricidade exportada aumenta à medida que a pressão de vapor na saída da caldeira se eleva, seguindo a mesma tendência 
do ciclo Convencional. Por outro lado, tal aumento já seria esperado, uma vez que houve aumento na eficiência exergética do ciclo.

$\mathrm{Na}$ condição de pressão de vapor mais elevada (cenário XV) obteve-se uma taxa de geração de eletricidade 143,9 kWh/tc contra 136,2 kWh/tc do ciclo Convencional nas mesmas condições (cenário $\mathrm{V}$ ), que corresponde a um ganho de $5,7 \%$. Na condição de operação de 20 bar, o benefício foi, como seria de se supor, ligeiramente menor de $88,5 \mathrm{kWh} / \mathrm{tc}$ (cenário IX) contra $84,9 \mathrm{kWh} / \mathrm{tc}$ (cenário I) de 4,2\% - pelo fato deste ser o limite inferior de pressão de trabalho em estudo. Esses achados abrem uma perspectiva de aprofundamento nos estudos voltados ao uso de reaquecimento em sistemas de cogeração projetados para operar a altas pressões, especialmente em termos econômicos para se avaliar a viabilidade do projeto.

Em termos de consumos de água de resfriamento e deionizada, os resultados não evidenciaram uma tendência consistente de aumento ou redução de consumo com a magnificação da pressão do vapor. Contudo, em relação aos cenários de referência percebe-se uma redução nos consumos específicos de águaem todas as condições de pressão na caldeira. A redução se potencializa à medida que aumenta a pressão de trabalho. A 20 bar, o consumo de água na torre para o cenário I foi de 441,6 kg/tc e de água deionizada,de $57,6 \mathrm{~kg} / \mathrm{tc}$. No sistema que conta com Reaquecimento (cenário XI) os mesmos consumos de água montam 426,6 kg/tc e 56,4 kg/tc, o que representa reduções de $3,4 \%$ e $2,1 \%$. A 100 bar, as reduções nos consumos de água foram ainda maiores, correspondendo a $7,6 \%$ e 3,7\%, respectivamente.

Os resultados da análise clássica de Primeira Lei são apresentados no Gráfico 11. 


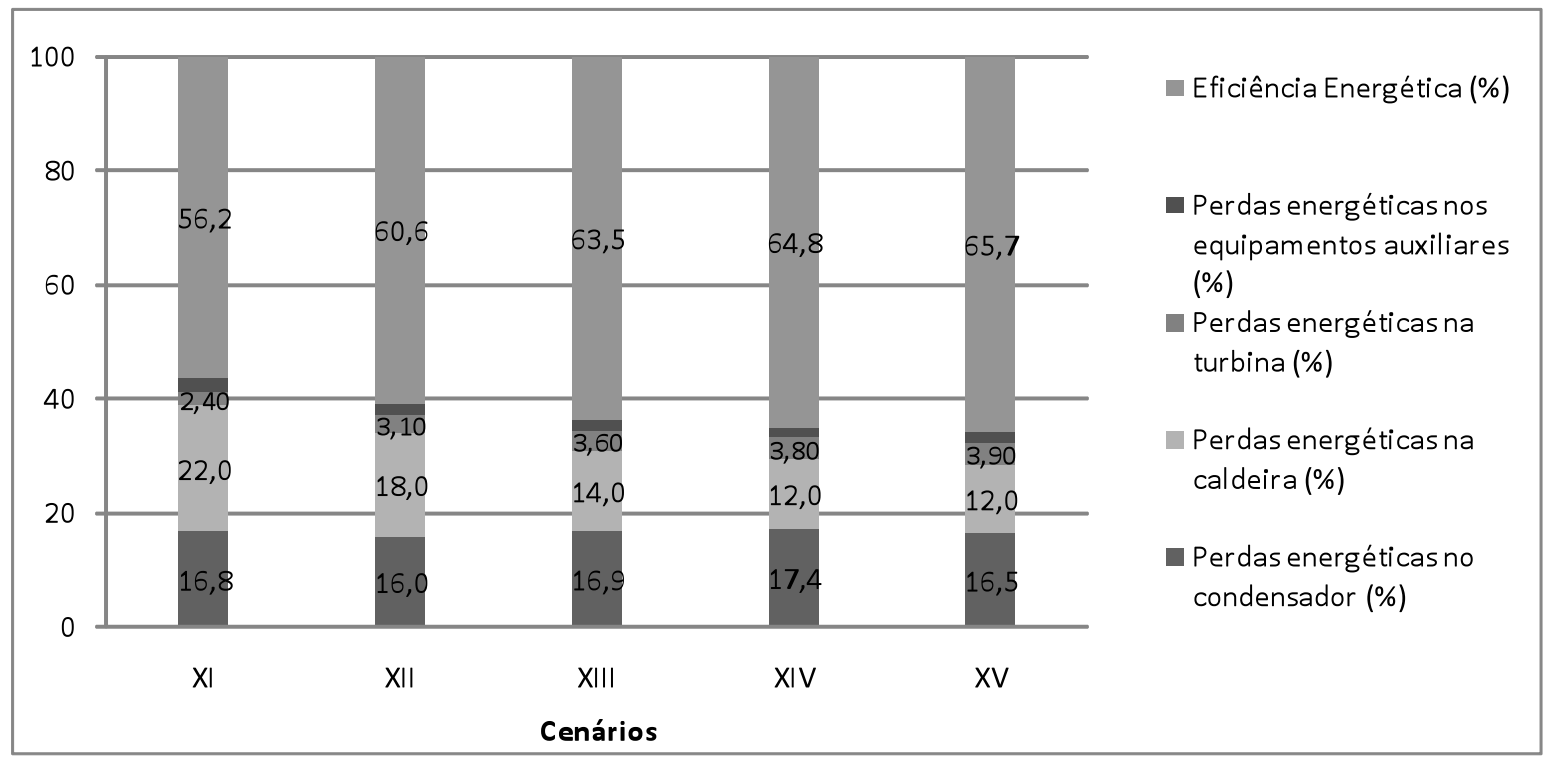

Gráfico 11 - Resultados da análise energética para os cenários XI a XV.

Observa-se que a distribuição das perdas energéticas constante do Gráfico 11 segue a mesma tendência dos resultados apresentados nos cenários de referência I a $\mathrm{V}$ para todos os elementos do ciclo. A principal diferença encontrada ao se comparar os diagnósticos de Primeira Lei dos cenários com Reaquecimento e Convencional sem considerar a queima da palhareside em uma diminuição de perdas energéticas no condensador para todos os cenários com sistema de Reaquecimento. Enquanto no cilco Convencional para 20bar estas representam 17,4\% (cenário I), no sistemacom Reaquecimento (cenário XI) os desperdícios foram de $16,8 \%$, ou seja, uma redução de $3,4 \%$. Para 100 bar de pressão, ocorreu o esperado, com uma redução expressiva nas perdas do condensador - de 7,8\% viaadoção da proposta de Reaquecimento.

As perdas energéticas na turbina aumentam de $2,4 \%$ para 3,9\% quando a pressão de alimentação teórica da turbina subiude 20 barpara 100 bar, um aumento discreto em comparação com os cenários de referência. Para os equipamentos auxiliares esses índices estiveram controlados para todos os cenários, perfil bastante semelhante ao dosresultados dos cenários de I a V. Verificou-se a partir das simulações que uma forma de reduzir a contribuição percentual dessas perdas está na maior introdução de energia térmica na cogeração, que pode ocorrer, por exemplo, via uso de palha. 
Os resultados obtidos à luz da Segunda Lei da Termodinâmica para os cenários XI a XV são apresentados no Gráfico 12.

Pode-se verificar que o diagnóstico exergético dos cenários XI a XV apresentou um perfil de destruição de exergia semelhante ao projetado para os cenários de referência para todos os elementos do ciclo. Novamente o elemento do ciclo responsável pela maior destruição exergética é a caldeira, e com o aumento da pressão de trabalho de o potencial de destruição de exergia no equipamento caiu de $68,8 \%$ para $57,7 \%$.

Em todos os casos analisados, o desempenho foi superior ao dos resultados obtidos para o ciclo Convencional na mesma condição de trabalho. Enquanto a destruição de exergia na caldeira atingiu a marca de $69,6 \%$ no cenário I, em seu correspondente com Reaquecimento (cenário XI) esse índice foi de $68,8 \%$, ou seja, uma redução de $1,1 \%$.

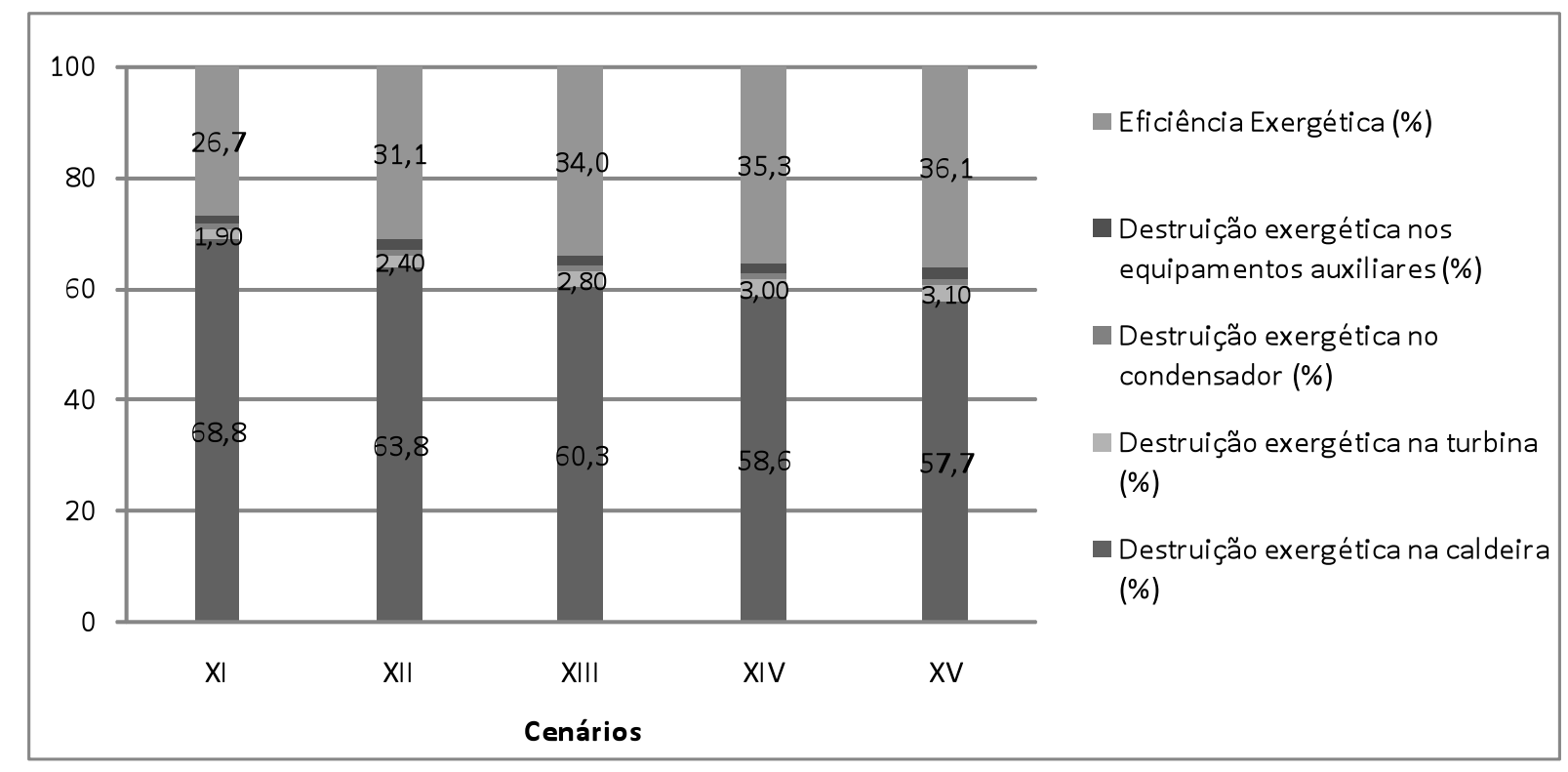

Gráfico 12 - Resultados da análise exergética para os cenários XI a XV.

$\mathrm{Na}$ condição de 100 bar, isso se potencializa, por meio de uma redução maior da ordem de 1,9\% na destruição de exergia na caldeiracom a incorporação do sistema de Reaquecimento.Muito embora discretos à primeira vista, deve-se destacar que os ganhos nesse segmento estão associados ao aumento da eficiência exergética do 
ciclo, e à geração de eletricidade, sendo portanto mais difíceis de serem conseguidos.

Ao comparar os resultados do ciclo com Reaquecimento e o ciclo Convencional, verifica-se que houve também uma redução na destruição de exergia na turbina em todas as condições de operação. Enquanto no ciclo Convencional a 20 bar esta foi de 2,1\%, no ciclo com Reaquecimento alcançou 1,9\%. A 100 bar a diferença é novamente de 3,6\% (cenário XV) contra 3,1\% (cenário V).Essa redução da destruição de exergia na turbina também contribuiu para o aumento da eficiência exergética global.

A exergia destruída no condensador foi de $1,0 \%$ a 20 bar e $1,1 \%$ a 100 bar. Embora sem apresentar diferença expressiva, esses resultados foram inferiores aos obtidos para o ciclo Convencional, de 1,1\% e 1,2\%, respectivamente. Esse balanço justifica o aumento da eficiência exergética do ciclo com Reaquecimento frente ao equivalente Convencional.

A contribuição percentual dos equipamentos auxiliares, na destruição de exergia ao longo do ciclo, seguiu a mesma tendência dos cenários de referência ficando assim, praticamente no mesmo patamar do ciclo convencional.

\subsubsection{Cenários XVI a XX: Ciclo com Reaquecimento e reaproveitamento da palha}

Nessa etapa é considerada a hipótese que $50 \%$ da palha gerada no campo é reaproveitada na caldeira e queimada junto com o bagaço. Mais uma vez aqui, os cenários $\mathrm{VI}$ a $\mathrm{X}$, que se referem ao ciclo Rankine Convencional com aproveitamento da palha, foram adotados como termos de comparação. Os resultados das simulações dos cenários $X V I$ a $X X$ em termos das eficiências energéticas e exergéticas são apresentados no Gráfico 5 . 


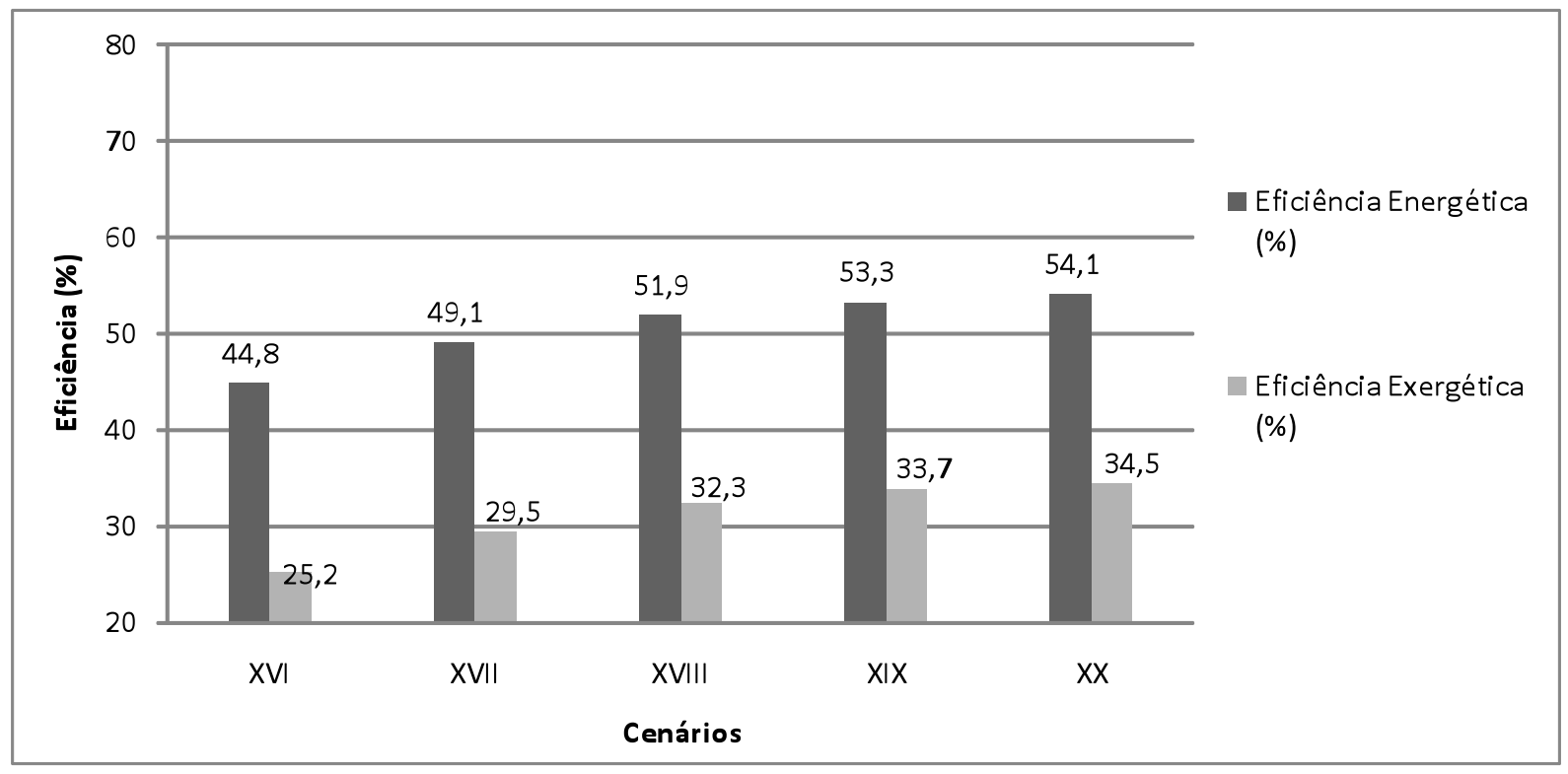

Gráfico 13 - Resultados da eficiência energética e exergética pra os cenários XVI a XX.

O Gráfico 13 mostra a mesma tendência de aumento das eficiências energéticas e exergéticas ciclo Rankine com Reaquecimento com o aumento da pressão, na hipótese onde é considerada a queima da palha. Em comparação com os resultados doacenários $\mathrm{VI}$ a $\mathrm{X}$ (Gráfico 5) o Reaquecimento trouxe aumento das eficiências energéticas e exergéticas em todas as condições de pressão na caldeira.

Nota-se que, da mesma forma como ocorreu para a condição sem aproveitamento da palha, os ganhos com Reaquecimento são maiores à medida que aumenta a pressão do vapor. A 20 bar, a eficiência energética do ciclo Convencional com uso palha foi de $44,1 \%$ enquanto para o ciclo com Reaquecimento esta atingiu $44,8 \%$; umaumento de 1,6\%. Para 100 bar a eficiência energética se elevou de $2,7 \%$ do cenário X para o cenário XX.

Em termos exergéticos, o ganho associado ao efeito do Reaquecimento do ciclo com uso de palha foi ainda maior se comparado com os mesmos cenários de referência. Verificaram-se nessas situações aumentos de $3,3 \%$ e $\quad 4,2 \%$ respectivamente para aspressões de 20 e 100 bar.

Os resultados dos indicadores de performance específicos para os cenários $\mathrm{XVI}$ a XX em termos de por tonelada de cana moída, são apresentados no Gráfico 14. 


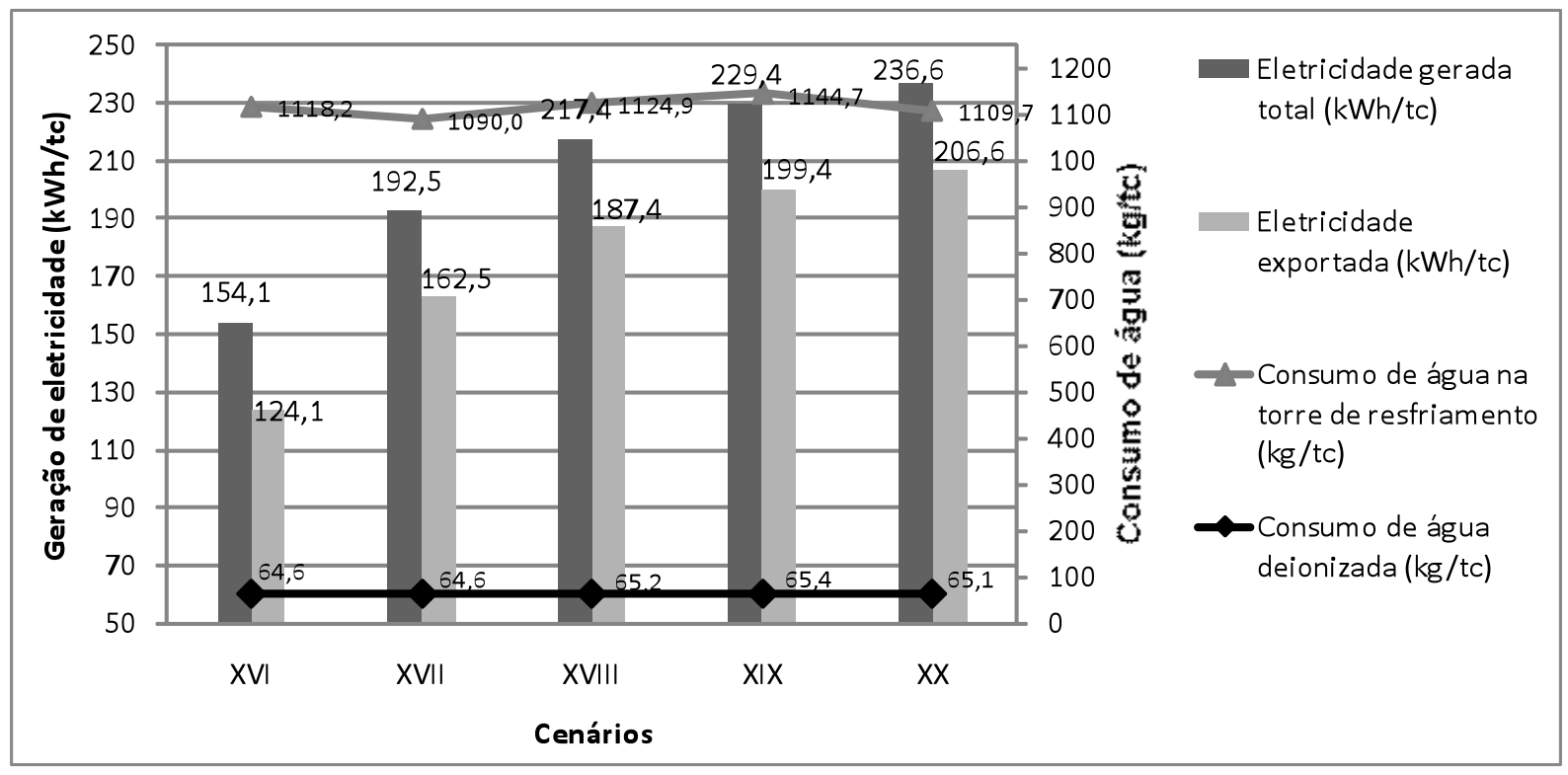

Gráfico 14 - Resultado dos indicadores de performance específicos, para os cenários XVI a XX.

Verifica-se nesse caso que a taxa de eletricidade exportada também se eleva com os acréscimos de pressão de vapor na saída da caldeira. Assim como no caso sem uso de palha o desempenho nesta situação foi superior aos do cenário Convencional. Na condição de pressão mais elevada (cenário XX) têm-se o melhor resultado, de 236,6 kWh/tc, em termos de geração de eletricidade, contra 224,3 $\mathrm{kWh} / \mathrm{tc}$ do Convencional (cenário $\mathrm{X}$ ), que em valores relativos compreende aumento de $5,5 \%$.

Os perfis de consumo de água na torre de resfriamento e água deionizada na caldeira apresentaram o mesmo comportamento do ciclo Rankine Convencional com uso da palha. Por exemplo, a 20 bar, no ciclo Convencional (cenário VI) o consumo de água na torre foi de $1145,4 \mathrm{~kg} / \mathrm{tc}$ e de água deionizada foi de $66,4 \mathrm{~kg} / \mathrm{tc}$, enquanto no ciclo com Reaquecimento (cenário XVI) esses índices foram de 1118,2 kg/tc e $64,6 \mathrm{~kg} / \mathrm{tc}$. Deduz-se portanto a conjuminação entre queima de palha $\mathrm{e}$ Reaquecimentotraz reduções de respectivamente $2,4 \%$ e 2,7\% nesse nível de operação. A 100 bar, houve decrescimos ainda maiores, de 4,6\% e 5,0\%, respectivamente.

Os resultados da análise energética são apresentados noGráfico 15. 


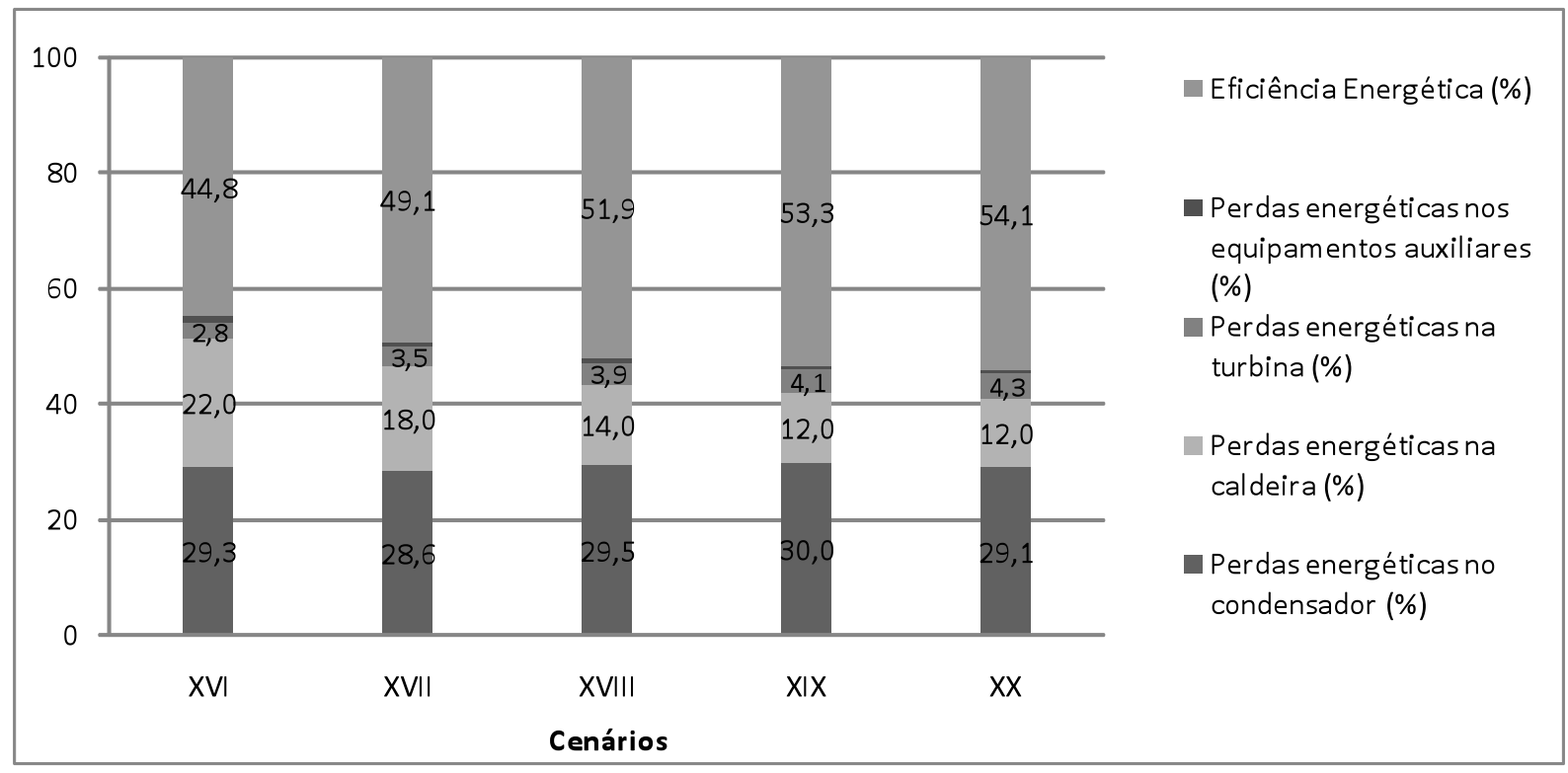

Gráfico 15 - Resultados da análise energética para os cenários XVI a XX.

A distribuição das perdas energéticas apresentada no Gráfico 15 segue a mesma tendência dos resultados apresentados nos cenários de referência $\mathrm{VI}$ a $\mathrm{X}$ (Ciclo Rankine Convencional com aproveitamento da palha). Adiferençaentre diagnósticos de Primeira Lei para os cenários com Reaquecimento e Convencional com queima da palha, está nas perdas energéticas no condensador. Enquanto as perdas energéticas no condensador representaram $30,1 \%$ no ciclo a 20 bar (cenário VI), naquele com Reaquecimento (cenário XVI) essas foram de 29,3\% - uma redução de 2,7\%. Na condição de 100 bar, as perdas energéticas no condensador, diminuíram de $4,6 \%$, quando se considera a possibilidade de Reaquecimento. A redução das perdas energéticas no condensador irá proporcionar menor consumo de água na torre.

As perdas energéticas na turbina aumentam de 2,8\% para 4,3\% quando a pressão de alimentação teórica da turbina aumentou de 20 bar para 100 bar. Em comparação com os cenários de referência $\mathrm{VI}$ a $\mathrm{X}$, foi verificado um aumento percentual discreto nesse indicador. As perdas energéticas nos equipamentos auxiliares estiveram abaixo de 1,2\% para todas as situações em análise, um perfil semelhante ao obtido para a condição de referência.

Os resultados obtidos à luz da Segunda Lei da Termodinâmica para os cenários XVI a XX são apresentados no Gráfico 16. 


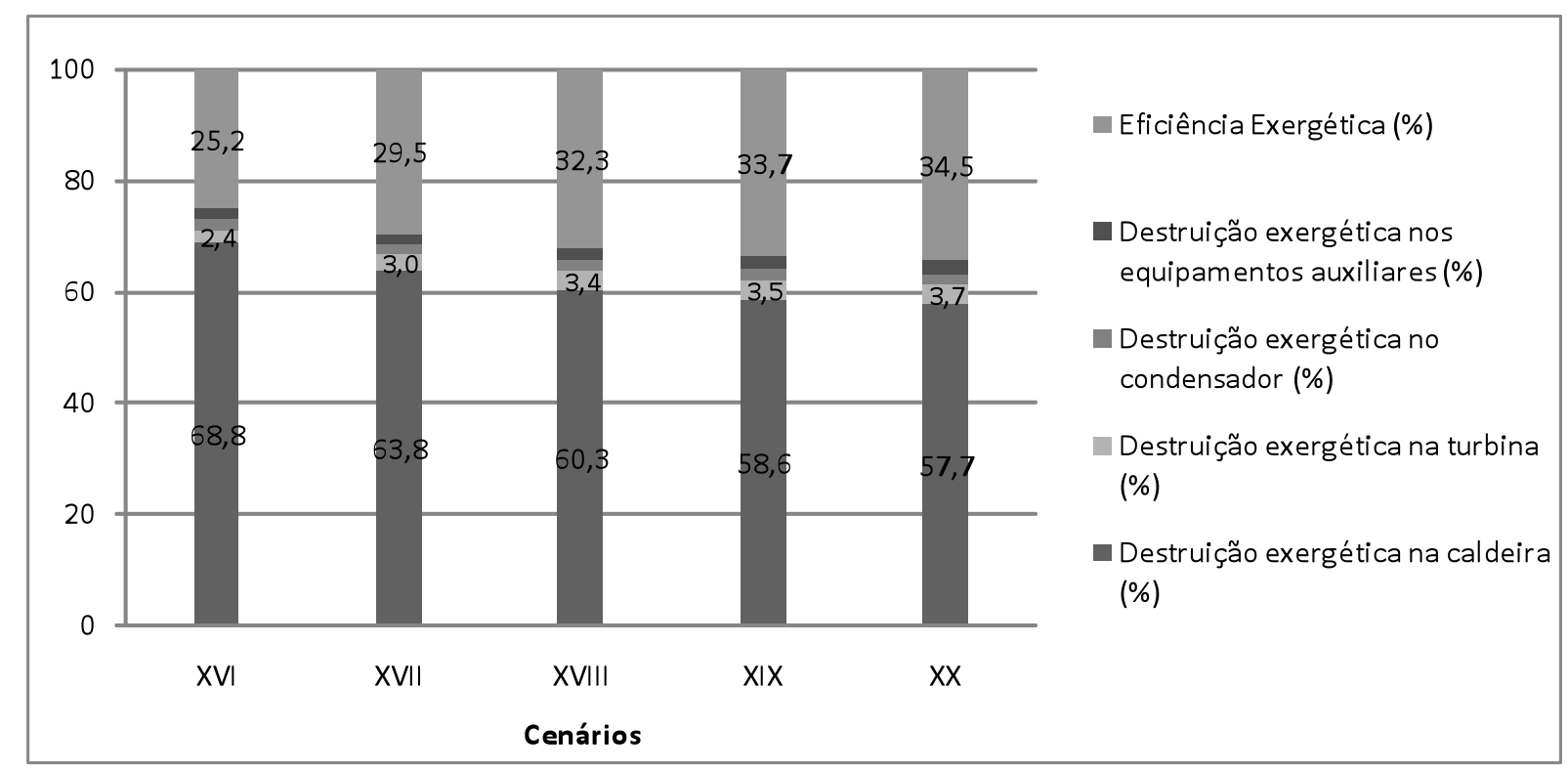

Gráfico 16 - Resultados da análise exergética para os cenários XVI a XX.

Pode-se verificar que o diagnóstico exergético dos cenários $X V I$ a $X X$, possui um perfil de distribuição da destruição de exergia semelhante ao projetado para os cenários de referência VI a $X$ (Ciclo Rankine Convencional com uso da palha). Novamente o elemento do ciclo responsável pela maior destruição exergética é a caldeira e com o aumento da pressão de trabalho de 20 para 100 bar, a destruição de exergia nesse equipamento caiu de $68,8 \%$ para $57,7 \%$.

Ao comparar os resultados do ciclo com Reaquecimento e o ciclo Convencional, verifica-se também redução na destruição de exergia na turbina. Enquanto no ciclo Convencional a 20 bar esta foi de $2,6 \%$, no ciclo com Reaquecimento perce-seligeira melhora,chegando a 2,4\%. A 100bar o decaimentofoi mais expressivo, passando de de $4,1 \%$ (cenário $X$ ) para $3,7 \%$ (cenário XX).

A exergia destruída no condensador foi da ordem de 1,9\% para todas as pressões, um resultadoligeiramente inferior ao obtido para o ciclo Convencional, de 2,0\% em ambas as condições de pressão. Nos equipamentos auxiliaresanalisados nesta etapa, a destruição de exergia seguiu a mesma tendência de aumento com a pressão verificada no ciclo Convencional. Os indices percentuais estiveram no mesmo patamaratingindo omáximo $2,1 \%$ a 100 bar. 


\subsubsection{Ciclo Rankine Regenerativo}

Conforme já reportado no Capítulo de Método, o ciclo Regenerativo definido para o sistema de cogeração possui três trocadores de calor. A interface do simulador de processos construído para representar o arranjo está indivada na Figura 37. A ampliação da Figura 37 com maior resolução está no Apêndice $C$.

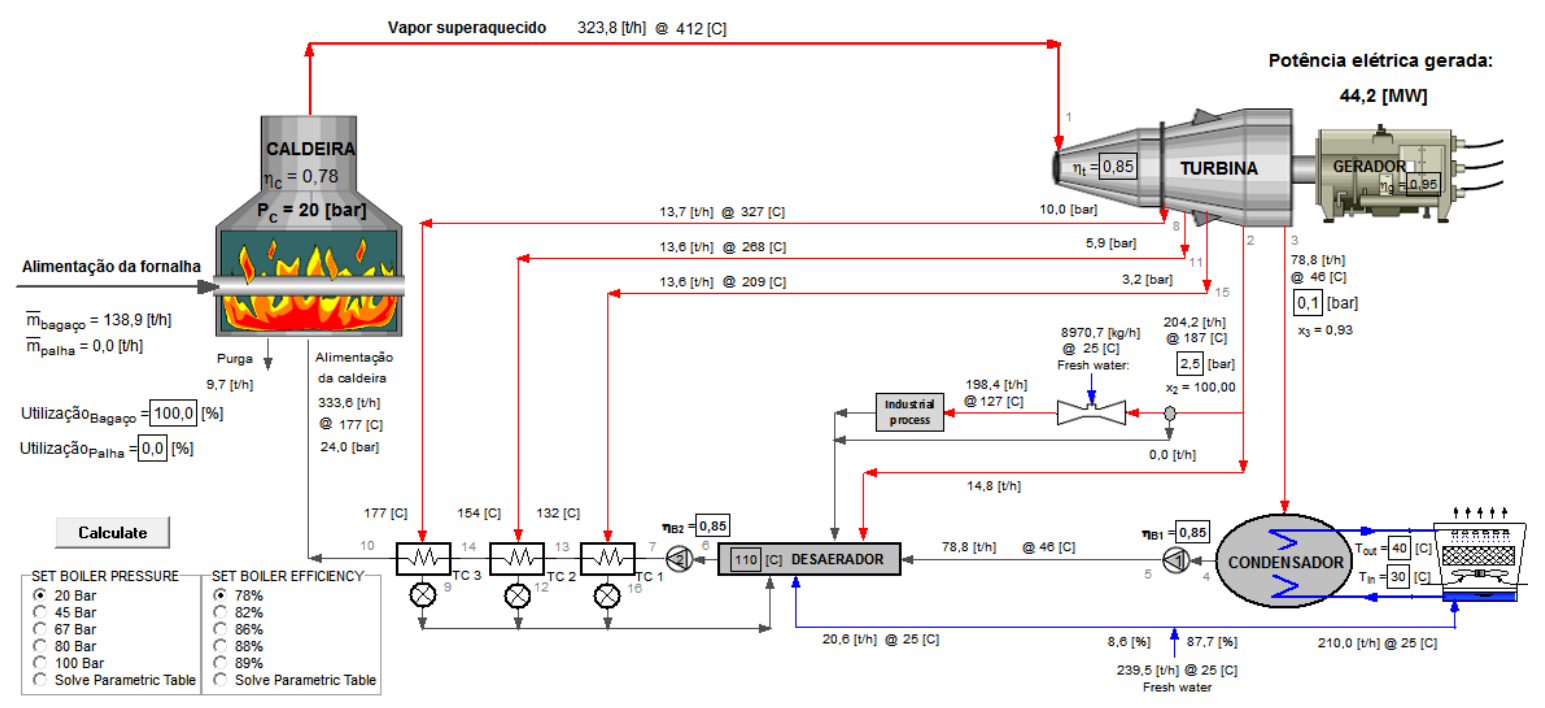

Figura 37 - Ciclo de vapor Regenerativo para uma planta de cogeração (Interface do simulador).

Omodelo possibilita a predição do comportamento termodinâmico dos cenários entre XXI a XXX apresentados na Tabela 3.

Tabela 3 - Características dos cenários de cogeração com ciclo Rankine Regenerativo.

\begin{tabular}{c|c|c|c}
\hline Cenários & Arranjo do Ciclo Rankine & $\begin{array}{c}\text { Uso da } \\
\text { palha }\end{array}$ & $\begin{array}{c}\text { Pressão e Temperatura } \\
\text { no gerador de vapor }\end{array}$ \\
\cline { 1 - 3 } Número & XXI & & 20 Bar e $412{ }^{\circ} \mathrm{C}$ \\
XXII & Ciclo Regenerativo & Não & 45 Bar e $457^{\circ} \mathrm{C}$ \\
XXIII & & & 67 Bar e $483^{\circ} \mathrm{C}$ \\
XXIV & & & 80 Bar e $495^{\circ} \mathrm{C}$ \\
XXV & & & 100 Bar e $511^{\circ} \mathrm{C}$ \\
\hline XXVI & & & 20 Bar e $412^{\circ} \mathrm{C}$ \\
XXVII & Sim & 45 Bar e $457^{\circ} \mathrm{C}$ \\
XXVIII & & & 67 Bar e $483^{\circ} \mathrm{C}$ \\
XXIX & & & 80 Bar e $495^{\circ} \mathrm{C}$ \\
XXX & & 100 Bar e $511^{\circ} \mathrm{C}$ \\
\hline
\end{tabular}

Como nos casos descritos antes, os resultados serão analisados em duas condições quanto ao aproveitamento da palha. 


\subsubsection{Cenários XXI a XXV: Ciclo Regenerativo sem aproveitamento da palha}

Para essa etapa da análise, fez-se a premissa de que a palha gerada na colheita da cana é deixada integralemente no campo. A título de manter a uniformidade da análise os cenários de I a V - ciclo Rankine Convencional sem aproveitamento da palha, foram adotados como referência para comparação dos resultados.Os resultados das simulações dos cenários XXI a XXVquanto as eficiências energéticas e exergéticas são apresentados no Gráfico 17.

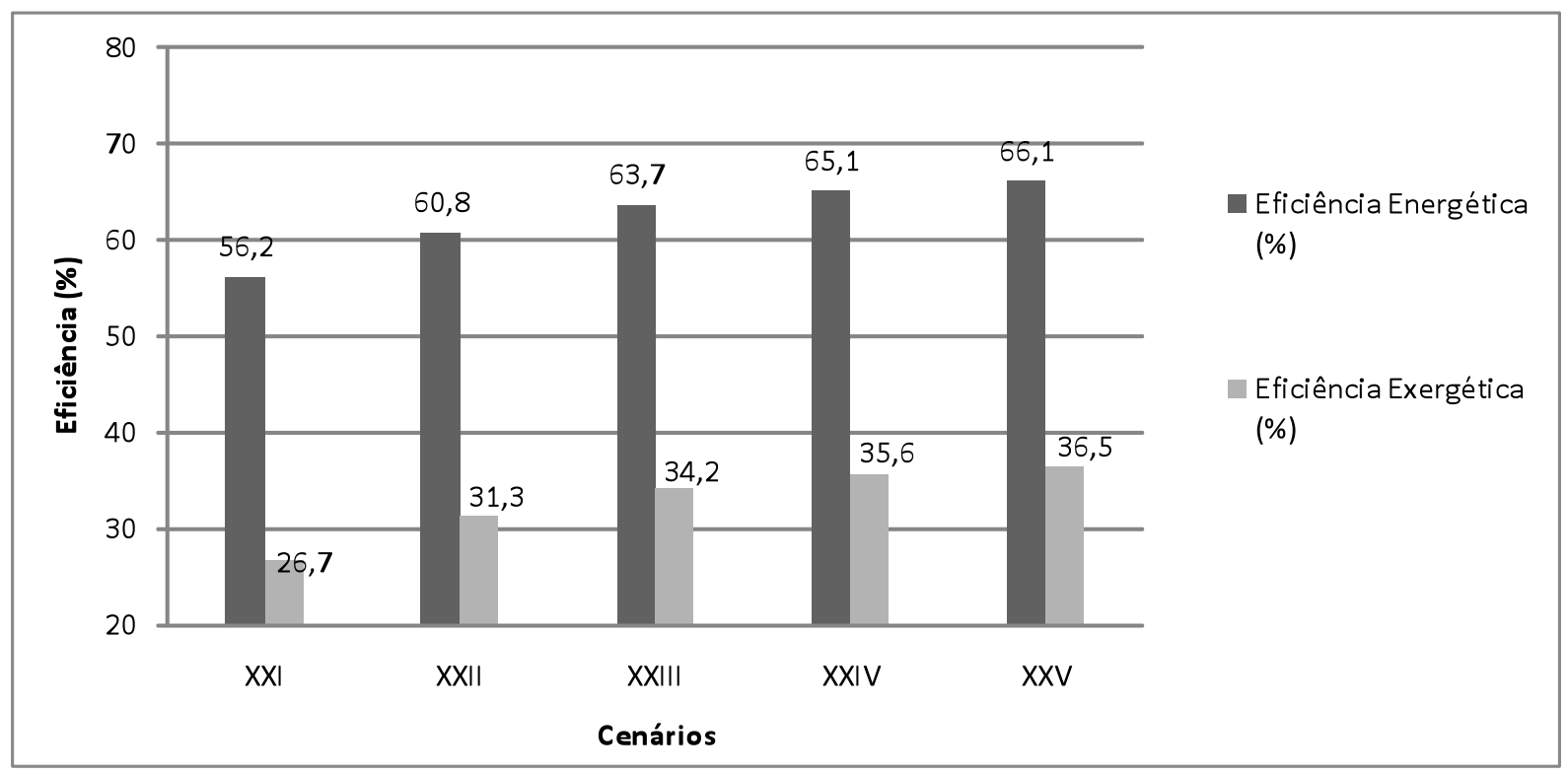

Gráfico 17 - Resultados da eficiência energética e exergética pra os cenários XXI a XXV.

Seguindo a mesma tendência do ciclo Rankine Convencional, o Gráfico 17 mostra que as que as eficiências energética e exergética do ciclo Regenerativo aumentam com a elevação da pressão. Ao comparar com os resultados do ciclo Convencional tendo em conta apenas o efeito da Regeneração, verificou-se que essa técnica de aumento de eficiência, bastantecomum em centrais termelétricas causouaumento das eficiências energéticas e exergéticas em todas as condições de pressão na caldeira.

Observou-se também que os ganhos com a Regeneração são maiores à medida que a pressão do vapor de saída da caldeira se eleva. A 20 bar a eficiência do ciclo Convencional foi de $55,6 \%$ e para o ciclo Regenerativo, de $56,2 \%$, o que corresponde a um aumento de 1,1\%. Esse desempenho idêntico ao obtido quando a confrotação ocorreu com o ciclo de Reaquecimento. 
A medida que a pressão da caldeira aumenta, os efeitos da Regeneração se destacam em relação ao deseus homólogos.Para 100 bar, a eficiência do ciclo Regenerativo superou a do Convencional em 2,8\%, ao passo que o Reaquecimento mostrou ganhos de $2,2 \%$ sobre a referência na mesma condição de trabalho.

Com vistas à Segunda Lei, o ganho associado ao efeito da Regeneração no ciclo foi ainda maior quando comparado com os cenários de referência ( $\mathrm{l}$ a $\mathrm{V})$. Verificaramse aumentos na eficiência exergética do ciclo,respectivamente de $2,3 \%$ e $4,9 \%$, paraas pressões de 20 e 100 bar.

Os resultados das simulações dos cenários $X X I$ a $X X V$ em termos dos indicadores de performance específicos- por tonelada de cana moída -constamdo Gráfico 18.

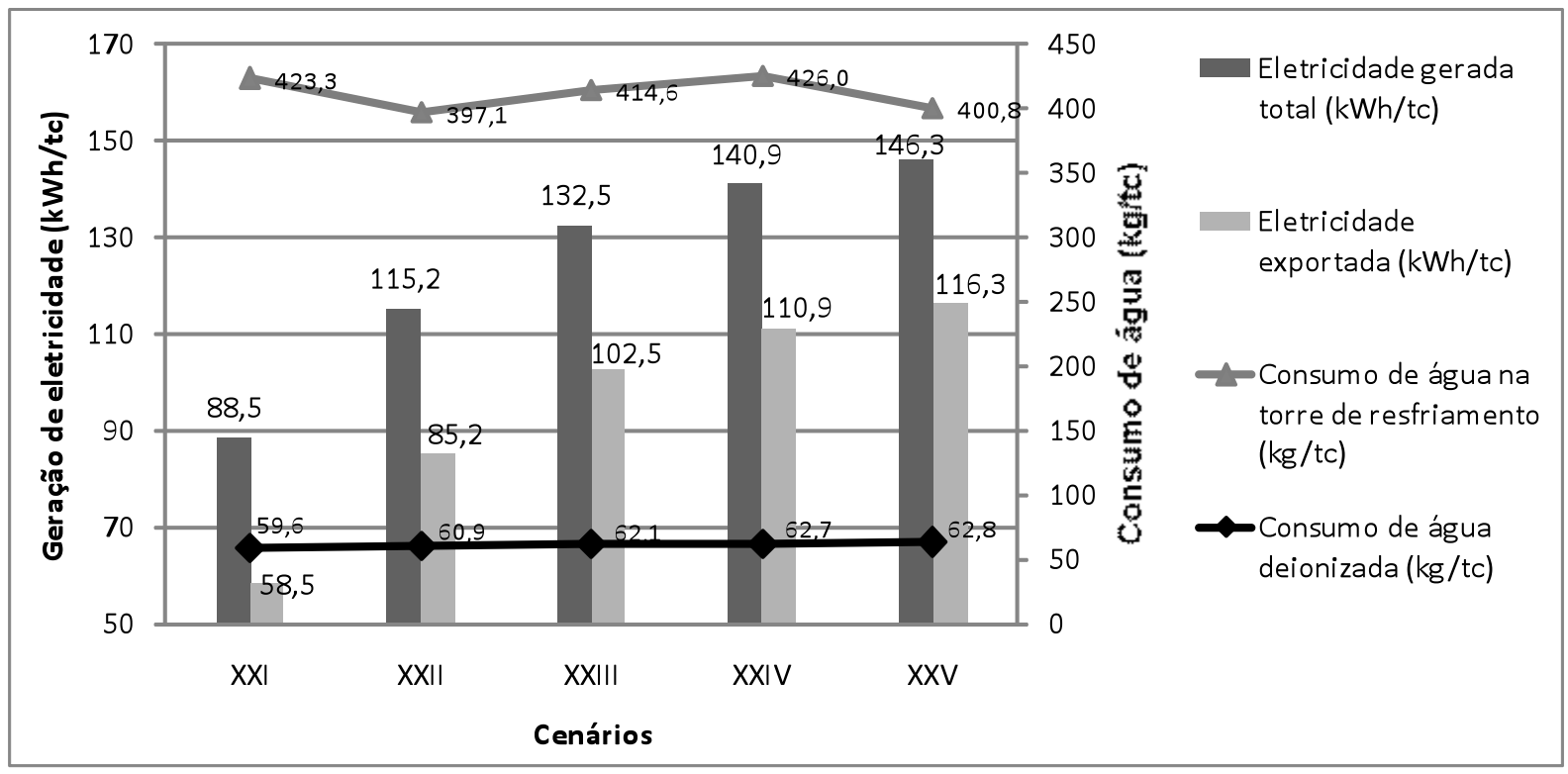

Gráfico 18 - Resultado dos indicadores de performance específicos, para os cenários XXI a XXV.

A análise desses resulatdosrevela mais uma vez que a taxa de eletricidade exportada aumenta à medida que a pressão de vapor na saída da caldeira se eleva. $\mathrm{Na}$ condição de pressão mais elevada (cenário XXI) obteve-se a maior geração de eletricidade - 146,3 kWh/tc - que correspondeu a um ganho de 7,4\% em comparação ao resultado do cenário V. Destacando-se inclusive, em relação ao ciclo com Reaquecimento, cujo aumento em relação ao ciclo Convencional foi de 5,7\%.

Para operação a 20 bar, a geração de eletricidade no ciclo Regenerativo chegou a $88,5 \mathrm{kWh} / \mathrm{tc}$ contra $84,9 \mathrm{kWh} / \mathrm{tc}$ do ciclo Convencional, um ganho de $4,2 \%$ que, aliás, se igualou àquele associado ao Reaquecimento. 
Em termos de consumos de águaos resultados também não denotaram tendências claras de variação com relação a elavação pressão de vapor na caldeira.Em relação aos cenários de referênciaa Regeneração ajudou a reduzir o consumo específico de água na torre de resfriamento. A redução se acentuou conforme a pressão de trabalho cresceu. A 20 bar, no ciclo Convencional (cenário I) o consumo de água na torre foi de $441,6 \mathrm{~kg} / \mathrm{tc}$, enquanto no ciclo Regenerativo (cenário XXI) este compreendeu 423,3 kg/tc, uma redução de 4,1\%. A 100 bar, a redução nos consumos da torre (cenário $V$ vs. XXV) correspondendo a $11,4 \%$.

Por outro lado, o consumo específico de água deionizada aumentou em relação aos cenários de referência. Esse aumento varia diretamente com o avanço da pressão de trabalho. A 20 baro ciclo Convencional consome $57,6 \mathrm{~kg} / \mathrm{tc}$ de água deionizada, ao passo que no ciclo Regenerativosão dispendidos $59,6 \mathrm{~kg} / \mathrm{tc}$ - umganho de $3,5 \%$. A 100 bar, o acrescimo de consumo de água deionizada chegou a $6,6 \%$.

Note-se que apesar do aumento no consumo específico de água deionizada no ciclo Regenerativo, o balanço global de água é positivo; Em outras palavras, o ciclo com Regeneração proporciona redução no consumo total de água em todas as condições de pressão estudadas, sendo que a 20 bar esta foi de $3,5 \%$ e a 100 bar,de $6,6 \%$. Vale ressaltar que o aquecimento da água de alimentação da caldeira através da regeneração, possibilita maior fluxo de água na caldeira, resultando assim num maior volume de purga e maior consumo de água deionizada de reposição.

Os resultados da análise clássica de Primeira Lei são apresentados no Gráfico 19.

Observa-se que a distribuição das perdas energéticas apresentada no Gráfico 19 segue a mesma tendência em termos de resultados que os cenários de I a V. De forma semelhante ao que foi identificado nos cenários com Reaquecimento, a diferença mais marcante ao se comparar em diagnósticos de Primeira Lei para os ciclos Convencional e Regenerativo está nas menores perdas energéticas que ocorrem no condensador para todos os cenários desta última alternativa. 


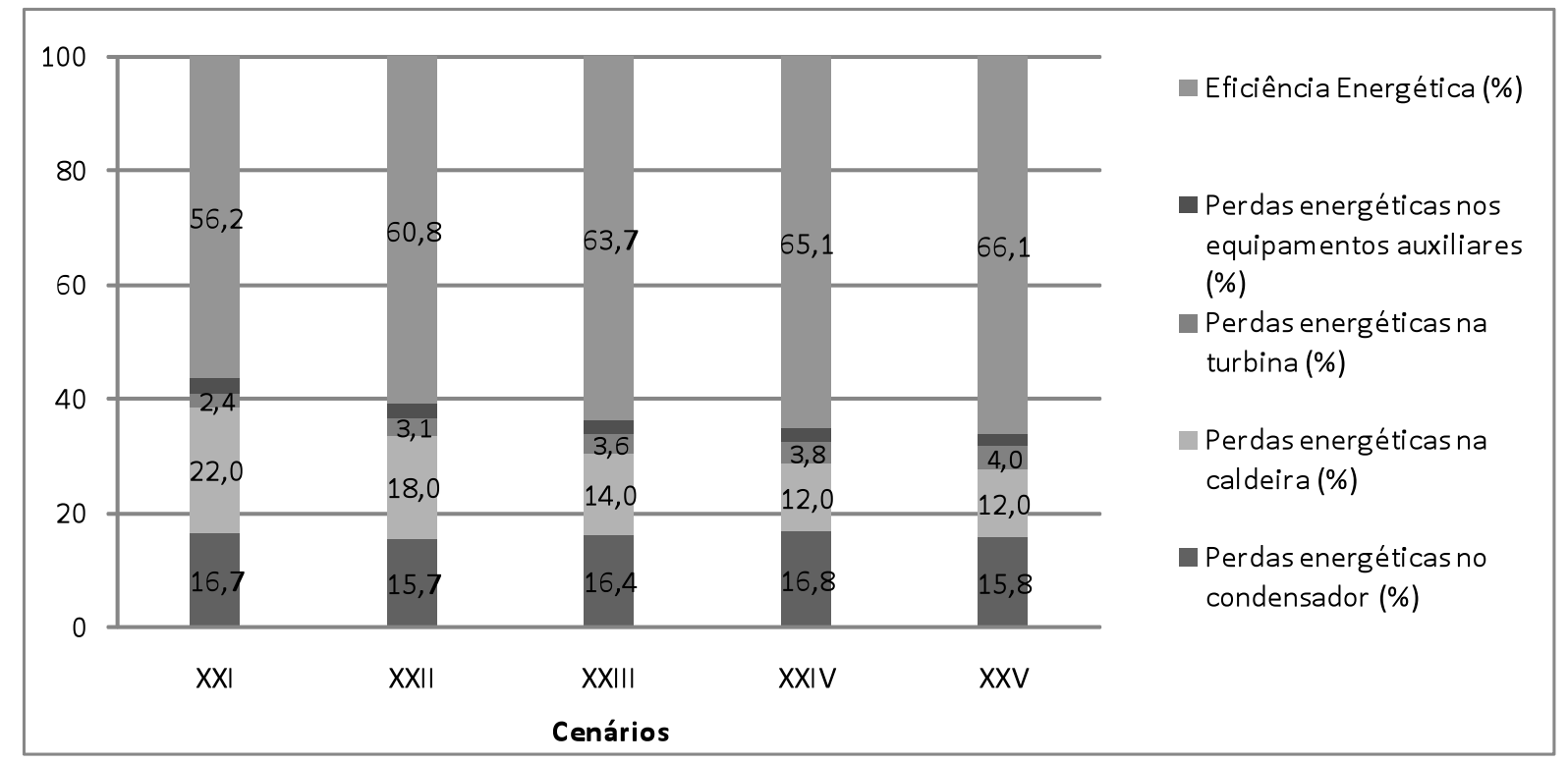

Gráfico 19 - Resultados da análise energética para os cenários XXI a XXV.

Enquanto tais perdas representaram $17,4 \%$ para o cenário I, no ciclo Regenerativo (cenário XXI) essas foram cerca de 4,0\% menores e na condição de 100 bar, notouse uma redução ainda maior, equivalente a $11,7 \%$. Esse resultado foi ainda maior que o obtido com a proposta de Reaquecimento, que na mesma avaliação apresentou uma redução de $7,8 \%$.

As perdas energéticas na turbina aumentam de $2,4 \%$ para $4,0 \%$ quando a pressão de alimentação teórica da turbina caminham de 20 bar para 100 bar. Em comparação com os cenários de referência I a $\mathrm{V}$, verifica-se um aumento nas perdas energéticas $4,3 \%$ e $2,6 \%$, respectivamente.

Finalmente, os resultados da análise de Primeira Lei mostraram não haver alterações significativas no percentual de perdas energéticas nos equipamentos auxiliares em relação aos cenários de referência.

O diagnóstico de desempenho exergético obtido a partir da aplicação da Segunda Lei da Termodinâmica para os cenários XXI a XXV aparece noGráfico 20. Pode-se verificar que o diagnóstico exergético dos cenários em questão, apresenta perfil de distribuição da destruição de exergia semelhante ao projetado para os cenários de referência I a V (Ciclo Rankine Convencional). 


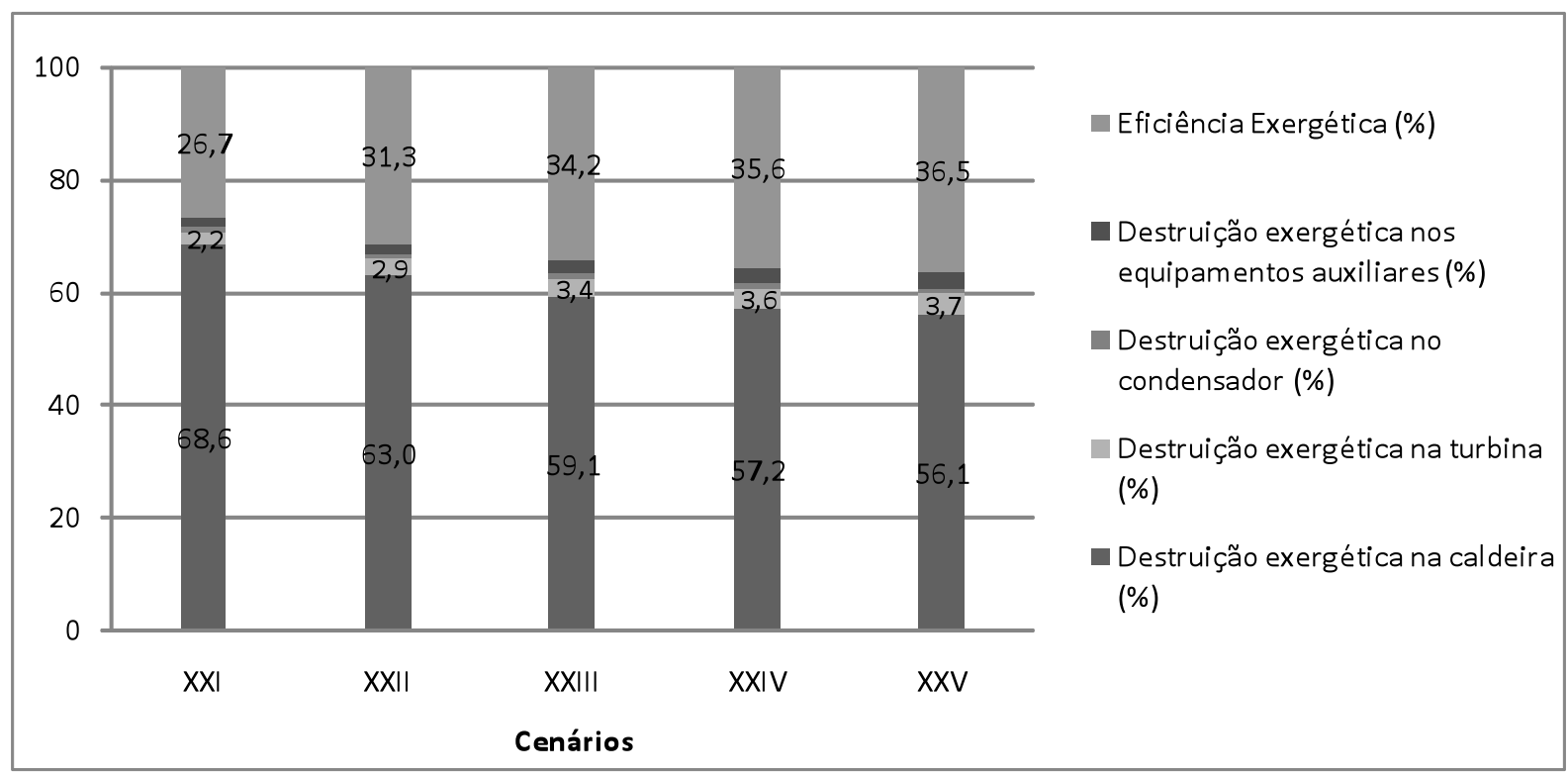

Gráfico 20 - Resultados da análise exergética para os cenários XXI a XXV

Assim sendo, o elemento responsável pela maior destruição exergética é a caldeira. Ao longo do aumento da pressão de trabalho a destruição de exergia no equipamento caiu de $68,6 \%$ para $56,1 \%$. Em todos os casos, a destruição de exergia foi inferior ao estimado pelo modelo dos cenários com ciclo Convencional na mesma condição de trabalho. Por exemplo, enquanto a destruição de exergia na caldeira foi de $69,6 \%$ no ciclo Convencional a 20 bar (cenário I), no ciclo Regenerativo (cenário XXI) a destruição foi de $68,6 \%$, que representa uma redução de $1,4 \%$. Na condição de 100 bar, a proposta de Regeneração proporcionou uma redução maior na destruição de exergia na caldeira em relação ao ciclo Convencional, sendo 56,1\% do ciclo Regenerativo contra $58,8 \%$ do ciclo Convencional, umaredução de 4,6\%.

Com relação à destruição de exergia na turbina, em todas as condições de operação estudadas houve aumento discreto em relação ao ciclo Convencional. No condenadoresta foi de $1,1 \%$ a 20 bar e $1,0 \%$ a 100 bar. Tal como no ciclo com Reaquecimento, o Regenerativo, mostrou ganhos de desempenho quanto à destruição de exergia com relação aos resultados obtidos para o ciclo Convencional. Nos equipamentos auxiliares seguiu-se a mesma tendência observada nos cenários de referência: o aumento da pressão de trabalho resultou elevação das perdas exergéticas. No entanto, as contribuições desses equipamentos foram maiores em todas as condições de pressão. Para 20 bar, a destruição de exergia no ciclo Convencional foi de $1,1 \%$, e no ciclo Regenerativo, de 1,4\%. A 100 bar, esta saltou de $1,6 \%$ no ciclo Convencional para $2,7 \%$ no Regenerativo. 
A diferença está associada à destruição de exergia nos trocadores de calor do ciclo Regenerativo. Mesmo desprezando perdas energéticas para o ambiente para efeito de modelagem dessas unidadesobserva-se um aumento de entropia associado à transferência de energia entre a corrente quente e a corrente fria. Note-se que tal discrepância não pode ser identificada pela análise clássica de Primeira Lei.

O saldo geral do balanço exergético para a proposta de Regeneração foi positivo, ou seja, a eficiência exergética do ciclo Rankine para o sistema de cogeração aumentou com a adoção dessa técnica.

\subsubsection{Cenários XXVI a XXX: Ciclo Regenerativo com aproveitamento da palha}

Nessa etapa volta-se a considerar a hipótese de que $50 \%$ da palha gerada no campo é queimada junto com o bagaço na caldeira. Os cenários $\mathrm{VI}$ a $\mathrm{X}$, que se referem ao ciclo Rankine Convencional com aproveitamento da palha, passam a ser adotados como referência para comparação dos resultados. Os resultados das simulações dos cenários $X X V I$ a $X X X$ em termos das eficiências energéticas e exergéticas são apresentados no Gráfico 21.

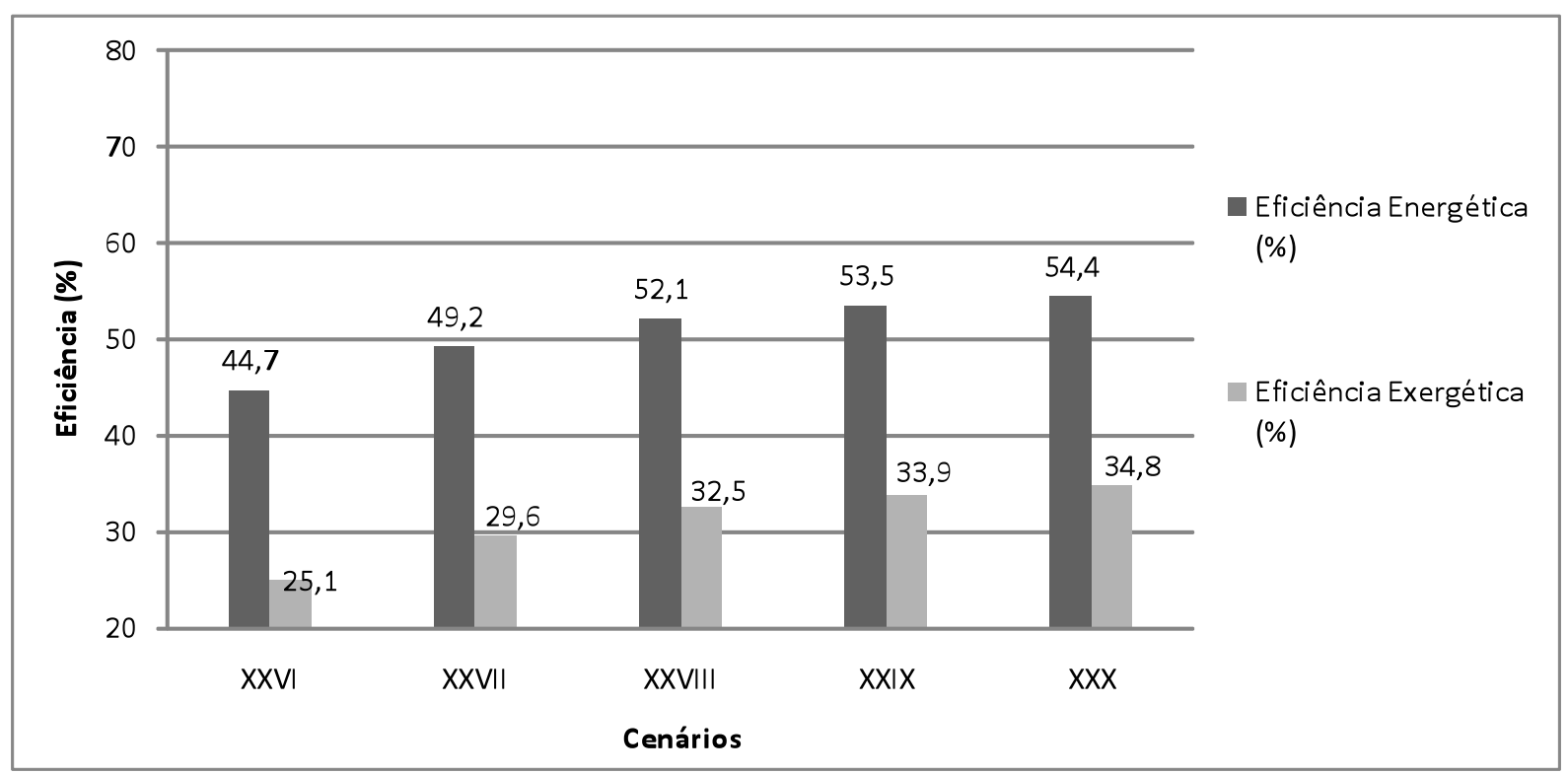

Gráfico 21 - Resultados da eficiência energética e exergética pra os cenários XXVI a XXX. 
O Gráfico 21 mostra que mesmo considerando o aproveitamento da palha como fonte de energia térmica na caldeira, as eficiências energéticas e exergéticas ciclo Rankine Regenerativo aumentam com o aumento da pressão, como já se poderia supor a partir dos resultados obtidos anteriormente. Em comparação ao ciclo Rankine Convencional com queima da palha (cenários VI a X), a Regeneração proporcionou aumento das eficiências energéticas e exergéticas em todas as condições de pressão na caldeira. Verificou-se também que os ganhos com a Regeneração são maiores à medida que a pressão da caldeira se eleva, mesma tendência identificada no Reaquecimento.

Assim, a 20 bar, a eficiência energética do ciclo Convencional com uso palha foi de $44,1 \%$ e ado ciclo Regenerativo, exatos $1,4 \%$ maior. À pressão de $100 \mathrm{bar}$, a eficiência energética do ciclo Convencional com uso palha foi de $52,7 \%$ enquanto para o ciclo Regenerativo atingiu-se $54,4 \%$ o que representou um aumento de $3,2 \%$.

À luz da Segunda Lei, o ganho associado ao efeito da Regeneração com uso de palha foi ainda maior se comparadosaos cenários de referência. Verificaram-se aumentos de $2,9 \%$ e 5,1\% nas eficiências exergéticas do ciclo, para pressões de 20 e 100 bar. O resultado para do ciclo Regenerativo a 100 bar foi melhor do que aquele obtido com o Reaquecimento, de ganho de $4,2 \%$ na eficiência exergética frente ao Convencional.

Os resultados dos indicadores de desempenho por tonelada de cana moída são apresentados no Gráfico 22. 


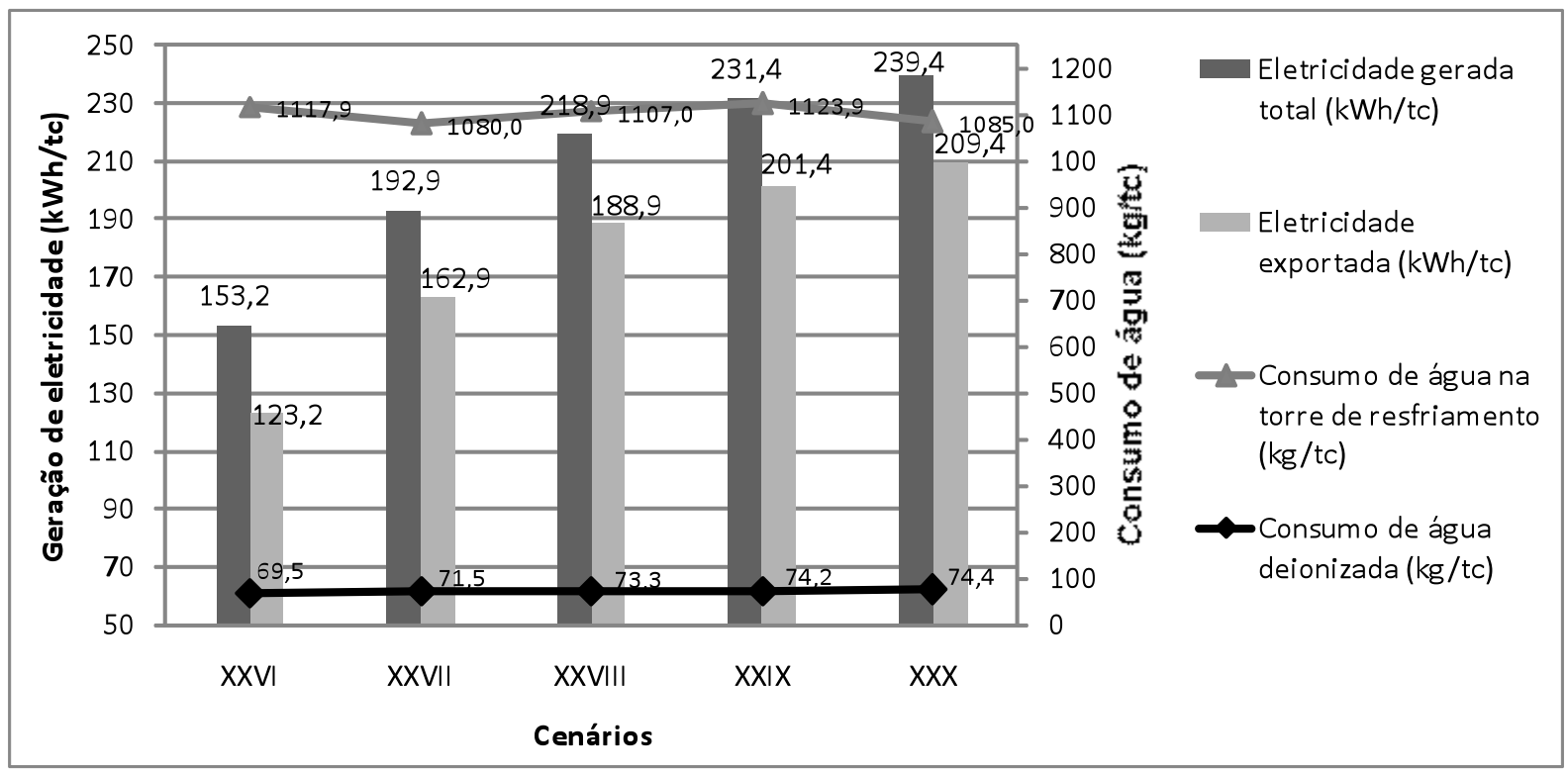

Gráfico 22 - Resultado dos indicadores de performance específicos, para os cenários XXVI a XXX.

Verificou-se a partir da análise do Gráfico 22 a mesma tendência para geração de eletricidade, de aumento à medida que a pressão de vapor na saída da caldeira se eleva. Como esperado, na condição de pressão de vapor mais elevada (cenário XXX) obteve-se uma geração de eletricidade de 239,4 kWh/tc, da ordem de 6,7\% maior que aquela observada para o cenário $X$, homólogo do ciclo Convencional. $\mathrm{Na}$ condição de operação de 20 bar, a geração de eletricidade foi de 153,2 kWh/tc contra 147,7 kWh/tc do ciclo Convencional nas mesmas condições, representando um aumento de $3,7 \%$.

Observa-se que o ganho potencial em termos de produção específica de eletricidade quando se trabalha com pressões mais baixas é para o ciclo com Reaquecimento do que com ciclo Regenerativo. Tanto isso é assim que o Reaquecimento a 20 bar gerou ganhos de $4,3 \%$ contra $3,7 \%$ do Regenerativo. Contudo essa situação se inverte com pressões mais elevadas, caso em que as simulações mostraram desempenho melhor da técnica de Regeração sobre a técnica de Reaquecimento. Isso se confirmou em ambas hipóteses de aproveitamento ou não da palha.

Tal como ocorreupara os cenários do ciclo Regenerativo sem usodepalha, os consumos de água na torre e na caldeira não mostraramnesta situação uma tendência de variação com o aumento da pressão de vapor na caldeira.

Em relação aos cenários $\mathrm{VI}$ a $\mathrm{X}$, houve redução do consumo específico de água na torre de resfriamento, associados à Regeneração, a qual se intensificou à medida 
que a pressão de trabalho aumentou. Tanto isso é assim que para o cenário $\mathrm{VI}-20$ bar e ciclo Convencional com uso da palha - água foi consumida na torre à razão de $1145,4 \mathrm{~kg} / \mathrm{tc}$, enquanto no cenário XXVI - para operação do ciclo Regenerativo em condições equivalentes - o make-up na torre foi de $1117,9 \mathrm{~kg} / \mathrm{tc}$. Já para 100 bar, a redução no consumo de água na torre alcançou ganhos de $6,7 \%$.

Por outro lado, o consumo específico de água deionizada aumentou em relação aos cenários de referência, principalmente, à medida que cresceu a pressão de trabalho. $\mathrm{O}$ caso para 20 bar é emblemático. Enquanto no ciclo Convencional com uso depalha o consumo de água deionizada foi de $66,4 \mathrm{~kg} / \mathrm{tc}$, no ciclo Regenerativo este indicador revelou dispêndios de 69,5 kg/tc, representando um aumento de 4,7\%. Para 100 bar, o aumento no consumo de água deionizada chegou a 8,6\%, superior inclusive àqueleatribuído a Regeneração sem uso da palha, que foi de $6,6 \%$. Isso ocorre pois com mais energia térmica fornecida na caldeira via queima de combustível e transferida para o fluido de trabalho é possível recircular maiores volumesdentro do ciclo; consequentemente as perdas de condensado associadas a purga na caldeira serão maiores, predispondo assim, demais água de reposição.

Apesar do aumento do consumo específico de água deionizada no ciclo Regenerativo com aproveitamento da palha, o balanço global de água foi mais uma vez positivo, com a Regeneração proporcionando uma redução no consumo total de água em todas as condições de pressão estudadas.

Os resultados da análise energética são apresentados no Gráfico 23. 


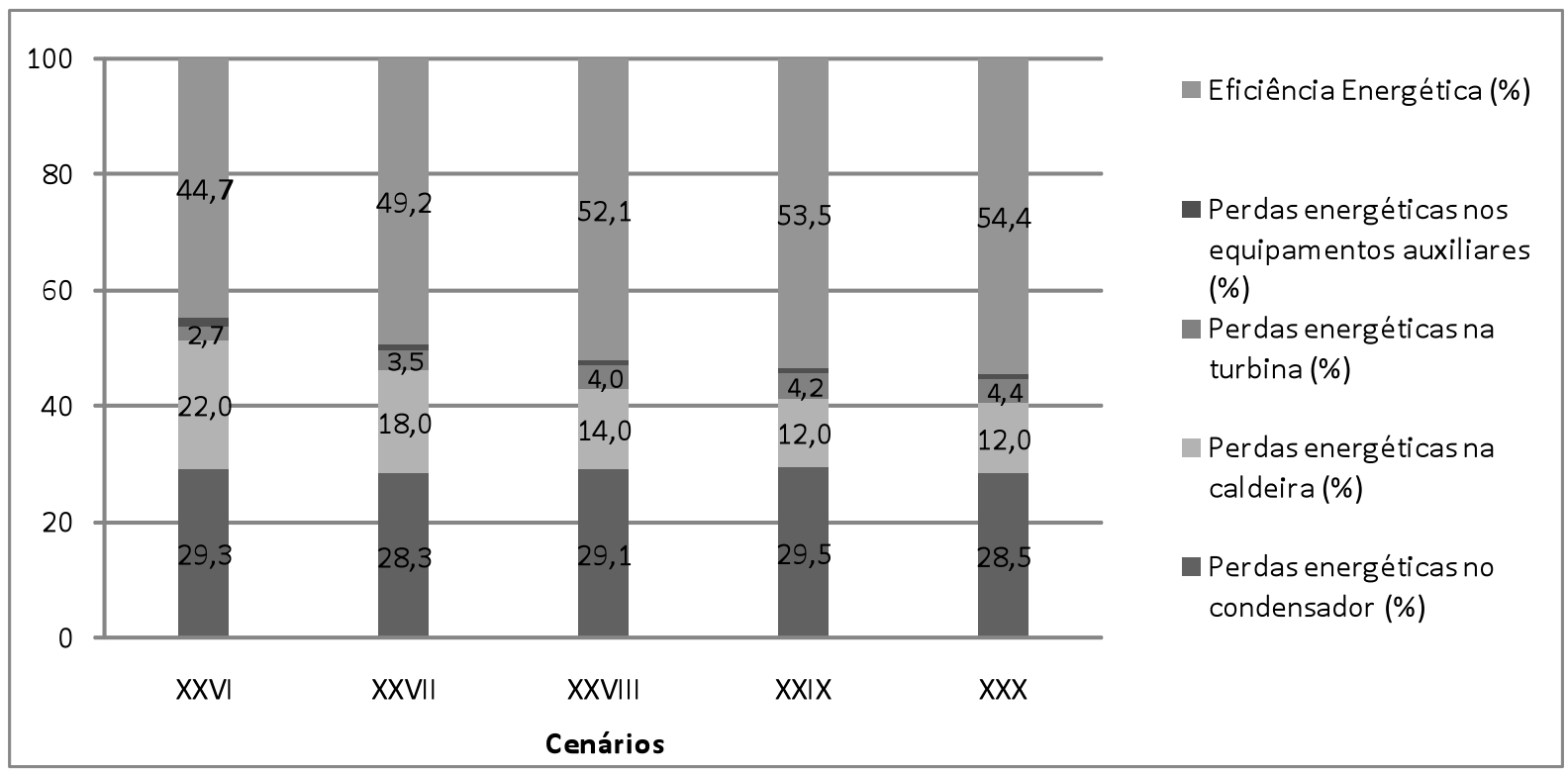

Gráfico 23 - Resultados da análise energética para os cenários XXVI a XXX.

A distribuição das perdas energéticas apresentada no Gráfico 23 seguiu a mesma tendência dos resultados identificados para os cenários $\mathrm{VI}$ a X.

Novamente, a principal diferença encontrada quando se comparamdiagnósticos de Primeira Lei dos cenários Regenerativo e Convencional, reside nas menores perdas energéticas no condensador. Enquanto no cenário $\mathrm{VI}$ as perdas no condensador são de $30,1 \%$, no ciclo Regenerativo (cenário XXVI) essas vão a $29,3 \%$, o que associa uma redução de $2,7 \%$. Para a condição de 100 bar, o condensador que consta do sistema Regenerativo aporta perdas de $28,5 \%$ (cenário XXX), revelando assim uma redução de $6,6 \%$.

As perdas energéticas na turbina aumentam de $2,7 \%$ para $4,4 \%$ quando a pressão de alimentação do vapor superaquecido se propaga de 20 bar para 100 bar. Para os cenários VI a X, estes valores chegam a $2,6 \%$ e $4,1 \%$, respectivamente. Esse aumento das perdas energéticas na turbina associado à Regeneração ocorre devido maior vazão mássica de vapor escoando através dos estágios da turbina para gerar maior potência elétrica. As perdas energéticas nos equipamentos auxiliares se mantiveramnos mesmos níveis dos cenários de referência.

Os resultados obtidos à luz da Segunda Lei da Termodinâmica para os cenários XXVI a XXX são apresentados no Gráfico 24. 


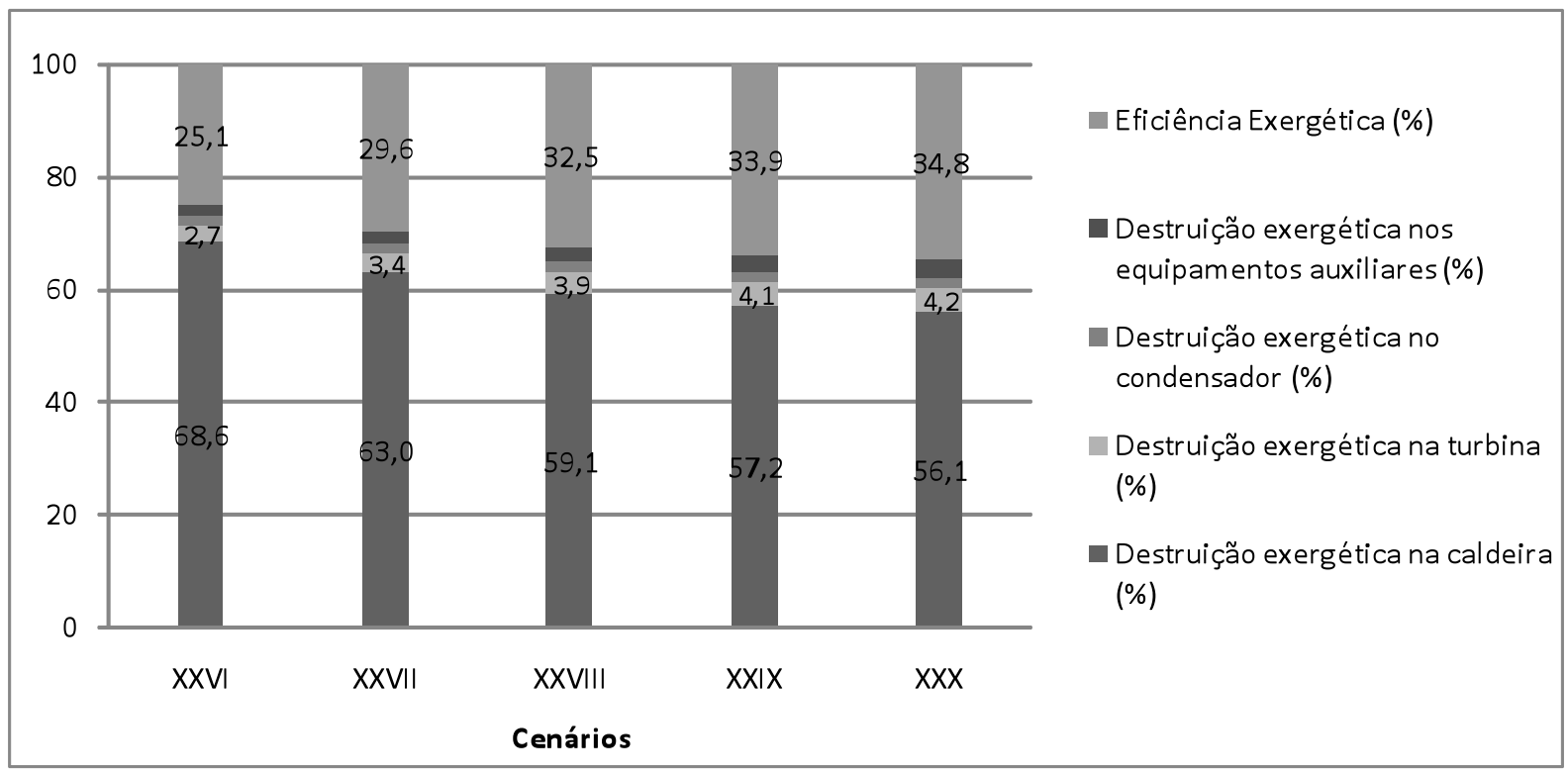

Gráfico 24 - Resultados da análise exergética para os cenários XXVI a XXX.

O perfil de distribuição da destruição de exergia apresentado no Gráfico 24 se assemelha ao projetado para os cenários $\mathrm{VI}$ a X.A caldeira proporcionou outra vez maior destruição exergética. Com o aumento concomitante da pressão de trabalho para 100 bar, a destruição de exergia nesse equipamento caiu de $68,6 \%$ para $56,1 \%$ sendo, inferior ao desempenho estimado pelo modelo para o ciclo Convencional na mesma condição de trabalho.

Ao comparar os resultados do ciclo Regenerativo com o ciclo Convencional, notouseum aumento generalizado na destruição de exergia na turbina, contrariando inclusive o que foi observado para o ciclo com Reaquecimento. Enquanto no ciclo Convencional a 20 bar a destruição de exergia na turbina foi de 2,6\%, no Regenerativo esta foi de 2,7\%. Para uma pressão de 100 bar, também houve aumento; enquanto no ciclo Convencional a destruição de exergia na turbina foi de $4,1 \%$, no ciclo Regenerativo foi de $4,2 \%$.

A exergia destruída no condensador para o ciclo Convencional se comportou de forma bastante semelhante àquela observada para o ciclo com Reaquecimento.

Nos equipamentos auxiliares, a destruição de exergia seguiu a mesma tendência de aumento com o aumento da pressão observada nos cenários de referência. Não obstante, as contribuições desses equipamentos foram maiores em todas as condições de pressão, de forma análoga a que foi verificada nos cenários com ciclo Regenerativo sem aproveitamento da palha. 
Considerando-se o uso da palha e pressão do vaporde 20 bar, a destruição de exergia no ciclo Convencionalfoi de 1,4\%, e no ciclo Regenerativo, de 1,7\%. A 100 bar, a destruição de exergia no ciclo Convencional foi de $2,0 \%$, e no ciclo Regenerativo, de 3,0\%. Essa diferença está associada à destruição de exergia nos trocadores de calor do ciclo Regenerativo, conforme discutido anteriormente.

Da mesma forma que observado nos cenários com ciclo Regenerativo em que não há aproveitamento da palha (cenários $X X$ a $X X V$ ), o saldo geral do balanço exergético para a proposta de Regeneração com uso da palha também foi positivo, ou seja, a eficiência exergética do ciclo Rankine para o sistema de cogeração aumentou com a adoção dessa técnica.

\subsubsection{Ciclo Rankine Resultante}

Assim como já foi descrito em outro momento do texto, a proposta de ciclo Rankine Resultante consiste de combinar as técnicas de Reaquecimento e Regeneração em um único ciclo, com o objetivo de potencializar a eficiência termodinâmica do sistema de cogeração e, consequentemente aumentar a capacidade de geração de energia térmica e elétrica.

A interface do simulador de processos que foi construído para representar o ciclo Rankine Resultante é apresentada na Figura 38. A ampliação da Figura 38 com maior resolução está no anexo D. 


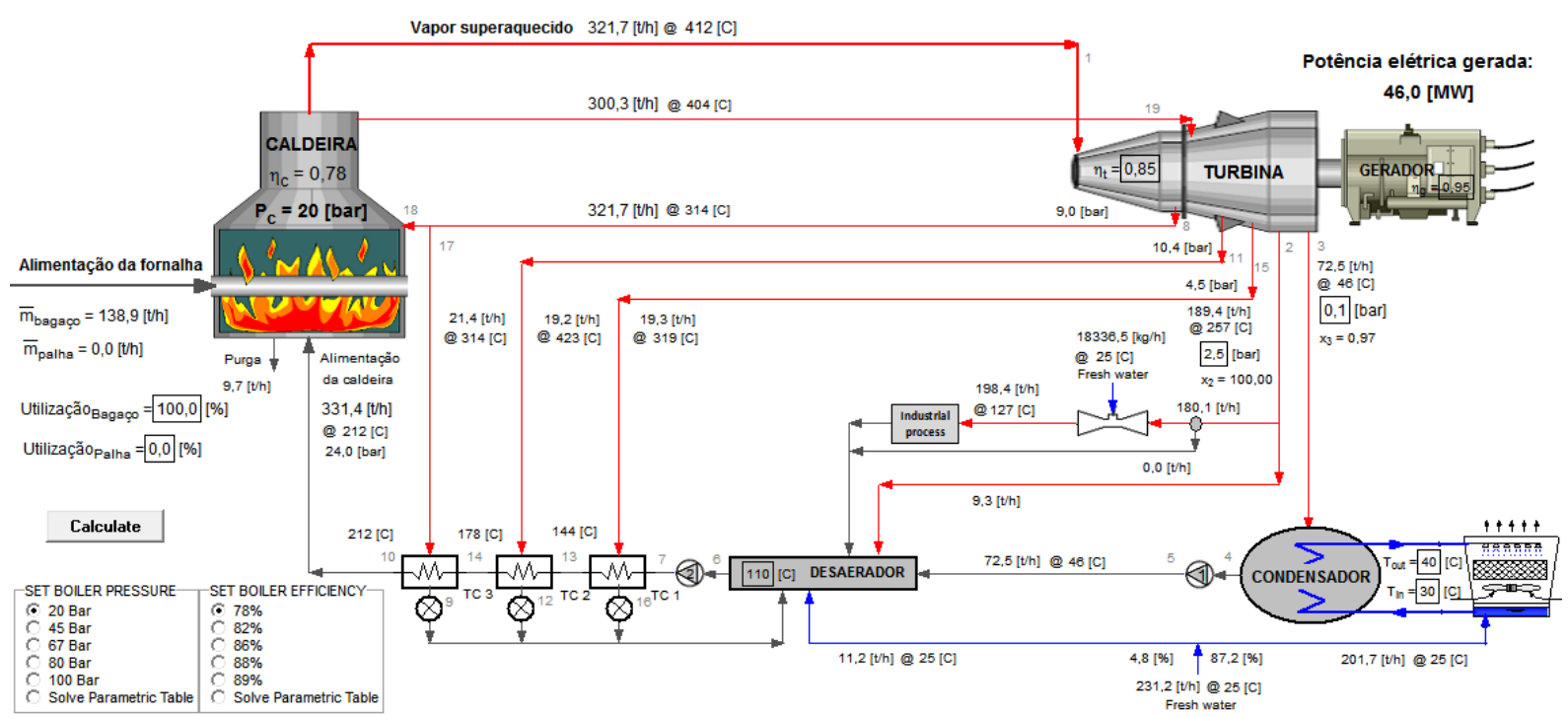

Figura 38 - Ciclo de vapor Resultante para uma planta de cogeração (Interface do simulador).

Esse simulador possibilita a predição do comportamento dos cenários de XXXI a XL apresentados a seguir na Tabela 4.

Tabela 4 - Características dos cenários de cogeração com ciclo Rankine Resultante.

\begin{tabular}{c|c|c|c}
\hline Cenários & Arranjo do Ciclo Rankine & $\begin{array}{c}\text { Uso da } \\
\text { palha }\end{array}$ & $\begin{array}{c}\text { Pressão e Temperatura } \\
\text { no gerador de vapor }\end{array}$ \\
\hline Número & & & 20 Bar e $412^{\circ} \mathrm{C}$ \\
XXXI & & Não & 45 Bar e $457^{\circ} \mathrm{C}$ \\
XXXII & Ciclo Resultante: Regenerativo com & & 67 Bar e $483^{\circ} \mathrm{C}$ \\
XXXIII & Reaquecimento & 80 Bar e $495^{\circ} \mathrm{C}$ \\
XXXIV & & & 100 Bar e $511^{\circ} \mathrm{C}$ \\
XXXV & & & 20 Bar e $412^{\circ} \mathrm{C}$ \\
\hline XXXVI & & Sim & 65 Bar e $457^{\circ} \mathrm{C}$ \\
XXXVII & & & 67 Bar e $483^{\circ} \mathrm{C}$ \\
XXXVIII & & 80 Bar e $495^{\circ} \mathrm{C}$ \\
XXXIX & & & 100 Bar e $511^{\circ} \mathrm{C}$ \\
XL & &
\end{tabular}

A fim de manter o mesmo padrão de análise dispensado aos cenários anteriores, os resultados obtidos para o ciclo Resultante a partir das simulações feitas no EES serão analisados considerando-se ausência e aproveitamento plenos da palha. 


\subsubsection{Cenários XXXI a XXXV: Ciclo Resultante sem aproveitamento da palha}

Novamente qui, os cenários I a V, que se referem ao ciclo Rankine Convencional sem aproveitamento da palha, foram adotados termos de referência para comparação dos resultados. No que se refere as eficiências energéticas e exergéticas - apresentadas a seguir no Gráfico 25 - estes serão confrontados com os cenários de XXXI a XXXV.

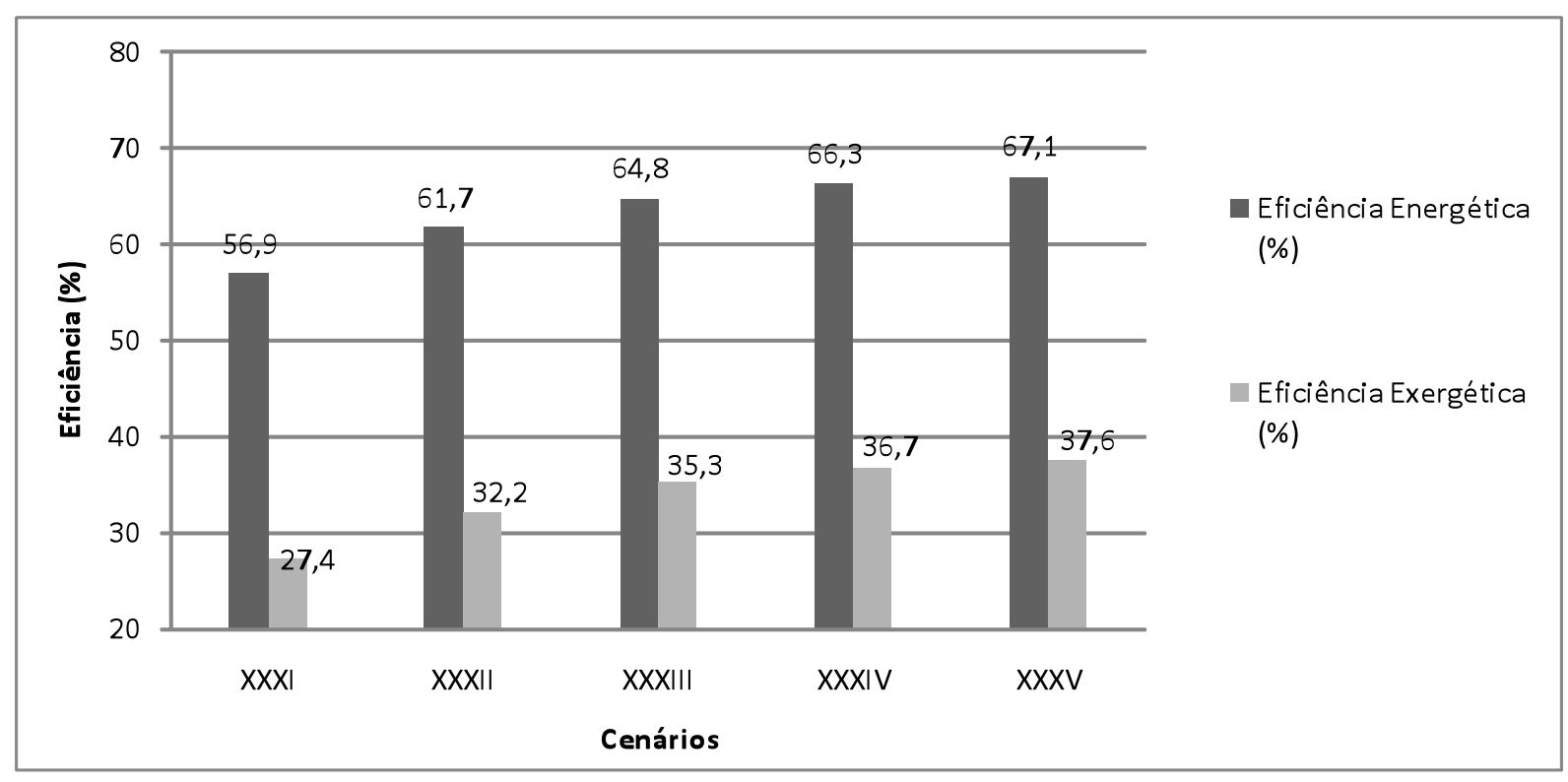

Gráfico 25 - Resultados da eficiência energética e exergética pra os cenários XXXI a XXXV.

Os resultados confirmaram a expectativade que as eficiências energética e exergética do ciclo Resultante seguema tendência enunciada para o ciclo Convencional; ou seja, estas aumentam com o aumento da pressão. Ao avaliar apenas os efeitos decorrentes da combinação entre Regeneração e Reaquecimentopercebe-se ser este o melhor resultado em termos desses parâmetros, entre todas as condições operacionais.

A eficiência energética do ciclo Resultante a 20 bar foi de $56,9 \%$, que representa um aumento de $2,3 \%$ em relação ao cenário I. À medida que aumenta a pressão do vapor que deixa a caldeira os efeitos da combinação entre Regeneração e Reaquecimento se destacam ainda mais até atingirem o patamar de $67,1 \%$ a 100 bar, que se traduz ganho de $4,4 \%$ em relação ao do ciclo Convencional (cenário V). Observe-se que este vapor supera os benefícios individualizados da 
Regeneração e do Reaquecimento, que para mesma condição de trabalho, alcançaram $2,8 \%$ e $2,2 \%$, respectivamente.

Verificaram-se aumentos de 5,0\% e 8,0\% nas eficiências exergéticas do sistema com a implantação do ciclo Resultante, quando da comparação deste com os cenários de referência parapressões de 20 e 100 bar, respectivamente.

Os resultados das simulações dos cenários $X X X I$ a $X X X V$ em termos dos indicadores de performance específicos, são apresentados noGráfico 26.

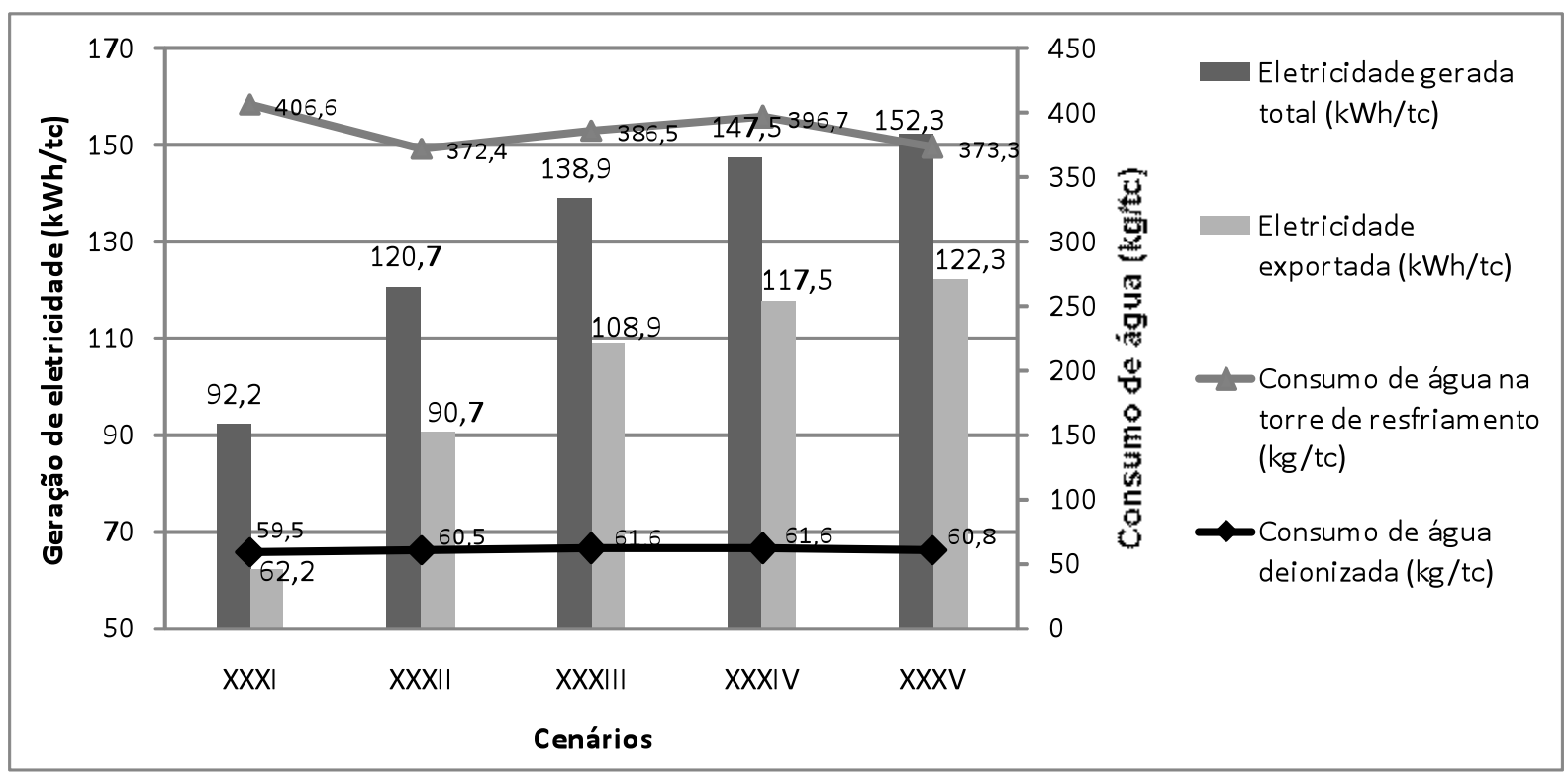

Gráfico 26 - Resultado dos indicadores de performance específicos, para os cenários XXXI a XXXV.

Conforme já era esperado, a taxa de eletricidade exportada aumenta à medida que a pressão de vapor na saída da caldeira e eleva, seguindo a mesma tendência do ciclo Convencional. O melhor resultado foi obtido no cenário XXXV, onde a geração de eletricidadealcançou 152,3 kWh/tc, correspondendo a um aumento de 11,8\% em relação ao cenário $\mathrm{V}$, de referência. $\mathrm{Na}$ condição de operação a 20 bar, a geração de eletricidade no ciclo Resultante foi de $92,2 \mathrm{kWh} / \mathrm{tc}$, superior em $8,6 \%$ ao resultado praticado pelo ciclo Convencional.

Analisando os consumos de água do ciclo Resultante, verificou-se terem ocorridoredução no consumo específico de água na torre de resfriamento, e aumento no dispêndio de água deionizada na caldeira em relação aos cenários de 
referência. Esses efeitos positivos e negativos foram potencializados à medida que se aumentou a pressão de trabalho.

Por exemplo, com relação so cenário I o consumo de água na torre obtido para o cenário XXXI mostrou redução de 7,9\%. A 100 bar, o ganho foi ainda mais expressivo, atingindo $17,5 \%$.

Por outro lado, o ciclo Resultante a 20 bar (cenário XXXI), apresentou consumo de água deionizada de 59,5 kg/tc contra $57,6 \mathrm{~kg} / \mathrm{tc}$ do ciclo convencional (cenário I). A 100 bar, o aumento no consumo de água deionizada manteve na mesma ordem de grandeza, e foi estimado pelo modelo em $3,2 \%$.

De qualquer maneira, apesar do aumento do consumo específico de água deionizada no ciclo Resultante, o balanço global de água foi positivo, e assim, a combinação entre Regeneração e Reaquecimento proporcionou uma redução no consumo total de água em todas as condições de pressão estudadas, entre $6,6 \%$ e $15,1 \%$ respectivamente entre os limites de pressão de 20 bar e 100 bar, acompanhando a tendência antes enunciada, das soluções técnicas de recuperação de energia antes avaliadas.

Os resultados da análise de Primeira Lei são apresentados no Gráfico 27.

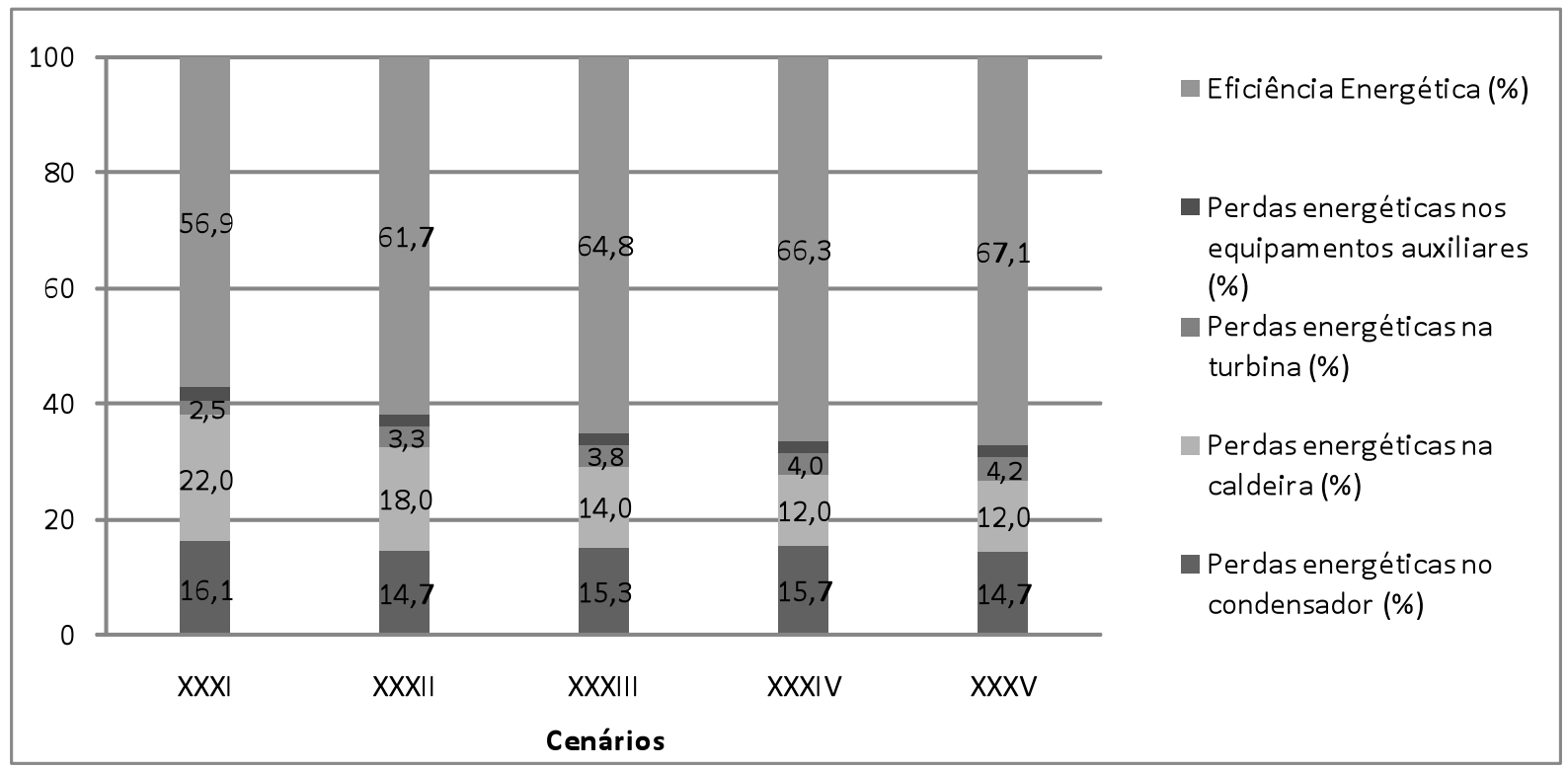

Gráfico 27 - Resultados da análise energética para os cenários XXXI a XXXV. 
O Gráfico 27 mostra que o perfil de distribuição das perdas energéticas estimadas pelo modelo matemático do ciclo Rankine Resultante segue a mesma tendência dos resultados apresentados nos cenários de referência I a V.

Assim como já seria de se supor após observar as tendências indicadas pelos ciclos com Reaquecimento e Regenerativo, a maior diferença observada no ciclo Resultando em relação ao Convencional está nas perdas energéticas no condensador. No cenário XXXI essas perdas foram de $16,1 \%$ contra $17,4 \%$ do cenário I, o que representa uma redução de 7,5\%. Para 100 bar de pressão, nota-se uma redução ainda bastante expressiva,de17,9\%, a partir da confrontação dos desempenhos entre os cenários $\mathrm{V}$ e XXXV.

As perdas energéticas na turbina aumentam de $2,5 \%$ para $4,2 \%$ com o aumento da pressão na entrada da turbina de 20 bar para 100 bar. Esses resultados foram maiores quando comparado com os cenários de referência I a $\mathrm{V}$, sendo no entanto exceder a mesma ordem de grandeza.As perdas energéticas nos equipamentos auxiliares permaneceram abaixo de $2,5 \%$ para todos os cenários, não apresentando grandes diferenças com os cenários de referência.

O diagnóstico obtido a partir da aplicação da Segunda Lei da Termodinâmica para os cenários XXXI a XXXV é apresentado no Gráfico 28.

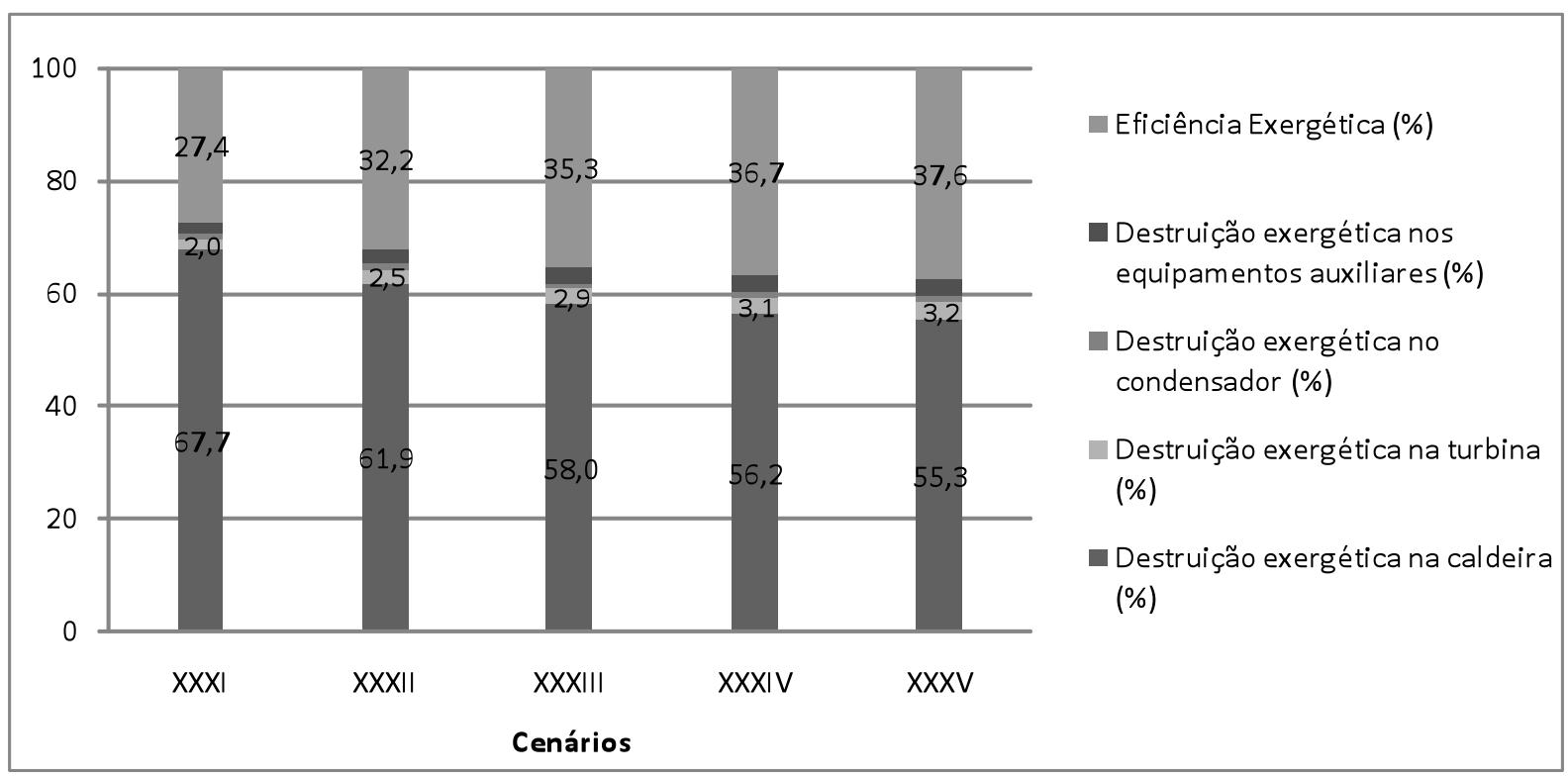

Gráfico 28 - Resultados da análise exergética para os cenários XXXI a XXXV. 
Pode-se verificar que o diagnóstico exergético dos cenários $X X X I$ a $X X X V$ apresentou perfil de distribuição da destruição de exergia semelhante ao dos cenários de I a V. No ciclo Resultante, a destruição de exergia na caldeira diminuiu de $67,7 \%$ para $55,3 \%$ conforme a pressão aumentou de 20 para 100 bar. Em todos os casos, a destruição de exergia foi inferior ao estimado pelo modelo dos cenários com ciclo Convencional na mesma condição de trabalho. Por exemplo, a 20 bar houveuma redução de $2,7 \%$ e na condição de 100 bar, a redução obtida foi de $6,0 \%$.

Com relação à destruição de exergia na turbina, percebeu-se tendência de redução em todas as condições de operação estudadas em relação ao ciclo Convencional. A exergia destruída no condensador foi de $1,0 \%$ em todos os cenários do ciclo Resultante um resultado que, se por um lado aparenta ser pouco expessivo, por outro é coerente com o perfil de desempenho desta solução tecnológica, que possui maiores índices de eficiência exergética e menor quantida de exergia é destruída no condensador.

As contribuições em termos de destruição exergética dos equipamentos auxiliares foram $1,9 \%$ a 20 bar e 2,9\% a 100 bar. Os resultados seguiram a mesma tendência de aumento com o aumento da pressão verificada no ciclo Convencional. Novamente, as contribuições desses equipamentos foram maiores devido à destruição de exergia associada aos trocadores de calor do ciclo Resultante, pelo mesmo motivo que foi apresentado e discutido na proposta do ciclo Regenerativo.

O saldo geral do balanço exergético para a proposta de ciclo Resultante foi positivo. A eficiência exergética do ciclo Rankine para o sistema de cogeração aumentou com a adoção dessa técnica, superando as estimativas da eficiência exergética dos modelos matemáticos dos ciclos com Reaquecimento e Regeneração avaliados em separado.

\subsubsection{Cenários XXXVI a XL: Ciclo Resultante com aproveitamento da palha}

Os cenários VI a X, foram adotados como referência para comparação de resultados. Como nos demais casos a análise foi conduzida para uso de $50 \%$ de palha como combustível auxiliar ao bagaço. 
Os resultados das simulações dos cenários XXXVI a XL em termos das eficiências energéticas e exergéticas são apresentados noGráfico 29.

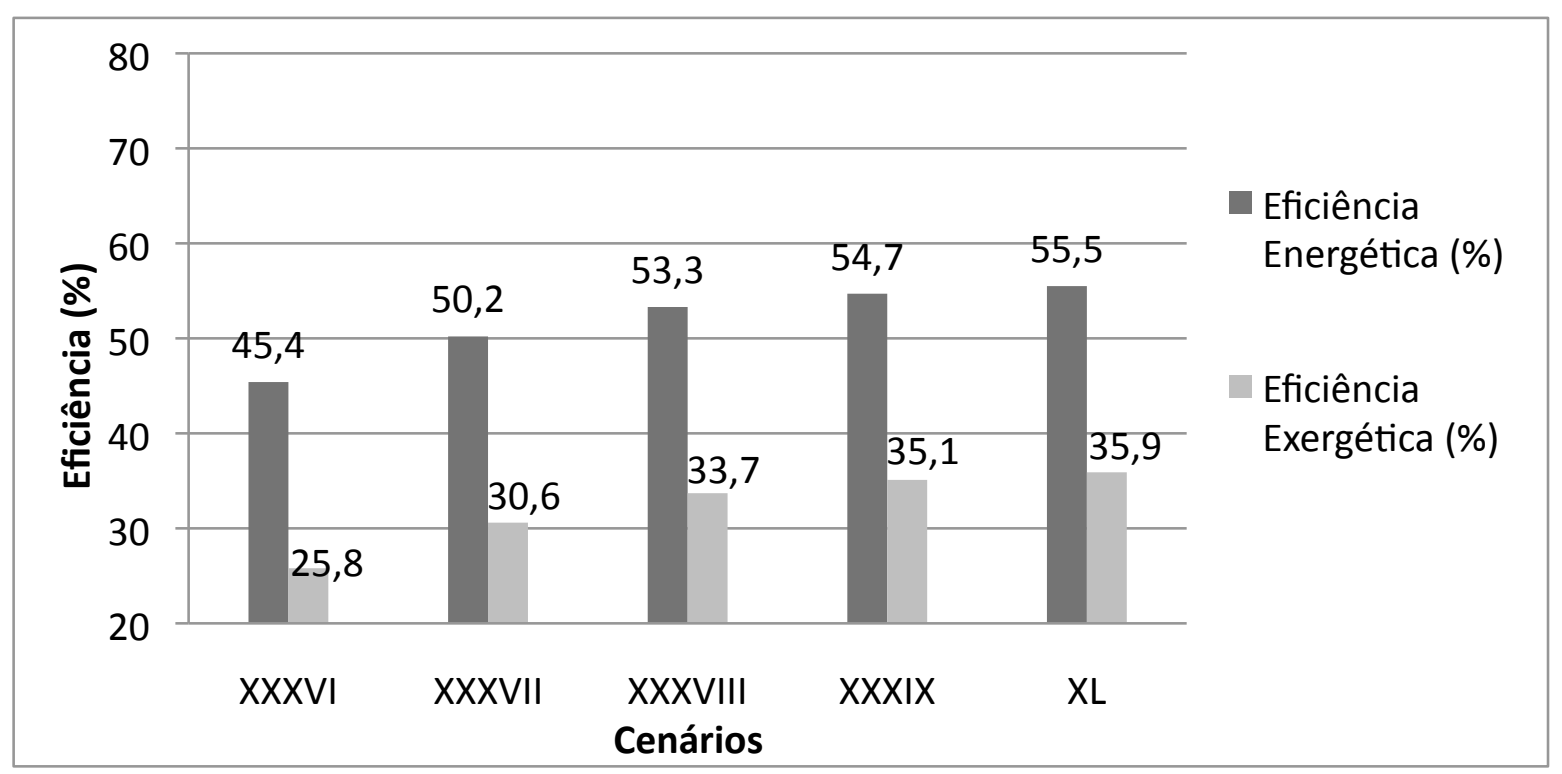

Gráfico 29 - Resultados da eficiência energética e exergética pra os cenários XXXVI a XL.

O Gráfico 29 mostra uma correlação direta entre a pressão do sistema e as eficiências energéticas e exergéticas do sistema. Em comparação ao ciclo Convencional com queima da palha (cenários $\mathrm{VI}$ a X), a proposta do ciclo Resultante gerou ganhos de eficiências energéticas e exergéticas em proporções superiores às que haviam sido observadas para os ciclos de Reaquecimento e Regeneração isoladamente. Ou seja, neste caso constatou-se portanto sinergia de efeitos. Verificou-se também que os mesmos diferenciais são potencializados à medida que cresce a pressão de operação.

A 20 bar, a eficiência energética do ciclo Resultante foi de 45,4\%, um valor em cerca de 2,9\% mais elevado que o alcançado pelo cenário VI na mesmacondição. Com o aumento da pressão, o efeito positivo do ciclo Resultante é ainda melhor, chegando a uma eficiência exergética de 35,9\%,que representa um aumento de 5,3\% em relação ao cenário de referência. Em termos exergéticos o ciclo Resultante com uso de palha superou em 5.7\% (para 20 bar) e em 8,5\% (a 100bar) o ciclo Convencional 
Os resultados dos indicadores de desempenho por tonelada de cana moída são apresentados no Gráfico 30.

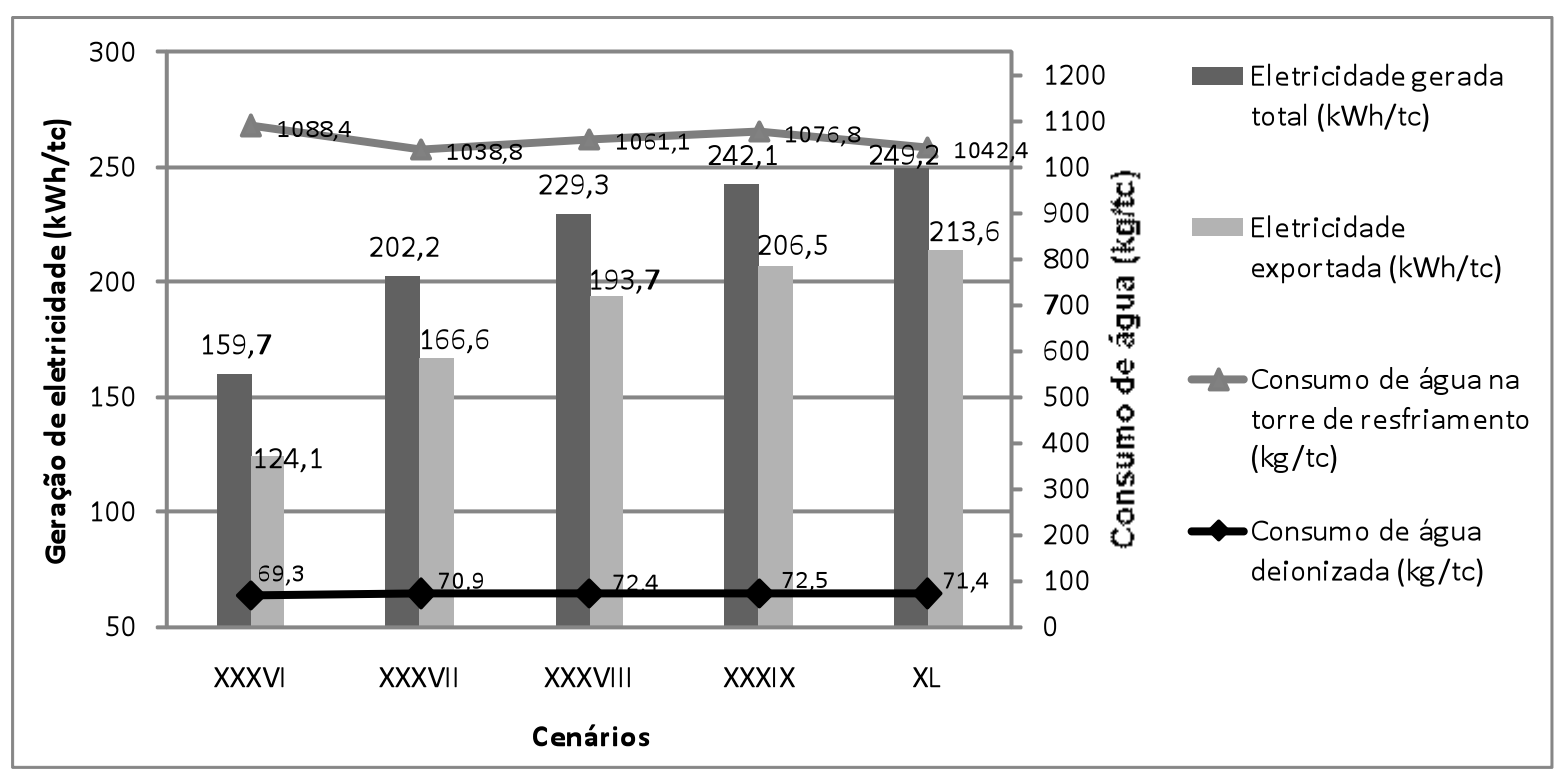

Gráfico 30 - Resultado dos indicadores de performance específicos, para os cenários XXXVI a XL.

A observação do Gráfico 30 apresenta claramente a manutenção da tendência de aumento na geração de eletricidade à medida que a pressão de vapor na saída da caldeira é elevada.

Dessa forma, na condição de pressão de vapor mais elevada (cenário $\mathrm{XL}$ ) obteve-se também a maior geração de eletricidade: $249,2 \mathrm{kWh} / \mathrm{tc}$. Esse resultado corresponde a um acréscimode $11,1 \%$ ao cenário $X$, usado como base quando comparado para as mesmas condições de trabalho. Na condição de operação mais branda (cenário XXXVI), a geração elétrica representouaumento de $8,1 \%$ em relação ao cenário de referência. Note-se que também neste caso o ciclo Resultante permitiu sinergizar os ganhos proporcionados por suas tecnologias componentes, independentemente de a queima de palha ser considerada como alternativa de provimento de energia.

Em relação ao consumo de água de resfriamento verificou-se uma leve tendência de redução de consumo com o aumento da pressão de vapor. Para a água deionizada essa propensão se inverteu. Enquantoo ciclo Resultante trouxe reduçõesdeconsumo de água específicos de resfriamento de 5,0\% (20 bar) e 10,4\% (100 bar), para a água deionizada, a mesma análise mostra aumento - de 4,4\% (20 bar) e 4,2\% 
(100bar) em relação aos cenários de referência. Complementarmente a isso, não háevidências de variação do consumo de água deionizada entre os ciclos Resultante e Convencional que se associe ao aumento de pressão na caldeira para a condição de uso da palha.

De qualquer forma, nobalanço global, houveredução no consumo de água no ciclo Resultante com aproveitamento da palha em relação aos cenários de referência, em todas as pressão estudadas; a 20 bar esta foi de $10,2 \%$ e a 100 bar,de $15,4 \%$.

Os resultados da análise energética são apresentados no Gráfico 31 .

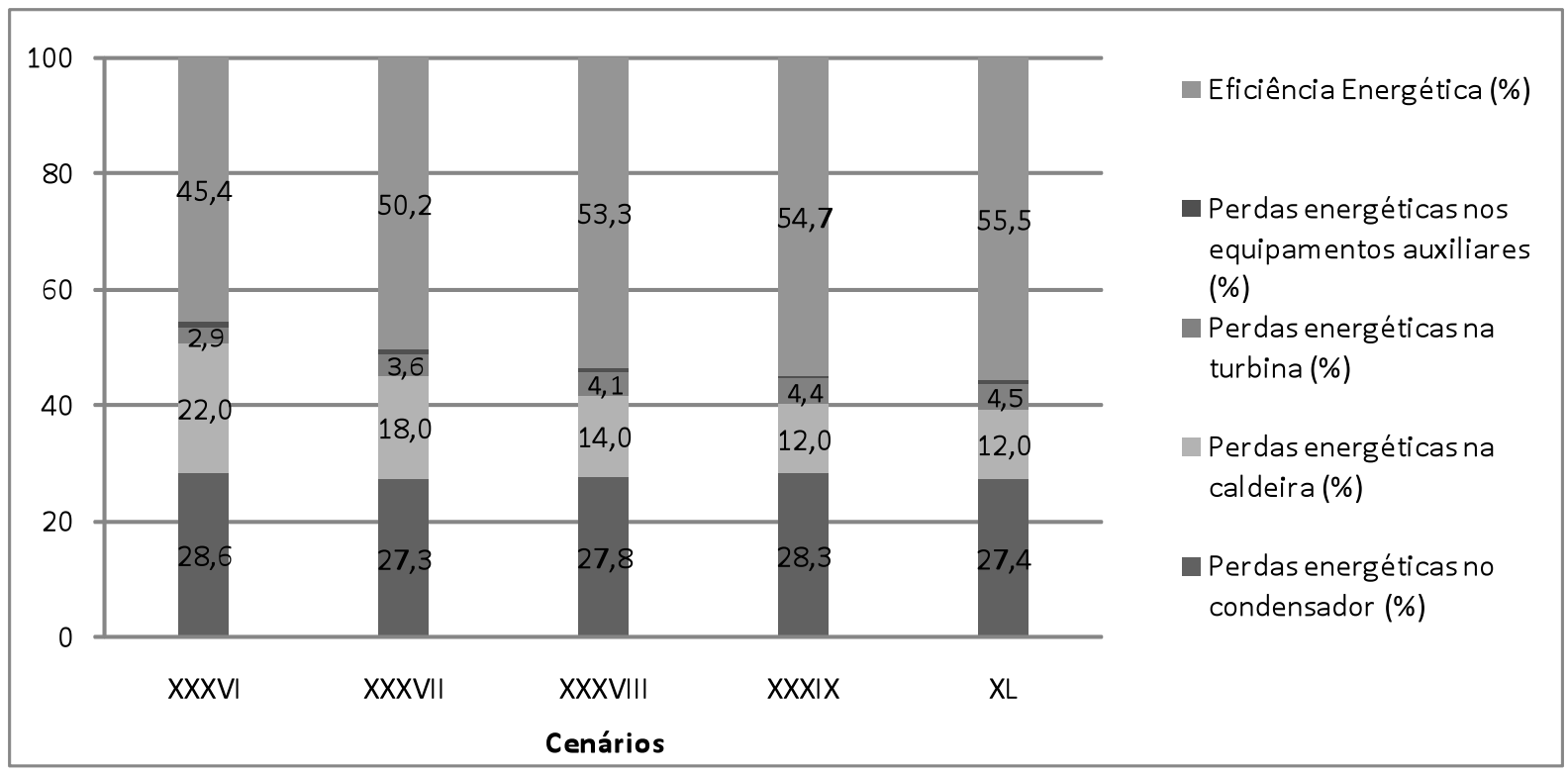

Gráfico 31 - Resultados da análise energética para os cenários XXXVI a XL.

Observa-se que o perfil de distribuição das perdas energéticas apresentado noGráfico 31 segue a mesma tendência dos resultados apresentados nos cenários de referência VI a X. As perdas energéticas no condensador reduziram-se de 28,6\% para $27,4 \%$ com o aumento da pressão de 20 bar para 100 bar. Em relação aos cenários de referência, verificou-se que as perdas energéticas no condensador do ciclo Resultante são menores em todas as condições operacionais que consideram o uso da palha, variando entre 5,0\% (20 bar) e 10,2\% (100bar).

Por outro lado, as perdas energéticas na turbina aumentam de 2,9\% para 4,5\% com a elevação de pressão, seguindo a tendência observada nos cenários de referência. No ciclo Resultante as perdas energéticas na turbina foram em torno de $10 \%$ 
maiores que as perdas ocorridas no ciclo Convencional em todas as condições de pressão. Isso ocorreu devido maior vazão mássica de vapor passando pelos estágios da turbina para gerar maior potência elétrica.

As perdas energéticas nos equipamentos auxiliares permaneceram abaixo de 1,2\% para todos os cenários, semelhante aos cenários de referência. Destaque-se aqui que a inclusão de trocadores de calor para pré-aquecimento da água de alimentação da caldeira não contribuiu para as perdas energéticas. Dado que esse comportamento já havia sido detectado para o ciclo Regenertivo, conclui-se que a associação daquela tecnologia com o Reaquecimento também não provoca influências negativas em termos do mesmo desempenho. $O$ resultadoem questão poderia ser de certa forma esperado, uma vez que foram desprezadas por ocasião da modelagem matemática, perdas de calor para o meio desde os mesmos equipamentos. Consequentemente, do ponto de vista da Primeira Lei, esses equipamentos não contribuem negativamente sobre eficiência do ciclocaso estivesse bem isolados.

Em Complementaçãoà análise clássica de Primeira Lei dos cenários XXXVI a XL, os resultados da análise exergética são apresentados no Gráfico 32.

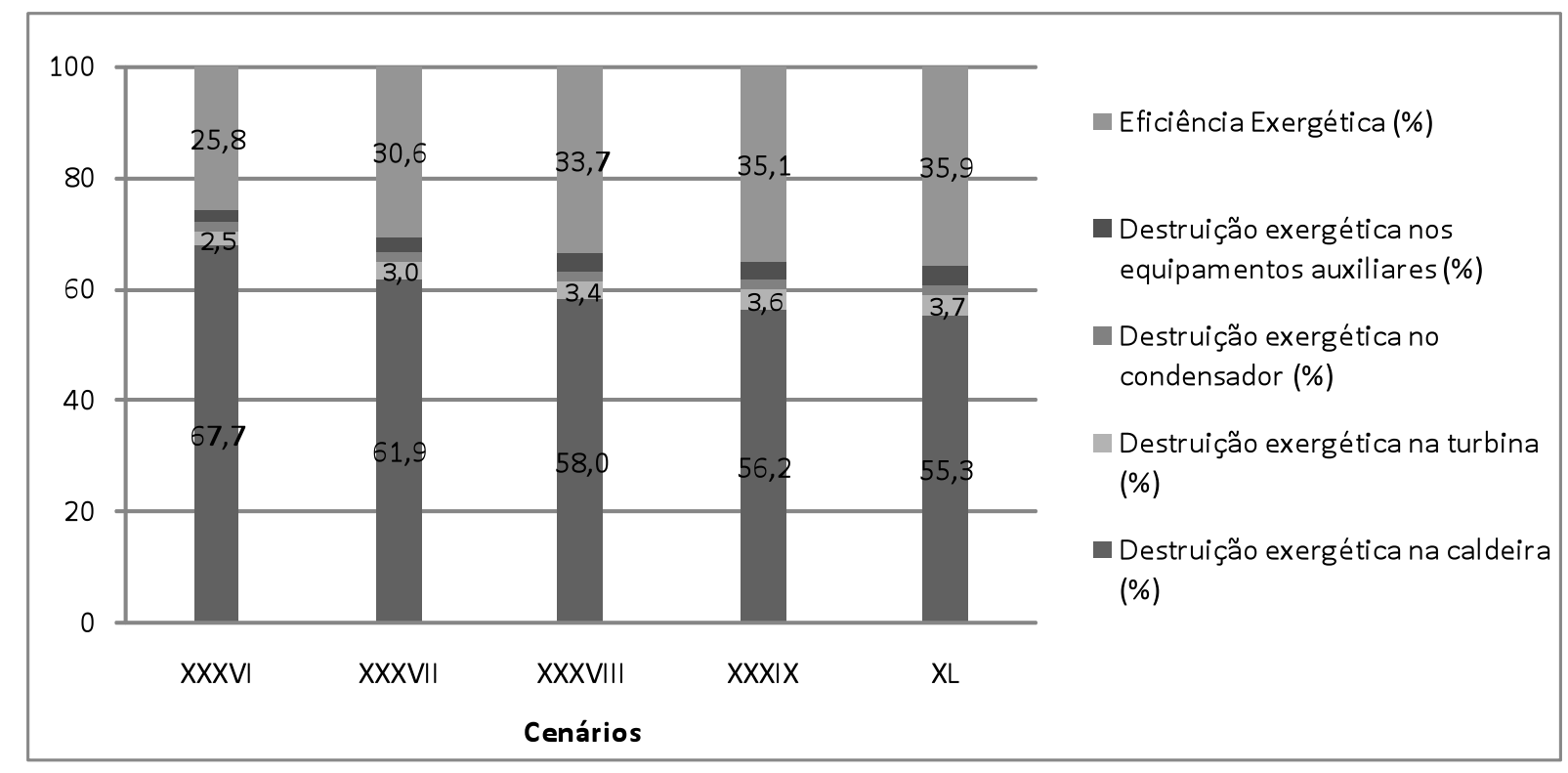

Gráfico 32 - Resultados da análise exergética para os cenários XXXVI a XL. 
O perfil de distribuição da destruição de exergia apresentado noGráfico 32 se assemelha ao projetado para os cenários VI a X. Assim como em situações anteriores a caldeira será o principal contribuinte. Com o aumento da pressão de trabalho de 20 para 100 bar, a destruição de exergia nesse equipamento caiu de $67,7 \%$ para $55,3 \%$ e, em todos os casos, foi inferior ao estimado pelo modelo dos cenários com ciclo Convencional na mesma condição de trabalho.

Ao comparar os resultados do ciclo Resultante com o ciclo Convencional, verificouse uma redução na destruição de exergia na turbina em todas as condições de operação estudadas. Por exemplo, a 20 bar esta foi de 3,8\% e a 100 bar, de 9,8\%.

A exergia destruída no condensador foi de 1,8\% a 20 bar, e de 2,0\% para a pressão de 100 bar no ciclo Regenerativo, resultados que em ambos os casos mostraram-se ligeiramente superiores aos manifestados para o ciclo Convencional.

Nos equipamentos auxiliares, a destruição de exergia seguiu a mesma tendência de aumento com o aumento da pressão verificada e discutida nos cenários de referência. As contribuições desses equipamentos para a destruição de exergia ao longo do ciclo foram maiores, devido principalmente à utilização de trocadores de calor para realizar a Regeneração, conforme discutido anteriormente.

O saldo geral do balanço exergético para a proposta do ciclo Resultante com uso da palha também foi positivo. Vale ressaltar que 0 efeito dessa técnica foi potencializado com o aumento da pressão de operação, o que desperta o interesse em realizar uma análise de viabilidade econômica considerando essa possibilidade, principalmente em projetos Greenfields de alta pressão. 


\subsection{ANÁLISE AMBIENTAL}

A partir da definição de objetivo e escopo do estudo de ACV apresentado no capítudo de Metodologia, os resultados da Análise Ambiental passam pela Análise de Inventário, Avaliação de Impactos Ambientais e Análise de Sensibilidade, que serão apresentados a seguir nesta mesma sequência.

\subsubsection{ANÁLISE DE INVENTÁRIO}

A análise de inventário dos cenários em estudo foi realizada a partir da modelagem do sistema de produto apresentado na Figura 34, considerando ou não a utilização da palha na caldeira. As premissas e considerações adotadas na modelagem de cada etapa do sistema de produto será apresentada a seguir.

\subsubsection{Produção de cana-de-açúcar}

Foram realizadas duas modelagens para produção de cana-de-açúcar em função de duas situações distintas: Sem aproveitamento da palha; e com aproveitamento de $50 \%$ da palha gerada no campo.

Na primeira condição da produção de cana, sem aproveitamento da palha, o objetivo é desenvolver um modelo que se aproxime da realidade do Estado de São Paulo, de forma que esse modelo possa fornecer uma predição do comportamento desse sistema nas condições médias atuais, em termos de impactos ambientais.

Na segunda condição, onde há aproveitamento da palha, procurou-se desenvolver um modelo que pudesse fornecer uma predição do comportamento de um sistema de produção de cana-de-açúcar futuro, nas mesmas condições da realidade de São Paulo, porém sem realizar queimada prévia nos canaviais e considerando que $50 \%$ da palha gerada no campo é enfardada e transportada para usina, enquanto o restante da palha é deixada no campo. A palha deixada no campo pode trazer vários benefícios, tais como reciclagem de nutrientes (Oliveira et al., 1999), redução de 
gases do efeito estufa, redução da infestação por plantas daninhas e, ainda aumentar a produtividade da cana (Gava et al., 2001). Por outro lado, grandes quantidades de palha deixada no campo poderia resultar também em impactos negativos, como aumentar risco de incêndios, aumentar incidência de insetos, etc (Cardoso et al., 2013). No Brasil é crescente a adoção de colheitas mecanizadas sem realização de queimadas, principalmente devido a aspectos ambientais, legais e redução do uso de mão de obra (Cardoso et al., 2013). Em consonância, está o crescente interesse na utilização da palha da cana como combustível, seja como fonte de energia térmica nas caldeiras, ou como matéria-prima para produção de etanol de segunda geração (Dias et al., 2012; Seabra et al., 2010).

O inventário da produção de cana-de-açúcar foi construído com dados secundários baseados no trabalho de Sugawara (2012) que foi construído a partir de uma parceria com o Laboratório Nacional de Ciência e Tecnologia do Bioetanol (CTBE). Considerou-se uma cobertura temporal de 2008 a 2011, adotando o estado de São Paulo como cobertura geográfica e, em termos de cobertura tecnológica adotou-se um mix das formas manual e mecanizada, tanto para plantio quanto para colheita. A partir desse mesmo trabalho de pesquisa, adotou-se como base de cálculo uma produtividade média de 86,50 tha.

O plantio de mudas de cana-de-açúcar ocorre em função da abertura de novas áreas, ou após a ocorrência de cinco cortes (ao longo de seis anos) nas áreas já existentes (áreas de reforma). O plantio pode ser realizado de forma semimecanizada - abertura e aterramento de sulco mecanizado; e distribuição das mudas, manual - ou inteiramente mecanizada. De acordo com Sugawara (2012), considerou-se no modelo que o plantio em nova área de expansão é de $12,0 \%$ e em área de reforma $88,0 \%$.

Com relação à aplicação dos resíduos industriais no campo, constituídos pela torta de filtro, vinhaça e cinzas, admitiu-se que esses resíduos gerados na etapa industrial de produção de etanol são integralmente aplicados no campo. A área coberta com esses resíduos depende da quantidade do material gerado na fase industrial. A partir do estudo de Sugawara (2012), a dosagem de aplicação e porcentagem da área total foi adotada como:

- Torta de filtro: $5.000 \mathrm{~kg} /($ ha*ano) e $11,2 \%$ da área total; 
- Vinhaça: $100 \mathrm{~kg} /\left(\mathrm{ha}^{*}\right.$ ano) e $51,8 \%$ da área total; e

- Cinzas: $5.000 \mathrm{~kg} /($ ha*ano) e $8,4 \%$ da área total.

Buscando um modelo que se aproxime da condição de produção de cana-de-açúcar atual, sem utilização da palha, a colheita pode ocorrer de forma manual ou mecanizada, com ou sem queima prévia do canavial. Utilizou-se nesse trabalho os dados adotados por Sugawara (2012), cujos percentuais de colheita manual de cana foram de $36,35 \%$ e colheita mecanizada de $63,65 \%$, sendo que há queima prévia em $94,9 \%$ das áreas onde a colheita é realizada manualmente e $25,6 \%$ quando a colheita é mecanizada.

Já na modelagem com aproveitamento da palha, considerando um cenário futuro, foi adotado que não há queima prévia dos canaviais mas que os percentuais de colheita manual e mecanizada foram preservados. Dessa forma, como para cada tonelada de cana-de-açúcar são gerados $140 \mathrm{~kg}$ (base seca) de palha, ou equivalente a $164,7 \mathrm{~kg}$ com $15 \%$ de umidade, considerando que $50 \%$ desse total será reaproveitado, $82,35 \mathrm{~kg}$ de palha será enfardado e transportado para a usina enquanto $82,35 \mathrm{~kg}$ será deixado no campo.

A partir da modelagem descrita na dissertação de Sugawara (2012), as Tabelas $13 \mathrm{e}$ 14 apresentam os inventários consolidados para modelar a produção de $1 \mathrm{~kg}$ de cana-de-açúcar nas duas situação distintas supracidatas: uma representando a realidade atual, sem aproveitamento da palha, onde há queimada prévia em parte dos canaviais ; e outra representando uma possibilidade futura, com aproveitamento de $50 \%$ da palha, sem queimada prévia.

Tabela 5 - Inventário consolidado da produção de $1 \mathrm{~kg}$ de cana - Com queimada prévia percentual definida, sem aproveitamento da palha.

\begin{tabular}{lcc}
\hline Entradas/saídas & Unidade & Quantidade \\
\hline Entradas & $\mathrm{kg}$ & 0,653 \\
Carbon dioxide, in air & $\mathrm{m}^{2}$ & 0,0106 \\
Transformation, from pasture and meadow & $\mathrm{m}^{2}$ & 0,1175 \\
Transformation, from arable, non-irrigated & \\
\hline
\end{tabular}




\begin{tabular}{|c|c|c|}
\hline Transformation, to arable, non-irrigated & $\mathrm{m}^{2}$ & 0,1281 \\
\hline Occupation, arable, non-irrigated & $\mathrm{m}^{2} \cdot \mathrm{a}$ & 0,1100 \\
\hline Ammonia, liquid, at regional storehouse/RER $U$ & $\mathrm{~kg}$ & 0,000094 \\
\hline Urea, as $\mathrm{N}$, at regional storehouse/RER $\mathrm{U}$ & $\mathrm{kg}$ & 0,000700 \\
\hline $\begin{array}{l}\text { Ammonium nitrate, as } \mathrm{N} \text {, at regional } \\
\text { storehouse/RER } \mathrm{U}\end{array}$ & $\mathrm{kg}$ & 0,000123 \\
\hline $\begin{array}{l}\text { Monoammonium phosphate, as } \mathrm{P} 2 \mathrm{O} 5 \text {, at } \\
\text { regional storehouse } / \mathrm{kg} / \mathrm{RER}\end{array}$ & $\mathrm{kg}$ & 0,000006 \\
\hline $\begin{array}{l}\text { Monoammonium phosphate, as } \mathrm{N} \text {, at regional } \\
\text { storehouse } / \mathrm{kg} / \mathrm{RER}\end{array}$ & $\mathrm{kg}$ & 0,000035 \\
\hline $\begin{array}{l}\text { Single superphosphate, as } \mathrm{P} 2 \mathrm{O} 5 \text {, at regional } \\
\text { storehouse/RER } U\end{array}$ & $\mathrm{~kg}$ & 0,000387 \\
\hline $\begin{array}{l}\text { Potassium chloride, as } \mathrm{K} 2 \mathrm{O} \text {, at regional } \\
\text { storehouse/RER } \mathrm{U}\end{array}$ & $\mathrm{kg}$ & 0,000774 \\
\hline Limestone, milled, loose, at plant/CH U & $\mathrm{kg}$ & 0,005156 \\
\hline Gypsum, mineral, at mine/CH U & $\mathrm{kg}$ & 0,002578 \\
\hline Vinasse, at etanol production & $\mathrm{kg}$ & 0,000811 \\
\hline Filter cake, at etanol production & $\mathrm{kg}$ & 0,007950 \\
\hline Diesel, at regional storage & $\mathrm{kg}$ & 0,002279 \\
\hline Glyphosate, at regional storehouse/RER U & $\mathrm{kg}$ & 0,000003 \\
\hline Diuron, at regional storehouse/RER $U$ & $\mathrm{~kg}$ & 0,000001 \\
\hline Carbofuran, at regional storehouse/RER U & $\mathrm{kg}$ & 0,000005 \\
\hline Herbicides, at regional storehouse/RER U & $\mathrm{kg}$ & 0,000003 \\
\hline Insecticides, at regional storehouse/RER U & $\mathrm{kg}$ & 0,0000005 \\
\hline Growth regulators, at regional storehouse & $\mathrm{kg}$ & 0,000001 \\
\hline Slurry spreading, by vacuum tanker/CH U & $\mathrm{m}^{3}$ & 0,000049 \\
\hline Electricity - medium voltage, at grid - BR & $\mathrm{kWh}$ & 0,000523 \\
\hline Diesel, burned in building machine/GLO U & MJ & 0,006538 \\
\hline Transport, transoceanic freight ship/OCE U & t.km & 0,026749 \\
\hline Transport, lorry 7,5-16t, EURO3/RER U & t.km & 0,003356 \\
\hline Transport, lorry 16-32t, EURO3/RER U & t.km & 0,011842 \\
\hline \multicolumn{3}{|l|}{ Emissões para o Ar } \\
\hline Carbon dioxide, land transformation & $\mathrm{kg}$ & 0,059403 \\
\hline Volatile organic compounds (VOC) & $\mathrm{kg}$ & 0,000442 \\
\hline
\end{tabular}




\begin{tabular}{|c|c|c|}
\hline Carbon monoxide, biogenic & $\mathrm{kg}$ & 0,005814 \\
\hline Nitrogen oxides & $\mathrm{kg}$ & 0,095961 \\
\hline Particulates, <10um & $\mathrm{kg}$ & 0,000493 \\
\hline Particulates, $<2,5$ um & $\mathrm{kg}$ & 0,012128 \\
\hline Sulfur oxides & $\mathrm{kg}$ & 0,000025 \\
\hline Dinitrogen monoxide & $\mathrm{kg}$ & 0,000040 \\
\hline Methane (biogenic) & $\mathrm{kg}$ & 0,000171 \\
\hline Ammonia & $\mathrm{kg}$ & 0,000133 \\
\hline Ammonium, ion & $\mathrm{kg}$ & 0,000159 \\
\hline Carbon dioxide, fossil & $\mathrm{kg}$ & 0,009570 \\
\hline Methane, fossil & $\mathrm{kg}$ & 0,0000003 \\
\hline Sulfur dioxide & $\mathrm{kg}$ & 0,000002 \\
\hline Benzene & $\mathrm{kg}$ & 0,000016 \\
\hline Cadmium & $\mathrm{kg}$ & $2,3^{*} 10^{-8}$ \\
\hline Chromium & $\mathrm{kg}$ & $1,1 * 10^{-7}$ \\
\hline Copper & $\mathrm{kg}$ & $3,8 * 10^{-6}$ \\
\hline Nickel & $\mathrm{kg}$ & $1,6 * 10^{-7}$ \\
\hline Selenium & $\mathrm{kg}$ & $2,3^{*} 10^{-8}$ \\
\hline Zinc & $\mathrm{kg}$ & $2,2 * 10^{-6}$ \\
\hline Benzo(a)pyrene & $\mathrm{kg}$ & $6,8 * 10^{-8}$ \\
\hline Hydrocarbons, aromatic & $\mathrm{kg}$ & 0,000007 \\
\hline Carbon monoxide, fossil & $\mathrm{kg}$ & 0,000012 \\
\hline $\begin{array}{l}\text { NMVOC, non-methane volatile organic } \\
\text { compounds }\end{array}$ & $\mathrm{kg}$ & 0,006762 \\
\hline Hydrocarbons, unspecified & $\mathrm{kg}$ & $8,9^{*} 10^{-8}$ \\
\hline Particulates, unspecified & $\mathrm{kg}$ & $4,3^{*} 10^{-8}$ \\
\hline \multicolumn{3}{|l|}{ Emissões para a Água } \\
\hline Nitrate & $\mathrm{kg}$ & 0,000155 \\
\hline \multicolumn{3}{|l|}{ Emissões para o Solo } \\
\hline Carbofuran & $\mathrm{kg}$ & 0,0000054 \\
\hline Diuron & $\mathrm{kg}$ & 0,0000012 \\
\hline Fipronil & $\mathrm{kg}$ & 0,0000005 \\
\hline
\end{tabular}




\begin{tabular}{lcc}
\hline Glyphosate & $\mathrm{kg}$ & 0,0000029 \\
Hexazinone & $\mathrm{kg}$ & 0,0000004 \\
Imazapic & $\mathrm{kg}$ & 0,0000016 \\
Tebuthiuron & $\mathrm{kg}$ & 0,0000013 \\
Trinexapac-ethyl & $\mathrm{kg}$ & 0,0000011 \\
Cadmium & $\mathrm{mg}$ & 0,0103480 \\
Lead & $\mathrm{mg}$ & 0,2220909 \\
Nickel & $\mathrm{mg}$ & 0,1205124 \\
Copper & $\mathrm{mg}$ & 0,1307754 \\
Zinc & $\mathrm{mg}$ & 0,5455398 \\
Chromium & $\mathrm{mg}$ & 0,1585222 \\
\hline
\end{tabular}

Fonte: Sugawara (2012).

No entanto ao considerar um cenário futuro onde não há queima nos canaviais, consequentemente não haverá emissões associadas à queimada da palha no campo, nesse aspecto, somente emissões adicionais de $\mathrm{N}_{2} \mathrm{O}$ resultantes da decomposição da palha deixada no campo são contabilizadas e apresentadas na Tabela 14.

Todos os demais consumos e emissões associados à etapa de produção de cana foram mantidos os mesmos em todos os cenários, conforme apresentado por Sugawara (2012), como por exemplo, os mesmos consumos dos corretivos (calcário e gesso), mesma quantidade de nutrientes $\left(\mathrm{N}, \mathrm{P}_{2} \mathrm{O}_{5}\right.$ e $\left.\mathrm{K}_{2} \mathrm{O}\right)$, fertilizantes minerais (amônia, sueprfosfato simples, etc) e pesticidas.

Tabela 6 - Inventário consolidado da produção de $1 \mathrm{~kg}$ de cana - Cenário futuro, sem queimada prévia e com aproveitamento de $50 \%$ da palha.

\begin{tabular}{lcc}
\hline Entradas/saídas & Unidade & Quantidade \\
\hline Entradas & $\mathrm{Kg}$ & 0,653 \\
Carbon dioxide, in air & $\mathrm{m}^{2}$ & 0,0106 \\
Transformation, from pasture and meadow & & \\
\hline
\end{tabular}




\begin{tabular}{|c|c|c|}
\hline Transformation, from arable, non-irrigated & $\mathrm{m}^{2}$ & 0,1175 \\
\hline Transformation, to arable, non-irrigated & $\mathrm{m}^{2}$ & 0,1281 \\
\hline Occupation, arable, non-irrigated & $m^{2} \cdot a$ & 0,1100 \\
\hline Ammonia, liquid, at regional storehouse/RER $U$ & $\mathrm{Kg}$ & 0,000094 \\
\hline Urea, as $\mathrm{N}$, at regional storehouse/RER $\mathrm{U}$ & $\mathrm{Kg}$ & 0,000823 \\
\hline $\begin{array}{l}\text { Monoammonium phosphate, as } \mathrm{P} 2 \mathrm{O} 5 \text {, at } \\
\text { regional storehouse/kg/RER }\end{array}$ & $\mathrm{Kg}$ & 0,000006 \\
\hline $\begin{array}{l}\text { Monoammonium phosphate, as } \mathrm{N} \text {, at regional } \\
\text { storehouse } / \mathrm{kg} / \mathrm{RER}\end{array}$ & $\mathrm{Kg}$ & 0,000035 \\
\hline $\begin{array}{l}\text { Single superphosphate, as } \mathrm{P} 2 \mathrm{O} 5 \text {, at regional } \\
\text { storehouse/RER } U\end{array}$ & $\mathrm{Kg}$ & 0,000387 \\
\hline $\begin{array}{l}\text { Potassium chloride, as } \mathrm{K} 2 \mathrm{O} \text {, at regional } \\
\text { storehouse/RER U }\end{array}$ & $\mathrm{Kg}$ & 0,000712 \\
\hline Limestone, milled, loose, at plant/CH U & $\mathrm{Kg}$ & 0,005156 \\
\hline Gypsum, mineral, at mine/CH U & $\mathrm{Kg}$ & 0,002578 \\
\hline Vinasse, at etanol production & $\mathrm{Kg}$ & 0,000811 \\
\hline Filter cake, at etanol production & $\mathrm{Kg}$ & 0,007950 \\
\hline Diesel, at regional storage & $\mathrm{Kg}$ & 0,002279 \\
\hline Glyphosate, at regional storehouse/RER U & $\mathrm{Kg}$ & 0,000003 \\
\hline Diuron, at regional storehouse/RER $U$ & $\mathrm{Kg}$ & 0,000001 \\
\hline Carbofuran, at regional storehouse/RER $U$ & $\mathrm{Kg}$ & 0,000005 \\
\hline Herbicides, at regional storehouse/RER $U$ & $\mathrm{Kg}$ & 0,000003 \\
\hline Insecticides, at regional storehouse/RER $U$ & $\mathrm{Kg}$ & 0,0000005 \\
\hline Growth regulators, at regional storehouse & $\mathrm{Kg}$ & 0,000001 \\
\hline Slurry spreading, by vacuum tanker/CH U & $\mathrm{m}^{3}$ & 0,000049 \\
\hline Electricity - medium voltage, at grid - BR & $\mathrm{kWh}$ & 0,000523 \\
\hline Diesel, burned in building machine/GLO U & MJ & 0,006538 \\
\hline Transport, transoceanic freight ship/OCE U & t.km & 0,026749 \\
\hline Transport, lorry 7,5-16t, EURO3/RER U & t.km & 0,003356 \\
\hline Transport, lorry 16-32t, EURO3/RER U & t.km & 0,011842 \\
\hline \multicolumn{3}{|l|}{ Emissões para o $\mathrm{Ar}$} \\
\hline Carbon dioxide, land transformation & $\mathrm{Kg}$ & 0,059403 \\
\hline Nitrogen oxides & $\mathrm{Kg}$ & 0,095803 \\
\hline Particulates, $<2,5$ um & $\mathrm{Kg}$ & 0,011882 \\
\hline
\end{tabular}




\begin{tabular}{|c|c|c|}
\hline Ammonia & $\mathrm{Kg}$ & 0,000133 \\
\hline Ammonium, ion & $\mathrm{Kg}$ & 0,000159 \\
\hline Carbon dioxide, fossil & $\mathrm{Kg}$ & 0,009570 \\
\hline Methane, fossil & $\mathrm{Kg}$ & 0,0000003 \\
\hline Sulfur dioxide & $\mathrm{Kg}$ & 0,000002 \\
\hline Benzene & $\mathrm{Kg}$ & 0,000016 \\
\hline Cadmium & $\mathrm{Kg}$ & $2,3^{*} 10^{-8}$ \\
\hline Chromium & $\mathrm{Kg}$ & $1,1^{*} 10^{-7}$ \\
\hline Copper & $\mathrm{Kg}$ & $3,8^{*} 10^{-6}$ \\
\hline Nickel & $\mathrm{Kg}$ & $1,6^{*} 10^{-7}$ \\
\hline Selenium & $\mathrm{Kg}$ & $2,3^{*} 10^{-8}$ \\
\hline Zinc & $\mathrm{Kg}$ & $2,2^{*} 10^{-6}$ \\
\hline Benzo(a)pyrene & $\mathrm{Kg}$ & $6,8^{*} 10^{-8}$ \\
\hline Hydrocarbons, aromatic & $\mathrm{Kg}$ & 0,000007 \\
\hline Carbon monoxide, fossil & $\mathrm{Kg}$ & 0,000012 \\
\hline $\begin{array}{l}\text { NMVOC, non-methane volatile organic } \\
\text { compounds }\end{array}$ & $\mathrm{Kg}$ & 0,006762 \\
\hline Hydrocarbons, unspecified & $\mathrm{Kg}$ & $8,9 * 10^{-8}$ \\
\hline Particulates, unspecified & $\mathrm{Kg}$ & $4,3^{*} 10^{-8}$ \\
\hline \multicolumn{3}{|l|}{ Emissões para a Água } \\
\hline Nitrate & $\mathrm{Kg}$ & 0,000182 \\
\hline \multicolumn{3}{|l|}{ Emissões para o Solo } \\
\hline Carbofuran & $\mathrm{Kg}$ & 0,0000054 \\
\hline Diuron & $\mathrm{Kg}$ & 0,0000012 \\
\hline Fipronil & $\mathrm{Kg}$ & 0,0000005 \\
\hline Glyphosate & $\mathrm{Kg}$ & 0,0000029 \\
\hline Hexazinone & $\mathrm{Kg}$ & 0,0000004 \\
\hline Imazapic & $\mathrm{Kg}$ & 0,0000016 \\
\hline Tebuthiuron & $\mathrm{Kg}$ & 0,0000013 \\
\hline Trinexapac-ethyl & $\mathrm{Kg}$ & 0,0000011 \\
\hline Cadmium & $\mathrm{Mg}$ & 0,0103480 \\
\hline Lead & $\mathrm{Mg}$ & 0,2220909 \\
\hline
\end{tabular}




\begin{tabular}{lll}
\hline Nickel & $M g$ & 0,1205124 \\
Copper & $M g$ & 0,1307754 \\
Zinc & $M g$ & 0,5455398 \\
Chromium & $M g$ & 0,1585222 \\
\hline
\end{tabular}

Fonte: Adaptado de Sugawara (2012).

Em todos os cenários considerou-se a captura de $\mathrm{CO}_{2}$, pois segundo Frischknecht e Jungbluth (2007), a captura de carbono deve ser inventariada na forma de $\mathrm{CO}_{2}$. Adotou-se o valor indicado por CGEE (2008), que corresponde a $653 \mathrm{~kg} \mathrm{CO}_{2} / \mathrm{t}$ cana.

As emissões para o ar ocorreram devido a queima de diesel nos maquinários agrícolas; oxidação de fertilizantes, oxidação de calcário, oxidação de resíduos industriais e uso do solo.

Emissões associadas à queima do canavial ocorreram somente nos cenários onde não há aproveitamento da palha. Nos cenários onde há aproveitamento da palha (cenários futuros), foi adotado que não há queima do canavial e a palha deixada no campo é responsável por emissões associadas a sua decomposição. De acordo com Franco (2008), 1,225\% do conteúdo de nitrogênio da palha é emitido na forma de $\mathrm{N}_{2} \mathrm{O}$ para o ar, sendo que o conteúdo total de nitrogênio na palha deixada no campo é de $0,477 \%$ (base seca). Já a palha enfardada e transportada até a usina tem suas emissões geradas no sistema de cogeração que será apresentado posteriormente.

No entanto, se ocorre queima do canavial, as emissões adotadas seguiram os fatores de emissão de Greet (2010), indicados na Tabela 15 por tonelada de palha (base seca). 
Tabela 7 - Fatores de emissão para a queima da palha anterior à colheita

\begin{tabular}{lcc}
\hline Emissão & Unidade & Quantidade \\
\hline Volatile organic compounds (VOC) & $\mathrm{kg} / \mathrm{t}$ palha & 7.0 \\
Carbon monoxide (biogenic) & $\mathrm{kg} / \mathrm{t}$ palha & 92.0 \\
Nitrogen oxides & $\mathrm{kg} / \mathrm{t} \mathrm{palha}$ & 2.5 \\
Particulates, <10um & $\mathrm{kg} / \mathrm{t} \mathrm{palha}$ & 7.8 \\
Particulates, <2,5um & $\mathrm{kg} / \mathrm{t} \mathrm{palha}$ & 3.9 \\
Sulfur dioxide & $\mathrm{kg} / \mathrm{t} \mathrm{palha}$ & 0.4 \\
Dinitrogen monoxide & $\mathrm{kg} / \mathrm{t}$ palha & 0.07 \\
Methane (biogenic) & $\mathrm{kg} / \mathrm{t} \mathrm{palha}$ & 2.7 \\
Methane (biogenic) & $\mathrm{kg} / \mathrm{t} \mathrm{palha}$ & 7.0 \\
\hline
\end{tabular}

Fonte: Greet, 2010.

Em termos de emissões para a água, Sugawara (2012) justifica que em razão dos solos brasileiros apresentarem um teor ácido, não ocorre a emissão de compostos de fósforo, nitrogênio e potássio para as águas superficiais. No entanto, o mesmo trabalho indica que $5 \%$ do total de $\mathrm{N}$ aplicado como uréia é convertido para nitrato, que acaba sendo lixiviado para águas subterrâneas.

Com relação às emissões para o solo, considerou-se que os metais pesados originados da aplicação de corretivos do solo e fertilizantes minerais, e os ingredientes ativos dos pesticidas. De acordou com Jungbluth (2007), considerou-se que toda entrada de ingrediente ativo dos defensivos agrícolas se torna uma emissão para o solo.

Vale ressaltar que nos cenários onde há aproveitamento da palha, a etapa agrícola de produção de cana conta com dois produtos: A cana (colmos) e a palha. Nesse caso há alocação das cargas ambientais, esta foi feita entre a cana e a palha por critério mássico, nas proporções já apresentadas.

\subsubsection{Transporte da cana-de-açúcar}

Nos cenários futuros, considerando que não há queimada prévia dos canaviais, várias possibilidades têm sido estudadas para colheita e transporte da cana-de- 
açúcar e da palha. Hassuani (2005), estudou aspectos positivos e negativos de quatro possíveis rotas para colheita e transporte da cana:

1. Cana colhida integralmente, carregada e transportada junto com a palha. Nesse caso a cana é limpa e separada da palha na usina;

2. Cana colhida integralmente, picada e limpa antes de ser transportada. A cana é transportada e a palha deixada no campo. A palha é enfardada no campo e transportada separadamente;

3. Cana é picada, limpa e carregada em caminhões durante a colheita. A palha deixada no campo é enfardada e transportada separadamente;

4. Cana é picada e carregada durante a colheita junto com a palha, nesse caso a limpeza da cana e a recuperação da palha é feita na usina.

Hassuani (2005) concluiu para as rotas 1 e 2 - que consideram a cana colhida integralmente - que as máquinas utilizadas no estudo deveriam ser aprimoradas melhor eficiêcia e que, as rotas 3 e 4 - que consideram a cana picada durante a colheita - apresentou melhores resultados de desempenho, contudo uma análise de custos deveria ser realizada.

Nesse trabalho, nos cenários onde há aproveitamento da palha, adotou-se como possibilidade futura a rota $\mathrm{C}$, onde a cana é picada e transportada durante a colheita e a palha deixada no campo. Dessa forma, de acordo com Hassuani (2005), as etapas de enfardamento, transporte da palha e moagem da palha antes de ser misturada ao bagaço para ser utilizada na caldeira, tornam-se indispensáveis ao processo. Nesse trabalho essas etapas adicionais serão analisadas separadamente.

Portanto, em todos os cenários analisados nesse trabalho, seja com ou sem queimada prévia dos canaviais, a cana é transportada separadamente para a usina através de transporte rodoviário. Admitiu-se nesse trabalho para efeito desta analise que a distância media entre o campo e a usina autônoma é de $32,3 \mathrm{~km}$. De acordo com Sugawara (2012), o mesmo valor foi adotado como referência considerando os principais municípios produtores de cana-de-açúcar em São Paulo.

As emissões associadas a essa etapa foram contabilizadas utilizando o banco de dados do Ecoinvent, utilizando o elemento Transport, lorry 16-32t, EURO4/RER U. 


\subsubsection{Moagem da Cana-de-acúcar}

Ao chegar do campo através de transporte rodoviário, a cana é descarregada diretamente em mesas alimentadoras e, no caso de cana picada, através de um tombador hidráulico para basculamento dos caminhões. Após a limpeza, a cana é picada em pedaços menores e depois desfibrada, para facilitar a extração do caldo. Após preparada, a cana é encaminhada para extração do caldo em moendas, ou alternativamente em difusores (Pistore, 2004). Na moagem, a cana passa por um conjunto de rolos de esmagamento, denominados ternos. Esta etapa tem a função de extrair o máximo de sacarose contida na cana proveniente do preparo. Depois de esmagada no primeiro terno, obtem-se o caldo primário, seguindo a massa até passar pelo último terno, de onde o bagaço final segue para as caldeiras. No processo de moagem, ocorre a embebição da massa a cada terno de moenda em contracorrente com a direção da moagem, favorecendo a lixiviação da sacarose contida na massa (Neto, 2009). A quantidade de água de embebição deve ser estabelecida de acordo com algumas características da cana, como por exemplo, teor de fibras e de açúcar, mas sempre respeitando os limites impostos pela capacidade de processamento das etapas posteriores à extração, pois quanto maior o volume de água empregado na embebição, maior será o consumo de energia utilizada para o bombeamento e evaporação do caldo (Pistore, 2004). Com base nos trabalhos apresentados por Neto (2009) e Pistore (2004), adotou-se uma embebição de $30 \%$ na etapa de moagem. Considerou-se na modelagem que as moendas são eletrificadas, em substituição às tradicionais turbinas, a fim de evitar perdas de energia por radiação nas tubulações de vapor, melhorar o controle do processo e sobretudo, contribuir com a geração de eletricidade no sistema de cogeração, direcionando todo vapor gerado para os turbogeradores. Com base no trabalho de Pistore (2004), considerou-se um consumo específico de eletricidade de $17 \mathrm{kWh} / \mathrm{t}_{\text {cana }}$ entre as etapas de recebimento e preparo da cana até obter o caldo e o bagaço. A energia elétrica fornecida nesse processo é produzida no sistema de cogeração.

A alocação entre o bagaço e o caldo produzido foi realizada por critério mássico.

O bagaço gerado com $50 \%$ de umidade segue para o sistema de cogeração e o caldo para produção de etanol. 


\subsubsection{Produção de Etanol Anidro}

Assim como no subsistema da produção de cana-de-açúcar, o inventário do subsistema de produção de etanol anidro foi construído a partir de dados secundários com base no trabalho de Sugawara (2012).

Nas usinas autônomas, todo o caldo extraído da moagem é utilizado para a produção de etanol enquanto nas usinas anexas, o caldo é repartido para a geração de etanol e açúcar. Nesse trabalho, o inventário considera somente a produção de etanol de primeira geração, a partir dos colmos da cana-de-açúcar em usinas autônomas. A cobertura geográfica compreendeu o estado de São Paulo. A cobertura temporal possui valores médios de produção de 2004 a 2010 e a cobertura tecnológica refere-se ao processo de produção de etanol típico das usinas brasileiras e, o processo de desidratação do etanol por destilação azeotrópica. Não foi aplicado alocação entre os produtos etanol, vinhaça e torta de filtro. $O$ etanol recebeu $100 \%$ da carga ambiental associada ao processo. Os dois subprodutos vinhaça e torta de filtro não saem da fronteira do sistema sendo utilizados na etapa de produção de cana.

Sugawara (2012) utilizou a modelagem do processo produtivo foi executada com o uso do software de simulação Aspen Plus, construído em parceria com CTBE. Esta abordagem levou em consideração aspectos técnicos, correntes de entrada e saída, consumos energéticos e rendimentos dos equipamentos para simular um processo de produção.

A modelagem baseou-se na produção de uma destilaria autônoma típica do cenário nacional, com autossuficiência na geração de energia e destilação azeotrópica do etanol hidratado com o uso de ciclohexano. Considerou-se nesse trabalho que não há venda do bagaço excedente, sendo portanto todo bagaço gerado utilizado no sistema de cogeração.

A Tabela 16 apresenta o inventário para a produção de $1 \mathrm{~kg}$ de etanol anidro em destilaria autônoma adaptado a partir do trabalho de Sugawara (2012). 
Tabela 8 - Inventário da produção de $1 \mathrm{~kg}$ de etanol anidro.

\begin{tabular}{|c|c|c|}
\hline Entradas/saídas & Unidade & Destilaria \\
\hline \multicolumn{3}{|l|}{ Entradas } \\
\hline Sugarcane & $\mathrm{kg}$ & 15,4503 \\
\hline Tap water & $\mathrm{kg}$ & 0,02318 \\
\hline $\begin{array}{l}\text { Lime, hydrated, packed, at } \\
\text { plant/CH U }\end{array}$ & $\mathrm{kg}$ & 0,01251 \\
\hline $\begin{array}{l}\text { Sulphuric acid, liquid, at } \\
\text { plant/RER } U\end{array}$ & $\mathrm{~kg}$ & 7,5861 \\
\hline $\begin{array}{l}\text { Chemicals inorganic, at } \\
\text { plant/GLO U }\end{array}$ & $\mathrm{kg}$ & 0,1205 \\
\hline Lubricating oil, at plant/RER $U$ & $\mathrm{~kg}$ & 0,00021 \\
\hline Cyclohexane, at plant/RER $U$ & $\mathrm{~kg}$ & 0,00107 \\
\hline \multicolumn{2}{|l|}{ EURO3/RER U } & 0,1861 \\
\hline \multicolumn{2}{|l|}{ EURO3/RER U } & 0,32613 \\
\hline Eletricidade, at cogeneration/BR & $\mathrm{kWh}$ & 0,20093 \\
\hline Steam, at cogeneration/BR & $\mathrm{kg}$ & 6,1824 \\
\hline \multicolumn{3}{|l|}{ Saídas } \\
\hline Vinhaça & $\mathrm{kg}$ & 13,72488 \\
\hline Torta de filtro & $\mathrm{kg}$ & 0,39567 \\
\hline Ethanol & $\mathrm{kg}$ & 0,00201 \\
\hline Carbon dioxide, biogenic & $\mathrm{kg}$ & 1,0185 \\
\hline
\end{tabular}

Fonte: Adaptado de Sugawara (2012).

As emissões de dioxido de carbono biogênico na etapa de produção de etanol são provenientes do processo de fermentação. 
Nos cenários futuros, onde há aproveitamento da palha, as etapas adicionais de enfardamento, transporte e moagem da palha são necessárias e serão apresentadas a seguir.

\subsubsection{Enfardamento da Palha}

Hassuani (2005), testou várias formas de enfardamento e transporte da palha. Concluiu que é possível recuperar a palha do campo utilizando equipamentos tradicionais para enfardamento. Três sistemas para enfardamento foram testados de forma a obter os seguintes produtos: Fardos cilindricos pequenos, fardos cilindricos grandes e fardos retangulares, os últimos com medidas de $800 \mathrm{~mm}$ de largura, $875 \mathrm{~mm}$ de altura e comprimento ajustável. Os melhores resultados em termos de prdutividade e qualidade foram obtidos com fardos retangulares. Neste caso utilizouse uma enfardadeira fabricada pela Case modelo 8575 e um trator com potência de $90 \mathrm{hp}$. A produtividade máxima alcançada com esses equipamento foi de $9,8 \mathrm{t} / \mathrm{h}$ de palha enfardada e o melhor nível de compactação foi de $175 \mathrm{~kg} / \mathrm{m}^{3}$. No pior cenário testado, a eficiência obtida para recuperação de palha foi de $56 \%$, contudo, como nesse trabalho é considerado o aproveitamento de $50 \%$ da palha gerada no campo, as eficiências dos máquinários utilizados seriam suficientes. Nessas condições, com base no trabalho de Hassuani (2005), considerou-se um consumo de 1,9 $\mathrm{L}$ de óleo diesel por tonelada de palha enfardada, com umidade $15 \%$. Considerou-se os mesmos fatores de emissão para a queima do óleo diesel adotados na etapa agrícola, utilizados por Sugawara (2012), conforme apresentado na Tabela 17.

Tabela 9 - Fatores de emissão para a queima de óleo diesel em maquinários agrícolas.

\begin{tabular}{lcc}
\hline Emissão & Unidade & Quantidade \\
\hline Carbon dioxide (fossil) & $\mathrm{g} / \mathrm{kg}$ diesel & $3,12 * 10^{3}$ \\
Methane (fossil) & $\mathrm{g} / \mathrm{kg}$ diesel & $1,29 * 10^{-1}$ \\
Dinitrogen monoxide & $\mathrm{g} / \mathrm{kg}$ diesel & $1,20 * 10^{-1}$ \\
Ammonia & $\mathrm{g} / \mathrm{kg}$ diesel & $2,00 * 10^{-2}$ \\
\hline
\end{tabular}




\begin{tabular}{lcc}
\hline Sulfur dioxide & g/kg diesel & 1,01 \\
Benzene & $\mathrm{g} / \mathrm{kg}$ diesel & $7,30 * 10^{-3}$ \\
Cadmium & $\mathrm{g} / \mathrm{kg}$ diesel & $1,00 * 10^{-5}$ \\
Chromium & $\mathrm{g} / \mathrm{kg}$ diesel & $5,00 * 10^{-5}$ \\
Copper & $\mathrm{g} / \mathrm{kg}$ diesel & $1,70 * 10^{-3}$ \\
Nickel & $\mathrm{g} / \mathrm{kg}$ diesel & $7,00 * 10^{-5}$ \\
Selenium & $\mathrm{g} / \mathrm{kg}$ diesel & $1,00 * 10^{-5}$ \\
Zinc & $\mathrm{g} / \mathrm{kg}$ diesel & $1,00 * 10^{-3}$ \\
Benzo(a)pyrene & $\mathrm{g} / \mathrm{kg}$ diesel & $3,00 * 10^{-5}$ \\
Polycyclic Aromatic Hydrocarbons & $\mathrm{g} / \mathrm{kg}$ diesel & $3,29 * 10^{-3}$ \\
Hydrocarbons & $\mathrm{g} / \mathrm{kg}$ diesel & 3,00 \\
Carbon monoxide (fossil) & $\mathrm{g} / \mathrm{kg}$ diesel & 5,40 \\
Nitrogen oxides & $\mathrm{g} / \mathrm{kg}$ diesel & $4,25 * 10^{1}$ \\
\hline Fonte: Nemecek e Käji (2007). & & \\
\hline
\end{tabular}

Fonte: Nemecek e Käji (2007).

\subsubsection{Transporte da Palha}

Após ser enfardada, a palha é transportada para a usina através de transporte rodoviário. A distância a ser transportada é mesma da cana-de-açúcar, ou seja, de $32,3 \mathrm{~km}$.

As emissões associadas a essa etapa foram contabilizadas utilizando o banco de dados do Ecoinvent, utilizando o elemento Transport, lorry 16-32t, EURO4/RER U.

\subsubsection{Moagem da Palha}

A palha enfardada é transportada até a usina, porém não está em condições adequadas para ser alimentada diretamente na fornalha da caldeira. Quando a palha 
é enfardada, torna-se necessário desmanchar o fardo e picar a palha antes de ser alimentada na caldeira junto com o bagaço (Hassuani, 2005).

Hassuani (2005), testou três marcas e modelos de moinhos para desmanchar e picar a palha, sendo um pequeno moinho de martelos fabricado pela Máquinas Tigre S. A., com potência instalada de $15 \mathrm{hp}$; um moinho de martelos fabricado pela Haybuster MFG, com potência instalada de $110 \mathrm{hp}$; e um moinho de facas fabricado pela Dedini, com $50 \mathrm{hp}$ de potência. Os melhores resultados foram o modelo de 110 hp (82 kW), cuja produtividade média foi de $1.200 \mathrm{~kg} / \mathrm{h}$. Nesse trabalho, adotou-se de forma conservadora, que a potência consumida é a potência nominal do equipamento. Logo, a potência consumida específica dada pela razão entre a potência nominal e a produtividade média, ou seja, $68,3 \mathrm{kWh} / \mathrm{t}_{\text {palha. }}$.

A Figura 39 ilustra o moinho utilizado como base para modelar essa etapa do processo.

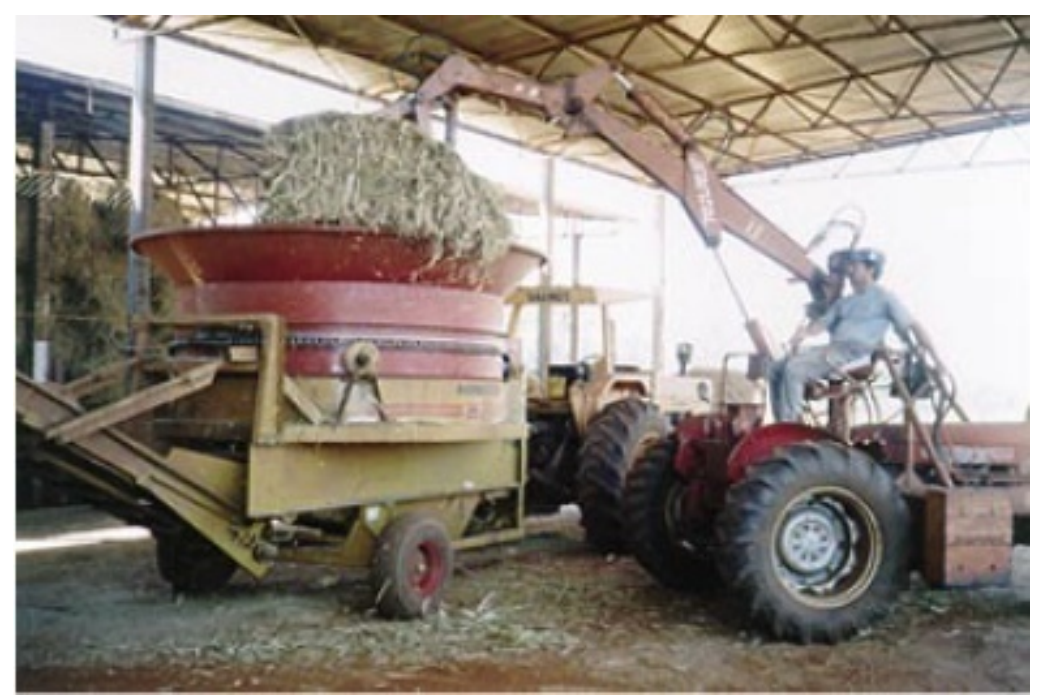

Figura 39 - Moinho Haybuster sendo alimentado com fardo de palha.

Fonte: Hassuani, 2005.

Vale ressaltar que a potência consumida pelo moinho é fornecida pelo sistema de cogeração, e representa um consumo de $5,6 \mathrm{kWh} / \mathrm{t}_{\text {cana, }}$, trazendo para base de cálculo por unidade de tonelada de cana. Esse consumo impacta na taxa de exportação de eletricidade do sistema de cogeração, pois quando não há utilização da palha, essa etapa não é necessária. Contudo, conforme apresentado nos Resultados e Discussão sobre a avaliação termodinâmica do sistema de cogeração, a geração de energia elétrica adicional a partir da queima da palha gera um saldo 
positivo para exportação de eletricidade, mesmo com a etapa adicinal de moagem da palha.

Finalmente, a palha picada misturada junto com o bagaço proveniente da etapa de moagem da cana e alimentada na fornalha da caldeira, do sistema de cogeração.

\subsubsection{Sistema de Cogeração}

O sistema de cogeração conta com 3 produtos principais: Eletricidade específica excedente disponível para exportação; eletricidade específica para ser utilizada na indústria (incluindo produção de etanol, moagem da cana e moagem da palha nos cenários onde há aproveitamento, etc.); e vapor saturado a 2,5 bar de pressão para ser utilizado no processo de produção de etanol anidro. As cinzas geradas foram consideradas como subproduto e foram direcionadas para a etapa agrícola e não recebem alocação.

A alocação entre eletricidade excedente, eletricidade consumida na produção de etanol e vapor saturado para processo, foi realizada por critério exergético. Como os valores dos produtos são direrente para cada cenário estudado, os fatores de alocação foram calculadas para cada cenário.

Os resultados dos cálculos para alocação em cada cenário com base nos resultados da Análise Termodinâmica são apresentados na Tabela 18 (sem aproveitamento da palha) e na Tabela 19 (com aproveitamento da palha). 
Tabela 10 - Percentuais de alocação para cenários sem aproveitamento da palha.

\begin{tabular}{|c|c|c|c|c|c|c|c|}
\hline \multirow[b]{2}{*}{ Descrição } & \multirow[b]{2}{*}{ Cenário } & \multicolumn{3}{|c|}{ Produtos da Cogeração (kWh/tc) } & \multicolumn{3}{|c|}{ ALOCAÇÃO (Exergia) \% } \\
\hline & & $\begin{array}{l}\text { Eletricidade } \\
\text { excedente }\end{array}$ & $\begin{array}{c}\text { Eletricidade } \\
\text { para indústria }\end{array}$ & $\begin{array}{c}\text { Vapor } \\
\text { para processo }\end{array}$ & $\begin{array}{c}\text { Eletricidade } \\
\text { excedente }\end{array}$ & $\begin{array}{c}\text { Eletricidade } \\
\text { para indústria }\end{array}$ & $\begin{array}{c}\text { Vapor para } \\
\text { processo }\end{array}$ \\
\hline \multirow{5}{*}{ 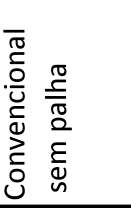 } & 1 & 54,9 & 30,0 & 242,4 & 35,7 & 19,5 & 44,8 \\
\hline & II & 78,7 & 30,0 & 242,4 & 44,4 & 16,9 & 38,7 \\
\hline & III & 94,3 & 30,0 & 242,4 & 48,9 & 15,5 & 35,6 \\
\hline & IV & 101,8 & 30,0 & 242,4 & 50,8 & 15,0 & 34,2 \\
\hline & $\mathrm{V}$ & 106,2 & 30,0 & 242,4 & 51,8 & 14,6 & 33,6 \\
\hline \multirow{5}{*}{ 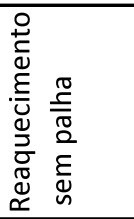 } & $\mathrm{XI}$ & 58,5 & 30,0 & 242,4 & 37,2 & 19,1 & 43,7 \\
\hline & XII & 84,4 & 30,0 & 242,4 & 46,1 & 16,4 & 37,5 \\
\hline & XIII & 101,1 & 30,0 & 242,4 & 50,6 & 15,0 & 34,4 \\
\hline & XIV & 109,1 & 30,0 & 242,4 & 52,5 & 14,4 & 33,1 \\
\hline & $x V$ & 113,9 & 30,0 & 242,4 & 53,6 & 14,1 & 32,3 \\
\hline \multirow{5}{*}{ 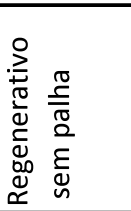 } & XXI & 58,5 & 30,0 & 242,4 & 37,2 & 19,1 & 43,7 \\
\hline & XXII & 85,2 & 30,0 & 242,4 & 46,3 & 16,3 & 37,4 \\
\hline & XXIII & 102,5 & 30,0 & 242,4 & 51,0 & 14,9 & 34,1 \\
\hline & XXIV & 110,9 & 30,0 & 242,4 & 52,9 & 14,3 & 32,8 \\
\hline & XXV & 116,3 & 30,0 & 242,4 & 54,1 & 14,0 & 31,9 \\
\hline \multirow{5}{*}{ 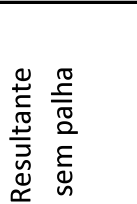 } & XXXI & 62,2 & 30,0 & 242,4 & 38,7 & 18,6 & 42,7 \\
\hline & XXXII & 90,7 & 30,0 & 242,4 & 47,9 & 15,8 & 36,3 \\
\hline & XXXIII & 108,9 & 30,0 & 242,4 & 52,5 & 14,5 & 33,0 \\
\hline & XXXIV & 117,5 & 30,0 & 242,4 & 54,3 & 13,9 & 31,8 \\
\hline & XXXV & 122,3 & 30,0 & 242,4 & 55,3 & 13,6 & 31,1 \\
\hline
\end{tabular}

Tabela 11 - Percentuais de alocação para cenários com aproveitamento da palha.

\begin{tabular}{|c|c|c|c|c|c|c|c|}
\hline \multirow[b]{2}{*}{ Descrição } & \multirow[b]{2}{*}{ Cenário } & \multicolumn{3}{|c|}{ Produtos da Cogeração (kWh/tc) } & \multicolumn{3}{|c|}{ ALOCAÇÃO (Exergia) \% } \\
\hline & & $\begin{array}{c}\text { Eletricidade } \\
\text { excedente }\end{array}$ & $\begin{array}{c}\text { Eletricidade } \\
\text { para indústria }\end{array}$ & $\begin{array}{c}\text { Vapor } \\
\text { para processo }\end{array}$ & $\begin{array}{c}\text { Eletricidade } \\
\text { excedente }\end{array}$ & $\begin{array}{c}\text { Eletricidade } \\
\text { para indústria }\end{array}$ & $\begin{array}{c}\text { Vapor para } \\
\text { processo }\end{array}$ \\
\hline \multirow{5}{*}{ 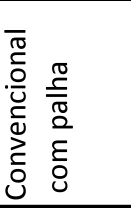 } & $\mathrm{VI}$ & 112,1 & 35,6 & 242,4 & 51,8 & 16,4 & 31,8 \\
\hline & VII & 147,6 & 35,6 & 242,4 & 58,6 & 14,1 & 27,3 \\
\hline & VIII & 170,9 & 35,6 & 242,4 & 62,1 & 12,9 & 25 \\
\hline & IX & 182,1 & 35,6 & 242,4 & 63,6 & 12,4 & 24 \\
\hline & $\mathrm{x}$ & 188,7 & 35,6 & 242,4 & 64,4 & 12,1 & 23,5 \\
\hline \multirow{5}{*}{ 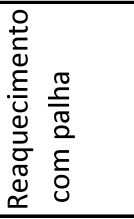 } & $\mathrm{XVI}$ & 118,5 & 35,6 & 242,4 & 53,2 & 16,0 & 30,8 \\
\hline & XVII & 156,9 & 35,6 & 242,4 & 60,1 & 13,6 & 26,3 \\
\hline & XVIII & 181,8 & 35,6 & 242,4 & 63,5 & 12,4 & 24,1 \\
\hline & $\mathrm{XIX}$ & 193,8 & 35,6 & 242,4 & 65 & 11,9 & 23,1 \\
\hline & $x X$ & 201 & 35,6 & 242,4 & 65,8 & 11,7 & 22,5 \\
\hline \multirow{5}{*}{ 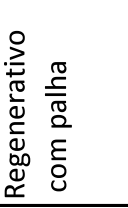 } & XXVI & 117,6 & 35,6 & 242,4 & 53,0 & 16,0 & 31,0 \\
\hline & XXVII & 157,3 & 35,6 & 242,4 & 60,1 & 13,6 & 26,3 \\
\hline & XXVIII & 183,3 & 35,6 & 242,4 & 63,7 & 12,4 & 23,9 \\
\hline & XXIX & 195,8 & 35,6 & 242,4 & 65,2 & 11,9 & 22,9 \\
\hline & $\mathrm{XXX}$ & 203,8 & 35,6 & 242,4 & 66,1 & 11,6 & 22,3 \\
\hline \multirow{5}{*}{ 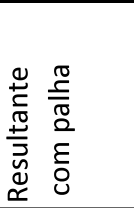 } & XXXVI & 124,1 & 35,6 & 242,4 & 54,3 & 15,6 & 30,1 \\
\hline & XXXVII & 166,6 & 35,6 & 242,4 & 61,5 & 13,1 & 25,4 \\
\hline & XXXVIII & 193,7 & 35,6 & 242,4 & 65,0 & 11,9 & 23,1 \\
\hline & XXXIX & 206,5 & 35,6 & 242,4 & 66,4 & 11,5 & 22,1 \\
\hline & $\mathrm{XXXX}$ & 213,6 & 35,6 & 242,4 & 67,2 & 11,2 & 21,6 \\
\hline
\end{tabular}

Nota-se que os consumos de energia na forma de vapor no processo são iguais em todos os cenários, pois adotou-se nesse trabalho um consumo de vapor saturado no processo de produção de etanol anidro de $400 \mathrm{~kg} / \mathrm{t}_{\text {cana }}$, conforme justificado 
anteriormente. Dessa forma, o conteúdo energético desse produto é o mesmo em todos os cenários $(242,2 \mathrm{kWh} / \mathrm{tc})$. Para determinar os fatores de alocação, foi calculado o conteúdo exergético dessa corrente através das técnicas apresentadas no capítudo de Metodologia desse trabalho. Já em relação às correntes de energia elétrica excedente e para o processo, o conteúdo exergético é o próprio valor específico da corrente, pois eletricidade é exergia pura.

É importante destacar que o consumo de eletricidade na indústria é maior nos cenários onde há aproveitamento da palha devido à introdução da etapa adicional de moagem da palha, que consome $5,6 \mathrm{kWh} / \mathrm{t}_{\text {cana. }}$.

Os principais recursos utilizados na cogeração são: bagaço (umidade $50 \%$ ); palha picada (umidade 15\%), nos cenários onde há aproveitamento da palha; água deionizada para reposição do fluido de trabalho; e água de uso geral, para reposição na torre de resfriamento.

Conforme apresentado no capítulo de Resultados e Discussão sobre a Análise Termodinâmica, cada um dos 40 cenários avaliados possuem uma capacidade diferente de geração dos produtos e também consumos diferentes de água. Todos esses dados obtidos a partir da Análise Termodinâmica dos 40 cenários foram utilizados para modelar cada sistema de cogeração no SimaPro, totalizando 40 propostas para cogeração, gerando um conjunto de impacto ambientais associados a cada cenário.

Em termos de emissões para o ar, considerou-se as emissões atmosféricas da queima do bagaço na caldeira a partir dos fatores de emissão indicados por Greet (2010). Os valores dos fatores de emissão adotados foram:
$\checkmark$ CO: 0,54597 $\mathrm{g} / \mathrm{kg}$ bagaço;
$\checkmark \mathrm{NO}_{\mathrm{x}}: 0,54318 \mathrm{~g} / \mathrm{kg}$ bagaço;
$\checkmark \mathrm{N}_{2} \mathrm{O}: 0,03000 \mathrm{~g} / \mathrm{kg}$ bagaço;
$\checkmark \mathrm{SO}_{\mathrm{x}}: 0,02915 \mathrm{~g} / \mathrm{kg}$ bagaço;
$\checkmark \mathrm{CH}_{4}: 0,22499 \mathrm{~g} / \mathrm{kg}$ bagaço;
$\checkmark$ VOC: $0,03797 \mathrm{~g} / \mathrm{kg}$ bagaço;
$\checkmark$ Particulados $<10 \mu \mathrm{m}: 0,61560 \mathrm{~g} / \mathrm{kg}$ bagaço; e
$\checkmark$ Particulados $<2,5 \mu \mathrm{m}: 0,30780 \mathrm{~g} / \mathrm{kg}$ bagaço.

Nos cenários onde há utilização da palha, considerou-se os mesmos fatores de emissão do bagaço, porém com ajuste de umidade para $15 \%$, na forma em que é queimada na fornalha da caldeira. 


\subsubsection{AVALIAÇÃO DE IMPACTO}

Encerrada a elaboração dos inventários de cada etapa do Sistema de Produto, partiu-se para a fase de Avaliação de Impacto. A avaliação foi realizada utilizando o método ReCiPe Midpoint (H) - versão 1.08 (Goedkoop et al., 2012).

O foco da ACV foi mantido na geração de eletricidade a partir da queima de bagaço e da palha da cana-de-açúcar no sistema de cogeração, de acordo com o Sistema de Produto apresentado na Figura 34. Os resultados serão discutidos com relação à geração de 1,0 MWh de eletricidade excedente, em condições de ser exportada para rede da concessionária.

Aspectos associados a infraestrutura e bens de capital foram desconsiderados no estudo após simulações realizadas mostrarem influência discreta nos impactos ambientais, da mesma forma que foi identificado pelos pesquisadores Guerra et al., (2014).

Como premissa desse estudo, foi estabelecido que o consumo de recursos e emissões, bem como as condições operacionais dos subsistemas de transporte da cana-de-açúcar, moagem da cana e produção de etanol foram os mesmos para todos os cenários avaliados. Os subsistemas adicionais de enfardamento, transporte e moagem da palha, que são previstos somente nos cenários em que há utilização da palha, apresentam o mesmo consumo de recursos e emissões quando são utilizados. No caso da etapa agrícola de produção de cana-de-açúcar, há duas possibilidades: há um consumo de recursos e emissões associados aos cenários onde não há aproveitamento da palha, através de um modelo que busca prever o comportamento do sistema real e; outro consumo de recursos e emissões onde $50 \%$ da palha gerada no campo é aproveitada, através de um modelo que busca prever o comportamento do sistema futuro, sem queimadas no canavial. Dessa forma, foi gerado um inventário agrícola para modelagem dos cenários sem utilizar a palha e outro para modelagem dos cenários onde há aproveitamento da palha, conforme discutido na Análise de Inventário.

Dentro desse enfoque e de acordo com o objetivo e escopo desse trabalho, foram selecionadas quatro categorias de impacto: Mudança Climática (CC); Formação de Materiais Particulados (PMF); Depleção de Água (WD); e Depleção de Fósseis (FD). 
A análise do desempenho ambiental dos cenários foi realizada de forma análoga à utilizada para realizar a análise de desempenho termodinâmico, sendo conduzida por meio da comparação dos resultados da Avaliação de Impacto para as quatro categorias destacadas. As comparações foram tomadas com relação aos resultados dos cenários de referência, correspondentes ao ciclo Rankine Convencional.

5.2.2.1. Análise comparativa entre Ciclo Rankine Convencional, com Reaquecimento, Regenerativo e Resultante

Inicialmente, avaliou-se a influência das condições de estado do vapor, nas hipóteses de se utilizar, ou não, a palha na caldeira, tal como descrito na Tabela . Posteriormente, os cenários foram utilizados como referência para avaliar a influência de alternativas de arranjos do ciclo Rankine (Tabela ).

Os resultados serão analisados em duas etapas: sem aproveitamento da palha; e com aproveitamento da palha.

De acordo com o objetivo e escopo desse trabalho, estudou-se o desempenho ambiental associados à geração de 1,0 MWh de eletricidade excedente. Os resultados obtidos para os cenários I a V (sem aproveitamendo da palha), são apresentados na Tabela 20, enquanto os resultados para os cenários VI a X (com aproveitamento da palha), são apresentados na Tabela 21.

Tabela 12 - Resultados da Avaliação de Impactos ambientais para os cenários I a V associados à geração de 1,0 MWh de eletricidade excedente, na unidade de cogeração.

\begin{tabular}{|l|c|c|c|c|c|c|}
\cline { 3 - 7 } \multicolumn{2}{c}{} & \multicolumn{3}{c|}{ Cenários do Ciclo Convencional sem uso de palha } \\
\cline { 3 - 7 } \multicolumn{2}{c|}{} & I & II & III & \multicolumn{1}{c|}{ IV } & V \\
\hline Categoria de Impacto & Unidade & $\mathbf{2 0}$ bar & $\mathbf{4 5}$ bar & $\mathbf{6 7}$ bar & $\mathbf{8 0}$ bar & $\mathbf{1 0 0}$ bar \\
\hline Mudaças climáticas & kg CO2 eq & 168,7 & 146,4 & 134,5 & 129,5 & 126,5 \\
\hline Dermação de material particulado & kg PM10 eq & 20,1 & 17,5 & 16,1 & 15,5 & 15,1 \\
\hline Depleção de água & $\mathrm{m} 3$ & 4,49 & 3,82 & 3,67 & 3,63 & 3,18 \\
\hline
\end{tabular}


Tabela 13 - Resultados da Avaliação de Impactos ambientais para os cenários $\mathrm{VI}$ a $\mathrm{X}$ associados à geração de 1,0 MWh de eletricidade excedente, na unidade de cogeração.

\begin{tabular}{|l|c|c|c|c|c|c|}
\cline { 3 - 7 } \multicolumn{2}{c|}{} & \multicolumn{5}{c|}{ Cenários do Ciclo Convencional com uso de palha } \\
\cline { 3 - 7 } \multicolumn{2}{c|}{} & VI & VII & VIII & IX & X \\
\hline Categoria de Impacto & Unidade & $\mathbf{2 0}$ bar & $\mathbf{4 5}$ bar & $\mathbf{6 7}$ bar & $\mathbf{8 0}$ bar & $\mathbf{1 0 0}$ bar \\
\hline Mudaças climáticas & kg CO2 eq & 155,7 & 133,8 & 122,4 & 117,7 & 115,0 \\
\hline Formação de material particulado & kg PM10 eq & 17,9 & 15,4 & 14,1 & 13,5 & 13,2 \\
\hline Depleção de água & $\mathrm{m} 3$ & 7,16 & 6,08 & 5,74 & 5,62 & 5,37 \\
\hline Depleção de material fóssil & $\mathrm{kg}$ oil eq & 8,26 & 7,09 & 6,49 & 6,24 & 6,10 \\
\hline
\end{tabular}

De forma geral, a análise do perfil de impactos ambientais apresentado na Tabela 20, mostra que o aumento da pressão de trabalho contribuiu para redução dos impactos ambientais em todas as categorias de impacto estudadas. A redução total quando se projeta um aumento de pressão de 20 para 100 bar foi na ordem de $25 \%$ para as todas as categorias, exceto para a categoria de depleção de água, cujo resultado foi ainda melhor, atingindo $29 \%$. O melhor resultado para a categoria de Depleção de Água pode ser explicado considerando-se que houve uma redução do consumo de água na torre em virtude do aumento da eficiência exergética do ciclo por conta da redução do rejeito de calor no conjunto condensador e torre.

Realizando a mesma análise para os cenários com uso da palha, apresentados na Tabela 21 , observa-se uma redução na ordem de $26 \%$ com o aumento da pressão em todas as categorias, inclusive de depleção de água. Nesse caso, redução do consumo de água na torre que ocorreria em virtude do aumento da eficiência exergética do ciclo foi balanceado pelo aumento da transferência de energia térmica para o fluido de trabalho na caldeira, com a utilização da palha.

A redução de impactos era de fato esperada com o aumento da pressão nos dois casos, com e sem aproveitamento da palha. Isto pode-se explicar de acordo com a Análise Termodinâmica que foi apresentada. No primeiro caso, onde não se aproveita a palha com ciclo Convencional, a geração de eletricidade excedente disponível para exportação aumentou de $54,9 \mathrm{kWh} / \mathrm{t}_{\text {cana }}$ a 20 bar para 106,2 $\mathrm{kWh} / \mathrm{t}_{\text {cana }}$ a 100 bar, a partir do mesmo consumo de insumos energéticos. No segundo caso, onde há aproveitamento da palha no ciclo Convencional, a geração de eletricidade excedente disponível para exportação aumentou de $117,7 \mathrm{kWh} / \mathrm{t}_{\text {cana }}$ a 20 bar para $194,3 \mathrm{kWh} / \mathrm{t}_{\text {cana }}$ a 100 bar a partir do mesmo consumo de insumos 
energéticos, que nesse caso incluiu $50 \%$ da palha gerada no campo. De forma análoga, todos os cenários em que houve aumento na geração de eletricidade observou-se redução nos impactos ambientais.

Em cada cenário estudado, uma nova alocação é realizada no sistema de cogeração, redistribuindo as cargas ambientais entre os produtos gerados. Como os consumos de vapor e eletricidade na produção de etanol são mantidos constantes, as cargas ambientais associadas a essas correntes serão menores à medida que se aumenta a geração de eletricidade excedente com o aumento da pressão na caldeira e com o uso da palha, causando redução de impactos ambientais associados também ao produto do subsistema de produção de etanol, que é o etanol anidro. Com isso, verificou-se que uma ação de melhoria numa etapa do processo pode ter influência positiva de caráter sistêmico. Os impactos ambientais associados à produção de etanol e os respectivos ganhos potenciais devido a adoção de práticas de racionamento energético não foram analisados e ficaram fora do objetivo e escopo desse trabalho, ficando essa tarefa como sugestão para trabalhos futuros.

A Figura 40 apresenta os dados das Tabelas 20 e 21 de forma consolidada para melhor vizualização e comparação dos perfis de impactos ambientais das quatro categorias analisadas para o sistema de cogeração que opera segundo o ciclo Convencional com e sem utilização de palha.

Foi observado um comportamento semelhante ao que foi discutido acima em termos de impactos ambientais associados ao aumento de pressão nos cenários com os diferentes arranjos do ciclo Rankine: com Reaquecimento, Regenerativo e Resultante. De fato, conforme discutido na Análise Termodinâmica, a melhorias no ciclo Rankine proporcionaram redução nas irreversibilidades do ciclo e aumento na eficiência exergética, gerando maior disponibilidade de eletricidade para exportação, o que resulta em menor nível de impactos ambientais. Esses resultados estão apresentados na forma gráfica, através das Figuras 41, 42 e 43, respectivamente. 
Mudanças Climáticas: Comparação do ciclo Convencional com e sem uso de palha na caldeira (kg CO2eq.)

- Convencionalsem palha $\quad$ Convencional com palha

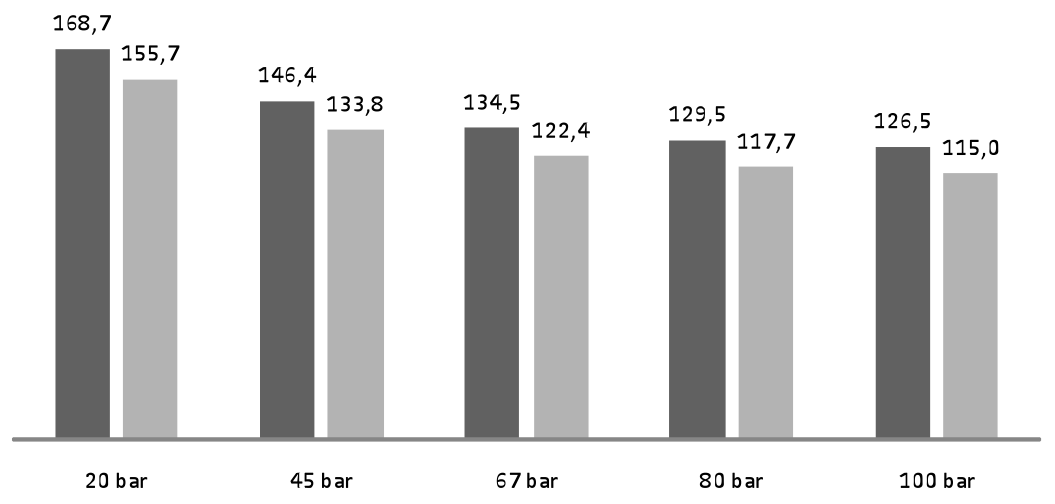

Depleção de água: Comparação do ciclo Convencionalcom e sem uso de palha na caldeira (m3)

- Convencionalsem palha convencional com palha

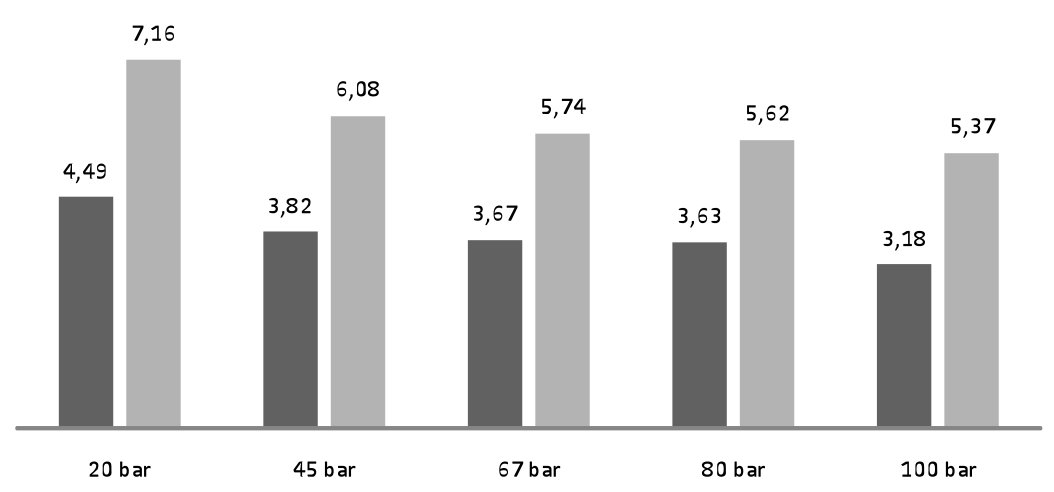

Formação de material particulado: Comparação do ciclo Convencional come sem uso de palha na caldeira (kg PM10 eq.)

Convencionalsem palha Convencional com palha

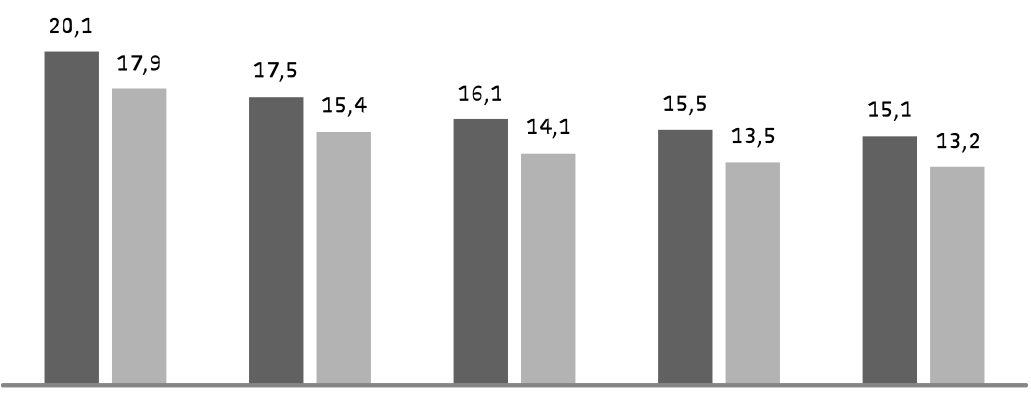

$20 \mathrm{bar}$

$45 \mathrm{bar}$

$67 \mathrm{bar}$

$80 \mathrm{bar}$

$100 \mathrm{bar}$

Depleção de material fossil: Comparação do ciclo Convencional come sem uso de palha na caldeira (kg oil eq.)

- convencionalsem palha Invencional compalha

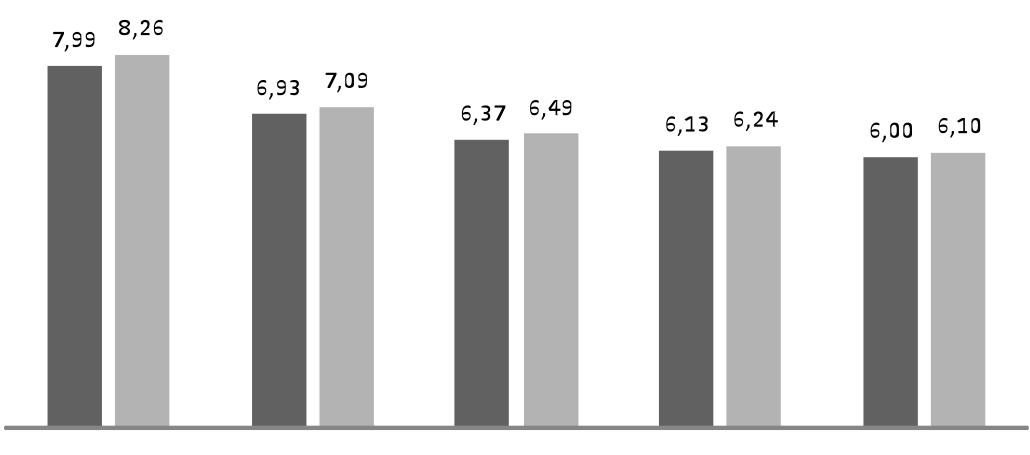

Figura 40 - Comparação dos resultados da Avaliação de Impactos ambientais associados à geração de 1,0 MWh de eletricidade excedente em sistema com ciclo Convencional, com e sem utilização de palha. 
Mudanças Climáticas: Comparação do ciclo com Reaquecimento com e sem uso de palha na caldeira (kg CO2eq.)

- Reaquecimentosem palha Reaquecimento com palha

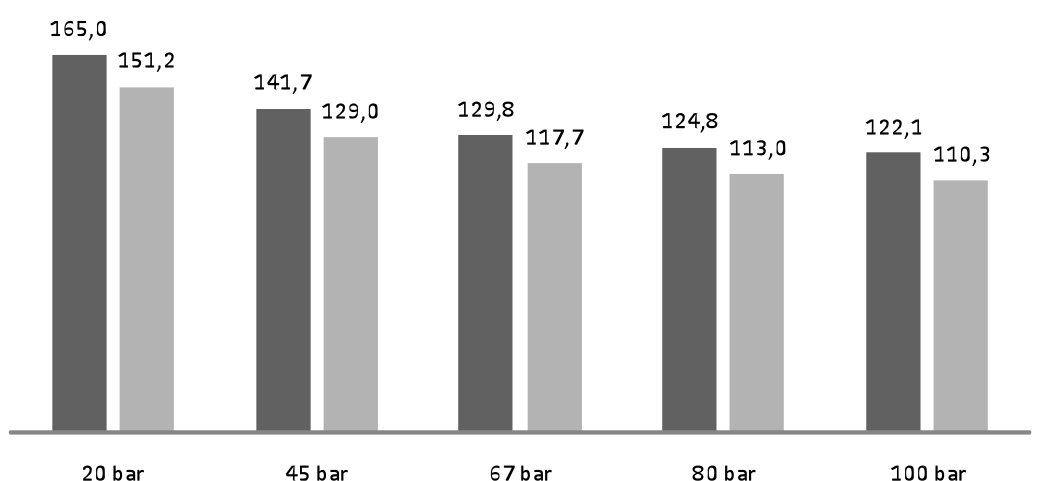

Depleção de água: Comparação do ciclo com Reaquecimento com e sem uso de palha na caldeira (m3)

- Reaqueciment osem palha $\|$ Reaquecimento com palha

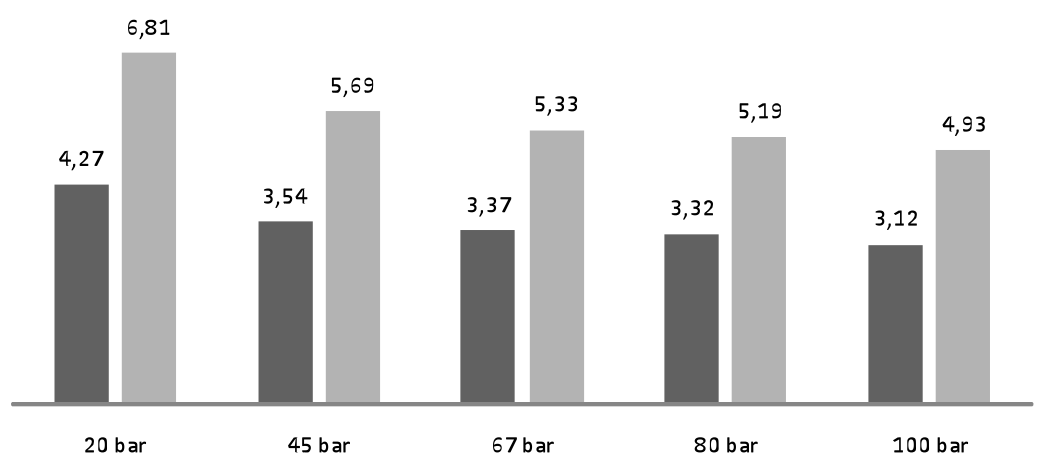

Formação de material particulado: Co mparação do ciclo com Reaquecimento com e sem uso de palha na caldeira (kg PM10 eq.)

- Reaquecimentosem palha $\square$ Reaque ciment o com palha

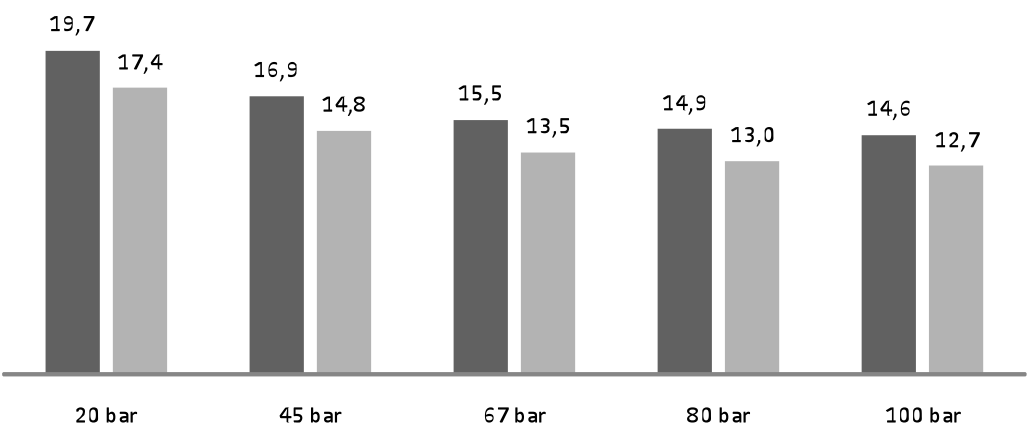

De pleção de material fossil: Comparaç̃o do ciclo com Reaquecimento com e sem uso de palha na caldeira (kg oil eq.)

- Reaquecimentosem palha $\square$ Reaquecimento com palha

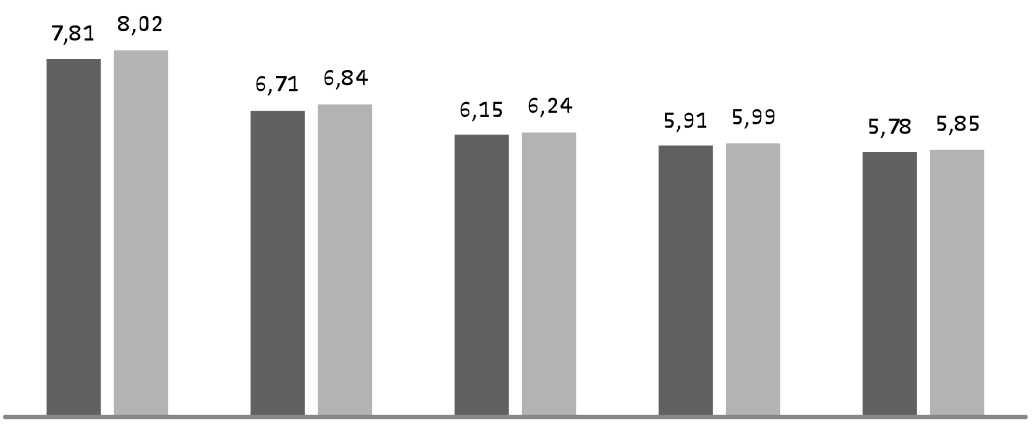

Figura 41 - Comparação dos resultados da Avaliação de Impactos ambientais associados à geração de 1,0 MWh de eletricidade excedente em sistema com Reaquecimento, com e sem utilização de palha. 
Mudanças Climáticas: Comparação do ciclo Regenerativo com e sem uso de palha na caldeira (kg CO2eq.)

$\square$ Regenerativo sem palha $\square$ Regenerativo com palha

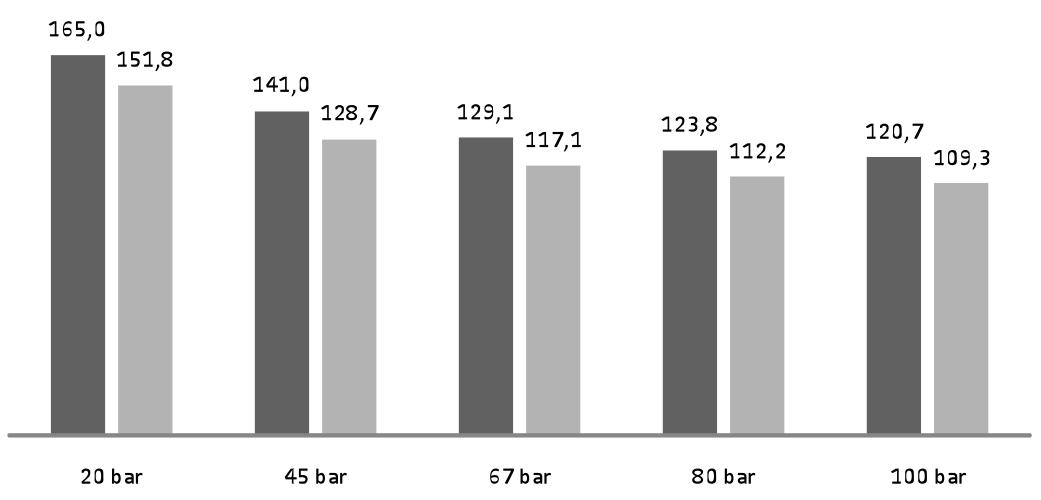

Depleção de água: Comparação do ciclo Regenerativo com e sem uso de palha na caldeira (m3)

- Regenerativo sem palha Regenerativo com palha

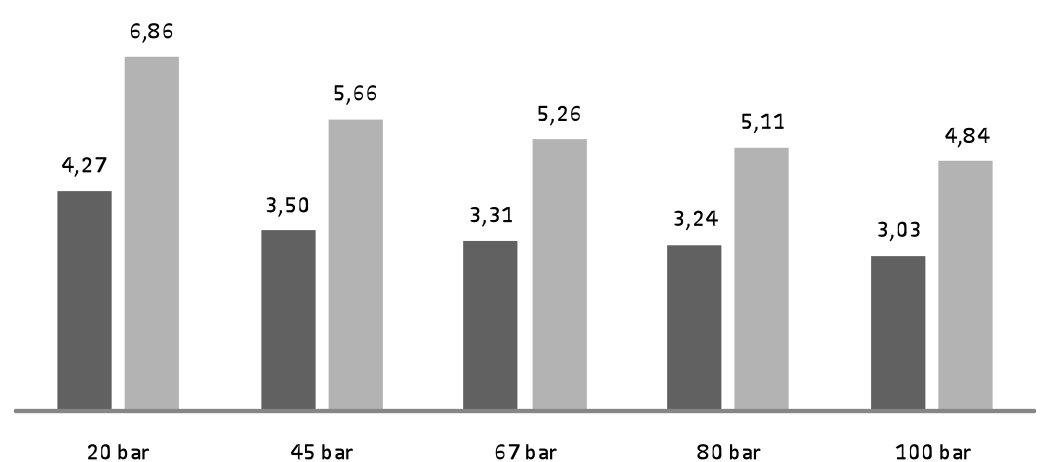

Formação de material particulado: Com paração do ciclo Regenerativo com e sem uso de palha na caldeira (kg PM10 eq.)

- Regenerativo sem palha $\square$ Regenerativo com palha

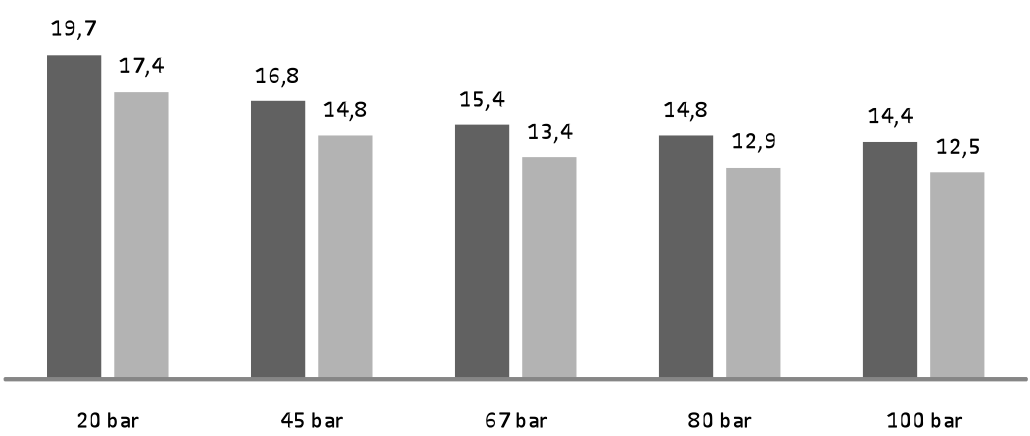

Depleção de material fossil: Comparação do ciclo Regenerativo com e sem uso de palha na caldeira (kg oil eq.)

- Regenerativo sem palha $\quad$ Regenerativo com palha

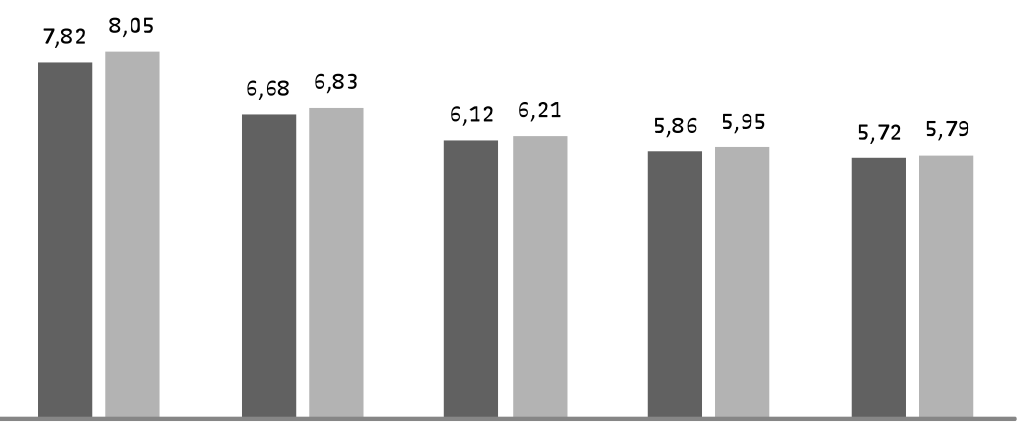

$20 \mathrm{bar}$
$67 \mathrm{bar}$
$100 \mathrm{bar}$

Figura 42 - Comparação dos resultados da Avaliação de Impactos ambientais associados à geração de 1,0 MWh de eletricidade excedente em sistema com ciclo Regenerativo, com e sem utilização de palha. 
Mudanças Climáticas: Comparação do ciclo Resultante com e sem uso de palha na caldeira (kg CO2eq.)

- Resultantesem palha $\quad$ Resultante com palha

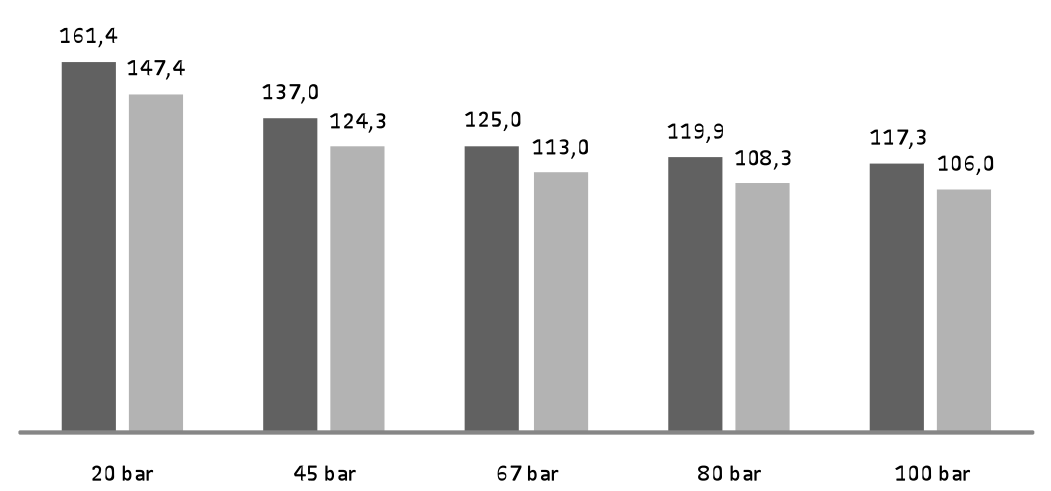

Depleção de água: Comparação do ciclo Resultante com e sem uso de palha na caldeira (m3)

- Resultantesem palha $\square$ Resultante com palha

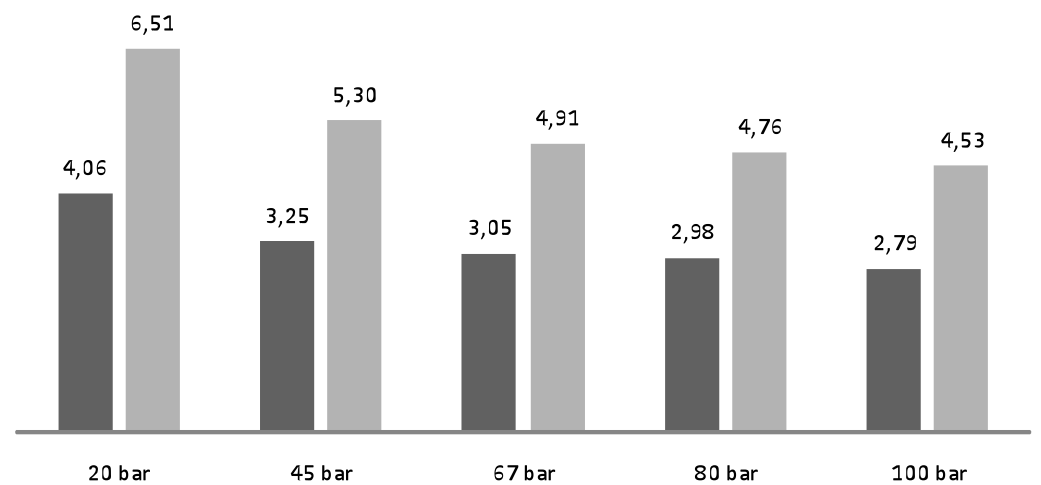

Formação de material particulado: Comparação do ciclo Resultante com e sem uso de palha na caldeira (kg PM10 eq.)

Resultantesem palha Resultante com palha

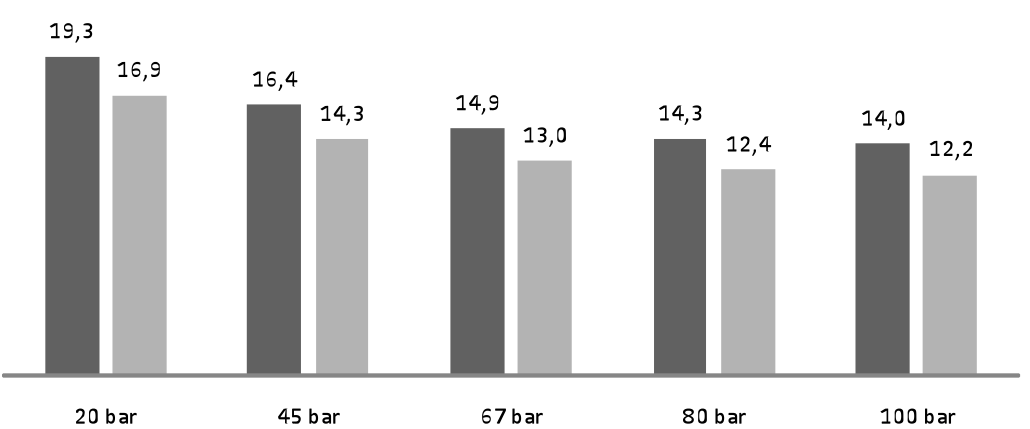

De pleção de material fossil: Com paração do ciclo Resultante com e sem uso de palha na caldeira (kg oil eq.)

- Resultantesem palha $\square$ Result ante com palha

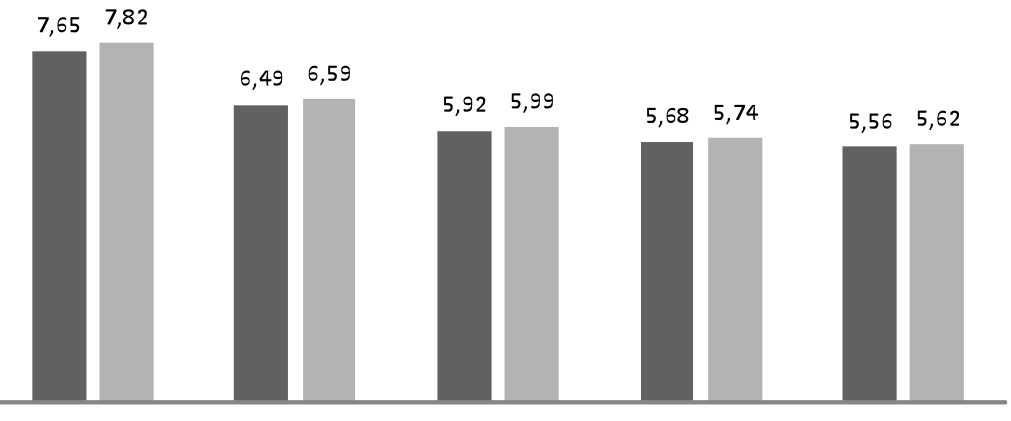

$20 \mathrm{bar}$

$67 \mathrm{bar}$

$80 \mathrm{bar}$

$100 \mathrm{bar}$

Figura 43 - Comparação dos resultados da Avaliação de Impactos ambientais associados à geração de 1,0 MWh de eletricidade excedente em sistema com ciclo Resultante, com e sem utilização de palha. 
A partir da análise das Figuras 40 a 43, que compreendem os cenários de I a XL, verificou-se claramente que a redução obtida com o aumento da pressão nas categorias analisadas não foi linear e mais se aproximou de uma curva logarítimica em todos os casos estudados. Por exemplo, no caso das categorias de Mudanças climáticas, Formação de material particuldo e Depleção de material fossil, nos cenários do ciclo Convencional sem aproveitamento da palha houve uma redução de $13,2 \%$ com o aumento de 20 para 45 bar, depois uma redução adicional de $8,1 \%$ quando se aumentou para 67 bar, posteriormente observou-se uma redução de $3,8 \%$ com o aumento da pressão até 80 bar e finalmente uma redução adicional de $2,3 \%$ quando se aumentou a pressão de 80 a 100 bar. Uma tendência semelhante também é observada para os cenários com aproveitamento de palha. Com isso, ratificou-se a importância de realizar uma análise de viabilidade econômica para se projetar um aumento de pressão quando se considera a variável ambiental, pois custos adicionais associados a aspectos construtivos são incrementados, conforme discutido anteriormente.

A partir das Figuras 40 a 43 também foi possível avaliar os resultados em termos ambientais proporcionados pela adoção das técnicas utilizadas para aumento da eficiência do ciclo Rankine, correspondendo aos cenários com Reaquecimento, Regeneração e Resultante. A análise comparativa dessas propostas em relação ao ciclo Rankine Convencional, mostrou que a redução dos impactos ambientais de acompanhou o aumento da eletricidade excedente em cada cenário, mas não na mesma proporção, pois a cada cenário em que há aumento na taxa de eletricidade excedente, a alocação entre os produtos do sistema de cogeração foi recalculada por critério exergético, o que traz benefícios também à produção de etanol, pois o vapor e a eletricidade utilizada no processo industrial passa a ter menor carga ambiental. Seguindo a mesma tendência apresentada na Análise Termodinâmica, os melhores resultados ambientais foram obtidos com a proposta do ciclo Resultante, que combina Reaquecimento e Regeneração num único ciclo. Nesse configuração, sem uso de palha as reduções partiram de $4,3 \%$ a 20 bar e chegaram a 7,3\% a 100 bar nas categorias de CC, PMF e DF. A redução em termos de WD foi de $9,5 \%$ a 20 bar e chegou a $12,4 \%$ a 100 bar. Nos cenários com utilização de palha, os resultados proporcionados pelo ciclo Resultante foram ainda melhores, a redução de impactos ambientais partiu de 5,3\% nos cenários a 20 bar e atingiu 7,8\% a 100 bar 
nas categorias de CC, PMF e DF. A redução em termos de WD foi de $9,0 \%$ a 20 bar e chegou a $15,6 \%$ a 100 bar. Os ganhos foram calculados sempre em relação aos cenários de referência com ciclo Convencional, usando mesmo critério de comparação da Análise Termodinâmica.

A Avaliação de Ciclo de Vida realizada nesse trabalho possibilitou identificar os principais elementos do processo produtivo que tiveram maior contribuição na geração de impactos ambientais, bem como identificar as principais substâncias poluentes e onde elas são geradas. Esses resultados obtidos a partir da modelagem e simulação no SimaPro serão apresentados e discutidos a seguir. Como o Sistema de Produto conta com duas possibilidades distintas, uma que prevê uma condição real, sem aproveitamento da palha e outra futura, com aproveitamento, a discussão da ACV é apresentada com foco nessas duas possibilidades.

Quando se compara os resultados obtidos com e sem utilização da palha, verificouse um comportamento direferente para cada categoria de impacto, conforme será discutido a seguir.

Em relação aos impactos associados às Mudanças Climáticas, a utilização da palha como fonte de energia térmica, além dos ganhos apresentados e discutidos pela Análise Termodinâmica de Primeira e Segunda Lei, proporcionou uma redução na emissão de gases que contribuem para as Mudanças Climáticas em todas as condições de pressão. As reduções foram ainda maiores com o aumento da pressão de trabalho. No ciclo Convencional, por exemplo, houve uma redução nas emissões em termos de $\mathrm{CO}_{2}$ eq. de $7,7 \%$ a 20 bar e $9,1 \%$ a 100 bar. Uma mesma tendência em termos percentuais foi observada também para os cenários com diferentes arranjos do ciclo Rankine, embora os valores absolutos dos impactos sejam menores com o aumento da complexidade do ciclo Rankine. Em termos ambientais a redução das emissões pode ser explicada devido ausência das queimadas no canavial e o uso da palha na caldeira para conversão de energia térmica em trabalho útil no sistema de cogeração, sob condições controladas. Esses benefícios suprimiram os impactos adicionais causados pelas etapas adicionais de enfardamento, transporte e moagem da palha. Portanto, o uso da palha na caldeira representou redução significativa nos impactos ambientais associados a essa categoria, em todas as condições operacionais do sistema de cogeração. 
A partir de uma perspectiva mais específica, as simulações dos cenários no SimaPro mostraram que para o Sistema de Produto estudado, os principais elementos do processo responsáveis pelas contibuições para a categoria de Mudanças Climáticas (CC) sem utilização de palha, foram: etapa agrícola com $71,7 \%$ das contribuições; a etapa de cogeração com $15,7 \%$ e depois o transporte da cana, com $5,4 \%$. Adotou-se como critério de importância, a fim de priorizar os processos e substâncias que mais se destacam na ACV, os processos e substâncias que apresentem suas contribuições somadas representando no mínimo $90 \%$ do total, respectivamente para cada análise.

Com aproveitamento da palha, a contribuição da etapa agrícola foi reduzida para $67,5 \%$, pois não há queimadas nesses cenários e as emissões da palha deixada no campo são referentes à decomposição desta biomassa; o sistema de cogeração passou a apresentar uma maior contruibuição, com 18,8\% das emissões, devido à queima da palha na caldeira; a etapa de transporte passou a contruibuir com $5,7 \%$, pois além da cana, a palha também é transportada por caminhões. Finalmente a etapa adicional de enfardamento da palha, contribuiu com 1,3\% dos impactos na categoria de CC.

Ao analisar as substâncias responsáveis pelas contribuições, verificou-se que as principais são:

$\checkmark$ Emissões de dióxido de carbono $\left(\mathrm{CO}_{2}\right)$ associado à transformação do solo: Tanto nos cenários sem uso de palha ou com uso de palha, este poluente representou $50,5 \%$ das contribuições, integralmente associado à etapa agrícola;

$\checkmark$ Emissões de monóxido de dinitrogênio $\left(\mathrm{N}_{2} \mathrm{O}\right)$ : Nos cenários sem uso de palha, este poluente representou $20,6 \%$ das contribuições, sendo que $48,9 \%$ está associado à etapa agrícola, devido aos processos de queimada dos canaviais, oxidação de fertilizantes nitrogenados, aplicação da vinhaça e torta de filtro, além da combustão de diesel nos maquinários agrícolas e 46,8\% associado ao sistema de cogeração, devido à queima do bagaço na caldeira. Já nos cenários com utilização da palha, o mesmo poluente representou $20,8 \%$ das contribuições. A parcela referente à etapa agrícola foi reduzida para $43,7 \%$, devido a hipótese de não haver queimada nos canaviais, 
enquanto a parcela referente ao sistema de cogeração aumentou para $55,7 \%$, pois além do bagaço, a palha também passou a ser queimada na caldeira.

$\checkmark$ Emissões de dioxido de carbono fóssil $\left(\mathrm{CO}_{2}\right.$, fossil): Nos cenários sem uso da palha, este poluente representou $19,0 \%$ das contribuições. A etapa agrícola contribuiu com 42,6\% das emissões desta substância, devido combustão de óleo diesel nos maquinários, aplicação de ureia e cal, seguido do transporte da cana até a usina, com $28,8 \%$. Nos cenários com aproveitamento da palha, a contribuição desse poluente aumentou para $20,8 \%$, devido às etapas adicionais de enfardamento e transporte da palha, onde óleo diesel é consumido. Com o aumento das emissões de $\mathrm{CO}_{2}$, fossil devido às etapas adicionais, a parcela referente à etapa agrícola foi reduzida para $38,8 \%$ das emissões desta substância, o transporte da cana até a usina caiu para $26,8 \%$ e as etapas adicionais de enfardamento e transporte da palha reponderam por $6,0 \%$ da emissão total de $\mathrm{CO}_{2}$, fossil. As contribuições restantes estão associadas à produção dos insumos agrícolas e ao transporte dos mesmos até a aplicação no campo. Por isso a importância no controle da aplicação dos insumos agrícolas, tanto em termos de redução de custos como de impactos ambientais.

Por fim, destaca-se também a emissão de metano biogênico, que nos cenários sem aproveitamento da palha ocorre na etapa agrícola devido queimada dos canaviais, representando 3,3\% dos impactos sobre mudanças climáticas. Nos cenários com aproveitamento da palha, como foi adotada a premissa de não haver queima dos canaviais, as emissões de metano biogênico passam para o sistema de cogeração.

Em relação à Formação de Material Particulado (PMF), a utilização da palha na caldeira proporcionou resultados ainda melhores em todas as condições de pressão. Houve uma redução de $11,2 \%$ a 20 bar e $12,6 \%$ a 100 bar. Essa redução expressiva é atribuída principalmente às condições de combustão da palha em ambiente controlado e sua conversão em trabalho útil.

De um ponto de vista mais específico, as emissões que impactam em PMF concentram-se nos processos de produção de cana-de-açúcar (etapa agrícola) e no sistema de cogeração. Nos cenários sem aproveitamento de palha esses processos foram responsáveis por $90,1 \%$ e 9,4\%, respectivamente. Com o aproveitamento da 
palha, a contribuição da etapa agrícola caiu para $87,9 \%$ - pois esses cenários não preveem queimada dos canaviais - enquanto o sistema de cogeração passou a contribuir com $11,8 \%$ - pois além do bagaço, a palha também é queimada na caldeira.

Em todos os cenários, a substância que apresentou maior contribuição para a categoria de de PMF, foi a liberação de materiais particulados com diâmetro < 2,5 $\mu \mathrm{m}$. Estes representaram $88,7 \%$ dos impactos nos cenários sem utilização de palha e 90,9\% nos cenários com utilização de palha, associados principalmente à etapa agrícola, que respondeu por $96,8 \%$ e $96,2 \%$ das emissões deste poluente em cada caso. O sistema de cogeração foi responsável por somente $3,2 \%$ das emissões de materiais particulados com diâmetro $<2,5 \mu \mathrm{m}$ nos cenários sem aproveitamento de palha e 3,8\% quando há uso de palha na caldeira. Já os materiais particulados com diâmetro < $10 \mu \mathrm{m}$ são gerados principalmente durante queima do bagaço e da palha. Contudo, quando se utiliza a palha na caldeira verificou-se um menor nível de emissão, pois trata-se de um processo de combustão controlado, onde os fatores de emissão são menores, conforme apresentado nas discussões sobre a Análise de Inventário. Com isso, quando não há mais queimadas nos canaviais e a palha passa a ser aproveitada e queimada na caldeira, o impacto na categoria PMF associado à emissão de materiais particulados com diâmetro < $10 \mu \mathrm{m}$ foi reduzido de 9,2\% para $6,9 \%$, concentrando-se integralmente no sistema de cogeração. As emissões de oxidos de nitrogênio representaram 1,6\% e 1,7\% nos cenários sem e com utilização de palha, respectivamente, evidenciando pouca influência da palha na emissão desse poluente.

Conforme acaba de ser apresentado e discutido, a utilização de palha na caldeira, sob as condições operacionais descritas, trouxe reduções significativas de impactos ambientais para as categorias de Mudanças Climáticas e Formação de Material Particulado. Por outro lado, a partir da Figura 40, verificou-se que os resultados pioraram para as categorias de Depleção de Água (WD) e Depleção Fossil (FD), que serão discutidas a seguir.

Com relação à categoria WD, houve um aumento médio na ordem de $60 \%$ no consumo de água associado à geração de 1,0 MWh de eletricidade excedente. Por exemplo, enquanto no sistema convencional a 20 bar sem usar a palha o impacto 
nessa categoria é de $4,49 \mathrm{~m}^{3}$, se a palha for utilizada o impacto passa a ser de 7,16 $\mathrm{m}^{3}$. Em todos os casos o consumo de água para geração de geração de 1,0 MWh de eletricidade excedente está associado principalmente ao sistema de cogeração. Esta observação pode ser explicada através da Análise Termodinâmica, pois o aumento na transferência de energia térmica da biomassa composta por bagaço e palha para o fluido de trabalho, se por um lado eleva a geração de eletricidade, por outro eleva também a quantidade de calor rejeitado, e consequentemente maior consumo de água para repor a evaporação, arraste e purga da torre de resfriamento. A Depleção de Água (WD) concentrou-se em consumo de água de rios (90,4\%) para utilização como água de uso geral (tap water) utilizada na torre de resfriamento.

Em termos de Depleção Fossil (FD), a utilização da palha provocou um aumento de impactos mais sutil, enquanto se consumiu $7,99 \mathrm{~kg}$ oil eq. sem utilizar palha para gerar 1,0 MWh de eletricidade excedente, se for utilizado palha, esse consumo aumenta para $8,26 \mathrm{~kg}$ oil eq., um aumento de 3,3\%. Com o aumento da pressão de trabalho os impactos em termos de FD para os sistemas com e sem palha tendem a se aproximar, pois com o aumento da eficiência exergética do ciclo há uma maior geração de eletricidade, o que passa a compensar os impactos adicionais causados pelas etapas de enfardamento, transporte e moagem da palha. No melhor cenário, a 100 bar, o uso da palha revelou um aumento de 1,7\% nas emissões nessa categoria.

Do ponto de vista da análise de processo, as simulações dos cenários no SimaPro mostraram que para os cenários onde não há aproveitamento da palha, $73,2 \%$ do consumo de combustíveis fosseis está na etapa agrícola e $26,8 \%$ no transporte da cana até a usina. No entanto, com o aproveitamento da palha, há um incremento nos valores absolutos de consumo devido adição de etapas de beneficiamento e transporte da palha, a participação da etapa agrícola é então reduzida para $69,2 \%$, o transporte da cana passa a representar $25,4 \%$ do total e, as etapas adicionais de enfardamento, transporte e moagem da palha respondem por $2,6 \%, 2,1 \%$ e $0,7 \%$, respectivamente. A principal substância associada a esta categoria foi o óleo cru, que representou $99,0 \%$, de onde é gerado o óleo diesel utilizado pelos maquinários agrícolas e pelos caminhões de transporte, sendo que 1,0\% foi associado ao consumo de gás natural, utilizados na preparação de fertilizantes sintéticos nitrogenados, como urea, MAP e DAP (Guerra et al., 2014). 
Como era esperado, as simulações no SimaPro mostraram que as proporções de contribuição de cada etapa do processo bem como as principais substâncias poluentes foram preservadas na mesma ordem de grandeza em todos os cenários que houve alterações no ciclo Rankine, uma vez que tais alterações ocorrem somente no sistema de cogeração e o percentual de alocação é recalculado para cada condição.

\subsubsection{ANÁlISE de SENSIBILIDADE}

Com o objetivo de avaliar a confiabilidade dos resultados finais e a vulnerabilidade com o critério de alocação, foi realizada uma análise de sensibilidade, mantendo todas as premissas iniciais e alterando o critério de alocação no sistema de cogeração de exergético para energético. Para essa análise foi escolhido o conjunto de cenários de I a X, com ciclo Rankine Convencional, sem e com aproveitamento da palha. Os novos fatores de alocação são apresentados nas Tabelas 22 e 23, respectivamente.

Tabela 14 - Percentuais de alocação por critério energético para cenários sem aproveitamento da palha.

\begin{tabular}{|c|c|c|c|c|c|c|c|}
\hline \multirow[b]{2}{*}{ Descrição } & \multirow[b]{2}{*}{ Cenário } & \multicolumn{3}{|c|}{ Produtos da Cogeração (kWh/tc) } & \multicolumn{3}{|c|}{ ALOCAÇÃO (Energia) \% } \\
\hline & & $\begin{array}{l}\text { Eletricidade } \\
\text { excedente }\end{array}$ & $\begin{array}{c}\text { Eletricidade } \\
\text { para indústria }\end{array}$ & $\begin{array}{c}\text { Vapor } \\
\text { para processo }\end{array}$ & $\begin{array}{l}\text { Eletricidade } \\
\text { excedente }\end{array}$ & $\begin{array}{c}\text { Eletricidade } \\
\text { para indústria }\end{array}$ & $\begin{array}{c}\text { Vapor para } \\
\text { processo }\end{array}$ \\
\hline \multirow{5}{*}{ 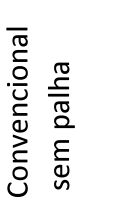 } & 1 & 54,9 & 30,0 & 242,4 & 16,8 & 9,2 & 74,0 \\
\hline & II & 78,7 & 30,0 & 242,4 & 22,4 & 8,5 & 69,1 \\
\hline & III & 94,3 & 30,0 & 242,4 & 25,7 & 8,2 & 66,1 \\
\hline & IV & 101,8 & 30,0 & 242,4 & 27,2 & 8,0 & 64,8 \\
\hline & V & 106,2 & 30,0 & 242,4 & 28,1 & 7,9 & 64,0 \\
\hline
\end{tabular}

Tabela 15 - Percentuais de alocação por critério energético para cenários com aproveitamento da palha.

\begin{tabular}{|c|c|c|c|c|c|c|c|}
\hline \multirow[b]{2}{*}{ Descrição } & \multirow[b]{2}{*}{ Cenário } & \multicolumn{3}{|c|}{ Produtos da Cogeração (kWh/tc) } & \multicolumn{3}{|c|}{ ALOCAÇÃO (Energia) \% } \\
\hline & & $\begin{array}{l}\text { Eletricidade } \\
\text { excedente }\end{array}$ & $\begin{array}{c}\text { Eletricidade } \\
\text { para indústria }\end{array}$ & $\begin{array}{c}\text { Vapor } \\
\text { para processo }\end{array}$ & $\begin{array}{c}\text { Eletricidade } \\
\text { excedente }\end{array}$ & $\begin{array}{c}\text { Eletricidade } \\
\text { para indústria }\end{array}$ & $\begin{array}{c}\text { Vapor para } \\
\text { processo }\end{array}$ \\
\hline \multirow{5}{*}{ 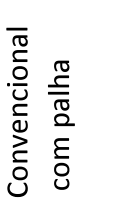 } & $\mathrm{VI}$ & 112,1 & 35,6 & 242,4 & 28,7 & 9,1 & 62,1 \\
\hline & VII & 147,6 & 35,6 & 242,4 & 34,7 & 8,4 & 57,0 \\
\hline & VIII & 170,9 & 35,6 & 242,4 & 38,1 & 7,9 & 54,0 \\
\hline & IX & 182,1 & 35,6 & 242,4 & 39,6 & 7,7 & 52,7 \\
\hline & $x$ & 188,7 & 35,6 & 242,4 & 40,4 & 7,6 & 51,9 \\
\hline
\end{tabular}


Diferentemente do critério de alocação exergético originalmente utilizado nesse trabalho, o critério energético considera todas as formas de energia como sendo iguais e não o potencial máximo de realizar trabalho, proveniente da aplicação do conceito de exergia. Portanto, o conteúdo energético é o próprio valor específico da corrente.

Observa-se a partir das Tabelas 22 e 23, que pelo critério energético o vapor de processo passa a receber maior fator de alocação, o que irá transferir maior carga ambiental para a produção de etanol e, a eletricidade excedente, que é o produto principal desse trabalho, receberá menor carga ambiental.

Os resultados da avaliação de impacto ambiental são apresentados na Figura 44. 
Mudanças Climáticas: Comparação do ciclo Convencional com e sem uso de palha na caldeira (kg CO2eq.)

- Convencionalsem palha $\quad$ Convencional compalha

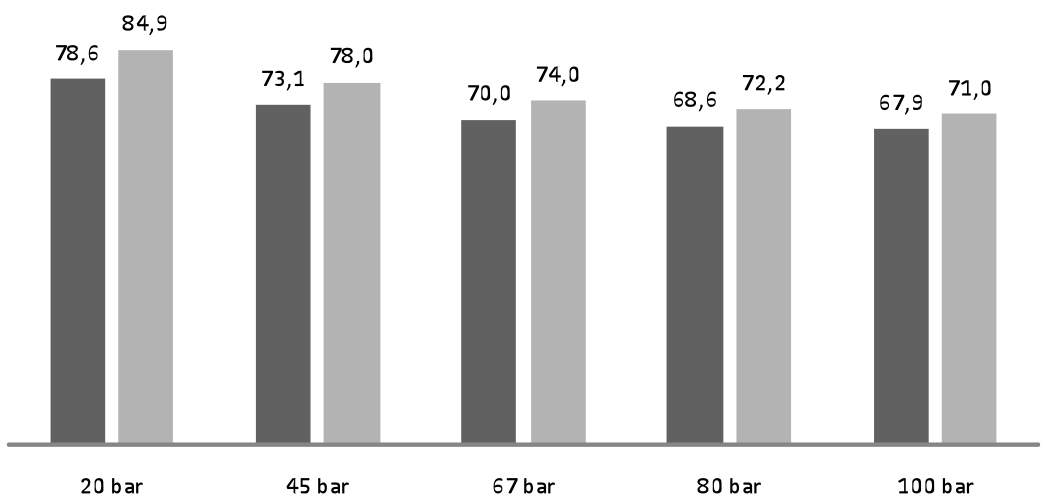

Depleção de água: Comparação do ciclo Convencionalcom e sem uso de palha na caldeira (m3)

- Convencionalsem palha Convencional com palha

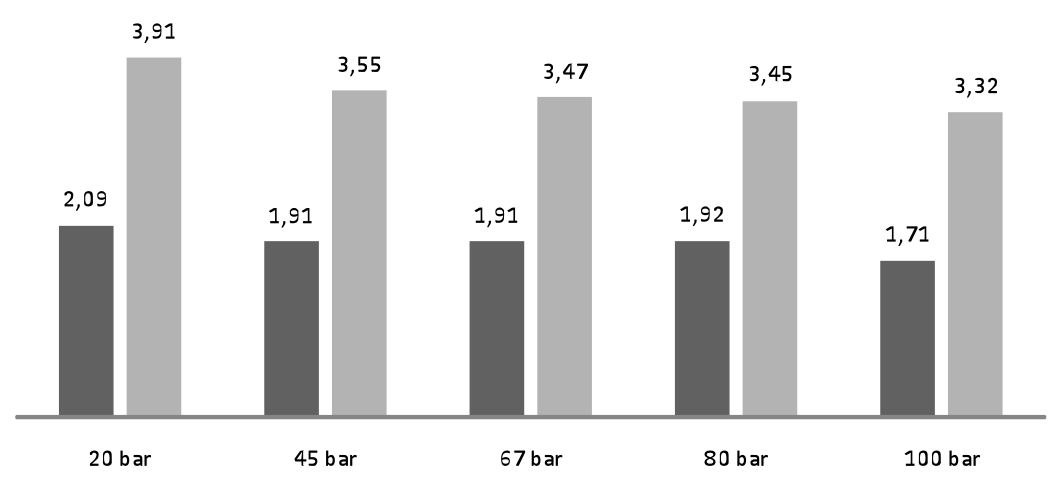

Formação de material particulado: Comparação do ciclo Convencional come sem uso de palha na caldeira (kg PM10 eq.)

Convencionalsem palha Convencional com palha

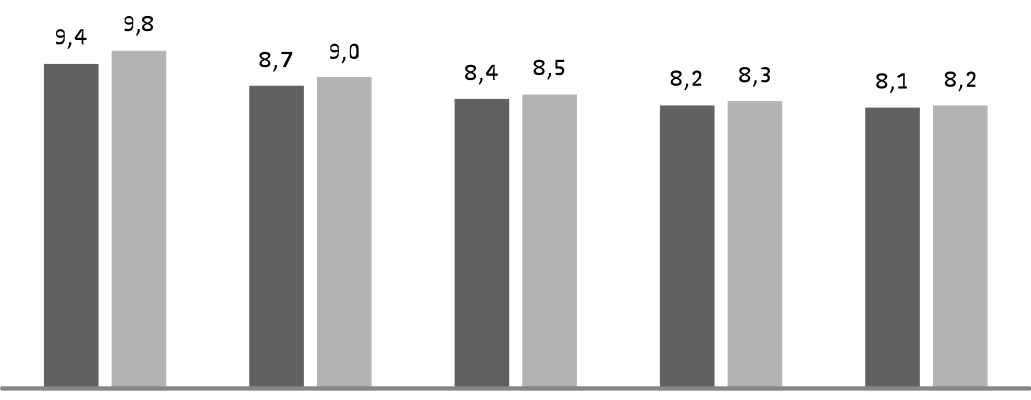

$20 \mathrm{bar}$

45 bar

$67 \mathrm{bar}$

$80 \mathrm{bar}$

$100 \mathrm{bar}$

Depleção de material fossil: Comparação do ciclo Convencional com e sem uso de palha na caldeira (kg oil eq.)

- conven cionalsem palha - Convencional com palha

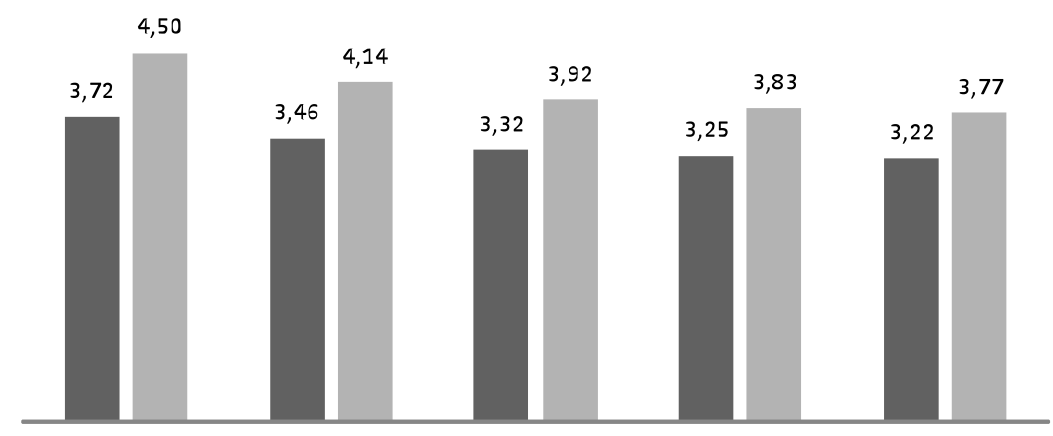

20 bar

$67 \mathrm{bar}$

$80 \mathrm{bar}$

$100 \mathrm{bar}$

Figura 44 - Comparação dos resultados da Avaliação de Impactos ambientais associados à geração de 1,0 MWh de eletricidade excedente em sistema com ciclo Convencional, com e sem utilização de palha, adotando critério energético de alocação no sistema de cogeração. 
A partir dos novos percentuais de alocação apresentados nas Tabelas 22 e 23, era de se esperar que os impactos ambientais associados à geração de 1,0 MWh de eletricidade excedente fossem reduzidos, o que de fato ocorreu em todos os casos. Por exemplo, sem considerar o uso da palha, a 20 bar houve uma redução de 53,4\% em todas categorias estudadas em relação ao mesmo cenário utilizando o critério de alocação exergético. Para cada condição de pressão, ocorreu um mesmo percentual de redução de impactos. A mesma situação foi observada para os cenários com uso de palha, por exemplo, a 20 bar, a mudança do critério de alocação para energético proporcionou uma redução de impacto de $45,4 \%$ em todas as categorias analisadas.

A redução dos impactos ambientais em todas as categorias obtida com a mudança do critério de alocação para energético, irá transferir para o etanol essas cargas ambientais. Trata-se portanto de uma redução aparente e não efetiva, pois outro produto que sai da fronteira do Sistema de Produto em estudo será penalizado. Contudo, a análise de impactos para o etanol não será apresentada nesse trabalho, conforme justificado anteriormente.

A análise de sensibilidade mostrou quão vulnerável é o modelo ao critério de alocação adotado. Nesse aspecto, justifica-se nesse trabalho a adoção do critério exergético na cogeração como mais adequado, pois todas as formas de energia são trazidas para uma mesma base de cálculo. Portanto, os conceitos da Segunda Lei da Termodinâmica através da análise exergética mostram-se importantes, ao avaliar não só a quantidade de energia dos fluxos de energia, mas também a qualidade dessa energia, quantificada através da máxima capacidade de realizar trabalho, ou seja, sua exergia. 


\section{CONCLUSÕES}

Os modelos termodinâmicos construídos possibilitaram realizar simulações dos cenários de cogeração definidos e gerar os diagnósticos de desempenho baseados na Primeira e Segunda Lei da Termodinâmica. Esses modelos possibilitaram comparar as condições operacionais e de projeto para diferentes status de implementação de alternativas tecnológicas, em termos dos diferentes arranjos dos ciclos Rankine analisados.

Os conceitos de reaquecimento e regeneração mostraram-se consideravelmente efetivos na melhoria da eficiência energética dos sistemas de cogeração. As alternativas de propostas para melhoria de desempenho do ciclo Rankine também projetaram redução de impactos ambientais em todas as categorias analisadas. Os resultados obtidos por este estudo ratificaram a expectativa do setor sucroalcooleiro de poder exportar eletricidade para a rede concessionária nos períodos de entressafra e ociosidade da instalação.

As simulações mostraram que a utilização de sistemas com reaquecimento e regeneração, combinados num só ciclo, podem gerar um aumento na eficiência exergética de $8,5 \%$, que tem impacto direto na conversão de energia térmica dos combustíveis em trabalho útil.

Essas alternativas para melhoria de desempenho termodinâmico operando com pressões mais elevadas também se reverteram em redução de impactos ambientais para todos os impactos ambientais analisadas, no melhor cenário, com ciclo Resultante e pressão de operação de 100 bar, identificou-se um potencial de redução de impactos ambientais de até $15,6 \%$.

Com relação ao uso da palha, a análise termodinâmica mostrou que a utilização de $50 \%$ da palha gerada no campo possui potencial para dobrar a geração de eletricidade excedente nas usinas de cogeração.

Contudo, a ACV mostrou pontos positivos e negativos sobre a utilização da palha: Se por um lado o uso da palha trouxe reduções significativas de impactos ambientais para as categorias de Mudanças Climáticas (CC) e Formação de Material Particulado (PMF). Por outro lado, verificou-se que há um aumento nos impactos ambientais devido ao uso da palha nas categorias de Depleção de Água (WD) e 
Depleção Fossil (FD). A redução dos impactos nas categorias CC e PMF atingiram $9,1 \%$ e $12,6 \%$, respectivamente. Enquanto para as cagorias WD e FD houve aumento de até $60,0 \%$ e 3,3\%, respectivamente. Portanto, na comparação de desempenho ambiental dos cenários com e sem utilização da palha, deve-se levar em consideração quais categorias serão priorizadas.

A análise proporcionada pela ACV para produção de eletricidade por meio de cogeração mostrou que os principais agentes causadores de impactos ambientais associados ao processo em análise estão concentrados na etapa agrícola da produção da cana-de-açúcar.

A inclusão da variável ambiental na avaliação das alternativas tecnológicas propostas para melhoria da eficiência energética do mesmo sistema proporcionou uma percepção diferente e uma abordagem sistêmica para a análise. A partir do diagnóstico proporcionado pela técnica de $\mathrm{ACV}$, foi possível perceber que a implementação de medidas efetivas de otimização e melhoria de processos, mesmo que restrita a somente um estágio do ciclo de vida de certo produto, podem resultar em reduções sistêmicas dos efeitos negativos no meio ambiente provocados por ações antrópicas. No caso específico deste esforço de pesquisa, esta constatação não dispensa a busca por novas tecnologias, práticas e comportamentos mais sustentáveis por parte dos tomadores de decisão que compões o setor sucroalcooleiro no Brasil.

De maneira ampla, esta análise vem confirmar a tendência de que o uso mais sustentável dos recursos naturais está diretamente relacionado com a adoção de práticas energéticas mais eficientes para sistemas de cogeração.

A combinação da análise exergética com a ACV proporcionou uma visão sistêmica do processo de obtenção de eletricidade a partir de sistemas de cogeração a partir da queima do bagaço e da palha de cana, o que estimula a aplicação do método da ACV no meio corporativo, que é um dos objetivos adjuntos a este trabalho.

De forma complementar, as conclusões sinalizam que o exercício da preocupação com as questões ambientais nas atividades de rotina - "Life Cycle Thinking" - deve ser estimulado dentro da indústria, a fim de agregar valor aos produtos e ao negócio. 


\section{RECOMENDAÇÕES PARA TRABALHOS FUTUROS}

Todos os cenários analisados nesse trabalho predispõem de alterações no projeto de máquinas e equipamentos. Portanto, aspectos relacionados à dimensão econômica, podem agregar informações ainda mais valiosas ao trabalho, que por indisponibilidade de tempo, não foram incorporadas ao escopo deste trabalho. Como foi evidenciado ganhos significativos em termos energético e ambientais com a adoção das técnicas de reaquecimento e regeneração, e para aplicação dessas técnicas é necessário investimentom recomenda-se uma análise de Retorno sobre Investimento (ROI), a partir de indicadores como Taxa Interna de Retorno (IRR), Valor Presente Líquido (VPL), payback time, etc.

Em relação à dimensão ambiental, outras categorias de impacto poderiam ser avaliadas, que também são importantes e refletem o desempenho ambiental do Sistema de Produto estudado, como por exemplo, Acidificação Terrestre (TA), Eutrofização de água fresca (FEU), Toxicidade Humada (HT) entre outras. Em termos de Análise de Impactos, outros métodos podem ser testados e comparados.

Uma recomendação importante seria analisar qual a influência das melhorias adotadas no sistema de cogeração através dos vários cenários estudos sobre a produção de etanol.

Em termos da qualidade dos resultados, uma melhoria recomendada seria elaborar inventários atualizados da etapa agrícola de produção de cana-de-açúcar. Associado a essa melhora, recomenda-se refinar a modelagem com utilização da palha e simular diferentes percentuais de queimada prévia dos canaviais, haja vista que a redução das queimadas vem ocorrendo de forma gradual. 


\section{REFERÊNCIAS}

ABNT - Associação Brasileira De Normas Técnicas. NBR ABNT NBR ISO 14040. Gestão Ambiental, Avaliação do Ciclo de Vida: definição de objetivo e escopo e Analise de Inventario. São Paulo: ABNT, 2009.

ABNT - Associação Brasileira De Normas Técnicas. NBR ABNT NBR ISO 14040. Gestão Ambiental, Avaliação do Ciclo de Vida: Princípios e estrutura. São Paulo: ABNT, 2009a.

ABNT - Associação Brasileira De Normas Técnicas. NBR ABNT NBR ISO 14044. Gestão Ambiental, Avaliação do Ciclo de Vida: requisitos e orientações. São Paulo: ABNT, 2009b.

AL-WAKED R.; BEHNIA M. CFD simulation of wet cooling towers. Appl Therm Eng,; 26(4): 382-395, 2006.

ANP - AGÊNCIA NACIONAL DE PETRÓLEO. Anuário estatístico brasileiro do petróleo, gás natural e biocombustíveis 2013. Rio de Janeiro: ANP, 2013.

ARREDONDO, H. I.; Avaliação Exergética e Exergo-ambiental da produção de Biocombustíveis, Tese de doutorado, Universidade de São Paulo, São Paulo, 2009.

BABCOCK and WILCOX Company: Steam, Its Generation and Use. New York: The 41st Ed.; 2005.

BALESTIERI, J.; Cogeração: geração combinada de eletricidade e calor. Florianópolis: UFSC. (279 p.), 2002.

BAUMANN, H.; TILLMAN, A.-M. The hitch hikers's guide to LCA: an orientation in life cycle assessment methodology and application. Sweden: Studentlitteratur, 2004.

BEJAN, A.; TSATSARONIS, G.; MORAN, M.; Thermal Design and Optimization, 3TH ed. New York: John Wiley \& Sons, 1996.

BERTELLI, G,: A verdadeira história do PROETANOL, Jornal Estado de São Paulo, São Paulo, 2005. 
BNDES - BANCO NACIONAL DE DESENVOLVIMENTO ECONÔMICO E SOCIAL. Bioetanol de cana-de-açúcar: energia para o desenvolvimento sustentável. Rio de Janeiro: BNDES, 2008.

BOCC,E.; Di CARLO, A.; MARCELO, D.; Power plant perspectives for sugarcanemills. Energy 34:689-698, 2009.

BRÄSCHER, F.; Simulação numérica de centrais termelétricas. Dissertação (Mestrado) - Universidade Federal de Santa Catarina, Florianópolis, 1991.

BRAUNBECK, O.; CORTEZ, L.; O Cultivo da cana-de-açúcar e o uso de resíduos. Uso da biomassa para produção de energia na indústria brasileira. Unicamp, Campinas/SP, 2005.

BYRD, R. H., NOCEDAL, J.; OZTOPRAK F.: An Inexact Successive Quadratic Approximation Method for Convex L-1 Regularized Optimization, 2013.

CAMARGO, A. de C.; USHIMA, A. H.; RIBEIRO, A. M. M.; PAIVA, M. E.; SANTOS, N. E. Conservação de Energia na Indústria do Açúcar e do Etanol. Instituto de Pesquisas Tecnológicas (IPT), São Paulo, 1990.

CARDOSO, T. F., CAVALETT, O., CHAGAS, M. F., MORAIS, E. R., CARVALHO, J. L. N., FRANCO, H. C., GALDOS, M. V., SCARPARE, F. V., BRAUNBECK, O. A., CORTEZ, L. A., BONOMI, A.; Technical and economic assessment of trash recovery in the sugarcane bioenergy production system; Scientia Agricolca v.70, n.5, p.353360, September/October, 2013.

CAVALETT, O.; JUNQUEIRA, T.L.; DIAS, M.O.S.; JESUS, C.D.F.; MANTELATTO, P.E.; CUNHA, M. P.; FRANCO, H.C.J.; CARDOSO, T.F.; MACIEL FILHO, R.; ROSSELL, C.E.V.; BONOMI, A.; Environmental and economic assessment of sugarcane first generation biorefineries in Brazil. Clean Technologies and Environmental Policy 14: 399-410, 2012.

CAVALETT, O.; CHAGAS, M.; Comparative LCA of ethanol versus gasoline in Brazil using different LCIA methods, Int J Life Cycle Assess, 18 (2013) 647-658, 2013.

CGEE (Centro de Gestão e Estudos Estratégicos), Bioethanol sugarcane: energy for sustainable development. BNDES, Rio de Janeiro, 2008. 
CHEHEBE, J. R. B.; Análise do ciclo de vida de produtos: ferramenta gerencial da ISO 14000. Rio de Janeiro: Qualitymark, 2002.

CHEREMISINOFF, N. P. Cooling Towers Operations. Handbook of Heat and Mass Transfer.V. 1,1065 p., 1986.

CONAB - COMPANHIA NACIONAL DE ABASTECIMENTO, Acompanhamento da safra brasileira: cana-de-açúcar safra 2010/2011. Brasília: Conab, 2011.

CORREIA, J. L. G., RIOS, M. T. T., NEBRA, S. A., Caracterização do bagaço de cana e estudo de um sistema de alimentação. Conferencia nacional de Engenharia Mecânica, Natal, Rio Grande do Norte, 2000.

CORRÊA NETO, V.,"Análise de viabilidade da cogeração de energia elétrica em ciclo combinado com gaseificação de biomassa de cana-de-açúcar e gás natural”, Tese (Doutorado), COPPE-UFRJ, Rio de Janeiro, 2001.

CORTEZ, L. A.; Bioetanol de cana-de-açúcar - P\&D para Produtividade e Sustentabilidade. 2010.

CORTINOVIS, G. F. Modelagem e otimização de um sistema de água de resfriamento e validação experimental. 159 f. Dissertação (Mestrado) Departamento de Engenharia Química, Escola Politécnica da Universidade de São Paulo, 2004.

CTC - Centro de Tecnologia Canavieira. www.ctcanavieira.com.br, acessado em 15/11/2012.

CTC - Centro de Tecnologia Canavieira. www.ctcanavieira.com.br, acessado em 10/01/2014.

DANTAS, D. N.; Uso da Biomassa da cana-de-açúcar para geração de energia elétrica: análise energética, exergética e ambiental de sistemas de cogeração em sucroetanoleiras do interior paulista. Dissertação de mestrado UFSCAR, São Carlos/SP, 2010.

DIAS, M.O.S.; JUNQUEIRA, T.L.; CAVALETT, O.; PAVANELLO, L. G.; CUNHA, M.P.; JESUS, C.D.F.; MACIEL FILHO, R.; BONOMI, A.; Biorefineries for the 
production of first and second generation ethanol. Applied Energy (109), $72-78$, 2013.

DIAS, M.O.S.; JUNQUEIRA, T.L.; CAVALETT, O.; CUNHA, M.P.; JESUS, C.D.F.; ROSSELL, C.E. V.; MACIEL FILHO, R.; BONOMI, A.; Integrated versus stand-alone second generation ethanol production from sugarcane bagasse and trash. Bioresource Technology 103: 152-161, 2012.

DIAS, M. O. S., CUNHA, M. P., JESUS, C. D., SCANDIFFIO, M., ROSELLA, C.E., MACIEL FILHO, R., BONOMI, A., Simulation of ethanol production from sugarcane in Brazil: economic study of an autonomous distillery; 20th European Symposium on Computer Aided Process Engineering, Elsevier, 2010.

EL-WAKIL, M. M.; Power plant technology. New York, Mc Graw-Hill, 2002.

EL-DESSOUKY, H. T. A.; AL-HADDAD, A.; AL JUWAYHEL, F. A modified analysis of counter flow wet cooling towers. Journal of Heat Transfer v.119(3), p.617-626, 1997.

ENSINAS, A. V., Integração térmica e otimização termoeconomica aplicadas ao processo industrial de produção de açucar e etanol a partir da cana-de-açucar; Tese (Doutorado), Universidade Estadual de Campinas, Campinas, 2008.

ENSINAS, A. V., MODESTO, M., NeBRA, LOZANO, M. A., S.A., SERRA, L.; Analysis of process steam demand reduction and electricity generation in sugar and ethanol production from sugarcane; Energy Conversion and Management 48 (2007) 2978-2987; 2007.

FRISCHKNECHT, R.; JUNGBLUTH, N. (Ed). Overview and Methodology. Ecoinvent Report No.1. Dübendorf: 2007.

ENSINAS, A. V., MODESTO, M., NEBRA, S.A., SERRA, L..; Reduction of irreversibility generation in sugar and ethanol production from sugarcane; Energy 34 (2009) 680-688; 2008.

GUERRA, J. P.; COLETA Jr., J.; ARRUDA, L.; SILVA, G.; KULAY, L.; Comparative analysis of electricity cogeneration scenarios in sugarcane production by LCA; Int J Life Cycle Assess (2014) 19:814-825; 2014. 
GREET - Greenhouse Gases, Regulated Emissions, and Energy Use in Transportation, version 1.8d. Argonne National Laboratory. Argonne, Illinois, USA, 2010.

DIAS, M.; MODESTO, M.; ENSINAS, A.; NEBRA, S.; FILHO, R.; ROSSEL, C.; "Improving bioethanol production from sugarcane: evaluation of distillation, thermal integration and cogeneration systems", Energy, 36 (2011) 3691-3703.

FIOMARI, M. C. Análise energética e exergética de uma usina sucroalcooleira do oeste paulista com sistema de cogeração de energia em expansão. 2004. 129 f. Dissertação (Mestrado em Engenharia Mecânica) - Faculdade de Engenharia de Ilha Solteira, Universidade Estadual Paulista, Ilha Solteira, 2004.

FRANCO, H. C. J.; Eficiência agronômica da adubação nitrogenada de cana planta. Tese (Doutorado). Escola Superior de Agricultura Luiz de Queiros. Universidade de São Paulo. Piracicaba, 2008.

FREUDENBERGER, R.; A guide to small-scale ethanol - Alcohol Fuel, Making and using ethanol as a renewable fuel, Canadá: New Society Publishers, 2009.

GAUDREAULT, C.; SANSSON, R.; STUART, P.; Energy decision making in a pulp and paper mill: selection of LCA system boundary. Int J Life Cycle Assess 15:198$211,2010$.

GAVA, G. J. C; TRIVELIN, P. C. O.; OlIVEIRA, M. W.; PENATTI, C. P.; Crescimento e acúmulo de nitrogênio em cana-de-açúcar cultivada em solo coberto com palhada. Pesquisa Agropecuária Brasileira, Brasília, 36: 1347-1354, 2001.

GIL, M.; MOYA, A.; DOMÍNGUES, E.; Life cycle assessment of the cogeneration processes in the Cuban sugar industry. Journal of Cleaner Production 41:222-231, 2013.

GOEDKOOP, M.; HEIJUNGS, R.; HUIJBREGTS, M.; DESCHRYVER, A.; STRUIJS, J.; "Description of the ReCiPe methodology for Life Assessment Impact Assessment”, http://www.lcia-recipe.net retrieved sept. 2012. 
GOLDEMBERG, J.; COELHO, S. T.; GUARDABASSI, P. M.; The sustentability of ethanol production from sugarcane. Energy Policy, v36, p. 2086-2097. Elsevier, 2008.

GOMAZAKO, M. S.; OLIVEIRA, C. J.; Geração de Bagaço e Cogeração de Energia Elétrica na Indústria Sucroetanoleira. $V$ Workshop Internacional Brasil-Japão em Biocombustíveis, Meio Ambiente e Biomassa. Campinas-SP. Unicamp, 2007.

GONZÁLES-GARCÍA, S.; IRIBARREN, D.; SUSMOZAS, A.; DUFOUR, J.; MURPHY, R.; Life cycle assessment of two alternative bioenergy systems involving Salix spp. biomass: bioethanol production and power generation. Appl Energy 95:111-122, 2012.

GRACIANO, V.; Análise e otimização termoeconômica aplicada a usina termelétrica de figueira; Dissertação (Mestrado), Universidade Federal do Paraná, Curitiba, 2007.

GRIPP, V. S.; Análise ambiental, energética e econômica de arranjo processual para reúso de água em refinaria de petróleo; Dissertação (Mestrado) - Escola Politécnica da Universidade de São Paulo, Departamento de Engenharia Química, São Paulo, 2013.

HASSUANI, S. J., Biomass power generation: sugar cane bagasse and trash / Suleiman José Hassuani, Manoel Regis Lima Verde Leal, Isaías de Carvalho Macedo - Piracicaba: PNUD-CTC , 2005.

HORLOCK, J. H. Cogeneration: Combined Heat and Power (CHP). Florida: Krieger,1997.

IDEA News Cana \& Indústria. Ano 11, revista n 140, 2012.

IEA - Instituto de Economia Agrícola. http://www.iea.sp.gov.br, acessado em 15/02/2012.

IEL - INSTITUTO EUVALDO LODI, Etanol Combustível. Série Indústria em Perspectiva - Brasília, IEL/NC, 2008.

INT - Instituto Nacional de Tecnologia, Informativo do INT, Vol. XII, n22, pg 3-23, 1979. 
JUNGBLUTH, N.(Ed).; Life Cycle Inventories of Bioenergy. Ecoinvent Report No. 17. Uster: 2007.

KAMATE, S. C.; GAGAVATI, P.B.; "Exergy analysis of cogeneration power plants in sugar industries", Applied Thermal Engineering, 29, 1187-1194, 2009.

KOTAS, T J.; The Exergy Method of Thermal Plant Analysis, Butterworth, London, 1995.

KULAY, L.; "Development of life-cycle analysis model suitable to Brazilian conditions: application to the simple superphosphate case", Dissertação de mestrado, Universidade de São Paulo, Sao Paulo, 2000.

LEITE, R.C.C.; LEAL, M.R.L.V.; CORTEZ, L.A.B.; GRIFFIN, W.M.; SCANDIFFIO, M.I.G.; Can Brazil replace $5 \%$ of the 2025 gasoline world demand with ethanol? Energy 34: 655-661, 2009.

LI, K. W.; PRIDDY, A. P.; Powerplant System Design. New York: Wiley,1985.

LINS, C.; SAAVEDRA, R.; Relatório do Setor Sucroalcooleiro. Fundação Brasileira para o Desenvolvimento Sustentável. 2007.

LIOR, N.; "Sustainable energy development: the present (2009) situation and possible paths to the future", Energy, 35, 3976-3994, 2010.

LIU C., HE, C., GAO, H., XU, X., Xu J., The Optimal Evaporation Temperature of Subcritical ORCBased on Second Law Efficiency for Waste Heat Recovery, Jornal of Entropy, 14, 491-504; 2012.

LORA, E. S., HAPP, J. F., CORTEZ, L. A. B., 'Caracterização e Disponibilidade da Biomassa'. In: Universidade do Amazonas, AM, Tecnologias de Conversão Energética da Biomassa, 1a ed., capítulo I, Manaus, Amazonas, Brasil, 1997.

LUO, L.; VOET, E.; HUPPES, G.; "Life cycle assessment and life cycle costing of bioethanol from sugarcane in Brazil", Renewable and Sustainable Energy Reviews, 13, 1613-1619, 2009. 
MACEDO, IC.; SEABRA, J.; SILVA, J.; Greenhouse gases emissions in the production and use of ethanol from sugarcane in Brazil: the 2005/2006 averages and a prediction for 2020; Biomass and Bioenergy, 32,582 - 595, 2008.

MAPA - Ministério da Agricultura Pecuária e Abastecimento, Secretaria de produção de bioenergia, açúcar e etanol no Brasil. Safra 2010-2011, Estatísticas da Indústria, Brasília, 2012.

MARCOCCIA, R.; A participação do etanol em uma nova perspectiva na matriz energética mundial. Dissertação de mestrado - Programa Interunidades de PósGraduação em Energia. Universidade de São Paulo, 2007.

MENEZES, B.; Etanol o combustível do Brasil. Editora Agranômica Ceres, São Paulo, 1980.

MME - Ministério de Minas e Energia - Resenha Energética Brasileira exercício 2010. Brasília, 2011.

MONTEIRO, M. F. Avaliação do Ciclo de Vida do Fertilizante Superfosfato Simples. Salvador: Universidade Federal da Bahia, 2008.

MORAN, M. J.; Availability Analysis - A guide to efficient energy use. New York: Asme Press, 1989.

MORAN, M. J.; SHAPIRO, H. N.; Fundamentals of Engineering Thermodynamics, 6th ed., John Wiley \& Sons, New York, 2008.

MOURAD, A. L.; GARCIA, E. E.; VILHENA, A.; Avaliação do ciclo de vida: princípios e aplicações. Campinas: CETEA; ITAL, 2002.

NEMECEK, T.; KÄGI, T.; Life Cycle Inventories of Agricultural Production Systems. Ecoinvent Report No. 15. Zürich e Dübendorf: 2007.

NEOENERGIA. www.neoenergia.com/section/historico-setor-eletrico.asp, acessado em 02/09/2011.

NETO, A. E.; Manual de conservação e reuso de água na indústria sucroenergética / Agência Nacional de Águas; Federação das Indústrias do Estado de São Paulo; 
União da Indústria da cana-de-açúcar; Centro de Tecnologia Canavieira. Brasília, 2009.

NGUYEN, T.; GHEEWALA, S.; Life cycle assessment of fuel ethanol from cane molasses in Thailand. Int J Life Cycle Assess 13:301-311, 2008.

NYKO, D.; FARIA, J.; DANTASS, A.; "Determinantes do baixo aproveitamento do potencial elétrico do setor sucroenergético: uma pesquisa de campo", Bioenergia, 33, 421-476, 2011.

OGBOJA, O.: A procedure for computer-aided design of water cooling towers. The Chemical Engineering Journal. v.35, 43-50 p, 1987.

OLIVEIRA Jr., S.; Exergy, Cost and Renewability, Cap.2, Springer-Verlag London. Universidade de São Paulo, São Paulo/SP, 2012.

OliVeIRA, M. W.; TRIVELIN, P. C. O.; PENATTI, C. P.; PICCOLlO, M.C.; Degradação da palhada da cana-de-açúcar, Pesquisa Agropecuária Brasileira 34: 2359-2362, 1999.

OLIVEIRA, V. F.; Diagnóstico de Eficiência energética de uma torre de resfriamento de água da Arcelormittal Inox Brasil. Dissertação (mestrado), Universidade Federal de Minas Gerais, Belo Horizonte, 2010.

OMETTO, A.; HAUSCHILD, M.; ROMA, W.; Lifecycle assessment of fuel ethanol from sugarcane in Brazil. Int J Life Cycle Assess 14:236-247, 2009.

OMETTO, A. R. Avaliação do ciclo de vida do álcool etílico hidratado combustível pelos métodos EDIP, exergia e emergia. Tese (Doutorado em Hidráulica e Saneamento) - Escola de Engenharia de São Carlos, Universidade de São Paulo, São Carlos, 2005.

PELLEGRINI, L. F.; OLIVEIRA, J. S; BURBANO, J. C.; Supercritical steam cycles and biomass integrated gasification combined cycles for sugarcane mills. 2009.

PEREIRA, S. W.; Análise ambiental do processo produtivo de pisos cerâmicos: Aplicação de avaliação do ciclo de vida. 2004. 122 p. Dissertação (Mestrado) Centro Tecnológico, Universidade Federal de Santa Catarina, Florianópolis, 2004. 
PISTORE, T. T.; Avaliação Técnico - Econômica e Ambiental da Eletrificação das Moendas na Indústria Sucroalcooleira. Dissertação (mestrado) - Universidade Federal de Itajubá, 2004.

RAVAGNANI, M. A. S.; SUAREZ, J. A. C.; Redes de trocadores de Calor, Ed. Eduem, 2012.

RENOUF, M.; PAGAN R.; WEGENER M.; Life cycle assessment of Australian sugarcane products with a focus on a cane processing. Int $\mathrm{J}$ Life Cycle Assess 16:125-137, 2011.

RIBEIRO, P. H.; Contribuição ao banco de dados brasileiro para apoio à avaliação do ciclo de vida: fertilizantes nitrogenados. 2009. 343 p. Tese (Doutorado) - Escola Politécnica, Universidade de São Paulo, São Paulo, 2009.

ROMÃO JUNIOR, R. A.; Análise da viabilidade do aproveitamento da palha da cana de açúcar para cogeração de energia numa usina sucroalcooleira; Dissertação (mestrado) - Universidade Estadual Paulista. Faculdade de Engenharia de Ilha Solteira, 2009.

ROSEN, M.A.; Assessing Energy Technologies and Environmental Impacts with the Principles of Thermodynamics. Applied Energy, v.72, p. 427-441, 2002.

SALISBURY, J. K.; "Steam Turbines and Their Cycles" 2a Ed., R. E. Krieger Publ. Co, 1974.

SALVADOR, N.; BUENO, M.; Sustentabilidade das Práticas de Gestão Empresarial de duas Usinas de Açúcar e Etanol de cana-de-açúcar no estado de São Paulo, 2012.

SANCHEZ, P., M., G.; Alternativas de Cogeração na Indústria Sucro-Alcooleira, Estudo de Caso. Tese (Doutorado) Faculdade de Engenharia Mecânica, Universidade Estadual de Campinas, Campinas, 2003.

SANTOS, C. Prevenção à Poluição Industrial: Identificação de Oportunidades, Análise dos Benefícios e Barreiras. São Carlos: Escola de Engenharia de São Carlos, Universidade de São Paulo, São Carlos, 2005. 
SEABRA, J.E.A.; Avaliação tecnico-economica de opções para o aproveitamento integral da biomassa de cana no Brasil, Tese (Doutorado), Universidade Estadual de Campinas, Campinas, 2008.

SEABRA, J.E.A.; TAO, L.; CHUM, H.L.; MACEDO, I.C., A technoeconomic evaluation of the effects of centralized cellulosic ethanol and co-products refinery options with sugarcane mill clustering. Biomass and Bioenergy 34: 1065-1078, 2010.

SHLYAKHIN, P.; "Steam Turbines: Theory and Design ", Peace Publishers, Moscow, 2005.

SILVA, G.A.; KULAY, L.; Avaliação do Ciclo de Vida. In: VILELA, A.; DEMAJOROVIC, J. Modelos e ferramentas de gestão ambiental: desafios e perspectivas para as organizações. São Paulo: Editora SENAC, 2006.

SILVA, G. A. Disciplina PQI 5849: Fundamentos da Proteção Ambiental e Segurança de Processos Industriais. São Paulo: Programa de Pós Graduação em Engenharia Química. Universidade de São Paulo, 2012.

SILVA, A. L. R. Desenvolvimento de fatores de normalização de impactos ambientais regionais para Avaliação de Ciclo de Vida de produtos no Estado de São Paulo. São Carlos: Escola de Engenharia de São Carlos, Universidade de São Paulo, 2010.

SKROTZI, B. G. A.; VOPAT, W. A.; Power Station Engineering and Economy. New York: McGraw-Hill, 1960.

SINGER, J. G., (Ed.), Combustion/Fossil Power Systems. Windsor, Con.: Combustion Engineering, 1981.

SOSA-ARNAO, J.; Caldeiras Aquatubulares de Bagaço - Estudo do sistema de recuperação de energia. 2008, Tese de doutorado, Universidade Estadual de Campinas, Campinas, SP, 2008.

SOUSA, E.; MACEDO, IC.; Ethanol and bioelectricity: sugarcane in the future energy mix. Communication Project, São Paulo, 2010.

STAFF, M. Cooling Tower Fundamentals. SPX Cooling Technologies, Inc. 2 ed., Kansas USA, 2006. 
STOECKER, W. F.; "Design of Thermal Systems" 3a ed., Mc Graw - Hill Book Company, Singapore,1989.

SUGAWARA, E. T.; Comparação dos desempenhos ambientais do B5 etílico de soja e de óleo diesel, por meio da avaliação do ciclo de vida (ACV) - Dissertação (mestrado) - Escola Politécnica da Universidade de São Paulo. Departamento de Engenharia Química -- São Paulo, 2012.

SZARGUT, J.; MORRIS, D. R.; STEWARD, F. R.; Exergy Analysis of Thermal, Chemical and Metallurgical Processes, 1988.

TINA, G.; PASSARELLO, G.; Short-term scheduling of industrial cogeneration systems for annual revenue maximisation. Energy 42:46-56, 2011.

TORQUATO, S. A., RAMOS, R. C.: Energia Renovável: Cogeração de bioeletricidade nas usinas signatárias do protocolo agroambiental Paulista - VI Workshop Agroenergia, Ribeirão Preto, 2012.

TORRES, E. A.; Avaliação Exergética e Termoeconômica de um Sistema de Cogeração de um Pólo Petroquímico, Tese de doutorado, Universidade Estadual de Campinas, Campinas/SP, 1999.

TSATSARONIS, G.; PARK, M.; On Avoidable and Unavoidable Exergy destructions and Investment Costs in Thermal Systems. Energy Conversion \& Management, v. 43, p.1259-1270, 2002.

ÚNICA - União da Indústria de cana-de-açúcar. Setor Sucroenergético - Mapa de Produção. 2012. Disponível em: www.unica.com.br/content/show.asp?cntCode= \{D6C39D36-69BA-458D-A95C-815C87E4404D/\}. Acessado em junho 2012.

USINA SANTA TEREZINHA LTDA, Resumo do projeto de cogeração de energia elétrica e aumento de produção. Paranacity: Usaçúcar, 2007. [Versão do projeto aprovado pelo BNDES em maio de 2008].

VAN NESS, H.C.; Introdução à Termodinâmica da Engenharia Química. The McGraw-Hill Companies, Inc., 7ª Ed., 2007, pg 216-223, 2007.

VAN WYLEN, G.J., SONTAG, R. E.; "Fundamentos da Termodinâmica Clássica" 2a ed., Editora Edgard Blücher, 1984. 
WALL, G.; Institute of theoretical Physics, Exergy - A Useful Concept Within Resource Accounting; Sweeden, 1977.

WOOD, B.; Applications of Thermodynamics, 2nd ed. Reading, Mass.: AddisonWesley, 1981. 
APÊNDICE A - Modelagem Termodinâmica do sistema de cogeração com ciclo Rankine Convencional 


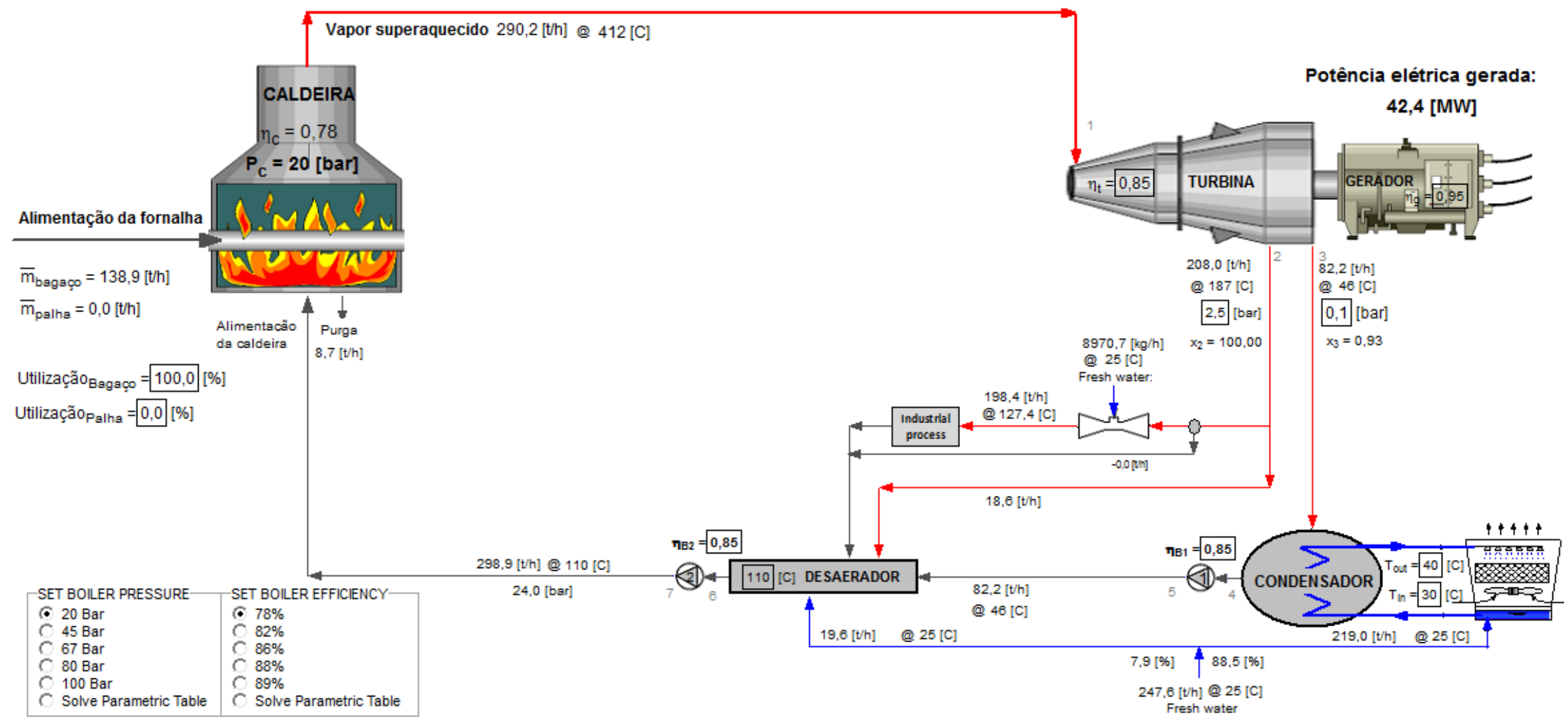

Figura 45 - Ciclo de vapor convencional para um sistema de cogeração (Interface do simulador) 
EES Ver. 9.433: \#0624: Depart. de Engenharia Mecanica Escola Politecnic, Escola Politecnica da USP, Sao Paulo, Brazil

1:

2:

3

10: m_dot_bagaço=Y_bagaço/100*M_dot_cana*Utilização_Bagaço/100 o de bagaço de cana na caldeira"

11: m_dot_palha=Y_palha/100*M_dot_cana*Utilização_Palha/100

o de palha de cana na caldeira"

12: Razão|vapor_biomassa=m_dot_vapor/m_dot_bagaço entre produção de vapor e consumo de biomassa"

13: m_bar_bagaço=m_dot_bagaço/1000 [t/h]

14: m_bar_palha=m_dot_palha/1000 [t/h]

15:

16:

17: "GERADOR DE VAPOR - Modelagem de conservação de matéria e energia"

18: "Balanço de massa"

19:

20: m_dot_agua $=m$ _dot_vapor $+\mathrm{m} \_d o t \_p u r g a$

21: m_dot_purga $=Y$ _purga*m_dot_vapor

22: Y_purga $=0,03$ purga"

23: M_bar_vapor=m_dot_vapor/1000[t/h] da vazão mássica de vapor de $\mathrm{kg} / \mathrm{h}$ para $\mathrm{t} / \mathrm{h}$ "

24:

25: "Balanço de energia"

26:

27: m_dot_agua*h[7] + Q_dot_c=m_dot_vapor*h[1]+m_dot_purga*h_purga

28: Q_dot_c=(m_dot_bagaço*PCl_bagaço+m_dot_palha*PCl_palha $)^{*}$ eta_c utilizada na fornecida na fornalha para evaporação da água"

29: POT_nominal_caldeira $=$ Q_dot_c*convert $(\mathrm{kJ} / \mathrm{h} ; \mathrm{MW})$ nominal da caldeira"

30: $h[1]=e n t h a l p y($ water; $T=T[1] ; P=P[1]): ~ h \_p u r g a=e n t h a l p y\left(\right.$ water; $\left.T=T \_p u r g a ; X=0\right)$

31: $P[7]=1,20 * P \_c: T \_p u r g a=T \_S A T\left(\right.$ water $\left.P=P \_c\right): P \_p u r g a=P \_c: P[1]=P \_c:$

32: $\mathrm{PCl}$ bagaço=7565: $\mathrm{PCl} \_$palha=12960 $[\mathrm{kJ} / \mathrm{kg}]$ calorífico inferior do bagaço (51\% umidade) e da palha de cana(15\% de umidade)"

33: $T[1]=T \_S A T($ water;P=P_c)+G_super a do vapor superaquecido"

34: G_super=200 [C] superaquecimento"

35:

36: "BOMBA 02 - ALIMENTAÇÃO DA CALDEIRA"

37:

38: $P[6]=P[2]$ de descarga da bomba igual a pressão do vapor de escape"

39: eta_B2=(h[6]-h7_iso)/(h[6]-h[7]) ão da entalpia real da vazão de líquido na descarga da bomba"

40: h7_iso=enthalpy(water;s=s[6];P=P[7]) para condição ideal isentrópica"

41: $\mathrm{h}[6]=$ enthalpy(water; $\mathrm{P}=\mathrm{P}[6] ; \mathrm{T}=\mathrm{T}[6])$ saída do desaerador"

42: $\mathrm{s}[6]=$ entropy(water; $\mathrm{P}=\mathrm{P}[6] ; \mathrm{T}=\mathrm{T}[6])$ na saída do desaerador é entropia do líquido saturado"

43: $\mathrm{T}[7]=$ temperature(water; $h=h[7] ; P=P[7])$
"Taxa de

"Alimentaçã

"Alimentaçã

"Razão

"Taxa de

"Conversão

"Energia

"Potência

"Poder

"Temperatur

"Grau de

"Pressão

"Determinaç

"Entalpia

"Entalpia na

"Entropia

"Temperatur 
EES Ver. 9.433: \#0624: Depart. de Engenharia Mecanica Escola Politecnic, Escola Politecnica da USP, Sao Paulo, Brazil

a de recalque"

44: s[7]=entropy(water;h=h[7];P=P[7])

"Entropia

da água de alimentação da caldeira"

45:

46: "BOMBA 01 - CONDENSADO"

47:

48: $P[5]=P[2]$

"Pressão

de descarga da bomba igual a pressão do vapor de escape"

"Determinaç

ão da entalpia real do líquido na descarga da bomba"

50: h5_iso=enthalpy(water;s=s[4];P=P[5])

"Entalpia

para condição ideal isentrópica"

51: $\mathrm{s}[4]=$ entropy(water; $P=P[4] ; X=0$ )

"Entropia

na saída do condensador - líquido saturado"

"Temperatur

a de recalque para desaerador"

53: $\mathrm{h}[4]=$ enthalpy(water; $\mathrm{P}=\mathrm{P}[4] ; \mathrm{x}=0$ )

"Entalpia da

saída do condensador é a entalpia de líquido saturado"

54: $\mathrm{T}[4]=\mathrm{T}[3]$

a de Entrada = temperatura de saída --> Somente troca calor latente"

"Temperatur

55: $\mathrm{P}[4]=\mathrm{P}[3]$

"Pressão

de sucção da bomba = pressão da cauda da turbina"

56: $\mathrm{s}[5]=$ entropy(water; $\mathrm{P}=\mathrm{P}[5] ; \mathrm{T}=\mathrm{T}[5])$

"Entropia

57:

da água de recalque da bomba 01"

58:

59: "TURBINA"

60: "Rendimento da turbina"

61:

62: eta_t $=(\mathrm{h}[1]-\mathrm{h}[2]) /(\mathrm{h}[1]-\mathrm{h} 2$ iso $)$

ão da entalpia real do vapor extraído para o desaerador através da eficiencia isoentrópica"

63: eta_t $=(\mathrm{h}[1]-\mathrm{h}[3]) /\left(\mathrm{h}[1]-\mathrm{h} 3 \_\right.$iso $)$

ão da entalpia real do vapor extraído para o condensador através da eficiencia isoentrópica"

64: h2_iso=enthalpy(water;s=s[1];P=P[2])

corrente de vapor de escape para condição ideal de expansão isoentrópica"

65: h3_iso=enthalpy(water;s=s[1];P=P[3])

corrente de vapor na cauda para condição ideal de expansão isoentrópica"

66: $\mathrm{s}[1]=$ =entropy(water; $\mathrm{P}=\mathrm{P}[1] ; \mathrm{T}=\mathrm{T}[1])$

definido por 2 propriedades independentes"

67: $T[2]=$ temperature (water; $h=h[2] ; P=P[2])$

do vapor de escape"

"Determinaç

"Determinaç

"Entalpia da

"Entalpia da

"Estado

"Temperatur

68: $T[3]=$ temperature (water; $h=h[3] ; P=P[3]$ )

"Temperatur

a do vapor de cauda"

69: s[2]=entropy(water;h=h[2];T=T[2])

"Entropia

do vapor de escape"

70: $\mathrm{s}[3]=e n t r o p y($ water; $\mathrm{h}=\mathrm{h}[3] ; \mathrm{T}=\mathrm{T}[3]$ )

"Entropia

do vapor de cauda"

71: $\mathrm{x}[2]=$ quality (water; $\mathrm{h}=\mathrm{h}[2] ; \mathrm{T}=\mathrm{T}[2])$

"Título do

vapor de escape"

72: $x[3]=$ quality (water; $\mathrm{h}=\mathrm{h}[3] ; \mathrm{T}=\mathrm{T}[3]$ )

"Título do

vapor na cauda da turbina"

73:

74: "Balanço de massa na turbina"

75:

76: m_dot_vapor=m_dot_vap.escape+m_dot_vap.cauda

77:

78:

79: "PURGA DE CONDENSADO ANTES DE SER USADO NO PROCESSO"

80 
EES Ver. 9.433: \#0624: Depart. de Engenharia Mecanica Escola Politecnic, Escola Politecnica da USP, Sao Paulo, Brazil

81: "RETORNO DE CONDENSADO DO PROCESSO INDUSTRIAL"

82:

83: m_dot_retorno $=\mathrm{m} \_$dot_vap.processo ${ }^{\star} 0,90$

"Considerad

o perdas no processo de $10 \%$ da vazão de vapor"

84: T_cond=90 [C]

"Considerad

o que todo condensado é coletado em um tanque de recuperação e retorna para o ciclo a $90 \mathrm{C}^{\prime \prime}$

85: $\mathrm{P} \_$cond $=\mathrm{P}[2]$

"Pressão

de retorno $=$ pressão no desaerador $=$ Pressão do vapor de escape"

86

87: m_agua.dessuper=if(x[2];100;0;m_dot_agua.dessuper;0) "Se o vapor de escape estiver superaquecido agua deve ser alimentada no dessuperaquecedor para obter vapor saturado para o processo de produção do etanol"

88: m_dot_purgador=if(x[2];100;-m_dot_agua.dessuper;0;0)

"Se o vapor

de escape tiver $x<1$ o condensado precisa ser retirado em purgadores"

89:

90: "DESSUPERAQUECEDOR E VAPOR DE PROCESSO"

91: "Balanços de massa"

92:

93: $m$ dot vap.escape $=m$ dot vap.dessuper $+m$ dot dop.desaerador

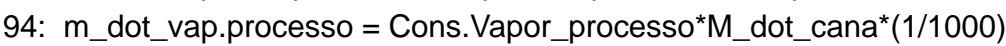

"Consumo

de vapor saturado para o processo a $P=2,5$ Bar" $^{\prime \prime}$

95: m_dot_vap.processo=m_dot_vap.dessuper+m_dot_agua.dessuper

96:

97: "Balanço de energia no dessuperaquecedor"

98:

99: m_dot_vap.processo*h_pro=m_dot_vap.dessuper*h[2]+m_dot_agua.dessuper*h_rep.des

100: h_pro=enthalpy(water;T=T_pro; $\mathrm{x}=1$ ): $\mathrm{T}$ _pro=T_sat(water; $\mathrm{P}=2,5$ )

"Processo

industrial utiliza vapor saturado"

101

102:

103:

104: "DESAERADOR"

105: "Balanço de massa no desaerador"

106:

107: m_dot_retorno+m_dot_vap.desaerador+m_dot_vap.cauda+m_dot_rep.desaerador+m_dot_purgador $=$ m_dot_agua

108:

109:

110: "Balanço de energia no desaerador"

$111:$

112: m_dot_retorno*h_cond+m_dot_vap.desaerador*h[2]+m_dot_vap.cauda*h[5]+m_dot_rep.desaerador*h_rep.des $+\mathrm{m} \_$dot_purgador*h_purgador=m_dot_agua*h[6]

113: $h \_$cond=enthalpy(water; $T=T \_$cond; $P=P \_$cond): $h \_p u r g a d o r=e n t h a l p y($ water; $P=P[2] ; x=0): h \_r e p . d e s=e n t h a l p y($ water; $T$ $\left.=T \_a m b ; P=P \_r e p . d e s\right): T \_a m b=25$

114: P_rep.des $=P[2]$

no desaerador é a pressão de escape da turbina"

115:

116: "Conversão de unidades de $\mathrm{kg} / \mathrm{h}$ para $t / h$ "

117:

118: m_bar_vap.escape=m_dot_vap.escape $/ 1000[\mathrm{t} / \mathrm{h}]$

119: m_bar_vap.cauda $=\mathrm{m} \_d o t \_v a p . c a u d a / 1000[\mathrm{t} / \mathrm{h}]$

120: m_bar_vap.processo=m_dot_vap.processo/1000 [t/h]

121: m_bar_vap.desaerador=m_dot_vap.desaerador/1000 [t/h]

122: m_bar_rep.desaerador $=m$ _dot_rep.desaerador $/ 1000[\mathrm{t} / \mathrm{h}]$

123: m_bar_feed.water.=m_dot_agua/1000 [t/h]

124: m_bar_purga.=m_dot_purga/1000 [t/h]

125: m_bar_purgador=m_dot_purgador/1000 [t/h]

126

127:

128: "CONDENSADOR"

129: 
EES Ver. 9.433: \#0624: Depart. de Engenharia Mecanica Escola Politecnic, Escola Politecnica da USP, Sao Paulo, Brazil

130: Q_dot_out $=$ m_dot_vap.cauda*(h[3]-h[4])

"Balanço de

energia --> Calor transferido da condensação do vapor para a torre de resfriamento" 131:

132:

133: "TORRE DE RESFRIAMENTO"

134:

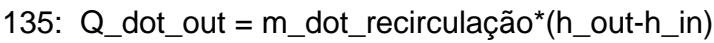

136: $h$ _out=enthalpy(water; $\left.P=P \_o u t ; T=T \_o u t\right): h \_i n=e n t h a l p y($ water; $P=P$ in; $T=T$ in): $P$ _in=1: $P$ _out=1:

137: m_dot_repos.torre $=Y \_$perdas*m_dot_recirculação

Y_perdas

corresponde a uma estimativa de perdas de água por evaporação, purga e arraste na torre de resfriamento"

138: m_dot_rep.total=m_dot_repos.torre+m_dot_rep.desaerador+m_agua.dessuper

139: m_bar_repos.torre=m_dot_repos.torre $/ 1000[\mathrm{t} / \mathrm{h}]$

140: m_bar_rep.total=m_dot_rep.total $/ 1000[\mathrm{t} / \mathrm{h}]$

141: m_bar_vap.dessuper=m_dot_vap.dessuper/1000 [t/h]

142: Perc.torre $=m$ _dot_repos.torre $/ m$ _dot_rep.total ${ }^{*} 100$

143: Perc.desaerador $=m \_d o t \_r e p . d e s a e r a d o r / m \_d o t \_r e p . t o t a l * 100$

144: Perc.dessuper $=m$ _dot_vap.dessuper/m_dot_rep.total ${ }^{\star} 100$

145: Tap.water_torre=m_dot_repos.torre $/($ m_dot_cana/1000)

146: Tap.water_deionised $=\left(\right.$ m_dot_rep.desaerador $+\mathrm{m} \_$agua.dessuper $) /($m_dot_cana/1000 $)$

147:

148:

149: "CÁLCULO DAS POTÊNCIAS ELÉTRICAS"

150: "Potência elétrica gerada"

151:

152: POT_elétr.gerada=(POT_1+POT_2) ${ }^{*}$ eta_g*convert(kJ/h;MW)

"Potencia

elétrica total gerada no turbogerador"

153: POT_1=m_dot_vap.escape*(h[1]-h[2])

"Potencia

gerada pelo vapor de escape a $P=2,5 b a r^{\prime \prime}$

154: POT_2=m_dot_vap.cauda*(h[1]-h[3])

"Potencia

gerada pelo vapor da cauda"

155:

156: "Consumo das bombas do ciclo"

157: POT_elétr.consumida=(POT_B1+POT_B2 $)^{\star} \operatorname{convert(kJ/h;MW)~}$

"Potência

consumida pelas bombas"

158: POT_B1=m_dot_vap.cauda* $(\mathrm{h}[5]-\mathrm{h}[4])$

"Potência

consumida pela bomba 1"

159: POT_B2=m_dot_agua*(h[7]-h[6])

"Potência

consumida pela bomba $2 "$

160:

161:

162: "EFICIÊNCIA GLOBAL DA UNIDADE DE COGERAÇÃO CONVENCIONAL"

163: "Cálculo da eficiência energética"

164:

165: eta_Energética.Global=(POT_elétr.líquida + POT_processo)/POT_entrada*100

166:

167: "Potência líquida gerada na unidade de cogeração"

168:

169: POT_elétr.líquida = POT_elétr.gerada - POT_elétr.consumida

170:

171: "Potência utilizada no processo industrial"

172:

173: POT_processo=m_dot_vap.processo*(h_pro-h_sat)*convert(kJ/h;MW)

174: POT_desaerador=m_dot_vap.desaerador ${ }^{\star}(\mathrm{h}[2]-\mathrm{h}[6])^{*}$ convert $(\mathrm{kJ} / \mathrm{h} ; \mathrm{MW})$

175: POT_desaerador.perc=POT_desaerador/POT_entrada*100

176: POT_processo.perc=POT_processo/POT_entrada*100

177: h_sat=enthalpy (water; $x=0 ; p=2,5)$

178:

179: "Alimentação energética na fornalha da caldeira"

180: POT_entrada $=\left(\mathrm{m} \text { _dot_bagaço* } \mathrm{PCl} \text { _bagaço+m_dot_palha* } \mathrm{PCl} \_p a l h a\right)^{\star}$ convert $(\mathrm{kJ} / \mathrm{h} ; \mathrm{MW})$ 
185: "Ambiente de referência considerado: $P o=1$ bar e To=25 C"

186: $\mathrm{TO}=25[\mathrm{C}]$

187: $\mathrm{P0}=1$ [Bar]

188: P00_h20=0,0303 [Bar]

189:

190: "LIMITE TEÓRICO DE EFICIÊNCIA - CICLO DE CARNOT"

191:

192: eta_Carnot $=(1-(T[3]+273,15) /(T[1]+273,15)) \star 100$

"Trabalho

máximo teórico que pode ser obtido se o ciclo fosse reversível" 193:

194: "Trabalho útil final - saída do gerador de eletricidade"

195:

196: EXERGY.in_fuel=POT_entrada

197: EXERGY.out_electricity=POT_elétr.líquida "energia elétrica é exergia pura"

198: EXERGY.out_electricity.perc=POT_elétr.líquida/B_fuel*100

199:

200: "Boiler"

201: B_1=m_dot_vapor*(h[1]-h[0]-(T0+273,15)*(s[1]-s[0]))*convert(kJ/h;MW) vapor de saída do gerador de vapor"

202: $\mathrm{h}[0]=$ enthalpy(water; $\mathrm{t}=\mathrm{T0} ; \mathrm{P}=\mathrm{P0}$ )

203: $s[0]=e n t r o p y($ water; $t=T 0 ; P=P 0$ )

204: B_fuel=EXERGY.in_fuel

205: \{No ciclo Rankine, considera-se somente a exergia física, porque tem sempre a mesma substância ou fluido de trabalho: água (Oliveira Jr, 2012). A título de curiosidade as exergias químicas também foram calculadas. Os resultados obtidos mostraram que e as ordens de grandeza da exergia química são despezíveis $(0,2 \%$ da exergia total)\}

206:

207: "TURBINE"

208: "Exergia das correntes de vapor de escape e cauda"

209:

210: B_2=m_dot_vap.escape*(h[2]-h[0]-(T0+273,15)*(s[2]-s[0]))*convert(kJ/h;MW)

"Exergia do vapor de escape"

211: B_3=m_dot_vap.cauda*(h[3]-h[0]-(T0+273,15)*(s[3]-s[0]) $)^{\star} \operatorname{convert}(\mathrm{kJ} / \mathrm{h} ; \mathrm{MW})$

"Exergia do vapor de cauda"

212:

213: "Balanço de exergia na turbina"

214:

215: Bdest_turbine=B_1-(B_2+B_3+POT_elétr.gerada/eta_g)

"Exergia

destruída na turbina"

216: Bdest_turbine.perc=Bdest_turbine/B_fuel${ }^{\star} 100$

"Percentual de exergia destruída na turbina"

217: B_2_perc=B_2/B_fuel*100

"Percentual de exergia no vapor de escape"

218: B_liq=POT_elétr.gerada/B_fuel ${ }^{\star} 100$

"Percentual 219: de exergia (trabalho) na saída do gerador"

220:

221: "Consumo de exergia no processo industrial associado ao consumo específico de vapor"

223: EXERGY.out_process=m_dot_vap.processo*(h_pro-h[0]-(T0+273,15)*(s_pro-s[0]))*convert(kJ/h;MW) corrente de vapor utilizado no processo de produção de etanol" 
EES Ver. 9.433: \#0624: Depart. de Engenharia Mecanica Escola Politecnic, Escola Politecnica da USP, Sao Paulo, Brazil

227: EXERGY.out_deaerator.perc=EXERGY.out_deaerator/B_fuel*100

228:

229: "DESSUPERAQUECEDOR"

230: "Balanço de entropia no dessuper"

231:

232: S_ger.dessuper=m_dot_vap.processo*s_pro - (m_agua.dessuper*s_agua + (m_dot_vap.dessuper-m_dot_purgador)*s[2])

233: $s \_a g u a=$ entropy $($ water $; \mathrm{p}=2,5 ; \mathrm{t}=25)$

234: Bdest_dessuper $=(\mathrm{T} 0+273,15)^{\star}$ S_ger.dessuper*convert(kJ/h;MW)

"Exergia

destruída no dessuperaquecedor"

235: Bdest_dessuper.perc=Bdest_dessuper/B fuel ${ }^{\star} 100$

"Percentual de exergia destruída no dessuperaquecedor"

236:

237: "CONDENSADOR"

238:

239: B_4=m_dot_vap.cauda*(h[4]-h[0]-(T0+273,15)*(s[4]-s[0]))*convert(kJ/h;MW)

"Exergia na saída do condensador"

240: Bdest_condenser=B_3-B_4

"Exergia

destruída no condensador"

"Percentual

241: Bdest_condenser.perc=Bdest_condenser/B_fuel*100

de exergia destruída no condensador"

242:

243: "BOMBA 1"

244:

245: B_5=m_dot_vap.cauda*(h[5]-h[0]-(T0+273,15)*(s[5]-s[0]) ${ }^{\star}$ convert $(\mathrm{kJ} / \mathrm{h} ; \mathrm{MW})$

"Exergia na saída da bomba 1"

246: Bdest_B1=B_4-B_5 +W_B1

"Exergia

destruída na bomba 1"

247: W_B1=m_dot_vap.cauda* $(\mathrm{h}[5]-\mathrm{h}[4])^{\star}$ convert $(\mathrm{kJ} / \mathrm{h} ; \mathrm{MW})$

"Trabalho

realizado pela bomba $B 1^{\prime \prime}$

248: Bdest_B1.perc=Bdest_B1/B_fuel*100

"Percentual de exergia destruída na bomba 1"

249:

250: "DESAERADOR"

251: "Balanço de entropia no dessuperaquecedor"

252:

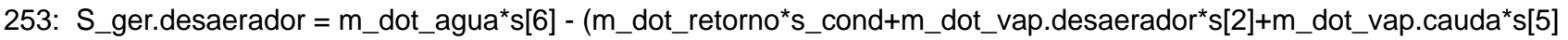

$+m$ _dot_rep.desaerador*s_agua $+m$ _dot_purgador*s_sat)

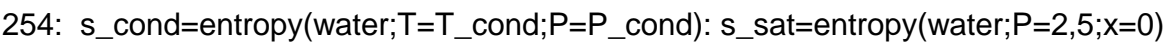

255: Bdest_desaerador $=(\mathrm{T} 0+273,15){ }^{\star}$ S_ger.desaerador ${ }^{\star}$ convert $(\mathrm{kJ} / \mathrm{h} ; \mathrm{MW})$

"Exergia

destruída no desaerador"

256: Bdest_desaerador.perc=Bdest_desaerador/B_fuel*100

"Percentual

de exergia destruída no desaerador"

257:

258: "BOMBA 2"

259:

260: B_7=m_dot_agua*(h[7]-h[0]-(T0+273,15)*(s[7]-s[0]) ${ }^{*}$ convert(kJ/h;MW)

"Exergia na saída da bomba 2"

261: B_6=m_dot_agua $(\mathrm{h}[6]-\mathrm{h}[0]-(\mathrm{T0}+273,15) \star(\mathrm{s}[6]-\mathrm{s}[0]))^{\star} \mathrm{convert}(\mathrm{kJ} / \mathrm{h} ; \mathrm{MW})$

"Exergia na entrada da bomba 2"

262: W_B2=m_dot_agua* $(\mathrm{h}[7]-\mathrm{h}[6])^{\star}$ convert $(\mathrm{kJ} / \mathrm{h} ; \mathrm{MW})$

"Trabalho realizado pela bomba $B 2^{\prime \prime}$

263: Bdest_B2=B_7-B_6 +W_B2

"Exergia

destruída na bomba 2"

264: Bdest_B2.perc=Bdest_B2/B_fuel ${ }^{\star} 100$

"Percentual de exergia destruída na bomba $2 "$

265

266:

267: "BOILER"

268: 
271: B_purga $=m$ _dot_purga*(h_purga-h[0]-(T0+273,15)*(s_purga-s[0]))*convert $(\mathrm{kJ} / \mathrm{h} ; \mathrm{MW})$

272: s_purga=entropy(water;h=h_purga;T=T_purga)

273:

274: Total_exergy.dest=Bdest_B1+Bdest_B2+Bdest_desaerador+Bdest_condenser+Bdest_boiler+Bdest_turbine

275: Total_exergy.dest.perc=Total_exergy.dest/B_fuel ${ }^{\star} 100$

276:

277:

278: "Eficiência Exergética"

279: "Cálculo da eficiência exergética global"

280:

281: eta_EXergética.Global=(POT_elétr.líquida + EXERGY.out_process)/B_fuel¹00

282:

283:

284: eta_Ex.ref.Carnot=eta_EXergética.Global/eta_Carnot*100

285:

286: "Distribuição de exergia entre vapor e eletricidade"

287:

288: Exergia_vapor.perc $=$ EXERGY.out_process/(POT_elétr.líquida + EXERGY.out_process) ${ }^{\star 100}$

289:

290: Exergia_eletricidade.perc $=$ POT_elétr.líquida/(POT_elétr.líquida + EXERGY.out_process)*100

291:

292:

293: "ANÁLISE COMPLEMENTAR 1A LEI - PERDAS ENERGÉTICAS"

294: "Perdas na Caldeira"

295:

296: Boiler_losses=POT_entrada*(1-eta_c)

297: Boiler_losses.perc=Boiler_losses/POT_entrada*100

298: Turbine_losses=(POT_1+POT_2) ${ }^{\star}(1 \text {-eta_t })^{*}$ convert(kJ/h;MW)

299: Turbine_losses.perc=Turbine_losses/POT_entrada*100

300:

301: "Perdas no condensador"

302:

303: POT_condensador $=$ Q_dot_out ${ }^{\star}$ convert $(\mathrm{kJ} / \mathrm{h} ; \mathrm{MW})$

perdida no condensador"

"Energia

304: POT_condensador.perc=POT_condensador/POT_entrada 100

305: Condenser_losses=POT_condensador

306:

307:

308: "Perdas no processo"

309:

310: process_losses = POT_entrada - (POT_processo+POT_elétr.gerada+POT_condensador+Turbine_losses+Boiler_losses)

311: process_losses.perc=process_losses/POT_entrada*100

312:

313:

314: "Cálculo da energia elétrica gerada por tela de cana"

315:

316: GeraçãoEletric.Espec.Total =POT_elétr.líquida*Período_safra*1000*24/Cana_safra

317: GeraçãoEletric.Espec.Excedente = GeraçãoEletric.Espec.Total - ConsumoEletr.Processo

318:

319:

320: "ALOCAÇÃO"

321:

322: "Critério energético"

323: POT_específica processo $=$ POT_processo*Período_safra*1000*24/Cana safra

324: Alocação_energia_vapor $=$ POT_específica_processo/(POT_específica_processo+GeraçãoEletric.Espec.Excedente 
EES Ver. 9.433: \#0624: Depart. de Engenharia Mecanica Escola Politecnic, Escola Politecnica da USP, Sao Paulo, Brazil

+ ConsumoEletr.Processo ${ }^{\star} 100$

325: Alocação_energia_eletr.exp = GeraçãoEletric.Espec.Excedente/(POT_específica_processo

+ GeraçãoEletric.Espec.Excedente+ConsumoEletr.Processo ${ }^{\star} 100$

326: Alocação_energia_eletr.proc = ConsumoEletr.Processo/(POT_específica_processo+GeraçãoEletric.Espec.Excedente +ConsumoEletr.Processo)*100

327:

328:

329: "Critério exergético"

330: EXERGY.out_específica_process $=$ EXERGY.out_process*Período_safra*1000*24/Cana_safra

331: Alocação_exergia_vapor = EXERGY.out_específica_process/(EXERGY.out_específica_process +GeraçãoEletric.Espec.Excedente+ConsumoEletr.Processo $)^{\star 100}$

332: Alocação_exergia_eletr.exp = GeraçãoEletric.Espec.Excedente/(EXERGY.out_específica_process + GeraçãoEletric.Espec.Excedente+ConsumoEletr.Processo ${ }^{\star} 100$

333: Alocação_exergia_eletr.proc = ConsumoEletr.Processo/(EXERGY.out_específica_process +GeraçãoEletric.Espec.Excedente+ConsumoEletr.Processo ${ }^{\star} 100$

334:

335:

336:

337:

338:

339:

340: "Distribuição de energia entre vapor e eletricidade"

341:

342: Energia_vapor.perc $=$ POT_processo/(POT_processo + POT_elétr.líquida $)^{\star 100}$

343:

344: Energia_eletricidade.perc $=$ POT_elétr.líquida/(POT_processo + POT_elétr.líquida)^100

APÊNDICE A - MODELAGEM TERMODINÂMICA DO SISTEMA DE COGERAÇÃO COM CICLO RANKINE CONVENCIONAL

Dados da Safra

$\dot{\mathrm{M}}_{\text {cana }}=\frac{\text { Cana }_{\text {safra }}}{\text { Período }_{\text {safra }}} \cdot \frac{1000}{24[\mathrm{~kg} / \mathrm{h}]}$ Taxa de Moagem de cana

$\dot{\mathrm{m}}_{\text {bagaço }}=\frac{\mathrm{Y}_{\text {bagaço }}}{100} \cdot \dot{\mathrm{M}}_{\text {cana }} \cdot \frac{\text { Utilização }_{\text {Bagaço }}}{100}$ Alimentação de bagaço de cana na caldeira

$\dot{\mathrm{m}}_{\text {palha }}=\frac{\mathrm{Y}_{\text {palha }}}{100} \cdot \dot{\mathrm{M}}_{\text {cana }} \cdot \frac{\text { Utilização }_{\text {Palha }}}{100}$ Alimentação de palha de cana na caldeira

$\operatorname{Razão}_{\text {biomasor }}^{\text {vassa }} \frac{\dot{\mathrm{m}}_{\text {vapor }}}{\dot{\mathrm{m}}_{\text {bagaço }}}$ Razão entre produção de vapor e consumo de biomassa

$\overline{\mathrm{m}}_{\text {bagaço }}=\frac{\dot{\mathrm{m}}_{\text {bagaço }}}{1000[\mathrm{t} / \mathrm{h}]}$

$\overline{\mathrm{m}}_{\mathrm{palha}}=\frac{\dot{\mathrm{m}}_{\mathrm{palha}}}{1000[\mathrm{t} / \mathrm{h}]}$

GERADOR DE VAPOR - Modelagem de conservação de matéria e energia

Balanço de massa

$\dot{\mathrm{m}}_{\text {agua }}=\dot{\mathrm{m}}_{\text {vapor }}+\dot{\mathrm{m}}_{\text {purga }}$

$\dot{\mathrm{m}}_{\text {purga }}=\mathrm{Y}_{\text {purga }} \cdot \dot{\mathrm{m}}_{\text {vapor }}$

$Y_{\text {purga }}=0,03$ Taxa de purga 
EES Ver. 9.433: \#0624: Depart. de Engenharia Mecanica Escola Politecnic, Escola Politecnica da USP, Sao Paulo, Brazil

$\overline{\mathrm{M}}_{\text {vapor }}=\frac{\dot{\mathrm{m}}_{\text {vapor }}}{1000[\mathrm{t} / \mathrm{h}]}$ Conversão da vazão mássica de vapor de $\mathrm{kg} / \mathrm{h}$ para $\mathrm{t} / \mathrm{h}$

Balanço de energia

$\dot{\mathrm{m}}_{\text {agua }} \cdot \mathrm{h}_{7}+\dot{\mathrm{Q}}_{\mathrm{c}}=\dot{\mathrm{m}}_{\text {vapor }} \cdot \mathrm{h}_{1}+\dot{\mathrm{m}}_{\text {purga }} \cdot \mathrm{h}_{\text {purga }}$

$\dot{\mathrm{Q}}_{\mathrm{c}}=\left[\dot{\mathrm{m}}_{\text {bagaço }} \cdot \mathrm{PCl}_{\text {bagaço }}+\dot{\mathrm{m}}_{\text {palha }} \cdot \mathrm{PCl}_{\text {palha }}\right] \cdot \eta_{\mathrm{c}}$ Energia utilizada na fornecida na fornalha para evaporação da água

$\mathrm{POT}_{\text {nominal;caldeira }}=\dot{\mathrm{Q}}_{\mathrm{c}} \cdot\left|2,77778 \times 10^{-7} \cdot \frac{\mathrm{MW}}{\mathrm{kJ} / \mathrm{h}}\right| \quad$ Potência nominal da caldeira

$\mathrm{h}_{1}=\mathbf{h}\left[\right.$ water $\left.; \mathrm{T}=\mathrm{T}_{1} ; \mathrm{P}=\mathrm{P}_{1}\right] \quad \mathrm{h}_{\text {purga }}=\mathbf{h}\left[\right.$ water $\left.; \mathrm{T}=\mathrm{T}_{\text {purga }} ; \mathrm{x}=0\right]$

$\mathrm{P}_{7}=1,2 \cdot \mathrm{P}_{\mathrm{c}} \quad \mathrm{T}_{\text {purga }}=\mathrm{T}_{\text {sat }}\left[\right.$ water $\left.; \mathrm{P}=\mathrm{P}_{\mathrm{c}}\right] \quad \mathrm{P}_{\text {purga }}=\mathrm{P}_{\mathrm{c}} \quad \mathrm{P}_{1}=\mathrm{P}_{\mathrm{c}}$

$\mathrm{PCl}_{\text {bagaço }}=7565 \quad \mathrm{PCl}_{\text {palha }}=12960[\mathrm{~kJ} / \mathrm{kg}]$ Poder calorífico inferior do bagaço (51\% umidade) e da palha de cana(15\% de umidade)

$\mathrm{T}_{1}=\mathbf{T}_{\text {sat }}\left[\right.$ water $\left.; \mathrm{P}=\mathrm{P}_{\mathrm{c}}\right]+\mathrm{G}_{\text {super }}$ Temperatura do vapor superaquecido

$\mathrm{G}_{\text {super }}=200 \quad[\mathrm{C}]$ Grau de superaquecimento

BOMBA 02 - ALIMENTAÇÃO DA CALDEIRA

$\mathrm{P}_{6}=\mathrm{p}_{2}$ Pressão de descarga da bomba igual a pressão do vapor de escape

$\eta_{\mathrm{B} 2}=\frac{\mathrm{h}_{6}-\mathrm{h} 7_{\text {iso }}}{\mathrm{h}_{6}-\mathrm{h}_{7}}$ Determinação da entalpia real da vazão de líquido na descarga da bomba

$\mathrm{h} 7_{\text {iso }}=\mathbf{h}\left[\right.$ water $\left.; \mathrm{s}=\mathrm{s}_{6} ; \mathrm{P}=\mathrm{P}_{7}\right]$ Entalpia para condição ideal isentrópica

$\mathrm{h}_{6}=\mathbf{h}\left[\right.$ water $\left.; \mathrm{P}=\mathrm{P}_{6} ; \mathrm{T}=\mathrm{T}_{6}\right]$ Entalpia na saída do desaerador

$\mathrm{S}_{6}=\mathbf{s}\left[\right.$ water $\left.; \mathrm{P}=\mathrm{P}_{6} ; \mathrm{T}=\mathrm{T}_{6}\right]$ Entropia na saída do desaerador é entropia do líquido saturado

$\mathrm{T}_{7}=\mathbf{T}\left[\right.$ water $\left.; \mathrm{h}=\mathrm{h}_{7} ; \mathrm{P}=\mathrm{P}_{7}\right]$ Temperatura de recalque

$\mathrm{s}_{7}=\mathbf{s}\left[\right.$ water $\left.; \mathrm{h}=\mathrm{h}_{7} ; \mathrm{P}=\mathrm{P}_{7}\right]$ Entropia da água de alimentação da caldeira

BOMBA 01 - CONDENSADO

$\mathrm{P}_{5}=\mathrm{p}_{2}$ Pressão de descarga da bomba igual a pressão do vapor de escape

$\eta_{\mathrm{B} 1}=\frac{\mathrm{h}_{4}-\mathrm{h}_{\text {iso }}}{\mathrm{h}_{4}-\mathrm{h}_{5}}$ Determinação da entalpia real do líquido na descarga da bomba

$\mathrm{h}_{\text {iso }}=\mathbf{h}\left[\right.$ water $\left.; \mathrm{s}=\mathrm{s}_{4} ; \mathrm{P}=\mathrm{P}_{5}\right]$ Entalpia para condição ideal isentrópica

$\mathrm{s}_{4}=\mathbf{s}\left[\right.$ water $\left.; \mathrm{P}=\mathrm{P}_{4} ; \mathrm{x}=0\right]$ Entropia na saída do condensador - líquido saturado

$\mathrm{T}_{5}=\mathbf{T}\left[\right.$ water $\left.; \mathrm{h}=\mathrm{h}_{5} ; \mathrm{P}=\mathrm{P}_{5}\right]$ Temperatura de recalque para desaerador

$\mathrm{h}_{4}=\mathbf{h}\left[\right.$ water $\left.; \mathrm{P}=\mathrm{P}_{4} ; \mathrm{x}=0\right]$ Entalpia da saída do condensador é a entalpia de líquido saturado

$\mathrm{T}_{4}=\mathrm{T}_{3}$ Temperatura de Entrada = temperatura de saída --> Somente troca calor latente

$\mathrm{P}_{4}=\mathrm{P}_{3}$ Pressão de sucção da bomba = pressão da cauda da turbina

$\mathrm{S}_{5}=\mathbf{s}\left[\right.$ water $\left.; \mathrm{P}=\mathrm{P}_{5} ; \mathrm{T}=\mathrm{T}_{5}\right]$ Entropia da água de recalque da bomba 01 
EES Ver. 9.433: \#0624: Depart. de Engenharia Mecanica Escola Politecnic, Escola Politecnica da USP, Sao Paulo, Brazil

\section{TURBINA}

Rendimento da turbina

$\eta_{\mathrm{t}}=\frac{\mathrm{h}_{1}-\mathrm{h}_{2}}{\mathrm{~h}_{1}-\mathrm{h} 2_{\text {iso }}}$ Determinação da entalpia real do vapor extraído para o desaerador através da eficiencia isoentrópica $\eta_{\mathrm{t}}=\frac{\mathrm{h}_{1}-\mathrm{h}_{3}}{\mathrm{~h}_{1}-\mathrm{h} 3_{\text {iso }}}$ Determinação da entalpia real do vapor extraído para o condensador através da eficiencia isoentrópica $\mathrm{h} 2_{\text {iso }}=\mathbf{h}\left[\right.$ water $\left.; \mathrm{s}=\mathrm{s}_{1} ; \mathrm{P}=\mathrm{p}_{2}\right]$ Entalpia da corrente de vapor de escape para condição ideal de expansão isoentrópica $\mathrm{h} 3_{\text {iso }}=\mathbf{h}\left[\right.$ water $\left.; \mathrm{s}=\mathrm{s}_{1} ; \mathrm{P}=\mathrm{P}_{3}\right]$ Entalpia da corrente de vapor na cauda para condição ideal de expansão isoentrópica $\mathrm{s}_{1}=\mathbf{s}\left[\right.$ water $\left.; \mathrm{P}=\mathrm{P}_{1} ; \mathrm{T}=\mathrm{T}_{1}\right] \quad$ Estado definido por 2 propriedades independentes

$\mathrm{T}_{2}=\mathbf{T}\left[\right.$ water $\left.; \mathrm{h}=\mathrm{h}_{2} ; \mathrm{P}=\mathrm{p}_{2}\right]$ Temperatura do vapor de escape

$\mathrm{T}_{3}=\mathbf{T}\left[\right.$ water $\left.; \mathrm{h}=\mathrm{h}_{3} ; \mathrm{P}=\mathrm{P}_{3}\right]$ Temperatura do vapor de cauda

$\mathrm{s}_{2}=\mathbf{s}\left[\right.$ water $\left.; \mathrm{h}=\mathrm{h}_{2} ; \mathrm{T}=\mathrm{T}_{2}\right]$ Entropia do vapor de escape

$\mathrm{s}_{3}=\mathbf{s}\left[\right.$ water $\left.; \mathrm{h}=\mathrm{h}_{3} ; \mathrm{T}=\mathrm{T}_{3}\right]$ Entropia do vapor de cauda

$\mathrm{x}_{2}=\mathbf{x}\left[\right.$ water $\left.; \mathrm{h}=\mathrm{h}_{2} ; \mathrm{T}=\mathrm{T}_{2}\right]$ Título do vapor de escape

$\mathrm{x}_{3}=\mathbf{x}\left[\right.$ water $\left.; \mathrm{h}=\mathrm{h}_{3} ; \mathrm{T}=\mathrm{T}_{3}\right]$ Título do vapor na cauda da turbina

Balanço de massa na turbina

$\dot{\mathrm{m}}_{\text {vapor }}=\dot{\mathrm{m}}_{\text {vap.escape }}+\dot{\mathrm{m}}_{\text {vap.cauda }}$

PURGA DE CONDENSADO ANTES DE SER USADO NO PROCESSO

RETORNO DE CONDENSADO DO PROCESSO INDUSTRIAL

$\dot{\mathrm{m}}_{\text {retorno }}=\dot{\mathrm{m}}_{\text {vap.processo }} \cdot 0,9$ Considerado perdas no processo de $10 \%$ da vazão de vapor

$\mathrm{T}_{\text {cond }}=90 \quad[\mathrm{C}]$ Considerado que todo condensado é coletado em um tanque de recuperação e retorna para o ciclo a $90 \mathrm{C}$

$\mathrm{P}_{\text {cond }}=\mathrm{p}_{2}$ Pressão de retorno $=$ pressão no desaerador $=$ Pressão do vapor de escape

$\mathrm{m}_{\text {agua.dessuper }}=$ If $\left[\mathrm{x}_{2} ; 100 ; 0 ; \dot{\mathrm{m}}_{\text {agua.dessuper }} ; 0\right]$

Se o vapor de escape estiver superaquecido agua deve ser alimentada no dessuperaquecedor para obter vapor saturado para o processo de produção do etanol

$\dot{\mathrm{m}}_{\text {purgador }}=$ If $\left[\mathrm{x}_{2} ; 100 ;-\dot{\mathrm{m}}_{\text {agua.dessuper }} ; 0 ; 0\right]$ Se o vapor de escape tiver $\mathrm{x}<1$ o condensado precisa ser retirado em purgadores

\section{DESSUPERAQUECEDOR E VAPOR DE PROCESSO}

Balanços de massa

$\dot{\mathrm{m}}_{\text {vap.escape }}=\dot{\mathrm{m}}_{\text {vap.dessuper }}+\dot{\mathrm{m}}_{\text {vap.desaerador }}$

$\dot{\mathrm{m}}_{\text {vap. processo }}=$ Cons.Vapor $_{\text {processo }} \cdot \dot{\mathrm{M}}_{\text {cana }} \cdot \frac{1}{1000}$ Consumo de vapor saturado para o processo a $P=2,5$ Bar 
File:Convencional - 2a Lei.EES

EES Ver. 9.433: \#0624: Depart. de Engenharia Mecanica Escola Politecnic, Escola Politecnica da USP, Sao Paulo, Brazil

$\dot{\mathrm{m}}_{\text {vap.processo }}=\dot{\mathrm{m}}_{\text {vap.dessuper }}+\dot{\mathrm{m}}_{\text {agua.dessuper }}$

Balanço de energia no dessuperaquecedor

$\dot{\mathrm{m}}_{\text {vap.processo }} \cdot \mathrm{h}_{\text {pro }}=\dot{\mathrm{m}}_{\text {vap.dessuper }} \cdot \mathrm{h}_{2}+\dot{\mathrm{m}}_{\text {agua.dessuper }} \cdot \mathrm{h}_{\text {rep.des }}$

$\mathrm{h}_{\text {pro }}=\mathbf{h}\left[\right.$ water $\left.; \mathrm{T}=\mathrm{T}_{\text {pro }} ; \mathrm{x}=1\right] \quad \mathrm{T}_{\text {pro }}=\mathbf{T}_{\text {sat }}[$ water $; \mathrm{P}=2,5]$ Processo industrial utiliza vapor saturado

\section{DESAERADOR}

Balanço de massa no desaerador

$\dot{\mathrm{m}}_{\text {retorno }}+\dot{\mathrm{m}}_{\text {vap.desaerador }}+\dot{\mathrm{m}}_{\text {vap.cauda }}+\dot{\mathrm{m}}_{\text {rep.desaerador }}+\dot{\mathrm{m}}_{\text {purgador }}=\dot{\mathrm{m}}_{\text {agua }}$

Balanço de energia no desaerador

$\dot{\mathrm{m}}_{\text {retorno }} \cdot \mathrm{h}_{\text {cond }}+\dot{\mathrm{m}}_{\text {vap.desaerador }} \cdot \mathrm{h}_{2}+\dot{\mathrm{m}}_{\text {vap.cauda }} \cdot \mathrm{h}_{5}+\dot{\mathrm{m}}_{\text {rep.desaerador }} \cdot \mathrm{h}_{\text {rep.des }}+\dot{\mathrm{m}}_{\text {purgador }}$

- $\mathrm{h}_{\text {purgador }}=\dot{\mathrm{m}}_{\text {agua }} \cdot \mathrm{h}_{6}$

$\mathrm{h}_{\text {cond }}=\mathbf{h}\left[\right.$ water $\left.; \mathrm{T}=\mathrm{T}_{\text {cond }} ; \mathrm{P}=\mathrm{P}_{\text {cond }}\right] \quad \mathrm{h}_{\text {purgador }}=\mathbf{h}\left[\right.$ water $\left.; \mathrm{P}=\mathrm{p}_{2} ; \mathrm{x}=0\right]$

$\mathrm{h}_{\text {rep.des }}=\mathbf{h}\left[\right.$ water $\left.; \mathrm{T}=\mathrm{T}_{\mathrm{amb}} ; \mathrm{P}=\mathrm{P}_{\text {rep.des }}\right] \quad \mathrm{T}_{\mathrm{amb}}=25$

$\mathrm{P}_{\text {rep.des }}=\mathrm{p}_{2}$ Pressão no desaerador é a pressão de escape da turbina

Conversão de unidades de $\mathrm{kg} / \mathrm{h}$ para $\mathrm{t} / \mathrm{h}$

$\overline{\mathrm{m}}_{\text {vap.escape }}=\frac{\dot{\mathrm{m}}_{\text {vap.escape }}}{1000[\mathrm{t} / \mathrm{h}]}$

$\overline{\mathrm{m}}_{\text {vap.cauda }}=\frac{\dot{\mathrm{m}}_{\text {vap.cauda }}}{1000[\mathrm{t} / \mathrm{h}]}$

$\overline{\mathrm{m}}_{\text {vap.processo }}=\frac{\dot{\mathrm{m}}_{\text {vap.processo }}}{1000[\mathrm{t} / \mathrm{h}]}$

$\overline{\mathrm{m}}_{\text {vap.desaerador }} \quad=\frac{\dot{\mathrm{m}}_{\text {vap.desaerador }}}{1000[\mathrm{t} / \mathrm{h}]}$

$\overline{\mathrm{m}}_{\text {rep.desaerador }}=\frac{\dot{\mathrm{m}}_{\text {rep.desaerador }}}{1000[\mathrm{t} / \mathrm{h}]}$

$\overline{\mathrm{m}}_{\text {feed.water. }}=\frac{\dot{\mathrm{m}}_{\text {agua }}}{1000[\mathrm{t} / \mathrm{h}]}$

$\overline{\mathrm{m}}_{\text {purga. }}=\frac{\dot{\mathrm{m}}_{\text {purga }}}{1000[\mathrm{t} / \mathrm{h}]}$

$\overline{\mathrm{m}}_{\text {purgador }}=\frac{\dot{\mathrm{m}}_{\text {purgador }}}{1000[\mathrm{t} / \mathrm{h}]}$

CONDENSADOR

$\dot{\mathrm{Q}}_{\text {out }}=\dot{\mathrm{m}}_{\text {vap.cauda }} \cdot\left[\mathrm{h}_{3}-\mathrm{h}_{4}\right]$ Balanço de energia --> Calor transferido da condensação do vapor para a torre de resfriamento

TORRE DE RESFRIAMENTO

$\dot{\mathrm{Q}}_{\text {out }}=\dot{\mathrm{m}}_{\text {recirculação }} \cdot\left[\mathrm{h}_{\text {out }}-\mathrm{h}_{\text {in }}\right]$ 
EES Ver. 9.433: \#0624: Depart. de Engenharia Mecanica Escola Politecnic, Escola Politecnica da USP, Sao Paulo, Brazil

$$
\begin{aligned}
& \mathrm{h}_{\text {out }}=\mathbf{h}\left[\text { water } ; \mathrm{P}=\mathrm{P}_{\text {out }} ; \mathrm{T}=\mathrm{T}_{\text {out }}\right] \quad \mathrm{h}_{\text {in }}=\mathbf{h}\left[\text { water } ; \mathrm{P}=\mathrm{P}_{\text {in }} ; \mathrm{T}=\mathrm{T}_{\text {in }}\right] \quad \mathrm{P}_{\text {in }}=1 \\
& \mathrm{P}_{\text {out }}=1 \\
& \dot{\mathrm{m}}_{\text {repos.torre }}=\mathrm{Y}_{\text {perdas }} \cdot \dot{\mathrm{m}}_{\text {recirculação }} \quad Y_{\text {perdas }} \text { corresponde a uma estimativa de perdas de água por evaporação, purga } \\
& \text { e arraste na torre de resfriamento } \\
& \dot{\mathrm{m}}_{\text {rep.total }}=\dot{\mathrm{m}}_{\text {repos.torre }}+\dot{\mathrm{m}}_{\text {rep.desaerador }}+\mathrm{m}_{\text {agua.dessuper }} \\
& \overline{\mathrm{m}}_{\text {repos.torre }}=\frac{\dot{\mathrm{m}}_{\text {repos.torre }}}{1000[\mathrm{t} / \mathrm{h}]} \\
& \overline{\mathrm{m}}_{\text {rep.total }}=\frac{\dot{\mathrm{m}}_{\text {rep.total }}}{1000[\mathrm{t} / \mathrm{h}]} \\
& \overline{\mathrm{m}}_{\text {vap.dessuper }}=\frac{\dot{\mathrm{m}}_{\text {vap.dessuper }}}{1000[\mathrm{t} / \mathrm{h}]} \\
& \text { Perc.torre }=\frac{\dot{\mathrm{m}}_{\text {repos.torre }}}{\dot{\mathrm{m}}_{\text {rep.total }}} \cdot 100 \\
& \text { Perc.desaerador }=\frac{\dot{\mathrm{m}}_{\text {rep.desaerador }}}{\dot{\mathrm{m}}_{\text {rep.total }}} \cdot 100 \\
& \text { Perc.dessuper }=\frac{\dot{\mathrm{m}}_{\text {vap.dessuper }}}{\dot{\mathrm{m}}_{\text {rep.total }}} \cdot 100 \\
& \text { Tap.water } r_{\text {torre }}=\frac{\dot{\mathrm{m}}_{\text {repos.torre }}}{\frac{\dot{\mathrm{M}}_{\text {cana }}}{1000}} \\
& \text { Tap.water }_{\text {deionised }}=\frac{\dot{\mathrm{m}}_{\text {rep.desaerador }}+\mathrm{m}_{\text {agua.dessuper }}}{\frac{\dot{\mathrm{M}}_{\text {cana }}}{1000}}
\end{aligned}
$$

\section{CÁLCULO DAS POTÊNCIAS ELÉTRICAS}

Potência elétrica gerada

$\mathrm{POT}_{\text {elétr.gerada }}=\left[\mathrm{POT}_{1}+\mathrm{POT}_{2}\right] \cdot \eta_{\mathrm{g}} \cdot\left|2,77778 \times 10^{-7} \cdot \frac{\mathrm{MW}}{\mathrm{kJ} / \mathrm{h}}\right|$ Potencia elétrica total gerada no turbogerador

$\mathrm{POT}_{1}=\dot{\mathrm{m}}_{\text {vap.escape }} \cdot\left[\mathrm{h}_{1}-\mathrm{h}_{2}\right]$ Potencia gerada pelo vapor de escape a $P=2,5$ bar

$\mathrm{POT}_{2}=\dot{\mathrm{m}}_{\text {vap.cauda }} \cdot\left[\mathrm{h}_{1}-\mathrm{h}_{3}\right]$ Potencia gerada pelo vapor da cauda

Consumo das bombas do ciclo

$\mathrm{POT}_{\text {elétr.consumida }}=\left[\mathrm{POT}_{\mathrm{B} 1}+\mathrm{POT}_{\mathrm{B} 2}\right] \cdot\left|2,77778 \times 10^{-7} \cdot \frac{\mathrm{MW}}{\mathrm{kJ} / \mathrm{h}}\right|$ Potência consumida pelas bombas

POT $_{\mathrm{B} 1}=\dot{\mathrm{m}}_{\text {vap.cauda }} \cdot\left[\mathrm{h}_{5}-\mathrm{h}_{4}\right]$ Potência consumida pela bomba 1

POT $_{\text {B2 }}=\dot{\mathrm{m}}_{\text {agua }} \cdot\left[\mathrm{h}_{7}-\mathrm{h}_{6}\right]$ Potência consumida pela bomba 2

\section{EFICIÊNCIA GLOBAL DA UNIDADE DE COGERAÇÃO CONVENCIONAL}


File:Convencional - 2a Lei.EES

EES Ver. 9.433: \#0624: Depart. de Engenharia Mecanica Escola Politecnic, Escola Politecnica da USP, Sao Paulo, Brazil

$\eta_{\text {Energética.Global }}=\left[\frac{\mathrm{POT}_{\text {elétr.líquida }}+\mathrm{POT}_{\text {processo }}}{\mathrm{POT}_{\text {entrada }}}\right] \cdot 100$

Potência líquida gerada na unidade de cogeração

$\mathrm{POT}_{\text {elétr.líquida }}=\mathrm{POT}_{\text {elétr.gerada }}-\mathrm{POT}_{\text {elétr.consumida }}$

Potência utilizada no processo industrial

$\mathrm{POT}_{\text {processo }}=\dot{\mathrm{m}}_{\text {vap.processo }} \cdot\left[\mathrm{h}_{\text {pro }}-\mathrm{h}_{\text {sat }}\right] \cdot\left|2,77778 \times 10^{-7} \cdot \frac{\mathrm{MW}}{\mathrm{kJ} / \mathrm{h}}\right|$
$\mathrm{POT}_{\text {desaerador }}=\dot{\mathrm{m}}_{\text {vap.desaerador }} \cdot\left[\mathrm{h}_{2}-\mathrm{h}_{6}\right] \cdot\left|2,77778 \times 10^{-7} \cdot \frac{\mathrm{MW}}{\mathrm{kJ} / \mathrm{h}}\right|$

$\mathrm{POT}_{\text {desaerador.perc }}=\frac{\mathrm{POT}_{\text {desaerador }}}{\mathrm{POT}_{\text {entrada }}} \cdot 100$

$\mathrm{POT}_{\text {processo.perc }}=\frac{\mathrm{POT}_{\text {processo }}}{\mathrm{POT}_{\text {entrada }}} \cdot 100$

$\mathrm{h}_{\text {sat }}=\mathbf{h}[$ water $; \mathrm{x}=0 ; \mathrm{P}=2,5]$

Alimentação energética na fornalha da caldeira

$\mathrm{POT}_{\text {entrada }}=\left[\dot{\mathrm{m}}_{\text {bagaço }} \cdot \mathrm{PCl}_{\text {bagaço }}+\dot{\mathrm{m}}_{\text {palha }} \cdot \mathrm{PCl}_{\text {palha }}\right] \cdot\left|2,77778 \times 10^{-7} \cdot \frac{\mathrm{MW}}{\mathrm{kJ} / \mathrm{h}}\right|$

APLICAÇÃO DA 2A LEI DA TERMODINÂMICA - ANÁLISE EXERGÉTICA

Ambiente de referência considerado: $P o=1$ bar e $T o=25 C$

$\mathrm{TO}=25[\mathrm{C}]$

$\mathrm{PO}=1[\mathrm{bar}]$

$\mathrm{P} 00_{\mathrm{h} 20}=0,0303 \quad[\mathrm{bar}]$

LIMITE TEÓRICO DE EFICIÊNCIA - CICLO DE CARNOT

$\eta$ Carnot $=\left[1-\left(\frac{T_{3}+273,15}{T_{1}+273,15}\right)\right] \cdot 100$ Trabalho máximo teórico que pode ser obtido se o ciclo fosse reversível

Trabalho útil final - saída do gerador de eletricidade

EXERGY.in fuel $_{\text {f }}=\mathrm{POT}_{\text {entrada }}$ Exergia do combustível é PCl do combustível (Oliveira Jr., 2012)

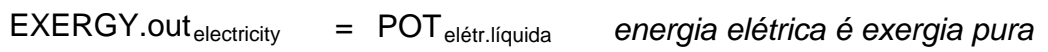

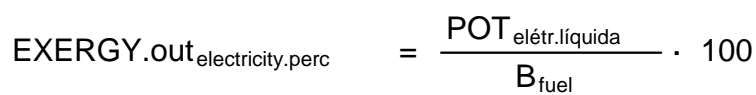

Boiler

$\mathrm{B}_{1}=\dot{\mathrm{m}}_{\text {vapor }} \cdot\left[\mathrm{h}_{1}-\mathrm{h}_{0}-\left([\mathrm{TO}+273,15] \cdot\left[\mathrm{s}_{1}-\mathrm{s}_{0}\right]\right)\right] \cdot\left|2,77778 \times 10^{-7} \cdot \frac{\mathrm{MW}}{\mathrm{kJ} / \mathrm{h}}\right|$ Exergia do vapor de saída do gerador de vapor

$\mathrm{h}_{0}=\mathbf{h}[$ water $; \mathrm{T}=\mathrm{TO} ; \mathrm{P}=\mathrm{PO}]$ 
$\mathrm{S}_{0}=\mathbf{s}[$ water $; \mathrm{T}=\mathrm{T} 0 ; \mathrm{P}=\mathrm{PO}]$

$B_{\text {fuel }}=$ EXERGY.in fuel

\section{TURBINE}

Exergia das correntes de vapor de escape e cauda

$\mathrm{B}_{2}=\dot{\mathrm{m}}_{\text {vap.escape }} \cdot\left[\mathrm{h}_{2}-\mathrm{h}_{0}-\left([\mathrm{TO}+273,15] \cdot\left[\mathrm{s}_{2}-\mathrm{s}_{0}\right]\right)\right] \cdot\left|2,77778 \times 10^{-7} \cdot \frac{\mathrm{MW}}{\mathrm{kJ} / \mathrm{h}}\right| \begin{array}{r}\text { Exergia do vapor } \\ \text { de escape }\end{array}$

$\mathrm{B}_{3}=\dot{\mathrm{m}}_{\text {vap.cauda }} \cdot\left[\mathrm{h}_{3}-\mathrm{h}_{0}-\left([\mathrm{TO}+273,15] \cdot\left[\mathrm{s}_{3}-\mathrm{s}_{0}\right]\right)\right] \cdot\left|2,77778 \times 10^{-7} \cdot \frac{\mathrm{MW}}{\mathrm{kJ} / \mathrm{h}}\right|$ Exergia do vapor de cauda

Balanço de exergia na turbina

Bdest $_{\text {turbine }}=\mathrm{B}_{1}-\left[\mathrm{B}_{2}+\mathrm{B}_{3}+\frac{\mathrm{POT}_{\text {elétr.gerada }}}{\eta_{\mathrm{g}}}\right]$ Exergia destruída na turbina

Bdest $_{\text {turbine.perc }}=\frac{\text { Bdest }_{\text {turbine }}}{\mathrm{B}_{\text {fuel }}} \cdot 100$ Percentual de exergia destruída na turbina

$\mathrm{B}_{2 ; p e r c}=\frac{\mathrm{B}_{2}}{\mathrm{~B}_{\text {fuel }}} \cdot 100$ Percentual de exergia no vapor de escape

$\mathrm{B}_{\text {liq }}=\frac{\mathrm{POT}_{\text {elétr.gerada }}}{\mathrm{B}_{\text {fuel }}} \cdot 100$ Percentual de exergia (trabalho) na saída do gerador

Consumo de exergia no processo industrial associado ao consumo específico de vapor

EXERGY.out process $=\dot{\mathrm{m}}_{\text {vap.processo }} \cdot\left[\mathrm{h}_{\text {pro }}-\mathrm{h}_{0}-\left([\mathrm{TO}+273,15] \cdot\left[\mathrm{s}_{\text {pro }}-\mathrm{s}_{0}\right]\right)\right] \cdot\left|2,77778 \times 10^{-7} \cdot \frac{\mathrm{MW}}{\mathrm{kJ} / \mathrm{h}}\right|$

Exergia da corrente de vapor utilizado no processo de produção de etanol

$\mathrm{s}_{\text {pro }}=\mathbf{s}[$ water $; \mathrm{P}=2,5 ; \mathrm{T}=127,5]$

EXERGY.out process.perc $_{\text {eXERGY.out }}=\frac{\text { Erocess }_{\text {fuel }}}{B_{\text {fuel }}} \cdot 100$

EXERGY.out $_{\text {deaerator }} \quad=B_{2}-$ EXERGY.out process

EXERGY.out deaerator.perc $_{\text {exERGY.out }}=\frac{\text { EXearator }_{\text {duel }}}{B_{\text {fuel }}} \cdot 100$

\section{DESSUPERAQUECEDOR}

Balanço de entropia no dessuper

$\mathrm{s}_{\text {ger.dessuper }}=\dot{\mathrm{m}}_{\text {vap.processo }} \cdot \mathrm{s}_{\text {pro }}-\left[\mathrm{m}_{\text {agua.dessuper }} \cdot \mathrm{s}_{\text {agua }}+\left(\dot{\mathrm{m}}_{\text {vap.dessuper }}-\dot{\mathrm{m}}_{\text {purgador }}\right) \cdot \mathrm{s}_{2}\right]$

$\mathrm{S}_{\text {agua }}=\mathbf{s}[$ water $; \mathrm{P}=2,5 ; \mathrm{T}=25]$

Bdest $_{\text {dessuper }}=[\mathrm{TO}+273,15] \cdot \mathrm{S}_{\text {ger.dessuper }} \cdot\left|2,77778 \times 10^{-7} \cdot \frac{\mathrm{MW}}{\mathrm{kJ} / \mathrm{h}}\right|$ Exergia destruída no dessuperaquecedor

Bdest $_{\text {dessuper.perc }}=\frac{\text { Bdest }_{\text {dessuper }}}{\mathrm{B}_{\text {fuel }}} \cdot 100$ Percentual de exergia destruída no dessuperaquecedor 
$\mathrm{B}_{4}=\dot{\mathrm{m}}_{\text {vap.cauda }} \cdot\left[\mathrm{h}_{4}-\mathrm{h}_{0}-\left([\mathrm{T} 0+273,15] \cdot\left[\mathrm{s}_{4}-\mathrm{s}_{0}\right]\right)\right] \cdot\left|2,77778 \times 10^{-7} \cdot \frac{\mathrm{MW}}{\mathrm{kJ} / \mathrm{h}}\right|$ Exergia na saída do condensador

Bdest $_{\text {condenser }}=\mathrm{B}_{3}-\mathrm{B}_{4}$ Exergia destruída no condensador

Bdest $_{\text {condenser.perc }}=\frac{\text { Bdest }_{\text {condenser }}}{\mathrm{B}_{\text {fuel }}} \cdot 100$ Percentual de exergia destruída no condensador

BOMBA 1

$\mathrm{B}_{5}=\dot{\mathrm{m}}_{\text {vap.cauda }} \cdot\left[\mathrm{h}_{5}-\mathrm{h}_{0}-\left([\mathrm{T} 0+273,15] \cdot\left[\mathrm{s}_{5}-\mathrm{s}_{0}\right]\right)\right] \cdot\left|2,77778 \times 10^{-7} \cdot \frac{\mathrm{MW}}{\mathrm{kJ} / \mathrm{h}}\right|$ Exergia na saída da bomba 1

Bdest $_{\mathrm{B} 1}=\mathrm{B}_{4}-\mathrm{B}_{5}+\mathrm{W}_{\mathrm{B} 1}$ Exergia destruída na bomba 1

$\mathrm{W}_{\mathrm{B} 1}=\dot{\mathrm{m}}_{\text {vap.cauda }} \cdot\left[\mathrm{h}_{5}-\mathrm{h}_{4}\right] \cdot\left|2,77778 \times 10^{-7} \cdot \frac{\mathrm{MW}}{\mathrm{kJ} / \mathrm{h}}\right|$ Trabalho realizado pela bomba $B 1$

Bdest $_{\mathrm{B} 1 \text {.perc }}=\frac{\text { Bdest }_{\mathrm{B} 1}}{\mathrm{~B}_{\mathrm{fuel}}} \cdot 100$ Percentual de exergia destruída na bomba 1

\section{DESAERADOR}

Balanço de entropia no dessuperaquecedor

$\mathrm{s}_{\text {ger.desaerador }}=\dot{\mathrm{m}}_{\text {agua }} \cdot \mathrm{s}_{6}-\left[\dot{\mathrm{m}}_{\text {retorno }} \cdot \mathrm{s}_{\text {cond }}+\dot{\mathrm{m}}_{\text {vap.desaerador }} \cdot \mathrm{s}_{2}+\dot{\mathrm{m}}_{\text {vap.cauda }} \cdot \mathrm{s}_{5}+\dot{\mathrm{m}}_{\text {rep.desaerador }}\right.$
$\left.\mathrm{s}_{\text {agua }}+\dot{\mathrm{m}}_{\text {purgador }} \cdot \mathrm{s}_{\mathrm{sat}}\right]$
Bdest $_{\text {desaerador }}=\left[\mathrm{s}\left[\right.\right.$ water $\left.; \mathrm{T}=\mathrm{T}_{\text {cond }} ; \mathrm{P}=\mathrm{P}_{\text {cond }}\right] \quad \mathrm{s}_{\mathrm{sat}}=\mathrm{s}[$ water $; \mathrm{P}=2,5 ; \mathrm{x}=0]$

Bdest $_{\text {desaerador.perc }}=\frac{\text { Bdest }_{\text {desaerador }}}{\mathrm{B}_{\text {fuel }}} \cdot 100$ Percentual de exergia destruída no desaerador

BOMBA 2

$\mathrm{B}_{7}=\dot{\mathrm{m}}_{\mathrm{agua}} \cdot\left[\mathrm{h}_{7}-\mathrm{h}_{0}-\left([\mathrm{TO}+273,15] \cdot\left[\mathrm{s}_{7}-\mathrm{s}_{0}\right]\right)\right] \cdot\left|2,77778 \times 10^{-7} \cdot \frac{\mathrm{MW}}{\mathrm{kJ} / \mathrm{h}}\right|$ Exergia na saída da bomba 2

$\mathrm{B}_{6}=\dot{\mathrm{m}}_{\text {agua }} \cdot\left[\mathrm{h}_{6}-\mathrm{h}_{0}-\left([\mathrm{T} 0+273,15] \cdot\left[\mathrm{s}_{6}-\mathrm{s}_{0}\right]\right)\right] \cdot\left|2,77778 \times 10^{-7} \cdot \frac{\mathrm{MW}}{\mathrm{kJ} / \mathrm{h}}\right|$ Exergia na entrada da bomba 2

$\mathrm{W}_{\mathrm{B} 2}=\dot{\mathrm{m}}_{\text {agua }} \cdot\left[\mathrm{h}_{7}-\mathrm{h}_{6}\right] \cdot\left|2,77778 \times 10^{-7} \cdot \frac{\mathrm{MW}}{\mathrm{kJ} / \mathrm{h}}\right|$ Trabalho realizado pela bomba $B 2$

Bdest $_{\mathrm{B} 2}=\mathrm{B}_{7}-\mathrm{B}_{6}+\mathrm{W}_{\mathrm{B} 2} \quad$ Exergia destruída na bomba 2

Bdest $_{\mathrm{B} 2 \text {.perc }}=\frac{\text { Bdest }_{\mathrm{B} 2}}{\mathrm{~B}_{\text {fuel }}} \cdot 100$ Percentual de exergia destruída na bomba 2

BOILER

$\mathrm{B}_{7}+\mathrm{B}_{\text {fuel }}=\mathrm{B}_{1}+\mathrm{B}_{\text {purga }}+$ Bdest $_{\text {boiler }}$ Balanço de exergia na caldeira 
Bdest $_{\text {boiler.perc }}=\frac{\text { Bdest }_{\text {boiler }}}{\mathrm{B}_{\text {fuel }}} \cdot 100$ Percentual de exergia destruída na caldeira

$\mathrm{B}_{\text {purga }}=\dot{\mathrm{m}}_{\text {purga }} \cdot\left[\mathrm{h}_{\text {purga }}-\mathrm{h}_{0}-\left([\mathrm{T0}+273,15] \cdot\left[\mathrm{s}_{\text {purga }}-\mathrm{s}_{0}\right]\right)\right] \cdot\left|2,77778 \times 10^{-7} \cdot \frac{\mathrm{MW}}{\mathrm{kJ} / \mathrm{h}}\right|$

$\mathrm{S}_{\text {purga }}=\mathbf{s}\left[\right.$ water $\left.; \mathrm{h}=\mathrm{h}_{\text {purga }} ; \mathrm{T}=\mathrm{T}_{\text {purga }}\right]$

Total $_{\text {exergy.dest }}=$ Bdest $_{\mathrm{B} 1}+$ Bdest $_{\mathrm{B} 2}+$ Bdest $_{\text {desaerador }}+$ Bdest $_{\text {condenser }}+$ Bdest $_{\text {boiler }}+$ Bdest $_{\text {turbine }}$

Total $_{\text {exergy.dest.perc }}=\frac{\text { Total }_{\text {exergy.dest }}}{\mathrm{B}_{\text {fuel }}} \cdot 100$

Eficiência Exergética

Cálculo da eficiência exergética global

$\eta_{\text {EXergética.Global }}=\left[\frac{\text { POT }_{\text {elétr.líquida }}+\text { EXERGY.out }_{\text {process }}}{B_{\text {fuel }}}\right] \cdot 100$

$\eta$ Ex.ref.Carnot $=\frac{\eta \text { EXergética.Global }}{\eta \text { Carnot }} \cdot 100$

Distribuição de exergia entre vapor e eletricidade

Exergia $_{\text {vapor.perc }}=\left[\frac{\text { EXERGY.out }_{\text {process }}}{\text { POT }_{\text {elétr.líquida }}+\text { EXERGY.out }_{\text {process }}}\right] \cdot 100$

Exergia $_{\text {eletricidade.perc }}=\left[\frac{\text { POT }_{\text {elétr.líquida }}}{\text { POT }_{\text {elétr.líquida }}+\text { EXERGY.out }_{\text {process }}}\right] \cdot 100$

ANÁLISE COMPLEMENTAR 1A LEI - PERDAS ENERGÉTICAS

Perdas na Caldeira

Boiler $_{\text {losses }}=\mathrm{POT}_{\text {entrada }} \cdot\left[1-\eta_{\mathrm{c}}\right]$

Boiler $_{\text {losses.perc }}=\frac{\text { Boiler }_{\text {losses }}}{\text { POT }_{\text {entrada }}} \cdot 100$

Turbine $_{\text {losses }}=\left[\left(\mathrm{POT}_{1}+\mathrm{POT}_{2}\right) \cdot\left(1-\eta_{\mathrm{t}}\right)\right] \cdot\left|2,77778 \times 10^{-7} \cdot \frac{\mathrm{MW}}{\mathrm{kJ} / \mathrm{h}}\right|$

Turbine $_{\text {losses.perc }}=\frac{\text { Turbine }_{\text {losses }}}{\text { POT }_{\text {entrada }}} \cdot 100$

Perdas no condensador

$\mathrm{POT}_{\text {condensador }}=\dot{\mathrm{Q}}_{\text {out }} \cdot\left|2,77778 \times 10^{-7} \cdot \frac{\mathrm{MW}}{\mathrm{kJ} / \mathrm{h}}\right|$ Energia perdida no condensador

$\mathrm{POT}_{\text {condensador.perc }}=\frac{\mathrm{POT}_{\text {condensador }}}{\mathrm{POT}_{\text {entrada }}} \cdot 100$

Condenser $_{\text {losses }}=\mathrm{POT}_{\text {condensador }}$

Perdas no processo 
File:Convencional - 2a Lei.EES

EES Ver. 9.433: \#0624: Depart. de Engenharia Mecanica Escola Politecnic, Escola Politecnica da USP, Sao Paulo, Brazil

$$
\begin{aligned}
& \text { process }_{\text {losses }}=\mathrm{POT}_{\text {entrada }}-\left[\mathrm{POT}_{\text {processo }}+\mathrm{POT}_{\text {elétr.gerada }}+\mathrm{POT}_{\text {condensador }}+\text { Turbine }_{\text {losses }}+\text { Boiler }_{\text {losses }}\right] \\
& \text { process }_{\text {losses.perc }}=\frac{\text { process }_{\text {losses }}}{\mathrm{POT}_{\text {entrada }}} \cdot 100
\end{aligned}
$$

Cálculo da energia elétrica gerada por tela de cana

GeraçãoEletric.Espec.Total $=\mathrm{POT}_{\text {elétr.líquida }} \cdot$ Período $_{\text {safra }} \cdot 1000 \cdot \frac{24}{\text { Cana }_{\text {safra }}}$

GeraçãoEletric.Espec.Excedente = GeraçãoEletric.Espec.Total - ConsumoEletr.Processo

ALOCAÇÃO

Critério energético

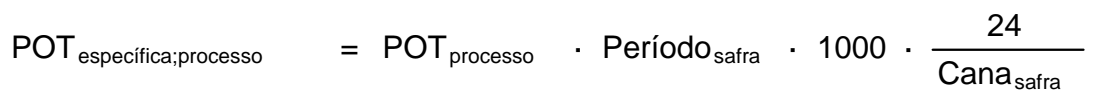

Alocação $_{\text {energia;vapor }}=\left[\frac{\text { POT }_{\text {específica;processo }}}{\text { POT }_{\text {específica;processo }+ \text { GeraçãoEletric.Espec.Excedente }+ \text { ConsumoEletr.Processo }}}\right] \cdot 100$

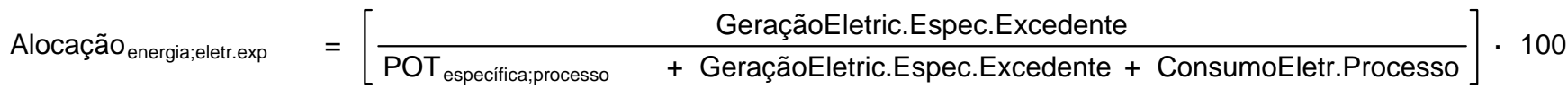

Alocação $_{\text {energia;eletr.proc }}=\left[\frac{\text { ConsumoEletr.Processo }}{\text { POT }_{\text {específica;processo }+ \text { GeraçãoEletric.Espec.Excedente }+ \text { ConsumoEletr.Processo }}}\right] \cdot 100$

Critério exergético

EXERGY.out $_{\text {específica;process }}=$ EXERGY.out $_{\text {process }} \cdot$ Período $_{\text {safra }} \cdot 1000 \cdot \frac{24}{\text { Cana }_{\text {safra }}}$

Alocação $_{\text {exergia;vapor }}=\left[\frac{\text { EXERGY.out }_{\text {específica;process }}}{\text { EXERGY.out }{ }_{\text {específica;process }}+\text { GeraçãoEletric.Espec.Excedente }+ \text { ConsumoEletr.Processo }}\right] \cdot 100$

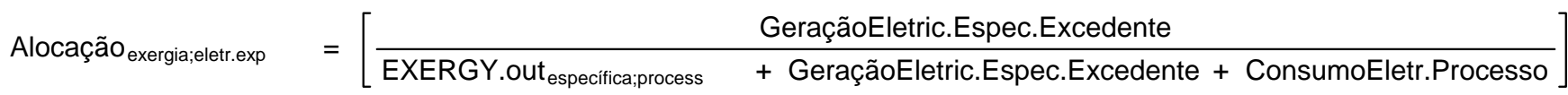

$\cdot 100$

Alocação $_{\text {exergia;eletr.proc }}=\left[\frac{\text { ConsumoEletr.Processo }}{\text { EXERGY.out }{ }_{\text {específica;process }}+\text { GeraçãoEletric.Espec.Excedente }+ \text { ConsumoEletr.Processo }}\right]$ . 100

Distribuição de energia entre vapor e eletricidade

Energia $_{\text {vapor.perc }}=\left[\frac{\mathrm{POT}_{\text {processo }}}{\mathrm{POT}_{\text {processo }}+\mathrm{POT}_{\text {elétr.líquida }}}\right] \cdot 100$
Energia $_{\text {eletricidade.perc }}=\left[\frac{\mathrm{POT}_{\text {elétr.líquida }}}{\mathrm{POT}_{\text {processo }}+\mathrm{POT}_{\text {elétr.líquida }}}\right] \cdot 100$


APÊNDICE B - Modelagem Termodinâmica do sistema de cogeração com ciclo Rankine com Reaquecimento 


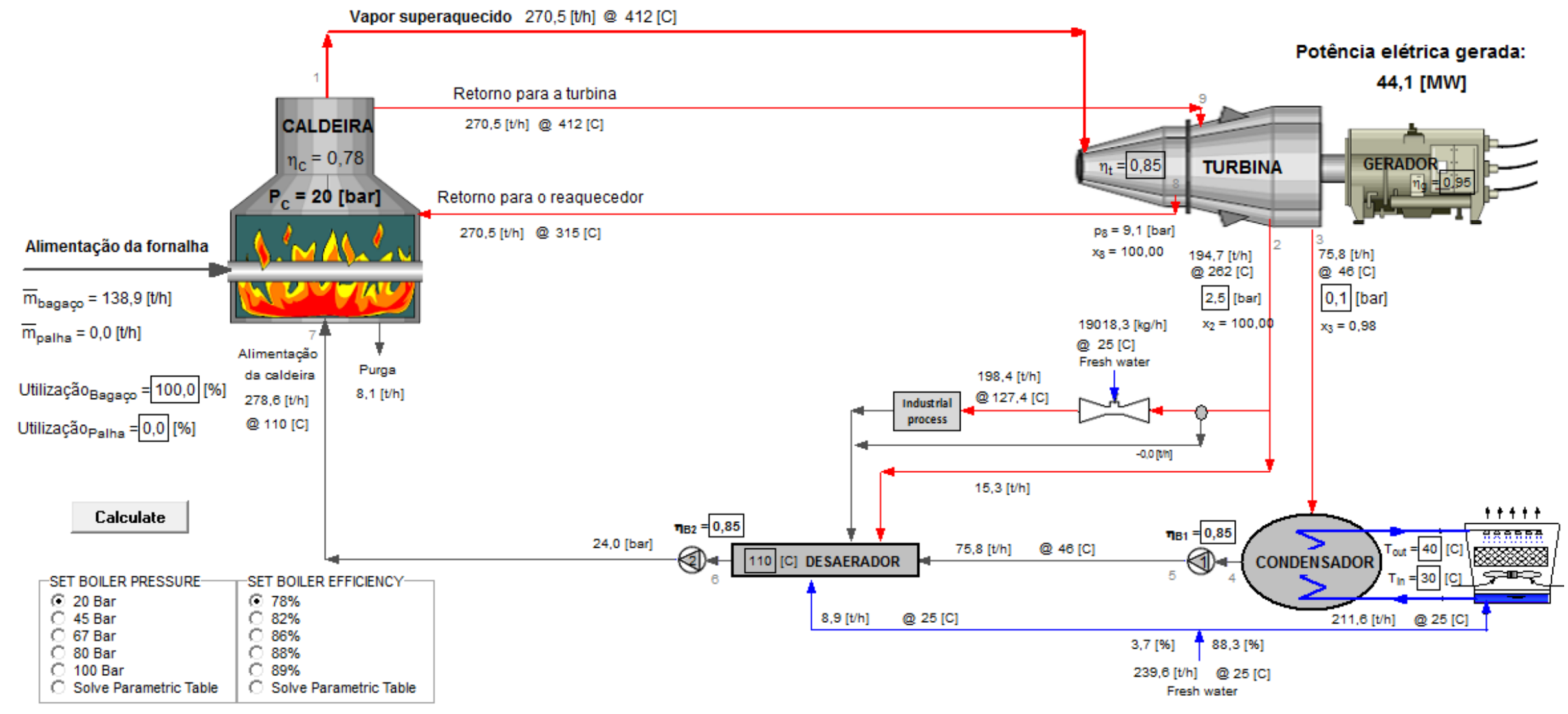

Figura 46 - Ciclo de vapor com reaquecimento para um sistema de cogeração (Interface do simulador) 
File:Reaquecimento - 2a Lei - otimizado.EES

EES Ver. 9.433: \#0624: Depart. de Engenharia Mecanica Escola Politecnic, Escola Politecnica da USP, Sao Paulo, Brazil

1:

2:

3: "APÊNDICE B - MODELAGEM TERMODINÂMICA DO SISTEMA DE COGERAÇÃO COM CICLO RANKINE COM REAQUECIMENTO"

4:

$5:$

6:

7: "Dados da Safra"

8:

9: $M \_d o t \_c a n a=$ Cana_safra/Período_safra*1000/24 [kg/h] Moagem de cana"

10: $\mathrm{m}$ _dot_bagaço=Y_bagaço/100*M_dot_cana*Utilização_Bagaço/100 o de bagaço de cana"

11: m_dot_palha=Y_palha/100*M_dot_cana*Utilização_Palha/100 o de palha de cana"

12: Razão|vapor_biomassa=m_dot_vapor/m_dot_bagaço entre produção de vapor e consumo de biomassa"

13: m_bar_bagaço=m_dot_bagaço/1000 [ton/h]

14: m_bar_palha=m_dot_palha/1000[ton/h]

15:

16: "GERADOR DE VAPOR - Modelagem de conservação de matéria e energia"

17: "Balanço de massa caldeira"

18:

19: m_dot_agua $=m$ _dot_vapor+m_dot_purga

20: m_dot_purga $=Y$ _purga ${ }^{\star}$ __dot_vapor

21: Y_purga $=0,03$ purga considerada $=3 \% "$

22: M_bar_vapor=m_dot_vapor/1000[ton/h]

23:

24: "Balanço de massa Reaquecimento"

25

26: m_dot_vap.reaq=m_dot_vapor superaquecido retorna para reaquecimento"

27: m_bar_vap.reaq=m_dot_vap.reaq/1000 [ton/h]

da vazão mássica de vapor de $\mathrm{Kg} / \mathrm{h}$ para ton/ $\mathrm{h}^{\prime \prime}$

28:

29: "Balanços de energia"

30:

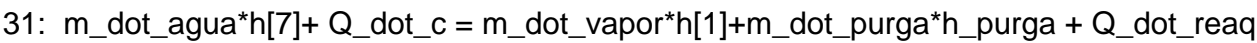

32: Q_dot_c=(m_dot_bagaço*PCl_bagaço+m_dot_palha*PCl_palha $)^{\star}$ eta_c utilizada na fornecida na fornalha para evaporação da água"

33: Q_dot_reaq=m_dot_vap.reaq*(h[9]-h[8])

34: $\mathrm{h}[1]=$ =enthalpy(water; $\mathrm{T}=\mathrm{T}[1] ; \mathrm{P}=\mathrm{P}[1])$ : $\mathrm{h} \_$purga=enthalpy(water;T=T_purga; $\mathrm{X}=0$ )

35: P[7]=1,20*P_c: T_purga=T_SAT(water;P=P_c): P_purga=P_c: P[1]=P_c:

36: PCl_bagaço=7565: PCl_palha=12960 [kJ/kg] cana (15\% de umidade)"

37: T[1]=T_SAT(water;P=P_c)+G_super

38: G_super=200 [C]

39:

40: "BOMBA 02 - ALIMENTAÇÃO DA CALDEIRA"

41:

42: $P[6]=P[2]$ escape"

43: eta_B2=(h[6]-h7_iso $) /(\mathrm{h}[6]-\mathrm{h}[7])$ da bomba"

44: h7_iso=enthalpy(water;s=s[6];P=P[7])

45: $h[6]=e n t h a l p y$ (water; $P=P[6] ; T=T[6])$

46: $s[6]=e n t r o p y($ water; $P=P[6] ; T=T[6])$

47: T[7]=temperature (water; $h=h[7] ; P=P[7])$

48: $s[7]=e n t r o p y($ water; $h=h[7] ; P=P[7])$
"Poder calorífico inferior do bagaço (51\% umidade) e da palha de

"Temperatura do vapor superaquecido"

"Grau de superaqucimento"

"Pressão de descarga da bomba igual a pressão do vapor de

"Determinação da entalpia real da vazão de líquido na descarga

"Entalpia para condição ideal isentrópica"

"Entalpia na saída do desaerador"

"Entropia na saída do desaerador é entropia do líquido saturado"

"Temperatura de recalque"

"Entropia da água de alimentação da caldeira"
"Taxa de

"Alimentaçã

"Alimentaçã

"Razão

"Taxa de

"Todo vapor

"Conversão

"Energia 
File:Reaquecimento - 2a Lei - otimizado.EES

EES Ver. 9.433: \#0624: Depart. de Engenharia Mecanica Escola Politecnic, Escola Politecnica da USP, Sao Paulo, Brazil

49:

50: "BOMBA 01 - CONDENSADO"

51:

52: $P[5]=P[2]$

escape"

53: eta_B1 $=(\mathrm{h}[4]-\mathrm{h} 5$ _iso $) /(\mathrm{h}[4]-\mathrm{h}[5])$

54: h5_iso=enthalpy(water;s=s[4];P=P[5])

55: $s[4]=$ entropy (water; $P=P[4] ; X=0)$

56: $T[5]=$ temperature(water; $h=h[5] ; P=P[5]$ )

57: $h[4]=$ enthalpy (water; $P=P[4] ; X=0)$

58: $\mathrm{T}[4]=\mathrm{T}[3]$

troca calor latente"

59: $P[4]=P[3]$

60: $s[5]=e n t r o p y($ water; $P=P[5] ; T=T[5])$

61:

62:

63: "REAQUECIMENTO"

64: "Extração de vapor da turbina"

65:

66: $P[8]=P[9]$

67: eta_t $=(\mathrm{h}[1]-\mathrm{h}[8]) /(\mathrm{h}[1]-\mathrm{h} 8$ iso $)$

eficiência isentrópica"

68: h8_iso=enthalpy(water;s=s[1];P=P[8])

69: $T[8]=$ temperature(water; $h=h[8] ; P=P[8]$ )

70: $s[8]=e n t r o p y($ water; $h=h[8] ; P=P[8])$

71: $x[8]=$ quality (water; $\mathrm{h}=\mathrm{h}[8] ; \mathrm{T}=\mathrm{T}[8]$ )

72:

73:

74: "TURBINA"

75: "Retorno de vapor da turbina"

76:

77: $\mathrm{T}[9]=\mathrm{T}[1]$

78: $\mathrm{s}[9]=$ entropy(water; $\mathrm{T}=\mathrm{T}[9] ; \mathrm{P}=\mathrm{P}[9])$

79: $\mathrm{h}[9]=$ =enthalpy(water; $\mathrm{T}=\mathrm{T}[9] ; \mathrm{P}=\mathrm{P}[9])$

80:

81: "Rendimento da turbina"

82:

83: eta_t $=(\mathrm{h}[9]-\mathrm{h}[2]) /(\mathrm{h}[9]-\mathrm{h} 2$ _iso $)$

desaerador através da eficiência isoentrópica"

84: eta_t $=(\mathrm{h}[9]-\mathrm{h}[3]) /(\mathrm{h}[9]-\mathrm{h} 3$ iso $)$

condensador através da eficiência isoentrópica"

85: h2_iso=enthalpy(water;s=s[9];P=P[2])

expansão isoentrópica"

86: h3_iso=enthalpy(water;s=s[9];P=P[3])

expansão isoentrópica"

87: $\mathrm{s}[1]=e n t r o p y($ water; $P=P[1] ; T=T[1])$

88: $T[2]=$ temperature $($ water; $h=h[2] ; P=P[2])$

89: $T[3]=$ temperature $($ water; $h=h[3] ; P=P[3])$

90: $\mathrm{s}[2]=e n t r o p y$ (water; $\mathrm{h}=\mathrm{h}[2] ; \mathrm{T}=\mathrm{T}[2]$ )

91: $\mathrm{s}[3]=e n t r o p y($ water; $\mathrm{h}=\mathrm{h}[3] ; \mathrm{T}=\mathrm{T}[3])$

92: $x[2]=$ quality (water; $\mathrm{h}=\mathrm{h}[2] ; \mathrm{T}=\mathrm{T}[2])$

93: $x[3]=$ quality $($ water; $h=h[3] ; T=T[3])$

94:

95: "Balanço de massa na turbina"

96:

97: m_dot_vapor=m_dot_vap.escape+m_dot_vap.cauda

98:

99

100: "PURGA DE CONDENSADO ANTES DE SER USADO NO PROCESSO"
"Pressão de descarga da bomba igual a pressão do vapor de

"Determinação da entalpia real do líquido na descarga da bomba" "Entalpia para condição ideal isentrópica"

"Entropia na saída do condensador - líquido saturado"

"Temperatura de recalque para desaerador"

"Entalpia da saída do condensador é a entalpia de líquido saturado"

"Temperatura de Entrada = temperatura de saída --> Somente

"Pressão de sucção da bomba = pressão da cauda da turbina"

"Entropia da água de recalque da bomba 01"

"Desprezadas perdas de carga no reaquecimento - ideal"

"Determinação da entalpia real do vapor extraído, através da

"Entalpia para condição ideal de expansão isoentrópica"

"Temperatura de saída para reaquecimento"

"Título do vapor na saída para reaquecimento"

"Parâmetro definido de projeto do reaquecedor"

"Determinação da entalpia real do vapor extraído para o

"Determinação da entalpia real do vapor extraído para o

"Entalpia da corrente de vapor de escape para condição ideal de

"Entalpia da corrente de vapor na cauda para condição ideal de

"Estado definido por 2 propriedades independentes"

"Temperatura do vapor de escape"

"Temperatura do vapor de cauda"

"Entropia do vapor de escape"

"Entropia do vapor de cauda"

"Título do vapor de escape"

"Título do vapor na cauda da turbina" 
File:Reaquecimento - 2a Lei - otimizado.EES

EES Ver. 9.433: \#0624: Depart. de Engenharia Mecanica Escola Politecnic, Escola Politecnica da USP, Sao Paulo, Brazil

101:

102: "RETORNO DE CONDENSADO DO PROCESSO INDUSTRIAL"

103: m_dot_retorno $=$ m_dot_vap.processo 0,90

"Considerado perdas no processo de 10\% da vazão de vapor"

104: T_cond=90 [C]

"Considerado que todo condensado é coletado em um tanque de

recuperação e retorna para o ciclo a $90 \mathrm{C}^{\prime \prime}$

105: P_cond=P[2]

"Pressão de retorno = pressão no desaerador = Pressão do vapor

de escape"

106:

107: m_agua.dessuper=if(x[2];100;0;m_dot_agua.dessuper;0) "Se o vapor de escape estiver superaquecido agua deve ser alimentada no dessuperaquecedor para obter vapor saturado para o processo de produção do etanol"

108: m_dot_purgador=if(x[2];100;-m_dot_agua.dessuper;0;0)

"Se o vapor

de escape tiver $x<1$ o condensado precisa ser retirado em purgadores"

109:

110: "DESSUPERAQUECEDOR E VAPOR DE PROCESSO"

111: "Balanços de massa"

112: m_dot_vap.escape=m_dot_vap.dessuper+m_dot_vap.desaerador

113: m_dot_vap.processo = Cons.Vapor_processo*M_dot_cana*(1/1000)

"Consumo

de vapor para o processo"

114: m_dot_vap.processo=m_dot_vap.dessuper $+m$ m_dot_agua.dessuper

115:

116: "Balanço de energia no dessuperaquecedor"

117: m_dot_vap.processo*h_pro=m_dot_vap.dessuper*h[2]+m_dot_agua.dessuper*h_rep.des

118: $h \_$pro=enthalpy(water;T=T_pro; $\left.x=1\right)$ : T_pro=T_sat(water; $\left.P=P[2]\right)$

"Considerad

o que o processo industrial utiliza vapor saturado"

119:

120

121:

122: "DESAERADOR"

123: "Balanço de massa no desaerador"

124:

125: m_dot_retorno+m_dot_vap.desaerador+m_dot_vap.cauda+m_dot_rep.desaerador+m_dot_purgador $=$ m_dot_agua

126

127: "Balanço de energia no desaerador"

128

129: m_dot_retorno*h_cond+m_dot_vap.desaerador*h[2]+m_dot_vap.cauda*h[5]+m_dot_rep.desaerador*h_rep.des

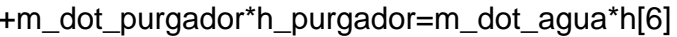

130: $h \_c o n d=e n t h a l p y\left(\right.$ water; $\left.T=T \_c o n d ; P=P \_c o n d\right): h \_p u r g a d o r=e n t h a l p y(w a t e r ; p=p[2] ; x=0): h \_r e p . d e s=e n t h a l p y(w a t e r ; T$ $\left.=T \_a m b ; P=P \_r e p . d e s\right): T \_a m b=25$

131: $P$ rep.des $=P[2]$

"Pressão no desaerador é a pressão de escape da turbina"

132:

133: "Conversão de unidades para ton/ $h$ "

134:

135: m_bar_vap.escape=m_dot_vap.escape/1000 [ton/h]

136: m_bar_vap.cauda=m_dot_vap.cauda/1000 [ton $/ \mathrm{h}]$

137: m_bar_vap.processo=m_dot_vap.processo/1000 [ton/h]

138: m_bar_vap.desaerador=m_dot_vap.desaerador/1000 [ton/h]

139: m_bar_rep.desaerador=m_dot_rep.desaerador/1000 [ton/h]

140: m_bar_feed.water.=m_dot_agua/1000 [ton $/ \mathrm{h}]$

141: m_bar_purga=m_dot_purga/1000 [ton/h]

142: m_bar_purgador=m_dot_purgador/1000 [ton/h]

143:

144: "CONDENSADOR"

145

146: Q_dot_out $=$ m_dot_vap.cauda* $(\mathrm{h}[3]-\mathrm{h}[4])$

vapor para a torre de resfriamento"

"Balanço de energia --> Calor transferido da condensação do

147

148:

149: "TORRE DE RESFRIAMENTO"

150: 
151: Q_dot_out $=m \_d o t \_r e c i r c u l a c ̧ a ̃ o *\left(h \_o u t-h \_i n\right)$

152: $h \_$_out=enthalpy(water; $\left.P=P \_o u t ; T=T \_o u t\right): h \_i n=e n t h a l p y\left(\right.$ water; $P=P \_$in;T=T_in): $P$ in $=1: P \_o u t=1:$

153: m_dot_repos.torre $=Y \_$perdas*m_dot_recirculação "Y_perdas corresponde a uma estimativa de perdas de água por evaporação, purga e arraste na torre de resfriamento"

154: m_dot_rep.total=m_dot_repos.torre+m_dot_rep.desaerador+m_dot_agua.dessuper

155: m_bar_repos.torre=m_dot_repos.torre $/ 1000[$ ton $/ \mathrm{h}]$

156: m_bar_rep.total=m_dot_rep.total $/ 1000[\mathrm{ton} / \mathrm{h}]$

157: m_bar_vap.dessuper=m_dot_vap.dessuper/1000 [ton/h]

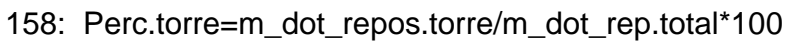

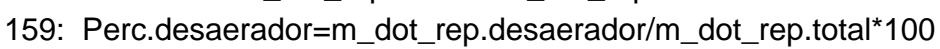

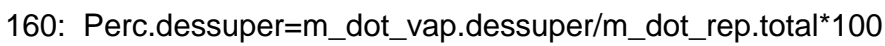

161: Tap.water_torre=m_dot_repos.torre/(m_dot_cana/1000)

162: Tap.water_deionised=(m_dot_rep.desaerador $+m$ _dot_agua.dessuper $) /($ m_dot_cana/1000)

163:

164:

165:

166: "CÁlCULO DAS POTÊNCIAS ELÉTRICAS"

167: "Potência elétrica gerada"

168:

169: POT_elétr.gerada=(POT_1+POT_2 + POT_reaq)*eta_g*convert(kJ/h;MW)

"Potencia elétrica total gerada no turbogerador"

170: POT_reaq=m_dot_vap.reaq*(h[1]-h[8]) "Potencia gerada pelo vapor da cauda"

171: POT_1=m_dot_vap.escape*(h[9]-h[2]) "Potencia gerada pelo vapor de escape a $\mathrm{P}=2,5 \mathrm{bar}$ "

172: POT_2=m_dot_vap.cauda*(h[9]-h[3]) "Potencia gerada pelo vapor da cauda"

173:

174: "Consumo das bombas do ciclo"

175:

176: POT_elétr.consumida=(POT_B1+POT_B2)* ${ }^{\star}$ convert(kJ/h;MW) consumida pelas bombas"

177: POT_B1=m_dot_vap.cauda*(h[5]-h[4])

"Potência consumida pela bomba 1"

178: POT_B2=m_dot_agua*(h[7]-h[6])

"Potência consumida pela bomba 1"

179:

180:

181: "EFICIÊNCIA GLOBAL DA UNIDADE DE COGERAÇÃO COM REAQUECIMENTO"

182: "Cálculo da eficiência energética"

183:

184: eta_Energética.Global=(POT_elétr.líquida + POT_processo)/POT_entrada*100

185:

186: "Potência líquida gerada na unidade de cogeração"

187:

188: POT_elétr.líquida = POT_elétr.gerada - POT_elétr.consumida

189:

190: "Potência utilizada no processo industrial"

191:

192: POT_processo=m_dot_vap.processo*(h_pro-h_sat)*convert $(\mathrm{kJ} / \mathrm{h} ; \mathrm{MW})$

193: POT_desaerador=m_dot_vap.desaerador* $(\mathrm{h}[2]-\mathrm{h}[6])^{\star}{ }^{\star} \operatorname{convert}(\mathrm{kJ} / \mathrm{h} ; \mathrm{MW})$

194: POT_desaerador.perc=POT_desaerador/POT_entrada*100

195: POT_processo.perc=POT_processo/POT_entrada*100

196: h_sat=enthalpy $($ water; $x=0 ; p=2,5)$

197:

198:

199: "Alimentação energética na fornalha da caldeira"

200:

201: POT_entrada $=\left(\mathrm{m}\right.$ _dot_bagaço*PCl_bagaço+m_dot_palha*PCl_palha ${ }^{*}{ }^{*}$ convert $(\mathrm{kJ} / \mathrm{h} ; \mathrm{MW})$

202:

203:

204: "APLICAÇÃO DA 2A LEI DA TERMODINÂMICA - ANÁLISE EXERGÉTICA"

205: "Ambiente de referência considerado: $P O=1$ bar e $T o=25 C$ "

206: 
File:Reaquecimento - 2a Lei - otimizado.EES

207: $\mathrm{TO}=25[\mathrm{C}]$

208: $\mathrm{P} 0=1[\mathrm{Bar}]$

209: P00_h20=0,0303 [Bar]

210:

211: "LIMITE TEÓRICO DE EFICIÊNCIA - CICLO DE CARNOT"

212:

213: eta_Carnot $=(1-(T[3]+273,15) /(T[1]+273,15)) \star 100 \quad$ "Trabalho máximo teórico"

214:

215: "Trabalho útil final - saída do gerador"

216:

217: EXERGY.in_fuel=POT_entrada

218: EXERGY.out_electricity=POT_elétr.líquida

219: EXERGY.out_electricity.perc=POT_elétr.líquida/POT_entrada*100

220:

221: "BOILER"

222:

223: B_1=m_dot_vapor*(h[1]-h[0]-(T0+273,15)*(s[1]-s[0]))*convert(kJ/h;MW)

"Exergia do vapor de saída do gerador de vapor"

224: $\mathrm{h}[0]=$ enthalpy (water; $\mathrm{t}=\mathrm{T} 0 ; \mathrm{P}=\mathrm{PO})$

225: $s[0]=$ entropy $($ water; $t=T 0 ; P=P 0)$

226: B_fuel=EXERGY.in_fuel

227:

228: "TURBINE"

229: "Exergia das correntes de vapor de escape e cauda"

230:

231: B_2=m_dot_vap.escape*(h[2]-h[0]-(T0+273,15)*(s[2]-s[0]))*convert(kJ/h;MW)

"Exergia do vapor de escape"

232: B_3=m_dot_vap.cauda*(h[3]-h[0]-(T0+273,15) $\left.{ }^{\star}(\mathrm{s}[3]-\mathrm{s}[0])\right)^{\star}$ convert(kJ/h;MW)

"Exergia do vapor de cauda"

233:

234: "Exergia da corrente de reaquecimento"

235:

236: B_8=m_dot_vapor* $(\mathrm{h}[8]-\mathrm{h}[0]-(\mathrm{T0}+273,15) *(\mathrm{~s}[8]-\mathrm{s}[0]))^{*} \operatorname{convert}(\mathrm{kJ} / \mathrm{h} ; \mathrm{MW})$

"Exergia do

vapor para reaquecimento na saída da turbina"

237: B_9=m_dot_vapor*(h[9]-h[0]-(T0+273,15)*(s[9]-s[0]))*convert(kJ/h;MW)

"Exergia do vapor após reaquecimento"

238:

239: "Balanço de exergia na turbina"

240:

241: Bdest_turbine=B_1+B_9 - (B_2+B_3+B_8+POT_elétr.gerada/eta_g)

"Exergia destruída na turbina"

242: Bdest_turbine.perc=Bdest_turbine/B_fuel*100

"Percentual

de exergia destruída na turbina"

243: B_2_perc=B_2/POT_entrada*100

"Percentual

de exergia no vapor de escape"

244: B_liq=POT_elétr.gerada/POT_entrada $* 100$

"Percentual

245:

246: "Consumo de exergia no processo industrial associado ao consumo específico de vapor"

247:

248: EXERGY.out_process=m_dot_vap.processo*(h_pro-h[0]-(T0+273,15)*(s_pro-s[0]))*convert(kJ/h;MW)

249: s_pro = entropy $($ water; $p=2,5 ; t=127,5)$

250: EXERGY.out_process.perc=EXERGY.out_process/POT_entrada*100

251: EXERGY.out_deaerator=B_2-EXERGY.out_process

252: EXERGY.out_deaerator.perc=EXERGY.out_deaerator/POT_entrada*100

253:

254: "DESSUPERAQUECEDOR"

255: "Balanço de entropia no dessuper"

256: 
257: S_ger.dessuper=m_dot_vap.processo*s_pro - (m_agua.dessuper*s_agua + (m_dot_vap.dessuper-m_dot_purgador)*s[2])

258: $s \_a g u a=$ entropy $($ water $; p=2,5 ; t=25)$

259: Bdest_dessuper $=(\mathrm{T} 0+273,15) \star S \_g e r . d e s s u p e{ }^{*}$ convert $(\mathrm{kJ} / \mathrm{h} ; \mathrm{MW})$

"Exergia

destruída no dessuperaquecedor"

260: Bdest_dessuper.perc=Bdest_dessuper/B_fuel*100

"Percentual

de exergia destruída no dessuperaquecedor"

261:

262: "CONDENSADOR"

263:

264: B_4=m_dot_vap.cauda*(h[4]-h[0]-(T0+273,15)*(s[4]-s[0]) $)^{\star}$ convert(kJ/h;MW)

"Exergia na

saída do condensador"

265: Bdest_condenser=B_3-B_4

"Exergia

destruída no condensador"

266: Bdest_condenser.perc=Bdest_condenser/B_fuel*100 "Percentual de exergia destruída no condensador"

267:

268: "BOMBA 1"

269:

270: B_5=m_dot_vap.cauda*(h[5]-h[0]-(T0+273,15)*(s[5]-s[0]))*convert(kJ/h;MW)

"Exergia na saída da bomba 1"

271: Bdest_B1=B_4-B_5 +W_B1

"Exergia

destruída na bomba 1"

272: W_B1=m_dot_vap.cauda* $(\mathrm{h}[5]-\mathrm{h}[4])^{*}$ convert(kJ/h;MW)

"Trabalho

realizado pela bomba $B 1^{\prime \prime}$

273: Bdest_B1.perc=Bdest_B1/B_fuel*100

"Percentual

de exergia destruída na bomba 1"

274:

275: "DESAERADOR"

276: "Balanço de entropia no dessuperaquecedor"

277:

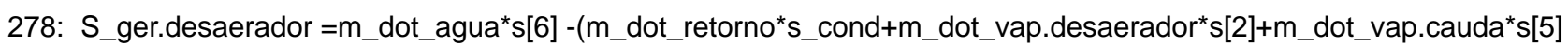

$+\mathrm{m} \_$dot_rep.desaerador*s_agua $+\mathrm{m} \_$dot_purgador*s_sat)

279: s_cond=entropy(water; $T=T$ _cond $P=P$ _cond): $s_{-}$sat=entropy (water; $P=2,5 ; X=0$ )

280: Bdest_desaerador $=(\mathrm{T} 0+273,15)^{\star}$ __ger.desaerador*convert $(\mathrm{kJ} / \mathrm{h} ; \mathrm{MW})$

"Exergia

destruída no desaerador"

281: Bdest_desaerador.perc=Bdest_desaerador/B_fuel*100

"Percentual

de exergia destruída no desaerador"

282:

283:

284: "BOMBA 2"

285:

286: B_7=m_dot_agua*(h[7]-h[0]-(T0+273,15)*(s[7]-s[0]))*convert(kJ/h;MW) saída da bomba $2^{\prime \prime}$

287: B_6=m_dot_agua*(h[6]-h[0]-(T0+273,15)*(s[6]-s[0]) ${ }^{\star}$ convert(kJ/h;MW) entrada da bomba 2"

288: W_B2=m_dot_agua* $(\mathrm{h}[7]-\mathrm{h}[6]){ }^{*}$ convert $(\mathrm{kJ} / \mathrm{h} ; \mathrm{MW})$

realizado pela bomba $B 2^{\prime \prime}$

289: Bdest_B2=B_7-B_6 +W_B2

destruída na bomba 2"

290: Bdest_B2.perc=Bdest_B2/B_fuel ${ }^{\star} 100$

"Exergia na

de exergia destruída na bomba $2 "$

291:

292: "BOILER"

293:

294: B_7 + B_fuel +B_8 = B_1+B_purga+B_9+Bdest_boiler

"Balanço de

exergia na caldeira"

295: Bdest_boiler.perc=Bdest_boiler/B_fuel ${ }^{\star} 100$

"Percentual

de exergia destruída na caldeira"

296: B_purga $=m$ _dot_purga* $\left(\mathrm{h} \_p u r g a-h[0]-(T 0+273,15)^{\star}\left(\mathrm{s} \_ \text {purga-s[0]) }\right)^{\star} \operatorname{convert}(\mathrm{kJ} / \mathrm{h} ; \mathrm{MW})\right.$

297: s_purga=entropy(water; $\left.h=h \_p u r g a ; T=T \_p u r g a\right)$ 
File:Reaquecimento - 2a Lei - otimizado.EES

EES Ver. 9.433: \#0624: Depart. de Engenharia Mecanica Escola Politecnic, Escola Politecnica da USP, Sao Paulo, Brazil

298:

299:

300: Total_exergy.dest=Bdest_B1+Bdest_B2+Bdest_desaerador+Bdest_condenser+Bdest_boiler+Bdest_turbine

301: Total_exergy.dest.perc=Total_exergy.dest/B_fuel*100

302:

303:

304: "Eficiência Exergética"

305: "Cálculo da eficiência exergética global"

306:

307: eta_EXergética.Global=(POT_elétr.líquida + EXERGY.out_process)/POT_entrada*100

308:

309: eta_Ex.ref.Carnot=eta_EXergética.Global/eta_Carnot ${ }^{\star} 100$

310:

311:

312: "Distribuição de exergia entre vapor e eletricidade"

313:

314: Exergia_vapor.perc $=$ EXERGY.out_process/(POT_elétr.líquida + EXERGY.out_process)^100

315:

316: Exergia_eletricidade.perc $=$ POT_elétr.líquida/(POT_elétr.líquida + EXERGY.out_process)*100

317:

318:

319:

320: "ANÁLISE COMPLEMENTAR 1A LEI - PERDAS ENERGÉTICAS"

321: "Perdas na Caldeira e turbina"

322:

323: Boiler_losses=POT_entrada*(1-eta_c)

324: Boiler_losses.perc=Boiler_losses/POT_entrada*100

325: Turbine_losses=(POT_1+POT_2+POT_reaq) ${ }^{\star}\left(1-e t a \_t\right){ }^{\star} \operatorname{convert}(\mathrm{kJ} / \mathrm{h} ; \mathrm{MW})$

326: Turbine_losses.perc $=\bar{T}$ Turbine_losses/POT_entrada ${ }^{*} 100$

327:

328: "Perdas no condensador"

329:

330: $\mathrm{POT}$ _condensador $=\mathrm{Q} \_$dot_out ${ }^{*} \operatorname{convert}(\mathrm{kJ} / \mathrm{h} ; \mathrm{MW})$

perdida no condensador"

331: POT_condensador.perc=POT_condensador/POT_entrada*100

332: Condenser_losses=POT_condensador

333:

334: "Perdas no processo"

335:

336: process_losses = POT_entrada - (POT_processo+POT_elétr.gerada+POT_condensador+Turbine_losses+Boiler_losses)

337: process_losses.perc=process_losses/POT_entrada*100

338:

339:

340: "Cálculo da energia elétrica gerada por tonela de cana por tonelada de cana"

341:

342: GeraçãoEletric.Espec.Total =POT_elétr.líquida*Período_safra*1000*24/Cana_safra

343: GeraçãoEletric.Espec.Excedente = GeraçãoEletric.Espec.Total - ConsumoEletr.Processo

344:

345:

346:

347: "ALOCAÇÃO"

348:

349: "Critério energético"

350: POT_específica_processo = POT_processo*Período_safra*1000*24/Cana_safra

351: Alocação_energia_vapor = POT_específica_processo/(POT_específica_processo+GeraçãoEletric.Espec.Excedente + ConsumoEletr.Processo ${ }^{\star} 100$

352: Alocação_energia_eletr.exp = GeraçãoEletric.Espec.Excedente/(POT_específica_processo + GeraçãoEletric.Espec. Excedente+ConsumoEletr.Processo ${ }^{\star} 100$

353: Alocação_energia_eletr.proc = ConsumoEletr.Processo/(POT_específica_processo+GeraçãoEletric.Espec.Excedente 
File:Reaquecimento - 2a Lei - otimizado.EES

EES Ver. 9.433: \#0624: Depart. de Engenharia Mecanica Escola Politecnic, Escola Politecnica da USP, Sao Paulo, Brazil

354:

+ConsumoEletr.Processo ${ }^{\star} 100$

355:

356: "Critério exergético"

357: EXERGY.out_específica_process = EXERGY.out_process*Período_safra*1000*24/Cana_safra

358: Alocação_exergia_vapor = EXERGY.out_específica_process/(EXERGY.out_específica_process

+GeraçãoEletric.Espec.Excedente+ConsumoEletr.Processo ${ }^{\star} 100$

359: Alocação_exergia_eletr.exp = GeraçãoEletric.Espec.Excedente/(EXERGY.out_específica_process

+GeraçãoEletric.Espec.Excedente+ConsumoEletr.Processo ${ }^{\star} 100$

360: Alocação_exergia_eletr.proc $=$ ConsumoEletr.Processo/(EXERGY.out_específica_process

+GeraçãoEletric.Espec.Excedente+ConsumoEletr.Processo ${ }^{\star} 100$

361:

362:

363:

364:

365: "Distribuição de energia entre vapor e eletricidade"

366:

367: Energia_vapor.perc = POT_processo/(POT_processo + POT_elétr.líquida)*100

368:

369: Energia_eletricidade.perc $=$ POT_elétr.líquida/(POT_processo + POT_elétr.líquida $)^{\star 100}$

APÊNDICE B - MODELAGEM TERMODINÂMICA DO SISTEMA DE COGERAÇÃO COM CICLO RANKINE COM REAQUECIMEN $O$

Dados da Safra

$\dot{\mathrm{M}}_{\text {cana }}=\frac{\text { Cana }_{\text {safra }}}{\text { Período }_{\text {safra }}} \cdot \frac{1000}{24[\mathrm{~kg} / \mathrm{h}]}$ Taxa de Moagem de cana

$\dot{\mathrm{m}}_{\text {bagaço }}=\frac{\mathrm{Y}_{\text {bagaço }}}{100} \cdot \dot{\mathrm{M}}_{\text {cana }} \cdot \frac{\text { Utilização }_{\text {Bagaço }}}{100}$ Alimentação de bagaço de cana

$\dot{\mathrm{m}}_{\text {palha }}=\frac{\mathrm{Y}_{\text {palha }}}{100} \cdot \dot{\mathrm{M}}_{\text {cana }} \cdot \frac{\text { Utilização }_{\text {Palha }}}{100}$ Alimentação de palha de cana

Razão ${ }_{\text {biomapor }}^{\text {vassa }} \frac{\dot{\mathrm{m}}_{\text {vapor }}^{\circ}}{\dot{m}_{\text {bagaço }}}$ Razão entre produção de vapor e consumo de biomassa

$\overline{\mathrm{m}}_{\text {bagaço }}=\frac{\dot{\mathrm{m}}_{\text {bagaço }}}{1000[\text { ton } / \mathrm{h}]}$

$\overline{\mathrm{m}}_{\text {palha }}=\frac{\dot{\mathrm{m}}_{\text {palha }}}{1000 \quad[\text { ton } / \mathrm{h}]}$

GERADOR DE VAPOR - Modelagem de conservação de matéria e energia

Balanço de massa caldeira

$\dot{\mathrm{m}}_{\text {agua }}=\dot{\mathrm{m}}_{\text {vapor }}+\dot{\mathrm{m}}_{\text {purga }}$

$\dot{\mathrm{m}}_{\text {purga }}=\mathrm{Y}_{\text {purga }} \cdot \dot{\mathrm{m}}_{\text {vapor }}$

$\mathrm{Y}_{\text {purga }}=0,03$ Taxa de purga considerada $=3 \%$

$\overline{\mathrm{M}}_{\text {vapor }}=\frac{\dot{\mathrm{m}}_{\text {vapor }}}{1000[\text { ton } / \mathrm{h}]}$

Balanço de massa Reaquecimento 
File:Reaquecimento - 2a Lei - otimizado.EES

EES Ver. 9.433: \#0624: Depart. de Engenharia Mecanica Escola Politecnic, Escola Politecnica da USP, Sao Paulo, Brazil

$\dot{\mathrm{m}}_{\text {vap.reaq }}=\dot{\mathrm{m}}_{\text {vapor }}$ Todo vapor superaquecido retorna para reaquecimento

$\overline{\mathrm{m}}_{\text {vap.reaq }}=\frac{\dot{\mathrm{m}}_{\text {vap.reaq }}}{1000[\text { ton } / \mathrm{h}]}$ Conversão da vazão mássica de vapor de $\mathrm{Kg} / \mathrm{h}$ para ton $/ \mathrm{h}$

Balanços de energia

$\dot{\mathrm{m}}_{\text {agua }} \cdot \mathrm{h}_{7}+\dot{\mathrm{Q}}_{\mathrm{c}}=\dot{\mathrm{m}}_{\text {vapor }} \cdot \mathrm{h}_{1}+\dot{\mathrm{m}}_{\text {purga }} \cdot \mathrm{h}_{\text {purga }}+\dot{\mathrm{Q}}_{\text {reaq }}$

$\dot{\mathrm{Q}}_{\mathrm{c}}=\left[\dot{\mathrm{m}}_{\text {bagaço }} \cdot \mathrm{PCl}_{\text {bagaço }}+\dot{\mathrm{m}}_{\text {palha }} \cdot \mathrm{PCl}_{\text {palha }}\right] \cdot \eta_{\mathrm{c}}$ Energia utilizada na fornecida na fornalha para evaporação da água

$\dot{\mathrm{Q}}_{\text {reaq }}=\dot{\mathrm{m}}_{\text {vap.reaq }} \cdot\left[\mathrm{h}_{9}-\mathrm{h}_{8}\right]$

$\mathrm{h}_{1}=\mathbf{h}\left[\right.$ water $\left.; \mathrm{T}=\mathrm{T}_{1} ; \mathrm{P}=\mathrm{P}_{1}\right] \quad \mathrm{h}_{\text {purga }}=\mathbf{h}\left[\right.$ water $\left.; \mathrm{T}=\mathrm{T}_{\text {purga }} ; \mathrm{x}=0\right]$

$\mathrm{P}_{7}=1,2 \cdot \mathrm{P}_{\mathrm{c}} \quad \mathrm{T}_{\text {purga }}=\mathrm{T}_{\text {sat }}\left[\right.$ water $\left.; \mathrm{P}=\mathrm{P}_{\mathrm{c}}\right] \quad \mathrm{P}_{\text {purga }}=\mathrm{P}_{\mathrm{c}} \quad \mathrm{P}_{1}=\mathrm{P}_{\mathrm{c}}$

$\mathrm{PCl}_{\text {bagaço }}=7565 \quad \mathrm{PCl}_{\text {palha }}=12960[\mathrm{~kJ} / \mathrm{kg}]$ Poder calorífico inferior do bagaço (51\% umidade) e da palha de cana (15\% de umidade)

$\mathrm{T}_{1}=\mathbf{T}_{\text {sat }}\left[\right.$ water $\left.; \mathrm{P}=\mathrm{P}_{\mathrm{c}}\right]+\mathrm{G}_{\text {super }}$ Temperatura do vapor superaquecido

$\mathrm{G}_{\text {super }}=200 \quad[\mathrm{C}]$ Grau de superaqucimento

BOMBA 02 - ALIMENTAÇÃO DA CALDEIRA

$\mathrm{P}_{6}=\mathrm{P}_{2}$ Pressão de descarga da bomba igual a pressão do vapor de escape

$\eta_{\text {в2 }}=\frac{\mathrm{h}_{6}-\mathrm{h} 7_{\text {iso }}}{\mathrm{h}_{6}-\mathrm{h}_{7}}$ Determinação da entalpia real da vazão de líquido na descarga da bomba

$\mathrm{h} 7_{\text {iso }}=\mathbf{h}\left[\right.$ water $\left.; \mathrm{s}=\mathrm{s}_{6} ; \mathrm{P}=\mathrm{P}_{7}\right]$ Entalpia para condição ideal isentrópica

$\mathrm{h}_{6}=\mathbf{h}\left[\right.$ water $\left.; \mathrm{P}=\mathrm{P}_{6} ; \mathrm{T}=\mathrm{T}_{6}\right]$ Entalpia na saída do desaerador

$\mathrm{s}_{6}=\mathbf{s}\left[\right.$ water $\left.; \mathrm{P}=\mathrm{P}_{6} ; \mathrm{T}=\mathrm{T}_{6}\right]$ Entropia na saída do desaerador é entropia do líquido saturado

$\mathrm{T}_{7}=\mathbf{T}\left[\right.$ water $\left.; \mathrm{h}=\mathrm{h}_{7} ; \mathrm{P}=\mathrm{P}_{7}\right]$ Temperatura de recalque

$\mathrm{s}_{7}=\mathbf{s}\left[\right.$ water $\left.; \mathrm{h}=\mathrm{h}_{7} ; \mathrm{P}=\mathrm{P}_{7}\right]$ Entropia da água de alimentação da caldeira

BOMBA 01 - CONDENSADO

$\mathrm{P}_{5}=\mathrm{P}_{2}$ Pressão de descarga da bomba igual a pressão do vapor de escape

$\eta_{\mathrm{B} 1}=\frac{\mathrm{h}_{4}-\mathrm{h}_{5_{\text {iso }}}}{\mathrm{h}_{4}-\mathrm{h}_{5}}$ Determinação da entalpia real do líquido na descarga da bomba

$\mathrm{h} 5_{\text {iso }}=\mathbf{h}\left[\right.$ water $\left.; \mathrm{s}=\mathrm{s}_{4} ; \mathrm{P}=\mathrm{P}_{5}\right]$ Entalpia para condição ideal isentrópica

$\mathrm{s}_{4}=\mathbf{s}\left[\right.$ water $; \mathrm{P}=\mathrm{P}_{4} ; \mathrm{x}=0$ ] Entropia na saída do condensador - líquido saturado

$\mathrm{T}_{5}=\mathbf{T}\left[\right.$ water $\left.; \mathrm{h}=\mathrm{h}_{5} ; \mathrm{P}=\mathrm{P}_{5}\right]$ Temperatura de recalque para desaerador

$\mathrm{h}_{4}=\mathbf{h}\left[\right.$ water $\left.; \mathrm{P}=\mathrm{P}_{4} ; \mathrm{x}=0\right]$ Entalpia da saída do condensador é a entalpia de líquido saturado

$\mathrm{T}_{4}=\mathrm{T}_{3}$ Temperatura de Entrada = temperatura de saída --> Somente troca calor latente

$\mathrm{P}_{4}=\mathrm{P}_{3}$ Pressão de sucção da bomba = pressão da cauda da turbina 
File:Reaquecimento - 2a Lei - otimizado.EES

EES Ver. 9.433: \#0624: Depart. de Engenharia Mecanica Escola Politecnic, Escola Politecnica da USP, Sao Paulo, Brazil

$\mathrm{S}_{5}=\mathbf{s}\left[\right.$ water $\left.; \mathrm{P}=\mathrm{P}_{5} ; \mathrm{T}=\mathrm{T}_{5}\right]$ Entropia da água de recalque da bomba 01

\section{REAQUECIMENTO}

Extração de vapor da turbina

$\mathrm{P}_{8}=\mathrm{P}_{9}$ Desprezadas perdas de carga no reaquecimento - ideal

$\eta_{\mathrm{t}}=\frac{\mathrm{h}_{1}-\mathrm{h}_{8}}{\mathrm{~h}_{1}-\mathrm{h} 8_{\text {iso }}}$ Determinação da entalpia real do vapor extraído, através da eficiência isentrópica

h8 $8_{\text {iso }}=\mathbf{h}\left[\right.$ water $\left.; \mathrm{s}=\mathrm{s}_{1} ; \mathrm{P}=\mathrm{P}_{8}\right]$ Entalpia para condição ideal de expansão isoentrópica

$\mathrm{T}_{8}=\mathbf{T}\left[\right.$ water $\left.; \mathrm{h}=\mathrm{h}_{8} ; \mathrm{P}=\mathrm{P}_{8}\right]$ Temperatura de saída para reaquecimento

$\mathrm{s}_{8}=\mathbf{s}\left[\right.$ water $\left.; \mathrm{h}=\mathrm{h}_{8} ; \mathrm{P}=\mathrm{P}_{8}\right]$

$\mathrm{x}_{8}=\mathbf{x}\left[\right.$ water $\left.; \mathrm{h}=\mathrm{h}_{8} ; \mathrm{T}=\mathrm{T}_{8}\right]$ Título do vapor na saída para reaquecimento

\section{TURBINA}

Retorno de vapor da turbina

$\mathrm{T}_{9}=\mathrm{T}_{1} \quad$ Parâmetro definido de projeto do reaquecedor

$\mathrm{S}_{9}=\mathbf{s}\left[\right.$ water $\left.; \mathrm{T}=\mathrm{T}_{9} ; \mathrm{P}=\mathrm{P}_{9}\right]$

$\mathrm{h}_{9}=\mathbf{h}\left[\right.$ water $\left.; \mathrm{T}=\mathrm{T}_{9} ; \mathrm{P}=\mathrm{P}_{9}\right]$

Rendimento da turbina

$\eta_{\mathrm{t}}=\frac{\mathrm{h}_{9}-\mathrm{h}_{2}}{\mathrm{~h}_{9}-\mathrm{h} 2_{\text {iso }}}$ Determinação da entalpia real do vapor extraído para o desaerador através da eficiência isoentrópica

$\eta_{\mathrm{t}}=\frac{\mathrm{h}_{9}-\mathrm{h}_{3}}{\mathrm{~h}_{9}-\mathrm{h} 3_{\text {iso }}}$ Determinação da entalpia real do vapor extraído para o condensador através da eficiência isoentrópica

$\mathrm{h} 2_{\text {iso }}=\mathbf{h}\left[\right.$ water $\left.; \mathrm{s}=\mathrm{s}_{9} ; \mathrm{P}=\mathrm{P}_{2}\right]$ Entalpia da corrente de vapor de escape para condição ideal de expansão isoentrópica

$\mathrm{h} 3_{\text {iso }}=\mathbf{h}\left[\right.$ water $\left.; \mathrm{s}=\mathrm{s}_{9} ; \mathrm{P}=\mathrm{P}_{3}\right]$ Entalpia da corrente de vapor na cauda para condição ideal de expansão isoentrópica

$\mathrm{s}_{1}=\mathbf{s}\left[\right.$ water $\left.; \mathrm{P}=\mathrm{P}_{1} ; \mathrm{T}=\mathrm{T}_{1}\right] \quad$ Estado definido por 2 propriedades independentes

$\mathrm{T}_{2}=\mathbf{T}\left[\right.$ water $\left.; \mathrm{h}=\mathrm{h}_{2} ; \mathrm{P}=\mathrm{P}_{2}\right]$ Temperatura do vapor de escape

$\mathrm{T}_{3}=\mathbf{T}\left[\right.$ water $\left.; \mathrm{h}=\mathrm{h}_{3} ; \mathrm{P}=\mathrm{P}_{3}\right]$ Temperatura do vapor de cauda

$\mathrm{s}_{2}=\mathbf{s}\left[\right.$ water $\left.; \mathrm{h}=\mathrm{h}_{2} ; \mathrm{T}=\mathrm{T}_{2}\right]$ Entropia do vapor de escape

$\mathrm{s}_{3}=\mathbf{s}\left[\right.$ water $\left.; \mathrm{h}=\mathrm{h}_{3} ; \mathrm{T}=\mathrm{T}_{3}\right]$ Entropia do vapor de cauda

$\mathrm{x}_{2}=\mathbf{x}\left[\right.$ water $\left.; \mathrm{h}=\mathrm{h}_{2} ; \mathrm{T}=\mathrm{T}_{2}\right]$ Título do vapor de escape

$\mathrm{x}_{3}=\mathbf{x}\left[\right.$ water $\left.; \mathrm{h}=\mathrm{h}_{3} ; \mathrm{T}=\mathrm{T}_{3}\right]$ Título do vapor na cauda da turbina

Balanço de massa na turbina

$\dot{\mathrm{m}}_{\text {vapor }}=\dot{\mathrm{m}}_{\text {vap.escape }}+\dot{\mathrm{m}}_{\text {vap.cauda }}$ 


\section{RETORNO DE CONDENSADO DO PROCESSO INDUSTRIAL}

$\dot{\mathrm{m}}_{\text {retorno }}=\dot{\mathrm{m}}_{\text {vap.processo }} \cdot 0,9$ Considerado perdas no processo de $10 \%$ da vazão de vapor

$\mathrm{T}_{\text {cond }}=90[\mathrm{C}]$ Considerado que todo condensado é coletado em um tanque de recuperação e retorna para o ciclo a $90 \mathrm{C}$

$\mathrm{P}_{\text {cond }}=\mathrm{P}_{2}$ Pressão de retorno $=$ pressão no desaerador $=$ Pressão do vapor de escape

$\mathrm{m}_{\text {agua.dessuper }} \quad=$ If $\left[\mathrm{x}_{2} ; 100 ; 0 ; \dot{\mathrm{m}}_{\text {agua.dessuper }} ; 0\right]$

Se o vapor de escape estiver superaquecido agua deve ser alimentada no dessuperaquecedor para obter vapor saturado para o processo de produção do etanol

$\dot{\mathrm{m}}_{\text {purgador }}=$ If $\left[\mathrm{x}_{2} ; 100 ;-\dot{\mathrm{m}}_{\text {agua.dessuper }} ; 0 ; 0\right]$ Se o vapor de escape tiver $x<1$ o condensado precisa ser retirado em purgadores

\section{DESSUPERAQUECEDOR E VAPOR DE PROCESSO}

Balanços de massa

$\dot{\mathrm{m}}_{\text {vap.escape }}=\dot{\mathrm{m}}_{\text {vap.dessuper }}+\dot{\mathrm{m}}_{\text {vap.desaerador }}$

$\dot{\mathrm{m}}_{\text {vap.processo }}=$ Cons.Vapor processo $\cdot \dot{\mathrm{M}}_{\text {cana }} \cdot \frac{1}{1000}$ Consumo de vapor para o processo

$\dot{\mathrm{m}}_{\text {vap.processo }}=\dot{\mathrm{m}}_{\text {vap.dessuper }}+\dot{\mathrm{m}}_{\text {agua.dessuper }}$

Balanço de energia no dessuperaquecedor

$\dot{\mathrm{m}}_{\text {vap.processo }} \cdot \mathrm{h}_{\text {pro }}=\dot{\mathrm{m}}_{\text {vap.dessuper }} \cdot \mathrm{h}_{2}+\dot{\mathrm{m}}_{\text {agua.dessuper }} \cdot \mathrm{h}_{\text {rep.des }}$

$\mathrm{h}_{\text {pro }}=\mathbf{h}\left[\right.$ water $\left.; \mathrm{T}=\mathrm{T}_{\text {pro }} ; \mathrm{x}=1\right] \quad \mathrm{T}_{\text {pro }}=\mathbf{T}_{\text {sat }}\left[\right.$ water $\left.; \mathrm{P}=\mathrm{P}_{2}\right]$ Considerado que o processo industrial utiliza vapor saturado

\section{DESAERADOR}

Balanço de massa no desaerador

$\dot{\mathrm{m}}_{\text {retorno }}+\dot{\mathrm{m}}_{\text {vap.desaerador }}+\dot{\mathrm{m}}_{\text {vap.cauda }}+\dot{\mathrm{m}}_{\text {rep.desaerador }}+\dot{\mathrm{m}}_{\text {purgador }}=\dot{\mathrm{m}}_{\text {agua }}$

Balanço de energia no desaerador

$\dot{\mathrm{m}}_{\text {retorno }} \cdot \mathrm{h}_{\text {cond }}+\dot{\mathrm{m}}_{\text {vap.desaerador }} \cdot \mathrm{h}_{2}+\dot{\mathrm{m}}_{\text {vap.cauda }} \cdot \mathrm{h}_{5}+\dot{\mathrm{m}}_{\text {rep.desaerador }} \cdot \mathrm{h}_{\text {rep.des }}+\dot{\mathrm{m}}_{\text {purgador }}$

$\cdot \mathrm{h}_{\text {purgador }}=\dot{\mathrm{m}}_{\text {agua }} \cdot \mathrm{h}_{6}$

$\mathrm{h}_{\text {cond }}=\mathbf{h}\left[\right.$ water $\left.; \mathrm{T}=\mathrm{T}_{\text {cond }} ; \mathrm{P}=\mathrm{P}_{\text {cond }}\right] \quad \mathrm{h}_{\text {purgador }}=\mathbf{h}\left[\right.$ water $\left.; \mathrm{P}=\mathrm{P}_{2} ; \mathrm{x}=0\right]$

$\mathrm{h}_{\text {rep.des }}=\mathbf{h}\left[\right.$ water $\left.; \mathrm{T}=\mathrm{T}_{\mathrm{amb}} ; \mathrm{P}=\mathrm{P}_{\text {rep.des }}\right] \quad \mathrm{T}_{\mathrm{amb}}=25$

$\mathrm{P}_{\text {rep.des }}=\mathrm{P}_{2}$ Pressão no desaerador é a pressão de escape da turbina

Conversão de unidades para ton/h

$$
\begin{aligned}
\overline{\mathrm{m}}_{\text {vap.escape }} & =\frac{\dot{\mathrm{m}}_{\text {vap.escape }}}{1000[\text { ton } / \mathrm{h}]} \\
\overline{\mathrm{m}}_{\text {vap.cauda }} & =\frac{\dot{\mathrm{m}}_{\text {vap.cauda }}}{1000[\text { ton } / \mathrm{h}]}
\end{aligned}
$$




$$
\begin{aligned}
& \overline{\mathrm{m}}_{\text {vap.processo }}=\frac{\dot{\mathrm{m}}_{\text {vap.processo }}}{1000 \text { [ton/h] }} \\
& \overline{\mathrm{m}}_{\text {vap.desaerador }}=\frac{\dot{\mathrm{m}}_{\text {vap.desaerador }}}{1000 \text { [ton/h] }} \\
& \overline{\mathrm{m}}_{\text {rep.desaerador }}=\frac{\dot{\mathrm{m}}_{\text {rep.desaerador }}}{1000 \text { [ton/h] }} \\
& \overline{\mathrm{m}}_{\text {feed.water. }}=\frac{\dot{\mathrm{m}}_{\text {agua }}}{1000[\text { ton } / \mathrm{h}]} \\
& \overline{\mathrm{m}}_{\text {purga }}=\frac{\dot{\mathrm{m}}_{\text {purga }}}{1000[\text { ton } / \mathrm{h}]} \\
& \overline{\mathrm{m}}_{\text {purgador }}=\frac{\dot{\mathrm{m}}_{\text {purgador }}}{1000 \text { [ton } / \mathrm{h}]}
\end{aligned}
$$

\section{CONDENSADOR}

$\dot{\mathrm{Q}}_{\text {out }}=\dot{\mathrm{m}}_{\text {vap.cauda }} \cdot\left[\mathrm{h}_{3}-\mathrm{h}_{4}\right]$ Balanço de energia --> Calor transferido da condensação do vapor para a torre de resfriamento

TORRE DE RESFRIAMENTO

$\dot{Q}_{\text {out }}=\dot{\mathrm{m}}_{\text {recirculação }} \cdot\left[\mathrm{h}_{\text {out }}-\mathrm{h}_{\text {in }}\right]$

$\mathrm{h}_{\text {out }}=\mathbf{h}\left[\right.$ water $\left.; \mathrm{P}=\mathrm{P}_{\text {out }} ; \mathrm{T}=\mathrm{T}_{\text {out }}\right]$

$$
\mathrm{h}_{\text {in }}=\mathbf{h}\left[\text { water } ; \mathrm{P}=\mathrm{P}_{\text {in }} ; \mathrm{T}=\mathrm{T}_{\text {in }}\right] \quad \mathrm{P}_{\text {in }}=1
$$

$P_{\text {out }}=1$

$\dot{\mathrm{m}}_{\text {repos.torre }}=\mathrm{Y}_{\text {perdas }} \cdot \dot{\mathrm{m}}_{\text {recirculação }} \quad Y_{\text {perdas }}$ corresponde a uma estimativa de perdas de água por evaporação, purga e arraste na torre de resfriamento

$\dot{\mathrm{m}}_{\text {rep.total }}=\dot{\mathrm{m}}_{\text {repos.torre }}+\dot{\mathrm{m}}_{\text {rep.desaerador }}+\dot{\mathrm{m}}_{\text {agua.dessuper }}$

$\overline{\mathrm{m}}_{\text {repos.torre }}=\frac{\dot{\mathrm{m}}_{\text {repos.torre }}}{1000[\text { ton } / \mathrm{h}]}$

$\overline{\mathrm{m}}_{\text {rep.total }}=\frac{\dot{\mathrm{m}}_{\text {rep.total }}}{1000[\text { ton } / \mathrm{h}]}$

$\overline{\mathrm{m}}_{\text {vap.dessuper }}=\frac{\dot{\mathrm{m}}_{\text {vap.dessuper }}}{1000[\text { ton } / \mathrm{h}]}$

Perc.torre $=\frac{\dot{\mathrm{m}}_{\text {repos.torre }}}{\dot{\mathrm{m}}_{\text {rep.total }}} \cdot 100$

Perc.desaerador $=\frac{\dot{\mathrm{m}}_{\text {rep.desaerador }}}{\dot{\mathrm{m}}_{\text {rep.total }}} \cdot 100$

Perc.dessuper $=\frac{\dot{\mathrm{m}}_{\text {vap.dessuper }}}{\dot{\mathrm{m}}_{\text {rep.total }}} \cdot 100$

Tap.water $r_{\text {torre }}=\frac{\dot{\mathrm{m}}_{\text {repos.torre }}}{\frac{\dot{\mathrm{M}}_{\text {cana }}}{1000}}$ 
File:Reaquecimento - 2a Lei - otimizado.EES

EES Ver. 9.433: \#0624: Depart. de Engenharia Mecanica Escola Politecnic, Escola Politecnica da USP, Sao Paulo, Brazil

Tap.water deionised $=\frac{\dot{\mathrm{m}}_{\text {rep.desaerador }}+\dot{\mathrm{m}}_{\text {agua.dessuper }}}{\frac{\dot{\mathrm{M}}_{\text {cana }}}{1000}}$

\section{CÁLCULO DAS POTÊNCIAS ELÉTRICAS}

Potência elétrica gerada

$\mathrm{POT}_{\text {elétr.gerada }}=\left[\mathrm{POT}_{1}+\mathrm{POT}_{2}+\mathrm{POT}_{\text {reaq }}\right] \cdot \eta_{\mathrm{g}} \cdot\left|2,77778 \times 10^{-7} \cdot \frac{\mathrm{MW}}{\mathrm{kJ} / \mathrm{h}}\right| \begin{gathered}\text { Potencia elétrica total gerada } \\ \text { no turbogerador }\end{gathered}$

$\mathrm{POT}_{\text {reaq }}=\dot{\mathrm{m}}_{\text {vap.reaq }} \cdot\left[\mathrm{h}_{1}-\mathrm{h}_{8}\right]$ Potencia gerada pelo vapor da cauda

POT $_{1}=\dot{\mathrm{m}}_{\text {vap.escape }} \cdot\left[\mathrm{h}_{9}-\mathrm{h}_{2}\right]$ Potencia gerada pelo vapor de escape a $\mathrm{P}=2,5$ bar

$\mathrm{POT}_{2}=\dot{\mathrm{m}}_{\text {vap.cauda }} \cdot\left[\mathrm{h}_{9}-\mathrm{h}_{3}\right]$ Potencia gerada pelo vapor da cauda

Consumo das bombas do ciclo

$\mathrm{POT}_{\text {elétr.consumida }}=\left[\mathrm{POT}_{\mathrm{B} 1}+\mathrm{POT}_{\mathrm{B} 2}\right] \cdot\left|2,77778 \times 10^{-7} \cdot \frac{\mathrm{MW}}{\mathrm{kJ} / \mathrm{h}}\right|$ Potência consumida pelas bombas

POT $_{\mathrm{B} 1}=\dot{\mathrm{m}}_{\text {vap.cauda }} \cdot\left[\mathrm{h}_{5}-\mathrm{h}_{4}\right]$ Potência consumida pela bomba 1

POT $_{\text {B2 }}=\dot{\mathrm{m}}_{\text {agua }} \cdot\left[\mathrm{h}_{7}-\mathrm{h}_{6}\right]$ Potência consumida pela bomba 1

\section{EFICIENNCIA GLOBAL DA UNIDADE DE COGERAÇÃO COM REAQUECIMENTO}

Cálculo da eficiência energética

$\eta$ Energética.Global

$$
=\left[\frac{\mathrm{POT}_{\text {elétr.líquida }}+\mathrm{POT}_{\text {processo }}}{\mathrm{POT}_{\text {entrada }}}\right] \cdot 100
$$

Potência líquida gerada na unidade de cogeração

$\mathrm{POT}_{\text {elétr.líquida }}=\mathrm{POT}_{\text {elétr.gerada }}-\mathrm{POT}_{\text {elétr.consumida }}$

Potência utilizada no processo industrial

$\mathrm{POT}_{\text {processo }}=\dot{\mathrm{m}}_{\text {vap.processo }} \cdot\left[\mathrm{h}_{\text {pro }}-\mathrm{h}_{\text {sat }}\right] \cdot\left|2,77778 \times 10^{-7} \cdot \frac{\mathrm{MW}}{\mathrm{kJ} / \mathrm{h}}\right|$
$\mathrm{POT}_{\text {desaerador }}=\dot{\mathrm{m}}_{\text {vap.desaerador }} \cdot\left[\mathrm{h}_{2}-\mathrm{h}_{6}\right] \cdot\left|2,77778 \times 10^{-7} \cdot \frac{\mathrm{MW}}{\mathrm{kJ} / \mathrm{h}}\right|$

$\mathrm{POT}_{\text {desaerador.perc }}=\frac{\mathrm{POT}_{\text {desaerador }}}{\mathrm{POT}_{\text {entrada }}} \cdot 100$

$\mathrm{POT}_{\text {processo.perc }}=\frac{\mathrm{POT}_{\text {processo }}}{\mathrm{POT}_{\text {entrada }}} \cdot 100$

$\mathrm{h}_{\text {sat }}=\mathbf{h}[$ water $; \mathrm{x}=0 ; \mathrm{P}=2,5]$

Alimentação energética na fornalha da caldeira

$\mathrm{POT}_{\text {entrada }}=\left[\dot{\mathrm{m}}_{\text {bagaço }} \cdot \mathrm{PCl}_{\text {bagaço }}+\dot{\mathrm{m}}_{\text {palha }} \cdot \mathrm{PCl}_{\text {palha }}\right] \cdot\left|2,77778 \times 10^{-7} \cdot \frac{\mathrm{MW}}{\mathrm{kJ} / \mathrm{h}}\right|$ 
Ambiente de referência considerado: $P o=1$ bar e $T o=25$ C

$$
\begin{aligned}
& \mathrm{TO}=25[\mathrm{C}] \\
& \mathrm{PO}=1 \quad[\text { bar }]
\end{aligned}
$$

$\mathrm{P} 00_{\mathrm{h} 20}=0,0303[\mathrm{bar}]$

LIMITE TEÓRICO DE EFICIÊNCIA - CICLO DE CARNOT

$\eta$ carnot $=\left[1-\left(\frac{T_{3}+273,15}{T_{1}+273,15}\right)\right] \cdot 100 \quad$ Trabalho máximo teórico

Trabalho útil final - saída do gerador

EXERGY.in fuel $^{=}$POT $_{\text {entrada }}$

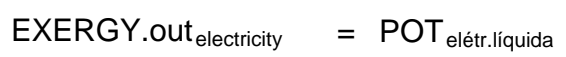

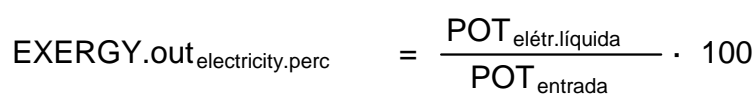

BOILER

$\mathrm{B}_{1}=\dot{\mathrm{m}}_{\mathrm{vapor}} \cdot\left[\mathrm{h}_{1}-\mathrm{h}_{0}-\left([\mathrm{TO}+273,15] \cdot\left[\mathrm{s}_{1}-\mathrm{s}_{0}\right]\right)\right] \cdot\left|2,77778 \times 10^{-7} \cdot \frac{\mathrm{MW}}{\mathrm{kJ} / \mathrm{h}}\right| \begin{array}{r}\text { Exergia do vapor de } \\ \text { saída do } \\ \text { gerador de vapor }\end{array}$

$\mathrm{h}_{0}=\mathbf{h}[$ water $; \mathrm{T}=\mathrm{TO} ; \mathrm{P}=\mathrm{PO}]$

$\mathrm{S}_{0}=\mathbf{s}[$ water $; \mathrm{T}=\mathrm{T} 0 ; \mathrm{P}=\mathrm{PO}]$

$B_{\text {fuel }}=E X E R G Y$. in $_{\text {fuel }}$

TURBINE

Exergia das correntes de vapor de escape e cauda

$\mathrm{B}_{2}=\dot{\mathrm{m}}_{\text {vap.escape }} \cdot\left[\mathrm{h}_{2}-\mathrm{h}_{0}-\left([\mathrm{TO}+273,15] \cdot\left[\mathrm{s}_{2}-\mathrm{s}_{0}\right]\right)\right] \cdot\left|2,77778 \times 10^{-7} \cdot \frac{\mathrm{MW}}{\mathrm{kJ} / \mathrm{h}}\right| \begin{array}{r}\text { Exergia do vapor } \\ \text { de escape }\end{array}$

$\mathrm{B}_{3}=\dot{\mathrm{m}}_{\text {vap.cauda }} \cdot\left[\mathrm{h}_{3}-\mathrm{h}_{0}-\left([\mathrm{TO}+273,15] \cdot\left[\mathrm{s}_{3}-\mathrm{s}_{0}\right]\right)\right] \cdot\left|2,77778 \times 10^{-7} \cdot \frac{\mathrm{MW}}{\mathrm{kJ} / \mathrm{h}}\right|$ Exergia do vapor de cauda

Exergia da corrente de reaquecimento

$\mathrm{B}_{8}=\dot{\mathrm{m}}_{\text {vapor }} \cdot\left[\mathrm{h}_{8}-\mathrm{h}_{0}-\left([\mathrm{T} 0+273,15] \cdot\left[\mathrm{s}_{8}-\mathrm{s}_{0}\right]\right)\right] \cdot\left|2,77778 \times 10^{-7} \cdot \frac{\mathrm{MW}}{\mathrm{kJ} / \mathrm{h}}\right| \begin{array}{r}\text { Exergia do vapor para } \\ \text { reaquecimento } \\ \text { na saída } \\ \text { da turbina }\end{array}$

$\mathrm{B}_{9}=\dot{\mathrm{m}}_{\mathrm{vapor}} \cdot\left[\mathrm{h}_{9}-\mathrm{h}_{0}-\left([\mathrm{TO}+273,15] \cdot\left[\mathrm{s}_{9}-\mathrm{s}_{0}\right]\right)\right] \cdot\left|2,77778 \times 10^{-7} \cdot \frac{\mathrm{MW}}{\mathrm{kJ} / \mathrm{h}}\right| \begin{array}{r}\text { Exergia do vapor após } \\ \text { reaquecimento }\end{array}$ 
Bdest $_{\text {turbine }}=\mathrm{B}_{1}+\mathrm{B}_{9}-\left[\mathrm{B}_{2}+\mathrm{B}_{3}+\mathrm{B}_{8}+\frac{\mathrm{POT}_{\text {elétr.gerada }}}{\eta_{\mathrm{g}}}\right]$ Exergia destruída na turbina

Bdest $_{\text {turbine.perc }}=\frac{\text { Bdest }_{\text {turbine }}}{\mathrm{B}_{\text {fuel }}} \cdot 100$ Percentual de exergia destruída na turbina

$\mathrm{B}_{2 ; \text { perc }}=\frac{\mathrm{B}_{2}}{\mathrm{POT}_{\text {entrada }}} \cdot 100$ Percentual de exergia no vapor de escape

$\mathrm{B}_{\text {liq }}=\frac{\mathrm{POT}_{\text {elétr.gerada }}}{\mathrm{POT}_{\text {entrada }}} \cdot 100$ Percentual de exergia (trabalho) na saída do gerador

Consumo de exergia no processo industrial associado ao consumo específico de vapor

EXERGY.out process $=\dot{\mathrm{m}}_{\text {vap.processo }} \cdot\left[\mathrm{h}_{\text {pro }}-\mathrm{h}_{0}-\left([\mathrm{TO}+273,15] \cdot\left[\mathrm{s}_{\text {pro }}-\mathrm{s}_{0}\right]\right)\right] \cdot\left|2,77778 \times 10^{-7} \cdot \frac{\mathrm{MW}}{\mathrm{kJ} / \mathrm{h}}\right|$

$\mathrm{S}_{\text {pro }}=\mathbf{s}[$ water $; \mathrm{P}=2,5 ; \mathrm{T}=127,5]$

EXERGY.out $_{\text {process.perc }}=\frac{\text { EXERGY.out }_{\text {process }}}{\text { POT }_{\text {entrada }}} \cdot 100$

EXERGY.out $_{\text {deaerator }}=B_{2}-$ EXERGY.out process

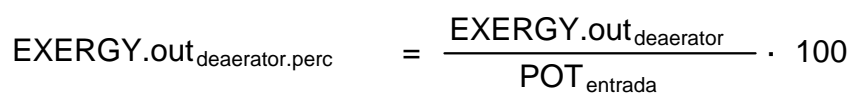

\section{DESSUPERAQUECEDOR}

Balanço de entropia no dessuper

$\mathrm{S}_{\text {ger.dessuper }}=\dot{\mathrm{m}}_{\text {vap.processo }} \cdot \mathrm{s}_{\text {pro }}-\left[\mathrm{m}_{\text {agua.dessuper }} \cdot \mathrm{s}_{\text {agua }}+\left(\dot{\mathrm{m}}_{\text {vap.dessuper }}-\dot{\mathrm{m}}_{\text {purgador }}\right) \cdot \mathrm{s}_{2}\right]$

$\mathrm{S}_{\text {agua }}=\mathbf{s}[$ water $; \mathrm{P}=2,5 ; \mathrm{T}=25]$

Bdest $_{\text {dessuper }}=[\mathrm{T0}+273,15] \cdot \mathrm{S}_{\text {ger.dessuper }} \cdot\left|2,77778 \times 10^{-7} \cdot \frac{\mathrm{MW}}{\mathrm{kJ} / \mathrm{h}}\right|$ Exergia destruída no dessuperaquecedor

Bdest $_{\text {dessuper.perc }}=\frac{\text { Bdest }_{\text {dessuper }}}{\mathrm{B}_{\text {fuel }}} \cdot 100$ Percentual de exergia destruída no dessuperaquecedor

CONDENSADOR

$\mathrm{B}_{4}=\dot{\mathrm{m}}_{\mathrm{vap} . c a u d a} \cdot\left[\mathrm{h}_{4}-\mathrm{h}_{0}-\left([\mathrm{T} 0+273,15] \cdot\left[\mathrm{s}_{4}-\mathrm{s}_{0}\right]\right)\right] \cdot\left|2,77778 \times 10^{-7} \cdot \frac{\mathrm{MW}}{\mathrm{kJ} / \mathrm{h}}\right|$ Exergia na saída do condensador

Bdest $_{\text {condenser }}=\mathrm{B}_{3}-\mathrm{B}_{4}$ Exergia destruída no condensador

Bdest $_{\text {condenser.perc }}=\frac{\text { Bdest }_{\text {condenser }}}{\mathrm{B}_{\text {fuel }}} \cdot 100$ Percentual de exergia destruída no condensador

BOMBA 1

$\mathrm{B}_{5}=\dot{\mathrm{m}}_{\text {vap.cauda }} \cdot\left[\mathrm{h}_{5}-\mathrm{h}_{0}-\left([\mathrm{T} 0+273,15] \cdot\left[\mathrm{s}_{5}-\mathrm{s}_{0}\right]\right)\right] \cdot\left|2,77778 \times 10^{-7} \cdot \frac{\mathrm{MW}}{\mathrm{kJ} / \mathrm{h}}\right|$ Exergia na saída da bomba 1 
EES Ver. 9.433: \#0624: Depart. de Engenharia Mecanica Escola Politecnic, Escola Politecnica da USP, Sao Paulo, Brazil

Bdest $_{\mathrm{B} 1}=\mathrm{B}_{4}-\mathrm{B}_{5}+\mathrm{W}_{\mathrm{B} 1}$ Exergia destruída na bomba 1

$\mathrm{W}_{\mathrm{B} 1}=\dot{\mathrm{m}}_{\text {vap.cauda }} \cdot\left[\mathrm{h}_{5}-\mathrm{h}_{4}\right] \cdot\left|2,77778 \times 10^{-7} \cdot \frac{\mathrm{MW}}{\mathrm{kJ} / \mathrm{h}}\right|$ Trabalho realizado pela bomba $B 1$

Bdest $_{\mathrm{B} 1 \text {.perc }}=\frac{\text { Bdest }_{\mathrm{B} 1}}{\mathrm{~B}_{\text {fuel }}} \cdot 100$ Percentual de exergia destruída na bomba 1

\section{DESAERADOR}

Balanço de entropia no dessuperaquecedor

$\mathrm{s}_{\text {ger.desaerador }}$
$\left.\cdot \mathrm{s}_{\text {agua }}+\dot{\mathrm{m}}_{\text {purgador }} \cdot \dot{\mathrm{m}}_{\text {sat }}\right]$

$\mathrm{S}_{\text {cond }}=\mathbf{s}\left[\right.$ water $\left.; \mathrm{T}=\mathrm{T}_{\text {cond }} ; \mathrm{P}=\mathrm{P}_{\text {cond }}\right] \quad \mathrm{S}_{\text {sat }}=\mathbf{s}[$ water $; \mathrm{P}=2,5 ; \mathrm{x}=0]$

Bdest $_{\text {desaerador }}=[\mathrm{T0}+273,15] \cdot \mathrm{S}_{\text {ger.desaerador }} \cdot\left|2,77778 \times 10^{-7} \cdot \frac{\mathrm{MW}}{\mathrm{kJ} / \mathrm{h}}\right|$ Exergia destruída no desaerador

Bdest $_{\text {desaerador.perc }}=\frac{\text { Bdest }_{\text {desaerador }}}{\mathrm{B}_{\text {fuel }}} \cdot 100$ Percentual de exergia destruída no desaerador

BOMBA 2

$\mathrm{B}_{7}=\dot{\mathrm{m}}_{\mathrm{agua}} \cdot\left[\mathrm{h}_{7}-\mathrm{h}_{0}-\left([\mathrm{T0}+273,15] \cdot\left[\mathrm{s}_{7}-\mathrm{s}_{0}\right]\right)\right] \cdot\left|2,77778 \times 10^{-7} \cdot \frac{\mathrm{MW}}{\mathrm{kJ} / \mathrm{h}}\right|$ Exergia na saída da bomba 2

$\mathrm{B}_{6}=\dot{\mathrm{m}}_{\text {agua }} \cdot\left[\mathrm{h}_{6}-\mathrm{h}_{0}-\left([\mathrm{T} 0+273,15] \cdot\left[\mathrm{s}_{6}-\mathrm{s}_{0}\right]\right)\right] \cdot\left|2,77778 \times 10^{-7} \cdot \frac{\mathrm{MW}}{\mathrm{kJ} / \mathrm{h}}\right| \begin{array}{r}\text { Exergia na entrada } \\ \text { da bomba } 2\end{array}$

$\mathrm{W}_{\mathrm{B} 2}=\dot{\mathrm{m}}_{\text {agua }} \cdot\left[\mathrm{h}_{7}-\mathrm{h}_{6}\right] \cdot\left|2,77778 \times 10^{-7} \cdot \frac{\mathrm{MW}}{\mathrm{kJ} / \mathrm{h}}\right|$ Trabalho realizado pela bomba B2

Bdest $_{\mathrm{B} 2}=\mathrm{B}_{7}-\mathrm{B}_{6}+\mathrm{W}_{\mathrm{B} 2} \quad$ Exergia destruída na bomba 2

Bdest $_{\mathrm{B} 2 \text {.perc }}=\frac{\text { Bdest }_{\mathrm{B} 2}}{\mathrm{~B}_{\text {fuel }}} \cdot 100$ Percentual de exergia destruída na bomba 2

BOILER

$\mathrm{B}_{7}+\mathrm{B}_{\text {fuel }}+\mathrm{B}_{8}=\mathrm{B}_{1}+\mathrm{B}_{\text {purga }}+\mathrm{B}_{9}+\mathrm{Bdest}_{\text {boiler }}$ Balanço de exergia na caldeira

Bdest $_{\text {boiler.perc }}=\frac{\text { Bdest }_{\text {boiler }}}{\mathrm{B}_{\text {fuel }}} \cdot 100$ Percentual de exergia destruída na caldeira

$\mathrm{B}_{\text {purga }}=\dot{\mathrm{m}}_{\text {purga }} \cdot\left[\mathrm{h}_{\text {purga }}-\mathrm{h}_{0}-\left([\mathrm{T0}+273,15] \cdot\left[\mathrm{s}_{\text {purga }}-\mathrm{s}_{0}\right]\right)\right] \cdot\left|2,77778 \times 10^{-7} \cdot \frac{\mathrm{MW}}{\mathrm{kJ} / \mathrm{h}}\right|$

$\mathrm{s}_{\text {purga }}=\mathbf{s}\left[\right.$ water $\left.; \mathrm{h}=\mathrm{h}_{\text {purga }} ; \mathrm{T}=\mathrm{T}_{\text {purga }}\right]$

Total $_{\text {exergy.dest }}=$ Bdest $_{\mathrm{B} 1}+$ Bdest $_{\mathrm{B} 2}+$ Bdest $_{\text {desaerador }}+$ Bdest $_{\text {condenser }}+$ Bdest $_{\text {boiler }}+$ Bdest $_{\text {turbine }}$

Total $_{\text {exergy.dest.perc }}=\frac{\text { Total }_{\text {exergy.dest }}}{\mathrm{B}_{\text {fuel }}} \cdot 100$

Eficiência Exergética

Cálculo da eficiência exergética global 
$\eta_{\text {EXergética.Global }}=\left[\frac{\text { POT }_{\text {elétr.líquida }}+\text { EXERGY.out }_{\text {process }}}{\text { POT }_{\text {entrada }}}\right] \cdot 100$

$\eta$ Ex.ref.Carnot $\quad=\frac{\eta \text { EXergética.Global }}{\eta \text { Carnot }} \cdot 100$

Distribuição de exergia entre vapor e eletricidade

Exergia $_{\text {vapor.perc }}=\left[\frac{\text { EXERGY.out }_{\text {process }}}{\mathrm{POT}_{\text {elétr.líquida }}+\text { EXERGY.out }_{\text {process }}}\right] \cdot 100$
Exergia $_{\text {eletricidade.perc }}=\left[\frac{\mathrm{POT}_{\text {elétr.líquida }}}{\mathrm{POT}_{\text {elétr.líquida }}+\text { EXERGY.out }_{\text {process }}}\right] \cdot 100$

ANÁLISE COMPLEMENTAR 1A LEI - PERDAS ENERGÉTICAS

Perdas na Caldeira e turbina

Boiler $_{\text {losses }}=\mathrm{POT}_{\text {entrada }} \cdot\left[1-\eta_{\mathrm{c}}\right]$

Boiler $_{\text {losses.perc }}=\frac{\text { Boiler }_{\text {losses }}}{\mathrm{POT}_{\text {entrada }}} \cdot 100$

Turbine $_{\text {losses }}=\left[\left(\mathrm{POT}_{1}+\mathrm{POT}_{2}+\mathrm{POT}_{\text {reaq }}\right) \cdot\left(1-\eta_{\mathrm{t}}\right)\right] \cdot\left|2,77778 \times 10^{-7} \cdot \frac{\mathrm{MW}}{\mathrm{kJ} / \mathrm{h}}\right|$

Turbine $_{\text {losses.perc }}=\frac{\text { Turbine }_{\text {losses }}}{\text { POT }_{\text {entrada }}} \cdot 100$

Perdas no condensador

$\mathrm{POT}_{\text {condensador }}=\dot{\mathrm{Q}}_{\text {out }} \cdot\left|2,77778 \times 10^{-7} \cdot \frac{\mathrm{MW}}{\mathrm{kJ} / \mathrm{h}}\right|$ Energia perdida no condensador

$\mathrm{POT}_{\text {condensador.perc }}=\frac{\mathrm{POT}_{\text {condensador }}}{\mathrm{POT}_{\text {entrada }}} \cdot 100$

Condenser $_{\text {losses }}=$ POT $_{\text {condensador }}$

Perdas no processo

process $_{\text {losses }}=\mathrm{POT}_{\text {entrada }}-\left[\mathrm{POT}_{\text {processo }}+\mathrm{POT}_{\text {elétr.gerada }}+\mathrm{POT}_{\text {condensador }}+\right.$ Turbine $_{\text {losses }}+$ Boiler $\left._{\text {losses }}\right]$

process $_{\text {losses.perc }}=\frac{\text { process }_{\text {losses }}}{\text { POT }_{\text {entrada }}} \cdot 100$

Cálculo da energia elétrica gerada por tonela de cana por tonelada de cana

GeraçãoEletric.Espec.Total $=$ POT $_{\text {elétr.líquida }} \cdot$ Período $_{\text {safra }} \cdot 1000 \cdot \frac{24}{\text { Cana }_{\text {safra }}}$

GeraçãoEletric.Espec.Excedente = GeraçãoEletric.Espec.Total - ConsumoEletr.Processo

ALOCAÇÃO

Critério energético 
File:Reaquecimento - 2a Lei - otimizado.EES

EES Ver. 9.433: \#0624: Depart. de Engenharia Mecanica Escola Politecnic, Escola Politecnica da USP, Sao Paulo, Brazil

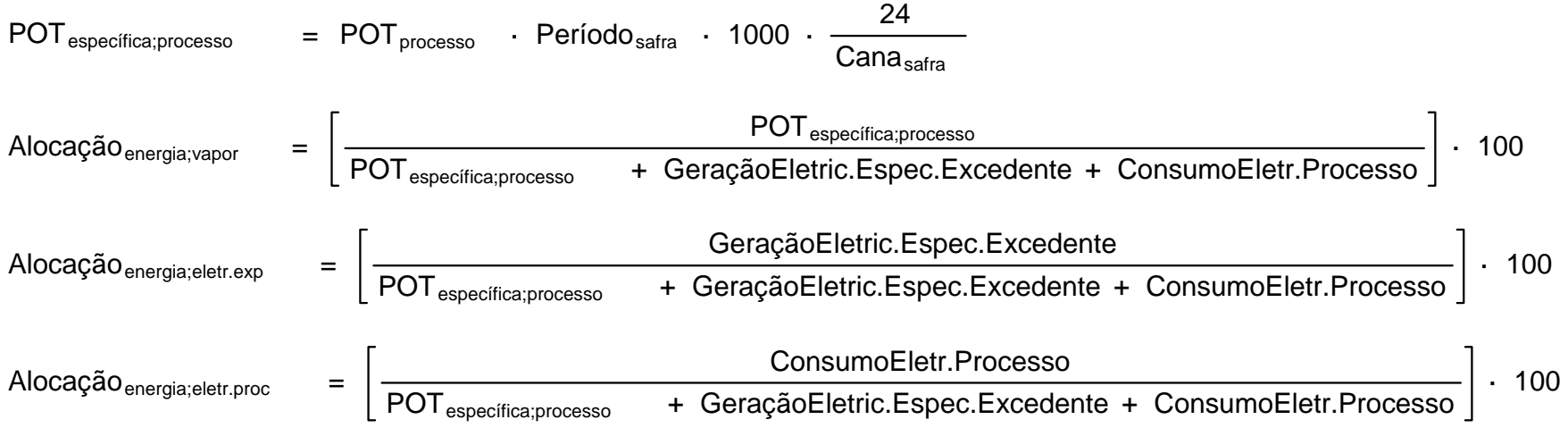

Critério exergético

EXERGY.out $_{\text {específica;process }}=$ EXERGY.out $_{\text {process }} \cdot$ Período $_{\text {safra }} \cdot 1000 \cdot \frac{24}{\text { Cana }_{\text {safra }}}$

Alocação $_{\text {exergia;vapor }}=\left[\frac{\text { EXERGY.out }_{\text {específica;process }}}{\text { EXERGY.out }_{\text {específica;process }}+\text { GeraçãoEletric.Espec.Excedente }+ \text { ConsumoEletr.Processo }}\right] \cdot 100$

Alocação $_{\text {exergia;eletr.exp }}=\left[\begin{array}{ll}\text { GeraçãoEletric.Espec.Excedente } \\ \hline \text { EXERGY.out }{ }_{\text {específica;process }}+\text { GeraçãoEletric.Espec.Excedente + ConsumoEletr.Processo }\end{array}\right]$

$\cdot 100$

Alocação $_{\text {exergia;eletr.proc }}=\left[\frac{\text { ConsumoEletr.Processo }}{\text { EXERGY.out }_{\text {específica;process }}+\text { GeraçãoEletric.Espec.Excedente }+ \text { ConsumoEletr.Processo }}\right]$

- 100

Distribuição de energia entre vapor e eletricidade

Energia $_{\text {vapor.perc }}=\left[\frac{\mathrm{POT}_{\text {processo }}}{\mathrm{POT}_{\text {processo }}+\mathrm{POT}_{\text {elétr.líquida }}}\right] \cdot 100$
Energia $_{\text {eletricidade.perc }}=\left[\frac{\mathrm{POT}_{\text {elétr.líquida }}}{\mathrm{POT}_{\text {processo }}+\mathrm{POT}_{\text {elétr.líquida }}}\right] \cdot 100$ 
APÊNDICE C - Modelagem Termodinâmica do sistema de cogeração com ciclo Rankine Regenerativo 


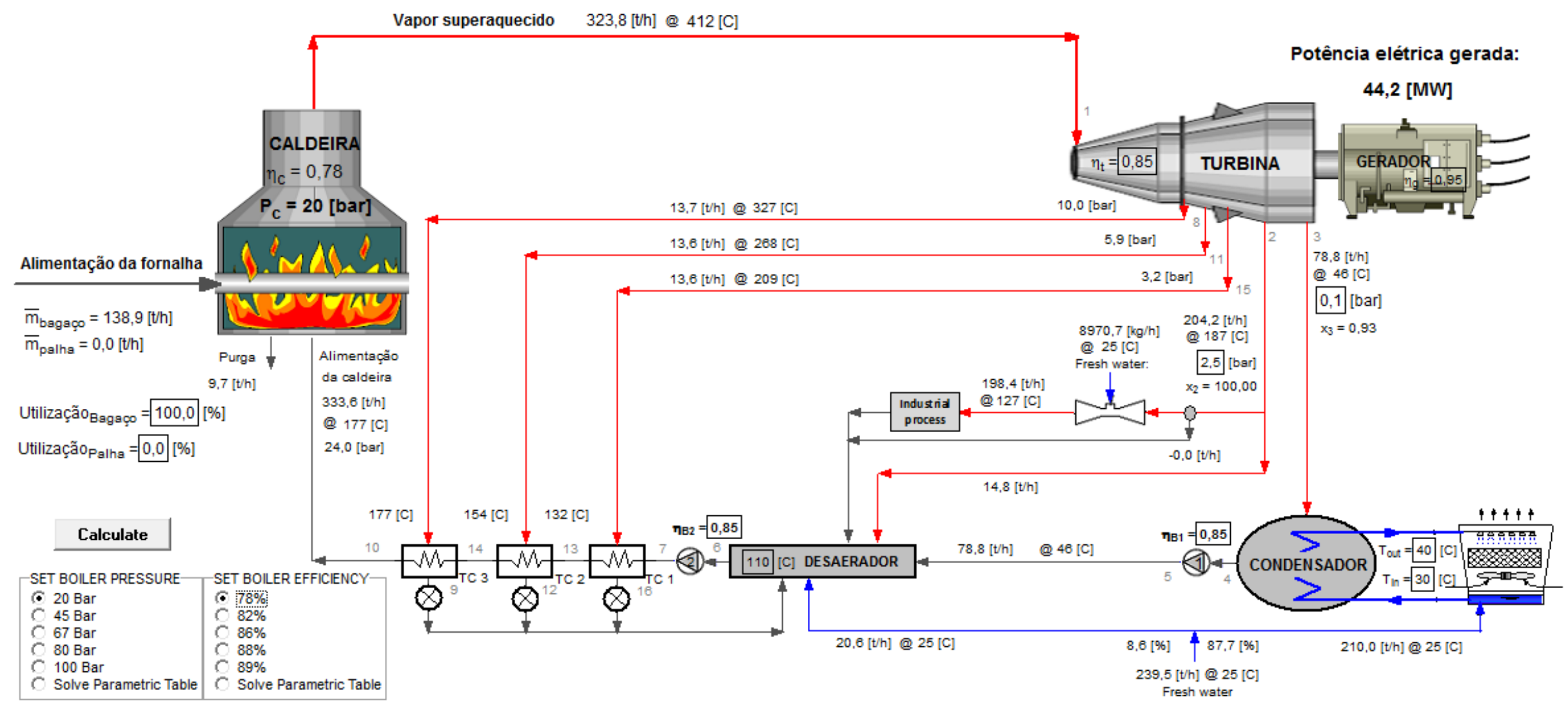

Figura 47 - Ciclo de vapor regenerativo para um sistema de cogeração (Interface do simulador) 
File:Regeneração - 2a Lei - Otimizado com 3 TC.EES

EES Ver. 9.433: \#0624: Depart. de Engenharia Mecanica Escola Politecnic, Escola Politecnica da USP, Sao Paulo, Brazil

1:

2:

3: "APÊNDICE C - MODELAGEM TERMODINÂMICA DO SISTEMA DE COGERAÇÃO COM CICLO RANKINE REGENERATIVO"

4:

$5:$

6:

7: "Dados da Safra"

8:

9: M_dot_cana $=$ Cana_safra/Período_safra*1000/24 [kg/h] Moagem de cana"

10: m_dot_bagaço=Y_bagaço/100*M_dot_cana*Utilização_Bagaço/100 o de bagaço de cana"

11: m_dot_palha=Y_palha/100*M_dot_cana*Utilização_Palha/100 o de palha de cana"

12: Razão|vapor_biomassa=m_dot_vapor/m_dot_bagaço entre produção de vapor e consumo de biomassa"

13: m_bar_bagaço=m_dot_bagaço/1000 [ton/h]

14: m_bar_palha=m_dot_palha/1000 [ton/h]

15:

16

17: "GERADOR DE VAPOR - Modelagem de conservação de matéria e energia"

18:

19: "Balanço de massa"

20: m_dot_agua $=\mathrm{m} \_d o t \_v a p o r+m \_d o t \_p u r g a$

21: m_dot_purga $=Y$ _purga*m_dot_vapor

22: Y_purga $=0,03$ purga"

23: M_bar_vapor=m_dot_vapor/1000[ton/h] da vazão mássica de vapor de $\mathrm{Kg} / \mathrm{h}$ para ton/ $\mathrm{h}^{\prime \prime}$

24:

25: "Balanço de energia"

26:

27: m_dot_agua*h[10]=m_dot_vapor*h[1]+m_dot_purga*h_purga - Q_dot_c

28: Q_dot_c=(m_dot_bagaço*PCl_bagaço+m_dot_palha*PCl_palha $)^{\star} e t a \_c$ utilizada na fornecida na fornalha para evaporação da água"

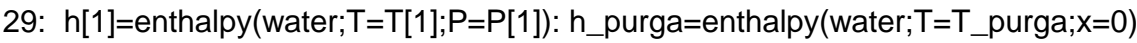

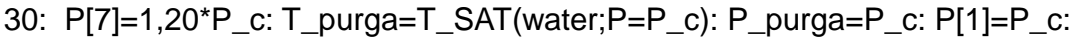

31: $\mathrm{PCl}$ bagaço $=7565: \mathrm{PCl} \_$palha $=12960[\mathrm{~kJ} / \mathrm{kg}]$

32: $T[1]=T \_S A T\left(\right.$ water; $\left.P=P \_c\right)+G \_s u p e r$

33: G_super=200 [C]

34:

35: "BOMBA 02 - ALIMENTAÇÃO DA CALDEIRA"

36:

37: $P[6]=P[2]$

escape"

38: eta_B2=(h[6]-h7_iso $) /(\mathrm{h}[6]-\mathrm{h}[7])$ da bomba"

39: h7_iso=enthalpy(water;s=s[6];P=P[7])

40: $h[6]=$ enthalpy (water; $P=P[6] ; T=T[6])$

41: $s[6]=e n t r o p y($ water; $P=P[6] ; T=T[6])$

42: $T[7]=$ temperature (water; $h=h[7] ; P=P[7])$

43: s[7]=entropy (water; $h=h[7] ; P=P[7])$

44:

45: "BOMBA 01 - CONDENSADO"

46:

47: $P[5]=P[2]$ escape"

48: eta_B1 $=(\mathrm{h}[4]-\mathrm{h} 5$ _iso $) /(\mathrm{h}[4]-\mathrm{h}[5])$

49: h5_iso=enthalpy(water;s=s[4];P=P[5])
"Poder calorífico inferior do bagaço e da palha de cana"

"Temperatura do vapor superaquecido"

"Grau de superaqucimento"

"Pressão de descarga da bomba igual a pressão do vapor de

"Determinação da entalpia real da vazão de líquido na descarga

"Entalpia para condição ideal isentrópica"

"Entalpia na saída do desaerador"

"Entropia na saída do desaerador é entropia do líquido saturado"

"Temperatura de recalque"

"Entropia da água de alimentação da caldeira"

"Pressão de descarga da bomba igual a pressão do vapor de

"Determinação da entalpia real do líquido na descarga da bomba" "Entalpia para condição ideal isentrópica" 
File:Regeneração - 2a Lei - Otimizado com 3 TC.EES

30/05/2014 18:42:34 Page 2

EES Ver. 9.433: \#0624: Depart. de Engenharia Mecanica Escola Politecnic, Escola Politecnica da USP, Sao Paulo, Brazil

50: $s[4]=e n t r o p y($ water; $P=P[4] ; X=0)$

51: $T[5]=$ temperature $($ water; $h=h[5] ; P=P[5])$

52: $h[4]=e n t h a l p y($ water; $P=P[4] ; X=0)$

53: $\mathrm{T}[4]=\mathrm{T}[3]$

troca calor latente"

54: $P[4]=P[3]$

55: $s[5]=$ entropy $($ water; $P=P[5] ; T=T[5])$

56:

57: "TURBINA"

58: "Rendimento da turbina"

59:

60: eta_t $=(\mathrm{h}[1]-\mathrm{h}[2]) /(\mathrm{h}[1]-\mathrm{h} 2$ iso $)$

desaerador através da eficiencia isoentrópica"

61: eta_t $=(\mathrm{h}[1]-\mathrm{h}[3]) /(\mathrm{h}[1]-\mathrm{h} 3$ _iso $)$

desaerador através da eficiencia isoentrópica"

62: eta_t $=(\mathrm{h}[1]-\mathrm{h}[8]) /(\mathrm{h}[1]-\mathrm{h} 8$ _iso $)$

eficiencia isoentrópica"

63: eta_t $=(\mathrm{h}[1]-\mathrm{h}[11]) /(\mathrm{h}[1]-\mathrm{h} 11$ _iso $)$

eficiencia isoentrópica"

64: eta_t $\mathrm{t}=(\mathrm{h}[1]-\mathrm{h}[15]) /(\mathrm{h}[1]-\mathrm{h} 15$ _iso $)$

eficiencia isoentrópica"

65: h15_iso=enthalpy(water;s=s[1];P=P[15])

expansão isoentrópica"

66: h11_iso=enthalpy(water;s=s[1];P=P[11])

expansão isoentrópica"

67: h2_iso=enthalpy(water;s=s[1];P=P[2]) expansão isoentrópica"

68: h3_iso=enthalpy(water;s=s[1];P=P[3]) expansão isoentrópica"

69: h8_iso=enthalpy(water;s=s[1];P=P[8]) expansão isoentrópica"

70: $\mathrm{T}[2]=$ temperature(water; $h=h[2] ; P=P[2])$

71: $\mathrm{T}[3]=$ temperature (water; $h=h[3] ; P=P[3])$

72: $T[8]=$ temperature (water; $h=h[8] ; P=P[8]$ )

73: $T[11]=$ temperature (water; $h=h[11] ; P=P[11]$ )

74: $T[15]=$ temperature (water; $h=h[15] ; P=P[15])$

75: $\mathrm{s}[1]=$ entropy(water; $P=P[1] ; T=T[1])$

76: $\mathrm{s}[2]=e n t r o p y($ water; $h=h[2] ; T=T[2])$

77: $\mathrm{s}[3]=e n t r o p y($ water; $h=h[3] ; \mathrm{T}=\mathrm{T}[3])$

78: $\mathrm{s}[8]=e n t r o p y($ water; $\mathrm{h}=\mathrm{h}[8] ; \mathrm{T}=\mathrm{T}[8])$

79: $\mathrm{s}[11]=e n t r o p y($ water; $\mathrm{h}=\mathrm{h}[11] ; \mathrm{T}=\mathrm{T}[11])$

80: $s[15]=e n t r o p y(w a t e r ; h=h[15] ; T=T[15])$

81: $x[2]=q u a l i t y($ water; $h=h[2] ; T=T[2])$

82: $x[3]=$ quality (water; $h=h[3] ; T=T[3])$

83:

84: "Balanço de massa na turbina"

85:

86: m_dot_vapor=m_dot_vap.escape+m_dot_vap.cauda + m_dot_vap.hx1+m_dot_vap.hx2+m_dot_vap.hx3

87:

88:

89: "PURGA DE CONDENSADO ANTES DE SER USADO NO PROCESSO"

90:

91: "RETORNO DE CONDENSADO DO PROCESSO INDUSTRIAL"

92:

93: m_dot_retorno=m_dot_vap.processo ${ }^{\star} 0,9$

94: T_cond=90 [C]

recuperação e retorna para o ciclo a $90 \mathrm{C}^{\prime \prime}$

95: P_cond=P[2]

de escape"
"Entropia na saída do condensador - líquido saturado"

"Temperatura de recalque para desaerador"

"Entalpia da saída do condensador é a entalpia de líquido saturado"

"Temperatura de Entrada = temperatura de saída --> Somente

"Pressão de sucção da bomba = pressão da cauda da turbina"

"Entropia da água de recalque da bomba 01"

"Determinação da entalpia real do vapor extraído para o

"Determinação da entalpia real do vapor extraído para o

"Determinação da entalpia real do vapor extraído através da

"Determinação da entalpia real do vapor extraído através da

"Determinação da entalpia real do vapor extraído através da

"Entalpia da corrente de vapor de escape para condição ideal de

"Entalpia da corrente de vapor de escape para condição ideal de

"Entalpia da corrente de vapor de escape para condição ideal de

"Entalpia da corrente de vapor na cauda para condição ideal de

"Entalpia da corrente de vapor extraído na condição ideal de

"Temperatura do vapor de escape"

"Temperatura do vapor de cauda"

"Temperatura do vapor extraído"

"Temperatura do vapor extraído"

"Temperatura do vapor extraído"

"Estado definido por 2 propriedades independentes"

"Entropia do vapor de escape"

"Entropia do vapor de cauda"

"Entropia do vapor extraído"

"Entropia do vapor extraído"

"Entropia do vapor extraído"

"Título do vapor de escape"

"Título do vapor na cauda da turbina"
"Considerado perdas no processo de 10\% da vazão de vapor"

"Considerado que todo condensado é coletado em um tanque de

"Pressão de retorno = pressão no desaerador = Pressão do vapor 
96:

97: m_agua.dessuper=if(x[2];100;0;m_dot_agua.dessuper;0) "Se o vapor de escape tiver $x<1$ o condensado precisa ser retirado em purgadores"

98: m_dot_purgador=if(x[2];100;-m_dot_agua.dessuper;0;0)

de escape tiver $x<1$ o condensado precisa ser retirado em purgadores"

"Se o vapor 99:

100: "DESSUPERAQUECEDOR E VAPOR DE PROCESSO"

101: "Balanços de massa"

102:

103: m_dot_vap.escape $=m$ _dot_vap.dessuper+m_dot_vap.desaerador

104: m_dot_vap.processo = Cons.Vapor_processo*M_dot_cana $(1 / 1000)$ de vapor saturado para o processo a $P=2,5$ Bar"

"Consumo

105: m_dot_vap.processo=m_dot_vap.dessuper+m_dot_agua.dessuper

106: m_bar_agua.dessuper $=$ m_dot_agua.dessuper $/ 1000$

107:

108: "Balanço de energia no dessuperaquecedor"

109:

110: m_dot_vap.processo*h_pro=m_dot_vap.dessuper*h[2]+m_dot_agua.dessuper*h_rep.des

111: h_pro=enthalpy(water; $T=T$ _pro; $x=1)$ : T_pro=T_sat(water; $P=2, \overline{5}$ )

"Processo industrial utiliza vapor saturado"

112:

113:

114: "DESAERADOR"

115: "Balanço de massa no desaerador"

116:

117: m_dot_retorno+m_dot_vap.desaerador+m_dot_vap.cauda + m_dot_rep.desaerador + m_dot_purgador + m_dot_vap.hx1 + m_dot_vap.hx2+m_dot_vap.hx3=m_dot_agua

118:

119: "Balanço de energia no desaerador"

120: m_dot_retorno*h_cond+m_dot_vap.desaerador*h[2]+m_dot_vap.cauda*h[5]+m_dot_rep.desaerador*h_rep.des

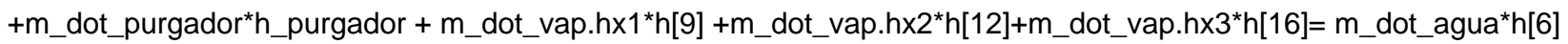

121: $h \_c o n d=e n t h a l p y\left(\right.$ water; $\left.T=T \_c o n d ; P=P \_c o n d\right): ~ h \_p u r g a d o r=e n t h a l p y($ water; $P=P[2] ; x=0): h \_r e p . d e s=e n t h a l p y($ water; $T$ $\left.=T \_a m b ; P=P \_r e p . d e s\right): T \_a m b=25$

122: $P$ _rep.des $=P[2]$

"Pressão no desaerador é a pressão de escape da turbina"

123:

124: "Conversão de unidades de $\mathrm{Kg} / \mathrm{h}$ para ton/h"

125:

126: m_bar_vap.escape=m_dot_vap.escape/1000 [ton/h]

127: m_bar_vap.cauda=m_dot_vap.cauda/1000 [ton $/ \mathrm{h}]$

128: m_bar_vap.processo=m_dot_vap.processo/1000 [ton/h]

129: m_bar_vap.desaerador=m_dot_vap.desaerador/1000 [ton/h]

130: m_bar_rep.desaerador=m_dot_rep.desaerador $/ 1000$ [ton $/ \mathrm{h}]$

131: m_bar_feed.water=m_dot_agua/1000 [ton/h]

132: m_bar_purga.=m_dot_purga/1000 [ton $/ \mathrm{h}]$

133: m_bar_purgador=m_dot_purgador/1000 [ton/h]

134:

135: "TROCADOR $h \times 1 "$

136:

137: $\mathrm{P}[9]=\mathrm{P}[8]$

138: $\mathrm{T}[9]=T \_$sat(water; $\left.P=P[8]\right)$

139: $h[9]=e n t h a l p y($ water; $P=P[9] ; X=0)$

140: $P[10]=P[7]$

141: $h[10]=e n t h a l p y$ (water; $T=T[10] ; P=P[10]$ )

142: m_dot_agua*h[14]+m_dot_vap.hx1*h[8] = m_dot_agua*h[10]+m_dot_vap.hx1*h[9] energia no $h \times 1^{\prime \prime}$

143: m_bar_vap.hx1=m_dot_vap.hx1/1000 [ton/h]

144:

145: "TROCADOR $h \times 2 "$

146: 


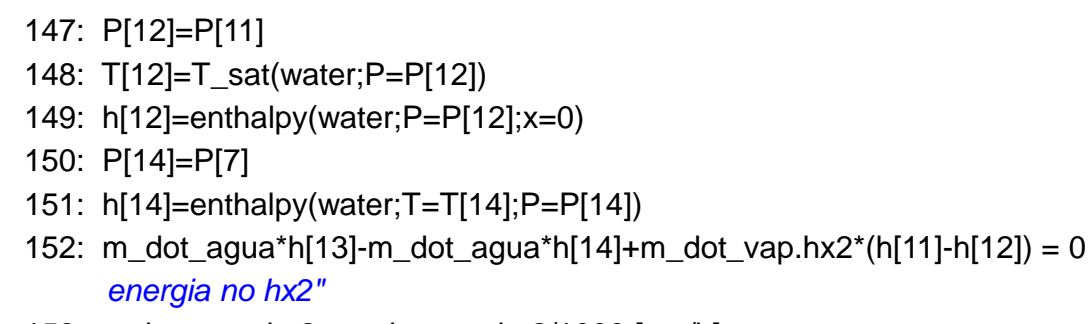

153: m_bar_vap.hx2=m_dot_vap.hx2/1000 [ton/h]

154:

155: "TROCADOR $h \times 3 "$

156:

157: $P[16]=P[15]$

158: $T[16]=T$ _sat(water; $P=P[16])$

159: $h[16]=e n t h a l p y($ water; $P=P[16] ; X=0)$

160: $P[13]=P[7]$

161: $\mathrm{h}[13]=e n t h a l p y($ water; $\mathrm{T}=\mathrm{T}[13] ; \mathrm{P}=\mathrm{P}[13]) \quad$ "T[13] é um set point, deve ser fixado para controlar vazão de vapor de extração"

162: m_dot_agua*h[7]-m_dot_agua*h[13]+m_dot_vap.h $\times 3 *(h[15]-h[16])=0$

"Balanço de energia no $h \times 3^{\prime \prime}$

163: m_bar_vap.hx3=m_dot_vap.hx3/1000 [ton/h]

164:

165:

166: "Otimização dos trocadores de calor"

167: "Cálculo da temperatura de saída de cada trocador de calor"

168:

169: $\mathrm{T}[13]=\mathrm{T}[7]+$ DeltaT_opt

trocador de calor a ser otimizado"

"DeltaT_opt é o incremento ótimo de temperatura em cada

170: $\mathrm{T}[14]=\mathrm{T}[13]+$ DeltaT_opt

171: $\mathrm{T}[10]=\mathrm{T}[14]+$ DeltaT_opt

172:

173: "Cálculo dos pontos ótimos de extração na turbina"

174: TTD= 3,5 [C]

175: TTD=T_sat_hx3 - T[13]

176: TTD=T_sat_hx2 - T[14]

177: TTD=T_sat_hx1 - T[10]

178:

179: $P[8]=P \_S A T($ water;T=T_sat_hx1)

180: $P[11]=P$ SAT (water;T=T_sat_hx2)

181: $P[15]=P \_S A T($ water; $T=T$ _sat_hx3)

182:

183:

184: "CONDENSADOR"

185:

186: Q_dot_out $=$ m_dot_vap.cauda $*(h[3]-h[4])$

vapor para a torre de resfriamento"

"Diferença de Temperatura Terminal, parâmetro de entrada"

$187:$

188:

189: "TORRE DE RESFRIAMENTO"

190:

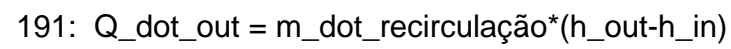

192: $h \_o u t=e n t h a l p y\left(\right.$ water; $\left.P=P \_o u t ; T=T \_o u t\right): h \_i n=e n t h a l p y\left(\right.$ water; $\left.P=P \_i n ; T=T \_i n\right): P \_i n=1: P \_o u t=1:$

193: m_dot_repos.torre $=$ Y_perdas*m_dot_recirculação "Y_perdas corresponde a uma estimativa de perdas de água por evaporação, purga e arraste na torre de resfriamento"

194: m_dot_rep.total=m_dot_repos.torre+m_dot_rep.desaerador+m_agua.dessuper

195: m_bar_repos.torre=m_dot_repos.torre/1000 [ton $/ \mathrm{h}]$

196: m_bar_rep.total=m_dot_rep.total/1000 [ton/h]

197: m_bar_vap.dessuper=m_dot_vap.dessuper/1000 [ton/h]

198: Perc.torre $=m \_d o t \_r e p o s . t o r r e / m \_d o t \_r e p . t o t a l * 100$

199: Perc.desaerador $=m \_$dot_rep.desaerador $/ m$ _dot_rep.total ${ }^{\star} 100$ 
200: Perc.dessuper=m_dot_vap.dessuper/m_dot_rep.total ${ }^{\star} 100$

201: Tap.water_torre $=$ m_dot_repos.torre $/($ m_dot_cana/1000)

202: Tap.water_deionised $=\left(\mathbf{m} \_\right.$dot_rep.desaerador + m_agua.dessuper $) /($m_dot_cana/1000)

203:

204:

205: "CÁLCULO DAS POTÊNCIAS ELÉTRICAS"

206: "Potência elétrica gerada"

207:

208: POT_elétr.gerada=(POT_1+POT_2 + POT_3+POT_4+POT_5)*eta_g*convert(kJ/h;MW) elétrica total gerada no turbogerador"

209: POT_1=m_dot_vap.escape*(h[1]-h[2])

210: POT_2=m_dot_vap.cauda ${ }^{\star}(\mathrm{h}[1]-\mathrm{h}[3])$

"Potencia gerada pelo vapor de escape a $P=2,5 b a r "$

211: POT_3=m_dot_vap.hx1*(h[1]-h[8]) turbina direcionado a trocador $h \times 1^{\prime \prime}$

212: POT_4=m_dot_vap.hx2*(h[1]-h[11]) turbina direcionado a trocador $h \times 2^{\prime \prime}$

213: POT_5=m_dot_vap.hx3*(h[1]-h[15]) turbina direcionado a trocador $h \times 3^{\prime \prime}$

"Potencia gerada pelo vapor da cauda"

"Potencia gerada pelo vapor extraído no primeiro estágio da

"Potencia gerada pelo vapor de extraído no segundo estágio da 214:

215: "Consumo das bombas do ciclo"

216:

217: POT_elétr.consumida=(POT_B1+POT_B2) ${ }^{\star}$ convert(kJ/h;MW)

"Potência consumida pelas bombas"

218: POT_B1=m_dot_vap.cauda*(h[5]-h[4])

219: POT_B2=m_dot_agua* $(\mathrm{h}[7]-\mathrm{h}[6])$

"Potencia gerada pelo vapor de extraído no terceiro estágio da

220:

221: "EFICIÊNCIA GLOBAL DA UNIDADE DE COGERAÇÃO COM REGENERAÇÃO"

222: "Cálculo da eficiência energética"

223:

224: eta_Energética.Global=(POT_elétr.líquida + POT_processo)/POT_entrada*100

225:

226: "Potência líquida gerada na unidade de cogeração"

227:

228: POT_elétr.líquida $=$ POT_elétr.gerada - POT_elétr.consumida

229:

230: "Potência utilizada no processo industrial e desaerador"

231:

232: POT_processo=m_dot_vap.processo ${ }^{\star}\left(\mathrm{h} \_p r o-h \_s a t\right){ }^{*} \operatorname{convert}(\mathrm{kJ} / \mathrm{h} ; \mathrm{MW})$

233: POT_desaerador $=m$ _dot_vap.desaerador* $(\mathrm{h}[2]-\mathrm{h}[6])^{*} \operatorname{convert}(\mathrm{kJ} / \mathrm{h} ; \mathrm{MW})$

234: POT_desaerador.perc=POT_desaerador/POT_entrada*100

235: POT_processo.perc=POT_processo/POT_entrada*100

236: h_sat=enthalpy $($ water; $x=0 ; p=2,5)$

237:

238:

239: "Alimentação energética na fornalha da caldeira"

240:

241: POT_entrada=(m_dot_bagaço*PCI_bagaço+m_dot_palha*PCI_palha $)^{\star}$ convert(kJ/h;MW)

242:

243:

244:

245: "APLICAÇÃO DA 2A LEI DA TERMODINÂMICA - ANÁLISE EXERGÉTICA"

246: "Ambiente de referência considerado: $P o=1$ bar e $T o=25 C^{\prime \prime}$

247: $\mathrm{T0}=25[\mathrm{C}]$

248: $\mathrm{P} 0=1[\mathrm{Bar}]$

249: P00_h20=0,0303 [Bar]

250:

251: "LIMITE TEÓRICO DE EFICIÊNCIA - CICLO DE CARNOT"

252: eta_Carnot $=(1-(\mathrm{T}[3]+273,15) /(\mathrm{T}[1]+273,15))^{\star} 100 \quad$ "Trabalho máximo que pode ser obtido"

253: 
254: "Trabalho útil final - saída do gerador"

255: EXERGY.in_fuel=POT_entrada

256: EXERGY.out_electricity=POT_elétr.líquida

"energia

elétrica é exergia pura"

257: EXERGY.out_electricity.perc=POT_elétr.líquida/POT_entrada*100

258:

259: "BOILER"

260: B_1=m_dot_vapor* $\left(\mathrm{h}[1]-\mathrm{h}[0]-(\mathrm{T} 0+273,15)^{\star}(\mathrm{s}[1]-\mathrm{s}[0])\right)^{\star} \operatorname{convert}(\mathrm{kJ} / \mathrm{h} ; \mathrm{MW})$

"Exergia do vapor de saída do gerador de vapor"

261: $\mathrm{h}[0]=$ enthalpy (water;t=T0;P=P0)

262: $s[0]=e n t r o p y($ water; $t=T 0 ; P=P 0)$

263: B_fuel=EXERGY.in_fuel

264:

265: "TURBINE"

266: "Exergia das correntes de vapor de escape e cauda"

267:

268: B_2=m_dot_vap.escape* $\left(\mathrm{h}[2]-\mathrm{h}[0]-(\mathrm{T} 0+273,15){ }^{\star}(\mathrm{s}[2]-\mathrm{s}[0])\right)^{\star} \operatorname{convert}(\mathrm{kJ} / \mathrm{h} ; \mathrm{MW})$

"Exergia do vapor de escape"

269: B_3=m_dot_vap.cauda* $\left(\mathrm{h}[3]-\mathrm{h}[0]-(\mathrm{T} 0+273,15)^{\star}(\mathrm{s}[3]-\mathrm{s}[0])\right)^{\star} \operatorname{convert}(\mathrm{kJ} / \mathrm{h} ; \mathrm{MW})$

"Exergia do

270:

271: "Exergia das correntes de regeneração para os trocadores $h \times 1$, $h \times 2$ e $h \times 3 "$

272:

273: B_8=m_dot_vap.hx1*(h[8]-h[0]-(T0+273,15)*(s[8]-s[0]))*convert(kJ/h;MW)

"Exergia do vapor da primeira extração da turbina"

274: B_11=m_dot_vap.hx2*(h[11]-h[0]-(T0+273,15)*(s[11]-s[0]))*convert(kJ/h;MW)

"Exergia do vapor da segunda extração da turbina"

275: B_15=m_dot_vap.hx3*(h[15]-h[0]-(T0+273,15)*(s[15]-s[0]))*convert(kJ/h;MW)

"Exergia do

276:

277: "Balanço de exergia na turbina"

278:

279: Bdest_turbine=B_1 - (B_2+B_3+B_8+B_11+B_15+POT_elétr.gerada/eta_g)

"Exergia

destruída na turbina"

280: Bdest_turbine.perc=Bdest_turbine/B_fuel*100

"Percentual

de exergia destruída na turbina"

281: B_2_perc=B_2/B_fuel*100

"Percentual

de exergia no vapor de escape"

282: B_liq=POT_elétr.gerada/B_fuel`100

"Percentual

283:

284: "Consumo de exergia no processo industrial associado ao consumo específico de vapor"

285:

286: EXERGY.out_process=m_dot_vap.processo*(h_pro-h[0]-(T0+273,15)*(s_pro-s[0]))*convert(kJ/h;MW)

287: s_pro = entropy $($ water; $p=2,5 ; t=127,5)$

288: EXERGY.out_process.perc=EXERGY.out_process/B_fuel*100

289: EXERGY.out_deaerator=B_2-EXERGY.out_process

290: EXERGY.out_deaerator.perc=EXERGY.out_deaerator/B_fuel ${ }^{\star} 100$

291:

292: "DESSUPERAQUECEDOR"

293: "Balanço de entropia no dessuper"

294:

295: S_ger.dessuper=m_dot_vap.processo*s_pro - (m_agua.dessupers_agua + (m_dot_vap.dessuper-m_dot_purgador)*s[2])

296: s_agua = entropy $($ water $; \mathrm{p}=2,5 ; \mathrm{t}=25)$

297: Bdest_dessuper $=(\mathrm{T0}+273,15) \star S \_g e r . d e s s u p e r * \operatorname{convert}(\mathrm{kJ} / \mathrm{h} ; \mathrm{MW})$

"Exergia destruída no dessuperaquecedor"

298: Bdest_dessuper.perc=Bdest_dessuper/B_fuel*100

"Percentual de exergia destruída no dessuperaquecedor" 299: 
EES Ver. 9.433: \#0624: Depart. de Engenharia Mecanica Escola Politecnic, Escola Politecnica da USP, Sao Paulo, Brazil

300: "CONDENSADOR"

301:

302: B_4=m_dot_vap.cauda*(h[4]-h[0]-(T0+273,15)*(s[4]-s[0]))*convert(kJ/h;MW)

"Exergia na

saída do condensador"

303: Bdest_condenser=B_3-B_4

"Exergia

destruída no condensador"

304: Bdest_condenser.perc=Bdest_condenser/B_fuel ${ }^{\star 100 \quad ~ " P e r c e n t u a l ~ d e ~ e x e r g i a ~ d e s t r u i ́ d a ~ n o ~ c o n d e n s a d o r " ~}$

305:

306: "BOMBA 1"

307:

308: B_5=m_dot_vap.cauda*(h[5]-h[0]-(T0+273,15)*(s[5]-s[0])**convert(kJ/h;MW) saída da bomba 1"

309: Bdest_B1=B_4-B_5 +W_B1

"Exergia na

destruída na bomba 1"

310: W_B1=m_dot_vap.cauda*(h[5]-h[4])*convert(kJ/h;MW)

"Exergia

realizado pela bomba $B 1^{\prime \prime}$

311: Bdest_B1.perc=Bdest_B1/B_fuel ${ }^{\star 100}$

"Trabalho

de exergia destruída na bomba 1"

312:

313: "DESAERADOR"

314: "Balanço de entropia no dessuperaquecedor"

315:

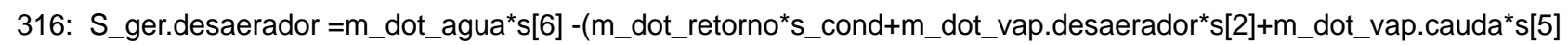

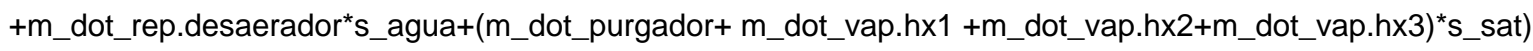

317: s_cond=entropy(water;T=T_cond;P=P_cond): s_sat=entropy(water; $P=2,5 ; x=0$ )

318: Bdest_desaerador $=(\mathrm{T} 0+273,15) \star S \_g e r . d e s a e r a d o r * c o n v e r t(\mathrm{~kJ} / \mathrm{h} ; \mathrm{MW})$

"Exergia

destruída no desaerador"

319: Bdest_desaerador.perc=Bdest_desaerador/B_fuel ${ }^{\star} 100$

"Percentual

de exergia destruída no desaerador"

320:

321: "BOMBA 2"

322:

323: B_7=m_dot_agua*(h[7]-h[0]-(T0+273,15)*(s[7]-s[0]) ${ }^{\star}$ convert(kJ/h;MW) saída da bomba $2^{\prime \prime}$

324: B_6=m_dot_agua* $(\mathrm{h}[6]-\mathrm{h}[0]-(\mathrm{T} 0+273,15) *(\mathrm{~s}[6]-\mathrm{s}[0]))^{\star}$ convert $(\mathrm{kJ} / \mathrm{h} ; \mathrm{MW})$ entrada da bomba $2^{\prime \prime}$

325: W_B2=m_dot_agua ${ }^{\star}(\mathrm{h}[7]-\mathrm{h}[6])^{\star} \operatorname{convert}(\mathrm{kJ} / \mathrm{h} ; \mathrm{MW})$ realizado pela bomba $B 2$ "

326: Bdest_B2=B_7-B_6 +W_B2 destruída na bomba $2 "$

327: Bdest_B2.perc=Bdest_B2/B_fuel ${ }^{\star} 100$

"Percentual de exergia destruída na bomba $2 "$

328:

329: "BOILER"

330:

331: B_10 + B_fuel = B_1+B_purga+Bdest_boiler

"Balanço de exergia na caldeira"

332: Bdest_boiler.perc=Bdest_boiler/B_fuel ${ }^{\star} 100$

"Percentual de exergia destruída na caldeira"

333: B_10=m_dot_agua* $\left(\mathrm{h}[10]-\mathrm{h}[0]-(\mathrm{T0}+273,15)^{\star}(\mathrm{s}[10]-\mathrm{s}[0])\right)^{\star} \operatorname{convert}(\mathrm{kJ} / \mathrm{h} ; \mathrm{MW})$

"Exergia na

"Exergia na

"Trabalho

"Exergia

"Percentual corrente de agua na entrada da caldeira"

334: B_purga=m_dot_purga*(h_purga-h[0]-(T0+273,15)*(s_purga-s[0]) $)^{\star}$ convert $(\mathrm{kJ} / \mathrm{h} ; \mathrm{MW})$

335: s_purga=entropy(water; $\left.h=h \_p u r g a ; T=T \_p u r g a\right): s[10]=e n t r o p y($ water; $T=T[10] ; P=P[10])$

336:

337:

338: "TROCADOR DE CALOR TC 1"

339: "Balanço de exergia no TC1"

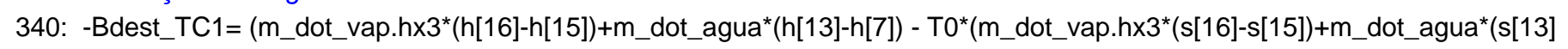
-s[7])))*convert(kJ/h;MW) 
341: $s[16]=e n t r o p y($ water; $p=p[16] ; x=0): s[13]=e n t r o p y($ water; $p=p[13] ; T=T[13])$

342: Bdest_TC1.perc=Bdest_TC1/B_fuel ${ }^{\star} 100$

"Percentual

de exergia destruída no TC1"

343:

344: "TROCADOR DE CALOR TC 2"

345: "Balanço de exergia no TC2"

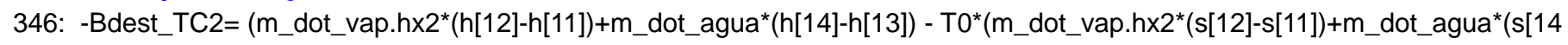
]-s[13])))*convert(kJ/h;MW)

347: $s[12]=e n t r o p y($ water; $p=p[12] ; x=0): s[14]=e n t r o p y($ water; $p=p[14] ; T=T[14])$

348: Bdest_TC2.perc $=$ Bdest_TC2/B_fuel ${ }^{\star} 100$

de exergia destruída no TC2"

349:

350: "TROCADOR DE CALOR TC 3"

351: "Balanço de exergia no TC3"

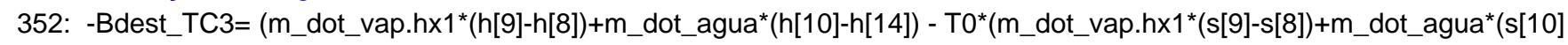
$-\mathrm{s}[14])))^{\star}$ convert(kJ/h;MW)

353: $s[9]=e n t r o p y($ water; $p=p[9] ; x=0)$ :

354: Bdest_TC3.perc=Bdest_TC3/B_fuel ${ }^{\star} 100$

"Percentual

355:

356: Total_exergy.dest=Bdest_B1+Bdest_B2+Bdest_desaerador+Bdest_condenser+Bdest_boiler+Bdest_turbine+Bdest_TC1 +Bdest_TC2+Bdest_TC3

357: Total_exergy.dest.perc=Total_exergy.dest/B_fuel ${ }^{\star} 100$

358:

359:

360: "Eficiência Exergética"

361: "Cálculo da eficiência exergética global"

362:

363: eta_EXergética.Global=(POT_elétr.líquida + EXERGY.out_process)/B_fuel¹00

364:

365: eta_Ex.ref.Carnot=eta_EXergética.Global/eta_Carnot*100

366:

367:

368: "Distribuição de exergia entre vapor e eletricidade"

369:

370: Exergia_vapor.perc $=$ EXERGY.out_process/(POT_elétr.líquida + EXERGY.out_process)*100

371:

372: Exergia_eletricidade.perc $=$ POT_elétr.líquida/(POT_elétr.líquida + EXERGY.out_process)*100

373:

374:

375:

376: "ALOCAÇÃO"

377:

378: "Critério energético"

379: POT_específica_processo = POT_processo*Período_safra*1000*24/Cana_safra

380: Alocação_energia_vapor = POT_específica_processo/(POT_específica_processo+GeraçãoEletric.Espec.Excedente +ConsumoEletr.Processo $)^{\star} 100$

381: Alocação_energia_eletr.exp = GeraçãoEletric.Espec.Excedente/(POT_específica_processo + GeraçãoEletric.Espec.Excedente+ConsumoEletr.Processo $)^{\star} 100$

382: Alocação_energia_eletr.proc = ConsumoEletr.Processo/(POT_específica_processo+GeraçãoEletric.Espec.Excedente +ConsumoEletr.Processo ${ }^{\star} 100$

383:

384:

385: "Critério exergético"

386: EXERGY.out_específica_process = EXERGY.out_process*Período_safra*1000*24/Cana_safra

387: Alocação_exergia_vapor = EXERGY.out_específica_process/(EXERGY.out_específica_process +GeraçãoEletric.Espec.Excedente+ConsumoEletr.Processo)*100

388: Alocação_exergia_eletr.exp = GeraçãoEletric.Espec.Excedente/(EXERGY.out_específica_process + GeraçãoEletric.Espec.Excedente+ConsumoEletr.Processo ${ }^{\star} 100$ 
389: Alocação_exergia_eletr.proc = ConsumoEletr.Processo/(EXERGY.out_específica_process 390:

+GeraçãoEletric.Espec.Excedente+ConsumoEletr.Processo)*100

391:

392:

393:

394:

395:

396:

397:

398: "ANÁLISE ENERGÉTICA DE 1A LEI - PERDAS ENERGÉTICAS"

399: "Perdas na Caldeira e turbina"

400:

401: Boiler_losses=POT_entrada*(1-eta_c)

402: Boiler_losses.perc=Boiler_losses/POT_entrada ${ }^{100}$

403: Turbine_losses=(POT_1+POT_2 + POT_3+POT_4+POT_5 $)^{\star}(1-\text { eta_t })^{\star}$ convert(kJ/h;MW)

404: Turbine_losses.perc $=$ Turbine_losses/POT_entrada*100

405:

406: "Perdas no condensador"

407:

408: POT_condensador $=$ Q_dot_out ${ }^{*}$ convert $(\mathrm{kJ} / \mathrm{h} ; \mathrm{MW})$

perdida no condensador"

"Energia

409: POT_condensador.perc=POT_condensador/POT_entrada*100

410: Condenser_losses=POT_condensador

411:

412: "Perdas no processo"

413:

414: process_losses = POT_entrada - (POT_processo+POT_elétr.gerada+POT_condensador+Turbine_losses+Boiler_losses)

415: process_losses.perc=process_losses/POT_entrada ${ }^{*} 100$

416:

417: "Cálculo da energia elétrica gerada por tonela de cana por tonelada de cana"

418:

419: GeraçãoEletric.Espec. Total =POT_elétr.líquida*Período_safra*1000*24/Cana_safra

420: GeraçãoEletric.Espec.Excedente = GeraçãoEletric. Espec. Total - ConsumoEletr.Processo

421:

422:

423: "Distribuição de energia entre vapor e eletricidade"

424:

425: Energia_vapor.perc $=$ POT_processo/(POT_processo + POT_elétr.líquida $)^{\star} 100$

426:

427: Energia_eletricidade.perc $=$ POT_elétr.líquida/(POT_processo + POT_elétr.líquida ${ }^{\star} 100$

APÊNDICE C - MODELAGEM TERMODINÂMICA DO SISTEMA DE COGERAÇÃO COM CICLO RANKINE REGENERATIVO

Dados da Safra

$\dot{\mathrm{M}}_{\text {cana }}=\frac{\text { Cana }_{\text {safra }}}{\text { Período }_{\text {safra }}} \cdot \frac{1000}{24[\mathrm{~kg} / \mathrm{h}]}$ Taxa de Moagem de cana

$\dot{\mathrm{m}}_{\text {bagaço }}=\frac{\mathrm{Y}_{\text {bagaço }}}{100} \cdot \dot{\mathrm{M}}_{\text {cana }} \cdot \frac{\text { Utilização }_{\text {Bagaço }}}{100}$ Alimentação de bagaço de cana

$\dot{\mathrm{m}}_{\text {palha }}=\frac{\mathrm{Y}_{\text {palha }}}{100} \cdot \dot{\mathrm{M}}_{\text {cana }} \cdot \frac{\text { Utilização }_{\text {Palha }}}{100}$ Alimentação de palha de cana

Razão ${ }_{\text {biomaror }}^{\text {vass }} \frac{\dot{\mathrm{m}}_{\text {vapor }}^{\circ}}{\dot{\mathrm{m}}_{\text {bagaço }}}$ Razão entre produção de vapor e consumo de biomassa 
EES Ver. 9.433: \#0624: Depart. de Engenharia Mecanica Escola Politecnic, Escola Politecnica da USP, Sao Paulo, Brazil

$\overline{\mathrm{m}}_{\text {bagaço }}=\frac{\dot{\mathrm{m}}_{\text {bagaço }}}{1000[\text { ton } / \mathrm{h}]}$

$\overline{\mathrm{m}}_{\text {palha }}=\frac{\dot{\mathrm{m}}_{\text {palha }}}{1000[\text { ton } / \mathrm{h}]}$

GERADOR DE VAPOR - Modelagem de conservação de matéria e energia

Balanço de massa

$\dot{\mathrm{m}}_{\text {agua }}=\dot{\mathrm{m}}_{\text {vapor }}+\dot{\mathrm{m}}_{\text {purga }}$

$\dot{\mathrm{m}}_{\text {purga }}=\mathrm{Y}_{\text {purga }} \cdot \dot{\mathrm{m}}_{\text {vapor }}$

$\mathrm{Y}_{\text {purga }}=0,03$ Taxa de purga

$\overline{\mathrm{M}}_{\text {vapor }}=\frac{\dot{\mathrm{m}}_{\text {vapor }}}{1000 \text { [ton/h] }}$ Conversão da vazão mássica de vapor de $\mathrm{Kg} / \mathrm{h}$ para ton $/ \mathrm{h}$

Balanço de energia

$\dot{\mathrm{m}}_{\text {agua }} \cdot \mathrm{h}_{10}=\dot{\mathrm{m}}_{\text {vapor }} \cdot \mathrm{h}_{1}+\dot{\mathrm{m}}_{\text {purga }} \cdot \mathrm{h}_{\text {purga }}-\dot{\mathrm{Q}}_{\mathrm{c}}$

$\dot{\mathrm{Q}}_{\mathrm{c}}=\left[\dot{\mathrm{m}}_{\text {bagaço }} \cdot \mathrm{PCl}_{\text {bagaço }}+\dot{\mathrm{m}}_{\text {palha }} \cdot \mathrm{PCl}_{\text {palha }}\right] \cdot \eta_{\mathrm{c}}$ Energia utilizada na fornecida na fornalha para evaporação da água

$\mathrm{h}_{1}=\mathbf{h}\left[\right.$ water $\left.; \mathrm{T}=\mathrm{T}_{1} ; \mathrm{P}=\mathrm{P}_{1}\right] \quad \mathrm{h}_{\text {purga }}=\mathbf{h}\left[\right.$ water $\left.; \mathrm{T}=\mathrm{T}_{\text {purga }} ; \mathrm{x}=0\right]$

$\mathrm{P}_{7}=1,2 \cdot \mathrm{P}_{\mathrm{c}} \quad \mathrm{T}_{\text {purga }}=\mathrm{T}_{\text {sat }}\left[\right.$ water $\left.; \mathrm{P}=\mathrm{P}_{\mathrm{c}}\right] \quad \mathrm{P}_{\text {purga }}=\mathrm{P}_{\mathrm{c}} \quad \mathrm{P}_{1}=\mathrm{P}_{\mathrm{c}}$

$\mathrm{PCl}_{\text {bagaço }}=7565 \quad \mathrm{PCl}_{\text {palha }}=12960[\mathrm{~kJ} / \mathrm{kg}]$ Poder calorífico inferior do bagaço e da palha de cana

$\mathrm{T}_{1}=\mathbf{T}_{\text {sat }}\left[\right.$ water $\left.; \mathrm{P}=\mathrm{P}_{\mathrm{c}}\right]+\mathrm{G}_{\text {super }}$ Temperatura do vapor superaquecido

$\mathrm{G}_{\text {super }}=200 \quad[\mathrm{C}]$ Grau de superaqucimento

BOMBA 02 - ALIMENTAÇÃO DA CALDEIRA

$\mathrm{P}_{6}=\mathrm{P}_{2}$ Pressão de descarga da bomba igual a pressão do vapor de escape

$\eta_{\mathrm{B} 2}=\frac{\mathrm{h}_{6}-\mathrm{h} 7_{\text {iso }}}{\mathrm{h}_{6}-\mathrm{h}_{7}}$ Determinação da entalpia real da vazão de líquido na descarga da bomba

$\mathrm{h} 7_{\text {iso }}=\mathbf{h}\left[\right.$ water $\left.; \mathrm{s}=\mathrm{s}_{6} ; \mathrm{P}=\mathrm{P}_{7}\right]$ Entalpia para condição ideal isentrópica

$\mathrm{h}_{6}=\mathbf{h}\left[\right.$ water $\left.; \mathrm{P}=\mathrm{P}_{6} ; \mathrm{T}=\mathrm{T}_{6}\right]$ Entalpia na saída do desaerador

$\mathrm{S}_{6}=\mathbf{s}\left[\right.$ water $\left.; \mathrm{P}=\mathrm{P}_{6} ; \mathrm{T}=\mathrm{T}_{6}\right]$ Entropia na saída do desaerador é entropia do líquido saturado

$\mathrm{T}_{7}=\mathbf{T}\left[\right.$ water $\left.; \mathrm{h}=\mathrm{h}_{7} ; \mathrm{P}=\mathrm{P}_{7}\right]$ Temperatura de recalque

$\mathrm{s}_{7}=\mathbf{s}\left[\right.$ water $\left.; \mathrm{h}=\mathrm{h}_{7} ; \mathrm{P}=\mathrm{P}_{7}\right]$ Entropia da água de alimentação da caldeira

BOMBA 01 - CONDENSADO

$\mathrm{P}_{5}=\mathrm{P}_{2}$ Pressão de descarga da bomba igual a pressão do vapor de escape

$\eta_{\mathrm{B} 1}=\frac{\mathrm{h}_{4}-\mathrm{h}_{\text {iso }}}{\mathrm{h}_{4}-\mathrm{h}_{5}}$ Determinação da entalpia real do líquido na descarga da bomba

$\mathrm{h}_{\text {iso }}=\mathbf{h}\left[\right.$ water $\left.; \mathrm{s}=\mathrm{s}_{4} ; \mathrm{P}=\mathrm{P}_{5}\right]$ Entalpia para condição ideal isentrópica 
$\mathrm{s}_{4}=\mathbf{s}\left[\right.$ water $\left.; \mathrm{P}=\mathrm{P}_{4} ; \mathrm{x}=0\right]$ Entropia na saída do condensador - líquido saturado

$\mathrm{T}_{5}=\mathbf{T}\left[\right.$ water $\left.; \mathrm{h}=\mathrm{h}_{5} ; \mathrm{P}=\mathrm{P}_{5}\right]$ Temperatura de recalque para desaerador

$\mathrm{h}_{4}=\mathbf{h}\left[\right.$ water $\left.; \mathrm{P}=\mathrm{P}_{4} ; \mathrm{x}=0\right]$ Entalpia da saída do condensador é a entalpia de líquido saturado

$\mathrm{T}_{4}=\mathrm{T}_{3}$ Temperatura de Entrada = temperatura de saída --> Somente troca calor latente

$\mathrm{P}_{4}=\mathrm{P}_{3}$ Pressão de sucção da bomba = pressão da cauda da turbina

$\mathrm{S}_{5}=\mathbf{s}\left[\right.$ water $\left.; \mathrm{P}=\mathrm{P}_{5} ; \mathrm{T}=\mathrm{T}_{5}\right]$ Entropia da água de recalque da bomba 01

\section{TURBINA}

Rendimento da turbina

$\eta_{\mathrm{t}}=\frac{\mathrm{h}_{1}-\mathrm{h}_{2}}{\mathrm{~h}_{1}-\mathrm{h} 2 \text { iso }}$ Determinação da entalpia real do vapor extraído para o desaerador através da eficiencia isoentrópica $\eta_{\mathrm{t}}=\frac{\mathrm{h}_{1}-\mathrm{h}_{3}}{\mathrm{~h}_{1}-\mathrm{h} 3_{\text {iso }}}$ Determinação da entalpia real do vapor extraído para o desaerador através da eficiencia isoentrópica $\eta_{\mathrm{t}}=\frac{\mathrm{h}_{1}-\mathrm{h}_{8}}{\mathrm{~h}_{1}-\mathrm{h} 8_{\text {iso }}}$ Determinação da entalpia real do vapor extraído através da eficiencia isoentrópica $\eta_{\mathrm{t}}=\frac{\mathrm{h}_{1}-\mathrm{h}_{11}}{\mathrm{~h}_{1}-\mathrm{h} 11_{\text {iso }}}$ Determinação da entalpia real do vapor extraído através da eficiencia isoentrópica $\eta_{\mathrm{t}}=\frac{\mathrm{h}_{1}-\mathrm{h}_{15}}{\mathrm{~h}_{1}-\mathrm{h} 15_{\text {iso }}}$ Determinação da entalpia real do vapor extraído através da eficiencia isoentrópica

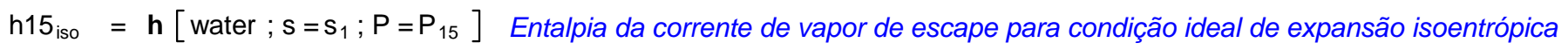
$\mathrm{h} 11_{\text {iso }}=\mathbf{h}\left[\right.$ water $\left.; \mathrm{s}=\mathrm{s}_{1} ; \mathrm{P}=\mathrm{P}_{11}\right]$ Entalpia da corrente de vapor de escape para condição ideal de expansão isoentrópica $\mathrm{h} 2_{\text {iso }}=\mathbf{h}\left[\right.$ water $\left.; \mathrm{s}=\mathrm{s}_{1} ; \mathrm{P}=\mathrm{P}_{2}\right]$ Entalpia da corrente de vapor de escape para condição ideal de expansão isoentrópica $\mathrm{h} 3_{\text {iso }}=\mathbf{h}\left[\right.$ water $\left.; \mathrm{s}=\mathrm{s}_{1} ; \mathrm{P}=\mathrm{P}_{3}\right]$ Entalpia da corrente de vapor na cauda para condição ideal de expansão isoentrópica h8 ${ }_{\text {iso }}=\mathbf{h}\left[\right.$ water $\left.; \mathrm{s}=\mathrm{s}_{1} ; \mathrm{P}=\mathrm{P}_{8}\right]$ Entalpia da corrente de vapor extraído na condição ideal de expansão isoentrópica $\mathrm{T}_{2}=\mathbf{T}\left[\right.$ water $\left.; \mathrm{h}=\mathrm{h}_{2} ; \mathrm{P}=\mathrm{P}_{2}\right]$ Temperatura do vapor de escape

$\mathrm{T}_{3}=\mathbf{T}\left[\right.$ water $\left.; \mathrm{h}=\mathrm{h}_{3} ; \mathrm{P}=\mathrm{P}_{3}\right]$ Temperatura do vapor de cauda

$\mathrm{T}_{8}=\mathbf{T}\left[\right.$ water $\left.; \mathrm{h}=\mathrm{h}_{8} ; \mathrm{P}=\mathrm{P}_{8}\right]$ Temperatura do vapor extraído

$\mathrm{T}_{11}=\mathbf{T}\left[\right.$ water $\left.; \mathrm{h}=\mathrm{h}_{11} ; \mathrm{P}=\mathrm{P}_{11}\right]$ Temperatura do vapor extraído

$\mathrm{T}_{15}=\mathbf{T}\left[\right.$ water $\left.; \mathrm{h}=\mathrm{h}_{15} ; \mathrm{P}=\mathrm{P}_{15}\right]$ Temperatura do vapor extraído

$\mathrm{s}_{1}=\mathbf{s}\left[\right.$ water $\left.; \mathrm{P}=\mathrm{P}_{1} ; \mathrm{T}=\mathrm{T}_{1}\right]$ Estado definido por 2 propriedades independentes

$\mathrm{s}_{2}=\mathbf{s}\left[\right.$ water $\left.; \mathrm{h}=\mathrm{h}_{2} ; \mathrm{T}=\mathrm{T}_{2}\right]$ Entropia do vapor de escape

$\mathrm{s}_{3}=\mathbf{s}\left[\right.$ water $\left.; \mathrm{h}=\mathrm{h}_{3} ; \mathrm{T}=\mathrm{T}_{3}\right] \quad$ Entropia do vapor de cauda

$\mathrm{s}_{8}=\mathbf{s}\left[\right.$ water $\left.; \mathrm{h}=\mathrm{h}_{8} ; \mathrm{T}=\mathrm{T}_{8}\right]$ Entropia do vapor extraído 
EES Ver. 9.433: \#0624: Depart. de Engenharia Mecanica Escola Politecnic, Escola Politecnica da USP, Sao Paulo, Brazil

$\mathrm{s}_{11}=\mathbf{s}\left[\right.$ water $\left.; \mathrm{h}=\mathrm{h}_{11} ; \mathrm{T}=\mathrm{T}_{11}\right]$ Entropia do vapor extraído

$\mathrm{s}_{15}=\mathbf{s}\left[\right.$ water $\left.; \mathrm{h}=\mathrm{h}_{15} ; \mathrm{T}=\mathrm{T}_{15}\right]$ Entropia do vapor extraído

$\mathrm{x}_{2}=\mathbf{x}\left[\right.$ water $\left.; \mathrm{h}=\mathrm{h}_{2} ; \mathrm{T}=\mathrm{T}_{2}\right]$ Título do vapor de escape

$\mathrm{x}_{3}=\mathbf{x}\left[\right.$ water $\left.; \mathrm{h}=\mathrm{h}_{3} ; \mathrm{T}=\mathrm{T}_{3}\right]$ Título do vapor na cauda da turbina

Balanço de massa na turbina

$\dot{\mathrm{m}}_{\text {vapor }}=\dot{\mathrm{m}}_{\text {vap.escape }}+\dot{\mathrm{m}}_{\text {vap.cauda }}+\dot{\mathrm{m}}_{\text {vap.hx1 }}+\dot{\mathrm{m}}_{\text {vap.hx2 }}+\dot{\mathrm{m}}_{\text {vap.hx3}}$

PURGA DE CONDENSADO ANTES DE SER USADO NO PROCESSO

\section{RETORNO DE CONDENSADO DO PROCESSO INDUSTRIAL}

$\dot{\mathrm{m}}_{\text {retorno }}=\dot{\mathrm{m}}_{\text {vap.processo }} \cdot 0,9$ Considerado perdas no processo de $10 \%$ da vazão de vapor

$\mathrm{T}_{\text {cond }}=90[\mathrm{C}]$ Considerado que todo condensado é coletado em um tanque de recuperação e retorna para o ciclo a $90 \mathrm{C}$

$\mathrm{P}_{\text {cond }}=\mathrm{P}_{2}$ Pressão de retorno $=$ pressão no desaerador $=$ Pressão do vapor de escape

$\mathrm{m}_{\text {agua.dessuper }} \quad=$ If $\left[\mathrm{x}_{2} ; 100 ; 0 ; \dot{\mathrm{m}}_{\text {agua.dessuper }} ; 0\right]$ Se o vapor de escape tiver $\mathrm{x}<1$ o condensado precisa ser retirado em purgadores

$\dot{\mathrm{m}}_{\text {purgador }}=$ If $\left[\mathrm{x}_{2} ; 100 ;-\dot{\mathrm{m}}_{\text {agua.dessuper }} ; 0 ; 0\right]$ Se o vapor de escape tiver $\mathrm{x}<1$ o condensado precisa ser retirado em purgadores

\section{DESSUPERAQUECEDOR E VAPOR DE PROCESSO}

Balanços de massa

$\dot{\mathrm{m}}_{\text {vap.escape }}=\dot{\mathrm{m}}_{\text {vap.dessuper }}+\dot{\mathrm{m}}_{\text {vap.desaerador }}$

$\dot{\mathrm{m}}_{\text {vap.processo }}=$ Cons.Vapor processo $\cdot \dot{\mathrm{M}}_{\text {cana }} \cdot \frac{1}{1000}$ Consumo de vapor saturado para o processo a $P=2,5$ Bar

$\dot{\mathrm{m}}_{\text {vap.processo }}=\dot{\mathrm{m}}_{\text {vap.dessuper }}+\dot{\mathrm{m}}_{\text {agua.dessuper }}$

$\overline{\mathrm{m}}_{\text {agua.dessuper }}=\frac{\dot{\mathrm{m}}_{\text {agua.dessuper }}}{1000}$

Balanço de energia no dessuperaquecedor

$\dot{\mathrm{m}}_{\text {vap.processo }} \cdot \mathrm{h}_{\text {pro }}=\dot{\mathrm{m}}_{\text {vap.dessuper }} \cdot \mathrm{h}_{2}+\dot{\mathrm{m}}_{\text {agua.dessuper }} \cdot \mathrm{h}_{\text {rep.des }}$

$\mathrm{h}_{\text {pro }}=\mathbf{h}\left[\right.$ water $\left.; \mathrm{T}=\mathrm{T}_{\text {pro }} ; \mathrm{x}=1\right] \quad \mathrm{T}_{\text {pro }}=\mathbf{T}_{\text {sat }}[$ water $; \mathrm{P}=2,5]$ Processo industrial utiliza vapor saturado

DESAERADOR

Balanço de massa no desaerador

$\dot{\mathrm{m}}_{\text {retorno }}+\dot{\mathrm{m}}_{\text {vap.desaerador }}+\dot{\mathrm{m}}_{\text {vap.cauda }}+\dot{\mathrm{m}}_{\text {rep.desaerador }}+\dot{\mathrm{m}}_{\text {purgador }}+\dot{\mathrm{m}}_{\text {vap.hx1 }}+\dot{\mathrm{m}}_{\text {vap.hx2 }}+\dot{\mathrm{m}}_{\text {vap.hx3 }}=\dot{\mathrm{m}}_{\text {agua }}$

Balanço de energia no desaerador

$\dot{\mathrm{m}}_{\text {retorno }} \cdot \mathrm{h}_{\text {cond }}+\dot{\mathrm{m}}_{\text {vap.desaerador }} \cdot \mathrm{h}_{2}+\dot{\mathrm{m}}_{\text {vap.cauda }} \cdot \mathrm{h}_{5}+\dot{\mathrm{m}}_{\text {rep.desaerador }} \cdot \mathrm{h}_{\text {rep.des }}+\dot{\mathrm{m}}_{\text {purgador }} \cdot \mathrm{h}_{\text {purgador }}$ $+\dot{\mathrm{m}}_{\text {vap.hx1 }} \cdot \mathrm{h}_{9}+\dot{\mathrm{m}}_{\text {vap.hx2 }} \cdot \mathrm{h}_{12}+\dot{\mathrm{m}}_{\text {vap.hx3}} \cdot \mathrm{h}_{16}=\dot{\mathrm{m}}_{\text {agua }} \cdot \mathrm{h}_{6}$

$\mathrm{h}_{\text {cond }}=\mathbf{h}\left[\right.$ water $\left.; \mathrm{T}=\mathrm{T}_{\text {cond }} ; \mathrm{P}=\mathrm{P}_{\text {cond }}\right] \quad \mathrm{h}_{\text {purgador }}=\mathbf{h}\left[\right.$ water $\left.; \mathrm{P}=\mathrm{P}_{2} ; \mathrm{x}=0\right]$ 


$$
\mathrm{T}_{\mathrm{amb}}=25
$$

$\mathrm{P}_{\text {rep.des }}=\mathrm{P}_{2}$ Pressão no desaerador é a pressão de escape da turbina

Conversão de unidades de $\mathrm{Kg} / \mathrm{h}$ para ton/h

$$
\begin{aligned}
& \overline{\mathrm{m}}_{\text {vap.escape }}=\frac{\dot{\mathrm{m}}_{\text {vap.escape }}}{1000[\text { ton } / \mathrm{h}]} \\
& \overline{\mathrm{m}}_{\text {vap.cauda }}=\frac{\dot{\mathrm{m}}_{\text {vap.cauda }}}{1000[\text { ton } / \mathrm{h}]} \\
& \overline{\mathrm{m}}_{\text {vap.processo }}=\frac{\dot{\mathrm{m}}_{\text {vap.processo }}}{1000[\text { ton } / \mathrm{h}]} \\
& \overline{\mathrm{m}}_{\text {vap.desaerador }}=\frac{\dot{\mathrm{m}}_{\text {vap.desaerador }}}{1000[\text { ton } / \mathrm{h}]} \\
& \overline{\mathrm{m}}_{\text {rep.desaerador }}=\frac{\dot{\mathrm{m}}_{\text {rep.desaerador }}}{1000[\text { ton } / \mathrm{h}]} \\
& \overline{\mathrm{m}}_{\text {feed.water }}=\frac{\dot{\mathrm{m}}_{\text {agua }}}{1000[\text { ton } / \mathrm{h}]} \\
& \overline{\mathrm{m}}_{\text {purga. }}=\frac{\dot{\mathrm{m}}_{\text {purga }}}{1000[\text { ton } / \mathrm{h}]} \\
& \overline{\mathrm{m}}_{\text {purgador }}=\frac{\dot{\mathrm{m}}_{\text {purgador }}}{1000[\text { ton } / \mathrm{h}]}
\end{aligned}
$$

\section{TROCADOR $h \times 1$}

$P_{9}=P_{8}$

$\mathrm{T}_{9}=\mathbf{T}_{\text {sat }}\left[\right.$ water $\left.; \mathrm{P}=\mathrm{P}_{8}\right]$

$\mathrm{h}_{9}=\mathbf{h}\left[\right.$ water $\left.; \mathrm{P}=\mathrm{P}_{9} ; \mathrm{x}=0\right]$

$P_{10}=P_{7}$

$\mathrm{h}_{10}=\mathbf{h}\left[\right.$ water $\left.; \mathrm{T}=\mathrm{T}_{10} ; \mathrm{P}=\mathrm{P}_{10}\right]$

$\dot{\mathrm{m}}_{\text {agua }} \cdot \mathrm{h}_{14}+\dot{\mathrm{m}}_{\text {vap.hx1 }} \cdot \mathrm{h}_{8}=\dot{\mathrm{m}}_{\text {agua }} \cdot \mathrm{h}_{10}+\dot{\mathrm{m}}_{\text {vap.hx1}} \cdot \mathrm{h}_{9} \quad$ Balanço de energia no $h \times 1$

$\overline{\mathrm{m}}_{\text {vap.hx1 }}=\frac{\dot{\mathrm{m}}_{\text {vap.hx1 }}}{1000[\text { ton/h] }}$

TROCADOR $h \times 2$

$P_{12}=P_{11}$

$\mathrm{T}_{12}=\mathbf{T}_{\text {sat }}\left[\right.$ water $\left.; \mathrm{P}=\mathrm{P}_{12}\right]$

$\mathrm{h}_{12}=\mathbf{h}\left[\right.$ water $\left.; \mathrm{P}=\mathrm{P}_{12} ; \mathrm{x}=0\right]$

$P_{14}=P_{7}$

$\mathrm{h}_{14}=\mathbf{h}\left[\right.$ water $\left.; \mathrm{T}=\mathrm{T}_{14} ; \mathrm{P}=\mathrm{P}_{14}\right]$

$\dot{\mathrm{m}}_{\text {agua }} \cdot \mathrm{h}_{13}-\dot{\mathrm{m}}_{\text {agua }} \cdot \mathrm{h}_{14}+\dot{\mathrm{m}}_{\text {vap.hx2 }} \cdot\left[\mathrm{h}_{11}-\mathrm{h}_{12}\right]=0$ Balanço de energia no $h \times 2$ 
$\overline{\mathrm{m}}_{\text {vap.hx2 }}=\frac{\dot{\mathrm{m}}_{\text {vap.hx2 }}}{1000[\text { ton } / \mathrm{h}]}$

TROCADOR $h \times 3$

$P_{16}=P_{15}$

$\mathrm{T}_{16}=\mathbf{T}_{\text {sat }}\left[\right.$ water $\left.; \mathrm{P}=\mathrm{P}_{16}\right]$

$\mathrm{h}_{16}=\mathbf{h}\left[\right.$ water $\left.; \mathrm{P}=\mathrm{P}_{16} ; \mathrm{x}=0\right]$

$P_{13}=P_{7}$

$\mathrm{h}_{13}=\mathbf{h}\left[\right.$ water $\left.; \mathrm{T}=\mathrm{T}_{13} ; \mathrm{P}=\mathrm{P}_{13}\right] \quad T_{13}$ é um set point, deve ser fixado para controlar vazão de vapor de extração

$\dot{\mathrm{m}}_{\text {agua }} \cdot \mathrm{h}_{7}-\dot{\mathrm{m}}_{\text {agua }} \cdot \mathrm{h}_{13}+\dot{\mathrm{m}}_{\text {vap.hx3 }} \cdot\left[\mathrm{h}_{15}-\mathrm{h}_{16}\right]=0$ Balanço de energia no $h \times 3$

$\overline{\mathrm{m}}_{\text {vap.hx3 }}=\frac{\dot{\mathrm{m}}_{\text {vap.hx3 }}}{1000[\text { ton } / \mathrm{h}]}$

Otimização dos trocadores de calor

Cálculo da temperatura de saída de cada trocador de calor

$\mathrm{T}_{13}=\mathrm{T}_{7}+\delta \mathrm{T}_{\mathrm{opt}} \quad$ Delta $T_{\text {opt }}$ é o incremento ótimo de temperatura em cada trocador de calor a ser otimizado

$\mathrm{T}_{14}=\mathrm{T}_{13}+\delta \mathrm{T}_{\mathrm{opt}}$

$\mathrm{T}_{10}=\mathrm{T}_{14}+\delta \mathrm{T}_{\mathrm{opt}}$

Cálculo dos pontos ótimos de extração na turbina

TTD = 3,5 [C] Diferença de Temperatura Terminal, parâmetro de entrada

TTD $=T_{\text {sat; } h \times 3}-T_{13}$

TTD $=T_{\text {sat; } h \times 2}-T_{14}$

$\mathrm{TTD}=\mathrm{T}_{\text {sat;hx1 }}-\mathrm{T}_{10}$

$\mathrm{P}_{8}=\mathbf{P}_{\text {sat }}\left[\right.$ water $\left.; \mathrm{T}=\mathrm{T}_{\text {sat } ; \mathrm{hx} 1}\right]$

$\mathrm{P}_{11}=\mathbf{P}_{\text {sat }}\left[\right.$ water $\left.; \mathrm{T}=\mathrm{T}_{\text {sat; } \mathrm{hx2}}\right]$

$\mathrm{P}_{15}=\mathbf{P}_{\text {sat }}\left[\right.$ water $\left.; \mathrm{T}=\mathrm{T}_{\text {sat; } \mathrm{hx3}}\right]$

\section{CONDENSADOR}

$\dot{\mathrm{Q}}_{\text {out }}=\dot{\mathrm{m}}_{\text {vap.cauda }} \cdot\left[\mathrm{h}_{3}-\mathrm{h}_{4}\right]$ Balanço de energia --> Calor transferido da condensação do vapor para a torre de resfriamento

TORRE DE RESFRIAMENTO

$\dot{\mathrm{Q}}_{\text {out }}=\dot{\mathrm{m}}_{\text {recirculação }} \cdot\left[\mathrm{h}_{\text {out }}-\mathrm{h}_{\text {in }}\right]$

$\mathrm{h}_{\text {out }}=\mathbf{h}\left[\right.$ water $\left.; \mathrm{P}=\mathrm{P}_{\text {out }} ; \mathrm{T}=\mathrm{T}_{\text {out }}\right]$

$\mathrm{h}_{\text {in }}=\mathbf{h}\left[\right.$ water $\left.; \mathrm{P}=\mathrm{P}_{\text {in }} ; \mathrm{T}=\mathrm{T}_{\text {in }}\right] \quad \mathrm{P}_{\text {in }}=1$

$P_{\text {out }}=1$ 
EES Ver. 9.433: \#0624: Depart. de Engenharia Mecanica Escola Politecnic, Escola Politecnica da USP, Sao Paulo, Brazil

$\dot{\mathrm{m}}_{\text {repos.torre }}=\mathrm{Y}_{\text {perdas }} \cdot \dot{\mathrm{m}}_{\text {recirculação }} \quad Y_{\text {perdas }}$ corresponde a uma estimativa de perdas de água por evaporação, purga e arraste na torre de resfriamento

$\dot{\mathrm{m}}_{\text {rep.total }}=\dot{\mathrm{m}}_{\text {repos.torre }}+\dot{\mathrm{m}}_{\text {rep.desaerador }}+\mathrm{m}_{\text {agua.dessuper }}$

$\overline{\mathrm{m}}_{\text {repos.torre }}=\frac{\dot{\mathrm{m}}_{\text {repos.torre }}}{1000[\text { ton } / \mathrm{h}]}$

$\overline{\mathrm{m}}_{\text {rep.total }}=\frac{\dot{\mathrm{m}}_{\text {rep.total }}}{1000[\text { ton } / \mathrm{h}]}$

$\overline{\mathrm{m}}_{\text {vap.dessuper }}=\frac{\dot{\mathrm{m}}_{\text {vap.dessuper }}}{1000[\text { ton } / \mathrm{h}]}$

Perc.torre $=\frac{\dot{\mathrm{m}}_{\text {repos.torre }}}{\dot{\mathrm{m}}_{\text {rep.total }}} \cdot 100$

Perc.desaerador $=\frac{\dot{\mathrm{m}}_{\text {rep.desaerador }}}{\dot{\mathrm{m}}_{\text {rep.total }}} \cdot 100$

Perc.dessuper $=\frac{\dot{\mathrm{m}}_{\text {vap.dessuper }}}{\dot{\mathrm{m}}_{\text {rep.total }}} \cdot 100$

Tap.water torre $=\frac{\dot{\mathrm{m}}_{\text {repos.torre }}}{\frac{\dot{\mathrm{M}}_{\text {cana }}}{1000}}$

Tap.water deionised $=\frac{\dot{\mathrm{m}}_{\text {rep.desaerador }}+\mathrm{m}_{\text {agua.dessuper }}}{\frac{\dot{\mathrm{M}}_{\text {cana }}}{1000}}$

\section{CÁLCULO DAS POTÊNCIAS ELÉTRICAS}

Potência elétrica gerada

$\mathrm{POT}_{\text {elétr.gerada }}=\left[\mathrm{POT}_{1}+\mathrm{POT}_{2}+\mathrm{POT}_{3}+\mathrm{POT}_{4}+\mathrm{POT}_{5}\right] \cdot \eta_{\mathrm{g}} \cdot\left|2,77778 \times 10^{-7} \cdot \frac{\mathrm{MW}}{\mathrm{kJ} / \mathrm{h}}\right|$ Potencia elétrica total gerada no turbogerador

$\mathrm{POT}_{1}=\dot{\mathrm{m}}_{\text {vap.escape }} \cdot\left[\mathrm{h}_{1}-\mathrm{h}_{2}\right]$ Potencia gerada pelo vapor de escape a $\mathrm{P}=2,5 \mathrm{bar}$

$\mathrm{POT}_{2}=\dot{\mathrm{m}}_{\text {vap.cauda }} \cdot\left[\mathrm{h}_{1}-\mathrm{h}_{3}\right]$ Potencia gerada pelo vapor da cauda

$\mathrm{POT}_{3}=\dot{\mathrm{m}}_{\text {vap.hx1 }} \cdot\left[\mathrm{h}_{1}-\mathrm{h}_{8}\right]$ Potencia gerada pelo vapor extraído no primeiro estágio da turbina direcionado a trocador $h \times 1$

$\mathrm{POT}_{4}=\dot{\mathrm{m}}_{\text {vap.hx2 }} \cdot\left[\mathrm{h}_{1}-\mathrm{h}_{11}\right]$ Potencia gerada pelo vapor de extraído no segundo estágio da turbina direcionado a trocador $h \times 2$

POT $_{5}=\dot{\mathrm{m}}_{\text {vap.hx3 }} \cdot\left[\mathrm{h}_{1}-\mathrm{h}_{15}\right]$ Potencia gerada pelo vapor de extraído no terceiro estágio da turbina direcionado a trocador $h \times 3$

Consumo das bombas do ciclo

$\mathrm{POT}_{\text {elétr.consumida }}=\left[\mathrm{POT}_{\mathrm{B} 1}+\mathrm{POT}_{\mathrm{B} 2}\right] \cdot\left|2,77778 \times 10^{-7} \cdot \frac{\mathrm{MW}}{\mathrm{kJ} / \mathrm{h}}\right|$ Potência consumida pelas bombas

$\mathrm{POT}_{\mathrm{B} 1}=\dot{\mathrm{m}}_{\text {vap.cauda }} \cdot\left[\mathrm{h}_{5}-\mathrm{h}_{4}\right]$ Potência consumida pela bomba 1 
$\mathrm{POT}_{\mathrm{B} 2}=\dot{\mathrm{m}}_{\text {agua }} \cdot\left[\mathrm{h}_{7}-\mathrm{h}_{6}\right]$ Potência consumida pela bomba 1

EFICIÊNCIA GLOBAL DA UNIDADE DE COGERAÇÃO COM REGENERAÇÃO

Cálculo da eficiência energética

$\eta$ Energética.Global $\quad=\left[\frac{\mathrm{POT}_{\text {elétr.líquida }}+\mathrm{POT}_{\text {processo }}}{\mathrm{POT}_{\text {entrada }}}\right] \cdot 100$

Potência líquida gerada na unidade de cogeração

$\mathrm{POT}_{\text {elétr.líquida }}=\mathrm{POT}_{\text {elétr.gerada }}-\mathrm{POT}_{\text {elétr.consumida }}$

Potência utilizada no processo industrial e desaerador

$\mathrm{POT}_{\text {processo }}=\dot{\mathrm{m}}_{\text {vap.processo }} \cdot\left[\mathrm{h}_{\text {pro }}-\mathrm{h}_{\text {sat }}\right] \cdot\left|2,77778 \times 10^{-7} \cdot \frac{\mathrm{MW}}{\mathrm{kJ} / \mathrm{h}}\right|$

$\mathrm{POT}_{\text {desaerador }}=\dot{\mathrm{m}}_{\text {vap.desaerador }} \cdot\left[\mathrm{h}_{2}-\mathrm{h}_{6}\right] \cdot\left|2,77778 \times 10^{-7} \cdot \frac{\mathrm{MW}}{\mathrm{kJ} / \mathrm{h}}\right|$

$\mathrm{POT}_{\text {desaerador.perc }}=\frac{\mathrm{POT}_{\text {desaerador }}}{\mathrm{POT}_{\text {entrada }}} \cdot 100$

$\mathrm{POT}_{\text {processo.perc }}=\frac{\mathrm{POT}_{\text {processo }}}{\mathrm{POT}_{\text {entrada }}} \cdot 100$

$\mathrm{h}_{\text {sat }}=\mathbf{h}[$ water $; \mathrm{x}=0 ; \mathrm{P}=2,5]$

Alimentação energética na fornalha da caldeira

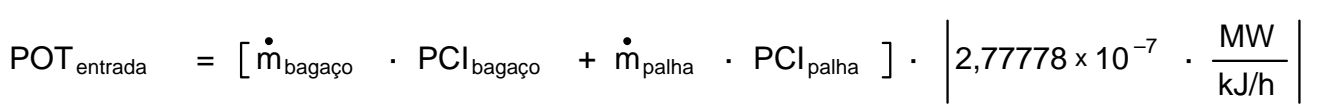

APLICAÇÃO DA 2A LEI DA TERMODINÂMICA - ANÁLISE EXERGÉTICA

Ambiente de referência considerado: $P o=1$ bar e $T o=25 C$

$\mathrm{TO}=25[\mathrm{C}]$

$\mathrm{PO}=1[\mathrm{bar}]$

$\mathrm{P} 00_{\mathrm{h} 20}=0,0303$ [bar $]$

LIMITE TEÓRICO DE EFICIÊNCIA - CICLO DE CARNOT

$\eta$ carnot $=\left[1-\left(\frac{T_{3}+273,15}{T_{1}+273,15}\right)\right] \cdot 100 \quad$ Trabalho máximo que pode ser obtido

Trabalho útil final - saída do gerador

EXERGY.in fuel $^{=}$POT $_{\text {entrada }}$

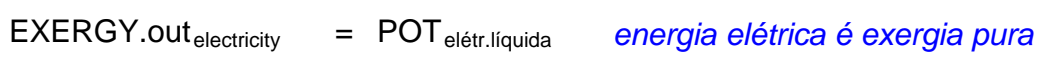

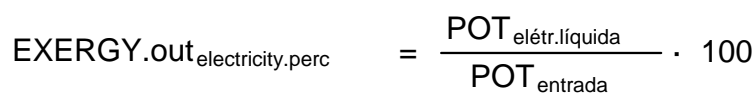



$\mathrm{B}_{1}=\dot{\mathrm{m}}_{\mathrm{vapor}} \cdot\left[\mathrm{h}_{1}-\mathrm{h}_{0}-\left([\mathrm{TO}+273,15] \cdot\left[\mathrm{s}_{1}-\mathrm{s}_{0}\right]\right)\right] \cdot\left|2,77778 \times 10^{-7} \cdot \frac{\mathrm{MW}}{\mathrm{kJ} / \mathrm{h}}\right| \begin{array}{r}\text { Exergia do vapor de } \\ \text { saída do }\end{array}$ gerador de vapor

$\mathrm{h}_{0}=\mathbf{h}[$ water $; \mathrm{T}=\mathrm{TO} ; \mathrm{P}=\mathrm{PO}]$

$\mathrm{S}_{0}=\mathbf{s}[$ water $; \mathrm{T}=\mathrm{TO} ; \mathrm{P}=\mathrm{PO}]$

$\mathrm{B}_{\text {fuel }}=$ EXERGY.in $\mathrm{n}_{\text {fuel }}$

TURBINE

Exergia das correntes de vapor de escape e cauda

$\mathrm{B}_{2}=\dot{\mathrm{m}}_{\text {vap.escape }} \cdot\left[\mathrm{h}_{2}-\mathrm{h}_{0}-\left([\mathrm{TO}+273,15] \cdot\left[\mathrm{s}_{2}-\mathrm{s}_{0}\right]\right)\right] \cdot\left|2,77778 \times 10^{-7} \cdot \frac{\mathrm{MW}}{\mathrm{kJ} / \mathrm{h}}\right| \begin{array}{r}\text { Exergia do vapor } \\ \text { de escape }\end{array}$

$\mathrm{B}_{3}=\dot{\mathrm{m}}_{\text {vap.cauda }} \cdot\left[\mathrm{h}_{3}-\mathrm{h}_{0}-\left([\mathrm{T0}+273,15] \cdot\left[\mathrm{s}_{3}-\mathrm{s}_{0}\right]\right)\right] \cdot\left|2,77778 \times 10^{-7} \cdot \frac{\mathrm{MW}}{\mathrm{kJ} / \mathrm{h}}\right|$ Exergia do vapor de cauda

Exergia das correntes de regeneração para os trocadores $h \times 1, h \times 2$ e $h \times 3$

$\mathrm{B}_{8}=\dot{\mathrm{m}}_{\text {vap.hx1 }} \cdot\left[\mathrm{h}_{8}-\mathrm{h}_{0}-\left([\mathrm{T0}+273,15] \cdot\left[\mathrm{s}_{8}-\mathrm{s}_{0}\right]\right)\right] \cdot\left|2,77778 \times 10^{-7} \cdot \frac{\mathrm{MW}}{\mathrm{kJ} / \mathrm{h}}\right|$ Exergia do vapor extração da turbina

$\mathrm{B}_{11}=\dot{\mathrm{m}}_{\text {vap.hx2 }} \cdot\left[\mathrm{h}_{11}-\mathrm{h}_{0}-\left([\mathrm{T0}+273,15] \cdot\left[\mathrm{s}_{11}-\mathrm{s}_{0}\right]\right)\right] \cdot\left|2,77778 \times 10^{-7} \cdot \frac{\mathrm{MW}}{\mathrm{kJ} / \mathrm{h}}\right|$ Exergia do vapor da segunda extração da turbina

$\mathrm{B}_{15}=\dot{\mathrm{m}}_{\text {vap.hx3 }} \cdot\left[\mathrm{h}_{15}-\mathrm{h}_{0}-\left([\mathrm{TO}+273,15] \cdot\left[\mathrm{s}_{15}-\mathrm{s}_{0}\right]\right)\right] \cdot\left|2,77778 \times 10^{-7} \cdot \frac{\mathrm{MW}}{\mathrm{kJ} / \mathrm{h}}\right|$ Exergia do vapor da segunda extração da turbina

Balanço de exergia na turbina

Bdest $_{\text {turbine }}=\mathrm{B}_{1}-\left[\mathrm{B}_{2}+\mathrm{B}_{3}+\mathrm{B}_{8}+\mathrm{B}_{11}+\mathrm{B}_{15}+\frac{\text { POT }_{\text {elétr.gerada }}}{\eta_{\mathrm{g}}}\right]$ Exergia destruída na turbina

Bdest $_{\text {turbine.perc }}=\frac{\text { Bdest turbine }_{\text {ful }}}{\mathrm{B}_{\text {fuel }}} \cdot 100$ Percentual de exergia destruída na turbina

$\mathrm{B}_{2 ; \text { perc }}=\frac{\mathrm{B}_{2}}{\mathrm{~B}_{\text {fuel }}} \cdot 100$ Percentual de exergia no vapor de escape

$\mathrm{B}_{\text {liq }}=\frac{\mathrm{POT}_{\text {elétr.gerada }}}{\mathrm{B}_{\text {fuel }}} \cdot 100$ Percentual de exergia (trabalho) na saída do gerador 
EXERGY.out process $=\dot{\mathrm{m}}_{\text {vap.processo }} \cdot\left[\mathrm{h}_{\text {pro }}-\mathrm{h}_{0}-\left([\mathrm{TO}+273,15] \cdot\left[\mathrm{s}_{\text {pro }}-\mathrm{s}_{0}\right]\right)\right] \cdot\left|2,77778 \times 10^{-7} \cdot \frac{\mathrm{MW}}{\mathrm{kJ} / \mathrm{h}}\right|$

$\mathrm{S}_{\text {pro }}=\mathbf{s}[$ water $; \mathrm{P}=2,5 ; \mathrm{T}=127,5]$

EXERGY.out $_{\text {process.perc }}=\frac{\text { EXERGY.out }_{\text {process }}}{B_{\text {fuel }}} \cdot 100$

EXERGY.out deaerator $=B_{2}-$ EXERGY.out $_{\text {process }}$

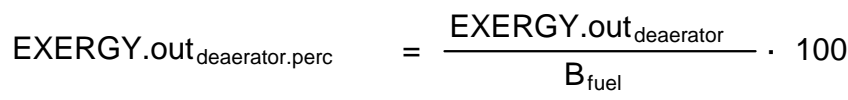

\section{DESSUPERAQUECEDOR}

Balanço de entropia no dessuper

$\mathrm{S}_{\text {ger.dessuper }}=\dot{\mathrm{m}}_{\text {vap.processo }} \cdot \mathrm{s}_{\text {pro }}-\left[\mathrm{m}_{\text {agua.dessuper }} \cdot \mathrm{s}_{\text {agua }}+\left(\dot{\mathrm{m}}_{\text {vap.dessuper }}-\dot{\mathrm{m}}_{\text {purgador }}\right) \cdot \mathrm{s}_{2}\right]$

$\mathrm{S}_{\text {agua }}=\mathbf{s}[$ water $; \mathrm{P}=2,5 ; \mathrm{T}=25]$

Bdest $_{\text {dessuper }}=[\mathrm{T0}+273,15] \cdot \mathrm{S}_{\text {ger.dessuper }} \cdot\left|2,77778 \times 10^{-7} \cdot \frac{\mathrm{MW}}{\mathrm{kJ} / \mathrm{h}}\right|$ Exergia destruída no dessuperaquecedor

Bdest $_{\text {dessuper.perc }}=\frac{\text { Bdest }_{\text {dessuper }}}{\mathrm{B}_{\text {fuel }}} \cdot 100$ Percentual de exergia destruída no dessuperaquecedor

CONDENSADOR

$\mathrm{B}_{4}=\dot{\mathrm{m}}_{\mathrm{vap.cauda}} \cdot\left[\mathrm{h}_{4}-\mathrm{h}_{0}-\left([\mathrm{T} 0+273,15] \cdot\left[\mathrm{s}_{4}-\mathrm{s}_{0}\right]\right)\right] \cdot\left|2,77778 \times 10^{-7} \cdot \frac{\mathrm{MW}}{\mathrm{kJ} / \mathrm{h}}\right|$ Exergia na saída

do condensador

Bdest $_{\text {condenser }}=\mathrm{B}_{3}-\mathrm{B}_{4}$ Exergia destruída no condensador

Bdest $_{\text {condenser.perc }}=\frac{\text { Bdest }_{\text {condenser }}}{\mathrm{B}_{\text {fuel }}} \cdot 100$ Percentual de exergia destruída no condensador

BOMBA 1

$\mathrm{B}_{5}=\dot{\mathrm{m}}_{\mathrm{vap} . c a u d a} \cdot\left[\mathrm{h}_{5}-\mathrm{h}_{0}-\left([\mathrm{T} 0+273,15] \cdot\left[\mathrm{s}_{5}-\mathrm{s}_{0}\right]\right)\right] \cdot\left|2,77778 \times 10^{-7} \cdot \frac{\mathrm{MW}}{\mathrm{kJ} / \mathrm{h}}\right|$ Exergia na saída

da bomba 1

Bdest $_{\mathrm{B} 1}=\mathrm{B}_{4}-\mathrm{B}_{5}+\mathrm{W}_{\mathrm{B} 1}$ Exergia destruída na bomba 1

$\mathrm{W}_{\mathrm{B} 1}=\dot{\mathrm{m}}_{\text {vap.cauda }} \cdot\left[\mathrm{h}_{5}-\mathrm{h}_{4}\right] \cdot\left|2,77778 \times 10^{-7} \cdot \frac{\mathrm{MW}}{\mathrm{kJ} / \mathrm{h}}\right|$ Trabalho realizado pela bomba $B 1$

Bdest $_{\mathrm{B} 1 \text {.perc }}=\frac{\text { Bdest }_{\mathrm{B} 1}}{\mathrm{~B}_{\text {fuel }}} \cdot 100$ Percentual de exergia destruída na bomba 1

\section{DESAERADOR}

Balanço de entropia no dessuperaquecedor

$$
\begin{aligned}
& \mathrm{s}_{\text {ger.desaerador }}=\dot{\mathrm{m}}_{\text {agua }} \cdot \mathrm{s}_{6}-\left[\dot{\mathrm{m}}_{\text {retorno }} \cdot \mathrm{s}_{\text {cond }}+\dot{\mathrm{m}}_{\text {vap.desaerador }} \cdot \mathrm{s}_{2}+\dot{\mathrm{m}}_{\text {vap.cauda }} \cdot \mathrm{s}_{5}+\dot{\mathrm{m}}_{\text {rep.desaerador }}\right. \\
& \left.\cdot \mathrm{s}_{\text {agua }}+\left(\dot{\mathrm{m}}_{\text {purgador }}+\dot{\mathrm{m}}_{\text {vap.hx1 }}+\dot{\mathrm{m}}_{\text {vap.hx2 }}+\dot{\mathrm{m}}_{\text {vap.hx3 }}\right) \cdot \mathrm{s}_{\text {sat }}\right] \\
& \mathrm{s}_{\text {cond }}=\mathrm{s}\left[\text { water } ; \mathrm{T}=\mathrm{T}_{\text {cond }} ; \mathrm{P}=\mathrm{P}_{\text {cond }}\right] \quad \mathrm{s}_{\text {sat }}=\mathrm{s}[\text { water } ; \mathrm{P}=2,5 ; \mathrm{x}=0]
\end{aligned}
$$


Bdest $_{\text {desaerador }}=[\mathrm{T0}+273,15] \cdot \mathrm{S}_{\text {ger.desaerador }} \cdot\left|2,77778 \times 10^{-7} \cdot \frac{\mathrm{MW}}{\mathrm{kJ} / \mathrm{h}}\right|$ Exergia destruída no desaerador Bdest $_{\text {desaerador.perc }}=\frac{\text { Bdest }_{\text {desaerador }}}{\mathrm{B}_{\text {fuel }}} \cdot 100$ Percentual de exergia destruída no desaerador

BOMBA 2

$\mathrm{B}_{7}=\dot{\mathrm{m}}_{\mathrm{agua}} \cdot\left[\mathrm{h}_{7}-\mathrm{h}_{0}-\left([\mathrm{TO}+273,15] \cdot\left[\mathrm{s}_{7}-\mathrm{s}_{0}\right]\right)\right] \cdot\left|2,77778 \times 10^{-7} \cdot \frac{\mathrm{MW}}{\mathrm{kJ} / \mathrm{h}}\right|$ Exergia na saída da bomba 2

$\mathrm{B}_{6}=\dot{\mathrm{m}}_{\text {agua }} \cdot\left[\mathrm{h}_{6}-\mathrm{h}_{0}-\left([\mathrm{T0}+273,15] \cdot\left[\mathrm{s}_{6}-\mathrm{s}_{0}\right]\right)\right] \cdot\left|2,77778 \times 10^{-7} \cdot \frac{\mathrm{MW}}{\mathrm{kJ} / \mathrm{h}}\right|$ Exergia na entrada da bomba 2

$\mathrm{W}_{\mathrm{B} 2}=\dot{\mathrm{m}}_{\text {agua }} \cdot\left[\mathrm{h}_{7}-\mathrm{h}_{6}\right] \cdot\left|2,77778 \times 10^{-7} \cdot \frac{\mathrm{MW}}{\mathrm{kJ} / \mathrm{h}}\right|$ Trabalho realizado pela bomba B2

Bdest $_{\mathrm{B} 2}=\mathrm{B}_{7}-\mathrm{B}_{6}+\mathrm{W}_{\mathrm{B} 2}$ Exergia destruída na bomba 2

Bdest $_{\mathrm{B} 2 . \text { perc }}=\frac{\text { Bdest }_{\mathrm{B} 2}}{\mathrm{~B}_{\text {fuel }}} \cdot 100$ Percentual de exergia destruída na bomba 2

BOILER

$\mathrm{B}_{10}+\mathrm{B}_{\text {fuel }}=\mathrm{B}_{1}+\mathrm{B}_{\text {purga }}+$ Bdest $_{\text {boiler }}$ Balanço de exergia na caldeira

Bdest $_{\text {boiler.perc }}=\frac{\text { Bdest }_{\text {boiler }}}{\mathrm{B}_{\text {fuel }}} \cdot 100$ Percentual de exergia destruída na caldeira $\mathrm{B}_{10}=\dot{\mathrm{m}}_{\text {agua }} \cdot\left[\mathrm{h}_{10}-\mathrm{h}_{0}-\left([\mathrm{TO}+273,15] \cdot\left[\mathrm{s}_{10}-\mathrm{s}_{0}\right]\right)\right] \cdot\left|2,77778 \times 10^{-7} \cdot \frac{\mathrm{MW}}{\mathrm{kJ} / \mathrm{h}}\right| \begin{gathered}\text { Exergia da corrente } \\ \text { de agua }\end{gathered}$ na entrada da caldeira

$\mathrm{B}_{\text {purga }}=\dot{\mathrm{m}}_{\text {purga }} \cdot\left[\mathrm{h}_{\text {purga }}-\mathrm{h}_{0}-\left([\mathrm{T0}+273,15] \cdot\left[\mathrm{s}_{\text {purga }}-\mathrm{s}_{0}\right]\right)\right] \cdot\left|2,77778 \times 10^{-7} \cdot \frac{\mathrm{MW}}{\mathrm{kJ} / \mathrm{h}}\right|$

$\mathrm{s}_{\text {purga }}=\mathbf{s}\left[\right.$ water $\left.; \mathrm{h}=\mathrm{h}_{\text {purga }} ; \mathrm{T}=\mathrm{T}_{\text {purga }}\right] \quad \mathrm{s}_{10}=\mathbf{s}\left[\right.$ water $\left.; \mathrm{T}=\mathrm{T}_{10} ; \mathrm{P}=\mathrm{P}_{10}\right]$

TROCADOR DE CALOR TC 1

Balanço de exergia no TC1

- Bdest $_{\mathrm{TC} 1}=\left[\dot{\mathrm{m}}_{\text {vap.hx3}} \cdot\left(\mathrm{h}_{16}-\mathrm{h}_{15}\right)+\dot{\mathrm{m}}_{\text {agua }} \cdot\left(\mathrm{h}_{13}-\mathrm{h}_{7}\right)-\mathrm{TO} \cdot\left(\dot{\mathrm{m}}_{\text {vap.hx3}} \cdot\left[\mathrm{s}_{16}-\mathrm{s}_{15}\right]+\dot{\mathrm{m}}_{\text {agua }}\right.\right.$

$$
\left.\left.\cdot\left[\mathrm{s}_{13}-\mathrm{s}_{7}\right]\right)\right] \cdot\left|2,77778 \times 10^{-7} \cdot \frac{\mathrm{MW}}{\mathrm{kJ} / \mathrm{h}}\right|
$$

$\mathrm{S}_{16}=\mathbf{s}\left[\right.$ water $\left.; \mathrm{P}=\mathrm{P}_{16} ; \mathrm{x}=0\right] \quad \mathrm{S}_{13}=\mathbf{s}\left[\right.$ water $\left.; \mathrm{P}=\mathrm{P}_{13} ; \mathrm{T}=\mathrm{T}_{13}\right]$

Bdest $_{\mathrm{TC1} \text {.perc }}=\frac{\text { Bdest }_{\mathrm{TC1}}}{\mathrm{B}_{\text {fuel }}} \cdot 100$ Percentual de exergia destruída no TC1 
- Bdest $_{\mathrm{TC2}}=\left[\dot{\mathrm{m}}_{\text {vap.hx2 }} \cdot\left(\mathrm{h}_{12}-\mathrm{h}_{11}\right)+\dot{\mathrm{m}}_{\text {agua }} \cdot\left(\mathrm{h}_{14}-\mathrm{h}_{13}\right)-\mathrm{TO} \cdot\left(\dot{\mathrm{m}}_{\text {vap.hx2 }} \cdot\left[\mathrm{s}_{12}-\mathrm{s}_{11}\right]+\dot{\mathrm{m}}_{\text {agua }}\right.\right.$ $\left.\left.\cdot\left[\mathrm{s}_{14}-\mathrm{s}_{13}\right]\right)\right] \cdot\left|2,77778 \times 10^{-7} \cdot \frac{\mathrm{MW}}{\mathrm{kJ} / \mathrm{h}}\right|$

$\mathrm{s}_{12}=\mathbf{s}\left[\right.$ water $\left.; \mathrm{P}=\mathrm{P}_{12} ; \mathrm{x}=0\right] \quad \mathrm{S}_{14}=\mathbf{s}\left[\right.$ water $\left.; \mathrm{P}=\mathrm{P}_{14} ; \mathrm{T}=\mathrm{T}_{14}\right]$

Bdest $_{\mathrm{TC2} \text {.perc }}=\frac{\text { Bdest }_{\mathrm{TC2}}}{\mathrm{B}_{\text {fuel }}} \cdot 100$ Percentual de exergia destruída no TC2

\section{TROCADOR DE CALOR TC 3}

Balanço de exergia no TC3

- Bdest $_{\mathrm{TC3}}=\left[\dot{\mathrm{m}}_{\text {vap.hx1 }} \cdot\left(\mathrm{h}_{9}-\mathrm{h}_{8}\right)+\dot{\mathrm{m}}_{\text {agua }} \cdot\left(\mathrm{h}_{10}-\mathrm{h}_{14}\right)-\right.$ T0 $\cdot\left(\dot{\mathrm{m}}_{\text {vap.hx1 }} \cdot\left[\mathrm{s}_{9}-\mathrm{s}_{8}\right]+\dot{\mathrm{m}}_{\text {agua }} \cdot\left[\mathrm{s}_{10}\right.\right.$

$\left.\left.\left.-\mathrm{s}_{14}\right]\right)\right] \cdot\left|2,77778 \times 10^{-7} \cdot \frac{\mathrm{MW}}{\mathrm{kJ} / \mathrm{h}}\right|$

$\mathrm{S}_{9}=\mathbf{s}\left[\right.$ water $\left.; \mathrm{P}=\mathrm{P}_{9} ; \mathrm{x}=0\right]$

Bdest $_{\mathrm{TC3} \text {.perc }}=\frac{\text { Bdest }_{\mathrm{TC3}}}{\mathrm{B}_{\text {fuel }}} \cdot 100$ Percentual de exergia destruída no TC3

Total $_{\text {exergy.dest }}=$ Bdest $_{\mathrm{B} 1}+$ Bdest $_{\mathrm{B} 2}+$ Bdest $_{\text {desaerador }}+$ Bdest $_{\text {condenser }}+$ Bdest $_{\text {boiler }}+$ Bdest $_{\text {turbine }}+$ Bdest $_{\mathrm{TC} 1}$ + Bdest $_{\mathrm{TC2}}+$ Bdest $_{\mathrm{TC} 3}$

Total $_{\text {exergy.dest.perc }}=\frac{\text { Total }_{\text {exergy.dest }}}{\mathrm{B}_{\text {fuel }}} \cdot 100$

Eficiência Exergética

Cálculo da eficiência exergética global

$\eta_{\text {EXergética.Global }}=\left[\frac{\text { POT }_{\text {elétr.líquida }}+\text { EXERGY.out }_{\text {process }}}{B_{\text {fuel }}}\right] \cdot 100$

$\eta$ Ex.ref.Carnot $\quad=\frac{\eta \text { EXergética.Global }}{\eta \text { Carnot }} \cdot 100$

Distribuição de exergia entre vapor e eletricidade

Exergia $_{\text {vapor.perc }}=\left[\frac{\text { EXERGY.out }_{\text {process }}}{\mathrm{POT}_{\text {elétr.líquida }}+\text { EXERGY.out }_{\text {process }}}\right] \cdot 100$

Exergia $_{\text {eletricidade.perc }}=\left[\frac{\text { POT }_{\text {elétr.líquida }}}{\text { POT }_{\text {elétr.líquida }}+\text { EXERGY.out }_{\text {process }}}\right] \cdot 100$

ALOCAÇÃO

Critério energético

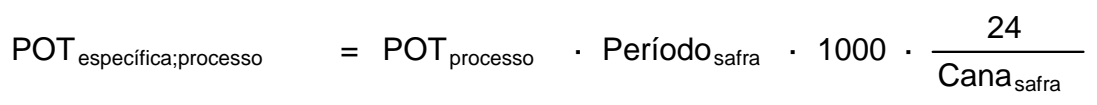

Alocação $_{\text {energia;vapor }}=\left[\frac{\text { POT }_{\text {específica;processo }}}{\text { POT }_{\text {específica;processo }}+\text { GeraçãoEletric.Espec.Excedente }+ \text { ConsumoEletr.Processo }}\right] \cdot 100$ 
EES Ver. 9.433: \#0624: Depart. de Engenharia Mecanica Escola Politecnic, Escola Politecnica da USP, Sao Paulo, Brazil

Alocação $_{\text {energia;eletr.exp }}=\left[\frac{\text { GeraçãoEletric.Espec.Excedente }}{\text { POT }_{\text {específica;processo }}+\text { GeraçãoEletric.Espec.Excedente }+ \text { ConsumoEletr.Processo }}\right] \cdot 100$
Alocação $_{\text {energia;eletr.proc }}=\left[\frac{\text { ConsumoEletr.Processo }}{\text { POT }_{\text {específica;processo }+ \text { GeraçãoEletric.Espec.Excedente }+ \text { ConsumoEletr.Processo }}}\right] \cdot 100$

Critério exergético

EXERGY.out $_{\text {específica;process }}=$ EXERGY.out $_{\text {process }} \cdot$ Período $_{\text {safra }} \cdot 1000 \cdot \frac{24}{\text { Cana }_{\text {safra }}}$

Alocação $_{\text {exergia;vapor }}=\left[\frac{\text { EXERGY.out }_{\text {específica;process }}}{\text { EXERGY.out } \text { específica;process }_{2}+\text { GeraçãoEletric.Espec.Excedente }+ \text { ConsumoEletr.Processo }_{2}}\right] \cdot 100$

Alocação $_{\text {exergia;eletr.exp }}=\left[\begin{array}{ll}\text { GeraçãoEletric.Espec.Excedente } \\ \hline \text { EXERGY.out } \text { específica;process }_{2}+\text { GeraçãoEletric.Espec.Excedente + ConsumoEletr.Processo }\end{array}\right]$

. 100

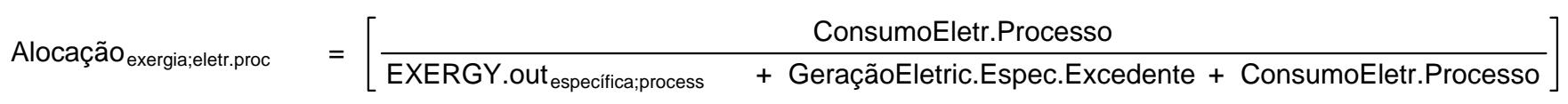
100

ANÁLISE ENERGÉTICA DE 1A LEI - PERDAS ENERGÉTICAS

Perdas na Caldeira e turbina

Boiler $_{\text {losses }}=\mathrm{POT}_{\text {entrada }} \cdot\left[1-\eta_{\mathrm{c}}\right]$

Boiler $_{\text {losses.perc }}=\frac{\text { Boiler }_{\text {losses }}}{\text { POT }_{\text {entrada }}} \cdot 100$

Turbine $_{\text {losses }}=\left[\left(\mathrm{POT}_{1}+\mathrm{POT}_{2}+\mathrm{POT}_{3}+\mathrm{POT}_{4}+\mathrm{POT}_{5}\right) \cdot\left(1-\eta_{\mathrm{t}}\right)\right] \cdot\left|2,77778 \times 10^{-7} \cdot \frac{\mathrm{MW}}{\mathrm{kJ} / \mathrm{h}}\right|$

Turbine $_{\text {losses.perc }}=\frac{\text { Turbine }_{\text {losses }}}{\mathrm{POT}_{\text {entrada }}} \cdot 100$

Perdas no condensador

$\mathrm{POT}_{\text {condensador }}=\dot{\mathrm{Q}}_{\text {out }} \cdot\left|2,77778 \times 10^{-7} \cdot \frac{\mathrm{MW}}{\mathrm{kJ} / \mathrm{h}}\right|$ Energia perdida no condensador

$\mathrm{POT}_{\text {condensador.perc }}=\frac{\mathrm{POT}_{\text {condensador }}}{\mathrm{POT}_{\text {entrada }}} \cdot 100$

Condenser $_{\text {losses }}=\mathrm{POT}_{\text {condensador }}$

Perdas no processo

process $_{\text {losses }}=\mathrm{POT}_{\text {entrada }}-\left[\mathrm{POT}_{\text {processo }}+\mathrm{POT}_{\text {elétr.gerada }}+\mathrm{POT}_{\text {condensador }}+\right.$ Turbine $_{\text {losses }}+$ Boiler $\left._{\text {losses }}\right]$

process $_{\text {losses.perc }}=\frac{\text { process }_{\text {losses }}}{\text { POT }_{\text {entrada }}} \cdot 100$

Cálculo da energia elétrica gerada por tonela de cana por tonelada de cana

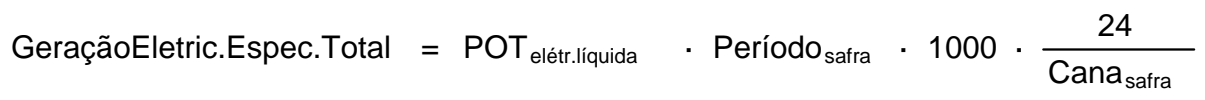


File:Regeneração - 2a Lei - Otimizado com 3 TC.EES

EES Ver. 9.433: \#0624: Depart. de Engenharia Mecanica Escola Politecnic, Escola Politecnica da USP, Sao Paulo, Brazil

GeraçãoEletric.Espec.Excedente = GeraçãoEletric.Espec.Total - ConsumoEletr.Processo

Distribuição de energia entre vapor e eletricidade

Energia $_{\text {vapor.perc }}=\left[\frac{\mathrm{POT}_{\text {processo }}}{\mathrm{POT}_{\text {processo }}+\mathrm{POT}_{\text {elétr.líquida }}}\right] \cdot 100$

Energia $_{\text {eletricidade.perc }}=\left[\frac{\mathrm{POT}_{\text {elétr.líquida }}}{\mathrm{POT}_{\text {processo }}+\mathrm{POT}_{\text {elétr.líquida }}}\right] \cdot 100$ 
APÊNDICE D- Modelagem Termodinâmica do sistema de cogeração com ciclo Rankine Resultante 


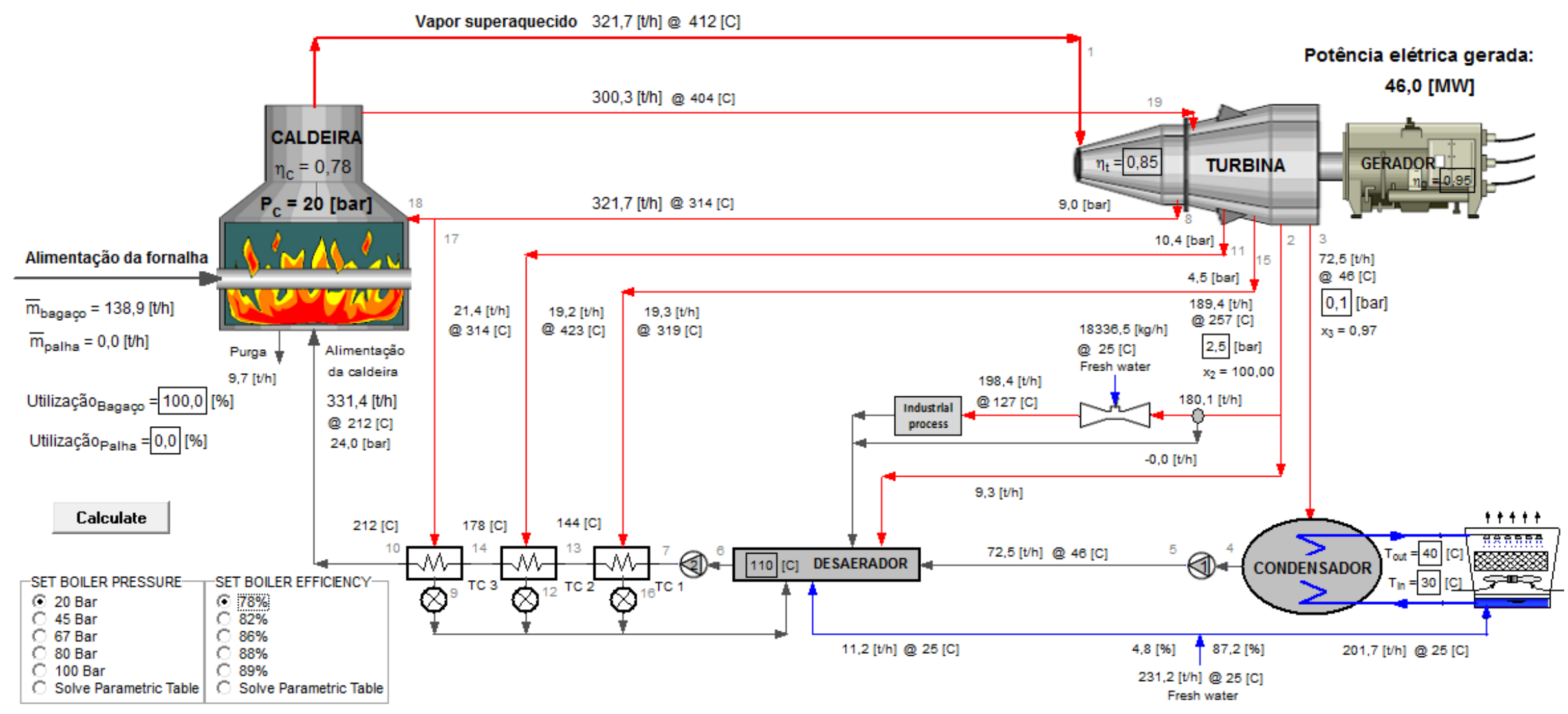

Figura 48 - Ciclo de vapor Resultante (com reaquecimento e regeneração) para um sistema de cogeração (Interface do simulador) 
File:Regeneração e Reaquecimento combinados - 2a Lei - otimizado.EES

EES Ver. 9.433: \#0624: Depart. de Engenharia Mecanica Escola Politecnic, Escola Politecnica da USP, Sao Paulo, Brazil

1:

2:

3:

4:

5:

6:

7: "Dados da Safra"

8:

9: M_dot_cana $=$ Cana_safra/Período_safra*1000/24 [kg/h] Moagem de cana"

10: m_dot_bagaço=Y_bagaço/100*M_dot_cana*Utilização_Bagaço/100 o de bagaço de cana"

11: m_dot_palha=Y_palha/100*M_dot_cana*Utilização_Palha/100 o de palha de cana"

12: Razão|vapor_biomassa=m_dot_vapor/m_dot_bagaço entre produção de vapor e consumo de biomassa"

13: m_bar_bagaço=m_dot_bagaço/1000 [ton/h]

14: m_bar_palha=m_dot_palha/1000[ton/h]

15:

16: "GERADOR DE VAPOR - Modelagem de conservação de matéria e energia"

17:

18: "Balanço de massa no gerador de vapor"

19:

20: m_dot_agua $+\mathrm{m} \_18=\mathrm{m} \_19+\mathrm{m} \_$dot_vapor+m_dot_purga

21: m_dot_purga $=Y \_p u r g a * m \_d o t \_v a p o r$

22: Y_purga $=0,03$ purga considerada $=3 \% "$

23: M_bar_vapor=m_dot_vapor/1000[ton/h]

24

25: "Balanço de massa Reaquecimento"

26:

27: m_bar_vap.reaq=m_18/1000 [ton/h]

28: $m \_8=m \_d o t \_v a p o r$

29: m_18=m_8 - m_17

30: m_bar_8=m_8/1000 [ton/h]

31:

32: "Balanços de energia no gerador de vapor"

33:

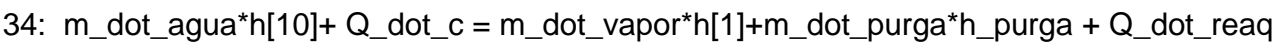

35: Q_dot_c=(m_dot_bagaço*PCl_bagaço+m_dot_palha*PCl_palha $)^{*}$ eta_c utilizada na fornecida na fornalha para evaporação da água"

36: Q_dot_reaq=m_18*(h[19]-h[18])

37: $h[1]=e n t h a l p y($ water; $T=T[1] ; P=P[1]): h \_p u r g a=e n t h a l p y\left(\right.$ water; $\left.T=T \_p u r g a ; X=0\right)$

38: $P[7]=1,20 * P \_c: T \_p u r g a=T \_S A T\left(\right.$ water $\left.P=P \_c\right): P \_p u r g a=P \_c: P[1]=P \_c:$

39: $\mathrm{PCl}$ bagaço=7565: $\mathrm{PCl} \_$palha=12960 $[\mathrm{kJ} / \mathrm{kg}]$

40: T[1]=T_SAT(water;P=P_c)+G_super

41: G_super=200 [C]

42:

43: "BOMBA 02 - ALIMENTAÇÃO DA CALDEIRA"

44

45: $P[6]=P[2]$ escape"

46: eta_B2=(h[6]-h7_iso)/(h[6]-h[7]) da bomba"

47: eta_B2 $=0,85$

48: h7_iso=enthalpy(water;s=s[6];P=P[7])

49: $h[6]=e n$ thalpy (water; $P=P[6] ; T=T[6])$

50: $s[6]=e n t r o p y($ water; $P=P[6] ; T=T[6])$

51: $T[7]=$ temperature (water; $h=h[7] ; P=P[7])$

52: $s[7]=e n t r o p y($ water; $h=h[7] ; P=P[7])$
"Poder calorífico inferior do bagaço e da palha de cana"

"Temperatura do vapor superaquecido"

"Grau de superaqucimento"

"Pressão de descarga da bomba igual a pressão do vapor de

"Determinação da entalpia real da vazão de líquido na descarga

"Entalpia para condição ideal isentrópica"

"Entalpia na saída do desaerador"

"Entropia na saída do desaerador é entropia do líquido saturado"

"Temperatura de recalque"

"Entropia da água de alimentação da caldeira"
"Taxa de

"Alimentaçã

"Alimentaçã

"Razão

"Taxa de

"Energia 
File:Regeneração e Reaquecimento combinados - 2a Lei - otimizado.EES

EES Ver. 9.433: \#0624: Depart. de Engenharia Mecanica Escola Politecnic, Escola Politecnica da USP, Sao Paulo, Brazil

53:

54: "BOMBA 01 - CONDENSADO"

55:

56: $P[5]=P[2]$

escape"

57: eta_B1=(h[4]-h5_iso) $/(\mathrm{h}[4]-\mathrm{h}[5])$

58: eta_B1 $=0,85$

59: h5_iso=enthalpy(water;s=s[4];P=P[5])

60: $s[4]=e n t r o p y($ water; $P=P[4] ; X=0)$

61: $T[5]=$ temperature $($ water; $h=h[5] ; P=P[5])$

62: $h[4]=$ enthalpy (water; $P=P[4] ; x=0)$

63: $\mathrm{T}[4]=\mathrm{T}[3]$

troca calor latente"

64: $P[4]=P[3]$

65: $s[5]=$ entropy(water; $P=P[5] ; T=T[5])$

66:

67: "TURBINA"

68: "REAQUECIMENTO"

69: "Extração de vapor da turbina"

70

71: eta_t $=(\mathrm{h}[1]-\mathrm{h}[8]) /(\mathrm{h}[1]-\mathrm{h} 8$ iso $)$

eficiencia isoentrópica"

72: h8_iso=enthalpy(water; $s=s[1] ; P=P[8]$ )

73: $T[8]=$ temperature(water; $h=h[8] ; P=P[8]$ )

74: $\mathrm{T}[18]=\mathrm{T}[8]$

75: $\mathrm{T}[17]=\mathrm{T}[8]$

76: $s[8]=e n t r o p y($ water; $h=h[8] ; P=P[8]$ )

77: $\mathrm{s}[18]=\mathrm{s}[8]$

78: $\mathrm{h}[18]=\mathrm{h}[8]$

79: $P[18]=P[8]$

80: $P[19]=P[8]$

81:

82: "Retorno de vapor da turbina"

83:

84: $h[19]=h[1]$

85: $T[19]=$ temperature (water; $h=h[19] ; P=P[19])$

86: $s[19]=e n t r o p y($ water; $T=T[19] ; P=P[19])$

87:

88

89: "Rendimento da turbina"

90:

91: eta_t $=(\mathrm{h}[19]-\mathrm{h}[2]) /(\mathrm{h}[19]-\mathrm{h} 2$ _iso $)$

desaerador através da eficiencia isoentrópica"

92: eta_t $=(\mathrm{h}[19]-\mathrm{h}[3]) /(\mathrm{h}[19]-\mathrm{h} 3$ _iso $)$

desaerador através da eficiencia isoentrópica"

93: eta_t $=(\mathrm{h}[19]-\mathrm{h}[11]) /(\mathrm{h}[19]-\mathrm{h} 11$ iso $)$ eficiencia isoentrópica"

94: eta_t $=(\mathrm{h}[19]-\mathrm{h}[15]) /(\mathrm{h}[19]-\mathrm{h} 15$ _iso $)$ eficiencia isoentrópica"

95: h15_iso=enthalpy(water;s=s[19];P=P[15]) expansão isoentrópica"

96: h11_iso=enthalpy(water;s=s[19]; $P=P[11]$ ) expansão isoentrópica"

97: h2_iso=enthalpy(water;s=s[19];P=P[2]) expansão isoentrópica"

98: h3_iso=enthalpy(water;s=s[19];P=P[3]) expansão isoentrópica"

99: $\mathrm{T}[2]=$ temperature (water; $\mathrm{h}=\mathrm{h}[2] ; \mathrm{P}=\mathrm{P}[2])$

100: $T[3]=$ temperature $($ water; $h=h[3] ; P=P[3])$
"Pressão de descarga da bomba igual a pressão do vapor de

"Determinação da entalpia real do líquido na descarga da bomba"

"Entalpia para condição ideal isentrópica"

"Entropia na saída do condensador - líquido saturado"

"Temperatura de recalque para desaerador"

"Entalpia da saída do condensador é a entalpia de líquido saturado"

"Temperatura de Entrada = temperatura de saída --> Somente

"Pressão de sucção da bomba = pressão da cauda da turbina" "Entropia da água de recalque da bomba 01"

"Determinação da entalpia real do vapor extraído através da

"Entalpia para condição ideal de expansão isoentrópica"

"Temperatura de saída para reaquecimento"

"Desprezadas perdas de carga no reaquecimento"

"Desprezadas perdas de carga no reaquecimento"

"Temperatura de retorno para turbina"

"Determinação da entalpia real do vapor extraído para o

"Determinação da entalpia real do vapor extraído para o

"Determinação da entalpia real do vapor extraído através da

"Determinação da entalpia real do vapor extraído através da

"Entalpia da corrente de vapor de escape para condição ideal de

"Entalpia da corrente de vapor de escape para condição ideal de

"Entalpia da corrente de vapor de escape para condição ideal de

"Entalpia da corrente de vapor na cauda para condição ideal de

"Temperatura do vapor de escape"

"Temperatura do vapor de cauda" 
101: $T[11]=$ temperature (water; $h=h[11] ; P=P[11])$

102: $T[15]=$ temperature $($ water; $h=h[15] ; P=P[15])$

103: $s[1]=e n t r o p y($ water; $P=P[1] ; T=T[1])$

104: s[2]=entropy(water;h=h[2];T=T[2])

105: s[3]=entropy(water;h=h[3];T=T[3])

106: $\mathrm{s}[11]=$ entropy $($ water; $\mathrm{h}=\mathrm{h}[11] ; \mathrm{T}=\mathrm{T}[11])$

107: $s[15]=e n t r o p y(w a t e r ; h=h[15] ; T=T[15])$

108: $x[2]=q u a l i t y($ water; $h=h[2] ; T=T[2])$

109: $x[3]=$ quality $($ water; $h=h[3] ; T=T[3])$

110:

111: "Balanço de massa na turbina"

112:

113: m_dot_vapor $+\mathrm{m} \_19=\mathrm{m} \_8+\mathrm{m} \_2+\mathrm{m} \_3+\mathrm{m} \_11+\mathrm{m} \_15$

114: m_18=m_19

115: m_dot_vap.escape $=$ m_2

116:

117: "DESSUPERAQUECEDOR E VAPOR DE PROCESSO"

118: "Balanços de massa"

119:

120: m_2=m_dot_vap.dessuper+m_dot_vap.desaerador

121: m_dot_vap.processo = Cons.Vapor_processo ${ }^{\star} \mathrm{M} \_$dot_cana ${ }^{\star}(1 / 1000)$

de vapor para o processo"

122: m_dot_vap.processo=m_dot_vap.dessuper+m_dot_agua.dessuper

123:

124: "Balanço de energia no dessuperaquecedor"

125: m_dot_vap.processo*h_pro=m_dot_vap.dessuper*h[2]+m_dot_agua.dessuper*h_rep.des

126: h_pro=enthalpy(water; $\left.T=T \_p r o ; x=1\right): T \_p r o=T \_s a t($ water; $P=P[2])$ industrial utiliza vapor saturado"

127:

128:

129: "PURGA DE CONDENSADO ANTES DE SER USADO NO PROCESSO"

130:

131: "RETORNO DE CONDENSADO DO PROCESSO INDUSTRIAL"

132: m_dot_retorno $=$ m_dot_vap.processo*0,9

133: T_cond=90 [C]

recuperação e retorna para o ciclo a 90 C"

134: $P \_$cond=P[2]

de escape"

135:

136: m_agua.dessuper=if(x[2];100;0;m_dot_agua.dessuper;0) "Se o vapor de escape estiver superaquecido agua deve ser alimentada no dessuperaquecedor para obter vapor saturado para o processo de produção do etanol"

137: m_dot_purgador=if(x[2];100;-m_dot_agua.dessuper;0;0)

de escape tiver $x<1$ o condensado precisa ser retirado em purgadores"

138:

139:

140: "DESAERADOR"

141: "Balanço de massa no desaerador"

142:

143: m_dot_retorno+m_dot_vap.desaerador+m_dot_vap.cauda+m_dot_rep.desaerador+m_dot_purgador + m_17 +m_11+m_15

$=$ m_dot_agua

144: m_dot_vap.cauda $=$ m_3

145:

146: "Balanço de energia no desaerador"

147:

148: m_dot_retorno*h_cond+m_dot_vap.desaerador*h[2]+m_dot_vap.cauda*h[5]+m_dot_rep.desaerador*h_rep.des

$+m \_d o t \_p u r g a d o r * h \_p u r g a d o r+m \_17^{*} h[9]+m \_11^{*} h[12]+m \_15^{*} h[16]=m \_d o t \_a g u a * h[6]$

149: $h \_$cond=enthalpy(water;T=T_cond; $P=P \_$cond): $h \_p u r g a d o r=e n t h a l p y($ water; $P=P[2] ; x=0): h \_r e p . d e s=e n t h a l p y($ water; $T$ $=\bar{T} \_$amb;P=P_rep.des): $T \_a m b=25$

150: $P$ rep.des $=P[2]$
"Temperatura do vapor extraído"
"Temperatura do vapor extraído"
"Estado definido por 2 propriedades independentes"
"Entropia do vapor de escape"
"Entropia do vapor de cauda"
"Entropia do vapor extraído"
"Entropia do vapor extraído"
"Título do vapor de escape"
"Título do vapor na cauda da turbina"

"Consumo

"Processo
"Considerado perdas no processo de 10\% da massa de vapor"

"Considerado que todo condensado é coletado em um tanque de

"Pressão de retorno = pressão no desaerador = Pressão do vapor 
File:Regeneração e Reaquecimento combinados - 2a Lei - otimizado.EES

151:

152:

153: "conversão de unidades para ton $/ h "$

154:

155: m_bar_vap.escape=m_2/1000 [ton/h]

156: m_bar_vap.cauda $=\mathrm{m} \_3 / 1000[$ ton $/ \mathrm{h}]$

157: m_bar_vap.processo=m_dot_vap.processo/1000 [ton/h]

158: m_bar_vap.desaerador=m_dot_vap.desaerador/1000 [ton/h]

159: m_bar_rep.desaerador=m_dot_rep.desaerador $/ 1000$ [ton $/ \mathrm{h}]$

160: $\mathrm{m}$ bar_feed.water. $=\mathrm{m}$ dot_agua $/ 1000[\mathrm{ton} / \mathrm{h}]$

161: m_bar_purga=m_dot_purga/1000 [ton/h]

162: m_bar_purgador=m_dot_purgador/1000 [ton/h]

163:

164:

165: "TROCADOR $h \times 1 "$

166:

167: $\mathrm{P}[9]=\mathrm{P}[8]$

168: $T[9]=T \_s a t($ water; $P=P[8])$

169: $h[9]=$ enthalpy (water; $P=P[9] ; X=0)$

170: $\mathrm{P}[10]=\mathrm{P}[7]$

"Desconside

rado perdas de carga para água de alimentação da caldeira nos trocadores de calor"

171: $h[10]=e n t h a l p y($ water; $T=T[10] ; P=P[10])$

172: m_dot_agua*h[14]-m_dot_agua*h[10]+m_17* $(\mathrm{h}[8]-\mathrm{h}[9])=0$

energia no $h \times 1 "$

"Balanço de

173: m_bar_vap.hx1=m_17/1000 [ton/h]

174: m_dot_vap.hx1=m_17

175: $\mathrm{h}[17]=\mathrm{h}[8]$

176:

177: "TROCADOR $h \times 2 "$

178:

179: $P[12]=P[11]$

180: $T[12]=T$ sat(water; $P=P[12])$

181: $h[12]=e n t h a l p y($ water; $P=P[12] ; X=0)$

182: $P[14]=P[7]$

183: $h[14]=$ enthalpy(water;T=T[14];P=P[14])

184: m_dot_agua*h[13]-m_dot_agua*h[14]+m_11* $(\mathrm{h}[11]-\mathrm{h}[12])=0$

"Balanço de energia no $h \times 2 "$

185: m_bar_vap.hx2=m_11/1000 [ton/h]

186: m_dot_vap.hx2=m_11

187:

188: "TROCADOR $h \times 3 "$

189:

190: $P[16]=P[15]$

191: $T[16]=T$ _sat(water; $P=P[16])$

192: $h[16]=$ enthalpy $($ water; $P=P[16] ; X=0)$

193: $P[13]=P[7]$

194: $h[13]=e n t h a l p y$ (water; $T=T[13] ; P=P[13]$ )

"T[13] deve ser fixado para controlar vazão de vapor de extração"

195: m_dot_agua*h[7]-m_dot_agua*h[13]+m_15* $(\mathrm{h}[15]-\mathrm{h}[16])=0$

"Balanço de energia no $h \times 3^{\prime \prime}$

196: m_bar_vap.hx3=m_15/1000 [ton/h]

197: m_dot_vap.hx3=m_15

198:

199: "Otimização dos trocadores de calor"

200: "Cálculo da temperatura de saída de cada trocador de calor"

201:

202: $\mathrm{T}[13]=\mathrm{T}[7]+$ DeltaT_opt trocador de calor a ser otimizado"

"DeltaT_opt é o incremento ótimo de temperatura em cada

203: $\mathrm{T}[14]=\mathrm{T}[13]+$ DeltaT_opt

204: $T[10]=T[14]+$ DeltaT_opt 
File:Regeneração e Reaquecimento combinados - 2a Lei - otimizado.EES

EES Ver. 9.433: \#0624: Depart. de Engenharia Mecanica Escola Politecnic, Escola Politecnica da USP, Sao Paulo, Brazil

205:

206: "Cálculo dos pontos ótimos de extração na turbina"

207:

208: $T T D=3,5[C]$

209: TTD=T_sat_hx3 - T[13]

"Diferença de Temperatura Terminal, parâmetro de entrada"

210: TTD=T_sat_hx2 - T[14]

211: TTD=T_sat_hx1 - T[10]

212:

213: "Pontos ótimos de extração"

214:

215: $P[17]=P \_S A T\left(\right.$ water; $\left.T=T \_s a t \_h \times 1\right)$

216: $P[11]=P$ SAT(water; $T=T$ _sat_hx2)

217: $P[15]=P \_S A T\left(\right.$ water; $\left.T=T \_s a t \_h \times 3\right)$

218:

219:

220: "CONDENSADOR"

221:

222: Q_dot_out $=\mathrm{m} \_3^{*}(\mathrm{~h}[3]-\mathrm{h}[4])$

vapor para a torre de resfriamento"

"Balanço de energia --> Calor transferido da condensação do

223:

224:

225: "TORRE DE RESFRIAMENTO"

226:

227: Q_dot_out $=m$ m_dot_recirculação*(h_out-h_in)

228: $h$ _out=enthalpy(water;P=P_out;T=T_out): $h$ _in=enthalpy(water;P=P_in;T=T_in): $P$ _in=1: $P$ _out=1:

229: m_dot_repos.torre $=Y$ Y_perdas*m_dot_recirculação $\quad$ "Y_perdas corresponde a uma estimativa de perdas de água por evaporação, purga e arraste na torre de resfriamento"

230: m_dot_rep.total $=m$ _dot_repos.torre $+\mathrm{m} \_$dot_rep.desaerador $+\mathrm{m}$ _dot_agua.dessuper

231: m_bar_repos.torre $=$ m_dot_repos.torre $/ 1000[$ ton $/ \mathrm{h}]$

232: m_bar_rep.total $=m \_d o t \_r e p . t o t a l / 1000[$ ton $/ \mathrm{h}]$

233: m_bar_vap.dessuper=m_dot_vap.dessuper/1000 [ton/h]

234: Perc.torre=m_dot_repos.torre/m_dot_rep.total*100

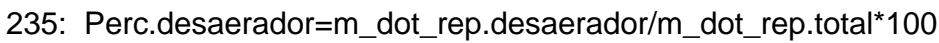

236: Perc.dessuper=m_dot_vap.dessuper/m_dot_rep.total ${ }^{\star} 100$

237: Tap.water_torre=m_dot_repos.torre/(m_dot_cana/1000)

238: Tap.water_deionised=(m_dot_rep.desaerador+m_dot_agua.dessuper) $/\left(\mathrm{m} \_d o t \_c a n a / 1000\right)$

239:

240:

241: "CÁlCULO DAS POTÊNCIAS ELÉTRICAS"

242: "Potência elétrica gerada"

243:

244: POT_elétr.gerada=(POT_1+POT_2 +POT_3 +POT_4 +POT_5 +POT_reaq)*eta_g*convert(kJ/h;MW)

"Potencia elétrica total gerada no turbogerador"

245: POT_reaq $=m$ _18* $(\mathrm{h}[1]-\mathrm{h}[8])$

246: POT_1=m_2*(h[19]-h[2])

247: POT_2=m_3*(h[19]-h[3])

248: POT_3=m_17*(h[1]-h[8]) turbina direcionado ao trocador $h \times 1 "$

249: POT_4=m_11*(h[19]-h[11]) turbina direcionado ao trocador $h \times 2^{\prime \prime}$

250: POT_5=m_15*(h[19]-h[15])

turbina direcionado ao trocador $h \times 3^{\prime \prime}$

251:

252: "Consumo das bombas do ciclo"

253:

254: POT_elétr.consumida=(POT_B1+POT_B2) ${ }^{\star}$ convert(kJ/h;MW)

"Potencia gerada pelo vapor de reaquecimento"

"Potencia gerada pelo vapor de escape a $P=2,5 b a r "$

"Potencia gerada pelo vapor da cauda"

"Potencia gerada pelo vapor extraído no primeiro estágio da

"Potencia gerada pelo vapor de extraído no segundo estágio da consumida pelas bombas"

255: POT_B1 $=m \_3 *(h[5]-h[4])$

256: POT_B2 $=$ m_dot_agua* $(\mathrm{h}[7]-\mathrm{h}[6])$

"Potência consumida pela bomba 1"

"Potência consumida pela bomba 1" 
File:Regeneração e Reaquecimento combinados - 2a Lei - otimizado.EES

EES Ver. 9.433: \#0624: Depart. de Engenharia Mecanica Escola Politecnic, Escola Politecnica da USP, Sao Paulo, Brazil

257:

258: "EFICIÊNCIA GLOBAL DA UNIDADE DE COGERAÇÃO"

259:

260: eta_Energética.Global=(POT_elétr.líquida + POT_processo)/POT_entrada*100

261:

262: "Potência líquida gerada na unidade de cogeração"

263:

264: POT_elétr.líquida = POT_elétr.gerada - POT_elétr.consumida

265:

266:

267: "Potência utilizada no processo industrial e desaerador"

268:

269: POT_processo=m_dot_vap.processo*(h_pro-h_sat)*convert(kJ/h;MW)

270: POT_desaerador=m_dot_vap.desaerador* $(\mathrm{h}[2]-\mathrm{h}[6])^{\star}{ }^{*} \operatorname{convert}(\mathrm{kJ} / \mathrm{h} ; \mathrm{MW})$

271: POT_desaerador.perc=POT_desaerador/POT_entrada*100

272: POT_processo.perc=POT_processo/POT_entrada*100

273: h_sat=enthalpy(water; $x=0 ; p=2,5)$

274:

275:

276: "Alimentação energética na fornalha da caldeira"

277: POT_entrada=(m_dot_bagaço*PCl_bagaço+m_dot_palha*PCI_palha ${ }^{*}$ convert $(\mathrm{kJ} / \mathrm{h} ; \mathrm{MW})$

278:

279:

280: "APLICAÇÃO DA 2A LEI DA TERMODINÂMICA - ANÁLISE EXERGÉTICA"

281: "Ambiente de referência considerado: $P o=1$ bar e To=25 C"

282: $\mathrm{TO}=25[\mathrm{C}]$

283: $\mathrm{PO}=1$ [Bar]

284: P00_h20=0,0303 [Bar]

285:

286: "LIMITE TEÓRICO DE EFICIÊNCIA - CICLO DE CARNOT"

287: eta_Carnot $=(1-(T[3]+273,15) /(T[1]+273,15))^{\star 100} \quad$ "Trabalho máximo que pode ser obtido"

288:

289: "Trabalho útil final - saída do gerador"

290: EXERGY.in_fuel=POT_entrada

291: EXERGY.out_electricity=POT_elétr.líquida

"energia elétrica é exergia pura"

292: EXERGY.out_electricity.perc=POT_elétr.líquida/POT_entrada*100

293:

294: "BOILER"

295: B_1=m_dot_vapor* $\left(\mathrm{h}[1]-\mathrm{h}[0]-(\mathrm{T0}+273,15)^{\star}(\mathrm{s}[1]-\mathrm{s}[0])\right)^{\star} \operatorname{convert}(\mathrm{kJ} / \mathrm{h} ; \mathrm{MW})$

"Exergia do vapor de saída do gerador de vapor"

296: $\mathrm{h}[0]=$ enthalpy (water; $\mathrm{t}=\mathrm{T0} ; \mathrm{P}=\mathrm{P0}$ )

297: $s[0]=e n t r o p y($ water; $t=T 0 ; P=P 0)$

298: B_fuel=EXERGY.in_fuel

299:

300:

301:

302: "TURBINE"

303: "Exergia das correntes de vapor de escape e cauda"

304:

305: B_2=m_dot_vap.escape ${ }^{*}\left(\mathrm{~h}[2]-\mathrm{h}[0]-(\mathrm{T0}+273,15)^{\star}(\mathrm{s}[2]-\mathrm{s}[0])\right)^{\star}$ convert $(\mathrm{kJ} / \mathrm{h} ; \mathrm{MW})$

vapor de escape"

306: B_3=m_dot_vap.cauda*(h[3]-h[0]-(T0+273,15)*(s[3]-s[0]) ${ }^{\star}$ convert(kJ/h;MW)

"Exergia do

vapor de cauda"

307:

308: "Exergia da corrente de reaquecimento"

309:

310: B_18=m_18*(h[18]-h[0]-(T0+273,15)*(s[18]-s[0]) ${ }^{\star}$ convert $(\mathrm{kJ} / \mathrm{h} ; \mathrm{MW})$

"Exergia do vapor para reaquecimento na saída da turbina" 
314: "Exergia das correntes de regeneração para os trocadores $h \times 1, h \times 2$ e hx3"

315:

316: B_17=m_dot_vap.hx1*(h[17]-h[0]-(T0+273,15)*(s[17]-s[0]))*convert(kJ/h;MW)

"Exergia do vapor da primeira extração da turbina"

317: $\mathrm{s}[17]=\mathrm{s}[8]$

318: B_11=m_dot_vap.hx2*(h[11]-h[0]-(T0+273,15)*(s[11]-s[0]))*convert(kJ/h;MW)

"Exergia do vapor da segunda extração da turbina"

319: B_15=m_dot_vap.hx3*(h[15]-h[0]-(T0+273,15)*(s[15]-s[0]) $)^{\star} \operatorname{convert}(\mathrm{kJ} / \mathrm{h} ; \mathrm{MW})$

"Exergia do

320

vapor da segunda extração da turbina"

322: "Balanço de exergia na turbina"

323:

324: Bdest turbine $=B \_1+B \_19-\left(B \_2+B \_3\right)-\left(B \_18\right)-\left(B \_17+B \_11+B \_15\right)-P O T \_e l e ́ t r . g e r a d a / e t a \_g$

"Exergia destruída na turbina"

325: Bdest_turbine.perc=Bdest_turbine/B_fuel ${ }^{\star} 100$

"Percentual de exergia destruída na turbina"

326: B_2_perc=B_2/B_fuel*100

"Percentual

de exergia no vapor de escape"

327: B_liq=POT_elétr.gerada/B_fuel*100

"Percentual 328

329: "Consumo de exergia no processo industrial associado ao consumo específico de vapor"

330:

331: EXERGY.out_process=m_dot_vap.processo*(h_pro-h[0]-(T0+273,15)*(s_pro-s[0]))*convert(kJ/h;MW)

332: s_pro $=$ entropy $($ water $; p=2,5 ; t=127,5)$

333: EXERGY.out_process.perc=EXERGY.out_process/B_fuel*100

334: EXERGY.out_deaerator=B_2-EXERGY.out_process

335: EXERGY.out_deaerator.perc=EXERGY.out_deaerator/B_fuel*100

336:

337:

338: "DESSUPERAQUECEDOR"

339: "Balanço de entropia no dessuper"

340:

341: S_ger.dessuper=m_dot_vap.processo*s_pro - $\left(\mathrm{m} \_\right.$agua.dessuper ${ }^{\star} \mathrm{s} \_$agua $\left.+\left(\mathrm{m} \_ \text {dot_vap.dessuper-m_dot_purgador }\right)^{\star} \mathrm{s}[2]\right)$

342: s_agua $=$ entropy $($ water $; p=2,5 ; t=25)$

343: Bdest_dessuper $=(\mathrm{T} 0+273,15) \star S \_g e r . d e s s u p e{ }^{\star}{ }^{*}$ convert(kJ/h;MW)

"Exergia

destruída no dessuperaquecedor"

344: Bdest_dessuper.perc=Bdest_dessuper/B_fuel ${ }^{\star} 100$

"Percentual

de exergia destruída no dessuperaquecedor"

345:

346: "CONDENSADOR"

347: B_4=m_dot_vap.cauda*(h[4]-h[0]-(T0+273,15)*(s[4]-s[0]))*convert(kJ/h;MW)

"Exergia na saída do condensador"

348: Bdest_condenser=B_3-B_4

"Exergia destruída no condensador"

349: Bdest_condenser.perc=Bdest_condenser/B_fuel*100 "Percentual de exergia destruída no condensador" 350:

351: "BOMBA 1"

352: B_5=m_dot_vap.cauda*(h[5]-h[0]-(T0+273,15)*(s[5]-s[0]))*convert(kJ/h;MW)

"Exergia na saída da bomba 1"

353: Bdest_B1=B_4-B_5 +W_B1

"Exergia destruída na bomba 1"

354: W_B1=m_dot_vap.cauda $(\mathrm{h}[5]-\mathrm{h}[4])^{\star} \operatorname{convert}(\mathrm{kJ} / \mathrm{h} ; \mathrm{MW})$

"Trabalho realizado pela bomba $B 1^{\prime \prime}$ 
357: "DESAERADOR"

358: "Balanço de entropia no dessuperaquecedor"

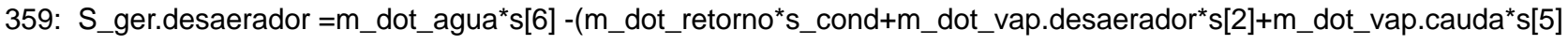

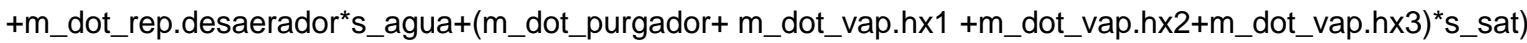

360: s_cond=entropy(water; $T=T$ _cond; $P=P$ _cond): $s_{-}$sat=entropy (water; $P=2,5 ; X=0$ )

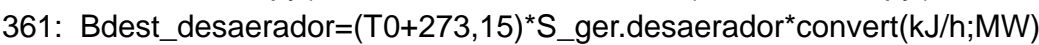

"Exergia destruída no desaerador"

362: Bdest_desaerador.perc=Bdest_desaerador/B_fuel ${ }^{\star} 100$

"Percentual de exergia destruída no desaerador"

363:

364: "BOMBA 2"

365: B_7=m_dot_agua*(h[7]-h[0]-(T0+273,15)*(s[7]-s[0]))*convert(kJ/h;MW)

"Exergia na saída da bomba 2"

366: B_6=m_dot_agua* $(\mathrm{h}[6]-\mathrm{h}[0]-(\mathrm{T0}+273,15) *(\mathrm{~s}[6]-\mathrm{s}[0]))^{*}$ convert $(\mathrm{kJ} / \mathrm{h} ; \mathrm{MW})$

"Exergia na entrada da bomba 2"

367: W_B2=m_dot_agua* $(\mathrm{h}[7]-\mathrm{h}[6]))^{*}$ convert $(\mathrm{kJ} / \mathrm{h} ; \mathrm{MW})$

"Trabalho realizado pela bomba $B 2^{\prime \prime}$

368: Bdest_B2=B_7-B_6 +W_B2

"Exergia

destruída na bomba 2 "

369: Bdest_B2.perc=Bdest_B2/B_fuel ${ }^{\star} 100$

"Percentual de exergia destruída na bomba $2^{\prime \prime}$

370:

371:

372: "BOILER"

373:

374: B_10 + B_fuel +B_18 = B_1+B_purga+B_19+Bdest_boiler

"Balanço de exergia na caldeira"

375: Bdest_boiler.perc=Bdest_boiler/B_fuel ${ }^{\star} 100$

"Percentual de exergia destruída na caldeira"

376: B_10=m_dot_agua*(h[10]-h[0]-(T0+273,15)*(s[10]-s[0]))*convert(kJ/h;MW)

"Exergia da corrente de agua na entrada da caldeira"

377: B_purga $=m$ _dot_purga* $\left(\mathrm{h} \_p u r g a-h[0]-(T 0+273,15) \star\left(s \_p u r g a-s[0]\right)\right)^{\star}$ convert $(\mathrm{kJ} / \mathrm{h} ; \mathrm{MW})$

378: s_purga=entropy(water;h=h_purga;T=T_purga):s[10]=entropy(water;T=T[10];P=P[10])

379:

380:

381: "TROCADOR DE CALOR TC 1"

382: "Balanço de exergia no TC1"

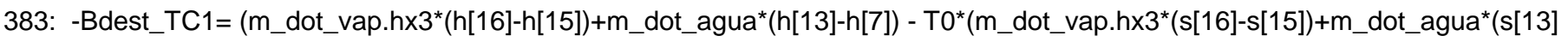
-s[7])))*convert(kJ/h;MW)

384: $s[16]=e n t r o p y(w a t e r ; p=p[16] ; x=0): s[13]=e n t r o p y($ water; $p=p[13] ; T=T[13])$

385: Bdest_TC1.perc=Bdest_TC1/B_fuel*100

"Percentual de exergia destruída no TC1"

386:

387: "TROCADOR DE CALOR TC 2"

388: "Balanço de exergia no TC2"

389: -Bdest_TC2 $=\left(\mathrm{m} \_\right.$dot_vap.hx2* $(\mathrm{h}[12]-\mathrm{h}[11])+\mathrm{m} \_$dot_agua ${ }^{\star}(\mathrm{h}[14]-\mathrm{h}[13])-\mathrm{T} 0^{\star}\left(\mathrm{m} \_\right.$dot_vap.hx2*$(\mathrm{s}[12]-\mathrm{s}[11])+\mathrm{m} \_$dot_agua $(\mathrm{s}[14$ ]-s[13])))*convert(kJ/h;MW)

390: $s[12]=e n t r o p y(w a t e r ; p=p[12] ; x=0): s[14]=e n t r o p y($ water; $p=p[14] ; T=T[14])$

391: Bdest_TC2.perc=Bdest_TC2/B_fuel ${ }^{\star} 100$

de exergia destruída no TC2"

392:

393: "TROCADOR DE CALOR TC 3"

394: "Balanço de exergia no TC3"

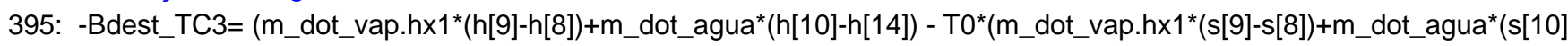
$-\mathrm{s}[14])))^{\star}$ convert(kJ/h;MW)

396: $s[9]=e n t r o p y($ water; $p=p[9] ; x=0)$ : 
File:Regeneração e Reaquecimento combinados - 2a Lei - otimizado.EES

30/05/2014 18:44:16 Page 9

EES Ver. 9.433: \#0624: Depart. de Engenharia Mecanica Escola Politecnic, Escola Politecnica da USP, Sao Paulo, Brazil

397: Bdest_TC3.perc=Bdest_TC3/B_fuel ${ }^{\star} 100$

"Percentual

de exergia destruída no TC3"

398:

399:

400: Total_exergy.dest=Bdest_B1+Bdest_B2+Bdest_desaerador+Bdest_condenser+Bdest_boiler+Bdest_turbine+Bdest_TC1

+Bdest_TC2+Bdest_TC3

401: Total_exergy.dest.perc=Total_exergy.dest/B_fuel`100

402:

403:

404:

405: "Eficiência Exergética"

406: "Cálculo da eficiência exergética global"

407:

408: eta_EXergética.Global=(POT_elétr.líquida + EXERGY.out_process)/B_fuel`100

"Energia

elétrica é exergia pura!"

409:

410: eta_Ex.ref.Carnot=eta_EXergética.Global/eta_Carnot¹00

411:

412:

413: "Distribuição de exergia entre vapor e eletricidade"

414:

415: Exergia_vapor.perc $=$ EXERGY.out_process/(POT_elétr.líquida + EXERGY.out_process)^100

416:

417: Exergia_eletricidade.perc $=$ POT_elétr.líquida/(POT_elétr.líquida + EXERGY.out_process)*100

418:

419:

420:

421: "ALOCAÇÃO"

422:

423: "Critério energético"

424: POT_específica_processo = POT_processo*Período_safra*1000*24/Cana_safra

425: Alocação_energia_vapor = POT_específica_processo/(POT_específica_processo+GeraçãoEletric.Espec.Excedente + ConsumoEletr.Processo ${ }^{\star} 100$

426: Alocação_energia_eletr.exp = GeraçãoEletric.Espec.Excedente/(POT_específica_processo

+GeraçãoEletric.Espec.Excedente+ConsumoEletr.Processo ${ }^{\star} 100$

427: Alocação_energia_eletr.proc = ConsumoEletr.Processo/(POT_específica_processo+GeraçãoEletric.Espec.Excedente + ConsumoEletr.Processo ${ }^{\star} 100$

428:

429:

430: "Critério exergético"

431: EXERGY.out_específica_process = EXERGY.out_process*Período_safra*1000*24/Cana_safra

432: Alocação_exergia_vapor $=$ EXERGY.out_específica_process/(EXERGY.out_específica_process + GeraçãoEletric.Espec.Excedente+ConsumoEletr.Processo $)^{\star} 100$

433: Alocação_exergia_eletr.exp = GeraçãoEletric.Espec.Excedente/(EXERGY.out_específica_process

+GeraçãoEletric.Espec.Excedente+ConsumoEletr.Processo)*100

434: Alocação_exergia_eletr.proc = ConsumoEletr.Processo/(EXERGY.out_específica_process

+GeraçãoEletric.Espec.Excedente+ConsumoEletr.Processo ${ }^{\star} 100$

435:

436:

437:

438:

439:

440:

441:

442:

443: "ANÁLISE COMPLEMENTAR 1A LEI - PERDAS ENERGÉTICAS"

444: "Perdas na Caldeira e turbina"

445:

446: Boiler_losses=POT_entrada*(1-eta_c) 
447: Boiler_losses.perc=Boiler_losses/POT_entrada*100

448: Turbine_losses=(POT_1+POT_2 +POT_3 +POT_4 +POT_5 +POT_reaq)*(1-eta_t)*convert(kJ/h;MW)

449: Turbine_losses.perc=Turbine_losses/POT_entrada $* 100$

450:

451: "Perdas no condensador"

452:

453: POT_condensador $=$ Q_dot_out*convert $(\mathrm{kJ} / \mathrm{h} ; \mathrm{MW})$

"Energia perdida no condensador"

454: POT_condensador.perc=POT_condensador/POT_entrada*100

455: Condenser_losses=POT_condensador

456:

457: "Perdas no processo"

458:

459: process_losses = POT_entrada - (POT_processo+POT_elétr.gerada+POT_condensador+Turbine_losses+Boiler_losses)

460: process_losses.perc=process_losses/POT_entrada*100

461:

462: "Cálculo da energia elétrica gerada por tonela de cana por tonelada de cana"

463:

464: GeraçãoEletric.Espec. Total =POT_elétr.líquida*Período_safra*1000*24/Cana_safra

465:

466: GeraçãoEletric.Espec.Excedente = GeraçãoEletric.Espec.Total - ConsumoEletr.Processo

467:

468:

469: "Distribuição de energia entre vapor e eletricidade"

470:

471: Energia_vapor.perc $=$ POT_processo/(POT_processo + POT_elétr.líquida $)^{\star 100}$

472:

473: Energia_eletricidade.perc $=$ POT_elétr.líquida/(POT_processo + POT_elétr.líquida)^100

474:

475:

APÊNDICE D - MODELAGEM TERMODINÂMICA DO SISTEMA DE COGERAÇÃO COM CICLO RANKINE RESULTANTE

Dados da Safra

$\dot{\mathrm{M}}_{\text {cana }}=\frac{\text { Cana }_{\text {safra }}}{\text { Período }_{\text {safra }}} \cdot \frac{1000}{24[\mathrm{~kg} / \mathrm{h}]}$ Taxa de Moagem de cana

$\dot{\mathrm{m}}_{\text {bagaço }}=\frac{\mathrm{Y}_{\text {bagaço }}}{100} \cdot \dot{\mathrm{M}}_{\text {cana }} \cdot \frac{\text { Utilização }_{\text {Bagaço }}}{100}$ Alimentação de bagaço de cana

$\dot{\mathrm{m}}_{\text {palha }}=\frac{\mathrm{Y}_{\text {palha }}}{100} \cdot \dot{\mathrm{M}}_{\text {cana }} \cdot \frac{\text { Utilização }_{\text {Palha }}}{100}$ Alimentação de palha de cana

Razão ${ }_{\text {biomassor }}^{\text {vassa. }} \frac{\dot{\mathrm{m}}_{\text {vapor }}}{\mathrm{m}_{\text {bagaço }}}$ Razão entre produção de vapor e consumo de biomassa

$\overline{\mathrm{m}}_{\text {bagaço }}=\frac{\dot{\mathrm{m}}_{\text {bagaço }}}{1000[\text { ton } / \mathrm{h}]}$

$\overline{\mathrm{m}}_{\text {palha }}=\frac{\dot{\mathrm{m}}_{\text {palha }}}{1000[\text { ton } / \mathrm{h}]}$

GERADOR DE VAPOR - Modelagem de conservação de matéria e energia

Balanço de massa no gerador de vapor

$\dot{\mathrm{m}}_{\text {agua }}+\mathrm{m}_{18}=\mathrm{m}_{19}+\dot{\mathrm{m}}_{\text {vapor }}+\dot{\mathrm{m}}_{\text {purga }}$ 
$\dot{\mathrm{m}}_{\text {purga }}=\mathrm{Y}_{\text {purga }} \cdot \dot{\mathrm{m}}_{\text {vapor }}$

$\mathrm{Y}_{\text {purga }}=0,03$ Taxa de purga considerada $=3 \%$

$\overline{\mathrm{M}}_{\text {vapor }}=\frac{\dot{\mathrm{m}}_{\text {vapor }}}{1000[\text { ton } / \mathrm{h}]}$

Balanço de massa Reaquecimento

$\overline{\mathrm{m}}_{\text {vap.reaq }}=\frac{\mathrm{m}_{18}}{1000[\mathrm{ton} / \mathrm{h}]}$

$\mathrm{m}_{8}=\dot{\mathrm{m}}_{\text {vapor }}$

$\mathrm{m}_{18}=\mathrm{m}_{8}-\mathrm{m}_{17}$

$\overline{\mathrm{m}}_{8}=\frac{\mathrm{m}_{8}}{1000[\text { ton } / \mathrm{h}]}$

Balanços de energia no gerador de vapor

$\dot{\mathrm{m}}_{\text {agua }} \cdot \mathrm{h}_{10}+\dot{\mathrm{Q}}_{\mathrm{c}}=\dot{\mathrm{m}}_{\text {vapor }} \cdot \mathrm{h}_{1}+\dot{\mathrm{m}}_{\text {purga }} \cdot \mathrm{h}_{\text {purga }}+\dot{\mathrm{Q}}_{\text {reaq }}$

$\dot{\mathrm{Q}}_{\mathrm{c}}=\left[\dot{\mathrm{m}}_{\text {bagaço }} \cdot \mathrm{PCl}_{\text {bagaço }}+\dot{\mathrm{m}}_{\text {palha }} \cdot \mathrm{PCl}_{\text {palha }}\right] \cdot \eta_{\mathrm{c}}$ Energia utilizada na fornecida na fornalha para evaporação da água $\dot{\mathrm{Q}}_{\text {reaq }}=\mathrm{m}_{18} \cdot\left[\mathrm{h}_{19}-\mathrm{h}_{18}\right]$

$\mathrm{h}_{1}=\mathbf{h}\left[\right.$ water $\left.; \mathrm{T}=\mathrm{T}_{1} ; \mathrm{P}=\mathrm{P}_{1}\right] \quad \mathrm{h}_{\text {purga }}=\mathbf{h}\left[\right.$ water $\left.; \mathrm{T}=\mathrm{T}_{\text {purga }} ; \mathrm{x}=0\right]$

$\mathrm{P}_{7}=1,2 \cdot \mathrm{P}_{\mathrm{c}} \quad \mathrm{T}_{\text {purga }}=\mathrm{T}_{\text {sat }}\left[\right.$ water $\left.; \mathrm{P}=\mathrm{P}_{\mathrm{c}}\right] \quad \mathrm{P}_{\text {purga }}=\mathrm{P}_{\mathrm{c}} \quad \mathrm{P}_{1}=\mathrm{P}_{\mathrm{c}}$

$\mathrm{PCl}_{\text {bagaço }}=7565 \quad \mathrm{PCl}_{\text {palha }}=12960[\mathrm{~kJ} / \mathrm{kg}]$ Poder calorífico inferior do bagaço e da palha de cana

$\mathrm{T}_{1}=\mathbf{T}_{\text {sat }}\left[\right.$ water $\left.; \mathrm{P}=\mathrm{P}_{\mathrm{c}}\right]+\mathrm{G}_{\text {super }}$ Temperatura do vapor superaquecido

$\mathrm{G}_{\text {super }}=200 \quad[\mathrm{C}]$ Grau de superaqucimento

BOMBA 02 - ALIMENTAÇÃO DA CALDEIRA

$\mathrm{P}_{6}=\mathrm{P}_{2}$ Pressão de descarga da bomba igual a pressão do vapor de escape

$\eta_{\mathrm{B} 2}=\frac{\mathrm{h}_{6}-\mathrm{h} 7_{\text {iso }}}{\mathrm{h}_{6}-\mathrm{h}_{7}}$ Determinação da entalpia real da vazão de líquido na descarga da bomba

$\eta_{\text {B2 }}=0,85$

$\mathrm{h} 7_{\text {iso }}=\mathbf{h}\left[\right.$ water $\left.; \mathrm{s}=\mathrm{s}_{6} ; \mathrm{P}=\mathrm{P}_{7}\right]$ Entalpia para condição ideal isentrópica

$\mathrm{h}_{6}=\mathbf{h}\left[\right.$ water $\left.; \mathrm{P}=\mathrm{P}_{6} ; \mathrm{T}=\mathrm{T}_{6}\right]$ Entalpia na saída do desaerador

$\mathrm{S}_{6}=\mathbf{s}\left[\right.$ water $\left.; \mathrm{P}=\mathrm{P}_{6} ; \mathrm{T}=\mathrm{T}_{6}\right]$ Entropia na saída do desaerador é entropia do líquido saturado

$\mathrm{T}_{7}=\mathbf{T}\left[\right.$ water $\left.; \mathrm{h}=\mathrm{h}_{7} ; \mathrm{P}=\mathrm{P}_{7}\right]$ Temperatura de recalque

$\mathrm{s}_{7}=\mathbf{s}\left[\right.$ water $\left.; \mathrm{h}=\mathrm{h}_{7} ; \mathrm{P}=\mathrm{P}_{7}\right]$ Entropia da água de alimentação da caldeira

BOMBA 01 - CONDENSADO

$\mathrm{P}_{5}=\mathrm{P}_{2}$ Pressão de descarga da bomba igual a pressão do vapor de escape 
$\eta_{\mathrm{B} 1}=\frac{\mathrm{h}_{4}-\mathrm{h}_{\text {iso }}}{\mathrm{h}_{4}-\mathrm{h}_{5}}$ Determinação da entalpia real do líquido na descarga da bomba

$\eta_{B 1}=0,85$

$\mathrm{h}_{\text {iso }}=\mathbf{h}\left[\right.$ water $\left.; \mathrm{s}=\mathrm{s}_{4} ; \mathrm{P}=\mathrm{P}_{5}\right]$ Entalpia para condição ideal isentrópica

$\mathrm{S}_{4}=\mathbf{s}\left[\right.$ water $; \mathrm{P}=\mathrm{P}_{4} ; \mathrm{x}=0$ ] Entropia na saída do condensador - líquido saturado

$\mathrm{T}_{5}=\mathbf{T}\left[\right.$ water $\left.; \mathrm{h}=\mathrm{h}_{5} ; \mathrm{P}=\mathrm{P}_{5}\right]$ Temperatura de recalque para desaerador

$\mathrm{h}_{4}=\mathbf{h}\left[\right.$ water $\left.; \mathrm{P}=\mathrm{P}_{4} ; \mathrm{x}=0\right]$ Entalpia da saída do condensador é a entalpia de líquido saturado

$\mathrm{T}_{4}=\mathrm{T}_{3}$ Temperatura de Entrada = temperatura de saída --> Somente troca calor latente

$\mathrm{P}_{4}=\mathrm{P}_{3}$ Pressão de sucção da bomba $=$ pressão da cauda da turbina

$\mathrm{S}_{5}=\mathbf{s}\left[\right.$ water $\left.; \mathrm{P}=\mathrm{P}_{5} ; \mathrm{T}=\mathrm{T}_{5}\right]$ Entropia da água de recalque da bomba 01

\section{TURBINA}

\section{REAQUECIMENTO}

Extração de vapor da turbina

$\eta_{\mathrm{t}}=\frac{\mathrm{h}_{1}-\mathrm{h}_{8}}{\mathrm{~h}_{1}-\mathrm{h} 8_{\text {iso }}}$ Determinação da entalpia real do vapor extraído através da eficiencia isoentrópica

h8 ${ }_{\text {iso }}=\mathbf{h}\left[\right.$ water $\left.; \mathrm{s}=\mathrm{s}_{1} ; \mathrm{P}=\mathrm{P}_{8}\right]$ Entalpia para condição ideal de expansão isoentrópica

$\mathrm{T}_{8}=\mathbf{T}\left[\right.$ water $\left.; \mathrm{h}=\mathrm{h}_{8} ; \mathrm{P}=\mathrm{P}_{8}\right]$ Temperatura de saída para reaquecimento

$\mathrm{T}_{18}=\mathrm{T}_{8}$

$\mathrm{T}_{17}=\mathrm{T}_{8}$

$\mathrm{s}_{8}=\mathbf{s}\left[\right.$ water $\left.; \mathrm{h}=\mathrm{h}_{8} ; \mathrm{P}=\mathrm{P}_{8}\right]$

$\mathrm{s}_{18}=\mathrm{s}_{8}$

$\mathrm{h}_{18}=\mathrm{h}_{8}$

$\mathrm{P}_{18}=\mathrm{P}_{8}$ Desprezadas perdas de carga no reaquecimento

$\mathrm{P}_{19}=\mathrm{P}_{8} \quad$ Desprezadas perdas de carga no reaquecimento

Retorno de vapor da turbina

$\mathrm{h}_{19}=\mathrm{h}_{1}$

$\mathrm{T}_{19}=\mathbf{T}\left[\right.$ water $\left.; \mathrm{h}=\mathrm{h}_{19} ; \mathrm{P}=\mathrm{P}_{19}\right]$ Temperatura de retorno para turbina

$\mathrm{S}_{19}=\mathbf{s}\left[\right.$ water $\left.; \mathrm{T}=\mathrm{T}_{19} ; \mathrm{P}=\mathrm{P}_{19}\right]$

Rendimento da turbina

$\eta_{\mathrm{t}}=\frac{\mathrm{h}_{19}-\mathrm{h}_{2}}{\mathrm{~h}_{19}-\mathrm{h} 2_{\text {iso }}}$ Determinação da entalpia real do vapor extraído para o desaerador através da eficiencia isoentrópica 
EES Ver. 9.433: \#0624: Depart. de Engenharia Mecanica Escola Politecnic, Escola Politecnica da USP, Sao Paulo, Brazil

$\eta_{\mathrm{t}}=\frac{\mathrm{h}_{19}-\mathrm{h}_{3}}{\mathrm{~h}_{19}-\mathrm{h} 3_{\text {iso }}}$ Determinação da entalpia real do vapor extraído para o desaerador através da eficiencia isoentrópica

$\eta_{\mathrm{t}}=\frac{\mathrm{h}_{19}-\mathrm{h}_{11}}{\mathrm{~h}_{19}-\mathrm{h}_{1} 1_{\text {iso }}}$ Determinação da entalpia real do vapor extraído através da eficiencia isoentrópica

$\eta_{\mathrm{t}}=\frac{\mathrm{h}_{19}-\mathrm{h}_{15}}{\mathrm{~h}_{19}-\mathrm{h} 15_{\text {iso }}}$ Determinação da entalpia real do vapor extraído através da eficiencia isoentrópica

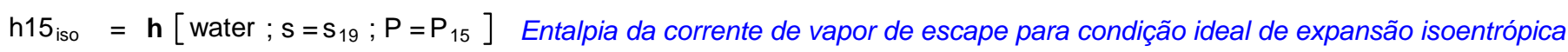

$\mathrm{h} 11_{\text {iso }}=\mathbf{h}\left[\right.$ water $\left.; \mathrm{s}=\mathrm{s}_{19} ; \mathrm{P}=\mathrm{P}_{11}\right]$ Entalpia da corrente de vapor de escape para condição ideal de expansão isoentrópica

$\mathrm{h} 2_{\text {iso }}=\mathbf{h}\left[\right.$ water $\left.; \mathrm{s}=\mathrm{s}_{19} ; \mathrm{P}=\mathrm{P}_{2}\right]$ Entalpia da corrente de vapor de escape para condição ideal de expansão isoentrópica

h3 $3_{\text {iso }}=\mathbf{h}\left[\right.$ water $\left.; \mathrm{s}=\mathrm{s}_{19} ; \mathrm{P}=\mathrm{P}_{3}\right]$ Entalpia da corrente de vapor na cauda para condição ideal de expansão isoentrópica

$\mathrm{T}_{2}=\mathbf{T}\left[\right.$ water $\left.; \mathrm{h}=\mathrm{h}_{2} ; \mathrm{P}=\mathrm{P}_{2}\right]$ Temperatura do vapor de escape

$\mathrm{T}_{3}=\mathbf{T}\left[\right.$ water $\left.; \mathrm{h}=\mathrm{h}_{3} ; \mathrm{P}=\mathrm{P}_{3}\right]$ Temperatura do vapor de cauda

$\mathrm{T}_{11}=\mathbf{T}\left[\right.$ water $\left.; \mathrm{h}=\mathrm{h}_{11} ; \mathrm{P}=\mathrm{P}_{11}\right]$ Temperatura do vapor extraído

$\mathrm{T}_{15}=\mathbf{T}\left[\right.$ water $\left.; \mathrm{h}=\mathrm{h}_{15} ; \mathrm{P}=\mathrm{P}_{15}\right]$ Temperatura do vapor extraído

$\mathrm{s}_{1}=\mathbf{s}\left[\right.$ water $\left.; \mathrm{P}=\mathrm{P}_{1} ; \mathrm{T}=\mathrm{T}_{1}\right] \quad$ Estado definido por 2 propriedades independentes

$\mathrm{s}_{2}=\mathbf{s}\left[\right.$ water $\left.; \mathrm{h}=\mathrm{h}_{2} ; \mathrm{T}=\mathrm{T}_{2}\right]$ Entropia do vapor de escape

$\mathrm{s}_{3}=\mathbf{s}\left[\right.$ water $\left.; \mathrm{h}=\mathrm{h}_{3} ; \mathrm{T}=\mathrm{T}_{3}\right]$ Entropia do vapor de cauda

$\mathrm{s}_{11}=\mathbf{s}\left[\right.$ water $\left.; \mathrm{h}=\mathrm{h}_{11} ; \mathrm{T}=\mathrm{T}_{11}\right]$ Entropia do vapor extraído

$\mathrm{s}_{15}=\mathbf{s}\left[\right.$ water $\left.; \mathrm{h}=\mathrm{h}_{15} ; \mathrm{T}=\mathrm{T}_{15}\right]$ Entropia do vapor extraído

$\mathrm{x}_{2}=\mathbf{x}\left[\right.$ water $\left.; \mathrm{h}=\mathrm{h}_{2} ; \mathrm{T}=\mathrm{T}_{2}\right]$ Título do vapor de escape

$\mathrm{x}_{3}=\mathbf{x}\left[\right.$ water $\left.; \mathrm{h}=\mathrm{h}_{3} ; \mathrm{T}=\mathrm{T}_{3}\right]$ Título do vapor na cauda da turbina

Balanço de massa na turbina

$\dot{\mathrm{m}}_{\text {vapor }}+\mathrm{m}_{19}=\mathrm{m}_{8}+\mathrm{m}_{2}+\mathrm{m}_{3}+\mathrm{m}_{11}+\mathrm{m}_{15}$

$\mathrm{m}_{18}=\mathrm{m}_{19}$

$\dot{\mathrm{m}}_{\text {vap.escape }}=\mathrm{m}_{2}$

DESSUPERAQUECEDOR E VAPOR DE PROCESSO

Balanços de massa

$\mathrm{m}_{2}=\dot{\mathrm{m}}_{\text {vap.dessuper }}+\dot{\mathrm{m}}_{\text {vap.desaerador }}$

$\dot{\mathrm{m}}_{\text {vap.processo }} \quad=$ Cons.Vapor $_{\text {processo }} \cdot \dot{\mathrm{M}}_{\text {cana }} \cdot \frac{1}{1000}$ Consumo de vapor para o processo

$\dot{\mathrm{m}}_{\text {vap.processo }}=\dot{\mathrm{m}}_{\text {vap.dessuper }}+\dot{\mathrm{m}}_{\text {agua.dessuper }}$

Balanço de energia no dessuperaquecedor 
File:Regeneração e Reaquecimento combinados - 2a Lei - otimizado.EES

EES Ver. 9.433: \#0624: Depart. de Engenharia Mecanica Escola Politecnic, Escola Politecnica da USP, Sao Paulo, Brazil

$\dot{\mathrm{m}}_{\text {vap.processo }} \cdot \mathrm{h}_{\text {pro }}=\dot{\mathrm{m}}_{\text {vap.dessuper }} \cdot \mathrm{h}_{2}+\dot{\mathrm{m}}_{\text {agua.dessuper }} \cdot \mathrm{h}_{\text {rep.des }}$

$\mathrm{h}_{\text {pro }}=\mathbf{h}\left[\right.$ water $\left.; \mathrm{T}=\mathrm{T}_{\text {pro }} ; \mathrm{x}=1\right] \quad \mathrm{T}_{\text {pro }}=\mathbf{T}_{\text {sat }}\left[\right.$ water $\left.; \mathrm{P}=\mathrm{P}_{2}\right]$ Processo industrial utiliza vapor saturado

\section{PURGA DE CONDENSADO ANTES DE SER USADO NO PROCESSO}

RETORNO DE CONDENSADO DO PROCESSO INDUSTRIAL

$\dot{\mathrm{m}}_{\text {retorno }}=\dot{\mathrm{m}}_{\text {vap.processo }} \cdot 0,9$ Considerado perdas no processo de $10 \%$ da massa de vapor

$\mathrm{T}_{\text {cond }}=90 \quad[\mathrm{C}]$ Considerado que todo condensado é coletado em um tanque de recuperação e retorna para o ciclo a $90 \mathrm{C}$

$\mathrm{P}_{\text {cond }}=\mathrm{P}_{2}$ Pressão de retorno = pressão no desaerador $=$ Pressão do vapor de escape

$\mathrm{m}_{\text {agua.dessuper }}=$ If $\left[\mathrm{x}_{2} ; 100 ; 0 ; \dot{\mathrm{m}}_{\text {agua.dessuper }} ; 0\right]$

Se o vapor de escape estiver superaquecido agua deve ser alimentada no dessuperaquecedor para obter vapor saturado para o processo de produção do etanol

$\dot{\mathrm{m}}_{\text {purgador }}=$ If $\left[\mathrm{x}_{2} ; 100 ;-\dot{\mathrm{m}}_{\text {agua.dessuper }} ; 0 ; 0\right]$ Se o vapor de escape tiver $\mathrm{x}<1$ o condensado precisa ser retirado em purgadores

\section{DESAERADOR}

Balanço de massa no desaerador

$\dot{\mathrm{m}}_{\text {retorno }}+\dot{\mathrm{m}}_{\text {vap.desaerador }}+\dot{\mathrm{m}}_{\text {vap.cauda }}+\dot{\mathrm{m}}_{\text {rep.desaerador }}+\dot{\mathrm{m}}_{\text {purgador }}+\mathrm{m}_{17}+\mathrm{m}_{11}+\mathrm{m}_{15}=\dot{\mathrm{m}}_{\text {agua }}$

$\dot{\mathrm{m}}_{\text {vap.cauda }}=\mathrm{m}_{3}$

Balanço de energia no desaerador

$\dot{\mathrm{m}}_{\text {retorno }} \cdot \mathrm{h}_{\text {cond }}+\dot{\mathrm{m}}_{\text {vap.desaerador }} \cdot \mathrm{h}_{2}+\dot{\mathrm{m}}_{\text {vap.cauda }} \cdot \mathrm{h}_{5}+\dot{\mathrm{m}}_{\text {rep.desaerador }} \cdot \mathrm{h}_{\text {rep.des }}+\dot{\mathrm{m}}_{\text {purgador }} \cdot \mathrm{h}_{\text {purgador }}$ $+\mathrm{m}_{17} \cdot \mathrm{h}_{9}+\mathrm{m}_{11} \cdot \mathrm{h}_{12}+\mathrm{m}_{15} \cdot \mathrm{h}_{16}=\dot{\mathrm{m}}_{\mathrm{agua}} \cdot \mathrm{h}_{6}$

$\mathrm{h}_{\text {cond }}=\mathbf{h}\left[\right.$ water $\left.; \mathrm{T}=\mathrm{T}_{\text {cond }} ; \mathrm{P}=\mathrm{P}_{\text {cond }}\right] \quad \mathrm{h}_{\text {purgador }}=\mathbf{h}\left[\right.$ water $\left.; \mathrm{P}=\mathrm{P}_{2} ; \mathrm{x}=0\right]$

$\mathrm{h}_{\text {rep.des }}=\mathbf{h}\left[\right.$ water $\left.; \mathrm{T}=\mathrm{T}_{\mathrm{amb}} ; \mathrm{P}=\mathrm{P}_{\text {rep.des }}\right] \quad \mathrm{T}_{\mathrm{amb}}=25$

$\mathrm{P}_{\text {rep.des }}=\mathrm{P}_{2}$ Pressão no desaerador é a pressão de escape da turbina

conversão de unidades para ton/h

$$
\begin{aligned}
& \overline{\mathrm{m}}_{\text {vap.escape }}=\frac{\mathrm{m}_{2}}{1000[\text { ton } / \mathrm{h}]} \\
& \overline{\mathrm{m}}_{\text {vap.cauda }}=\frac{\mathrm{m}_{3}}{1000[\text { ton } / \mathrm{h}]} \\
& \overline{\mathrm{m}}_{\text {vap.processo }}=\frac{\dot{\mathrm{m}}_{\text {vap.processo }}}{1000[\text { ton } / \mathrm{h}]} \\
& \overline{\mathrm{m}}_{\text {vap.desaerador }}=\frac{\dot{\mathrm{m}}_{\text {vap.desaerador }}}{1000[\text { ton } / \mathrm{h}]} \\
& \overline{\mathrm{m}}_{\text {rep.desaerador }} \\
& =\frac{\dot{\mathrm{m}}_{\text {rep.desaerador }}}{1000[\text { ton } / \mathrm{h}]} \\
& \overline{\mathrm{m}}_{\text {feed.water. }}=\frac{\dot{\mathrm{m}}_{\text {agua }}}{1000[\text { ton } / \mathrm{h}]}
\end{aligned}
$$




$$
\begin{aligned}
& \overline{\mathrm{m}}_{\text {purga }}=\frac{\dot{\mathrm{m}}_{\text {purga }}}{1000[\text { ton } / \mathrm{h}]} \\
& \overline{\mathrm{m}}_{\text {purgador }}=\frac{\dot{\mathrm{m}}_{\text {purgador }}}{1000[\text { ton } / \mathrm{h}]}
\end{aligned}
$$

\section{TROCADOR $h \times 1$}

$P_{9}=P_{8}$

$\mathrm{T}_{9}=\mathbf{T}_{\text {sat }}\left[\right.$ water $\left.; \mathrm{P}=\mathrm{P}_{8}\right]$

$\mathrm{h}_{9}=\mathbf{h}\left[\right.$ water $\left.; \mathrm{P}=\mathrm{P}_{9} ; \mathrm{x}=0\right]$

$\mathrm{P}_{10}=\mathrm{P}_{7}$ Desconsiderado perdas de carga para água de alimentação da caldeira nos trocadores de calor

$\mathrm{h}_{10}=\mathbf{h}\left[\right.$ water $\left.; \mathrm{T}=\mathrm{T}_{10} ; \mathrm{P}=\mathrm{P}_{10}\right]$

$\dot{\mathrm{m}}_{\text {agua }} \cdot \mathrm{h}_{14}-\dot{\mathrm{m}}_{\text {agua }} \cdot \mathrm{h}_{10}+\mathrm{m}_{17} \cdot\left[\mathrm{h}_{8}-\mathrm{h}_{9}\right]=0$ Balanço de energia no $h \times 1$

$\overline{\mathrm{m}}_{\mathrm{vap} . \mathrm{hx} 1}=\frac{\mathrm{m}_{17}}{1000[\text { ton } / \mathrm{h}]}$

$\dot{\mathrm{m}}_{\mathrm{vap} . \mathrm{h} \times 1}=\mathrm{m}_{17}$

$\mathrm{h}_{17}=\mathrm{h}_{8}$

TROCADOR $h \times 2$

$P_{12}=P_{11}$

$\mathrm{T}_{12}=\mathbf{T}_{\text {sat }}\left[\right.$ water $\left.; \mathrm{P}=\mathrm{P}_{12}\right]$

$\mathrm{h}_{12}=\mathbf{h}\left[\right.$ water $\left.; \mathrm{P}=\mathrm{P}_{12} ; \mathrm{x}=0\right]$

$P_{14}=P_{7}$

$\mathrm{h}_{14}=\mathbf{h}\left[\right.$ water $\left.; \mathrm{T}=\mathrm{T}_{14} ; \mathrm{P}=\mathrm{P}_{14}\right]$

$\dot{\mathrm{m}}_{\text {agua }} \cdot \mathrm{h}_{13}-\dot{\mathrm{m}}_{\text {agua }} \cdot \mathrm{h}_{14}+\mathrm{m}_{11} \cdot\left[\mathrm{h}_{11}-\mathrm{h}_{12}\right]=0$ Balanço de energia no $h \times 2$

$\overline{\mathrm{m}}_{\mathrm{vap} . \mathrm{hx} 2}=\frac{\mathrm{m}_{11}}{1000[\text { ton } / \mathrm{h}]}$

$\dot{\mathrm{m}}_{\text {vap.hx2 }}=\mathrm{m}_{11}$

TROCADOR $h \times 3$

$P_{16}=P_{15}$

$\mathrm{T}_{16}=\mathbf{T}_{\text {sat }}\left[\right.$ water $\left.; \mathrm{P}=\mathrm{P}_{16}\right]$

$\mathrm{h}_{16}=\mathbf{h}\left[\right.$ water $\left.; \mathrm{P}=\mathrm{P}_{16} ; \mathrm{x}=0\right]$

$P_{13}=P_{7}$

$\mathrm{h}_{13}=\mathbf{h}\left[\right.$ water $\left.; \mathrm{T}=\mathrm{T}_{13} ; \mathrm{P}=\mathrm{P}_{13}\right] \quad T_{13}$ deve ser fixado para controlar vazão de vapor de extração

$\dot{\mathrm{m}}_{\text {agua }} \cdot \mathrm{h}_{7}-\dot{\mathrm{m}}_{\text {agua }} \cdot \mathrm{h}_{13}+\mathrm{m}_{15} \cdot\left[\mathrm{h}_{15}-\mathrm{h}_{16}\right]=0$ Balanço de energia no $h \times 3$ 
$\overline{\mathrm{m}}_{\text {vap.hx3 }}=\frac{\mathrm{m}_{15}}{1000[\mathrm{ton} / \mathrm{h}]}$
$\dot{\mathrm{m}}_{\text {vap.hx3 }}=\mathrm{m}_{15}$

Otimização dos trocadores de calor

Cálculo da temperatura de saída de cada trocador de calor

$\mathrm{T}_{13}=\mathrm{T}_{7}+\delta \mathrm{T}_{\mathrm{opt}} \quad$ Delta $T_{\text {opt }}$ é o incremento ótimo de temperatura em cada trocador de calor a ser otimizado

$\mathrm{T}_{14}=\mathrm{T}_{13}+\delta \mathrm{T}_{\mathrm{opt}}$

$\mathrm{T}_{10}=\mathrm{T}_{14}+\delta \mathrm{T}_{\mathrm{opt}}$

Cálculo dos pontos ótimos de extração na turbina

TTD = 3,5 [C] Diferença de Temperatura Terminal, parâmetro de entrada

TTD $=\mathrm{T}_{\text {sat; } \mathrm{h} \times 3}-\mathrm{T}_{13}$

TTD $=\mathrm{T}_{\text {sat; } \mathrm{h} \times 2}-\mathrm{T}_{14}$

TTD $=T_{\text {sat:hx1 }}-T_{10}$

Pontos ótimos de extração

$\mathrm{P}_{17}=\mathbf{P}_{\text {sat }}\left[\right.$ water $\left.; \mathrm{T}=\mathrm{T}_{\text {sat; } \mathrm{hx} 1}\right]$

$\mathrm{P}_{11}=\mathbf{P}_{\text {sat }}\left[\right.$ water $\left.; \mathrm{T}=\mathrm{T}_{\text {sat }, \mathrm{h} \times 2}\right]$

$\mathrm{P}_{15}=\mathbf{P}_{\text {sat }}\left[\right.$ water $\left.; \mathrm{T}=\mathrm{T}_{\text {sat; } \mathrm{h} \times 3}\right]$

\section{CONDENSADOR}

$\dot{\mathrm{Q}}_{\text {out }}=\mathrm{m}_{3} \cdot\left[\mathrm{h}_{3}-\mathrm{h}_{4}\right]$ Balanço de energia --> Calor transferido da condensação do vapor para a torre de resfriamento TORRE DE RESFRIAMENTO

$\dot{Q}_{\text {out }}=\dot{\mathrm{m}}_{\text {recirculação }} \cdot\left[\mathrm{h}_{\text {out }}-\mathrm{h}_{\text {in }}\right]$

$\mathrm{h}_{\text {out }}=\mathbf{h}\left[\right.$ water $\left.; \mathrm{P}=\mathrm{P}_{\text {out }} ; \mathrm{T}=\mathrm{T}_{\text {out }}\right]$

$\mathrm{h}_{\text {in }}=\mathbf{h}\left[\right.$ water $\left.; \mathrm{P}=\mathrm{P}_{\text {in }} ; \mathrm{T}=\mathrm{T}_{\text {in }}\right] \quad \mathrm{P}_{\text {in }}=1$

$\mathrm{P}_{\text {out }}=1$

$\dot{\mathrm{m}}_{\text {repos.torre }}=\mathrm{Y}_{\text {perdas }} \cdot \dot{\mathrm{m}}_{\text {recirculação }} \quad Y_{\text {perdas }}$ corresponde a uma estimativa de perdas de água por evaporação, purga e arraste na torre de resfriamento

$\dot{\mathrm{m}}_{\text {rep.total }}=\dot{\mathrm{m}}_{\text {repos.torre }}+\dot{\mathrm{m}}_{\text {rep.desaerador }}+\dot{\mathrm{m}}_{\text {agua.dessuper }}$

$\overline{\mathrm{m}}_{\text {repos.torre }}=\frac{\dot{\mathrm{m}}_{\text {repos.torre }}}{1000[\text { ton } / \mathrm{h}]}$

$\overline{\mathrm{m}}_{\text {rep.total }}=\frac{\dot{\mathrm{m}}_{\text {rep.total }}}{1000[\text { ton } / \mathrm{h}]}$

$\overline{\mathrm{m}}_{\text {vap.dessuper }}=\frac{\dot{\mathrm{m}}_{\text {vap.dessuper }}}{1000[\text { ton } / \mathrm{h}]}$ 
Perc.torre $=\frac{\dot{\mathrm{m}}_{\text {repos.torre }}}{\dot{\mathrm{m}}_{\text {rep.total }}} \cdot 100$

Perc.desaerador $=\frac{\dot{\mathrm{m}}_{\text {rep.desaerador }}}{\dot{\mathrm{m}}_{\text {rep.total }}} \cdot 100$

Perc.dessuper $=\frac{\dot{\mathrm{m}}_{\text {vap.dessuper }}}{\dot{\mathrm{m}}_{\text {rep.total }}} \cdot 100$

Tap.water $r_{\text {torre }}=\frac{\dot{\mathrm{m}}_{\text {repos.torre }}}{\frac{\dot{\mathrm{M}}_{\text {cana }}}{1000}}$

Tap.water deionised $=\frac{\dot{\mathrm{m}}_{\text {rep.desaerador }}+\dot{\mathrm{m}}_{\text {agua.dessuper }}}{\frac{\dot{\mathrm{M}}_{\text {cana }}}{1000}}$

\section{CÁLCULO DAS POTÊNCIAS ELÉTRICAS}

Potência elétrica gerada

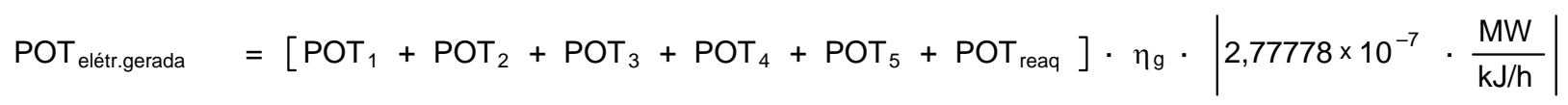

Potencia elétrica total gerada no turbogerador

$\mathrm{POT}_{\text {reaq }}=\mathrm{m}_{18} \cdot\left[\mathrm{h}_{1}-\mathrm{h}_{8}\right]$ Potencia gerada pelo vapor de reaquecimento

$\mathrm{POT}_{1}=\mathrm{m}_{2} \cdot\left[\mathrm{h}_{19}-\mathrm{h}_{2}\right]$ Potencia gerada pelo vapor de escape a $P=2,5 \mathrm{bar}$

$\mathrm{POT}_{2}=\mathrm{m}_{3} \cdot\left[\mathrm{h}_{19}-\mathrm{h}_{3}\right]$ Potencia gerada pelo vapor da cauda

$\mathrm{POT}_{3}=\mathrm{m}_{17} \cdot\left[\mathrm{h}_{1}-\mathrm{h}_{8}\right]$ Potencia gerada pelo vapor extraído no primeiro estágio da turbina direcionado ao trocador $h \times 1$

$\mathrm{POT}_{4}=\mathrm{m}_{11} \cdot\left[\mathrm{h}_{19}-\mathrm{h}_{11}\right]$ Potencia gerada pelo vapor de extraído no segundo estágio da turbina direcionado ao trocador $h \times 2$

POT $_{5}=\mathrm{m}_{15} \cdot\left[\mathrm{h}_{19}-\mathrm{h}_{15}\right]$ Potencia gerada pelo vapor de extraído no terceiro estágio da turbina direcionado ao trocador $h \times 3$

Consumo das bombas do ciclo

$\mathrm{POT}_{\text {elétr.consumida }}=\left[\mathrm{POT}_{\mathrm{B} 1}+\mathrm{POT}_{\mathrm{B} 2}\right] \cdot\left|2,77778 \times 10^{-7} \cdot \frac{\mathrm{MW}}{\mathrm{kJ} / \mathrm{h}}\right|$ Potência consumida pelas bombas

POT $_{\mathrm{B} 1}=\mathrm{m}_{3} \cdot\left[\mathrm{h}_{5}-\mathrm{h}_{4}\right]$ Potência consumida pela bomba 1

$\mathrm{POT}_{\text {B2 }}=\dot{\mathrm{m}}_{\text {agua }} \cdot\left[\mathrm{h}_{7}-\mathrm{h}_{6}\right]$ Potência consumida pela bomba 1

EFICIÊNCIA GLOBAL DA UNIDADE DE COGERAÇÃO

$\eta_{\text {Energética.Global }}=\left[\frac{\text { POT }_{\text {elétr.líquida }}+\mathrm{POT}_{\text {processo }}}{\text { POT }_{\text {entrada }}}\right] \cdot 100$

Potência líquida gerada na unidade de cogeração

$\mathrm{POT}_{\text {elétr.líquida }}=\mathrm{POT}_{\text {elétr.gerada }}-\mathrm{POT}_{\text {elétr.consumida }}$

Potência utilizada no processo industrial e desaerador 


$$
\begin{aligned}
& \mathrm{POT}_{\text {processo }}=\dot{\mathrm{m}}_{\text {vap.processo }} \cdot\left[\mathrm{h}_{\text {pro }}-\mathrm{h}_{\text {sat }}\right] \cdot\left|2,77778 \times 10^{-7} \cdot \frac{\mathrm{MW}}{\mathrm{kJ} / \mathrm{h}}\right| \\
& \mathrm{POT}_{\text {desaerador }}=\dot{\mathrm{m}}_{\text {vap.desaerador }} \cdot\left[\mathrm{h}_{2}-\mathrm{h}_{6}\right] \cdot\left|2,77778 \times 10^{-7} \cdot \frac{\mathrm{MW}}{\mathrm{kJ} / \mathrm{h}}\right|
\end{aligned}
$$

$\mathrm{POT}_{\text {desaerador.perc }}=\frac{\mathrm{POT}_{\text {desaerador }}}{\mathrm{POT}_{\text {entrada }}} \cdot 100$

$\mathrm{POT}_{\text {processo.perc }}=\frac{\mathrm{POT}_{\text {processo }}}{\mathrm{POT}_{\text {entrada }}} \cdot 100$

$\mathrm{h}_{\mathrm{sat}}=\mathbf{h}[$ water $; \mathrm{x}=0 ; \mathrm{P}=2,5]$

Alimentação energética na fornalha da caldeira

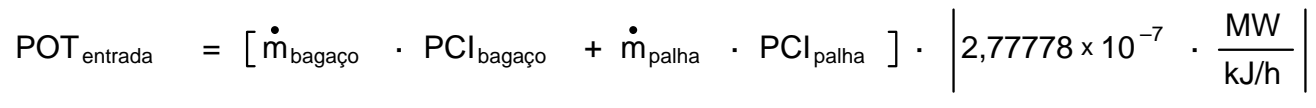

\section{APLICAÇÃO DA 2A LEI DA TERMODINÂMICA - ANÁLISE EXERGÉTICA}

Ambiente de referência considerado: $P o=1$ bar e $T o=25 C$

$\mathrm{TO}=25[\mathrm{C}]$

$\mathrm{PO}=1[\mathrm{bar}]$

$\mathrm{P}_{\mathrm{h} 20}=0,0303[$ bar $]$

LIMITE TEÓRICO DE EFICIEANCIA - CICLO DE CARNOT

$\eta$ carnot $=\left[1-\left(\frac{T_{3}+273,15}{T_{1}+273,15}\right)\right] \cdot 100 \quad$ Trabalho máximo que pode ser obtido

Trabalho útil final - saída do gerador

EXERGY.in fuel $^{=}=\mathrm{POT}_{\text {entrada }}$

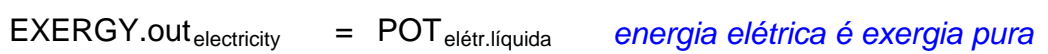

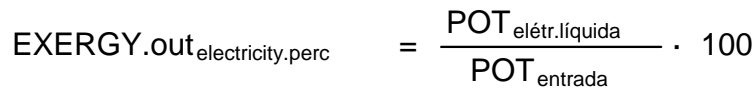

BOILER

$\mathrm{B}_{1}=\dot{\mathrm{m}}_{\mathrm{vapor}} \cdot\left[\mathrm{h}_{1}-\mathrm{h}_{0}-\left([\mathrm{T} 0+273,15] \cdot\left[\mathrm{s}_{1}-\mathrm{s}_{0}\right]\right)\right] \cdot\left|2,77778 \times 10^{-7} \cdot \frac{\mathrm{MW}}{\mathrm{kJ} / \mathrm{h}}\right|$ Exergia do vapor de saída do gerador de vapor

$\mathrm{h}_{0}=\mathbf{h}[$ water $; \mathrm{T}=\mathrm{TO} ; \mathrm{P}=\mathrm{PO}]$

$\mathrm{S}_{0}=\mathbf{s}[$ water $; \mathrm{T}=\mathrm{T} 0 ; \mathrm{P}=\mathrm{PO}]$

$B_{\text {fuel }}=E X E R G Y . i n_{\text {fuel }}$

\section{TURBINE}


$\mathrm{B}_{2}=\dot{\mathrm{m}}_{\text {vap.escape }} \cdot\left[\mathrm{h}_{2}-\mathrm{h}_{0}-\left([\mathrm{TO}+273,15] \cdot\left[\mathrm{s}_{2}-\mathrm{s}_{0}\right]\right)\right] \cdot\left|2,77778 \times 10^{-7} \cdot \frac{\mathrm{MW}}{\mathrm{kJ} / \mathrm{h}}\right| \begin{array}{r}\text { Exergia do vapor } \\ \text { de escape }\end{array}$ $\mathrm{B}_{3}=\dot{\mathrm{m}}_{\text {vap.cauda }} \cdot\left[\mathrm{h}_{3}-\mathrm{h}_{0}-\left([\mathrm{T0}+273,15] \cdot\left[\mathrm{s}_{3}-\mathrm{s}_{0}\right]\right)\right] \cdot\left|2,77778 \times 10^{-7} \cdot \frac{\mathrm{MW}}{\mathrm{kJ} / \mathrm{h}}\right|$ Exergia do vapor de cauda

Exergia da corrente de reaquecimento

$\mathrm{B}_{18}=\mathrm{m}_{18} \cdot\left[\mathrm{h}_{18}-\mathrm{h}_{0}-\left([\mathrm{T} 0+273,15] \cdot\left[\mathrm{s}_{18}-\mathrm{s}_{0}\right]\right)\right] \cdot\left|2,77778 \times 10^{-7} \cdot \frac{\mathrm{MW}}{\mathrm{kJ} / \mathrm{h}}\right|$ Exergia do vapor para reaquecimento na saída da turbina

$\mathrm{B}_{19}=\mathrm{m}_{18} \cdot\left[\mathrm{h}_{19}-\mathrm{h}_{0}-\left([\mathrm{T0}+273,15] \cdot\left[\mathrm{s}_{19}-\mathrm{s}_{0}\right]\right)\right] \cdot\left|2,77778 \times 10^{-7} \cdot \frac{\mathrm{MW}}{\mathrm{kJ} / \mathrm{h}}\right| \begin{array}{r}\text { Exergia do vapor após } \\ \text { reaquecimento }\end{array}$

Exergia das correntes de regeneração para os trocadores $h \times 1, h \times 2$ e $h \times 3$

$\mathrm{B}_{17}=\dot{\mathrm{m}}_{\text {vap.hx1 }} \cdot\left[\mathrm{h}_{17}-\mathrm{h}_{0}-\left([\mathrm{T0}+273,15] \cdot\left[\mathrm{s}_{17}-\mathrm{s}_{0}\right]\right)\right] \cdot\left|2,77778 \times 10^{-7} \cdot \frac{\mathrm{MW}}{\mathrm{kJ} / \mathrm{h}}\right|$ Exergia do vapor da primeira extração da turbina

$\mathrm{s}_{17}=\mathrm{s}_{8}$

$\mathrm{B}_{11}=\dot{\mathrm{m}}_{\mathrm{vap} . \mathrm{hx2}} \cdot\left[\mathrm{h}_{11}-\mathrm{h}_{0}-\left([\mathrm{T} 0+273,15] \cdot\left[\mathrm{s}_{11}-\mathrm{s}_{0}\right]\right)\right] \cdot\left|2,77778 \times 10^{-7} \cdot \frac{\mathrm{MW}}{\mathrm{kJ} / \mathrm{h}}\right|$ Exergia do vapor da segunda extração da turbina

$\mathrm{B}_{15}=\dot{\mathrm{m}}_{\text {vap.hx3 }} \cdot\left[\mathrm{h}_{15}-\mathrm{h}_{0}-\left([\mathrm{T} 0+273,15] \cdot\left[\mathrm{s}_{15}-\mathrm{s}_{0}\right]\right)\right] \cdot\left|2,77778 \times 10^{-7} \cdot \frac{\mathrm{MW}}{\mathrm{kJ} / \mathrm{h}}\right|$ Exergia do vapor da segunda extração da turbina

Balanço de exergia na turbina

Bdest $_{\text {turbine }}=\mathrm{B}_{1}+\mathrm{B}_{19}-\left[\mathrm{B}_{2}+\mathrm{B}_{3}\right]-\mathrm{B}_{18}-\left[\mathrm{B}_{17}+\mathrm{B}_{11}+\mathrm{B}_{15}\right]-\frac{\mathrm{POT}_{\text {elétr.gerada }}}{\eta_{\mathrm{g}}} \begin{array}{r}\text { Exergia destruída } \\ \text { na turbina }\end{array}$

Bdest $_{\text {turbine.perc }}=\frac{\text { Bdest }_{\text {turbine }}}{\mathrm{B}_{\text {fuel }}} \cdot 100$ Percentual de exergia destruída na turbina

$\mathrm{B}_{2 ; \text { perc }}=\frac{\mathrm{B}_{2}}{\mathrm{~B}_{\text {fuel }}} \cdot 100$ Percentual de exergia no vapor de escape

$\mathrm{B}_{\text {liq }}=\frac{\mathrm{POT}_{\text {elétr.gerada }}}{\mathrm{B}_{\text {fuel }}} \cdot 100$ Percentual de exergia (trabalho) na saída do gerador

Consumo de exergia no processo industrial associado ao consumo específico de vapor

EXERGY.out process $=\dot{\mathrm{m}}_{\text {vap.processo }} \cdot\left[\mathrm{h}_{\text {pro }}-\mathrm{h}_{0}-\left([\mathrm{TO}+273,15] \cdot\left[\mathrm{s}_{\text {pro }}-\mathrm{s}_{0}\right]\right)\right] \cdot\left|2,77778 \times 10^{-7} \cdot \frac{\mathrm{MW}}{\mathrm{kJ} / \mathrm{h}}\right|$ 
$\mathrm{S}_{\text {pro }}=\mathbf{s}[$ water $; \mathrm{P}=2,5 ; \mathrm{T}=127,5]$

EXERGY.out $_{\text {process.perc }}=\frac{\text { EXERGY.out }_{\text {process }}}{B_{\text {fuel }}} \cdot 100$

EXERGY.out $_{\text {deaerator }} \quad=B_{2}-$ EXERGY.out process

EXERGY.out deaerator.perc $=\frac{\text { EXERGY.out }}{\text { deaerator }}_{B_{\text {fuel }}} \cdot 100$

\section{DESSUPERAQUECEDOR}

Balanço de entropia no dessuper

$\mathrm{s}_{\text {ger.dessuper }}=\dot{\mathrm{m}}_{\text {vap.processo }} \cdot \mathrm{s}_{\text {pro }}-\left[\mathrm{m}_{\text {agua.dessuper }} \cdot \mathrm{s}_{\text {agua }}+\left(\dot{\mathrm{m}}_{\text {vap.dessuper }}-\dot{\mathrm{m}}_{\text {purgador }}\right) \cdot \mathrm{s}_{2}\right]$

$\mathrm{S}_{\text {agua }}=\mathbf{s}[$ water $; \mathrm{P}=2,5 ; \mathrm{T}=25]$

Bdest $_{\text {dessuper }}=[\mathrm{TO}+273,15] \cdot \mathrm{S}_{\text {ger.dessuper }} \cdot\left|2,77778 \times 10^{-7} \cdot \frac{\mathrm{MW}}{\mathrm{kJ} / \mathrm{h}}\right|$ Exergia destruída no dessuperaquecedor

Bdest $_{\text {dessuper.perc }}=\frac{\text { Bdest }_{\text {dessuper }}}{\mathrm{B}_{\text {fuel }}} \cdot 100$ Percentual de exergia destruída no dessuperaquecedor

CONDENSADOR

$\mathrm{B}_{4}=\dot{\mathrm{m}}_{\text {vap.cauda }} \cdot\left[\mathrm{h}_{4}-\mathrm{h}_{0}-\left([\mathrm{T} 0+273,15] \cdot\left[\mathrm{s}_{4}-\mathrm{s}_{0}\right]\right)\right] \cdot\left|2,77778 \times 10^{-7} \cdot \frac{\mathrm{MW}}{\mathrm{kJ} / \mathrm{h}}\right|$ Exergia na saída do condensador

Bdest $_{\text {condenser }}=\mathrm{B}_{3}-\mathrm{B}_{4}$ Exergia destruída no condensador

Bdest $_{\text {condenser.perc }} \quad=\frac{\text { Bdest }_{\text {condenser }}}{\mathrm{B}_{\text {fuel }}} \cdot 100$ Percentual de exergia destruída no condensador

BOMBA 1

$\mathrm{B}_{5}=\dot{\mathrm{m}}_{\text {vap.cauda }} \cdot\left[\mathrm{h}_{5}-\mathrm{h}_{0}-\left([\mathrm{T} 0+273,15] \cdot\left[\mathrm{s}_{5}-\mathrm{s}_{0}\right]\right)\right] \cdot\left|2,77778 \times 10^{-7} \cdot \frac{\mathrm{MW}}{\mathrm{kJ} / \mathrm{h}}\right|$ Exergia na saída da bomba 1

Bdest $_{\mathrm{B} 1}=\mathrm{B}_{4}-\mathrm{B}_{5}+\mathrm{W}_{\mathrm{B} 1}$ Exergia destruída na bomba 1

$\mathrm{W}_{\mathrm{B} 1}=\dot{\mathrm{m}}_{\text {vap.cauda }} \cdot\left[\mathrm{h}_{5}-\mathrm{h}_{4}\right] \cdot\left|2,77778 \times 10^{-7} \cdot \frac{\mathrm{MW}}{\mathrm{kJ} / \mathrm{h}}\right| \quad$ Trabalho realizado pela bomba B1

Bdest $_{\mathrm{B} 1 \text {.perc }}=\frac{\text { Bdest }_{\mathrm{B} 1}}{\mathrm{~B}_{\text {fuel }}} \cdot 100$ Percentual de exergia destruída na bomba 1

\section{DESAERADOR}

Balanço de entropia no dessuperaquecedor

$$
\begin{aligned}
& \mathrm{s}_{\text {ger.desaerador }}=\dot{\mathrm{m}}_{\text {agua }} \cdot \mathrm{s}_{6}-\left[\dot{\mathrm{m}}_{\text {retorno }} \cdot \mathrm{s}_{\text {cond }}+\dot{\mathrm{m}}_{\text {vap.desaerador }} \cdot \mathrm{s}_{2}+\dot{\mathrm{m}}_{\text {vap.cauda }} \cdot \mathrm{s}_{5}+\dot{\mathrm{m}}_{\text {rep.desaerador }}\right. \\
& \left.\cdot \mathrm{s}_{\text {agua }}+\left(\dot{\mathrm{m}}_{\text {purgador }}+\dot{\mathrm{m}}_{\text {vap.hx1 }}+\dot{\mathrm{m}}_{\text {vap.hx2 }}+\dot{\mathrm{m}}_{\text {vap.hx3 }}\right) \cdot \mathrm{s}_{\mathrm{sat}}\right] \\
& \mathrm{s}_{\text {cond }}=\mathrm{s}\left[\text { water } ; \mathrm{T}=\mathrm{T}_{\text {cond }} ; \mathrm{P}=\mathrm{P}_{\text {cond }}\right] \quad \mathrm{s}_{\text {sat }}=\mathrm{s}[\text { water } ; \mathrm{P}=2,5 ; \mathrm{x}=0]
\end{aligned}
$$


Bdest $_{\text {desaerador }}=[\mathrm{T0}+273,15] \cdot \mathrm{S}_{\text {ger.desaerador }} \cdot\left|2,77778 \times 10^{-7} \cdot \frac{\mathrm{MW}}{\mathrm{kJ} / \mathrm{h}}\right|$ Exergia destruída no desaerador

Bdest $_{\text {desaerador.perc }}=\frac{\text { Bdest }_{\text {desaerador }}}{\mathrm{B}_{\text {fuel }}} \cdot 100$ Percentual de exergia destruída no desaerador

BOMBA 2

$\mathrm{B}_{7}=\dot{\mathrm{m}}_{\text {agua }} \cdot\left[\mathrm{h}_{7}-\mathrm{h}_{0}-\left([\mathrm{T0}+273,15] \cdot\left[\mathrm{s}_{7}-\mathrm{s}_{0}\right]\right)\right] \cdot\left|2,77778 \times 10^{-7} \cdot \frac{\mathrm{MW}}{\mathrm{kJ} / \mathrm{h}}\right|$ Exergia na saída da bomba 2

$\mathrm{B}_{6}=\dot{\mathrm{m}}_{\text {agua }} \cdot\left[\mathrm{h}_{6}-\mathrm{h}_{0}-\left([\mathrm{T} 0+273,15] \cdot\left[\mathrm{s}_{6}-\mathrm{s}_{0}\right]\right)\right] \cdot\left|2,77778 \times 10^{-7} \cdot \frac{\mathrm{MW}}{\mathrm{kJ} / \mathrm{h}}\right|$ Exergia na entrada da bomba 2

$\mathrm{W}_{\mathrm{B} 2}=\dot{\mathrm{m}}_{\text {agua }} \cdot\left[\mathrm{h}_{7}-\mathrm{h}_{6}\right] \cdot\left|2,77778 \times 10^{-7} \cdot \frac{\mathrm{MW}}{\mathrm{kJ} / \mathrm{h}}\right|$ Trabalho realizado pela bomba B2

Bdest $_{\mathrm{B} 2}=\mathrm{B}_{7}-\mathrm{B}_{6}+\mathrm{W}_{\mathrm{B} 2} \quad$ Exergia destruída na bomba 2

Bdest $_{\mathrm{B} 2 \text {.perc }}=\frac{\text { Bdest }_{\mathrm{B} 2}}{\mathrm{~B}_{\text {fuel }}} \cdot 100$ Percentual de exergia destruída na bomba 2

BOILER

$\mathrm{B}_{10}+\mathrm{B}_{\text {fuel }}+\mathrm{B}_{18}=\mathrm{B}_{1}+\mathrm{B}_{\text {purga }}+\mathrm{B}_{19}+$ Bdest $_{\text {boiler }}$ Balanço de exergia na caldeira

Bdest $_{\text {boiler.perc }}=\frac{\text { Bdest }_{\text {boiler }}}{\mathrm{B}_{\text {fuel }}} \cdot 100$ Percentual de exergia destruída na caldeira $\mathrm{B}_{10}=\dot{\mathrm{m}}_{\text {agua }} \cdot\left[\mathrm{h}_{10}-\mathrm{h}_{0}-\left([\mathrm{T0}+273,15] \cdot\left[\mathrm{s}_{10}-\mathrm{s}_{0}\right]\right)\right] \cdot\left|2,77778 \times 10^{-7} \cdot \frac{\mathrm{MW}}{\mathrm{kJ} / \mathrm{h}}\right| \begin{gathered}\text { Exergia da corrente } \\ \text { de agua }\end{gathered}$ na entrada da caldeira

$\mathrm{B}_{\text {purga }}=\dot{\mathrm{m}}_{\text {purga }} \cdot\left[\mathrm{h}_{\text {purga }}-\mathrm{h}_{0}-\left([\mathrm{T0}+273,15] \cdot\left[\mathrm{s}_{\text {purga }}-\mathrm{s}_{0}\right]\right)\right] \cdot\left|2,77778 \times 10^{-7} \cdot \frac{\mathrm{MW}}{\mathrm{kJ} / \mathrm{h}}\right|$

$\mathrm{S}_{\text {purga }}=\mathbf{s}\left[\right.$ water $\left.; \mathrm{h}=\mathrm{h}_{\text {purga }} ; \mathrm{T}=\mathrm{T}_{\text {purga }}\right] \quad \mathrm{s}_{10}=\mathbf{s}\left[\right.$ water $\left.; \mathrm{T}=\mathrm{T}_{10} ; \mathrm{P}=\mathrm{P}_{10}\right]$

TROCADOR DE CALOR TC 1

Balanço de exergia no TC1

- Bdest $_{\mathrm{TC} 1}=\left[\dot{\mathrm{m}}_{\text {vap.hx3}} \cdot\left(\mathrm{h}_{16}-\mathrm{h}_{15}\right)+\dot{\mathrm{m}}_{\text {agua }} \cdot\left(\mathrm{h}_{13}-\mathrm{h}_{7}\right)-\mathrm{TO} \cdot\left(\dot{\mathrm{m}}_{\text {vap.hx3}} \cdot\left[\mathrm{s}_{16}-\mathrm{s}_{15}\right]+\dot{\mathrm{m}}_{\text {agua }}\right.\right.$ $\left.\left.\cdot\left[\mathrm{s}_{13}-\mathrm{s}_{7}\right]\right)\right] \cdot\left|2,77778 \times 10^{-7} \cdot \frac{\mathrm{MW}}{\mathrm{kJ} / \mathrm{h}}\right|$

$\mathrm{s}_{16}=\mathbf{s}\left[\right.$ water $\left.; \mathrm{P}=\mathrm{P}_{16} ; \mathrm{x}=0\right] \quad \mathrm{S}_{13}=\mathbf{s}\left[\right.$ water $\left.; \mathrm{P}=\mathrm{P}_{13} ; \mathrm{T}=\mathrm{T}_{13}\right]$

Bdest $_{\mathrm{TC1} \text {.perc }}=\frac{\text { Bdest }_{\mathrm{TC1}}}{\mathrm{B}_{\text {fuel }}} \cdot 100$ Percentual de exergia destruída no TC1

TROCADOR DE CALOR TC 2

Balanço de exergia no TC2 
- Bdest $_{\mathrm{TC2}}=\left[\dot{\mathrm{m}}_{\text {vap.hx2 }} \cdot\left(\mathrm{h}_{12}-\mathrm{h}_{11}\right)+\dot{\mathrm{m}}_{\text {agua }} \cdot\left(\mathrm{h}_{14}-\mathrm{h}_{13}\right)-\mathrm{TO} \cdot\left(\dot{\mathrm{m}}_{\text {vap.hx2 }} \cdot\left[\mathrm{s}_{12}-\mathrm{s}_{11}\right]+\dot{\mathrm{m}}_{\text {agua }}\right.\right.$ $\left.\left.\cdot\left[\mathrm{s}_{14}-\mathrm{s}_{13}\right]\right)\right] \cdot\left|2,77778 \times 10^{-7} \cdot \frac{\mathrm{MW}}{\mathrm{kJ} / \mathrm{h}}\right|$

$\mathrm{S}_{12}=\mathbf{s}\left[\right.$ water $\left.; \mathrm{P}=\mathrm{P}_{12} ; \mathrm{x}=0\right] \quad \mathrm{S}_{14}=\mathbf{s}\left[\right.$ water $\left.; \mathrm{P}=\mathrm{P}_{14} ; \mathrm{T}=\mathrm{T}_{14}\right]$

Bdest $_{\mathrm{TC2} \text {.perc }}=\frac{\text { Bdest }_{\mathrm{TC2}}}{\mathrm{B}_{\text {fuel }}} \cdot 100$ Percentual de exergia destruída no TC2

TROCADOR DE CALOR TC 3

Balanço de exergia no TC3

- Bdest $_{\text {TC3 }}=\left[\dot{\mathrm{m}}_{\text {vap.hx1 }} \cdot\left(\mathrm{h}_{9}-\mathrm{h}_{8}\right)+\dot{\mathrm{m}}_{\text {agua }} \cdot\left(\mathrm{h}_{10}-\mathrm{h}_{14}\right)-\right.$ TO $\cdot\left(\dot{\mathrm{m}}_{\text {vap.hx1}} \cdot\left[\mathrm{s}_{9}-\mathrm{s}_{8}\right]+\dot{\mathrm{m}}_{\text {agua }} \cdot\left[\mathrm{s}_{10}\right.\right.$

$\left.\left.\left.-\mathrm{s}_{14}\right]\right)\right] \cdot\left|2,77778 \times 10^{-7} \cdot \frac{\mathrm{MW}}{\mathrm{kJ} / \mathrm{h}}\right|$

$\mathrm{S}_{9}=\mathbf{s}\left[\right.$ water $\left.; \mathrm{P}=\mathrm{P}_{9} ; \mathrm{x}=0\right]$

Bdest $_{\mathrm{TC3} \text {.perc }}=\frac{\text { Bdest }_{\mathrm{TC3}}}{\mathrm{B}_{\text {fuel }}} \cdot 100$ Percentual de exergia destruída no TC3

Total $_{\text {exergy.dest }}=$ Bdest $_{\mathrm{B} 1}+$ Bdest $_{\mathrm{B} 2}+$ Bdest $_{\text {desaerador }}+$ Bdest $_{\text {condenser }}+$ Bdest $_{\text {boiler }}+$ Bdest $_{\text {turbine }}+$ Bdest $_{\mathrm{TC} 1}$

+ Bdest $_{\mathrm{TC2}}+$ Bdest $_{\mathrm{TC} 3}$

Total $_{\text {exergy.dest.perc }}=\frac{\text { Total }_{\text {exergy.dest }}}{\mathrm{B}_{\text {fuel }}} \cdot 100$

Eficiência Exergética

Cálculo da eficiência exergética global

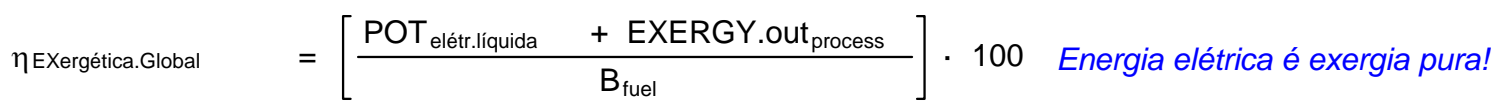

$\eta$ Ex.ref.Carnot $\quad=\frac{\eta \text { EXergética.Global }}{\eta \text { Carnot }} \cdot 100$

Distribuição de exergia entre vapor e eletricidade

Exergia $_{\text {vapor.perc }}=\left[\frac{\text { EXERGY.out }_{\text {process }}}{\text { POT }_{\text {elétr.líquida }}+\text { EXERGY.out }_{\text {process }}}\right] \cdot 100$

Exergia eletricidade.perc

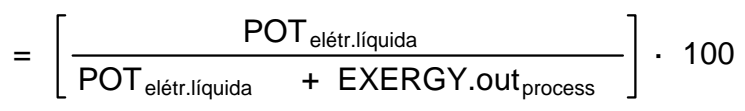

ALOCAÇÃO

Critério energético

POT específica;processo

$=\mathrm{POT}_{\text {processo }} \cdot$ Período $_{\text {safra }} \cdot 1000 \cdot \frac{24}{\text { Cana }_{\text {safra }}}$

Alocação energia;vapor

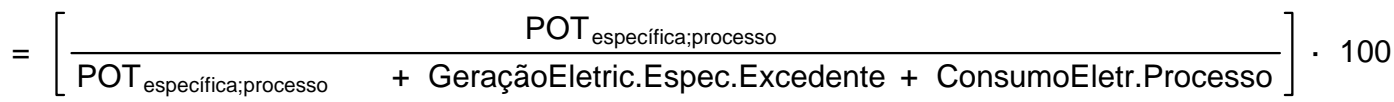


EES Ver. 9.433: \#0624: Depart. de Engenharia Mecanica Escola Politecnic, Escola Politecnica da USP, Sao Paulo, Brazil

Alocação $_{\text {energia;eletr.exp }}=\left[\frac{\text { GeraçãoEletric.Espec.Excedente }}{\text { POT }_{\text {específica;processo }}+\text { GeraçãoEletric.Espec.Excedente }+ \text { ConsumoEletr.Processo }}\right] \cdot 100$
Alocação $_{\text {energia;eletr.proc }}=\left[\frac{\text { ConsumoEletr.Processo }}{\text { POT }_{\text {específica;processo }+ \text { GeraçãoEletric.Espec.Excedente }+ \text { ConsumoEletr.Processo }}}\right] \cdot 100$

Critério exergético

EXERGY.out $_{\text {específica;process }}=$ EXERGY.out $_{\text {process }} \cdot$ Período $_{\text {safra }} \cdot 1000 \cdot \frac{24}{\text { Cana }_{\text {safra }}}$

Alocação $_{\text {exergia;vapor }}=\left[\frac{\text { EXERGY.out }_{\text {específica;process }}}{\text { EXERGY.out } \text { específica;process }_{2}+\text { GeraçãoEletric.Espec.Excedente }+ \text { ConsumoEletr.Processo }_{2}}\right] \cdot 100$

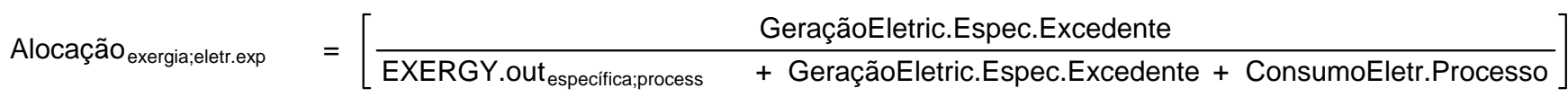

$\cdot 100$

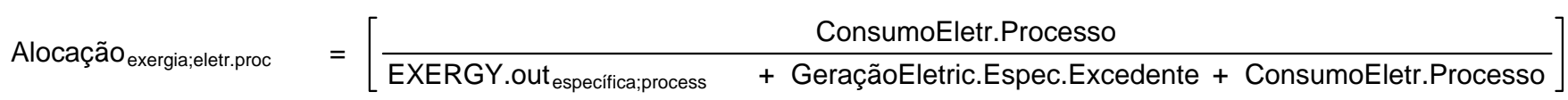

$\cdot 100$

ANÁLISE COMPLEMENTAR 1A LEI - PERDAS ENERGÉTICAS

Perdas na Caldeira e turbina

Boiler losses $=\mathrm{POT}_{\text {entrada }} \cdot\left[1-\eta_{\mathrm{c}}\right]$

Boiler $_{\text {losses.perc }}=\frac{\text { Boiler }_{\text {losses }}}{\text { POT }_{\text {entrada }}} \cdot 100$

Turbine $_{\text {losses }}=\left[\left(\mathrm{POT}_{1}+\mathrm{POT}_{2}+\mathrm{POT}_{3}+\mathrm{POT}_{4}+\mathrm{POT}_{5}+\mathrm{POT}_{\text {reaq }}\right) \cdot\left(1-\eta_{\mathrm{t}}\right)\right] \cdot\left|2,77778 \times 10^{-7} \cdot \frac{\mathrm{MW}}{\mathrm{kJ} / \mathrm{h}}\right|$

Turbine $_{\text {losses.perc }}=\frac{\text { Turbine }_{\text {losses }}}{\text { POT }_{\text {entrada }}} \cdot 100$

Perdas no condensador

$\mathrm{POT}_{\text {condensador }}=\dot{\mathrm{Q}}_{\text {out }} \cdot\left|2,77778 \times 10^{-7} \cdot \frac{\mathrm{MW}}{\mathrm{kJ} / \mathrm{h}}\right|$ Energia perdida no condensador

$\mathrm{POT}_{\text {condensador.perc }}=\frac{\mathrm{POT}_{\text {condensador }}}{\mathrm{POT}_{\text {entrada }}} \cdot 100$

Condenser $_{\text {losses }}=\mathrm{POT}_{\text {condensador }}$

Perdas no processo

process $_{\text {losses }}=\mathrm{POT}_{\text {entrada }}-\left[\mathrm{POT}_{\text {processo }}+\mathrm{POT}_{\text {elétr.gerada }}+\mathrm{POT}_{\text {condensador }}+\right.$ Turbine $_{\text {losses }}+$ Boiler $\left._{\text {losses }}\right]$

process $_{\text {losses.perc }}=\frac{\text { process }_{\text {losses }}}{\text { POT }_{\text {entrada }}} \cdot 100$

Cálculo da energia elétrica gerada por tonela de cana por tonelada de cana

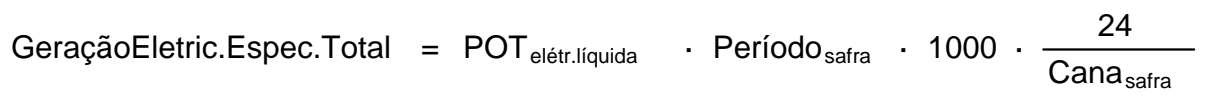


File:Regeneração e Reaquecimento combinados - 2a Lei - otimizado.EES

EES Ver. 9.433: \#0624: Depart. de Engenharia Mecanica Escola Politecnic, Escola Politecnica da USP, Sao Paulo, Brazil

GeraçãoEletric.Espec.Excedente = GeraçãoEletric.Espec.Total - ConsumoEletr.Processo

Distribuição de energia entre vapor e eletricidade

Energia $_{\text {vapor.perc }}=\left[\frac{\mathrm{POT}_{\text {processo }}}{\mathrm{POT}_{\text {processo }}+\mathrm{POT}_{\text {elétr.líquida }}}\right] \cdot 100$

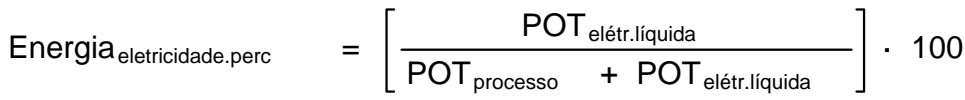


APÊNDICE E- Modelagem Termodinâmica do sistema de cogeração com ciclo Rankine Regenerativo para avaliação da influência do número de trocadores de calor na eficiência exergética 
File:Regeneração - 2a Lei - Escolha do número de trocadores de calor.EES

EES Ver. 9.433: \#0624: Depart. de Engenharia Mecanica Escola Politecnic, Escola Politecnica da USP, Sao Paulo, Brazil

1:

2: $3:$

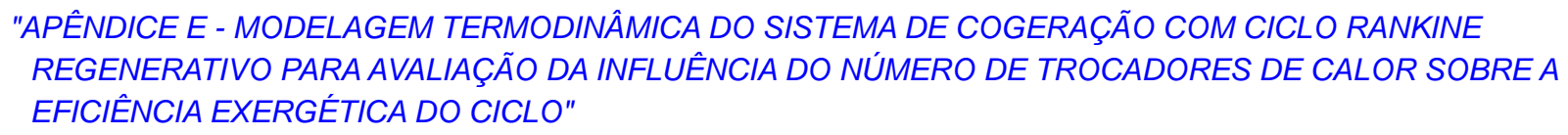

4:

5:

6:

7:

8: "Dados da Safra"

9:

10: M_dot_cana $=$ Cana_safra/Período_safra*1000/24 [kg/h] Moagem de cana"

11: m_dot_bagaço=Y_bagaço/100*M_dot_cana*(1-Perdas_bagaço/100) o de bagaço de cana"

12: m_dot_palha=Y_palha/100*M_dot_cana*(1-Perdas_palha/100) o de palha de cana"

13: Razão|vapor_biomassa=m_dot_vapor/m_dot_bagaço entre produção de vapor e consumo de biomassa"

14: m_bar_bagaço=m_dot_bagaço/1000 [ton/h]

15: m_bar_palha=m_dot_palha/1000 [ton/h]

16:

17:

18: "GERADOR DE VAPOR - Modelagem de conservação de matéria e energia"

19:

20: "Balanço de massa"

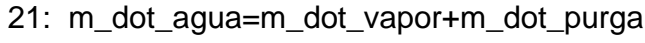

22: m_dot_purga $=Y$ _purga*m_dot_vapor

23: Y_purga $=0,03$ purga"

24: M_bar_vapor=m_dot_vapor/1000[ton/h] da vazão mássica de vapor de $\mathrm{Kg} / \mathrm{h}$ para ton/ $\mathrm{h}^{\prime \prime}$

25:

26: "Balanço de energia"

27:

28: m_dot_agua*h[10]=m_dot_vapor*h[1]+m_dot_purga*h_purga - Q_dot_c

29: Q_dot_c=(m_dot_bagaço*PCl_bagaço+m_dot_palha*PCl_palha $)^{\star}$ eta_c utilizada na fornecida na fornalha para evaporação da água"

30: $h[1]=e n t h a l p y($ water; $T=T[1] ; P=P[1]): ~ h \_p u r g a=e n t h a l p y\left(\right.$ water; $\left.T=T \_p u r g a ; X=0\right)$

31: $P[7]=1,20 * P$ _c: T_purga=T_SAT(water; $P=P$ _c): P_purga=P_c: P[1]=P_C:

32: $\mathrm{PCl}$ bagaço=7565: $\mathrm{PCl} \_$palha $=12960[\mathrm{~kJ} / \mathrm{kg}]$

33: $T[1]=T$ SAT (water; $\left.P=P \_c\right)+G \_$super

34: G_super $=200[C]$

35:

36: "BOMBA 02 - ALIMENTAÇÃO DA CALDEIRA"

37:

38: $P[6]=P[2]$ escape"

39: eta_B2=(h[6]-h7_iso $) /(\mathrm{h}[6]-\mathrm{h}[7])$ da bomba"

40: h7_iso=enthalpy(water;s=s[6];P=P[7])

41: $h[6]=$ enthalpy (water; $P=P[6] ; T=T[6])$

42: $\mathrm{s}[6]=$ entropy(water; $\mathrm{P}=\mathrm{P}[6] ; \mathrm{T}=\mathrm{T}[6])$

43: $T[7]=$ temperature(water; $h=h[7] ; P=P[7])$

44: $s[7]=e n t r o p y($ water; $h=h[7] ; P=P[7])$

45:

46: "BOMBA 01 - CONDENSADO"

47:

48: $P[5]=P[2]$

escape"

"Taxa de

"Taxa de

"Alimentaçã

"Alimentaçã

"Razão

"Conversão

"Energia
"Poder calorífico inferior do bagaço e da palha de cana"

"Temperatura do vapor superaquecido"

"Grau de superaqucimento"

"Pressão de descarga da bomba igual a pressão do vapor de

"Determinação da entalpia real da vazão de líquido na descarga

"Entalpia para condição ideal isentrópica"

"Entalpia na saída do desaerador"

"Entropia na saída do desaerador é entropia do líquido saturado"

"Temperatura de recalque"

"Entropia da água de alimentação da caldeira"

"Pressão de descarga da bomba igual a pressão do vapor de 
File:Regeneração - 2a Lei - Escolha do número de trocadores de calor.EES

EES Ver. 9.433: \#0624: Depart. de Engenharia Mecanica Escola Politecnic, Escola Politecnica da USP, Sao Paulo, Brazil

49: eta_B1=(h[4]-h5_iso $) /(\mathrm{h}[4]-\mathrm{h}[5])$

50: h5_iso=enthalpy(water;s=s[4];P=P[5])

51: $s[4]=e n$ tropy (water; $P=P[4] ; X=0$ )

52: $\mathrm{T}[5]=$ temperature(water; $h=h[5] ; P=P[5])$

53: $h[4]=$ enthalpy(water; $P=P[4] ; X=0)$

54: $\mathrm{T}[4]=\mathrm{T}[3]$

troca calor latente"

55: $P[4]=P[3]$

56: $s[5]=$ entropy(water; $P=P[5] ; T=T[5])$

57:

58: "TURBINA"

59: "Rendimento da turbina"

60:

61: eta_t $=(\mathrm{h}[1]-\mathrm{h}[2]) /(\mathrm{h}[1]-\mathrm{h} 2$ _iso $)$

desaerador através da eficiencia isoentrópica"

62: eta_t $=(\mathrm{h}[1]-\mathrm{h}[3]) /(\mathrm{h}[1]-\mathrm{h} 3$ iso $)$

desaerador através da eficiencia isoentrópica"

63: eta_t $=(\mathrm{h}[1]-\mathrm{h}[8]) /(\mathrm{h}[1]-\mathrm{h} 8$ iso $)$

eficiencia isoentrópica"

64: eta_t $=(\mathrm{h}[1]-\mathrm{h}[11]) /(\mathrm{h}[1]-\mathrm{h} 11$ iso $)$

eficiencia isoentrópica"

65: eta_t $=(\mathrm{h}[1]-\mathrm{h}[15]) /(\mathrm{h}[1]-\mathrm{h} 15$ _iso $)$

eficiencia isoentrópica"

66: eta_t $=(\mathrm{h}[1]-\mathrm{h}[20]) /(\mathrm{h}[1]-\mathrm{h} 20$ _iso $)$

eficiencia isoentrópica"

67: eta_t $=(\mathrm{h}[1]-\mathrm{h}[23]) /(\mathrm{h}[1]-\mathrm{h} 23$ iso $)$ eficiencia isoentrópica"

68: eta_t $=(\mathrm{h}[1]-\mathrm{h}[26]) /(\mathrm{h}[1]-\mathrm{h} 26$ iso $)$ eficiencia isoentrópica"

69: eta_t $=(\mathrm{h}[1]-\mathrm{h}[29]) /(\mathrm{h}[1]-\mathrm{h} 29$ iso $)$ eficiencia isoentrópica"

70: eta_t $=(\mathrm{h}[1]-\mathrm{h}[32]) /(\mathrm{h}[1]-\mathrm{h} 32$ iso $)$ eficiencia isoentrópica"

71: eta_t $=(\mathrm{h}[1]-\mathrm{h}[35]) /(\mathrm{h}[1]-\mathrm{h} 35$ _iso $)$ eficiencia isoentrópica"

72: eta_t $=(\mathrm{h}[1]-\mathrm{h}[38]) /(\mathrm{h}[1]-\mathrm{h} 38$ iso $)$ eficiencia isoentrópica"

73:

74: "Entalpia Isentrópica"

75: h15_iso=enthalpy(water;s=s[1];P=P[15]) expansão isoentrópica"

76: h11_iso=enthalpy(water;s=s[1];P=P[11]) expansão isoentrópica"

77: h2_iso=enthalpy(water;s=s[1];P=P[2]) expansão isoentrópica"

78: h3_iso=enthalpy(water;s=s[1];P=P[3]) expansão isoentrópica"

79: h8_iso=enthalpy(water;s=s[1];P=P[8]) expansão isoentrópica"

80: h20_iso=enthalpy(water;s=s[1];P=P[20]) expansão isoentrópica"

81: h23_iso=enthalpy(water;s=s[1];P=P[23]) expansão isoentrópica"

82: h26_iso=enthalpy(water;s=s[1];P=P[26]) expansão isoentrópica"

83: h29_iso=enthalpy(water;s=s[1];P=P[29]) expansão isoentrópica"

84: h32_iso=enthalpy(water;s=s[1];P=P[32]) expansão isoentrópica"
"Determinação da entalpia real do líquido na descarga da bomba"

"Entalpia para condição ideal isentrópica"

"Entropia na saída do condensador - líquido saturado"

"Temperatura de recalque para desaerador"

"Entalpia da saída do condensador é a entalpia de líquido saturado"

"Temperatura de Entrada = temperatura de saída --> Somente

"Pressão de sucção da bomba = pressão da cauda da turbina"

"Entropia da água de recalque da bomba 01"

"Determinação da entalpia real do vapor extraído para o

"Determinação da entalpia real do vapor extraído para o

"Determinação da entalpia real do vapor extraído através da

"Determinação da entalpia real do vapor extraído através da

"Determinação da entalpia real do vapor extraído através da

"Determinação da entalpia real do vapor extraído através da

"Determinação da entalpia real do vapor extraído através da

"Determinação da entalpia real do vapor extraído através da

"Determinação da entalpia real do vapor extraído através da

"Determinação da entalpia real do vapor extraído através da

"Determinação da entalpia real do vapor extraído através da

"Determinação da entalpia real do vapor extraído através da

"Entalpia da corrente de vapor de escape para condição ideal de

"Entalpia da corrente de vapor de escape para condição ideal de

"Entalpia da corrente de vapor de escape para condição ideal de

"Entalpia da corrente de vapor na cauda para condição ideal de

"Entalpia da corrente de vapor extraído na condição ideal de

"Entalpia da corrente de vapor extraído na condição ideal de

"Entalpia da corrente de vapor extraído na condição ideal de

"Entalpia da corrente de vapor extraído na condição ideal de

"Entalpia da corrente de vapor extraído na condição ideal de

"Entalpia da corrente de vapor extraído na condição ideal de 
File:Regeneração - 2a Lei - Escolha do número de trocadores de calor.EES

EES Ver. 9.433: \#0624: Depart. de Engenharia Mecanica Escola Politecnic, Escola Politecnica da USP, Sao Paulo, Brazil

85: h35_iso=enthalpy(water;s=s[1];P=P[35])

expansão isoentrópica"

86: h38_iso=enthalpy(water; $\mathrm{S}=\mathrm{s}[1] ; \mathrm{P}=\mathrm{P}[38]$ )

expansão isoentrópica"

87:

88:

89: "Cálculo da temperatura do valor de escape em cada ponto de extração"

90: $T[2]=$ temperature(water; $h=h[2] ; P=P[2])$

91: $\mathrm{T}[3]=$ temperature $($ water; $\mathrm{h}=\mathrm{h}[3] ; \mathrm{P}=\mathrm{P}[3])$

92: $T[8]=$ temperature (water; $h=h[8] ; P=P[8])$

93: $T[11]=$ temperature (water; $h=h[11] ; P=P[11])$

94: $T[15]=$ temperature (water; $h=h[15] ; P=P[15])$

95: $\mathrm{T}[20]=$ temperature $($ water; $h=h[20] ; P=P[20])$

96: $T[23]=$ temperature (water; $h=h[23] ; P=P[23])$

97: $\mathrm{T}[26]=$ temperature (water; $h=h[26] ; P=P[26])$

98: $\mathrm{T}[29]=$ temperature (water; $h=h[29] ; P=P[29])$

99: $T[32]=$ temperature (water; $h=h[32] ; P=P[32])$

100: $T[35]=$ temperature (water; $h=h[35] ; P=P[35])$

101: $T[38]=$ temperature (water; $h=h[38] ; P=P[38])$

102:

103: "Cálculo da entropia real do vapor no ponto de extração"

104: $s[1]=e n t r o p y($ water; $P=P[1] ; T=T[1]$ )

105: $\mathrm{s}[2]=e n t r o p y($ water; $\mathrm{h}=\mathrm{h}[2] ; \mathrm{T}=\mathrm{T}[2])$

106: $s[3]=e n t r o p y(w a t e r ; h=h[3] ; T=T[3])$

107: s[8]=entropy(water;h=h[8];T=T[8])

108: $s[11]=e n t r o p y($ water; $h=h[11] ; T=T[11])$

109: $\mathrm{s}[15]=e n t r o p y($ water; $h=h[15] ; T=T[15])$

110: $\mathrm{s}[20]=e n t r o p y($ water; $\mathrm{h}=\mathrm{h}[20] ; \mathrm{T}=\mathrm{T}[20])$

111: $s[23]=e n t r o p y($ water; $h=h[23] ; T=T[23])$

112: $\mathrm{s}[26]=e n t r o p y($ water; $\mathrm{h}=\mathrm{h}[26] ; \mathrm{T}=\mathrm{T}[26])$

113: $s[29]=e n t r o p y($ water; $h=h[29] ; T=T[29])$

114: $\mathrm{s}[32]=e n t r o p y($ water; $\mathrm{h}=\mathrm{h}[32] ; \mathrm{T}=\mathrm{T}[32])$

115: $s[35]=e n t r o p y($ water; $h=h[35] ; T=T[35])$

116: $s[38]=e n t r o p y($ water; $h=h[38] ; T=T[38])$

117:

118:

119: "Qualidade do vapor nos pontos de extração de escape e cauda"

120: $x[2]=$ quality (water; $\mathrm{h}=\mathrm{h}[2] ; \mathrm{T}=\mathrm{T}[2])$

121: $x[3]=q u a l i t y($ water; $h=h[3] ; T=T[3])$

"Título do vapor de escape"

"Título do vapor na cauda da turbina"

122:

123: "Balanço de massa na turbina"

124:

125: m_dot_vapor=m_dot_vap.escape+m_dot_vap.cauda + m_dot_vap.hx1+m_dot_vap.hx2+m_dot_vap.hx3+m_dot_vap.hx4 +m_dot_vap.hx5+m_dot_vap.hx6+m_dot_vap.hx7+m_dot_vap.hx8+m_dot_vap.hx9+m_dot_vap.hx10

126

127:

128: "PURGA DE CONDENSADO ANTES DE SER USADO NO PROCESSO"

129:

130: "RETORNO DE CONDENSADO DO PROCESSO INDUSTRIAL"

131:

132: m_dot_retorno=m_dot_vap.processo ${ }^{\star} 0,9$

133: T_cond=90 [C]

recuperação e retorna para o ciclo a 90 C"

134: $\mathrm{P} \_$cond=P[2]

de escape"

135:

136: m_agua.dessuper=if(x[2];100;0;m_dot_agua.dessuper;0) "Se o vapor de escape tiver $x<1$ o condensado precisa ser retirado em purgadores"

137: m_dot_purgador=if(x[2];100;-m_dot_agua.dessuper;0;0)
"Considerado perdas no processo de 10\% da vazão de vapor" "Considerado que todo condensado é coletado em um tanque de

"Pressão de retorno = pressão no desaerador = Pressão do vapor
"Temperatura do vapor de escape"

"Temperatura do vapor de cauda"

"Temperatura do vapor extraído"

"Temperatura do vapor extraído"

"Temperatura do vapor extraído"

"Temperatura do vapor extraído

"Entropia do vapor de escape"

"Entropia do vapor extraído"

"Entropia do vapor extraído"

"Entropia do vapor extraído"

"Entropia do vapor extraído"

"Entropia do vapor extraído"

"Entropia do vapor extraído"

"Entropia do vapor extraído"

"Se o vapor 
File:Regeneração - 2a Lei - Escolha do número de trocadores de calor.EES

EES Ver. 9.433: \#0624: Depart. de Engenharia Mecanica Escola Politecnic, Escola Politecnica da USP, Sao Paulo, Brazil

de escape tiver $x<1$ o condensado precisa ser retirado em purgadores"

138:

139: "DESSUPERAQUECEDOR E VAPOR DE PROCESSO"

140: "Balanços de massa"

141:

142: m_dot_vap.escape=m_dot_vap.dessuper+m_dot_vap.desaerador

143: m_dot_vap.processo = Cons.Vapor_processo*M_dot_cana*(1/1000)

"Consumo

de vapor saturado para o processo a $P=2,5$ Bar"

144: m_dot_vap.processo=m_dot_vap.dessuper+m_dot_agua.dessuper

145: m_bar_agua.dessuper $=$ m_dot_agua.dessuper $/ 1000$

146:

147: "Balanço de energia no dessuperaquecedor"

148:

149: m_dot_vap.processo*h_pro=m_dot_vap.dessuper*h[2]+m_dot_agua.dessuper*h_rep.des

150: $\mathrm{h} \_$pro=enthalpy(water;T=T_pro; $\left.\mathrm{x}=1\right)$ : T_pro=T_sat(water; $\left.\mathrm{P}=2,5\right)$

"Processo

industrial utiliza vapor saturado"

151:

152:

153: "DESAERADOR"

154: "Balanço de massa no desaerador"

155:

156: m_dot_retorno+m_dot_vap.desaerador + m_dot_vap.cauda $+m$ _dot_rep.desaerador + m_dot_purgador + m_dot_vap.hx1 + m_dot_vap.hx2+m_dot_vap.hx3+m_dot_vap.hx4+m_dot_vap.hx5+m_dot_vap.hx6+m_dot_vap.hx7+m_dot_vap.hx8

+ m_dot_vap.hx9+m_dot_vap.hx10=m_dot_agua

157:

158: "Balanço de energia no desaerador"

159: m_dot_retorno*h_cond+m_dot_vap.desaerador*h[2]+m_dot_vap.cauda*h[5]+m_dot_rep.desaerador*h_rep.des

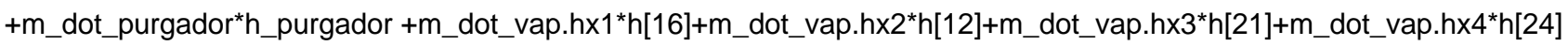

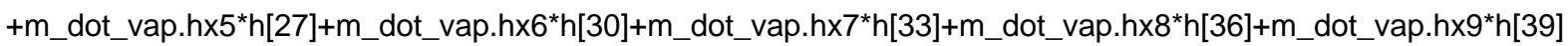
+ m_dot_vap.hx10*h[9] $=$ m_dot_agua*h[6]

160: $h \_c o n d=e n t h a l p y\left(\right.$ water; $\left.T=T \_c o n d ; P=P \_c o n d\right): ~ h \_p u r g a d o r=e n t h a l p y($ water; $P=P[2] ; x=0): h \_r e p . d e s=e n t h a l p y($ water; $T$ $\left.=T \_a m b ; P=P \_r e p . d e s\right): T \_a m b=25$
161: P_rep.des $=P[2]$
"Pressão no desaerador é a pressão de escape da turbina"

162:

163: "Conversão de unidades de $\mathrm{Kg} / \mathrm{h}$ para ton/h"

164:

165: m_bar_vap.escape=m_dot_vap.escape/1000 [ton/h]

166: m_bar_vap.cauda=m_dot_vap.cauda/1000 [ton $/ \mathrm{h}]$

167: m_bar_vap.processo=m_dot_vap.processo/1000 [ton/h]

168: m_bar_vap.desaerador=m_dot_vap.desaerador/1000 [ton/h]

169: m_bar_rep.desaerador=m_dot_rep.desaerador/1000 [ton $/ \mathrm{h}]$

170: m_bar_feed.water=m_dot_agua/1000 [ton/h]

171: m_bar_purga.=m_dot_purga/1000 [ton $/ \mathrm{h}]$

172: m_bar_purgador=m_dot_purgador/1000 [ton/h]

173:

174:

175: "TROCADOR $h \times 1 "$

176:

177: $P[16]=P[15]$

178: $T[16]=T \_s a t($ water; $P=P[16])$

179: $h[16]=e n t h a l p y($ water; $P=P[16] ; x=0)$

180: $\mathrm{h}[13]=$ enthalpy (water; $\mathrm{T}=\mathrm{T}[13] ; \mathrm{P}=\mathrm{P}[13])$ vapor de extração"

"T[13] é um set point, deve ser fixado para controlar vazão de

181: m_dot_agua*h[7]-m_dot_agua*h[13]+m_dot_vap.hx1* $(\mathrm{h}[15]-\mathrm{h}[16])=0$

energia"

182: m_bar_vap.hx1=m_dot_vap.hx1/1000[ton/h]

183: $P[13]=P[7]: P[14]=P[7]: P[22]=P[7]: P[25]=P[7]: P[28]=P[7]: P[31]=P[7]: P[34]=P[7]: P[37]=P[7]: P[40]=P[7]$ "Desconsiderado perdas de carga nos trocadores casco e tubo"

184: 
File:Regeneração - 2a Lei - Escolha do número de trocadores de calor.EES

185:

186: "TROCADOR $h \times 2 "$

187:

188: $P[12]=P[11]$

189: $h[12]=e n t h a l p y($ water; $P=P[12] ; x=0)$

190: $h[14]=e n t h a l p y($ water; $T=T[14] ; P=P[14])$

191: m_dot_agua*h[13]-m_dot_agua*h[14]+m_dot_vap.hx2*(h[11]-h[12]) $=0$ energia"

192: m_bar_vap.hx2=m_dot_vap.hx2/1000 [ton/h]

193:

194: "TROCADOR $h \times 3 "$

195:

196: $P[20]=P[21]$

197: $h[21]=e n t h a l p y($ water; $P=P[21] ; X=0)$

198: $h[22]=e n t h a l p y($ water; $T=T[22] ; P=P[22])$

199: m_dot_agua* $(\mathrm{h}[14]-\mathrm{h}[22])+\mathrm{m}$ _dot_vap.hx3*(h[20]-h[21] $)=0$

"Balanço de energia"

200: m_bar_vap.hx3=m_dot_vap.hx3/1000 [ton/h]

201:

202: "TROCADOR $h \times 4 "$

203:

204: $P[23]=P[24]$

205: $h[24]=$ enthalpy (water; $P=P[24] ; x=0)$

206: $h[25]=e n t h a l p y($ water; $T=T[25] ; P=P[25])$

207: m_dot_agua* $(\mathrm{h}[22]-\mathrm{h}[25])+\mathrm{m}$ _dot_vap.hx $4^{*}(\mathrm{~h}[23]-\mathrm{h}[24])=0$

"Balanço de energia"

208: m_bar_vap.hx4=m_dot_vap.hx4/1000 [ton/h]

209:

210: "TROCADOR $h \times 5 "$

211:

212: $P[26]=P[27]$

213: $h[27]=$ enthalpy (water; $P=P[27] ; x=0)$

214: $\mathrm{h}[28]=$ enthalpy (water; $\mathrm{T}=\mathrm{T}[28] ; \mathrm{P}=\mathrm{P}[28]$ )

215: m_dot_agua* $(\mathrm{h}[25]-\mathrm{h}[28])+\mathrm{m}$ _dot_vap.h $\times 5^{\star}(\mathrm{h}[26]-\mathrm{h}[27])=0$

"Balanço de energia"

216: m_bar_vap.hx5=m_dot_vap.hx5/1000 [ton/h]

217:

218: "TROCADOR $h \times 6 "$

219:

220: $P[29]=P[30]$

221: $h[30]=$ enthalpy $($ water; $P=P[30] ; x=0)$

222: $h[31]=$ enthalpy (water; $T=T[31] ; P=P[31]$ )

223: m_dot_agua* $(\mathrm{h}[28]-\mathrm{h}[31])+\mathrm{m}$ _dot_vap.hx6* $(\mathrm{h}[29]-\mathrm{h}[30])=0$

"Balanço de energia"

224: m_bar_vap.hx6=m_dot_vap.hx6/1000 [ton/h]

225:

226: "TROCADOR $h \times 7 "$

227:

228: $P[32]=P[33]$

229: $h[33]=e n t h a l p y($ water $; P=P[33] ; x=0)$

230: $h[34]=e n$ thalpy(water; $T=T[34] ; P=P[34])$

231: m_dot_agua* $(\mathrm{h}[31]-\mathrm{h}[34])+\mathrm{m}$ _dot_vap.hx7*(h[32]-h[33])=0

"Balanço de energia"

232: m_bar_vap.hx7=m_dot_vap.hx7/1000 [ton/h]

233:

234: "TROCADOR hx8"

235:

236: $P[35]=P[36]$

237: $h[36]=$ enthalpy $($ water; $P=P[36] ; x=0)$ 
238: $h[37]=e n t h a l p y($ water; $T=T[37] ; P=P[37])$

239: m_dot_agua* $(\mathrm{h}[34]-\mathrm{h}[37])+\mathrm{m} \_d o t \_v a p . h \times 8^{\star}(\mathrm{h}[35]-\mathrm{h}[36])=0$

"Balanço de energia"

240: m_bar_vap.hx8=m_dot_vap.hx8/1000 [ton/h]

241:

242: "TROCADOR $h \times 9 "$

243:

244: $P[38]=P[39]$

245: $h[39]=$ enthalpy (water; $P=P[39] ; X=0)$

246: $h[40]=e n t h a l p y($ water; $T=T[40] ; P=P[40])$

247: m_dot_agua* $(\mathrm{h}[37]-\mathrm{h}[40])+\mathrm{m} \_d o t \_v a p . h \times 9 *(h[38]-\mathrm{h}[39])=0$

"Balanço de energia"

248: m_bar_vap.hx9=m_dot_vap.hx9/1000 [ton/h]

249:

250:

251: "TROCADOR $h \times 10 "$

252:

253: $P[9]=P[8]$

254: $T[9]=T \_$sat(water; $\left.P=P[8]\right)$

255: $h[9]=$ enthalpy $($ water; $P=P[9] ; X=0)$

256: $P[10]=P[7]$

257: $h[10]=e n t h a l p y($ water; $T=T[10] ; P=P[10]$ )

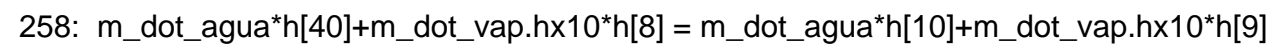

"Balanço de energia no $h \times 10^{\prime \prime}$

259: m_bar_vap.hx10=m_dot_vap.hx10/1000 [ton/h]

260:

261:

262:

263: "Otimização dos trocadores de calor"

264: "Cálculo da temperatura de saída de cada trocador de calor"

265:

266: $\mathrm{T}[13]=\mathrm{T}[7]+$ DeltaT_opt ${ }^{\star} \mathrm{c} 1$ trocador de calor a ser otimizado"

267: $\mathrm{T}[14]=\mathrm{T}[13]+$ DeltaT_opt ${ }^{\star} \mathrm{C} 2$ TCS"

268: $T[22]=T[14]+$ DeltaT_opt ${ }^{\star} c 3$

269: $\mathrm{T}[25]=\mathrm{T}[22]+$ DeltaT_opt ${ }^{\star} \mathrm{c} 4$

270: $\mathrm{T}[28]=\mathrm{T}[25]+$ DeltaT_opt ${ }^{*} \mathrm{c} 5$

271: $\mathrm{T}[31]=\mathrm{T}[28]+$ DeltaT_opt ${ }^{\star} \mathrm{c} 6$

272: $\mathrm{T}[34]=\mathrm{T}[31]+$ DeltaT_opt ${ }^{\star} \mathrm{c} 7$

273: $\mathrm{T}[37]=\mathrm{T}[34]+$ DeltaT_opt ${ }^{\star} \mathrm{c} 8$

274: $\mathrm{T}[40]=\mathrm{T}[37]+$ DeltaT_opt ${ }^{\star} \mathrm{c} 9$

275: $\mathrm{T}[10]=\mathrm{T}[40]+$ DeltaT_opt ${ }^{\star} \mathrm{c} 10$

276:

277:

278: "Cálculo dos pontos ótimos de extração na turbina"

279: TTD $=3,5[\mathrm{C}]$

280: TTD=T_sat_hx1 - T[13]

281: TTD=T_sat_hx2 - T[14]

282: TTD=T_sat_hx3 - T[22]

283: TTD=T_sat_hx4 - T[25]

284: TTD=T_sat_hx5 - T[28]

285: TTD=T_sat_hx6 - T[31]

286: TTD=T_sat_hx7 - T[34]

287: TTD=T_sat_hx8 - T[37]

288: TTD=T_sat_hx9 - T[40]

289: TTD=T_sat_hx10 - T[10]

290:

291: P[15]=P_SAT(water;T=T_sat_hx1)

"Diferença de Temperatura Terminal, parâmetro de entrada" 
File:Regeneração - 2a Lei - Escolha do número de trocadores de calor.EES

EES Ver. 9.433: \#0624: Depart. de Engenharia Mecanica Escola Politecnic, Escola Politecnica da USP, Sao Paulo, Brazil

292: $P[11]=P \_S A T($ water; T=T_sat_hx2)

293: P[20]=P_SAT(water;T=T_sat_hx3)

294: $P[23]=P$ SAT (water; $T=T$ _sat_hx4)

295: P[26]=P_SAT(water;T=T_sat_hx5)

296: P[29]=P_SAT(water;T=T_sat_hx6)

297: P[32]=P_SAT(water;T=T_sat_hx7)

298: $P[35]=P \_S A T($ water; T=T_sat_hx8)

299: $P[38]=P$ _SAT (water; $T=T$ _sat_hx9)

300: $P[8]=P$ SAT $($ water; $T=T$ sat_h $\times 10)$

301:

302:

303: "CONDENSADOR"

304:

305: Q_dot_out $=$ m_dot_vap.cauda ${ }^{*}(\mathrm{~h}[3]-\mathrm{h}[4])$

"Balanço de energia --> Calor transferido da condensação do

vapor para a torre de resfriamento"

306:

307:

308: "TORRE DE RESFRIAMENTO"

309:

310: Q_dot_out $=m \_d o t \_r e c i r c u l a c ̧ a ̃ o *\left(h \_o u t-h \_i n\right)$

311: $h \_o u t=e n t h a l p y\left(\right.$ water; $\left.P=P \_o u t ; T=T \_o u t\right): h \_i n=e n t h a l p y\left(\right.$ water; $P=P \_$in; $\left.T=T \_i n\right): P \_i n=1: P \_o u t=1$ :

312: m_dot_repos.torre $=Y$ Y_perdas*m_dot_recirculação $\quad$ "Y_perdas corresponde a uma estimativa de perdas de água por evaporação, purga e arraste na torre de resfriamento"

313: m_dot_rep.total=m_dot_repos.torre+m_dot_rep.desaerador+m_agua.dessuper

314: m_bar_repos.torre=m_dot_repos.torre/1000 [ton/h]

315: m_bar_rep.total $=\mathrm{m} \_$dot_rep.total $/ 1000[\mathrm{ton} / \mathrm{h}]$

316: m_bar_vap.dessuper=m_dot_vap.dessuper/1000 [ton/h]

317: Perc.torre $=m \_d o t \_r e p o s . t o r r e / m \_d o t \_r e p . t o t a l{ }^{\star} 100$

318: Perc.desaerador $=\mathrm{m} \_$dot_rep.desaerador/m_dot_rep.total ${ }^{\star} 100$

319: Perc.dessuper $=m \_d o t \_v a p . d e s s u p e r / m \_d o t \_r e p . t o t a l{ }^{\star} 100$

320: Tap.water_torre=m_dot_repos.torre $/\left(m \_d o t \_c a n a / 1000\right)$

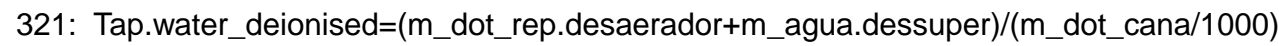

322:

323:

324: "CÁlCULO DAS POTÊNCIAS ELÉTRICAS"

325: "Potência elétrica gerada"

326:

327: POT_elétr.gerada=(POT_esc+POT_cau +POT_1+POT_2+POT_3+POT_4+POT_5+POT_6+POT_7+POT_8+POT_9 +POT_10)*eta_g*convert(kJ/h;MW)

328: POT_esc=m_dot_vap.escape*(h[1]-h[2])

329: POT_cau=m_dot_vap.cauda*(h[1]-h[3])

330: POT_2=m_dot_vap.hx2*(h[1]-h[11]) turbina direcionado a trocador $h \times 2^{\prime \prime}$

331: POT_1=m_dot_vap.hx1*(h[1]-h[15]) turbina direcionado a trocador $h \times 1^{\prime \prime}$

332: POT_3=m_dot_vap.hx3*(h[1]-h[20])

333: POT_4=m_dot_vap.hx4*(h[1]-h[23])

334: POT_5=m_dot_vap.hx5*(h[1]-h[26])

335: POT_6=m_dot_vap.hx6*(h[1]-h[29])

336: POT_7=m_dot_vap.hx7*(h[1]-h[32])

337: POT_8=m_dot_vap.hx8*(h[1]-h[35])

338: POT_9=m_dot_vap.hx9*(h[1]-h[38])

339: POT_10=m_dot_vap.hx10*(h[1]-h[8]) turbina direcionado a trocador $h \times 10^{\prime \prime}$

"Potencia elétrica total gerada no turbogerador"

"Potencia gerada pelo vapor de escape a $P=2,5 b a r "$

"Potencia gerada pelo vapor da cauda"

"Potencia gerada pelo vapor de extraído no segundo estágio da

"Potencia gerada pelo vapor de extraído no terceiro estágio da

340:

341:

342: "Consumo das bombas do ciclo"

343:

344: POT_elétr.consumida=(POT_B1+POT_B2 $)^{\star}$ convert $(\mathrm{kJ} / \mathrm{h} ; \mathrm{MW})$

"Potencia gerada pelo vapor de extraído na turbina" "Potencia gerada pelo vapor de extraído na turbina" "Potencia gerada pelo vapor de extraído na turbina" "Potencia gerada pelo vapor de extraído na turbina" "Potencia gerada pelo vapor de extraído na turbina" "Potencia gerada pelo vapor de extraído na turbina" "Potencia gerada pelo vapor de extraído na turbina" "Potencia gerada pelo vapor extraído no primeiro estágio da 
File:Regeneração - 2a Lei - Escolha do número de trocadores de calor.EES

consumida pelas bombas"

345: POT_B1=m_dot_vap.cauda*(h[5]-h[4])

"Potência consumida pela bomba 1"

346: POT_B2=m_dot_agua* $(\mathrm{h}[7]-\mathrm{h}[6])$

"Potência consumida pela bomba 1"

347:

348: "EFICIÊNCIA GLOBAL DA UNIDADE DE COGERAÇÃO COM REGENERAÇÃO"

349: "Cálculo da eficiência energética"

350:

351: eta_Energética.Global=(POT_elétr.líquida + POT_processo)/POT_entrada*100

352:

353: "Potência líquida gerada na unidade de cogeração"

354:

355: POT_elétr.líquida $=$ POT_elétr.gerada - POT_elétr.consumida

356:

357: "Potência utilizada no processo industrial e desaerador"

358:

359: POT_processo=m_dot_vap.processo*(h_pro-h_sat)*convert(kJ/h;MW)

360: POT_desaerador=m_dot_vap.desaerador* $(\mathrm{h}[2]-\mathrm{h}[6])^{\star}{ }^{\star} \operatorname{convert}(\mathrm{kJ} / \mathrm{h} ; \mathrm{MW})$

361: POT_desaerador.perc=POT_desaerador/POT_entrada ${ }^{\star} 100$

362: POT_processo.perc=POT_processo/POT_entrada ${ }^{\star} 100$

363: h_sat=enthalpy $($ water $; x=0 ; p=2,5)$

364:

365:

366: "Alimentação energética na fornalha da caldeira"

367:

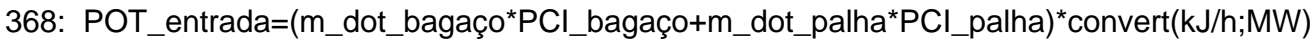

369:

370:

371:

372: "APLICAÇÃO DA 2A LEI DA TERMODINÂMICA - ANÁLISE EXERGÉTICA"

373: "Ambiente de referência considerado: $P O=1$ bar e $T o=25 C^{\prime \prime}$

374: $\mathrm{TO}=25[\mathrm{C}]$

375: $\mathrm{P} 0=1$ [Bar]

376: P00_h20=0,0303 [Bar]

377:

378: "LIMITE TEÓRICO DE EFICIÊNCIA - CICLO DE CARNOT"

379: eta_Carnot $=(1-(\mathrm{T}[3]+273,15) /(\mathrm{T}[1]+273,15)) \star 100 \quad$ "Trabalho máximo que pode ser obtido"

380:

381: "Trabalho útil final - saída do gerador"

382: EXERGY.in_fuel=POT_entrada

383: EXERGY.out_electricity=POT_elétr.líquida

"energia

elétrica é exergia pura"

384: EXERGY.out_electricity.perc=POT_elétr.líquida/POT_entrada*100

385:

386: "BOILER"

387: B_1=m_dot_vapor*(h[1]-h[0]-(T0+273,15)*(s[1]-s[0]))*convert(kJ/h;MW) + Bch_1

"Exergia

total do vapor de saída do gerador de vapor"

388: Bch_1=m_dot_vapor* $\left(-8590+8,314^{\star}(T 0+273,15) * \ln (1 / 0,0303)\right)^{\star}$ convert $(\mathrm{kJ} / \mathrm{h} ; \mathrm{MW}) / 18$

química do vapor de saída do gerador de vapor"

"Exegia

389: $\mathrm{h}[0]=$ enthalpy (water; $\mathrm{t}=\mathrm{T} 0 ; \mathrm{P}=\mathrm{PO})$

390: $s[0]=e n t r o p y($ water; $t=T 0 ; P=P 0)$

391: B_fuel=EXERGY.in_fuel

392:

393: "TURBINE"

394: "Exergia das correntes de vapor de escape e cauda"

395:

396: B_2=m_dot_vap.escape*(h[2]-h[0]-(T0+273,15)*(s[2]-s[0]))*convert(kJ/h;MW) + Bch_2 total do vapor de escape"

397: Bch_2=m_dot_vap.escape ${ }^{\star}\left(-8590+8,314^{\star}(\mathrm{T} 0+273,15){ }^{\star} \ln (1 / 0,0303)\right)^{\star}$ convert $(\mathrm{kJ} / \mathrm{h} ; \mathrm{MW}) / 18$ química do vapor de escape" 
398: B_3=m_dot_vap.cauda*(h[3]-h[0]-(T0+273,15)*(s[3]-s[0]))*convert(kJ/h;MW) + Bch_3

"Exergia total do vapor de cauda"

399: Bch_3=m_dot_vap.cauda* $\left(-8590+8,314^{*}(T 0+273,15) * \ln (1 / 0,0303)\right)^{*} \operatorname{convert}(\mathrm{kJ} / \mathrm{h} ; \mathrm{MW}) / 18$

química do vapor de cauda"

400:

401: "Exergia das correntes de regeneração para os trocadores hx10, hx2 e hx1"

402:

403: B_8=m_dot_vap.hx10*(h[8]-h[0]-(T0+273,15)*(s[8]-s[0]))*convert(kJ/h;MW) + Bch_8 total do vapor da primeira extração da turbina"

404: Bch_8=m_dot_vap.hx10*(-8590+8,314* $(T 0+273,15) * \ln (1 / 0,0303))^{*}$ convert(kJ/h;MW)/18 química do vapor da primeira extração da turbina"

405: B_11=m_dot_vap.hx2*(h[11]-h[0]-(T0+273,15)*(s[11]-s[0])**convert $(\mathrm{kJ} / \mathrm{h} ; \mathrm{MW})+$ Bch_11 total do vapor da segunda extração da turbina"

406: Bch_11=m_dot_vap.hx2*(-8590+8,314* $(\mathrm{T0}+273,15) * \ln (1 / 0,0303))^{*} \operatorname{convert}(\mathrm{kJ} / \mathrm{h} ; \mathrm{MW}) / 18$ química do vapor da segunda extração da turbina"

407: B_15=m_dot_vap.hx1*(h[15]-h[0]-(T0+273,15)*(s[15]-s[0]))*convert(kJ/h;MW) + Bch_15 total do vapor da segunda extração da turbina"

408: Bch_15=m_dot_vap.hx1*(-8590+8,314*(T0+273,15)*In $(1 / 0,0303))^{\star} \operatorname{convert}(\mathrm{kJ} / \mathrm{h} ; \mathrm{MW}) / 18$ química do vapor da segunda extração da turbina"

"Exegia 09:

410: "Balanço de exergia na turbina"

411:

412: Bdest_turbine=B_1 - (B_2+B_3+B_8+B_11+B_15+POT_elétr.gerada/eta_g) destruída na turbina"

413: Bdest_turbine.perc=Bdest_turbine/B_fuel ${ }^{\star} 100$

"Percentual de exergia destruída na turbina"

414: B_2_perc=B_2/B_fue ${ }^{*} 100$

"Percentual de exergia no vapor de escape"

415: B_liq=POT_elétr.gerada/B_fuel ${ }^{\star} 100$

"Percentual de exergia (trabalho) na saída do gerador"

416:

417: "Consumo de exergia no processo industrial associado ao consumo específico de vapor"

418:

419: EXERGY.out_process=m_dot_vap.processo*(h_pro-h[0]-(T0+273,15)*(s_pro-s[0]) ${ }^{\star}$ convert(kJ/h;MW) + Bch_pro

420: Bch_pro=m_dot_vap.processo* $\left(-8590+8,314^{*}(\mathrm{~T} 0+273,15){ }^{\star} \ln (1 / 0,0303)\right)^{*} \operatorname{convert}(\mathrm{kJ} / \mathrm{h} ; \mathrm{MW}) / 18$

"Exegia química do vapor do processo"

421: s_pro = entropy(water; $\mathrm{p}=2,5 ; \mathrm{t}=127,5)$

422: EXERGY.out_process.perc=EXERGY.out_process/B_fuel ${ }^{\star} 100$

423: EXERGY.out_deaerator=B_2-EXERGY.out_process

424: EXERGY.out_deaerator.perc=EXERGY.out_deaerator/B_fuel ${ }^{\star} 100$

425:

426: "DESSUPERAQUECEDOR"

427: "Balanço de entropia no dessuper"

428:

429: S_ger.dessuper=m_dot_vap.processo*s_pro - (m_agua.dessuper*s_agua + (m_dot_vap.dessuper-m_dot_purgador)*s[2])

430: s_agua $=$ entropy $($ water $; p=2,5 ; t=25)$

431: Bdest_dessuper $=(\mathrm{T} 0+273,15) \star S \_g e r . d e s s u p e{ }^{\star}$ convert(kJ/h;MW) "Exergia destruída no dessuperaquecedor"

432: Bdest_dessuper.perc=Bdest_dessuper/B_fuel ${ }^{\star} 100$

"Percentual de exergia destruída no dessuperaquecedor"

433:

434: "CONDENSADOR"

435:

436: B_4=m_dot_vap.cauda*(h[4]-h[0]-(T0+273,15)*(s[4]-s[0]))*convert(kJ/h;MW) + Bch_4

"Exergia total na saída do condensador"

437: Bch_4=m_dot_vap.cauda $\left(-8590+8,314^{\star}(\mathrm{T} 0+273,15) \star \ln (1 / 0,0303)\right)^{\star} \operatorname{convert}(\mathrm{kJ} / \mathrm{h} ; \mathrm{MW}) / 18$ química na saída do condensador"

438: Bdest_condenser=B_3-B_4 destruída no condensador" 
File:Regeneração - 2a Lei - Escolha do número de trocadores de calor.EES

EES Ver. 9.433: \#0624: Depart. de Engenharia Mecanica Escola Politecnic, Escola Politecnica da USP, Sao Paulo, Brazil

439: Bdest_condenser.perc=Bdest_condenser/B_fuel*100

"Percentual de exergia destruída no condensador"

440:

441: "BOMBA 1"

442:

443: B_5=m_dot_vap.cauda*(h[5]-h[0]-(T0+273,15)*(s[5]-s[0]))*convert(kJ/h;MW)

"Exergia na

saída da bomba 1"

444: Bdest_B1=B_4-B_5 +W_B1

"Exergia

destruída na bomba 1"

445: W_B1=m_dot_vap.cauda*(h[5]-h[4])*convert(kJ/h;MW)

"Trabalho

realizado pela bomba $B 1^{\prime \prime}$

446: Bdest_B1.perc=Bdest_B1/B_fuel ${ }^{\star} 100$

"Percentual

de exergia destruída na bomba 1"

447:

448: "DESAERADOR"

449: "Balanço de entropia no dessuperaquecedor"

450:

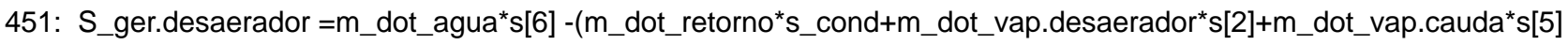

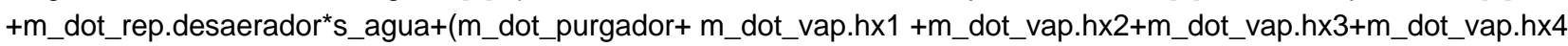
+ m_dot_vap.hx5+m_dot_vap.hx6+m_dot_vap.hx7+m_dot_vap.hx8+m_dot_vap.hx9+m_dot_vap.hx10)*s_sat)

452: s_cond=entropy(water; $T=T$ _cond $; P=P \_$cond): $s_{-}$sat $=$entropy $($water $; P=2,5 ; x=0$ )

453: Bdest_desaerador $=(\mathrm{TO}+273,15){ }^{\star}$ __ger.desaerador* ${ }^{*}$ convert $(\mathrm{kJ} / \mathrm{h} ; \mathrm{MW})$ destruída no desaerador"

454: Bdest_desaerador.perc=Bdest_desaerador/B_fuel ${ }^{\star} 100$

de exergia destruída no desaerador"

455:

456: "BOMBA 2"

457:

458: B_7=m_dot_agua* $(\mathrm{h}[7]-\mathrm{h}[0]-(\mathrm{T0}+273,15) \star(s[7]-\mathrm{s}[0]))^{\star} \operatorname{convert}(\mathrm{kJ} / \mathrm{h} ; \mathrm{MW})$ saída da bomba $2^{\prime \prime}$

459: B_6=m_dot_agua* $(\mathrm{h}[6]-\mathrm{h}[0]-(\mathrm{T0}+273,15) \star(s[6]-\mathrm{s}[0]))^{\star} \operatorname{convert}(\mathrm{kJ} / \mathrm{h} ; \mathrm{MW})$ entrada da bomba $2 "$

460: W_B2=m_dot_agua* $(\mathrm{h}[7]-\mathrm{h}[6])^{*}$ convert(kJ/h;MW) realizado pela bomba $B 2 "$

461: Bdest_B2=B_7-B_6 +W_B2

destruída na bomba $2^{\prime \prime}$

462: Bdest_B2.perc=Bdest_B2/B_fuel ${ }^{\star} 100$

de exergia destruída na bomba $2 "$

463:

464: "BOILER"

465:

466: B_10 + B_fuel = B_1+B_purga+Bdest_boiler

exergia na caldeira"

467: Bdest_boiler.perc=Bdest_boiler/B_fuel ${ }^{\star} 100$

"Exergia

"Percentual

de exergia destruída na caldeira"

468: B_10=m_dot_agua* $(\mathrm{h}[10]-\mathrm{h}[0]-(\mathrm{T0}+273,15) *(\mathrm{~s}[10]-\mathrm{s}[0]))^{\star}$ convert(kJ/h;MW)

corrente de agua na entrada da caldeira"

469: B_purga $=m$ _dot_purga* $\left(\mathrm{h} \_ \text {purga-h[0]-(T0+273,15)*(s_purga-s[0]) }\right)^{\star} \operatorname{convert}(\mathrm{kJ} / \mathrm{h} ; \mathrm{MW})$

470: s_purga=entropy(water;h=h_purga;T=T_purga): s[10]=entropy(water;T=T[10];P=P[10])

471:

472: Total_exergy.dest=Bdest_B1+Bdest_B2+Bdest_desaerador+Bdest_condenser+Bdest_boiler+Bdest_turbine

473: Total_exergy.dest.perc=Total_exergy.dest/B_fuel ${ }^{\star} 100$

474:

475:

476: "Eficiência Exergética"

477: "Cálculo da eficiência exergética global"

478:

479: eta_EXergética.Global=(POT_elétr.líquida + EXERGY.out_process)/B_fuel`100

480:

481: 
483: "ANÁLISE ENERGÉTICA DE 1A LEI - PERDAS ENERGÉTICAS"

484: "Perdas na Caldeira e turbina"

485:

486: Boiler_losses=POT_entrada*(1-eta_c)

487: Boiler_losses.perc=-Boiler_losses/POT_entrada*100

488: Turbine_losses=(POT_esc+POT_cau + POT_1+POT_2+POT_3+POT_4+POT_5+POT_6+POT_7+POT_8+POT_9 + POT_10 $)^{\star}(1-\text { eta_t })^{\star}$ convert $(\mathrm{kJ} / \mathrm{h} ; \mathrm{MW})$

489: Turbine_losses.perc=Turbine_losses/POT_entrada*100

490:

491: "Perdas no condensador"

492:

493: POT_condensador $=\mathrm{Q} \_d o t \_o u{ }^{\star}{ }^{\star}$ convert $(\mathrm{kJ} / \mathrm{h} ; \mathrm{MW})$

perdida no condensador"

"Energia

494: POT_condensador.perc=POT_condensador/POT_entrada*100

495: Condenser_losses=POT_condensador

496:

497: "Perdas no processo"

498:

499: process_losses = POT_entrada - (POT_processo+POT_elétr.gerada+POT_condensador+Turbine_losses+Boiler_losses)

500: process_losses.perc=process_losses/POT_entrada*100

501:

502: "Cálculo da energia elétrica gerada por tonela de cana por tonelada de cana"

503:

504: GeraçãoEletric.Espec.Total =POT_elétr.líquida*Período_safra*1000*24/Cana_safra

505: GeraçãoEletric.Espec. Excedente = GeraçãoEletric.Espec. Total - ConsumoEletr.Processo

506:

507:

508: "Fechamento dos balanços"

509:

510: Useful.Energy=eta_Energética.Global

511: Energy.Losses=100-Useful.Energy

512:

513: useful.Exergy=eta_EXergética.Global

514: Exergy.losses=100-eta_EXergética.Global

515:

$516:$

APÊNDICE E - MODELAGEM TERMODINÂMICA DO SISTEMA DE COGERAÇÃO COM CICLO RANKINE REGENERATIVO PARA AVALIAÇÃO DA INFLUÊNCIA DO NÚMERO DE TROCADORES DE CALOR SOBRE A EFICIÊNCIA EXERGÉTICA DO CICLO

Dados da Safra

$\dot{\mathrm{M}}_{\text {cana }}=\frac{\text { Cana }_{\text {safra }}}{\text { Período }_{\text {safra }}} \cdot \frac{1000}{24[\mathrm{~kg} / \mathrm{h}]}$ Taxa de Moagem de cana

$\dot{\mathrm{m}}_{\text {bagaço }}=\frac{\mathrm{Y}_{\text {bagaço }}}{100} \cdot \dot{\mathrm{M}}_{\text {cana }} \cdot\left[1-\frac{\text { Perdas }_{\text {bagaço }}}{100}\right]$ Alimentação de bagaço de cana

$\dot{\mathrm{m}}_{\text {palha }}=\frac{\mathrm{Y}_{\text {palha }}}{100} \cdot \dot{\mathrm{M}}_{\text {cana }} \cdot\left[1-\frac{\text { Perdas }_{\text {palha }}}{100}\right]$ Alimentação de palha de cana

Razão ${ }_{\text {biomaror }}^{\text {vassa }} \frac{\dot{\mathrm{m}}_{\text {vapor }}^{\circ}}{\dot{\mathrm{m}}_{\text {bagaço }}}$ Razão entre produção de vapor e consumo de biomassa

$\overline{\mathrm{m}}_{\text {bagaço }}=\frac{\dot{\mathrm{m}}_{\text {bagaço }}}{1000[\text { ton } / \mathrm{h}]}$ 
File:Regeneração - 2a Lei - Escolha do número de trocadores de calor.EES

EES Ver. 9.433: \#0624: Depart. de Engenharia Mecanica Escola Politecnic, Escola Politecnica da USP, Sao Paulo, Brazil

$\overline{\mathrm{m}}_{\text {palha }}=\frac{\dot{\mathrm{m}}_{\text {palha }}}{1000[\text { ton } / \mathrm{h}]}$

GERADOR DE VAPOR - Modelagem de conservação de matéria e energia

Balanço de massa

$\dot{\mathrm{m}}_{\text {agua }}=\dot{\mathrm{m}}_{\text {vapor }}+\dot{\mathrm{m}}_{\text {purga }}$

$\dot{\mathrm{m}}_{\text {purga }}=\mathrm{Y}_{\text {purga }} \cdot \dot{\mathrm{m}}_{\text {vapor }}$

$\mathrm{Y}_{\text {purga }}=0,03$ Taxa de purga

$\overline{\mathrm{M}}_{\text {vapor }}=\frac{\dot{\mathrm{m}}_{\text {vapor }}}{1000 \text { [ton/h] }}$ Conversão da vazão mássica de vapor de $\mathrm{Kg} / \mathrm{h}$ para ton $/ \mathrm{h}$

Balanço de energia

$\dot{\mathrm{m}}_{\text {agua }} \cdot \mathrm{h}_{10}=\dot{\mathrm{m}}_{\text {vapor }} \cdot \mathrm{h}_{1}+\dot{\mathrm{m}}_{\text {purga }} \cdot \mathrm{h}_{\text {purga }}-\dot{\mathrm{Q}}_{\mathrm{c}}$

$\dot{\mathrm{Q}}_{\mathrm{c}}=\left[\dot{\mathrm{m}}_{\text {bagaço }} \cdot \mathrm{PCl}_{\text {bagaço }}+\dot{\mathrm{m}}_{\text {palha }} \cdot \mathrm{PCl}_{\text {palha }}\right] \cdot \eta_{\mathrm{c}}$ Energia utilizada na fornecida na fornalha para evaporação da água

$\mathrm{h}_{1}=\mathbf{h}\left[\right.$ water $\left.; \mathrm{T}=\mathrm{T}_{1} ; \mathrm{P}=\mathrm{P}_{1}\right] \quad \mathrm{h}_{\text {purga }}=\mathbf{h}\left[\right.$ water $\left.; \mathrm{T}=\mathrm{T}_{\text {purga }} ; \mathrm{x}=0\right]$

$\mathrm{P}_{7}=1,2 \cdot \mathrm{P}_{\mathrm{c}} \quad \mathrm{T}_{\text {purga }}=\mathrm{T}_{\text {sat }}\left[\right.$ water $\left.; \mathrm{P}=\mathrm{P}_{\mathrm{c}}\right] \quad \mathrm{P}_{\text {purga }}=\mathrm{P}_{\mathrm{c}} \quad \mathrm{P}_{1}=\mathrm{P}_{\mathrm{c}}$

$\mathrm{PCl}_{\text {bagaço }}=7565 \quad \mathrm{PCl}_{\text {palha }}=12960[\mathrm{~kJ} / \mathrm{kg}]$ Poder calorífico inferior do bagaço e da palha de cana

$\mathrm{T}_{1}=\mathbf{T}_{\text {sat }}\left[\right.$ water $\left.; \mathrm{P}=\mathrm{P}_{\mathrm{c}}\right]+\mathrm{G}_{\text {super }}$ Temperatura do vapor superaquecido

$\mathrm{G}_{\text {super }}=200 \quad[\mathrm{C}]$ Grau de superaqucimento

BOMBA 02 - ALIMENTAÇÃO DA CALDEIRA

$\mathrm{P}_{6}=\mathrm{P}_{2}$ Pressão de descarga da bomba igual a pressão do vapor de escape

$\eta_{\mathrm{B} 2}=\frac{\mathrm{h}_{6}-\mathrm{h} 7_{\text {iso }}}{\mathrm{h}_{6}-\mathrm{h}_{7}}$ Determinação da entalpia real da vazão de líquido na descarga da bomba

$\mathbf{h} 7_{\text {iso }}=\mathbf{h}\left[\right.$ water $\left.; \mathrm{s}=\mathrm{s}_{6} ; \mathrm{P}=\mathrm{P}_{7}\right]$ Entalpia para condição ideal isentrópica

$\mathrm{h}_{6}=\mathbf{h}\left[\right.$ water $\left.; \mathrm{P}=\mathrm{P}_{6} ; \mathrm{T}=\mathrm{T}_{6}\right]$ Entalpia na saída do desaerador

$\mathrm{S}_{6}=\mathbf{s}\left[\right.$ water $\left.; \mathrm{P}=\mathrm{P}_{6} ; \mathrm{T}=\mathrm{T}_{6}\right]$ Entropia na saída do desaerador é entropia do líquido saturado

$\mathrm{T}_{7}=\mathbf{T}\left[\right.$ water $\left.; \mathrm{h}=\mathrm{h}_{7} ; \mathrm{P}=\mathrm{P}_{7}\right]$ Temperatura de recalque

$\mathrm{s}_{7}=\mathbf{s}\left[\right.$ water $\left.; \mathrm{h}=\mathrm{h}_{7} ; \mathrm{P}=\mathrm{P}_{7}\right]$ Entropia da água de alimentação da caldeira

BOMBA 01 - CONDENSADO

$\mathrm{P}_{5}=\mathrm{P}_{2}$ Pressão de descarga da bomba igual a pressão do vapor de escape

$\eta_{\mathrm{B} 1}=\frac{\mathrm{h}_{4}-\mathrm{h}_{5_{\text {iso }}}}{\mathrm{h}_{4}-\mathrm{h}_{5}}$ Determinação da entalpia real do líquido na descarga da bomba

$\mathrm{h} 5_{\text {iso }}=\mathbf{h}\left[\right.$ water $\left.; \mathrm{s}=\mathrm{s}_{4} ; \mathrm{P}=\mathrm{P}_{5}\right]$ Entalpia para condição ideal isentrópica

$\mathrm{s}_{4}=\mathbf{s}\left[\right.$ water $\left.; \mathrm{P}=\mathrm{P}_{4} ; \mathrm{x}=0\right]$ Entropia na saída do condensador - líquido saturado 
File:Regeneração - 2a Lei - Escolha do número de trocadores de calor.EES

EES Ver. 9.433: \#0624: Depart. de Engenharia Mecanica Escola Politecnic, Escola Politecnica da USP, Sao Paulo, Brazil

$\mathrm{T}_{5}=\mathbf{T}\left[\right.$ water $\left.; \mathrm{h}=\mathrm{h}_{5} ; \mathrm{P}=\mathrm{P}_{5}\right]$ Temperatura de recalque para desaerador

$\mathrm{h}_{4}=\mathbf{h}\left[\right.$ water $\left.; \mathrm{P}=\mathrm{P}_{4} ; \mathrm{x}=0\right]$ Entalpia da saída do condensador é a entalpia de líquido saturado

$\mathrm{T}_{4}=\mathrm{T}_{3}$ Temperatura de Entrada = temperatura de saída --> Somente troca calor latente

$\mathrm{P}_{4}=\mathrm{P}_{3}$ Pressão de sucção da bomba = pressão da cauda da turbina

$\mathrm{S}_{5}=\mathbf{s}\left[\right.$ water $\left.; \mathrm{P}=\mathrm{P}_{5} ; \mathrm{T}=\mathrm{T}_{5}\right]$ Entropia da água de recalque da bomba 01

\section{TURBINA}

Rendimento da turbina

$\eta_{\mathrm{t}}=\frac{\mathrm{h}_{1}-\mathrm{h}_{2}}{\mathrm{~h}_{1}-\mathrm{h} 2_{\text {iso }}}$ Determinação da entalpia real do vapor extraído para o desaerador através da eficiencia isoentrópica

$\eta_{\mathrm{t}}=\frac{\mathrm{h}_{1}-\mathrm{h}_{3}}{\mathrm{~h}_{1}-\mathrm{h} 3_{\text {iso }}}$ Determinação da entalpia real do vapor extraído para o desaerador através da eficiencia isoentrópica

$\eta_{\mathrm{t}}=\frac{\mathrm{h}_{1}-\mathrm{h}_{8}}{\mathrm{~h}_{1}-\mathrm{h} 8_{\text {iso }}}$ Determinação da entalpia real do vapor extraído através da eficiencia isoentrópica

$\eta_{\mathrm{t}}=\frac{\mathrm{h}_{1}-\mathrm{h}_{11}}{\mathrm{~h}_{1}-\mathrm{h} 11_{\text {iso }}}$ Determinação da entalpia real do vapor extraído através da eficiencia isoentrópica

$\eta_{\mathrm{t}}=\frac{\mathrm{h}_{1}-\mathrm{h}_{15}}{\mathrm{~h}_{1}-\mathrm{h} 15_{\text {iso }}}$ Determinação da entalpia real do vapor extraído através da eficiencia isoentrópica

$\eta_{\mathrm{t}}=\frac{\mathrm{h}_{1}-\mathrm{h}_{20}}{\mathrm{~h}_{1}-\mathrm{h} 2 \mathrm{O}_{\text {iso }}}$ Determinação da entalpia real do vapor extraído através da eficiencia isoentrópica

$\eta_{\mathrm{t}}=\frac{\mathrm{h}_{1}-\mathrm{h}_{23}}{\mathrm{~h}_{1}-\mathrm{h} 23_{\text {iso }}}$ Determinação da entalpia real do vapor extraído através da eficiencia isoentrópica

$\eta_{\mathrm{t}}=\frac{\mathrm{h}_{1}-\mathrm{h}_{26}}{\mathrm{~h}_{1}-\mathrm{h} 26_{\text {iso }}}$ Determinação da entalpia real do vapor extraído através da eficiencia isoentrópica

$\eta_{\mathrm{t}}=\frac{\mathrm{h}_{1}-\mathrm{h}_{29}}{\mathrm{~h}_{1}-\mathrm{h} 29_{\text {iso }}}$ Determinação da entalpia real do vapor extraído através da eficiencia isoentrópica

$\eta_{\mathrm{t}}=\frac{\mathrm{h}_{1}-\mathrm{h}_{32}}{\mathrm{~h}_{1}-\mathrm{h} 32_{\text {iso }}}$ Determinação da entalpia real do vapor extraído através da eficiencia isoentrópica

$\eta_{\mathrm{t}}=\frac{\mathrm{h}_{1}-\mathrm{h}_{35}}{\mathrm{~h}_{1}-\mathrm{h} 35_{\text {iso }}}$ Determinação da entalpia real do vapor extraído através da eficiencia isoentrópica

$\eta_{\mathrm{t}}=\frac{\mathrm{h}_{1}-\mathrm{h}_{38}}{\mathrm{~h}_{1}-\mathrm{h} 38_{\text {iso }}}$ Determinação da entalpia real do vapor extraído através da eficiencia isoentrópica

\section{Entalpia Isentrópica}

$\mathrm{h} 15_{\text {iso }}=\mathbf{h}\left[\right.$ water $\left.; \mathrm{s}=\mathrm{s}_{1} ; \mathrm{P}=\mathrm{P}_{15}\right]$ Entalpia da corrente de vapor de escape para condição ideal de expansão isoentrópica

$\mathrm{h} 11_{\text {iso }}=\mathbf{h}\left[\right.$ water $\left.; \mathrm{s}=\mathrm{s}_{1} ; \mathrm{P}=\mathrm{P}_{11}\right]$ Entalpia da corrente de vapor de escape para condição ideal de expansão isoentrópica

$\mathrm{h} 2_{\text {iso }}=\mathbf{h}\left[\right.$ water $\left.; \mathrm{s}=\mathrm{s}_{1} ; \mathrm{P}=\mathrm{P}_{2}\right]$ Entalpia da corrente de vapor de escape para condição ideal de expansão isoentrópica

$\mathrm{h} 3_{\text {iso }}=\mathbf{h}\left[\right.$ water $\left.; \mathrm{s}=\mathrm{s}_{1} ; \mathrm{P}=\mathrm{P}_{3}\right]$ Entalpia da corrente de vapor na cauda para condição ideal de expansão isoentrópica 
EES Ver. 9.433: \#0624: Depart. de Engenharia Mecanica Escola Politecnic, Escola Politecnica da USP, Sao Paulo, Brazil

$\mathrm{h}_{\text {iso }}=\mathbf{h}\left[\right.$ water $\left.; \mathrm{s}=\mathrm{s}_{1} ; \mathrm{P}=\mathrm{P}_{8}\right]$ Entalpia da corrente de vapor extraído na condição ideal de expansão isoentrópica

$\mathrm{h} 20_{\text {iso }}=\mathbf{h}\left[\right.$ water $\left.; \mathrm{s}=\mathrm{s}_{1} ; \mathrm{P}=\mathrm{P}_{20}\right]$ Entalpia da corrente de vapor extraído na condição ideal de expansão isoentrópica

h23 iso $=\mathbf{h}\left[\right.$ water $\left.; \mathrm{s}=\mathrm{s}_{1} ; \mathrm{P}=\mathrm{P}_{23}\right]$ Entalpia da corrente de vapor extraído na condição ideal de expansão isoentrópica

$\mathrm{h} 26_{\text {iso }}=\mathbf{h}\left[\right.$ water $\left.; \mathrm{s}=\mathrm{s}_{1} ; \mathrm{P}=\mathrm{P}_{26}\right]$ Entalpia da corrente de vapor extraído na condição ideal de expansão isoentrópica

h29 $9_{\text {iso }}=\mathbf{h}\left[\right.$ water $\left.; \mathrm{s}=\mathrm{s}_{1} ; \mathrm{P}=\mathrm{P}_{29}\right]$ Entalpia da corrente de vapor extraído na condição ideal de expansão isoentrópica

h32 iso $=\mathbf{h}\left[\right.$ water $\left.; \mathrm{s}=\mathrm{s}_{1} ; \mathrm{P}=\mathrm{P}_{32}\right]$ Entalpia da corrente de vapor extraído na condição ideal de expansão isoentrópica

$\mathrm{h} 35_{\text {iso }}=\mathbf{h}\left[\right.$ water $\left.; \mathrm{s}=\mathrm{s}_{1} ; \mathrm{P}=\mathrm{P}_{35}\right]$ Entalpia da corrente de vapor extraído na condição ideal de expansão isoentrópica

h38 $8_{\text {iso }}=\mathbf{h}\left[\right.$ water $\left.; \mathrm{s}=\mathrm{s}_{1} ; \mathrm{P}=\mathrm{P}_{38}\right]$ Entalpia da corrente de vapor extraído na condição ideal de expansão isoentrópica

Cálculo da temperatura do valor de escape em cada ponto de extração

$\mathrm{T}_{2}=\mathbf{T}\left[\right.$ water $\left.; \mathrm{h}=\mathrm{h}_{2} ; \mathrm{P}=\mathrm{P}_{2}\right]$ Temperatura do vapor de escape

$\mathrm{T}_{3}=\mathbf{T}\left[\right.$ water $\left.; \mathrm{h}=\mathrm{h}_{3} ; \mathrm{P}=\mathrm{P}_{3}\right]$ Temperatura do vapor de cauda

$\mathrm{T}_{8}=\mathbf{T}\left[\right.$ water $\left.; \mathrm{h}=\mathrm{h}_{8} ; \mathrm{P}=\mathrm{P}_{8}\right]$ Temperatura do vapor extraído

$\mathrm{T}_{11}=\mathbf{T}\left[\right.$ water $\left.; \mathrm{h}=\mathrm{h}_{11} ; \mathrm{P}=\mathrm{P}_{11}\right]$ Temperatura do vapor extraído

$\mathrm{T}_{15}=\mathbf{T}\left[\right.$ water $\left.; \mathrm{h}=\mathrm{h}_{15} ; \mathrm{P}=\mathrm{P}_{15}\right]$ Temperatura do vapor extraído

$\mathrm{T}_{20}=\mathbf{T}\left[\right.$ water $\left.; \mathrm{h}=\mathrm{h}_{20} ; \mathrm{P}=\mathrm{P}_{20}\right]$ Temperatura do vapor extraído

$\mathrm{T}_{23}=\mathbf{T}\left[\right.$ water $\left.; \mathrm{h}=\mathrm{h}_{23} ; \mathrm{P}=\mathrm{P}_{23}\right]$ Temperatura do vapor extraído

$\mathrm{T}_{26}=\mathbf{T}\left[\right.$ water $\left.; \mathrm{h}=\mathrm{h}_{26} ; \mathrm{P}=\mathrm{P}_{26}\right]$ Temperatura do vapor extraído

$\mathrm{T}_{29}=\mathbf{T}\left[\right.$ water $\left.; \mathrm{h}=\mathrm{h}_{29} ; \mathrm{P}=\mathrm{P}_{29}\right]$ Temperatura do vapor extraído

$\mathrm{T}_{32}=\mathbf{T}\left[\right.$ water $\left.; \mathrm{h}=\mathrm{h}_{32} ; \mathrm{P}=\mathrm{P}_{32}\right]$ Temperatura do vapor extraído

$\mathrm{T}_{35}=\mathbf{T}\left[\right.$ water $\left.; \mathrm{h}=\mathrm{h}_{35} ; \mathrm{P}=\mathrm{P}_{35}\right]$ Temperatura do vapor extraído

$\mathrm{T}_{38}=\mathbf{T}\left[\right.$ water $\left.; \mathrm{h}=\mathrm{h}_{38} ; \mathrm{P}=\mathrm{P}_{38}\right]$ Temperatura do vapor extraído

Cálculo da entropia real do vapor no ponto de extração

$\mathrm{s}_{1}=\mathbf{s}\left[\right.$ water $\left.; \mathrm{P}=\mathrm{P}_{1} ; \mathrm{T}=\mathrm{T}_{1}\right]$ Estado definido por 2 propriedades independentes

$\mathrm{s}_{2}=\mathbf{s}\left[\right.$ water $\left.; \mathrm{h}=\mathrm{h}_{2} ; \mathrm{T}=\mathrm{T}_{2}\right]$ Entropia do vapor de escape

$\mathrm{s}_{3}=\mathbf{s}\left[\right.$ water $\left.; \mathrm{h}=\mathrm{h}_{3} ; \mathrm{T}=\mathrm{T}_{3}\right]$ Entropia do vapor de cauda

$\mathrm{s}_{8}=\mathbf{s}\left[\right.$ water $\left.; \mathrm{h}=\mathrm{h}_{8} ; \mathrm{T}=\mathrm{T}_{8}\right]$ Entropia do vapor extraído

$\mathrm{s}_{11}=\mathbf{s}\left[\right.$ water $\left.; \mathrm{h}=\mathrm{h}_{11} ; \mathrm{T}=\mathrm{T}_{11}\right]$ Entropia do vapor extraído

$\mathrm{s}_{15}=\mathbf{s}\left[\right.$ water $\left.; \mathrm{h}=\mathrm{h}_{15} ; \mathrm{T}=\mathrm{T}_{15}\right]$ Entropia do vapor extraído

$\mathrm{s}_{20}=\mathbf{s}\left[\right.$ water $\left.; \mathrm{h}=\mathrm{h}_{20} ; \mathrm{T}=\mathrm{T}_{20}\right]$ Entropia do vapor extraído

$\mathrm{s}_{23}=\mathbf{s}\left[\right.$ water $\left.; \mathrm{h}=\mathrm{h}_{23} ; \mathrm{T}=\mathrm{T}_{23}\right]$ Entropia do vapor extraído 
$\mathrm{s}_{26}=\mathbf{s}\left[\right.$ water $\left.; \mathrm{h}=\mathrm{h}_{26} ; \mathrm{T}=\mathrm{T}_{26}\right]$ Entropia do vapor extraído

$\mathrm{s}_{29}=\mathbf{s}\left[\right.$ water $\left.; \mathrm{h}=\mathrm{h}_{29} ; \mathrm{T}=\mathrm{T}_{29}\right]$ Entropia do vapor extraído

$\mathrm{s}_{32}=\mathbf{s}\left[\right.$ water $\left.; \mathrm{h}=\mathrm{h}_{32} ; \mathrm{T}=\mathrm{T}_{32}\right]$ Entropia do vapor extraído

$\mathrm{s}_{35}=\mathbf{s}\left[\right.$ water $\left.; \mathrm{h}=\mathrm{h}_{35} ; \mathrm{T}=\mathrm{T}_{35}\right]$ Entropia do vapor extraído

$\mathrm{s}_{38}=\mathbf{s}\left[\right.$ water $\left.; \mathrm{h}=\mathrm{h}_{38} ; \mathrm{T}=\mathrm{T}_{38}\right]$ Entropia do vapor extraído

Qualidade do vapor nos pontos de extração de escape e cauda

$\mathrm{x}_{2}=\mathbf{x}\left[\right.$ water $\left.; \mathrm{h}=\mathrm{h}_{2} ; \mathrm{T}=\mathrm{T}_{2}\right]$ Título do vapor de escape

$\mathrm{x}_{3}=\mathbf{x}\left[\right.$ water $\left.; \mathrm{h}=\mathrm{h}_{3} ; \mathrm{T}=\mathrm{T}_{3}\right]$ Título do vapor na cauda da turbina

Balanço de massa na turbina

$\dot{\mathrm{m}}_{\text {vapor }}=\dot{\mathrm{m}}_{\text {vap.escape }}+\dot{\mathrm{m}}_{\text {vap.cauda }}+\dot{\mathrm{m}}_{\text {vap.hx1 }}+\dot{\mathrm{m}}_{\text {vap.hx2}}+\dot{\mathrm{m}}_{\text {vap.hx3}}+\dot{\mathrm{m}}_{\text {vap.hx4 }}+\dot{\mathrm{m}}_{\text {vap.hx5 }}+\dot{\mathrm{m}}_{\text {vap.hx6}}$ $+\dot{\mathrm{m}}_{\text {vap.hx7 }}+\dot{\mathrm{m}}_{\text {vap.hx8 }}+\dot{\mathrm{m}}_{\text {vap.hx9 }}+\dot{\mathrm{m}}_{\text {vap.hx10 }}$

\section{PURGA DE CONDENSADO ANTES DE SER USADO NO PROCESSO}

RETORNO DE CONDENSADO DO PROCESSO INDUSTRIAL

$\dot{\mathrm{m}}_{\text {retorno }}=\dot{\mathrm{m}}_{\text {vap.processo }} \cdot 0,9$ Considerado perdas no processo de $10 \%$ da vazão de vapor

$\mathrm{T}_{\text {cond }}=90[\mathrm{C}]$ Considerado que todo condensado é coletado em um tanque de recuperação e retorna para o ciclo a $90 \mathrm{C}$

$\mathrm{P}_{\text {cond }}=\mathrm{P}_{2} \quad$ Pressão de retorno = pressão no desaerador = Pressão do vapor de escape

$\mathrm{m}_{\text {agua.dessuper }} \quad=$ If $\left[\mathrm{x}_{2} ; 100 ; 0 ; \dot{\mathrm{m}}_{\text {agua.dessuper }} ; 0\right]$ Se o vapor de escape tiver $\mathrm{x}<1$ o condensado precisa ser retirado em purgadores

$\dot{\mathrm{m}}_{\text {purgador }}=$ If $\left[\mathrm{x}_{2} ; 100 ;-\dot{\mathrm{m}}_{\text {agua.dessuper }} ; 0 ; 0\right]$ Se o vapor de escape tiver $\mathrm{x}<1$ o condensado precisa ser retirado em purgadores

\section{DESSUPERAQUECEDOR E VAPOR DE PROCESSO}

Balanços de massa

$\dot{\mathrm{m}}_{\text {vap.escape }}=\dot{\mathrm{m}}_{\text {vap.dessuper }}+\dot{\mathrm{m}}_{\text {vap.desaerador }}$

$\dot{\mathrm{m}}_{\text {vap.processo }}=$ Cons.Vapor $_{\text {processo }} \cdot \dot{\mathrm{M}}_{\text {cana }} \cdot \frac{1}{1000}$ Consumo de vapor saturado para o processo a $P=2,5$ Bar

$\dot{\mathrm{m}}_{\text {vap.processo }}=\dot{\mathrm{m}}_{\text {vap.dessuper }}+\dot{\mathrm{m}}_{\text {agua.dessuper }}$

$\overline{\mathrm{m}}_{\text {agua.dessuper }}=\frac{\dot{\mathrm{m}}_{\text {agua.dessuper }}}{1000}$

Balanço de energia no dessuperaquecedor

$\dot{\mathrm{m}}_{\text {vap.processo }} \cdot \mathrm{h}_{\text {pro }}=\dot{\mathrm{m}}_{\text {vap.dessuper }} \cdot \mathrm{h}_{2}+\dot{\mathrm{m}}_{\text {agua.dessuper }} \cdot \mathrm{h}_{\text {rep.des }}$

$\mathrm{h}_{\text {pro }}=\mathbf{h}\left[\right.$ water $\left.; \mathrm{T}=\mathrm{T}_{\text {pro }} ; \mathrm{x}=1\right] \quad \mathrm{T}_{\text {pro }}=\mathbf{T}_{\text {sat }}[$ water $; \mathrm{P}=2,5]$ Processo industrial utiliza vapor saturado

\section{DESAERADOR}




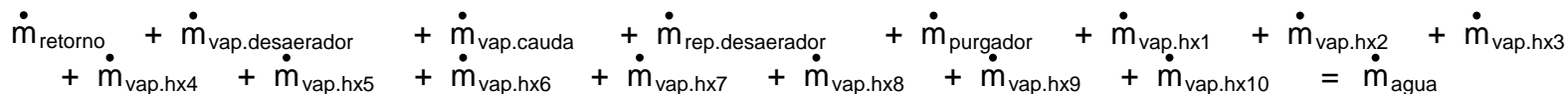

Balanço de energia no desaerador

$$
\begin{aligned}
& \dot{\mathrm{m}}_{\text {retorno }} \cdot \mathrm{h}_{\text {cond }}+\dot{\mathrm{m}}_{\text {vap.desaerador }} \cdot \mathrm{h}_{2}+\dot{\mathrm{m}}_{\text {vap.cauda }} \cdot \mathrm{h}_{5}+\dot{\mathrm{m}}_{\text {rep.desaerador }} \cdot \mathrm{h}_{\text {rep.des }}+\dot{\mathrm{m}}_{\text {purgador }} \cdot \mathrm{h}_{\text {purgador }} \\
& +\dot{\mathrm{m}}_{\text {vap.hx1 }} \cdot \mathrm{h}_{16}+\dot{\mathrm{m}}_{\text {vap.hx2 }} \cdot \mathrm{h}_{12}+\dot{\mathrm{m}}_{\text {vap.hx3}} \cdot \mathrm{h}_{21}+\dot{\mathrm{m}}_{\text {vap.hx4 }} \cdot \mathrm{h}_{24}+\dot{\mathrm{m}}_{\text {vap.hx5}} \cdot \mathrm{h}_{27}+\dot{\mathrm{m}}_{\text {vap.hx6}} \cdot \mathrm{h}_{30} \\
& +\dot{\mathrm{m}}_{\text {vap.hx7 }} \cdot \mathrm{h}_{33}+\dot{\mathrm{m}}_{\text {vap.hx8}} \cdot \mathrm{h}_{36}+\dot{\mathrm{m}}_{\text {vap.hx9}} \cdot \mathrm{h}_{39}+\dot{\mathrm{m}}_{\text {vap.hx10}} \cdot \mathrm{h}_{9}=\dot{\mathrm{m}}_{\text {agua }} \cdot \mathrm{h}_{6} \\
& \mathrm{~h}_{\text {cond }}=\mathbf{h}\left[\text { water } ; \mathrm{T}=\mathrm{T}_{\text {cond }} ; \mathrm{P}=\mathrm{P}_{\text {cond }}\right] \quad \mathrm{h}_{\text {purgador }}=\mathbf{h}\left[\text { water } ; \mathrm{P}=\mathrm{P}_{2} ; \mathrm{x}=0\right] \\
& \mathrm{h}_{\text {rep.des }}=\mathbf{h}\left[\text { water } ; \mathrm{T}=\mathrm{T}_{\mathrm{amb}} ; \mathrm{P}=\mathrm{P}_{\text {rep.des }}\right] \quad \mathrm{T}_{\mathrm{amb}}=25
\end{aligned}
$$

Conversão de unidades de $\mathrm{Kg} / \mathrm{h}$ para ton/h

$$
\begin{aligned}
& \overline{\mathrm{m}}_{\text {vap.escape }}=\frac{\dot{\mathrm{m}}_{\text {vap.escape }}}{1000[\text { ton } / \mathrm{h}]} \\
& \overline{\mathrm{m}}_{\text {vap.cauda }}=\frac{\dot{\mathrm{m}}_{\text {vap.cauda }}}{1000[\text { ton } / \mathrm{h}]} \\
& \overline{\mathrm{m}}_{\text {vap.processo }}=\frac{\dot{\mathrm{m}}_{\text {vap.processo }}}{1000[\text { ton } / \mathrm{h}]} \\
& \overline{\mathrm{m}}_{\text {vap.desaerador }}=\frac{\dot{\mathrm{m}}_{\text {vap.desaerador }}}{1000[\text { ton } / \mathrm{h}]} \\
& \overline{\mathrm{m}}_{\text {rep.desaerador }}=\frac{\dot{\mathrm{m}}_{\text {rep.desaerador }}}{1000[\text { ton } / \mathrm{h}]} \\
& \overline{\mathrm{m}}_{\text {feed.water }}=\frac{\dot{\mathrm{m}}_{\text {agua }}}{1000[\text { ton } / \mathrm{h}]} \\
& \overline{\mathrm{m}}_{\text {purga. }}=\frac{\dot{\mathrm{m}}_{\text {purga }}}{1000[\text { ton } / \mathrm{h}]} \\
& \overline{\mathrm{m}}_{\text {purgador }}=\frac{\dot{\mathrm{m}}_{\text {purgador }}}{1000[\text { ton } / \mathrm{h}]}
\end{aligned}
$$

\section{TROCADOR $h \times 1$}

$P_{16}=P_{15}$

$\mathrm{T}_{16}=\mathbf{T}_{\text {sat }}\left[\right.$ water $\left.; \mathrm{P}=\mathrm{P}_{16}\right]$

$\mathrm{h}_{16}=\mathbf{h}\left[\right.$ water $\left.; \mathrm{P}=\mathrm{P}_{16} ; \mathrm{x}=0\right]$

$\mathrm{h}_{13}=\mathbf{h}\left[\right.$ water $\left.; \mathrm{T}=\mathrm{T}_{13} ; \mathrm{P}=\mathrm{P}_{13}\right] \quad T_{13}$ é um set point, deve ser fixado para controlar vazão de vapor de extração

$\dot{\mathrm{m}}_{\text {agua }} \cdot \mathrm{h}_{7}-\dot{\mathrm{m}}_{\text {agua }} \cdot \mathrm{h}_{13}+\dot{\mathrm{m}}_{\text {vap.hx1 }} \cdot\left[\mathrm{h}_{15}-\mathrm{h}_{16}\right]=0$ Balanço de energia

$\overline{\mathrm{m}}_{\text {vap.hx1 }}=\frac{\dot{\mathrm{m}}_{\text {vap.hx1 }}}{1000[\text { ton } / \mathrm{h}]}$
$\mathrm{P}_{13}=\mathrm{P}_{7}$
$P_{14}=P_{7}$
$P_{22}=P_{7}$
$\mathrm{P}_{25}=\mathrm{P}_{7}$
$\mathrm{P}_{28}=\mathrm{P}_{7}$ 


$$
P_{34}=P_{7} \quad P_{37}=P_{7}
$$

\section{TROCADOR $h \times 2$}

$P_{12}=P_{11}$

$\mathrm{h}_{12}=\mathbf{h}\left[\right.$ water $\left.; \mathrm{P}=\mathrm{P}_{12} ; \mathrm{x}=0\right]$

$\mathrm{h}_{14}=\mathbf{h}\left[\right.$ water $\left.; \mathrm{T}=\mathrm{T}_{14} ; \mathrm{P}=\mathrm{P}_{14}\right]$

$\dot{\mathrm{m}}_{\text {agua }} \cdot \mathrm{h}_{13}-\dot{\mathrm{m}}_{\text {agua }} \cdot \mathrm{h}_{14}+\dot{\mathrm{m}}_{\text {vap.hx2 }} \cdot\left[\mathrm{h}_{11}-\mathrm{h}_{12}\right]=0 \quad$ Balanço de energia

$\overline{\mathrm{m}}_{\text {vap.hx2 }}=\frac{\dot{\mathrm{m}}_{\text {vap.hx2 }}}{1000[\text { ton } / \mathrm{h}]}$

TROCADOR $h \times 3$

$P_{20}=P_{21}$

$\mathrm{h}_{21}=\mathbf{h}\left[\right.$ water $\left.; \mathrm{P}=\mathrm{P}_{21} ; \mathrm{x}=0\right]$

$\mathrm{h}_{22}=\mathbf{h}\left[\right.$ water $\left.; \mathrm{T}=\mathrm{T}_{22} ; \mathrm{P}=\mathrm{P}_{22}\right]$

$\dot{\mathrm{m}}_{\text {agua }} \cdot\left[\mathrm{h}_{14}-\mathrm{h}_{22}\right]+\dot{\mathrm{m}}_{\text {vap.hx3 }} \cdot\left[\mathrm{h}_{20}-\mathrm{h}_{21}\right]=0 \quad$ Balanço de energia

$\overline{\mathrm{m}}_{\text {vap.hx3 }}=\frac{\dot{\mathrm{m}}_{\text {vap.hx3 }}}{1000[\text { ton } / \mathrm{h}]}$

TROCADOR $h \times 4$

$P_{23}=P_{24}$

$\mathrm{h}_{24}=\mathbf{h}\left[\right.$ water $\left.; \mathrm{P}=\mathrm{P}_{24} ; \mathrm{x}=0\right]$

$\mathrm{h}_{25}=\mathbf{h}\left[\right.$ water $\left.; \mathrm{T}=\mathrm{T}_{25} ; \mathrm{P}=\mathrm{P}_{25}\right]$

$\dot{\mathrm{m}}_{\text {agua }} \cdot\left[\mathrm{h}_{22}-\mathrm{h}_{25}\right]+\dot{\mathrm{m}}_{\text {vap.hx4 }} \cdot\left[\mathrm{h}_{23}-\mathrm{h}_{24}\right]=0$ Balanço de energia

$\overline{\mathrm{m}}_{\text {vap.hx4 }}=\frac{\dot{\mathrm{m}}_{\text {vap.hx4 }}}{1000[\text { ton/h] }}$

TROCADOR $h \times 5$

$P_{26}=P_{27}$

$\mathrm{h}_{27}=\mathbf{h}\left[\right.$ water $\left.; \mathrm{P}=\mathrm{P}_{27} ; \mathrm{x}=0\right]$

$\mathrm{h}_{28}=\mathbf{h}\left[\right.$ water $\left.; \mathrm{T}=\mathrm{T}_{28} ; \mathrm{P}=\mathrm{P}_{28}\right]$

$\dot{\mathrm{m}}_{\text {agua }} \cdot\left[\mathrm{h}_{25}-\mathrm{h}_{28}\right]+\dot{\mathrm{m}}_{\text {vap.hx5 }} \cdot\left[\mathrm{h}_{26}-\mathrm{h}_{27}\right]=0$ Balanço de energia

$\overline{\mathrm{m}}_{\text {vap.hx5 }}=\frac{\dot{\mathrm{m}}_{\text {vap.hx5 }}}{1000[\text { ton } / \mathrm{h}]}$

TROCADOR $h \times 6$

$P_{29}=P_{30}$

$\mathrm{h}_{30}=\mathbf{h}\left[\right.$ water $\left.; \mathrm{P}=\mathrm{P}_{30} ; \mathrm{x}=0\right]$ 
$\mathrm{h}_{31}=\mathbf{h}\left[\right.$ water $\left.; \mathrm{T}=\mathrm{T}_{31} ; \mathrm{P}=\mathrm{P}_{31}\right]$

$\dot{\mathrm{m}}_{\text {agua }} \cdot\left[\mathrm{h}_{28}-\mathrm{h}_{31}\right]+\dot{\mathrm{m}}_{\text {vap.hx6}} \cdot\left[\mathrm{h}_{29}-\mathrm{h}_{30}\right]=0$ Balanço de energia

$\overline{\mathrm{m}}_{\text {vap.hx6}}=\frac{\dot{\mathrm{m}}_{\text {vap.hx6 }}}{1000[\text { ton } / \mathrm{h}]}$

TROCADOR $h \times 7$

$P_{32}=P_{33}$

$\mathrm{h}_{33}=\mathbf{h}\left[\right.$ water $\left.; \mathrm{P}=\mathrm{P}_{33} ; \mathrm{x}=0\right]$

$\mathrm{h}_{34}=\mathbf{h}\left[\right.$ water $\left.; \mathrm{T}=\mathrm{T}_{34} ; \mathrm{P}=\mathrm{P}_{34}\right]$

$\dot{\mathrm{m}}_{\text {agua }} \cdot\left[\mathrm{h}_{31}-\mathrm{h}_{34}\right]+\dot{\mathrm{m}}_{\text {vap.hx7 }} \cdot\left[\mathrm{h}_{32}-\mathrm{h}_{33}\right]=0$ Balanço de energia

$\overline{\mathrm{m}}_{\text {vap.hx7 }}=\frac{\dot{\mathrm{m}}_{\text {vap.hx7 }}}{1000[\text { ton } / \mathrm{h}]}$

TROCADOR $h \times 8$

$\mathrm{P}_{35}=\mathrm{P}_{36}$

$\mathrm{h}_{36}=\mathbf{h}\left[\right.$ water $\left.; \mathrm{P}=\mathrm{P}_{36} ; \mathrm{x}=0\right]$

$\mathrm{h}_{37}=\mathbf{h}\left[\right.$ water $\left.; \mathrm{T}=\mathrm{T}_{37} ; \mathrm{P}=\mathrm{P}_{37}\right]$

$\dot{\mathrm{m}}_{\text {agua }} \cdot\left[\mathrm{h}_{34}-\mathrm{h}_{37}\right]+\dot{\mathrm{m}}_{\text {vap.hx8 }} \cdot\left[\mathrm{h}_{35}-\mathrm{h}_{36}\right]=0$ Balanço de energia

$\overline{\mathrm{m}}_{\text {vap.hx8 }}=\frac{\dot{\mathrm{m}}_{\text {vap.hx8 }}}{1000[\text { ton } / \mathrm{h}]}$

TROCADOR $h \times 9$

$\mathrm{P}_{38}=\mathrm{P}_{39}$

$\mathrm{h}_{39}=\mathbf{h}\left[\right.$ water $\left.; \mathrm{P}=\mathrm{P}_{39} ; \mathrm{x}=0\right]$

$\mathrm{h}_{40}=\mathbf{h}\left[\right.$ water $\left.; \mathrm{T}=\mathrm{T}_{40} ; \mathrm{P}=\mathrm{P}_{40}\right]$

$\dot{\mathrm{m}}_{\text {agua }} \cdot\left[\mathrm{h}_{37}-\mathrm{h}_{40}\right]+\dot{\mathrm{m}}_{\mathrm{vap} . \mathrm{hx9}} \cdot\left[\mathrm{h}_{38}-\mathrm{h}_{39}\right]=0$ Balanço de energia

$\overline{\mathrm{m}}_{\text {vap.hx9 }}=\frac{\dot{\mathrm{m}}_{\text {vap.hx9 }}}{1000[\text { ton } / \mathrm{h}]}$

TROCADOR $h \times 10$

$P_{9}=P_{8}$

$\mathrm{T}_{9}=\mathbf{T}_{\text {sat }}\left[\right.$ water $\left.; \mathrm{P}=\mathrm{P}_{8}\right]$

$\mathrm{h}_{9}=\mathbf{h}\left[\right.$ water $\left.; \mathrm{P}=\mathrm{P}_{9} ; \mathrm{x}=0\right]$

$P_{10}=P_{7}$

$\mathrm{h}_{10}=\mathbf{h}\left[\right.$ water $\left.; \mathrm{T}=\mathrm{T}_{10} ; \mathrm{P}=\mathrm{P}_{10}\right]$

$\dot{\mathrm{m}}_{\text {agua }} \cdot \mathrm{h}_{40}+\dot{\mathrm{m}}_{\text {vap.hx10}} \cdot \mathrm{h}_{8}=\dot{\mathrm{m}}_{\text {agua }} \cdot \mathrm{h}_{10}+\dot{\mathrm{m}}_{\text {vap.hx10}} \cdot \mathrm{h}_{9} \quad$ Balanço de energia no $h \times 10$ 
$\overline{\mathrm{m}}_{\text {vap.hx10 }}=\frac{\dot{\mathrm{m}}_{\text {vap.hx10 }}}{1000[\text { ton } / \mathrm{h}]}$

Otimização dos trocadores de calor

Cálculo da temperatura de saída de cada trocador de calor

$\mathrm{T}_{13}=\mathrm{T}_{7}+\delta \mathrm{T}_{\mathrm{opt}} \cdot \mathrm{c} 1$ Delta $T_{\text {opt }}$ é o incremento ótimo de temperatura em cada trocador de calor a ser otimizado

$\mathrm{T}_{14}=\mathrm{T}_{13}+\delta \mathrm{T}_{\mathrm{opt}} \cdot \mathrm{c} 2$ Constantes $\mathrm{c1}, \mathrm{c2}$, recebem valores 1 ou 0 para ligar ou desligar TCs

$\mathrm{T}_{22}=\mathrm{T}_{14}+\delta \mathrm{T}_{\mathrm{opt}} \cdot \mathrm{c3}$

$\mathrm{T}_{25}=\mathrm{T}_{22}+\delta \mathrm{T}_{\mathrm{opt}} \cdot \mathrm{c} 4$

$\mathrm{T}_{28}=\mathrm{T}_{25}+\delta \mathrm{T}_{\mathrm{opt}} \cdot \mathrm{c5}$

$\mathrm{T}_{31}=\mathrm{T}_{28}+\delta \mathrm{T}_{\mathrm{opt}} \cdot \mathrm{c} 6$

$\mathrm{T}_{34}=\mathrm{T}_{31}+\delta \mathrm{T}_{\mathrm{opt}} \cdot \mathrm{c} 7$

$\mathrm{T}_{37}=\mathrm{T}_{34}+\delta \mathrm{T}_{\mathrm{opt}} \cdot \mathrm{c} 8$

$\mathrm{T}_{40}=\mathrm{T}_{37}+\delta \mathrm{T}_{\mathrm{opt}} \cdot \mathrm{c} 9$

$\mathrm{T}_{10}=\mathrm{T}_{40}+\delta \mathrm{T}_{\mathrm{opt}} \cdot \mathrm{c} 10$

Cálculo dos pontos ótimos de extração na turbina

TTD = 3,5 [C] Diferença de Temperatura Terminal, parâmetro de entrada

TTD $=\mathrm{T}_{\text {sat; } \mathrm{h} \times 1}-\mathrm{T}_{13}$

TTD $=T_{\text {sat:hx2 }}-T_{14}$

TTD $=T_{\text {sat; } h \times 3}-T_{22}$

TTD $=T_{\text {sat;hx4 }}-\mathrm{T}_{25}$

TTD $=\mathrm{T}_{\text {sat; }}$ x5 $-\mathrm{T}_{28}$

TTD $=\mathrm{T}_{\text {sat; }}$ hx6 $-\mathrm{T}_{31}$

TTD $=\mathrm{T}_{\text {sat; } \mathrm{hx} 7}-\mathrm{T}_{34}$

TTD $=T_{\text {sat;hx8 }}-T_{37}$

TTD $=T_{\text {sat;hx9 }}-T_{40}$

TTD $=T_{\text {sat;hx10 }}-T_{10}$

$\mathrm{P}_{15}=\mathbf{P}_{\text {sat }}\left[\right.$ water $\left.; \mathrm{T}=\mathrm{T}_{\text {sat }, \mathrm{hx} 1}\right]$

$\mathrm{P}_{11}=\mathbf{P}_{\text {sat }}\left[\right.$ water $\left.; \mathrm{T}=\mathrm{T}_{\text {sat }, \mathrm{h} \times 2}\right]$

$\mathrm{P}_{20}=\mathbf{P}_{\text {sat }}\left[\right.$ water $\left.; \mathrm{T}=\mathrm{T}_{\text {sat; } h \times 3}\right]$

$\mathrm{P}_{23}=\mathbf{P}_{\text {sat }}\left[\right.$ water $\left.; \mathrm{T}=\mathrm{T}_{\text {sat }, \mathrm{hx} 4}\right]$ 
$\mathrm{P}_{26}=\mathbf{P}_{\text {sat }}\left[\right.$ water $\left.; \mathrm{T}=\mathrm{T}_{\text {sat; } h \times 5}\right]$

$\mathrm{P}_{29}=\mathbf{P}_{\text {sat }}\left[\right.$ water $\left.; \mathrm{T}=\mathrm{T}_{\text {sat; } h \times 6}\right]$

$\mathrm{P}_{32}=\mathbf{P}_{\text {sat }}\left[\right.$ water $\left.; \mathrm{T}=\mathrm{T}_{\text {sat; } \mathrm{hx} \text { }}\right]$

$\mathrm{P}_{35}=\mathbf{P}_{\text {sat }}\left[\right.$ water $\left.; \mathrm{T}=\mathrm{T}_{\text {sat; } h \times 8}\right]$

$\mathrm{P}_{38}=\mathbf{P}_{\text {sat }}\left[\right.$ water $\left.; \mathrm{T}=\mathrm{T}_{\text {sat; } \mathrm{h} \times 9}\right]$

$\mathrm{P}_{8}=\mathbf{P}_{\text {sat }}\left[\right.$ water $\left.; \mathrm{T}=\mathrm{T}_{\text {sat; }, \mathrm{h} \times 10}\right]$

CONDENSADOR

$\dot{\mathrm{Q}}_{\text {out }}=\dot{\mathrm{m}}_{\text {vap.cauda }} \cdot\left[\mathrm{h}_{3}-\mathrm{h}_{4}\right]$ Balanço de energia --> Calor transferido da condensação do vapor para a torre de resfriamento

TORRE DE RESFRIAMENTO

$\dot{\mathrm{Q}}_{\text {out }}=\dot{\mathrm{m}}_{\text {recirculação }} \cdot\left[\mathrm{h}_{\text {out }}-\mathrm{h}_{\text {in }}\right]$

$\mathrm{h}_{\text {out }}=\mathbf{h}\left[\right.$ water $\left.; \mathrm{P}=\mathrm{P}_{\text {out }} ; \mathrm{T}=\mathrm{T}_{\text {out }}\right]$

$\mathrm{h}_{\text {in }}=\mathbf{h}\left[\right.$ water $\left.; \mathrm{P}=\mathrm{P}_{\text {in }} ; \mathrm{T}=\mathrm{T}_{\text {in }}\right] \quad \mathrm{P}_{\text {in }}=1$

$P_{\text {out }}=1$

$\dot{\mathrm{m}}_{\text {repos.torre }}=\mathrm{Y}_{\text {perdas }} \cdot \dot{\mathrm{m}}_{\text {recirculação }} \quad Y_{\text {perdas }}$ corresponde a uma estimativa de perdas de água por evaporação, purga e arraste na torre de resfriamento

$\dot{\mathrm{m}}_{\text {rep.total }}=\dot{\mathrm{m}}_{\text {repos.torre }}+\dot{\mathrm{m}}_{\text {rep.desaerador }}+\mathrm{m}_{\text {agua.dessuper }}$

$\overline{\mathrm{m}}_{\text {repos.torre }}=\frac{\dot{\mathrm{m}}_{\text {repos.torre }}}{1000[\text { ton } / \mathrm{h}]}$

$\overline{\mathrm{m}}_{\text {rep.total }}=\frac{\dot{\mathrm{m}}_{\text {rep.total }}}{1000[\text { ton } / \mathrm{h}]}$

$\overline{\mathrm{m}}_{\text {vap.dessuper }}=\frac{\dot{\mathrm{m}}_{\text {vap.dessuper }}}{1000[\text { ton } / \mathrm{h}]}$

Perc.torre $=\frac{\dot{\mathrm{m}}_{\text {repos.torre }}}{\dot{\mathrm{m}}_{\text {rep.total }}} \cdot 100$

Perc.desaerador $=\frac{\dot{\mathrm{m}}_{\text {rep.desaerador }}}{\dot{\mathrm{m}}_{\text {rep.total }}} \cdot 100$

Perc.dessuper $=\frac{\dot{\mathrm{m}}_{\text {vap.dessuper }}}{\dot{\mathrm{m}}_{\text {rep.total }}} \cdot 100$

Tap.water $r_{\text {torre }}=\frac{\dot{\mathrm{m}}_{\text {repos.torre }}}{\frac{\dot{\mathrm{M}}_{\text {cana }}}{1000}}$

Tap.water $r_{\text {deionised }}=\frac{\dot{\mathrm{m}}_{\text {rep.desaerador }}+\mathrm{m}_{\text {agua.dessuper }}}{\frac{\dot{\mathrm{M}}_{\text {cana }}}{1000}}$ 


$$
\begin{aligned}
& \mathrm{POT}_{\text {elétr.gerada }}=\left[\mathrm{POT}_{\text {esc }}+\mathrm{POT}_{\text {cau }}+\mathrm{POT}_{1}+\mathrm{POT}_{2}+\mathrm{POT}_{3}+\mathrm{POT}_{4}+\mathrm{POT}_{5}+\mathrm{POT}_{6}+\mathrm{POT}_{7}+\mathrm{POT}_{8}\right. \\
& \left.+\mathrm{POT}_{9}+\mathrm{POT}_{10}\right] \cdot \eta_{\mathrm{g}} \cdot\left|2,77778 \times 10^{-7} \cdot \frac{\mathrm{MW}}{\mathrm{kJ} / \mathrm{h}}\right|
\end{aligned}
$$

Potencia elétrica total gerada no turbogerador

$\mathrm{POT}_{\text {esc }}=\dot{\mathrm{m}}_{\text {vap.escape }} \cdot\left[\mathrm{h}_{1}-\mathrm{h}_{2}\right]$ Potencia gerada pelo vapor de escape a $\mathrm{P}=2,5 \mathrm{bar}$

POT $_{\text {cau }}=\dot{\mathrm{m}}_{\text {vap.cauda }} \cdot\left[\mathrm{h}_{1}-\mathrm{h}_{3}\right]$ Potencia gerada pelo vapor da cauda

$\mathrm{POT}_{2}=\dot{\mathrm{m}}_{\text {vap.hx2 }} \cdot\left[\mathrm{h}_{1}-\mathrm{h}_{11}\right]$ Potencia gerada pelo vapor de extraído no segundo estágio da turbina direcionado a trocador $h \times 2$

POT $_{1}=\dot{\mathrm{m}}_{\text {vap.hx1 }} \cdot\left[\mathrm{h}_{1}-\mathrm{h}_{15}\right]$ Potencia gerada pelo vapor de extraído no terceiro estágio da turbina direcionado a trocador $h \times 1$

$\mathrm{POT}_{3}=\dot{\mathrm{m}}_{\text {vap.hx3 }} \cdot\left[\mathrm{h}_{1}-\mathrm{h}_{20}\right]$ Potencia gerada pelo vapor de extraído na turbina

$\mathrm{POT}_{4}=\dot{\mathrm{m}}_{\text {vap.hx4 }} \cdot\left[\mathrm{h}_{1}-\mathrm{h}_{23}\right]$ Potencia gerada pelo vapor de extraído na turbina

$\mathrm{POT}_{5}=\dot{\mathrm{m}}_{\text {vap.hx5}} \cdot\left[\mathrm{h}_{1}-\mathrm{h}_{26}\right]$ Potencia gerada pelo vapor de extraído na turbina

POT $_{6}=\dot{\mathrm{m}}_{\text {vap.hx6 }} \cdot\left[\mathrm{h}_{1}-\mathrm{h}_{29}\right]$ Potencia gerada pelo vapor de extraído na turbina

$\mathrm{POT}_{7}=\dot{\mathrm{m}}_{\text {vap.hx7 }} \cdot\left[\mathrm{h}_{1}-\mathrm{h}_{32}\right]$ Potencia gerada pelo vapor de extraído na turbina

$\mathrm{POT}_{8}=\dot{\mathrm{m}}_{\text {vap.hx8 }} \cdot\left[\mathrm{h}_{1}-\mathrm{h}_{35}\right]$ Potencia gerada pelo vapor de extraído na turbina

POT $_{9}=\dot{\mathrm{m}}_{\text {vap.hx9 }} \cdot\left[\mathrm{h}_{1}-\mathrm{h}_{38}\right]$ Potencia gerada pelo vapor de extraído na turbina

POT $_{10}=\dot{\mathrm{m}}_{\text {vap.hx10 }} \cdot\left[\mathrm{h}_{1}-\mathrm{h}_{8}\right]$ Potencia gerada pelo vapor extraído no primeiro estágio da turbina direcionado a trocador $h \times 10$

Consumo das bombas do ciclo

POT $_{\text {elétr.consumida }}=\left[\mathrm{POT}_{\mathrm{B} 1}+\mathrm{POT}_{\mathrm{B} 2}\right] \cdot\left|2,77778 \times 10^{-7} \cdot \frac{\mathrm{MW}}{\mathrm{kJ} / \mathrm{h}}\right|$ Potência consumida pelas bombas

POT $_{\mathrm{B} 1}=\dot{\mathrm{m}}_{\text {vap.cauda }} \cdot\left[\mathrm{h}_{5}-\mathrm{h}_{4}\right]$ Potência consumida pela bomba 1

$\mathrm{POT}_{\text {B2 }}=\dot{\mathrm{m}}_{\text {agua }} \cdot\left[\mathrm{h}_{7}-\mathrm{h}_{6}\right]$ Potência consumida pela bomba 1

EFICIÊNCIA GLOBAL DA UNIDADE DE COGERAÇÃO COM REGENERAÇÃO

Cálculo da eficiência energética

$\eta$ Energética.Global

$$
=\left[\frac{\text { POT }_{\text {elétr.líquida }}+\text { POT }_{\text {processo }}}{\text { POT }_{\text {entrada }}}\right] \cdot 100
$$

Potência líquida gerada na unidade de cogeração

$\mathrm{POT}_{\text {elétr.líquida }}=\mathrm{POT}_{\text {elétr.gerada }}-\mathrm{POT}_{\text {elétr.consumida }}$

Potência utilizada no processo industrial e desaerador

$$
\begin{aligned}
& \mathrm{POT}_{\text {processo }}=\dot{\mathrm{m}}_{\text {vap.processo }} \cdot\left[\mathrm{h}_{\text {pro }}-\mathrm{h}_{\text {sat }}\right] \cdot\left|2,77778 \times 10^{-7} \cdot \frac{\mathrm{MW}}{\mathrm{kJ} / \mathrm{h}}\right| \\
& \mathrm{POT}_{\text {desaerador }}=\dot{\mathrm{m}}_{\text {vap.desaerador }} \cdot\left[\mathrm{h}_{2}-\mathrm{h}_{6}\right] \cdot\left|2,77778 \times 10^{-7} \cdot \frac{\mathrm{MW}}{\mathrm{kJ} / \mathrm{h}}\right|
\end{aligned}
$$


$\mathrm{POT}_{\text {desaerador.perc }}=\frac{\mathrm{POT}_{\text {desaerador }}}{\mathrm{POT}_{\text {entrada }}} \cdot 100$

$\mathrm{POT}_{\text {processo.perc }}=\frac{\mathrm{POT}_{\text {processo }}}{\mathrm{POT}_{\text {entrada }}} \cdot 100$

$\mathrm{h}_{\text {sat }}=\mathbf{h}[$ water $; \mathrm{x}=0 ; \mathrm{P}=2,5]$

Alimentação energética na fornalha da caldeira

$\mathrm{POT}_{\text {entrada }}=\left[\begin{array}{lll}\dot{\mathrm{m}}_{\text {bagaço }} & \cdot \mathrm{PCl}_{\text {bagaço }}+\dot{\mathrm{m}}_{\text {palha }} \cdot \mathrm{PCl}_{\text {palha }}\end{array}\right] \cdot\left|2,77778 \times 10^{-7} \cdot \frac{\mathrm{MW}}{\mathrm{kJ} / \mathrm{h}}\right|$

APLICAÇÃO DA 2A LEI DA TERMODINÂMICA - ANÁLISE EXERGÉTICA

Ambiente de referência considerado: $P o=1$ bar e $T o=25 C$

$\mathrm{TO}=25[\mathrm{C}]$

$\mathrm{PO}=1[\mathrm{bar}]$

$\mathrm{P} 00_{\mathrm{h} 20}=0,0303$ [bar $]$

LIMITE TEÓRICO DE EFICIÊNCIA - CICLO DE CARNOT

$\eta$ carnot $=\left[1-\left(\frac{T_{3}+273,15}{T_{1}+273,15}\right)\right] \cdot 100$ Trabalho máximo que pode ser obtido

Trabalho útil final - saída do gerador

EXERGY.in fuel $_{\text {fontrada }}$

EXERGY.out ${ }_{\text {electricity }}=\mathrm{POT}_{\text {elétr.líquida energia elétrica é exergia pura }}$

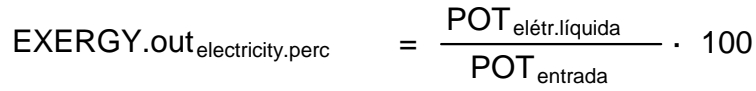

BOILER

$\mathrm{B}_{1}=\dot{\mathrm{m}}_{\text {vapor }} \cdot\left[\mathrm{h}_{1}-\mathrm{h}_{0}-\left([\mathrm{T} 0+273,15] \cdot\left[\mathrm{s}_{1}-\mathrm{s}_{0}\right]\right)\right] \cdot\left|2,77778 \times 10^{-7} \cdot \frac{\mathrm{MW}}{\mathrm{kJ} / \mathrm{h}}\right|+$ Bch $_{1} \begin{gathered}\text { Exergia total } \\ \text { do }\end{gathered}$ vapo de saída do gerador de va or

$\mathrm{Bch}_{1}=\dot{\mathrm{m}}_{\mathrm{vapor}} \cdot\left[-8590+8,314 \cdot(\mathrm{T0}+273,15) \cdot \ln \left(\frac{1}{0,0303}\right)\right] \cdot \frac{\left|2,77778 \times 10^{-7} \cdot \frac{\mathrm{MW}}{\mathrm{kJ} / \mathrm{h}}\right|}{18}$ Exegia química vapor de saída do gerador de va or 
$\mathrm{h}_{0}=\mathbf{h}[$ water $; \mathrm{T}=\mathrm{T} 0 ; \mathrm{P}=\mathrm{PO}]$

$\mathrm{S}_{0}=\mathbf{s}[$ water $; \mathrm{T}=\mathrm{T} 0 ; \mathrm{P}=\mathrm{PO}]$

$B_{\text {fuel }}=$ EXERGY.in fuel

\section{TURBINE}

Exergia das correntes de vapor de escape e cauda

$\mathrm{B}_{2}=\dot{\mathrm{m}}_{\text {vap.escape }} \cdot\left[\mathrm{h}_{2}-\mathrm{h}_{0}-\left([\mathrm{TO}+273,15] \cdot\left[\mathrm{s}_{2}-\mathrm{s}_{0}\right]\right)\right] \cdot\left|2,77778 \times 10^{-7} \cdot \frac{\mathrm{MW}}{\mathrm{kJ} / \mathrm{h}}\right|+\mathrm{Bch}_{2} \quad$ Exergia total do vapor de escap

$\mathrm{Bch}_{2}=\dot{\mathrm{m}}_{\text {vap.escape }} \cdot\left[-8590+8,314 \cdot(\mathrm{T} 0+273,15) \cdot \ln \left(\frac{1}{0,0303}\right)\right] \cdot \frac{\left|2,77778 \times 10^{-7} \cdot \frac{\mathrm{MW}}{\mathrm{kJ} / \mathrm{h}}\right|}{18}$ Exegia química do vapor de escap

$\mathrm{B}_{3}=\dot{\mathrm{m}}_{\text {vap.cauda }} \cdot\left[\mathrm{h}_{3}-\mathrm{h}_{0}-\left([\mathrm{T} 0+273,15] \cdot\left[\mathrm{s}_{3}-\mathrm{s}_{0}\right]\right)\right] \cdot\left|2,77778 \times 10^{-7} \cdot \frac{\mathrm{MW}}{\mathrm{kJ} / \mathrm{h}}\right|+$ Bch $_{3}$ Exergia total do vapor de auda

$\mathrm{Bch}_{3}=\dot{\mathrm{m}}_{\text {vap.cauda }} \cdot\left[-8590+8,314 \cdot(\mathrm{T} 0+273,15) \cdot \ln \left(\frac{1}{0,0303}\right)\right] \cdot \frac{\left|2,77778 \times 10^{-7} \cdot \frac{\mathrm{MW}}{\mathrm{kJ} / \mathrm{h}}\right|}{18}$ Exegia química do vapor de auda

Exergia das correntes de regeneração para os trocadores $h \times 10, h \times 2$ e $h \times 1$

$\mathrm{B}_{8}=\dot{\mathrm{m}}_{\mathrm{vap} . \mathrm{h} \times 10} \cdot\left[\mathrm{h}_{8}-\mathrm{h}_{0}-\left([\mathrm{T} 0+273,15] \cdot\left[\mathrm{s}_{8}-\mathrm{s}_{0}\right]\right)\right] \cdot\left|2,77778 \times 10^{-7} \cdot \frac{\mathrm{MW}}{\mathrm{kJ} / \mathrm{h}}\right|+$ Bch $_{8} \quad$ Exergia total do vapor da primeira extração da turbina

$\mathrm{Bch}_{8}=\dot{\mathrm{m}}_{\text {vap.hx10 }} \cdot\left[-8590+8,314 \cdot(\mathrm{T} 0+273,15) \cdot \ln \left(\frac{1}{0,0303}\right)\right] \cdot \frac{\left|2,77778 \times 10^{-7} \cdot \frac{\mathrm{MW}}{\mathrm{kJ} / \mathrm{h}}\right|}{18}$ Exegia 


$$
\begin{aligned}
& \text { primeira } \\
& \text { extração } \\
& \text { da turbina } \\
& \mathrm{B}_{11}=\dot{\mathrm{m}}_{\text {vap.hx2 }} \cdot\left[\mathrm{h}_{11}-\mathrm{h}_{0}-\left([\mathrm{T0}+273,15] \cdot\left[\mathrm{s}_{11}-\mathrm{s}_{0}\right]\right)\right] \cdot\left|2,77778 \times 10^{-7} \cdot \frac{\mathrm{MW}}{\mathrm{kJ} / \mathrm{h}}\right|+\mathrm{Bch}_{11} \text { Exergia } \\
& \text { total } \\
& \text { do } \\
& \text { vapor } \\
& \text { da } \\
& \text { segund } \\
& \text { extraçã } \\
& \text { da turb } \\
& \text { na } \\
& \mathrm{Bch}_{11}=\dot{\mathrm{m}}_{\mathrm{vap} . \mathrm{hx} 2} \cdot\left[-8590+8,314 \cdot(\mathrm{T} 0+273,15) \cdot \ln \left(\frac{1}{0,0303}\right)\right] \cdot \frac{\left|2,77778 \times 10^{-7} \cdot \frac{\mathrm{MW}}{\mathrm{kJ} / \mathrm{h}}\right|}{18} \text { Exegia } \\
& \mathrm{B}_{15}=\dot{\mathrm{m}}_{\text {vap.hx1 }} \cdot\left[\mathrm{h}_{15}-\mathrm{h}_{0}-\left([\mathrm{T0}+273,15] \cdot\left[\mathrm{s}_{15}-\mathrm{s}_{0}\right]\right)\right] \cdot\left|2,77778 \times 10^{-7} \cdot \frac{\mathrm{MW}}{\mathrm{kJ} / \mathrm{h}}\right|+\mathrm{Bch}_{15} \text { Exergia } \\
& \text { total } \\
& \text { do } \\
& \text { vapor } \\
& \text { da } \\
& \text { segund } \\
& \text { extraçã } \\
& \text { da turb } \\
& \text { na } \\
& \mathrm{Bch}_{15}=\dot{\mathrm{m}}_{\mathrm{vap} . \mathrm{hx} 1} \cdot\left[-8590+8,314 \cdot(\mathrm{T} 0+273,15) \cdot \ln \left(\frac{1}{0,0303}\right)\right] \cdot \frac{\left|2,77778 \times 10^{-7} \cdot \frac{\mathrm{MW}}{\mathrm{kJ} / \mathrm{h}}\right|}{18} \text { Exegia } \\
& \text { química } \\
& \text { do } \\
& \text { vapor } \\
& \text { da } \\
& \text { segunda } \\
& \text { extração } \\
& \text { da turbina }
\end{aligned}
$$

Balanço de exergia na turbina

$$
\begin{aligned}
& \text { Bdest }_{\text {turbine }}=\mathrm{B}_{1}-\left[\mathrm{B}_{2}+\mathrm{B}_{3}+\mathrm{B}_{8}+\mathrm{B}_{11}+\mathrm{B}_{15}+\frac{\mathrm{POT}_{\text {elétr.gerada }}}{\eta_{\mathrm{g}}}\right] \text { Exergia destruída na turbina } \\
& \text { Bdest }_{\text {turbine.perc }}=\frac{\text { Bdest }_{\text {turbine }}}{\mathrm{B}_{\text {fuel }}} \cdot 100 \text { Percentual de exergia destruída na turbina }
\end{aligned}
$$


$\mathrm{B}_{2 ; \mathrm{perc}}=\frac{\mathrm{B}_{2}}{\mathrm{~B}_{\text {fuel }}} \cdot 100$ Percentual de exergia no vapor de escape

$\mathrm{B}_{\text {liq }}=\frac{\mathrm{POT}_{\text {elétr.gerada }}}{\mathrm{B}_{\text {fuel }}} \cdot 100$ Percentual de exergia (trabalho) na saída do gerador

Consumo de exergia no processo industrial associado ao consumo específico de vapor

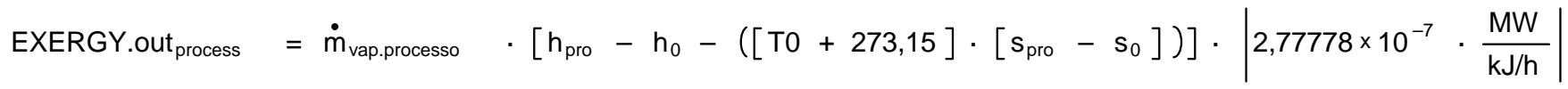
+ Bch $_{\text {pro }}$

$\operatorname{Bch}_{\text {pro }}=\dot{\mathrm{m}}_{\text {vap.processo }} \cdot\left[-8590+8,314 \cdot(\mathrm{T} 0+273,15) \cdot \ln \left(\frac{1}{0,0303}\right)\right] \cdot \frac{\left|2,77778 \times 10^{-7} \cdot \frac{\mathrm{MW}}{\mathrm{kJ} / \mathrm{h}}\right|}{18} \mathrm{Exegia}$ quím ca do vapor do $\mathrm{pr}$ cesso

$\mathrm{S}_{\text {pro }}=\mathbf{s}[$ water $; \mathrm{P}=2,5 ; \mathrm{T}=127,5]$

EXERGY.out $_{\text {process.perc }}=\frac{\text { EXERGY.out }_{\text {process }}}{B_{\text {fuel }}} \cdot 100$

EXERGY.out $_{\text {deaerator }}=\mathrm{B}_{2}-$ EXERGY.out $_{\text {process }}$

EXERGY.out deaerator.perc $_{\text {ex }}=\frac{\text { EXERGY.out }_{\text {deaerator }}}{B_{\text {fuel }}} \cdot 100$

\section{DESSUPERAQUECEDOR}

Balanço de entropia no dessuper

$\mathrm{S}_{\text {ger.dessuper }}=\dot{\mathrm{m}}_{\text {vap.processo }} \cdot \mathrm{s}_{\text {pro }}-\left[\mathrm{m}_{\text {agua.dessuper }} \cdot \mathrm{s}_{\text {agua }}+\left(\dot{\mathrm{m}}_{\text {vap.dessuper }}-\dot{\mathrm{m}}_{\text {purgador }}\right) \cdot \mathrm{s}_{2}\right]$

$\mathrm{S}_{\text {agua }}=\mathbf{s}[$ water $; \mathrm{P}=2,5 ; \mathrm{T}=25]$

Bdest $_{\text {dessuper }}=[\mathrm{TO}+273,15] \cdot \mathrm{S}_{\text {ger.dessuper }} \cdot\left|2,77778 \times 10^{-7} \cdot \frac{\mathrm{MW}}{\mathrm{kJ} / \mathrm{h}}\right|$ Exergia destruída no dessuperaquecedor

Bdest $_{\text {dessuper.perc }}=\frac{\text { Bdest }_{\text {dessuper }}}{\mathrm{B}_{\text {fuel }}} \cdot 100$ Percentual de exergia destruída no dessuperaquecedor

CONDENSADOR

$\mathrm{B}_{4}=\dot{\mathrm{m}}_{\text {vap.cauda }} \cdot\left[\mathrm{h}_{4}-\mathrm{h}_{0}-\left([\mathrm{T} 0+273,15] \cdot\left[\mathrm{s}_{4}-\mathrm{s}_{0}\right]\right)\right] \cdot\left|2,77778 \times 10^{-7} \cdot \frac{\mathrm{MW}}{\mathrm{kJ} / \mathrm{h}}\right|+\mathrm{Bch}_{4}$ Exergia 
$\mathrm{Bch}_{4}=\dot{\mathrm{m}}_{\text {vap.cauda }} \cdot\left[-8590+8,314 \cdot(\mathrm{T} 0+273,15) \cdot \ln \left(\frac{1}{0,0303}\right)\right] \cdot \frac{\left|2,77778 \times 10^{-7} \cdot \frac{\mathrm{MW}}{\mathrm{kJ} / \mathrm{h}}\right|}{18}$ Exegia química na saída do condensa or

Bdest $_{\text {condenser }}=\mathrm{B}_{3}-\mathrm{B}_{4}$ Exergia destruída no condensador

Bdest $_{\text {condenser.perc }}=\frac{\text { Bdest }_{\text {condenser }}}{\mathrm{B}_{\text {fuel }}} \cdot 100$ Percentual de exergia destruída no condensador

BOMBA 1

$\mathrm{B}_{5}=\dot{\mathrm{m}}_{\mathrm{vap.cauda}} \cdot\left[\mathrm{h}_{5}-\mathrm{h}_{0}-\left([\mathrm{T} 0+273,15] \cdot\left[\mathrm{s}_{5}-\mathrm{s}_{0}\right]\right)\right] \cdot\left|2,77778 \times 10^{-7} \cdot \frac{\mathrm{MW}}{\mathrm{kJ} / \mathrm{h}}\right|$ Exergia na saída da bomba 1

Bdest $_{\mathrm{B} 1}=\mathrm{B}_{4}-\mathrm{B}_{5}+\mathrm{W}_{\mathrm{B} 1}$ Exergia destruída na bomba 1

$\mathrm{W}_{\mathrm{B} 1}=\dot{\mathrm{m}}_{\text {vap.cauda }} \cdot\left[\mathrm{h}_{5}-\mathrm{h}_{4}\right] \cdot\left|2,77778 \times 10^{-7} \cdot \frac{\mathrm{MW}}{\mathrm{kJ} / \mathrm{h}}\right|$ Trabalho realizado pela bomba $B 1$

Bdest $_{\mathrm{B} 1 . \text { perc }}=\frac{\text { Bdest }_{\mathrm{B} 1}}{\mathrm{~B}_{\text {fuel }}} \cdot 100$ Percentual de exergia destruída na bomba 1

\section{DESAERADOR}

Balanço de entropia no dessuperaquecedor

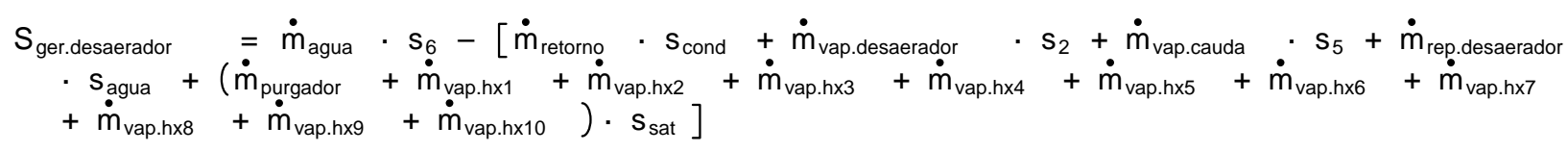

$\mathrm{s}_{\text {cond }}=\mathbf{s}\left[\right.$ water $\left.; \mathrm{T}=\mathrm{T}_{\text {cond }} ; \mathrm{P}=\mathrm{P}_{\text {cond }}\right] \quad \mathrm{s}_{\text {sat }}=\mathbf{s}[$ water $; \mathrm{P}=2,5 ; \mathrm{x}=0]$

Bdest $_{\text {desaerador }}=[\mathrm{T0}+273,15] \cdot \mathrm{S}_{\text {ger.desaerador }} \cdot\left|2,77778 \times 10^{-7} \cdot \frac{\mathrm{MW}}{\mathrm{kJ} / \mathrm{h}}\right|$ Exergia destruída no desaerador

Bdest $_{\text {desaerador.perc }}=\frac{\text { Bdest }_{\text {desaerador }}}{\mathrm{B}_{\text {fuel }}} \cdot 100$ Percentual de exergia destruída no desaerador

BOMBA 2

$\mathrm{B}_{7}=\dot{\mathrm{m}}_{\text {agua }} \cdot\left[\mathrm{h}_{7}-\mathrm{h}_{0}-\left([\mathrm{TO}+273,15] \cdot\left[\mathrm{s}_{7}-\mathrm{s}_{0}\right]\right)\right] \cdot\left|2,77778 \times 10^{-7} \cdot \frac{\mathrm{MW}}{\mathrm{kJ} / \mathrm{h}}\right|$ Exergia na saída da bomba 2

$\mathrm{B}_{6}=\dot{\mathrm{m}}_{\text {agua }} \cdot\left[\mathrm{h}_{6}-\mathrm{h}_{0}-\left([\mathrm{TO}+273,15] \cdot\left[\mathrm{s}_{6}-\mathrm{s}_{0}\right]\right)\right] \cdot\left|2,77778 \times 10^{-7} \cdot \frac{\mathrm{MW}}{\mathrm{kJ} / \mathrm{h}}\right| \begin{array}{r}\text { Exergia na entrada } \\ \text { da bomba } 2\end{array}$

$\mathrm{W}_{\mathrm{B} 2}=\dot{\mathrm{m}}_{\text {agua }} \cdot\left[\mathrm{h}_{7}-\mathrm{h}_{6}\right] \cdot\left|2,77778 \times 10^{-7} \cdot \frac{\mathrm{MW}}{\mathrm{kJ} / \mathrm{h}}\right|$ Trabalho realizado pela bomba $B 2$

Bdest $_{\mathrm{B} 2}=\mathrm{B}_{7}-\mathrm{B}_{6}+\mathrm{W}_{\mathrm{B} 2} \quad$ Exergia destruída na bomba 2 
Bdest $_{\mathrm{B} 2 . \text { perc }}=\frac{\text { Bdest }_{\mathrm{B} 2}}{\mathrm{~B}_{\text {fuel }}} \cdot 100$ Percentual de exergia destruída na bomba 2

BOILER

$\mathrm{B}_{10}+\mathrm{B}_{\text {fuel }}=\mathrm{B}_{1}+\mathrm{B}_{\text {purga }}+$ Bdest $_{\text {boiler }} \quad$ Balanço de exergia na caldeira

Bdest $_{\text {boiler.perc }}=\frac{\text { Bdest }_{\text {boiler }}}{\mathrm{B}_{\text {fuel }}} \cdot 100$ Percentual de exergia destruída na caldeira $\mathrm{B}_{10}=\dot{\mathrm{m}}_{\text {agua }} \cdot\left[\mathrm{h}_{10}-\mathrm{h}_{0}-\left([\mathrm{T} 0+273,15] \cdot\left[\mathrm{s}_{10}-\mathrm{s}_{0}\right]\right)\right] \cdot\left|2,77778 \times 10^{-7} \cdot \frac{\mathrm{MW}}{\mathrm{kJ} / \mathrm{h}}\right| \begin{gathered}\text { Exergia da corrente } \\ \text { de agua }\end{gathered}$ na entrada da caldeira

$\mathrm{B}_{\text {purga }}=\dot{\mathrm{m}}_{\text {purga }} \cdot\left[\mathrm{h}_{\text {purga }}-\mathrm{h}_{0}-\left([\mathrm{T0}+273,15] \cdot\left[\mathrm{s}_{\text {purga }}-\mathrm{s}_{0}\right]\right)\right] \cdot\left|2,77778 \times 10^{-7} \cdot \frac{\mathrm{MW}}{\mathrm{kJ} / \mathrm{h}}\right|$

$\mathrm{s}_{\text {purga }}=\mathbf{s}\left[\right.$ water $\left.; \mathrm{h}=\mathrm{h}_{\text {purga }} ; \mathrm{T}=\mathrm{T}_{\text {purga }}\right] \quad \mathrm{s}_{10}=\mathbf{s}\left[\right.$ water $\left.; \mathrm{T}=\mathrm{T}_{10} ; \mathrm{P}=\mathrm{P}_{10}\right]$

Total $_{\text {exergy.dest }}=$ Bdest $_{\mathrm{B} 1}+$ Bdest $_{\mathrm{B} 2}+$ Bdest $_{\text {desaerador }}+$ Bdest $_{\text {condenser }}+$ Bdest $_{\text {boiler }}+$ Bdest $_{\text {turbine }}$

Total $_{\text {exergy.dest.perc }}=\frac{\text { Total }_{\text {exergy.dest }}}{\mathrm{B}_{\text {fuel }}} \cdot 100$

Eficiência Exergética

Cálculo da eficiência exergética global

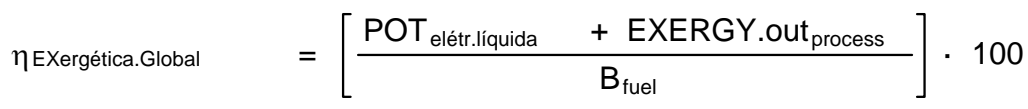

ANÁLISE ENERGÉTICA DE 1A LEI - PERDAS ENERGÉTICAS

Perdas na Caldeira e turbina

Boiler $_{\text {losses }}=$ POT $_{\text {entrada }} \cdot\left[1-\eta_{c}\right]$

Boiler $_{\text {losses.perc }}=\frac{\text { Boiler }_{\text {losses }}}{\text { POT }_{\text {entrada }}} \cdot 100$

Turbine $_{\text {losses }}=\left[\left(\mathrm{POT}_{\text {esc }}+\mathrm{POT}_{\text {cau }}+\mathrm{POT}_{1}+\mathrm{POT}_{2}+\mathrm{POT}_{3}+\mathrm{POT}_{4}+\mathrm{POT}_{5}+\mathrm{POT}_{6}+\mathrm{POT}_{7}+\mathrm{POT}_{8}\right.\right.$

$\left.\left.+\mathrm{POT}_{9}+\mathrm{POT}_{10}\right) \cdot\left(1-\eta_{\mathrm{t}}\right)\right] \cdot\left|2,77778 \times 10^{-7} \cdot \frac{\mathrm{MW}}{\mathrm{kJ} / \mathrm{h}}\right|$

Turbine $_{\text {losses.perc }}=\frac{\text { Turbine }_{\text {losses }}}{\text { POT }_{\text {entrada }}} \cdot 100$

Perdas no condensador

$\mathrm{POT}_{\text {condensador }}=\dot{\mathrm{Q}}_{\text {out }} \cdot\left|2,77778 \times 10^{-7} \cdot \frac{\mathrm{MW}}{\mathrm{kJ} / \mathrm{h}}\right|$ Energia perdida no condensador

$\mathrm{POT}_{\text {condensador.perc }}=\frac{\mathrm{POT}_{\text {condensador }}}{\mathrm{POT}_{\text {entrada }}} \cdot 100$

Condenser $_{\text {losses }}=\mathrm{POT}_{\text {condensador }}$ 


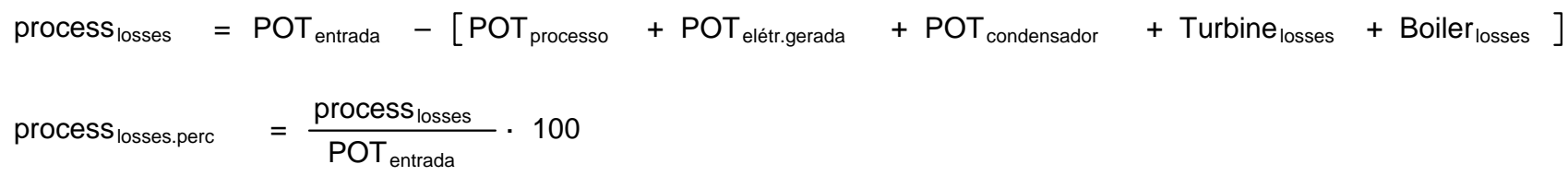

Cálculo da energia elétrica gerada por tonela de cana por tonelada de cana

GeraçãoEletric.Espec.Total $=\mathrm{POT}_{\text {elétr.líquida }} \cdot$ Período $_{\text {safra }} \cdot 1000 \cdot \frac{24}{\text { Cana }_{\text {safra }}}$

GeraçãoEletric.Espec.Excedente = GeraçãoEletric.Espec.Total - ConsumoEletr.Processo

Fechamento dos balanços

Useful.Energy $=\eta$ Energética.Global

Energy.Losses = $100-$ Useful.Energy

useful.Exergy $=\eta$ Exergética.Global

Exergy.losses $=100-\eta$ Exergética.Global 


\section{APÊNDICE F - Resultados da análise paramétrica para determinar a influência da adição de trocadores de calor no ciclo Convencional, obtendo assim o ciclo Regenerativo}

Tabela 16 - Influência da adição de trocadores de calor sobre a eficiência exergética do ciclo Rankine, na condição de pressão de operação de 20 bar.

\begin{tabular}{|c|c|c|c|c|}
\hline $\begin{array}{c}\text { Número de } \\
\text { trocadores de calor (TC) }\end{array}$ & $\begin{array}{c}\text { Eficiência } \\
\text { Exergética }\end{array}$ & Incremento & $\begin{array}{c}\text { Incremento } \\
\text { Acumulado }\end{array}$ & $\begin{array}{c}\text { Incremento } \\
\text { relativo }\end{array}$ \\
\hline Convencional & $26,12 \%$ & $0,00 \%$ & $0,00 \%$ & $0,00 \%$ \\
\hline 1 TC & $26,59 \%$ & $1,80 \%$ & $1,80 \%$ & $55,95 \%$ \\
\hline 2 TC & $26,73 \%$ & $0,53 \%$ & $2,34 \%$ & $72,62 \%$ \\
\hline 3 TC & $26,81 \%$ & $0,30 \%$ & $2,64 \%$ & $82,14 \%$ \\
\hline 4 TC & $26,85 \%$ & $0,15 \%$ & $2,79 \%$ & $86,90 \%$ \\
\hline 5 TC & $26,89 \%$ & $0,15 \%$ & $2,95 \%$ & $91,67 \%$ \\
\hline 6 TC & $26,91 \%$ & $0,07 \%$ & $3,02 \%$ & $94,05 \%$ \\
\hline 7 TC & $26,92 \%$ & $0,04 \%$ & $3,06 \%$ & $95,24 \%$ \\
\hline 8 TC & $26,94 \%$ & $0,07 \%$ & $3,14 \%$ & $97,62 \%$ \\
\hline 9 TC & $26,95 \%$ & $0,04 \%$ & $3,18 \%$ & $98,81 \%$ \\
\hline 10 TC & $26,96 \%$ & $0,04 \%$ & $3,22 \%$ & $100,00 \%$ \\
\hline
\end{tabular}

Tabela 17 - Influência da adição de trocadores de calor sobre a eficiência exergética do ciclo Rankine, na condição de pressão de operação de 45 bar.

\begin{tabular}{|c|c|c|c|c|}
\hline $\begin{array}{c}\text { Número de } \\
\text { trocadores de calor (TC) }\end{array}$ & $\begin{array}{c}\text { Eficiência } \\
\text { Exergética }\end{array}$ & Incremento & $\begin{array}{c}\text { Incremento } \\
\text { Acumulado }\end{array}$ & $\begin{array}{c}\text { Incremento } \\
\text { relativo }\end{array}$ \\
\hline Convencional & $30,24 \%$ & $0,00 \%$ & $0,00 \%$ & $0,00 \%$ \\
\hline 1 TC & $30,93 \%$ & $2,28 \%$ & $2,28 \%$ & $50,00 \%$ \\
\hline 2 TC & $31,19 \%$ & $0,84 \%$ & $3,14 \%$ & $68,84 \%$ \\
\hline 3 TC & $31,33 \%$ & $0,45 \%$ & $3,60 \%$ & $78,99 \%$ \\
\hline 4 TC & $31,42 \%$ & $0,29 \%$ & $3,90 \%$ & $85,51 \%$ \\
\hline 5 TC & $31,48 \%$ & $0,19 \%$ & $4,10 \%$ & $89,86 \%$ \\
\hline 6 TC & $31,52 \%$ & $0,13 \%$ & $4,23 \%$ & $92,75 \%$ \\
\hline 7 TC & $31,55 \%$ & $0,10 \%$ & $4,33 \%$ & $94,93 \%$ \\
\hline 8 TC & $31,58 \%$ & $0,10 \%$ & $4,43 \%$ & $97,10 \%$ \\
\hline 9 TC & $31,60 \%$ & $0,06 \%$ & $4,50 \%$ & $98,55 \%$ \\
\hline 10 TC & $31,62 \%$ & $0,06 \%$ & $4,56 \%$ & $100,00 \%$ \\
\hline
\end{tabular}


Tabela 18 - Influência da adição de trocadores de calor sobre a eficiência exergética do ciclo Rankine, na condição de pressão de operação de 67 bar.

\begin{tabular}{|c|c|c|c|c|}
\hline 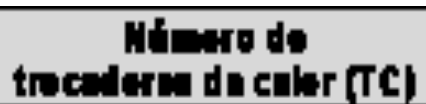 & $\begin{array}{l}\text { Efilund } \\
\text { enoritlen }\end{array}$ & Imenare & 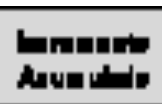 & 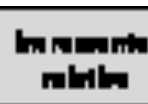 \\
\hline Comendenal & $82,0 \times x$ & 0,036 & 9,000 & $0,00 \mathrm{~s}$ \\
\hline $1 \mathrm{TC}$ & 03,706 & 2.86 & 2856 & $49 / 4 \times$ \\
\hline $2 \mathrm{TE}$ & $4,10 \%$ & $101 \%$ & $9.71 \%$ & 50,548 \\
\hline 9TC & $94,26 x$ & $0.55 \%$ & $42 \%$ & $7021 \%$ \\
\hline dTC & $8,40 \mathrm{n}$ & 0,925 & $4 \sqrt{k+3}$ & 15,95\% \\
\hline $5 \mathrm{TC}$ & A4tak & 0.206 & $487 x$ & 旦Fin \\
\hline $5 T 5$ & $4,5 \%$ & $0,15 \%$ & $502 \times$ & 92,700 \\
\hline $7 \mathrm{TC}$ & 94,503 & $0,14 *$ & $517 \%$ & $05,51 *$ \\
\hline $\mathrm{ITC}$ & $\mathbf{E , B 1 \%}$ & $0,00 x$ & $525 n$ & $9719 \%$ \\
\hline DTC & $8,64 x$ & $0,00 \%$ & $98 \mathrm{gn}$ & 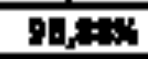 \\
\hline $10 \mathrm{TC}$ & $84,66 x$ & DEDS & 5415 & 10000\% \\
\hline
\end{tabular}

Tabela 19 - Influência da adição de trocadores de calor sobre a eficiência exergética do ciclo Rankine, na condição de pressão de operação de 80 bar.

\begin{tabular}{|c|c|c|c|c|}
\hline $\begin{array}{c}\text { Número de } \\
\text { trocadores de calor (TC) }\end{array}$ & $\begin{array}{c}\text { Eficiência } \\
\text { Exergética }\end{array}$ & Incremento & $\begin{array}{c}\text { Incremento } \\
\text { Acumulado }\end{array}$ & $\begin{array}{c}\text { Incremento } \\
\text { relativo }\end{array}$ \\
\hline Convencional & $34,16 \%$ & $0,00 \%$ & $0,00 \%$ & $0,00 \%$ \\
\hline 1 TC & $35,13 \%$ & $2,84 \%$ & $2,84 \%$ & $49,24 \%$ \\
\hline 2 TC & $35,51 \%$ & $1,08 \%$ & $3,95 \%$ & $68,53 \%$ \\
\hline 3 TC & $35,71 \%$ & $0,56 \%$ & $4,54 \%$ & $78,68 \%$ \\
\hline 4 TC & $35,84 \%$ & $0,36 \%$ & $4,92 \%$ & $85,28 \%$ \\
\hline 5 TC & $35,92 \%$ & $0,22 \%$ & $5,15 \%$ & $89,34 \%$ \\
\hline 6 TC & $35,99 \%$ & $0,19 \%$ & $5,36 \%$ & $92,89 \%$ \\
\hline 7 TC & $36,03 \%$ & $0,11 \%$ & $5,47 \%$ & $94,92 \%$ \\
\hline 8 TC & $36,07 \%$ & $0,11 \%$ & $5,59 \%$ & $96,95 \%$ \\
\hline 9 TC & $36,10 \%$ & $0,08 \%$ & $5,68 \%$ & $98,48 \%$ \\
\hline 10 TC & $36,13 \%$ & $0,08 \%$ & $5,77 \%$ & $100,00 \%$ \\
\hline
\end{tabular}


Tabela 20 - Influência da adição de trocadores de calor sobre a eficiência exergética do ciclo Rankine, na condição de pressão de operação de 100 bar.

\begin{tabular}{|c|c|c|c|c|}
\hline $\begin{array}{c}\text { Número de } \\
\text { trocadores de calor (TC) }\end{array}$ & $\begin{array}{c}\text { Eficiência } \\
\text { Exergética }\end{array}$ & Incremento & $\begin{array}{c}\text { Incremento } \\
\text { Acumulado }\end{array}$ & $\begin{array}{c}\text { Incremento } \\
\text { relativo }\end{array}$ \\
\hline Convencional & $34,92 \%$ & $0,00 \%$ & $0,00 \%$ & $0,0 \%$ \\
\hline 1 TC & $35,98 \%$ & $3,04 \%$ & $3,04 \%$ & $48,8 \%$ \\
\hline 2 TC & $36,39 \%$ & $1,14 \%$ & $4,21 \%$ & $67,7 \%$ \\
\hline 3 TC & $36,62 \%$ & $0,63 \%$ & $4,87 \%$ & $78,3 \%$ \\
\hline 4 TC & $36,76 \%$ & $0,38 \%$ & $5,27 \%$ & $84,8 \%$ \\
\hline 5 TC & $36,86 \%$ & $0,27 \%$ & $5,56 \%$ & $89,4 \%$ \\
\hline 6 TC & $36,93 \%$ & $0,19 \%$ & $5,76 \%$ & $92,6 \%$ \\
\hline 7 TC & $36,98 \%$ & $0,14 \%$ & $5,90 \%$ & $94,9 \%$ \\
\hline 8 TC & $37,02 \%$ & $0,11 \%$ & $6,01 \%$ & $96,8 \%$ \\
\hline 9 TC & $37,06 \%$ & $0,11 \%$ & $6,13 \%$ & $98,6 \%$ \\
\hline 10 TC & $37,09 \%$ & $0,08 \%$ & $6,21 \%$ & $100,0 \%$ \\
\hline
\end{tabular}

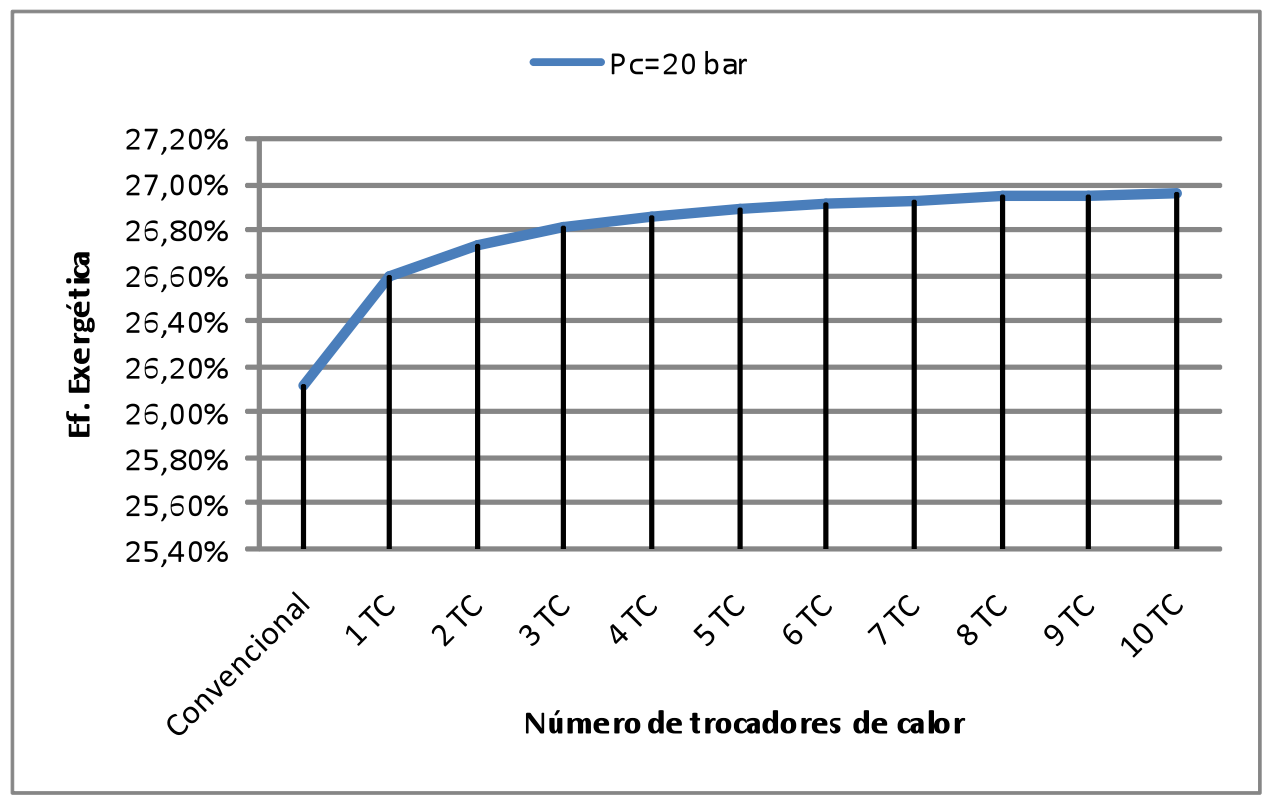

Gráfico 33 - Influência da adição de trocadores de calor sobre a eficiência exergética do ciclo Rankine, na condição de pressão de operação de 20 bar. 


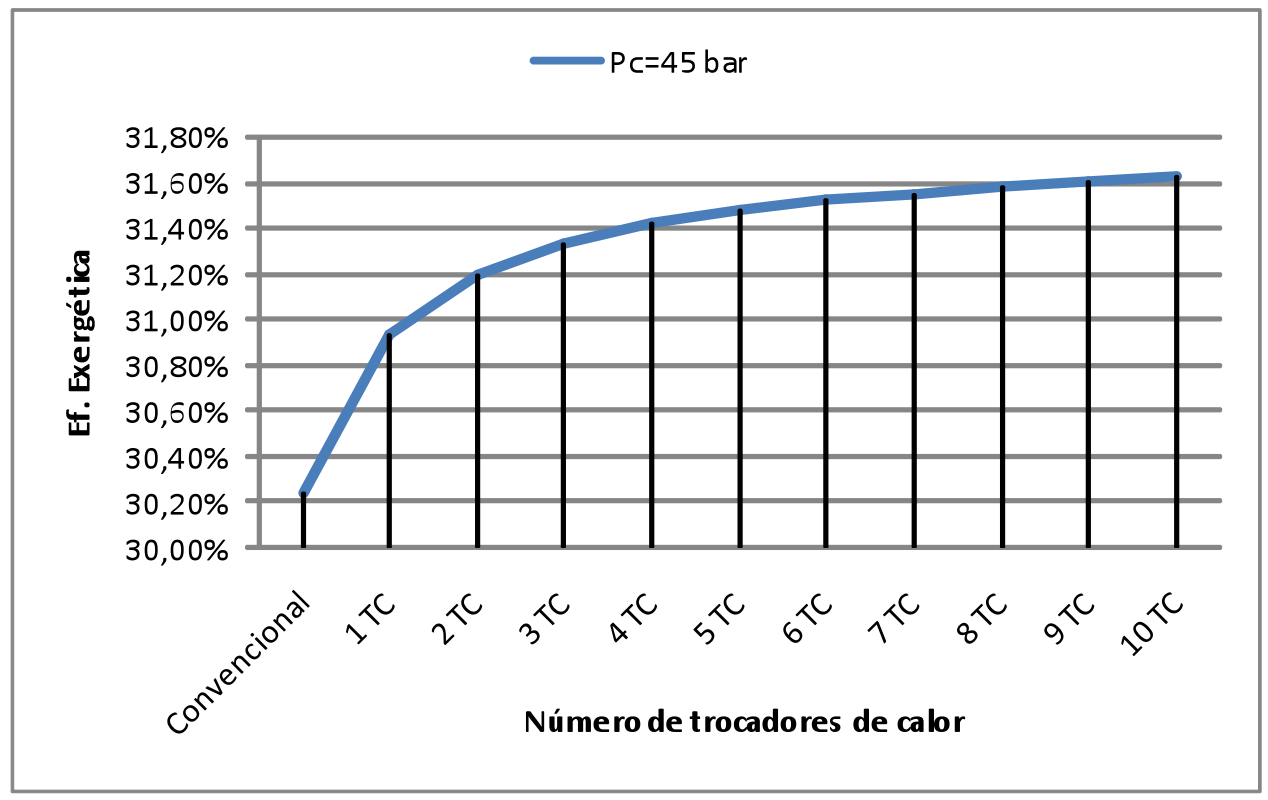

Gráfico 34 - Influência da adição de trocadores de calor sobre a eficiência exergética do ciclo Rankine, na condição de pressão de operação de 45 bar.

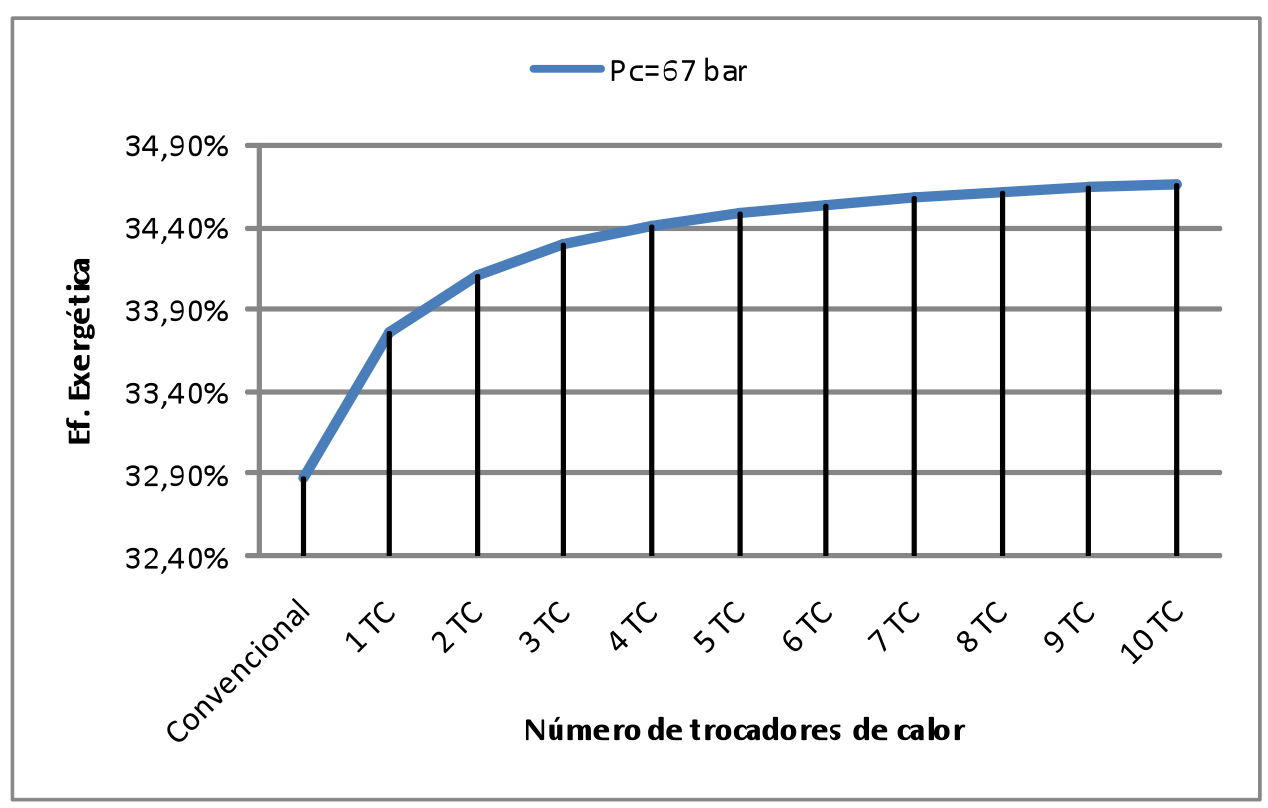

Gráfico 35 - Influência da adição de trocadores de calor sobre a eficiência exergética do ciclo Rankine, na condição de pressão de operação de 67 bar. 


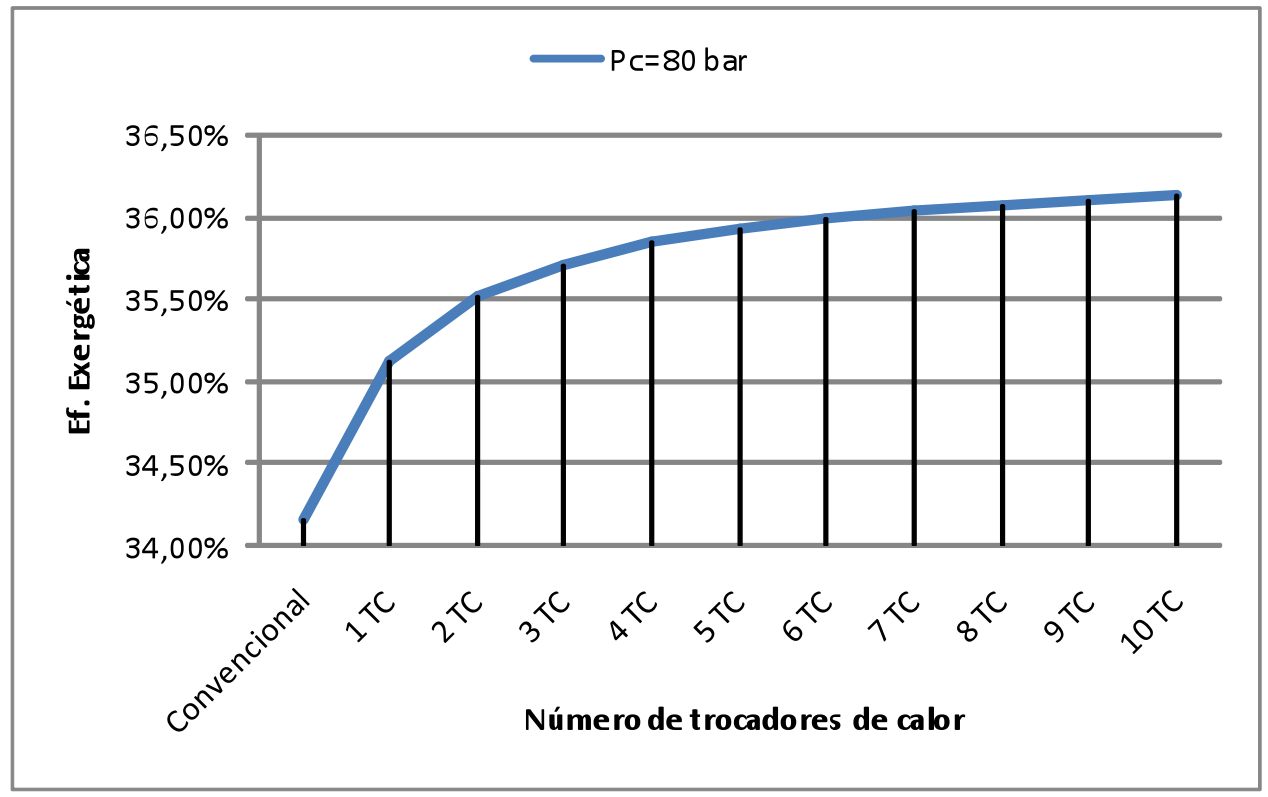

Gráfico 36 - Influência da adição de trocadores de calor sobre a eficiência exergética do ciclo Rankine, na condição de pressão de operação de 80 bar.

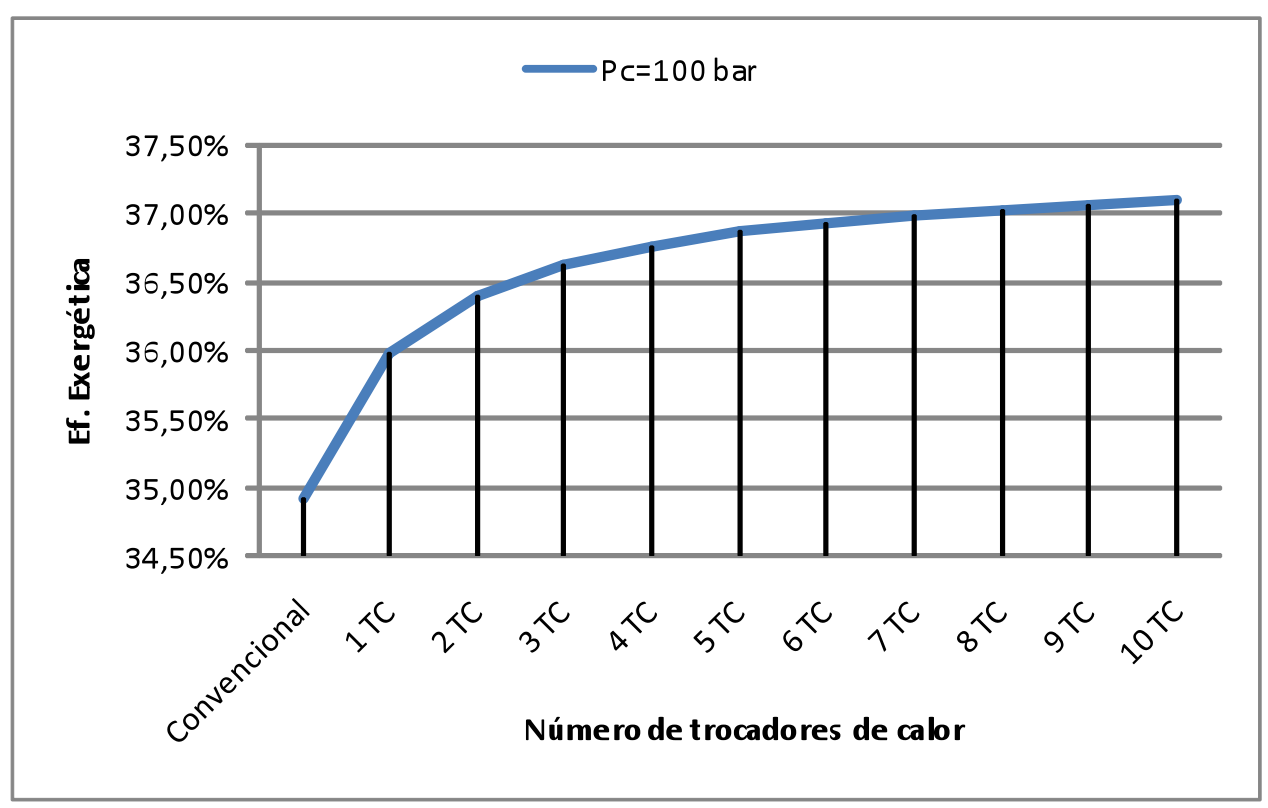

Gráfico 37 - Influência da adição de trocadores de calor sobre a eficiência exergética do ciclo Rankine, na condição de pressão de operação de 100 bar. 